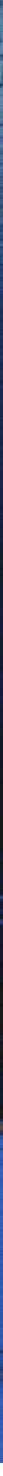

\title{
Portraits of Labor Market Exclusion
}

Ramya Sundaram, Ulrich Hoerning, Natasha De Andrade Falcao, Natalia Millan, Carla Tokman, and Michele Zini
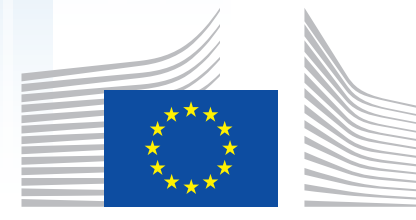



\title{
Portraits of Labor Market Exclusion
}

\author{
Ramya Sundaram, Ulrich Hoerning, Natasha De Andrade Falcao, Natalia \\ Millan, Carla Tokman, and Michele Zini
}

Financed by the European Commission

(DG Employment, Social Affairs and Inclusion)

Washington DC, August 2014

The World Bank

Europe and Central Asia Region

Human Development Unit 
(C) 2014 The International Bank for Reconstruction and Development / The World Bank 1818 H Street, NW, Washington, DC 20433 Telephone 202-473-1000; Internet www.worldbank.org

E-mail feedback@worldbank.org

All rights reserved

This work is a product of the staff of The World Bank. The findings, interpretations, and conclusions expressed in this work do not necessarily reflect the views of The World Bank, its Board of Executive Directors, or the governments they represent. The World Bank does not guarantee the accuracy of the data included in this work. The boundaries, colors, denominations, and other information shown on any map in this work do not imply any judgment on the part of The World Bank concerning the legal status of any territory or the endorsement or acceptance of such boundaries.

The European Commission support for the production of this publication does not constitute endorsement of the contents which reflects the views only of the authors, and the Commission cannot be held responsible for any use which may be made of the information contained therein.

Cover photograph by Dominic Chavez/World Bank (2013).

\section{Rights and Permissions}

The material in this work is copyrighted. Copying and/or transmitting portions or all of this work without permission may be a violation of applicable law. The World Bank encourages dissemination of its work and will normally grant permission promptly. For permission to photocopy or reprint any part of this work, please send a request with complete information to the Copyright Clearance Center, Inc., 222 Rosewood Drive, Danvers, MA 01923, USA, telephone 978-750-8400, fax 978-750-4470, www.copyright.com. All other queries on rights and licenses, including subsidiary rights, should be addressed to the Office of the Publisher, World Bank, 1818 H Street NW, Washington, DC 20433, USA, fax 202-522-2422, e-mail pubrights@worldbank.org.

For any use or reproduction of photos which are not under European Union copyright, permission must be sought directly from the copyright holder(s). 


\section{Contents}

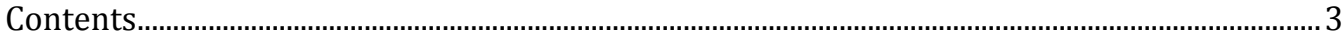

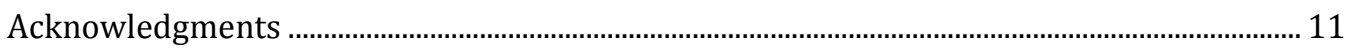

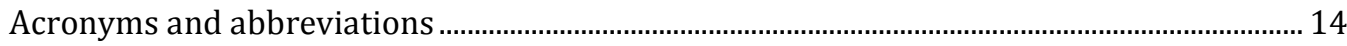

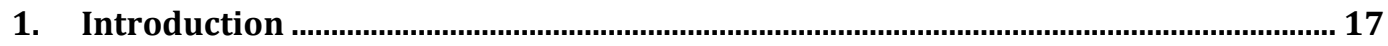

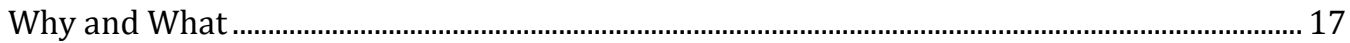

2. Portraits of Labor Market Exclusion ……................................................................... 29

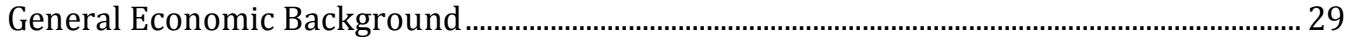

Stylized Issues Emerging from the Analysis …………………………………………................ 32

Selected Issues for Further Policy Dialogue ................................................................................. 41

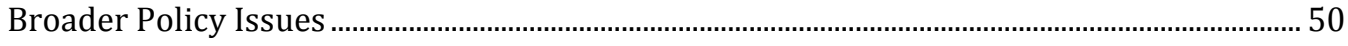

3. Latent Class Analysis of the Out-of-Work Population in Bulgaria 2007-2011....... 53

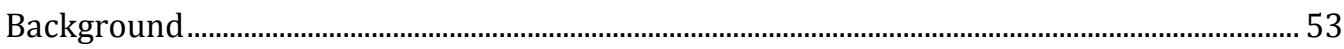

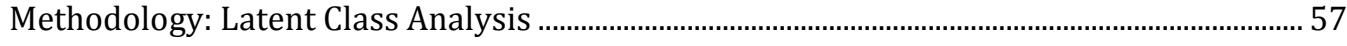

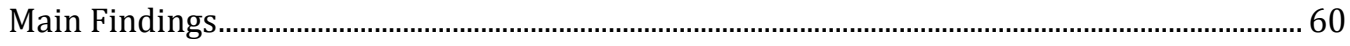

From Profiling to Activation......................................................................................................... 78

4. Latent Class Analysis of the Out-of-Work Population in Estonia 2007-2011......... 91

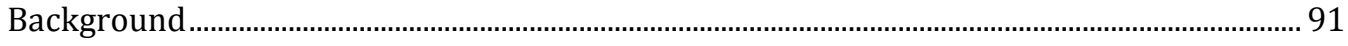

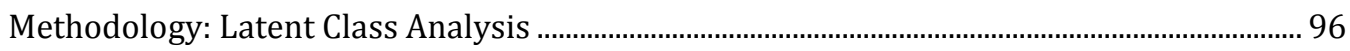

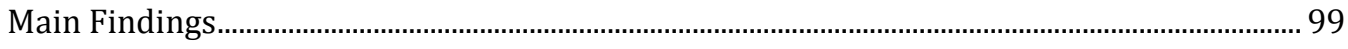

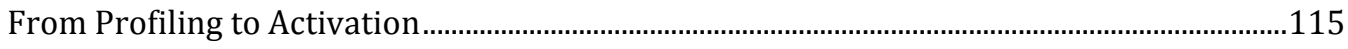

5. Latent Class Analysis of the Out-of-Work Population in Greece 2007-2011 ........127

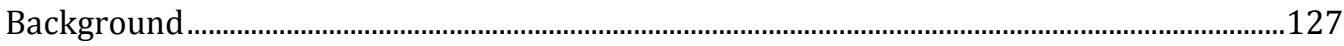

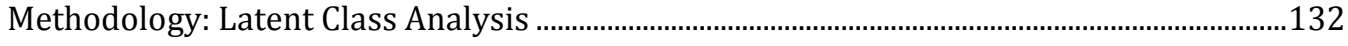

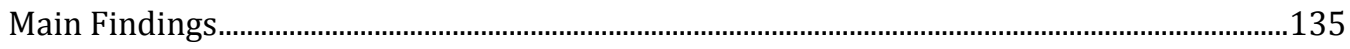

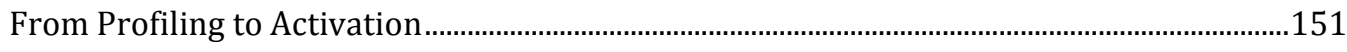

6. Latent Class Analysis of the Out-of-Work Population in Hungary 2007-2011 ....163

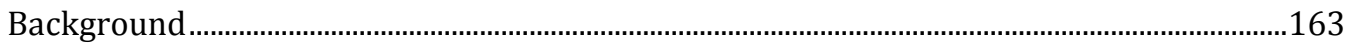

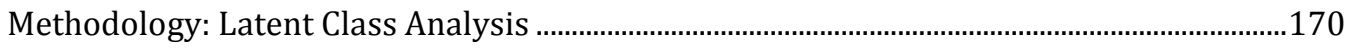


Main Findings.. 173

From Profiling to Activation. 195

7. Latent Class Analysis of the Out-of-Work Population in Lithuania 2007-2011 .. 207

Background 207

Methodology: Latent Class Analysis 212

Main Findings 215

From Profiling to Activation. 230

8. Latent Class Analysis of the Out-of-Work Population in Romania 2008-2011 ... 241

Background . .241

Methodology: Latent Class Analysis .246

Main Findings .249

From Profiling to Activation. 270

9. Proceedings of Workshop in Brussels 283

\section{TABLE OF FIGURES}

FIGURE 1.1 LABOR MARKET AND SOCIAL EXCLUSION, GOVERNMENT ACTIVITIES .....................18

FIGURE 2.1 ANNUAL REAL GDP GROWTH (2003 -2013) .........................................................29

FIGURE 2.2 GENDER GAP IN UNEMPLOYMENT RATES (2003-2013) .........................................30

FIGURE 2.3 LONG-TERM UNEMPLOYMENT AS A SHARE OF TOTAL UNEMPLOYMENT (2003-2013)

30

FIGURE 2.4 OUT-OF-WORK POPULATION (IN THOUSANDS) AND SHARE OF TOTAL WORKING-AGE POPULATION, 2007(*)/2008 AND 2011

FIGURE 2.5 LABOR FORCE PARTICIPATION AMONG YOUTH AGED 15 TO 24, EUROPEAN COUNTRIES, (2013) 35

FIGURE 2.6 NEET RATES, EUROPEAN COUNTRIES, (2008 AND 2013) .36

FIGURE 2.7 LABOR FORCE PARTICIPATION AS SHARE OF AGE GROUP, EUROPEAN COUNTRIES (2013)

FIGURE 2.8 LABOR FORCE PARTICIPATION AS A PERCENTAGE OF THE TOTAL POPULATION AGED 15-64, BY GENDER, EUROPEAN COUNTRIES (2013)

FIGURE 2.9 FORMAL CHILD CARE AS A PERCENTAGE OF ALL CHILDREN LESS THAN 3 YEARS OLD,

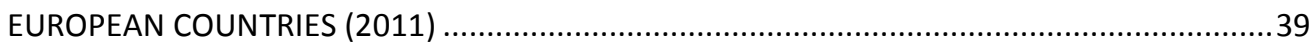

FIGURE 2.10 ACTIVATION TYPES OF PRIORITIZED CLUSTERS..............................................43

FIGURE 2.11 MUTUALLY REINFORCING BARRIERS TO EMPLOYMENT FOR YOUNGER AND OLDER WORKERS, WOMEN AND ETHNIC MINORITIES..........................................................49 FIGURE 3.1 LONG-TERM UNEMPLOYMENT AS A SHARE OF TOTAL UNEMPLOYMENT (2003-2013) 
FIGURE 3.2 UNEMPLOYMENT AMONG 15 TO 64-YEAR- OLDS BY EDUCATIONAL LEVEL IN BULGARIA (2003-2013)

FIGURE 3.3 DISTRIBUTION OF OUT-OF-WORK POPULATION IN BULGARIA (2008 AND 2011).......56

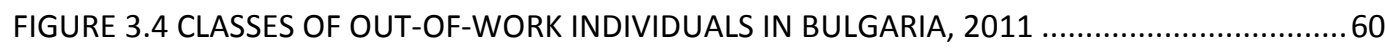

FIGURE 3.5 CLASSES OF OUT-OF-WORK POPULATION IN BULGARIA (2008-2011), THOUSANDS OF INDIVIDUALS. 68

FIGURE 3.6 LABOR FORCE PARTICIPATION AMONG YOUTH AGED 15 TO 24, EUROPEAN COUNTRIES (2013) 69

FIGURE 3.7 EXPENDITURES ON DISABILITY BENEFITS AS A SHARE OF GDP IN EUROPE (2008 AND 2010) 70

FIGURE 3.8 DEMOGRAPHIC CHANGE IN BULGARIA. .71

FIGURE 3.9 LABOR MARKET POLICY (LMP) SPENDING IN BULGARIA AS A SHARE OF GDP ............79 FIGURE 3.10 COMPOSITION OF SPENDING ON LABOR MARKET POLICIES IN BULGARIA (2011) ... 79

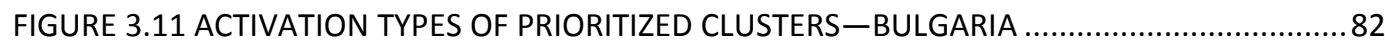
FIGURE 4.1 UNEMPLOYMENT RATES BY GENDER AND AGE, ESTONIA (2003-2013) ..................92 FIGURE 4.2 LONG-TERM UNEMPLOYMENT AS A SHARE OF TOTAL UNEMPLOYMENT, ESTONIA

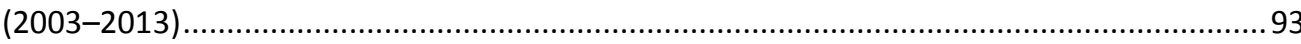

FIGURE 4.3 EVOLUTION OF OUT-OF-WORK POPULATION IN ESTONIA (16-64), ..........................93 FIGURE 4.4 COMPOSITION OF WORKING-AGE POPULATION IN ESTONIA (16-64) BY LABOR

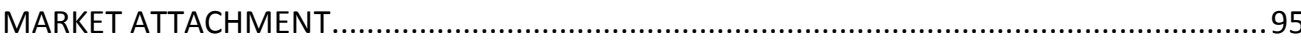

FIGURE 4.5 DISTRIBUTION OF OUT-OF-WORK POPULATION IN ESTONIA, 2007 AND 2011...........95 FIGURE 4.6 CLASSES OF OUT-OF-WORK INDIVIDUALS IN ESTONIA (2011) .................................99 FIGURE 4.7 CLASSES OF OUT-OF-WORK INDIVIDUALS IN ESTONIA, 2007, 2009 AND 2011 (NUMBER OF INDIVIDUALS) 107

FIGURE 4.8 LABOR FORCE PARTICIPATION AMONG YOUTH AGED 15 TO 24, EUROPEAN COUNTRIES (2013) 109

FIGURE 4.9 EXPENDITURES ON DISABILITY BENEFITS AS A SHARE OF GDP IN EUROPE (2008 AND 2010) 110 FIGURE 4.10 LABOR MARKET POLICY (LMP) SPENDING IN ESTONIA AS A SHARE OF GDP...........117 FIGURE 4.11 LABOR MARKET POLICY BENEFICIARIES IN ESTONIA (ANNUAL) 117 FIGURE 4.12 COMPOSITION OF SPENDING ON ALMPS IN ESTONIA (EURO MILLIONS), 2008 AND 2011 118 FIGURE 4.13 ACTIVATION TYPES OF PRIORITIZED CLUSTERS IN ESTONIA ...............................120 FIGURE 5.1 UNEMPLOYMENT RATES BY AGE AND GENDER (2007-2013) ................................128 FIGURE 5.2 LONG-TERM UNEMPLOYMENT AS A SHARE OF TOTAL UNEMPLOYMENT (2003-2013)

FIGURE 5.3 DISTRIBUTION OF WORKING-AGE POPULATION (16-64) BY LABOR MARKET ATTACHMENT IN GREECE (2007 AND 2011) 131 FIGURE 5.4 CLASSES OF OUT-OF-WORK INDIVIDUALS IN GREECE (2011) 135 FIGURE 5.5 CLASSES OF OUT-OF-WORK POPULATION IN GREECE, 2007, 2009 AND 2011

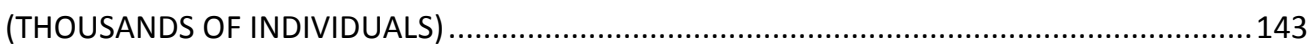
FIGURE 5.6 FEMALE LABOR FORCE PARTICIPATION RATE FOR 15-64-YEAR-OLDS (2013)...........144 FIGURE 5.7 LABOR FORCE PARTICIPATION RATE (AGES 55-64), 2013 
FIGURE 5.8 ACTIVATION TYPES OF PRIORITIZED CLUSTERS-GREECE

FIGURE 6.1 UNEMPLOYMENT RATE BY GENDER AND AGE (2007-2013)

164

FIGURE 6.2 LONG-TERM UNEMPLOYMENT AS A SHARE OF TOTAL UNEMPLOYMENT (2003-2013)

165

FIGURE 6.3 DISTRIBUTION OF OUT-OF-WORK POPULATION IN HUNGARY (2008 AND 2011) .....167

FIGURE 6.4 CLASSES OF OUT-OF-WORK POPULATION IN HUNGARY, 2011 .173

FIGURE 6.5 CLASSES OF OUT-OF-WORK POPULATION IN HUNGARY, 2008- 2011 (NUMBER OF

INDIVIDUALS) 185

FIGURE 6.6 LABOR FORCE PARTICIPATION AMONG YOUTH AGED 15 TO 24, EUROPEAN

COUNTRIES (2013) 186

FIGURE 6.7 LABOR TAX WEDGES IN EUROPE (2008 AND 2010) .187

FIGURE 6.8 LABOR FORCE PARTICIPATION, AGES 55 TO 59, EUROPEAN COUNTRIES (2013) ......188 FIGURE 6.9 EXPENDITURES ON OLD-AGE BENEFITS AS A SHARE OF GDP IN EUROPE (2008 AND 2010) 189

FIGURE 6.10 FORMAL CHILD CARE AS A PERCENTAGE OF ALL CHILDREN LESS THAN 3 YEARS OLD, EUROPEAN COUNTRIES (2011) 190

FIGURE 6.11 PERCENTAGE OF INACTIVE WOMEN THAT REPORT LOOKING AFTER CHILDREN OR INCAPACITATED ADULTS AS THE MAIN REASON FOR NOT SEEKING EMPLOYMENT, EUROPEAN COUNTRIES (2013) 190

FIGURE 6.12 LABOR MARKET POLICY (LMP) SPENDING IN HUNGARY AS A SHARE OF GDP ........195 FIGURE 6.13 COMPOSITION OF SPENDING ON ALMPS IN HUNGARY (IN MILLIONS OF EUROS), 2008 AND 2011 196

FIGURE 6.14 SHARE OF PARTICIPANTS IN TRAINING AS AN ACTIVE LABOR MARKET TOOL, EUROPEAN COUNTRIES (2011) 197

FIGURE 6.15 ACTIVATION TYPES OF PRIORITIZED CLUSTERS IN HUNGARY 199

FIGURE 7.1 UNEMPLOYMENT RATES BY GENDER AND AGE (2007-2013) 208 FIGURE 7.2 LONG-TERM UNEMPLOYMENT AS A SHARE OF TOTAL UNEMPLOYMENT (2003-2013)

FIGURE 7.3 EVOLUTION OF OUT-OF-WORK POPULATION IN LITHUANIA (16-64) ..... 209 FIGURE 7.4 COMPOSITION OF WORKING-AGE POPULATION (16-64) BY LABOR MARKET ATTACHMENT IN LITHUANIA 211

FIGURE 7.5 DISTRIBUTION OF OUT-OF-WORK POPULATION IN LITHUANIA (2007 AND 2011)....211 FIGURE 7.6 CLASSES OF OUT-OF-WORK INDIVIDUALS IN LITHUANIA (2011) 215

FIGURE 7.7 CLASSES OF OUT-OF-WORK POPULATION IN LITHUANIA (2007, 2009 AND 2011),

NUMBER OF INDIVIDUALS 222

FIGURE 7.8 LABOR FORCE PARTICIPATION AMONG YOUTH AGED 15 TO 24, EUROPEAN COUNTRIES (2013) 224

FIGURE 7.9 EXPENDITURES ON DISABILITY BENEFITS AS A SHARE OF GDP IN EUROPE (2008 AND 2010) 225

FIGURE 7.10 LABOR MARKET POLICY (LMP) SPENDING IN LITHUANIA AS A SHARE OF GDP .......231 FIGURE 7.11 LABOR MARKET POLICY (LMP) BENEFICIARIES IN LITHUANIA (2006-2010), NUMBER OF INDIVIDUALS .232 
FIGURE 7.12 COMPOSITION OF SPENDING ON ALMPS IN LITHUANIA (EURO MILLIONS), 2008 AND 2011

FIGURE 7.13 ACTIVATION TYPES OF PRIORITIZED CLUSTERS IN LITHUANIA ............................234

FIGURE 8.1 UNEMPLOYMENT AND NEET RATES-ROMANIA (2003-2013) ................................242

FIGURE 8.2 UNEMPLOYMENT RATES BY GENDER AND AGE-ROMANIA (2007-2013) ...............242

FIGURE 8.3 LONG-TERM UNEMPLOYMENT AS A SHARE OF TOTAL UNEMPLOYMENT (2003-2013)

FIGURE 8.4 DISTRIBUTION OF OUT-OF-WORK POPULATION IN ROMANIA (2008 AND 2011) .....245

FIGURE 8.5 CLASSES OF OUT-OF-WORK INDIVIDUALS IN ROMANIA (2011) 249

FIGURE 8.6 CLASSES OF OUT-OF-WORK POPULATION IN ROMANIA (2008- 2011), (IN THOUSANDS OF INDIVIDUALS). 260

FIGURE 8.7 LABOR FORCE PARTICIPATION AMONG YOUTH AGED 15 TO 24, EUROPEAN COUNTRIES (2013) 261

FIGURE 8.8 LABOR FORCE PARTICIPATION, AGES 55 TO 59, EUROPEAN COUNTRIES (2013) .......262 FIGURE 8.9 EXPENDITURES ON OLD-AGE BENEFITS AS A SHARE OF GDP IN EUROPE (2008 AND 2010) .263

FIGURE 8.10 LABOR FORCE PARTICIPATION AMONG WOMEN AGED 25 TO 54, EUROPEAN COUNTRIES, (2013) .263

FIGURE 8.11 LABOR MARKET POLICY (LMP) BENEFICIARIES IN ROMANIA (NUMBER OF INDIVIDUALS) 271

FIGURE 8.12 COMPOSITION OF SPENDING ON ALMPS IN ROMANIA (EURO MILLIONS), 2008 AND 2011 271

FIGURE 8.13 LABOR MARKET POLICY (LMP) SPENDING IN ROMANIA AS A SHARE OF GDP.........272 FIGURE 8.14 ACTIVATION TYPES OF PRIORITIZED CLUSTERS-ROMANIA................................275 FIGURE 9.1 GREECE: HIGHLY EDUCATED YOUTH NOT IN EMPLOYMENT, EDUCATION OR TRAINING

284

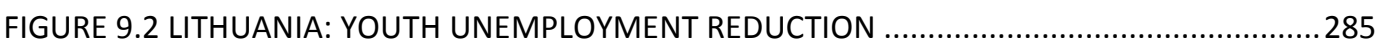

FIGURE 9. 3 ESTONIA: REFORMING INCAPACITY FOR WORK SCHEME ...................................286

FIGURE 9.4 ROMANIA: THE REFORM OF THE ROMANIAN SOCIAL ASSISTANCE SYSTEM .............287 FIGURE 9.5 HUNGARY: ACTIVE LABOR MARKET PROGRAMS--GOOD PRACTICES TO PREVENT LABOR MARKET EXCLUSION 288

FIGURE 9. 6 BULGARIA: MEASURES FOR INTEGRATION OF INACTIVE AND DISCOURAGED PEOPLE

\section{TABLE OF TABLES}

TABLE 1.1 KEY STATISTICS OF SELECTED COUNTRIES (2013) 24

TABLE 2.1 ACTIVATION PRIORITY: OVERVIEW OF INACTIVE CLUSTERS WITH HIGH AND MEDIUM PRIORITY FOR ACTION

TABLE 3.1 NUMBER AND PERCENTAGE OF WORKING AGE INDIVIDUALS (16-64) BY LABOR MARKET ATTACHMENT IN BULGARIA (2008 AND 2011), IN THOUSANDS

TABLE 3.2 SUMMARY CHARACTERISTICS OF LATENT CLASSES OF OUT-OF-WORK POPULATION IN BULGARIA (2011) 
TABLE 3.3 LATENT CLASSES OF OUT-OF-WORK POPULATION IN BULGARIA-INDICATORS (2011)

TABLE 3.4 LATENT CLASSES OF OUT-OF-WORK POPULATION IN BULGARIA-ACTIVE COVARIATES (2011) . .65

TABLE 3.5 CLASSES OF OUT-OF-WORK POPULATION IN BULGARIA (2008-2011), AS PERCENT OF TOTAL OUT-OF-WORK POPULATION

TABLE 3.6 LONGITUDINAL ANALYSIS: SUMMARY CHARACTERISTICS OF LATENT CLASSES OF OUTOF-WORK POPULATION IN BULGARIA, (2010).

TABLE 3.7 COMPOSITION OF 2010 CLUSTERS BASED ON 2008 LABOR MARKET STATUSBULGARIA (COLUMN PERCENTAGES)

TABLE 3.8 COMPOSITION OF 2010 CLUSTERS BASED ON 2008 LABOR MARKET STATUSBULGARIA (ROW PERCENTAGES)

TABLE 3.9 ACTIVATION PRIORITY: OVERVIEW OF INACTIVE CLUSTERS AND PRIORITY FOR ACTION - BULGARIA

TABLE 4.1 SUMMARY CHARACTERISTICS OF LATENT CLASSES OF OUT-OF-WORK POPULATION IN ESTONIA, (2011)

TABLE 4.2 LATENT CLASSES OF OUT-OF-WORK POPULATION IN ESTONIA- INDICATORS (2011).103

TABLE 4.3 LATENT CLASSES OF OUT-OF-WORK POPULATION IN ESTONIA-ACTIVE COVARIATES (2011) 104

TABLE 4.4 CLASSES OF OUT-OF-WORK INDIVIDUALS IN ESTONIA, 2007, 2009 AND 2011 (AS PERCENTAGE OF TOTAL OUT-OF-WORK POPULATION) 106

TABLE 4.5 LONGITUDINAL ANALYSIS: SUMMARY CHARACTERISTICS OF LATENT CLASSES OF OUTOF-WORK POPULATION IN ESTONIA (2010)

TABLE 4.6 COMPOSITION OF 2010 CLUSTERS BASED ON 2008 LABOR STATUS-ESTONIA (COLUMN PERCENTAGES)

TABLE 4.7 COMPOSITION OF 2010 CLUSTERS BASED ON 2008 LABOR STATUS-ESTONIA (ROW PERCENTAGES)

TABLE 4.8 ACTIVATION NEED AND POTENTIAL OF DIFFERENT CLUSTERS-ESTONIA 119

TABLE 5.1 NUMBER AND PERCENTAGE OF WORKING-AGE INDIVIDUALS (16-64) BY LABOR MARKET ATTACHMENT IN GREECE (2007 AND 2011), IN THOUSANDS 130

TABLE 5.2 SUMMARY CHARACTERISTICS OF LATENT CLASSES OF OUT-OF-WORK POPULATION IN GREECE (2011) 136

TABLE 5.3 LATENT CLASSES OF OUT-OF-WORK POPULATION IN GREECE-INDICATORS (2011).139 TABLE 5.4 LATENT CLASSES OF OUT-OF-WORK POPULATION IN GREECE-COVARIATES (2011).140 TABLE 5.5 CLASSES OF OUT-OF-WORK POPULATION IN GREECE, 2007, 2009 AND 2011, AS PERCENT OF TOTAL OUT-OF-WORK POPULATION

TABLE 5.6 . LONGITUDINAL ANALYSIS: SUMMARY CHARACTERISTICS OF LATENT CLASSES OF THE OUT-OF-WORK POPULATION IN GREECE (2010)

TABLE 5.7 COMPOSITION OF 2010 CLUSTERS BASED ON 2008 LABOR MARKET STATUS-GREECE (COLUMN PERCENTAGES) 149

TABLE 5.8 COMPOSITION OF 2010 CLUSTERS BASED ON 2008 LABOR MARKET STATUS, (ROW PERCENTAGES) 
TABLE 5.9 NUMBER OF BENEFICIARIES AND BUDGET OF SELECTED ALMP INTERVENTIONS OF

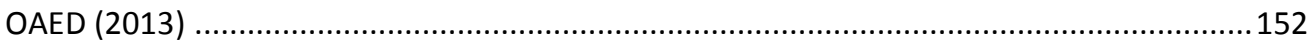

TABLE 5.10 ACTIVATION NEED AND POTENTIAL OF DIFFERENT CLUSTERS-GREECE ................153

TABLE 6.1 NUMBER AND PERCENTAGE OF WORKING AGE INDIVIDUALS (16-64) BY LABOR MARKET ATTACHMENT IN HUNGARY, 2008 AND 2011 (NUMBER IN THOUSANDS) ............166

TABLE 6.2 SUMMARY CHARACTERISTICS OF LATENT CLASSES OF THE OUT-OF-WORK POPULATION IN HUNGARY (2011) 174

TABLE 6.3 LATENT CLASSES OF OUT-OF-WORK POPULATION IN HUNGARY-INDICATORS (2011) 180

TABLE 6.4 LATENT CLASSES OF OUT-OF-WORK POPULATION IN HUNGARY-ACTIVE COVARIATES (2011) 181

TABLE 6.5 CLASSES OF OUT-OF-WORK POPULATION IN HUNGARY, 2008- 2011, AS PERCENT OF TOTAL OUT-OF-WORK POPULATION 184

TABLE 6.6 LONGITUDINAL ANALYSIS: SUMMARY CHARACTERISTICS OF LATENT CLASSES OF OUTOF-WORK POPULATION IN HUNGARY (2010). 191

TABLE 6.7 COMPOSITION OF 2010 CLUSTERS BASED ON 2008 LABOR STATUS-HUNGARY (COLUMN PERCENTAGES) 193

TABLE 6.8 COMPOSITION OF 2010 CLUSTERS BASED ON 2008 LABOR STATUS-HUNGARY (ROW PERCENTAGES) 194

TABLE 6.9 ACTIVATION NEED AND POTENTIAL OF DIFFERENT CLUSTERS. 198

TABLE 7.1 SUMMARY CHARACTERISTICS OF LATENT CLASSES OF THE OUT-OF-WORK POPULATION IN LITHUANIA (2011) .215

TABLE 7.2 LATENT CLASSES OF THE OUT-OF-WORK POPULATION IN LITHUANIA-INDICATORS (2011)

TABLE 7.3 LATENT CLASSES OF OUT-OF-WORK POPULATION IN LITHUANIA-ACTIVE COVARIATES (2011)

TABLE 7.4 CLASSES OF OUT-OF-WORK POPULATION IN LITHUANIA (2007, 2009 AND 2011), AS PERCENT OF TOTAL OUT-OF-WORK POPULATION 221

TABLE 7.5 LONGITUDINAL ANALYSIS: SUMMARY CHARACTERISTICS OF LATENT CLASSES OF OUTOF-WORK POPULATION IN LITHUANIA (2010) 227

TABLE 7.6 COMPOSITION OF 2010 CLUSTERS BASED ON 2008 LABOR STATUS—LITHUANIA (COLUMN PERCENTAGES)

TABLE 7.7 COMPOSITION OF 2010 CLUSTERS BASED ON 2008 LABOR STATUS-LITHUANIA (ROW PERCENTAGES) 229

TABLE 7.8 ACTIVATION NEED AND P OTENTIAL OF DIFFERENT CLUSTERS IN LITHUANIA ........233

TABLE 8.1 NUMBER AND PERCENTAGE OF WORKING AGE INDIVIDUALS (16-64) BY LABOR MARKET ATTACHMENT IN ROMANIA (2008 AND 2011)(IN THOUSANDS) .244

TABLE 8.2 SUMMARY CHARACTERISTICS OF LATENT CLASSES OF OUT-OF-WORK POPULATION IN ROMANIA (2011) 249

TABLE 8.3 LATENT CLASSES OF OUT-OF-WORK POPULATION IN ROMANIA-INDICATORS (2011) 255

TABLE 8.4 LATENT CLASSES OF OUT-OF-WORK POPULATION IN ROMANIA-ACTIVE COVARIATES (2011) 256 
TABLE 8.5 CLASSES OF OUT-OF-WORK POPULATION IN ROMANIA (2008- 2011) AS PERCENT OF

TOTAL OUT-OF-WORK POPULATION

TABLE 8.6 LONGITUDINAL ANALYSIS: SUMMARY CHARACTERISTICS OF LATENT CLASSES OF OUT-

OF-WORK INDIVIDUALS IN ROMANIA (2010)

265

TABLE 8.7 COMPOSITION OF 2010 CLUSTERS BASED ON 2008 LABOR STATUS IN ROMANIA

(COLUMN PERCENTAGES)

267

TABLE 8.8 COMPOSITION OF 2010 CLUSTERS BASED ON 2008 LABOR STATUS IN ROMANIA (ROW

PERCENTAGES)

267

TABLE 8.9 ACTIVATION NEED AND POTENTIAL OF DIFFERENT CLUSTERS-ROMANIA

.274

\section{TABLE OF BOXES}

BOX 1.1 LATENT CLASS ANALYSIS--A SWEET AND INTUITIVE EXAMPLE ...................................19

BOX 1.2 THE STATISTICAL BASIS BEHIND LATENT CLASS ANALYSIS ..........................................21

BOX 1.3 DEFINITION OF LABOR MARKET STATUS AND EDUCATIONAL LEVELS USED IN THIS

REPORT .22

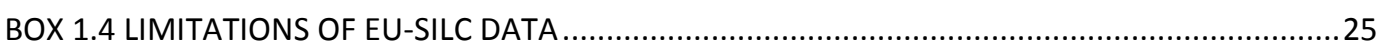

BOX 2.1 AT-RISK-OF-POVERTY RATE IN THE EU AND IN THIS REPORT ....................................34

BOX 2.2 BACK TO WORK: GROWING WITH JOBS IN EUROPE AND CENTRAL ASIA .......................48

BOX 3.1 ROMA POPULATION AND LABOR MARKET EXCLUSION ............................................76

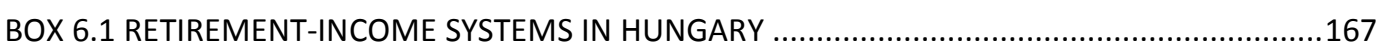

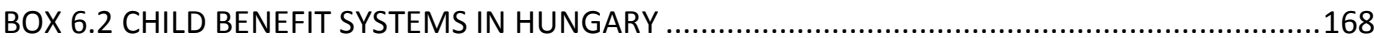

BOX 9.1 ROMA POPULATION AND LABOR MARKET EXCLUSION IN ROMANIA ........................268 


\section{Acknowledgments}

This report was produced by a World Bank team co-led by Ramya Sundaram (Senior Economist) and Ulrich Hoerning (Senior Social Protection Economist), and including Natasha De Andrade Falcao (Economist), Natalia Millan (Economist), Carla Tokman (Economist), and Michele Zini (Economist). The team wishes to thank Frieda Vandeninden, Gady Saiovici, Victoria Strokova, Sandor Karacsony, Romain Falloux, Matteo Morgandi, and Aylin IsikDikmelik for their contributions and advice. Sreypov Tep and Carmen Laurente provided excellent assistance to the team.

This report is a joint World Bank and European Commission (EC) product and would not have been possible without the financial and technical support of the EC's Directorate General of Employment, Social Affairs and Inclusion. Istvan Vanyolos (Policy Officer, Active Inclusion of Disadvantaged Groups, Fight against Poverty) and Bérengère Steppé (Policy Officer, Social Services and Active Inclusion) led the efforts from the Directorate for Employment, Social Affairs and Inclusion's side. From the European Social Funds Country Units, the team wishes to thank Ventsislav Petrov (F.5-Bulgaria), George Taskoudis (F.3Greece), Marcia Kammitsi (F.3-Greece), Katalin Szatmari (E.5-Hungary), Ina Sesciliene (E.5-Lithuania), Laurent Sens (E.5-Lithuania), Dana Verbal (F.5-Romania), and Sirje Sepp (E.5-Estonia) for comments and guidance. From the Horizontal Units, we wish to thank Panagiota Stamatiou (D.2), Kornelia Kozovska (D.1), Nicholas Costello (D.1), Isabel Engsted-Maquet (A.2), Céline Thevenot (A.2), and Valdis Zagorskis (D.3) for comments and guidance. From the EC Representative Office, we wish to thank Ms. Katrin Hoovelson (EU Representative Office, Talinn), and Ms. Liliána Zúgó (EU Representative Office Budapest).

Overall guidance on the World Bank side was provided by Kathy Lindert (former Social Protection Sector Manager, Europe and Central Asia, and currently Sector Leader, Latin American and Caribbean Region), Andrew Mason (Social Protection Sector Manager, Europe and Central Asia), Ana Revenga (Former Director of Human Development, Europe and Central Asia), Omar Arias (Human Development Economics Sector Manager, Europe and Central Asia), Alberto Rodriguez (Acting Director, Europe and Central Asia), Mamta Murthi (Country Director for Central Europe and the Baltic Countries), Dirk Reinermann (Program Manager for Southern Europe Countries), Markus Repnik (Country Manager for Bulgaria, Czech Republic and Slovakia, World Bank), Elisabetta Campanelli (Country Manager for Romania and Hungary, World Bank), and Xavier Devictor (Country Manager for Poland, Latvia, Lithuania, and Estonia).

Peer review comments were received at different stages from Arvo Kuddo (Senior Labor Economist, World Bank), Edmundo Murrugarra (Senior Social Protection Economist, World Bank), Dena Ringold (Lead Economist, World Bank), Bérengère Steppé, Kathy Lindert, Herwig Immervoll (Senior Economist, Head of Employment-Oriented Social Policies, OECD), Roumeen Islam (Economic Advisor, World Bank), Zeljko Bogetic (Lead Economist and Country Sector Coordinator for Western Balkans, World Bank), Maria Davalos (Economist, World Bank), Doerte Doemeland (Senior Economist, World Bank), Francis Rowe (Senior

Portraits of Labor Market Exclusion | 11 
Economist, World Bank), Corina Grigore (Analyst, World Bank), and Richard Florescu (Senior Operations Officer, World Bank). The editor was Elizabeth Schwinn.

The team benefitted from extensive interaction and guidance from officials representing the Governments of the countries covered in this study. In particular, the team would like to thank the following counterparts:

- Government of Bulgaria. From the Ministry of Labour and Social Policy: Elka Dimitrova (Director of Labour Market Policy and Labour Migration Directorate), Eleonora Pachedzieva (Director of Policy for People with Disabilities, Equal Opportunities and Social Assistance), Emil Miroslavov (Director of Labour Law, Social Security and Working Conditions), Natalia Efremova (Director General of the Managing Authority of the Operational Program, Human Resources Development). From the Employment Agency, Asen Angelov (Executive Director). From the Ministry of Finance, Marinela Petrova (Director of Economic and Financial Policy Directorate).

- Government of Estonia. Nele Gerberson (Ministry of Social Affairs), Karin Kuum (Ministry of Social Affairs), Ülle Marksoo (Ministry of Social Affairs), Merlin Tatrik (Ministry of Social Affairs), Pille Liimal (Estonian Unemployment Insurance FundTöötukassa), Mariliis Niidla (Estonian Unemployment Insurance Fund-Töötukassa), Kristi Villsaar (Estonian Unemployment Insurance Fund-Töötukassa), and Elo Piksarv (Ministry of Finance).

- Government of Greece. Meropi Komninou (Head of Special Unit Planning and Management, Operational Program Human Resources Development, Ministry of Labour, Social Security and Welfare), Katerina Giantsiou (ESF Coordination and Monitoring Authority, Ministry of Labour, Social Security and Welfare), Panagiotis Oikonomakos (Head of the Managing Authority of O.P. Human Resources Development, Ministry of Labour, Social Security and Welfare ), Kalliopi Kastani (Head of the Social Protection and Social Cohesion Directorate, Ministry of Labour, Social Security and Welfare), Stella Graikioti (Department of Social Protection-Registry of Social Economy), Georgios Nerantzis (Deputy Head of the Migrant's Employment UnitEmployment Directorate, Ministry of Labour, Social Security and Welfare), Athina Diakounakou (Head of Employment Directorate, Ministry of Labour, Social Security and Welfare), Kostas Geormas (Deputy Head of Department of Social Protection-Registry of Social Economy, Ministry of Labour, Social Security and Welfare).

- Government of Hungary. Noémi Danajka (Ministry for National Economy, Head of Department, Department for Employment Programmes), Irén Busch (National Labour Office), Norbert Takács (Ministry of Human Resources), Csilla Lajosné Sárközi (Ministry of Human Resources), Anna Marosi (Ministry for National Economy), Zsolt Ruszkai (Ministry for National Economy), Zsófia Tóth (Ministry of Human Resources),Gábor Horváth(Ministry for National Economy).

- Government of Lithuania. Egle Radišauskienė (Deputy Director Labour Department, Ministry of Social Security and Labour), Kristina Ščerbickaitè (Senior Specialist, Labour Market Division, Ministry of Social Security and Labour), Evaldas Bacevičius (Head of European Union Division, Ministry of Social Security and Labour), Daiva Zabarauskienè (Deputy Head, Equal Opportunity Division, Ministry of Social Security and Labour), Lina 
Charašauskaite (Senior Specialist, Equal Opportunity Division, Ministry of Social Security and Labour), Alvydas Puodžiukas (Deputy Director, Lithuanian Labour Exchange), Inga Liubertè (Head of Labour Resources Division, Lithuanian Labour Exchange).

- Government of Romania. Lăcrămioara Corcheş (Ministry of Labour, Family, Social Protection and the Elderly) and team, as well as several representatives of the Public Employment Service (ANOFM). 


\section{Acronyms and abbreviations}

\begin{tabular}{|c|c|}
\hline ALMPs & Active labor market policies \\
\hline BIC & Bayesian indicator criterion \\
\hline CIF & Center for International Futures \\
\hline EC & European Commission \\
\hline EC DG EMPL & $\begin{array}{l}\text { European Commission, Directorates-General Employment, Social Affairs } \\
\text { and Inclusion }\end{array}$ \\
\hline EEAG & European Economic Advisory Group \\
\hline ESF & European Social Fund \\
\hline ESF OP & European Social Fund Operational Programme \\
\hline ESSPROS & European System of integrated Social PROtection Statistics \\
\hline EU & European Union \\
\hline EUIF & Estonian Unemployment Insurance Fund \\
\hline EU-LFS & European Union Labor Force Survey \\
\hline EU-SILC & European Union Statistics of Income and Living Conditions \\
\hline GDP & Gross domestic product \\
\hline GMI & Guaranteed minimum income \\
\hline ICT & Information and communications technologies \\
\hline ILO & International Labor Organization \\
\hline ISCED & International Standard Classification of Education \\
\hline LCA & Latent Class Analysis \\
\hline LFPR & Labor force participation rate \\
\hline LLE & Lithuanian Labor Exchange \\
\hline LMP & Labor market policy \\
\hline MLFSPE & Ministry of Labor, Family Social Protection and the Elderly of Romania \\
\hline NEA & Romanian National Employment Agency \\
\hline NEET & Not in employment, education or training \\
\hline
\end{tabular}


OAED Organismou Apascholisis Ergatikou Dynamikou (Greek Public Employment Services)

OECD Organization for Economic Co-operation and Development

PES Public employment services

RAS Reimbursable advisory services

TVET Technical and vocational education and training

UIF Unemployment Insurance Fund

UNESCO United Nations Educational, Scientific and Cultural Organization

WB World Bank 


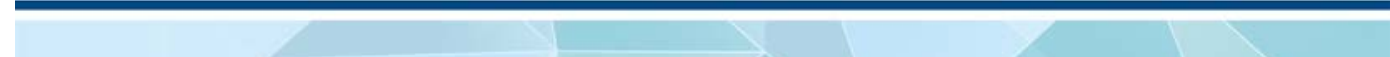

16 | Portraits of Labor Market Exclusion 


\section{Introduction}

\section{Why and What}

The financial crisis that hit the global market in the middle of 2008 gave way to the sharpest contraction of the European economies since the Great Depression. In 2009 the economic output in the countries of the European Union shrank 4.5 percent, the largest reduction in GDP since its creation. Since then, the economies have slowly recovered, but unemployment has continued to rise, reaching 11 percent in 2013, up from 7.1 percent in 2008.

The economy of the European Union shrank 4.5 percent, the largest reduction in its GDP since the Union's creation. Furthermore, for the European Union as a whole, long-term unemployment among 15- to 64-year-olds has increased from 37.2 percent in 2008 to 47.5 percent of total unemployment in 2013. In several countries more than half of those unemployed are long-term unemployed, that is, they have been looking for jobs for more than 12 months. In Greece and Bulgaria the share of long-term unemployed in 2013 was 67.5 percent and 57.3 percent, respectively. Youth unemployment, on the other hand, has increased almost 8 percent since 2008, reaching 23.3 percent in 2013 in the EU-28 countries. In Bulgaria, Romania and Hungary, around a fourth of 15- to 24-year-olds are unemployed; in Greece close to 60 percent of youth were unemployed in 2013.

Long spells of unemployment expose individuals to impoverishment. They can also lead to deterioration of skills and detachment from the labor market. Youth unemployment is particularly concerning as it risks damaging longer-term employment prospects for young people, leading them to face higher risks of exclusion and poverty. Youth unemployment also has growth implications as a generation of educated and productive people are not working at their potential. Finally, very high levels of youth unemployment for long periods of time can become a threat to social stability.

Another issue of concern is the demographic change in Europe. As the baby boomers' cohort approaches retirement, the younger cohorts entering the labor market are smaller due to the low birth rate of the past decades. The results are a population that is older, and an active labor force that is shrinking over time. This demographic change, coupled with high youth unemployment, will have significant effects on Europe's fiscal balances at a time when the size of the older generations in need of adequate pensions and health care continues to increase.

With government budgets under stress and an environment marked by demographic changes, using the labor force to its full potential is key. Knowing what the out-of-work population looks like is fundamental to a holistic approach to policymaking with respect to the inactive and the unemployed. To this end, this report presents "profiles" or "portraits" of individuals who have no or limited labor-market attachment. The profiles are derived using the latest available European Union Statistics of Income and Living Conditions (EU-SILC) 
surveys and focus on those who defined themselves as unemployed, retired or inactive at the time of the survey.

The portraits attach stories to statistics. They identify distinct groups of individuals who are the potential clients of income - and employment - support policies by examining detailed labor market, demographic and social circumstances. The analysis is a pragmatic way of looking at individuals through the lenses of both poverty/welfare status and labor market indicators. In a sense it combines labor market analysis and poverty profiling.

\section{Figure 1.1 Labor Market and Social Exclusion, Government Activities}

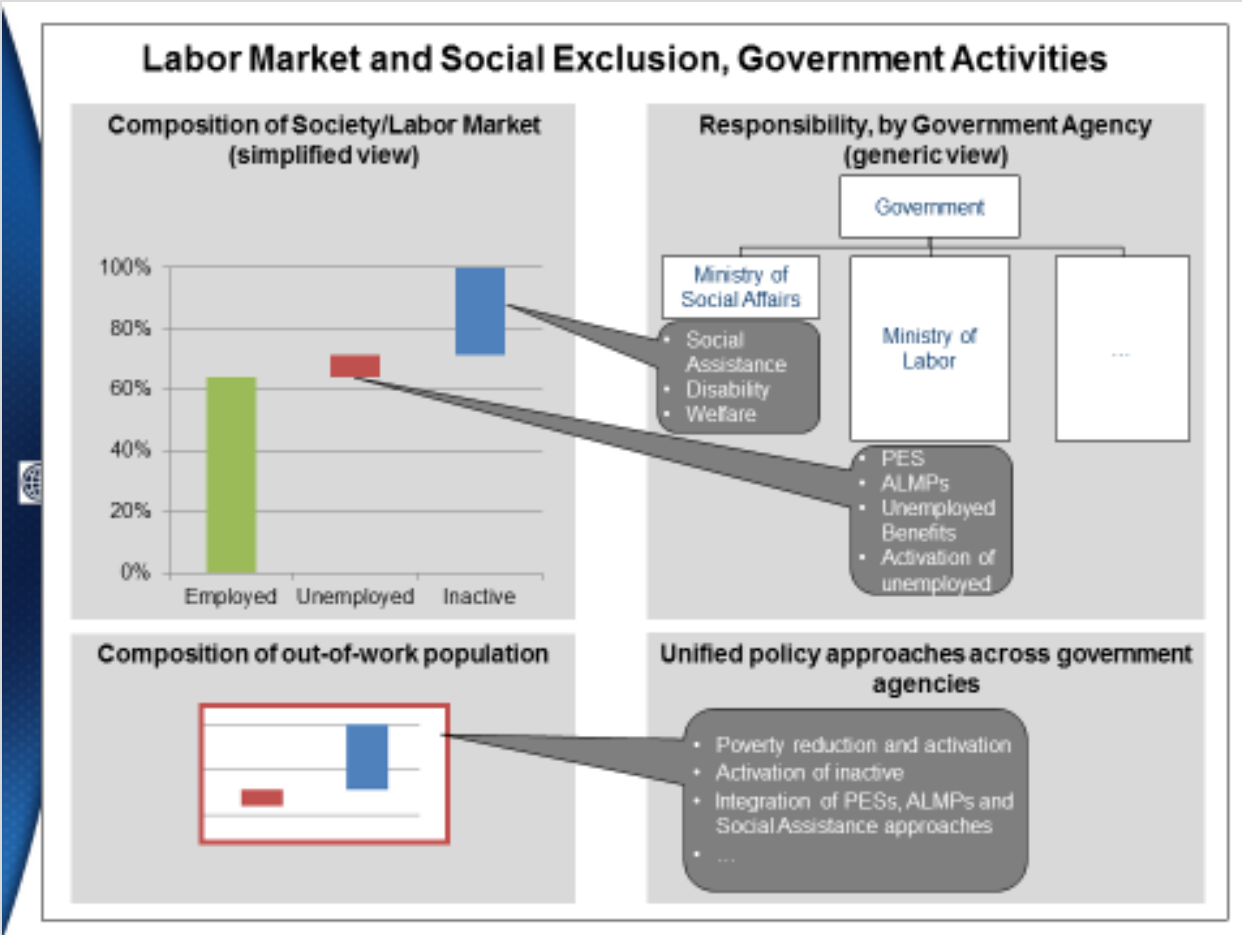

Source: World Bank staff assessment 2014

Portraits of Labor Market Exclusion analysis takes a comprehensive view of policy making, focusing on both the labor market attachment of a country's out-of-work population and the social assistance package and poverty profile of the same segment of the population. Through this examination of the characteristics of different subgroups, this analysis aims to contribute policy-relevant information about the social and economic risks these subgroups are facing, and on the barriers that hold back their labor market integration. In doing so, it can facilitate effective formulation and targeting of policies that seek to alleviate these barriers. In this sense, the portraits help move the dialogue on activation from a labor market-centric view to a broader dialogue that includes social policy as a whole. This is an important shift; for instance, social protection programs, such as family benefits and maternity benefits, and broader social policy issues such as retirement ages, often have a great impact on who remains inactive. By creating a space for dialogue between citizens and between different public organizations (social, labor, health, child care, and so on) who 
normally do not speak to each other, analyses such as Portraits of Labor Market Exclusion take additional steps toward more successful labor market inclusion of citizens.

Specifically, the report presents portraits of the out-of-work population of six countries (Bulgaria, Estonia, Greece, Hungary, Lithuania and Romania) in terms of distance from the labor market, human capital, and labor supply conditions, as well as demographic conditions. The analysis relies on the EU-SILC surveys for the years 2007 to $2011 .{ }^{1} 1$ Latent class analysis methodology allows multidimensional profiling of the out-of-work population, and identifies classes or groups of out-of-work individuals that are as homogeneous as possible within each class according to a set of observable characteristics, and as distant as possible between classes. In so doing, this analysis provide a much richer glimpse of the very different barriers to labor market integration that these various groups experience, considerably augmenting the limited amount of information contained in traditional descriptive statistics.

Box 1.1 tries to provide an intuitive understanding of latent class methodology, while Box 1.2 explains the statistical underpinning behind this methodology. The emerging profiles can then be contrasted with the design and targeting of current activation policies, to identify potential gaps and to enhance their design features.

\section{Box 1.1 Latent Class Analysis — a Sweet and Intuitive Example}

Latent class analysis (LCA) is used in several fields, including the medical profession and behavioral sciences, to identify hidden and underlying subgroups of individuals that share observable characteristics within a population of interest. To intuitively understand how this statistical methodology works, a simple example may help. WeMakeTheWorldHappier Ltd., a producer of "all things sweet," is interested in better understanding patterns behind the consumption of its products (ice cream, chocolate, and so on) among children and early teenagers so that it can more efficiently target marketing campaigns. Also, for prevention purposes, policymakers are trying to identify specific groups at risk of obesity or diabetes that are not noticeable to the naked eye. Now assume that individual surveys were conducted among a diverse group of children that included data on ice cream and chocolate consumption. Think of these data as "indicators," the noticeable symptoms of an underlying vulnerability or disease. For simplicity, let's say that individuals were asked about the frequency of their chocolate and ice cream (ab)use; each activity could be categorized as frequent/regular (I sneak to the fridge once dad and mom are asleep), occasional (unfortunately the fridge is usually locked at night), or non-existent (we have actually never seen such a child but we are told they exist).

\footnotetext{
1 Years the survey is available differ among countries analyzed.
} 
Furthermore, the survey collected information on certain main demographic characteristics (such as gender-we are told women enjoy chocolate more than men-age, and having siblings), and early-stage behaviors that are typically associated with high consumption of sweets (regular attendance at friends' parties, spending lots of time at grandparents' house(s), and regularly playing sports or not). Think of these as the main correlates of a given condition (for example, chocolate addiction); in LCA jargon, these are the active covariates. Finally, the survey includes other demographic information such as economic and social background, race, nationality, and so forth; in LCA terminology, these are the inactive covariates that will simply help describe the unobservable groups.

By running latent class analysis on the dataset, each child surveyed will be placed in a specific group (or latent cluster), based on his or her probability of answering the sweetsconsumption questions in a certain way given his/her active covariates (which, in this example, are the main demographic and behavioral characteristics). The number of groups obtained is not predetermined and will vary based on how well a certain model fits the available data; however, the groups are such that every individual can be assigned to one group only (the groups are mutually exclusive) and all observations will be assigned to a group (collectively exhaustive). Each group can then be further analyzed along additional demographic lines (the inactive covariates) that do not affect the fit of the model but allow us to get a more detailed profile of candy-devourers.

For illustrative purposes, LCA methodology applied to the described dataset will construct unobservable clusters of children that, given certain features, have the same probability of a certain pattern of consumption. For instance, LCA might detect the existence of a cluster of "will-eat-ice-cream-in-my-sleep" young children of both genders, who are very active, mostly started binge-eating ice-cream at their grandparents', and attend the birthday parties of every child in town (even if they are not invited). LCA might also define a smaller group of young chocolate-addicted girls who do well in school and have one or two older brothers who are often mean to them. It might identify a group of "candy monsters" (undiscriminating candy eaters), who consume as much chocolate and ice cream as they can, often stash goodies under their beds, live in open defiance of their desperate parents, are not very active in sports, and so on. The analysis could identify more clusters, each of which would differ from the others in at least one dimension. Knowledge of these groups would allow for the identification of early-warning signs of candy addiction, and would allow parents to take preventive measures. Note to kids: you may want to hide this research.

Source: Adapted from LCA Applied Example, The Methodology Center, Penn State University 


\section{Box 1.2 The Statistical Basis behind Latent Class Analysis}

Descriptive statistics enable the illustration of the heterogeneity of a particular population in a limited number of dimensions. Without other measures, it is challenging to synthetically describe individuals in the population according to their prevailing characteristics.

The main purpose of latent class analysis (LCA) is to identify an organizing principle for a complex array of variables. This latent variable model uses "categorical observed variables, representing characteristics, behaviors, symptoms, or the like as the basis for organizing people into two or more meaningful homogeneous subgroups" (Collins and Lanza 2010). Formally, LCA enables a characterization of a categorical latent (unobserved) variable, starting from an analysis of the relationships among several observed variables (named "indicators"), using a maximum likelihood estimation method. The estimation model used in this study also includes covariates, which are "variables that may be used to describe or predict (rather than to define or measure) the latent classes and if active, to reduce classification error" (Vermunt and Magidson, 2005).

Through LCA, individuals are scored according to the likelihood of belonging to each of the computed latent classes, and then assigned to the class to which they have the highest posterior probability of belonging (modal assignment) given their observed characteristics. Statistics such as the Bayesian Indicator Criterion (BIC) are used to identify the most appropriate number of classes, that is, the model that has on average the highest likelihood of predicting class membership for all individuals in the given sample.

A fundamental assumption underlying LCA is that of local independence, which implies that each of the chosen indicator variables is related to the others uniquely through the latent class membership, and a random error. Advanced computational techniques allow detecting and, in part, controlling for the correlation between the residuals of selected indicators, thus enabling the use of the available information to construct categories.

Source: Adapted from Collins and Lanza 2010; Vermunt and Magidson 2005.

The identification of latent classes relies on a number of "indicator variables" to capture different "symptoms" of an overall latent condition (in this case, joblessness). The challenge in such models is to identify a discrete number of variables that can best explain the heterogeneity of individual outcomes. In this report, two or three sets of categorical variables were selected to show the extent of labor market distance and to capture some of the main factors that can affect employment on the supply side: labor supply conditions (household-level incentives to work and physical ability to work), prior work experience, and human capital (Box 1.3 explains the definitions of labor market status and education levels used in this report).

In addition to indicators, the model includes active covariates, which are used to improve the classification of individuals into each class. Demographic variables that are normally used to disaggregate labor market outcomes, like age, gender, highest educational level achieved and degree of urbanization are typically active covariates.

Portraits of Labor Market Exclusion | 21 
Once the latent classes have been defined, inactive covariates that were not included in the model can be used to characterize the individuals in each class and the households in which they live in great detail. Examples of these covariates are variables that indicate household welfare conditions, such as income quintile, labor market status of a partner and household ownership, and variables for household demographics such as household size and whether the household has children under six years old, among others.

The resulting groups are then labeled according to their main distinguishing characteristics. Given that a large number of characteristics describe each group, often a few salient ones are used to name the group. In short, the labeling of groups can be considered more of an art than a science. However, the names do represent an important starting point in the design of social policies, and in the prioritization of activation policies.

Box 1.3 Definition of Labor Market Status and Educational Levels Used in this Report

In order to categorize the out-of-work population according to labor market status, we first use the EU-SILC household register variable corresponding to the self-defined current activity at the time of the household interview. This variable allows for the classification of individuals as employed, unemployed, retired, or "other inactive." Next, the variable from the personal questionnaire, in which individuals again self-define their labor market status, is used to further classify the inactive into disabled or "other inactive." ${ }^{2}$ The EU-SILC selfdefined employed status differs from the standard ILO (International Labor Organization) definition used in European Union Labor Force Surveys (EU-LFS), which classifies as employed anyone who has worked for at least one hour or had a job from which they were temporarily absent during the reference period. Self-reporting of employment may lead to a larger out-of-work population, to the extent that individuals working very few hours may not perceive themselves as employed. In the same vein, the EU-SILC definition of unemployment also differs from the standard ILO definition, which restricts the unemployed to those who have actively searched for work during the reference period (usually two to four weeks) and who are also available for work in the near future. ${ }^{3}$ Moreover, it is worth noting that because disability status (that is, permanently disabled or unfit for work) is also based on self-perception, individuals who self-report as disabled do not necessarily also report limitations on their activities due to health problems, and vice versa. Finally, in this report, individuals who self-define as unemployed are further classified as (short-term) unemployed and long-term unemployed. Specifically, individuals who report having been unemployed for the calendar year prior to the survey year are considered to be long-term unemployed.

\footnotetext{
2 Individuals aged 16 to 24 who self-classified as students were excluded from the sample.

3 This explains why a variable indicating whether or not the individual has been engaged in an active job search is also included as part of the inactive covariates that describe the clusters.
} 
As regards the education variable used as an active covariate, this variable is divided into three main categories: primary, secondary, and tertiary. Primary education refers to individuals who have completed at most ISCED ${ }^{4}$ level 1; secondary refers to individuals who have completed at most ISCED level 3 (upper secondary school) and tertiary refers to individuals who have completed ISCED levels 5 or 6 (the first or second stages of tertiary education). ${ }^{5}$ In order to provide greater detail on educational attainment, education levels are further disaggregated in the list of covariates, this time among the six ISCED levels: distinguishing between no education or some primary education; primary; lower secondary; upper secondary; post-secondary; and tertiary (levels 5 and 6 are combined into one level due to a very low number of out-of-work individuals with level 6 education, that is, doctoral degrees). Unfortunately, EU-SILC data does not provide further detail regarding the qualification status of individuals, such as vocation versus general education, or any training or certificates received.

Source: World Bank staff analysis 2014

The overarching objective of this activity is to help reduce the risk of poverty and/or labor market exclusion by strengthening the evidence base for designing and targeting income support, activation, and employment support policies. In this sense, LCA is not an operational tool, but one that can guide policy making.

Nevertheless, "without demand, everything is nothing in the labor market." In economies where there is little or no growth, it is difficult to create demand for workers in an open labor market, even with the most sophisticated profiling and targeting of activation policies. This is not to say that labor supply side interventions like training, activation or payment of benefits (linked to activation) would be useless, but they can only "grease the wheels" of the labor market. Linkage of activation with job creation and local economic development policies, enterprise growth policies and overall market conditions is critical.

A second caveat arises from the use of survey data from 2011. The suggestions for future policy discussions have been derived from the analysis of the EU-SILC data from 2007 to 2011. Since that time, general economic development and country level policy reforms might have improved the labor market integration and activation of some of the groups identified. The World Bank team remains willing to use national EU-SILC complete datasets to update analysis and provide more up-to-date results (provided additional reimbursement advisory services_-RAS— or trust funds are available).

The report presents the analysis for six countries: Bulgaria, Estonia, Greece, Lithuania, Hungary and Romania. The current set of countries represents a pilot group for this firsttime analysis. The priority for analysis in these countries was decided by the European Commission, Directorate General of Employment, Social Affairs and Inclusion (EC DG EMPL),

${ }^{4}$ ISCED refers to the International Standard Classification of Education, developed by UNESCO (United Nations Educational, Scientific and Cultural Organization) in order to facilitate the comparison of education statistics and indicators across countries.

5 The educational classification used in EU-SILC data is the International Standard Classification of Education (ISCED1997), coded according to the seven ISCED-97 categories.

Portraits of Labor Market Exclusion | 23 
in light of recent economic and labor market developments. The World Bank team contributed advice on the selection of countries. The country-specific reports provide a starting point to the discussion and the enrichment of the country-specific recommendation process of the European Semester. Table 1.1 presents some key statistics for the selected countries.

Table 1.1 Key Statistics of Selected Countries (2013)

\begin{tabular}{|c|c|c|c|c|c|c|}
\hline Country & Flag & $\begin{array}{l}\text { Population } \\
\text { (annual } \\
\text { average, } \\
\text { thousands) }\end{array}$ & $\begin{array}{c}\text { Inactive } \\
\text { Population } \\
\text { ( } \% \text { of } \\
\text { population } \\
\text { aged } 15 \text { to } 64 \text { ) }\end{array}$ & $\begin{array}{c}\text { GDP } \\
\text { (Millions } \\
\text { of Euro) }\end{array}$ & $\begin{array}{c}\text { GDP per } \\
\text { capita(Euro) }\end{array}$ & $\begin{array}{c}\text { GDP } \\
2013 / \\
\text { GDP } \\
2008\end{array}$ \\
\hline Bulgaria & & 7,242 & 31.6 & 39,940 & 5,500 & 0.98 \\
\hline Estonia & & 1,316 & 24.9 & 18,435 & 13,800 & 1.01 \\
\hline Greece & 现 & 10,999 & 32.0 & 182,054 & $16,466^{*}$ & 0.77 \\
\hline Hungary & & 9,779 & 34.9 & 98,071 & 9,900 & 0.95 \\
\hline Lithuania & & 2,960 & 27.6 & 36,601 & 11,700 & 0.98 \\
\hline Romania & & 21,286 & 35.4 & 142,245 & 7,100 & 0.98 \\
\hline
\end{tabular}

The Portraits of Labor Market Exclusion country analysis reports were written based on EUSILC/Eurostat data according to a common methodology. After a first draft was submitted by the World Bank team, a first review with the respective EC DG EMPL Country Desk was conducted in Brussels. Following feedback, changes and additions received from these meetings, a second draft of the report was presented and discussed during joint country missions of EC DG EMPL and the World Bank with the respective Member States. Joint country missions occurred on the following dates (all 2014): Bulgaria (January 23), Lithuania (March 13), Estonia (March 14), Romania (April 7), Greece (April 10), Hungary (April 25). During and after the joint country missions, Member States provided feedback and additional material for the reports.

The report proceeds as follows: Chapter 2 starts by presenting an overview of the general economic background and unemployment situation of the countries, followed by the main facts. The following chapters present Portraits of Labor Market Exclusion reports for each country separately. 


\section{Box 1.4 Limitations of EU-SILC Data}

This report relies on 2011 harmonized EU-SILC data (published in 2013) in order to present profiles of the out-of-work population according to their socio-economic and labor market characteristics. EU-SILC data, as opposed to EU-LFS data, was chosen for this analysis because it provides more detailed information regarding income; EU-LFS income data, on the other hand, is limited to labor earnings and does not provide information on income from benefits ${ }^{6}$ or other sources. Having this more comprehensive income information is useful for prioritizing interventions among the identified clusters according to their risk of poverty, an important welfare dimension. Furthermore, EU-SILC data allows for the identification of broad categories of benefits received, as well the percentage of household income that can be attributable to benefits. Again, this type of information can be instrumental in analyzing the current welfare situation of the out of work, as well as in formulating active inclusion policies. Despite this comparative advantage of EU-SILC data, there are some limitations to the data that are worth mentioning.

One limitation of EU-SILC data is that it does not result in the same official labor market statistics that are officially reported by Eurostat using the EU-LFS surveys. There are several reasons for this. First, the anonymized EU-SILC data provided by Eurostat relies on selfreported labor market status, rather than the standard ILO definitions used by EU-LFS. Selfdefinition of employment may overestimate the out-of-work population if individuals who work few hours self-identify as inactive, and unemployment may be overestimated if individuals self-identify as unemployed because of their willingness to work rather than their engagement in an active job search and availability for work in the near future. While the individual EU-SILC country questionnaires may allow for the calculation of official ILO labor market status, the May 2011 description of target variables provided by Eurostat suggests that only out-of-work individuals below the official retirement age should be asked if they have been actively searching for a job. Thus, unemployment may be underestimated among the population under 64 years of age that has already reached retirement age. Another important difference between the two data sources is the time horizon; the EU-SILC survey is conducted only at one point during the year, whereas the EU-LFS survey is conducted continuously throughout the year. Lastly, the EU-LFS survey includes individuals as young as 15 , while EU-SILC only surveys individuals aged 16 and over in its personal questionnaire.

${ }^{6}$ The EU-LFS survey only includes information regarding whether or not unemployment benefits are received. 
Unlike EU-LFS data, EU-SILC survey data also provide relatively little detail concerning the educational status of individuals. In particular, the EU-SILC survey only allows for differentiation by highest ISCED level achieved. In contrast with the EU-LFS survey, no information regarding vocational versus general education, field of study, or additional training or certifications is provided. More detailed knowledge regarding the qualifications of the out-of-work would be useful for tailoring active labor market policies, especially those related to training. Nonetheless, it is worth noting that even with a more detailed survey, sample limitations may still generally preclude the labeling of clusters according to their educational status. In this report, education was only used in a cluster's label if a clear pattern emerged, with the education status of its members visibly differentiated from that of other groups.

Another limitation of EU-SILC data concerns benefit data. The anonymized EU-SILC databases provided by Eurostat aggregate social benefits according to nine categories: oldage, survivor, family/child, unemployment, sickness, disability, social exclusion, housing, and education. While this categorization can be useful, it is nonetheless limited. On the one hand, "unemployment" and "old-age" benefits do not distinguish between social insurance and social assistance. This distinction would be helpful for evaluating the targeting of social benefits toward more socially disadvantaged groups. What is more, family/child benefits are not differentiated, for example, between child benefits and maternity leave. These two types of benefits can have profoundly different effects on female labor force participation. Differentiating between the two could also aid in further research on how benefits affect women's decisions to participate in the labor market. Perhaps in the future Eurostat could categorize individual EU-SILC country data regarding benefits in such a way that at least the contributory or social assistance nature of benefits can be identified.

Some of the profiles of the out-of-work, especially those who are most vulnerable due to low education levels, unemployment, and at-risk-of-poverty status, may comprise a significant portion of the Roma population. However, we can only arrive at this conclusion because of what is known about Roma from other sources. EU-SILC survey data do not include information regarding ethnicity. ${ }^{7}$ Knowledge of which groups include Roma, and to what extent, can aid in prioritizing policies that aim toward Roma inclusion, including reaching out to their often isolated communities and addressing discrimination in the work force. Information regarding ethnicity could aid in making the vulnerable situation of out-of-work Roma more visible, and even perhaps in eliminating stereotypes of Roma as not being interested in participating in the labor market and actively seeking work. As mentioned in this report, the integration of Roma in the labor market is not only a moral imperative but also smart economics in light of the aging populations and shrinking working-age populations among EU countries with significant Roma populations.

${ }^{7}$ EU-LFS surveys also do not inquire about ethnicity. 
Finally, it is worth pointing out that latent class analysis benefits greatly from large sample sizes, as they allow for a larger number of clusters to be identified that can be differentiated from each other with a certain degree of statistical significance. A larger number of identified clusters can result in identified clusters that are more homogenous within themselves and more heterogeneous among each other. It is possible that with a significantly larger sample size, similar to that of the EU-LFS surveys, ${ }^{8}$ a greater number of, and more importantly, more homogenous clusters of out-of-work population could be identified, allowing for the formulation of policies that are even more specifically tailored toward the activation potential and need faced by each group.

Source: World Bank staff analysis 2014

8 Depending on the country, EU-LFS surveys can include 10 times more observations than EU-SILC surveys. 


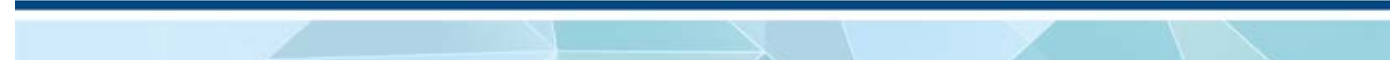

28 | Portraits of Labor Market Exclusion 


\section{Portraits of Labor Market Exclusion}

\section{General Economic Background}

After years of moderate growth, Europe was adversely impacted by the global financial crisis and has yet to fully recover. For the countries presented in this study, the period leading to the global financial crisis was one of high output growth. Bulgaria, Estonia, Lithuania and Romania all grew at over 6 percent on average from 2003 to 2007 (Figure 2.1), more than twice the average rate of the region as a whole.

\section{Figure 2.1 Annual Real GDP Growth (2003 -2013)}

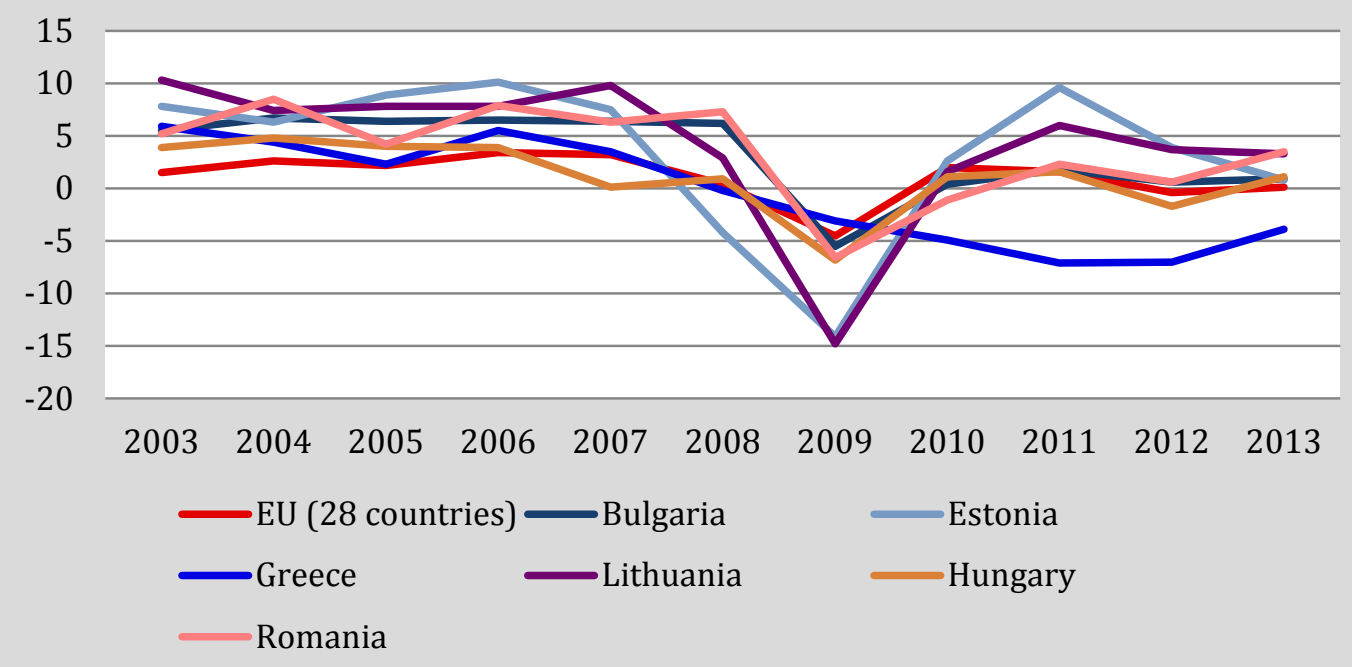

Source: Eurostat

The timing and magnitude of the contraction that followed the crisis varied among the countries in the region. On average, the economies of the six countries analyzed contracted 8.5 percent during 2009. While Lithuania and Estonia recovered from the shock more quickly and have since experienced positive growth rates, post-crisis growth in Bulgaria, Hungary, and Romania has been more anemic, and has not reached pre-crisis growth levels. Greece, meanwhile, continued to contract through 2013, with GDP declining by almost 25 percent since the onset of the crisis.

As the crisis unraveled, unemployment rates deteriorated sharply. As unemployment rose, young workers were among the worst affected - an adverse situation that was observed in all six countries. Youth unemployment in Greece was a staggering 58 percent in 2012, and one-fourth of the 15-to-24 cohort remained without a job in Bulgaria and Hungary at the end of 2013. 
Figure 2.2 Gender Gap in Unemployment Rates (2003-2013)

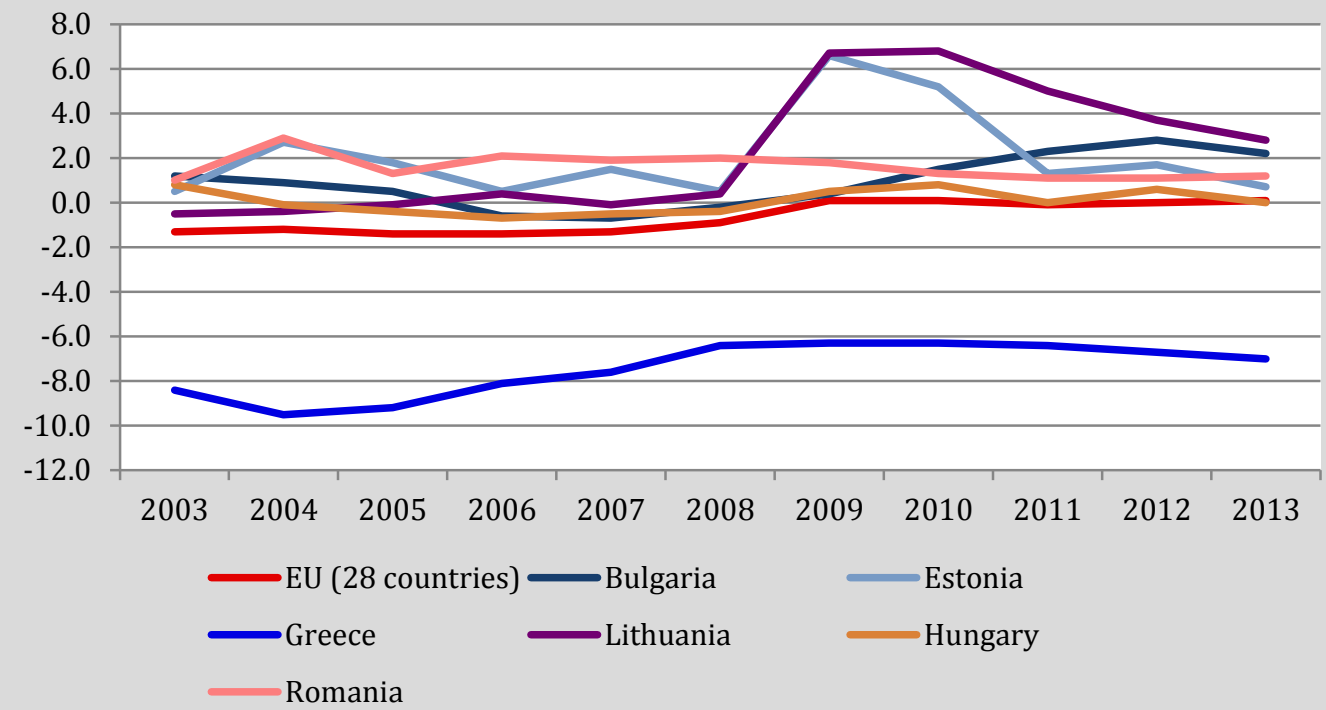

Source: Eurostat, EU-LFS

Note: Gap is calculated by subtracting the female unemployment rate from the unemployment rate of males.

Figure 2.3 Long-Term Unemployment as a Share of Total Unemployment (2003-2013)

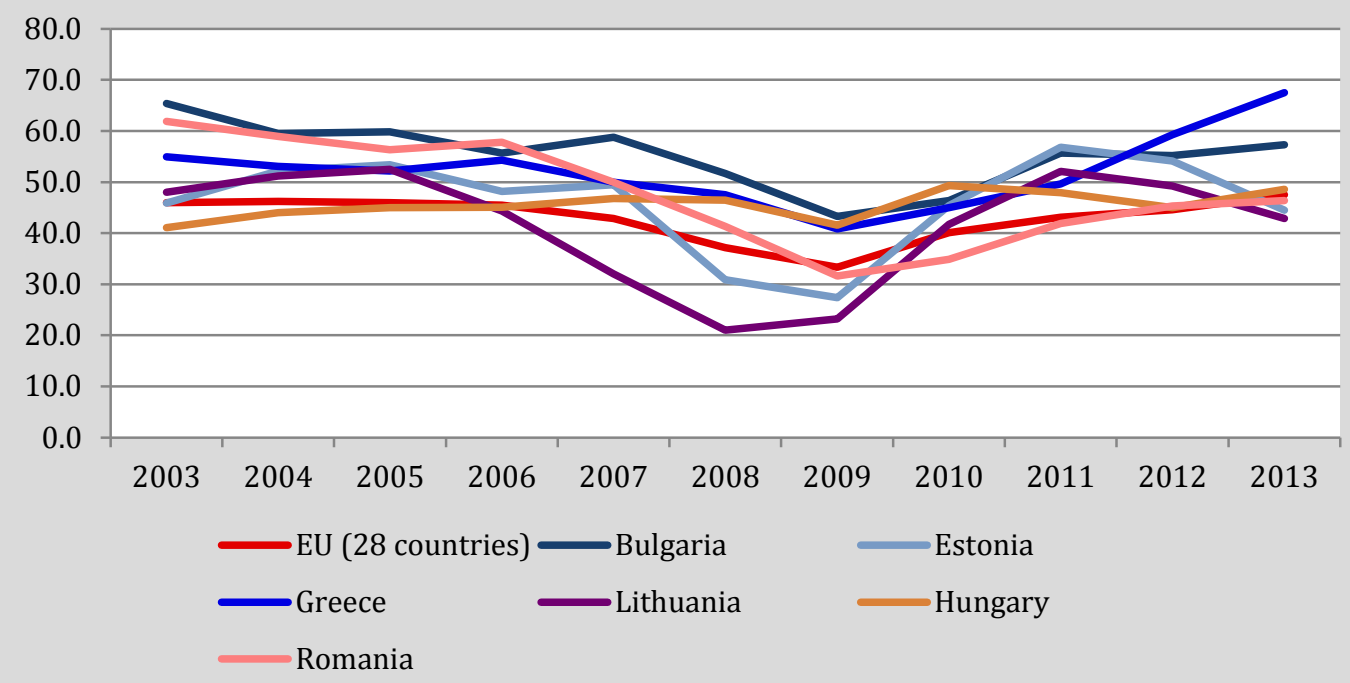

Source: Eurostat, EU-LFS

A look at the unemployment rates disaggregated by gender shows that there is no common pattern among all the countries. For the average EU-28 member country prior to the crisis there was a difference of less than 1 percent between the unemployment rate of men and women, a difference that disappeared after 2009 (see Figure 2.2). Greece is the only country 
where women had higher unemployment rates throughout the period, with gaps ranging from 6.3 to 9.5 percentage points.

One of the most worrying developments of the crisis is the significant increase in the share of long-term unemployed. In 2013, as shown in Figure 2.3, more than 47.5 percent of the unemployed had been looking for work for more than 12 months in the average EU-28 country. For Bulgaria and Greece, more than half of the unemployed are long-term: 57.3 percent in Bulgaria and 67.5 percent in Greece.

Employment levels also deteriorated following the crisis. The average employment rate for the EU-28 had been slowly rising and peaked at 65.7 percent in 2009; it had fallen to 64.1 by 2013. The fall in employment in some of the countries studied was more pronounced. After six years of recession, employment in Greece had fallen more than ten percentage points, from 61.9 to 49.3 percent, from 2008 to 2013.

In summary, the global financial crisis impacted both output and employment outcomes in the EU region. While the magnitude and timing of the crisis and subsequent recovery have varied in the countries studied, unemployment levels are still above pre-crisis levels. Of particular concern are the increase in the share of long-term unemployment and the adverse labor situation that youth face. These, along with other key structural issues that have emerged from the analysis of the EU-SILC data of the countries, are discussed in the following section. 


\section{Stylized Issues Emerging from the Analysis}

The analysis of the EU-SILC data using latent class methodology in this report focuses on the out-of-work among the working-age population (16- to 64-year olds). ${ }^{9}$ Only the working-age population is analyzed because labor activation options-the main policy focus of this note-are only viable for that segment of the population.

The total out-of-work population analyzed in this document has increased in five of the six countries studied (see Figure 2.4). Estonia and Lithuania had the greatest increase in the out-of-work population, both increasing 33 percent from 2007 to 2011, but they had the smallest increase in terms of absolute number of individuals (55,000 and 152,000, respectively). In Greece this group increased almost 26 percent, by more than 550,000 people. Hungary had a small increase in the out-of-work population $(25,000)$, but had the highest share of out-of-work in 2008 and second highest in 2011 (37 and 38 percent respectively). Only in Romania did the out-of-work population decrease (2.5 percent or $106,000)$, but it remains a large share of the total working-age population (31.2 percent).

Figure 2.4 Out-of-Work Population (in Thousands) and Share of Total Working-Age Population, 2007( $\left.{ }^{*}\right) / 2008$ and 2011
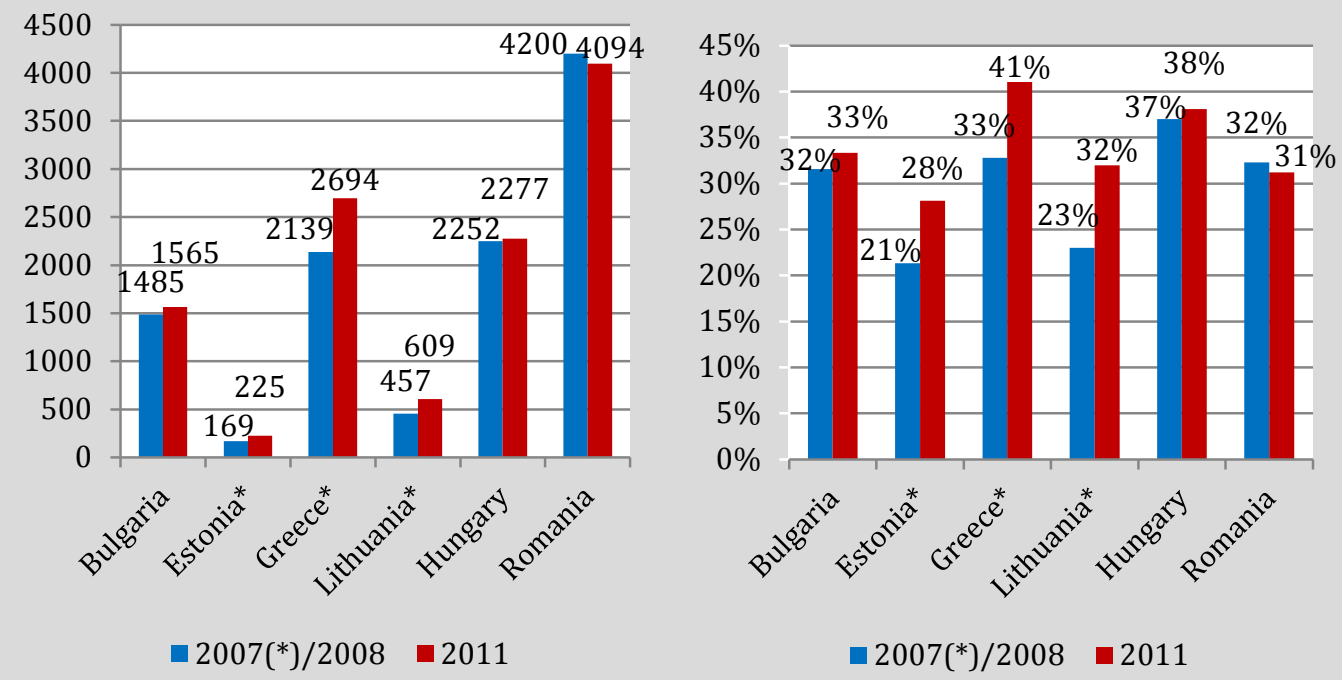

Source: World Bank staff analysis based on EU-SILC.

Such increases in the out-of-work population are of great concern, particularly given the rapidly aging populations in these countries. As expenditures on pension and disability

\footnotetext{
${ }^{9}$ Specifically, only individuals aged 25 to 64 years who are not employed, and individuals aged 16 to 24 who were not employed, in education or training are considered. Individuals aged 16 to 24 who are out of work and enrolled in education are excluded from the sample; they are considered to be investing in their final stages of human capital formation and therefore are not a particular target group for activation policies. Individuals aged 25 and 64 enrolled in school are, however, included in the latent class analysis and will be grouped under "other inactive." It is important to note that this group of students, those older than 24, accounts for only 1 percent of total population of working age in each of the countries studied.
} 
benefits are expected to continue to grow, increasing labor force participation rates and addressing the barriers to employment of the various groups emerge as priorities to sustain the economic recovery and overall standards of living.

Addressing barriers to employment effectively requires first understanding the distinct groups that make up the out-of-work population. This report determines such groups using latent class methodology. Integration of distinct groups into the labor market may involve a variety of solutions - such as increasing the transport options for rural populations, providing young mothers with child-care options, back-to-work bonuses, and so on. Developing comprehensive solutions to the barriers faced by the distinct groups identified is outside the scope of this report. Rather, this report focuses on the first step in this process: developing distinct "portraits" of the out-of-work.

The characteristics of the groups of out-of-work population vary from country to country. Based on the EU-SILC survey for 2011, Estonia, Bulgaria, and Greece have seven groups of out-of-work individuals, while Lithuania and Romania have eight groups, and Hungary has ten. Nevertheless, there are some general groups that can be identified in all six countries. Clusters of middle-aged unemployed, long-term unemployed, retirees, disabled, inactive women or mothers, NEETs (young people not in employment, education or training) and young unemployed are present in every country. The size, share and profile characteristics of these groups differ, reflecting the demographics and labor market of a particular country.

Detailed findings for the groups in each country are presented in their respective country chapters. In this section, we draw the main stylized facts that emerge in common across these countries. Against the backdrop of the economic crisis and recovery in the European Union, the analysis yields a number of insights across countries.

\section{Middle-aged Job Losers}

In most countries, the number of middle-aged job losers has grown in absolute and relative terms. This issue is observed in Greece, Bulgaria, and Lithuania, where clusters of middleaged unemployed account for around 20 percent of the out-of-work population. In Lithuania, there are two middle-aged unemployed groups, the middle-aged poor rural long-term unemployed and the middle-aged educated unemployed family men. Together they represent 37 percent of the out-of-work population of 2011. Most concerning is that the middle-aged poor rural long-term unemployed cluster more than tripled in number between 2007 and 2011, and the share that have been unemployed for more than 12 months grew from 49 to 71 percent. Although part of the increase may be ascribed to the global downturn, this group of low-income unemployed adults is now a structural feature of the Lithuanian labor market.

In Estonia, the largest cluster identified in 2011 is also composed mainly of middle-aged individuals, but unlike the groups mentioned above, 92 percent declare themselves as disabled (and thus not unemployed, but rather, inactive). This group represents 21 percent of the out-of-work population in 2011, has grown significantly since 2007 (24 percent) and is at high poverty risk, ${ }^{10}$ as more than half of it is in the poorest income quintile and only 35

${ }^{10}$ See text box below for a definition of "at-risk-of-poverty."

Portraits of Labor Market Exclusion | 33 
percent of households have at least one working adult. Although a large majority declare themselves to be disabled, and 93 percent say they receive disability benefits, only 43 percent report that they have strong limitations in performing their usual activities because of health problems.

Households confronted with job losses face increased poverty risk, owing partly to limited benefit receipts (a low level of social inclusion benefits or the short duration of unemployment insurance benefits) and to large household sizes. Some households were able to counter such job losses, possibly with the labor market entry of another household member.

\section{Box 2.1 At-Risk-of-Poverty Rate in the EU and in This Report}

According to Eurostat, "the at-risk-of-poverty rate is the share of people with an equivalized disposable income (after social transfers) below the at-risk-of-poverty threshold, which is set at 60 percent of the national median equivalized disposable income after social transfers. This indicator does not measure wealth or poverty, but low income in comparison to other residents in that country, which does not necessarily imply a low standard of living." The table below shows the "at-risk-of-poverty rate" in the six countries covered in this report, as reported in the Eurostat data base and based on EU-SILC 2011 data.

\section{Country}

Eurostat "At-risk-of-poverty rate" (2011) ( $\%$ of population below $60 \%$ of median income)

\begin{tabular}{|ll|}
\hline Bulgaria & 22.2 \\
\hline Estonia & 17.4 \\
\hline Greece & 21.3 \\
\hline Lithuania & 19.2 \\
\hline Hungary & 13.8 \\
\hline Romania & 22.2 \\
\hline
\end{tabular}

However, for this report's purposes, we define the at-risk-of-poverty rate as the relative risk of being in the first quintile of the income distribution. This enables us to provide more detail on the analyzed population. Instead of simply presenting clusters along the "at risk of poverty" or "not at risk of poverty" dimension, we present income information for all clusters divided by quintiles, and we refer to the first quintile as "at risk of poverty." Furthermore, as shown in the table above, in five of the six countries analyzed in this report the at-risk-of-poverty rate in 2011 as defined by Eurostat was very close to 20 percent (that is, it was very similar to the probability of falling in the bottom quintile of a country's income distribution). In other words, by looking at the first quintile of the income distribution in all countries except Hungary, one can get a good sense of what the at-risk-of-poverty rate would look like if defined following Eurostat's guidelines.

Sources: http://epp.Eurostat.ec.europa.eu/statistics_explained/index.php/Glossary:At-risk-ofpoverty_rate 
An increase in the size of the NEET population was also observed in many countries, with young adults continuing to live in multi-generational households and struggling to enter the labor market. Labor force participation was low among youth in many of the countries studied to begin with (see Figure 2.5). Further, the percent of young individuals aged 15 to 24 that are not in employment, or education, or training (NEET rate) was high and increased in all countries following the crisis (Figure 2.6). For the region as a whole, the NEET rate, which had fallen to 10.9 percent in 2008, in 2013 was back at 2003 levels (13 percent).

Figure 2.5 Labor Force Participation Among Youth Aged 15 to 24, European Countries, (2013)

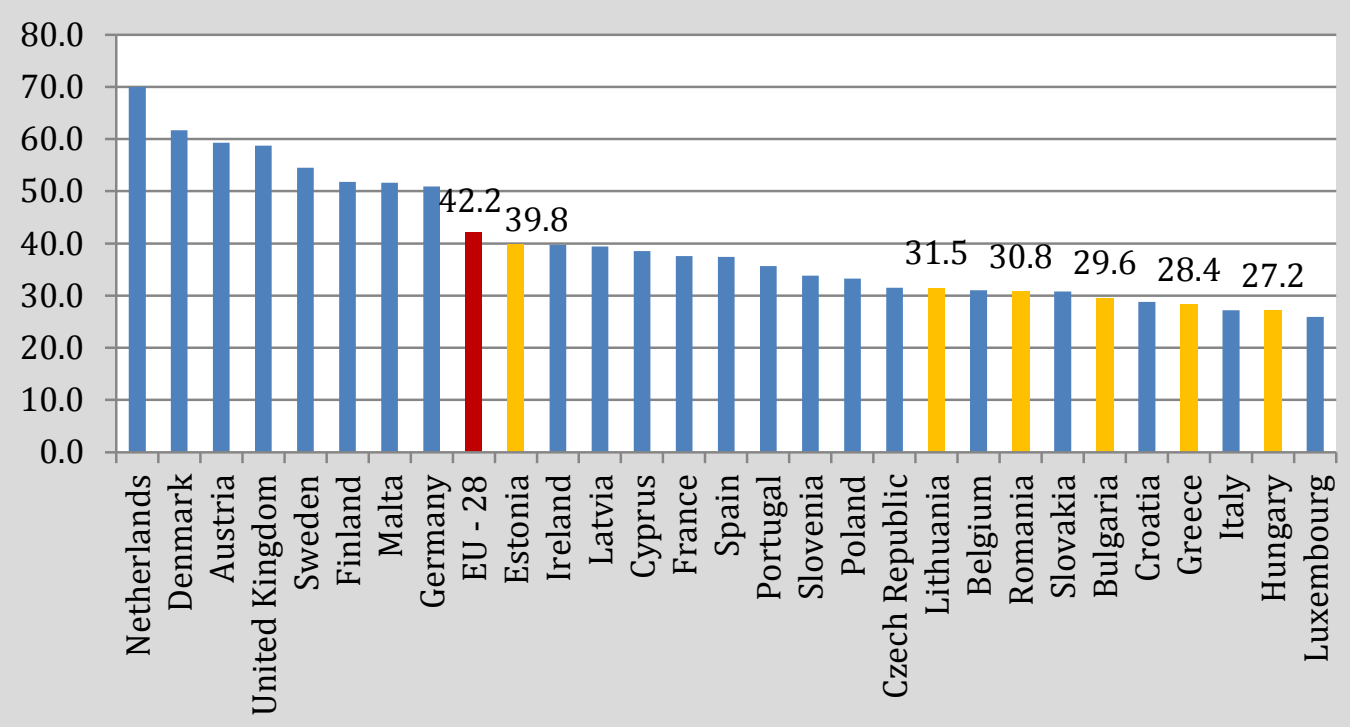

Source: Eurostat, EU-LFS

The adverse labor situation faced by youth is also captured in the latent class analysis of the EU-SILC data. In all six countries analyzed, it is possible to identify a cluster of youth or NEETs that make up an important share of the out-of-work population. In Estonia this cluster almost doubled in size from 2007 to 2011 (from 11,000 to 20,000 individuals). The NEET cluster in Greece grew more than 25 percent from 2007 to 2011 and accounted for almost half a million individuals in 2011. In Bulgaria, on the other hand, this cluster grew from 197,000 individuals in 2008 to 233,000 in 2011. About 80 percent of the Estonians, 60 percent of the Bulgarians, and 46 percent of the Greeks in these clusters have no prior work experience, and around 40 percent of the Estonians and Bulgarians belong to the first income quintile (27 percent of the Greeks do). The activation of these individuals should be a priority for policymakers, to avoid the further depreciation of the stock of human capital among these young individuals and to promote their long-term wellbeing. 
Quite importantly, some of the NEET clusters in the portraits include individuals above the age of 24 (the usual age limit of NEET categorization). ${ }^{11}$ It may be crucial to ensure that such young adults, who continue to remain vulnerable, are also considered for first-time labor market entrants' programs.

Figure 2.6 NEET Rates, European Countries, (2008 and 2013)

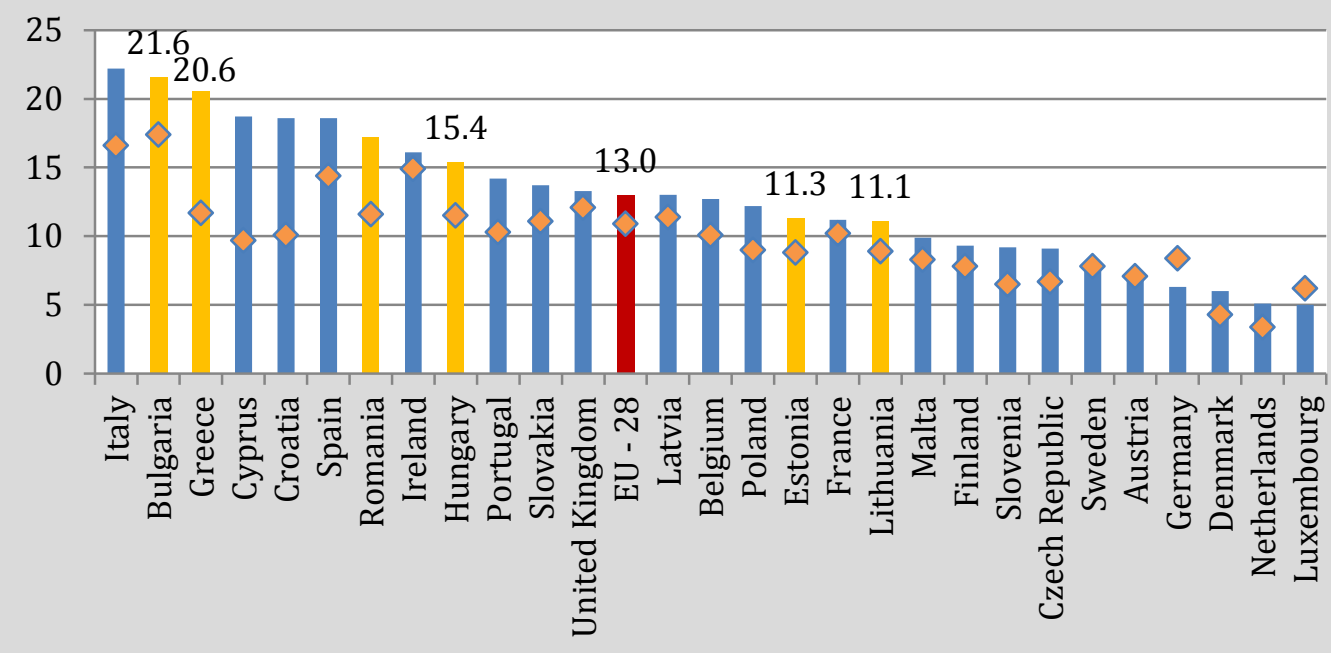

- $2013 \diamond 2008$

Source: Eurostat, EU-LFS

Note: NEET rate is calculated as the percentage of the population aged 15 to 24 that is not in employment, education or training.

\section{Early Retirees}

The labor force participation rate for older people in the countries under study is, in general, among the lowest in Europe. As Figure 2.7 shows, this is especially true for Romania, Greece and Hungary, whose labor force participation rate for both the 55- to 59-year old and 55- to 64-year old cohort is much lower than the EU-28 average of 70.3 and 54.3 percent, respectively. The low labor participation for the 55- to 64-year old cohort may reflect in part that a relatively high percentage of the population aged 60 to 64 have reached retirement age in all these countries, particularly among females.

Retirees (below 64 years) and early retirees (in this report, below 60 years) are a noteworthy phenomenon in most of the countries under study. Many of the members in these profiles also declare themselves to be limited in their ability to work. In many countries, the welfare position (risk of poverty) of the retiree and early retiree households is rather favorable in comparison to the other out-of-work population groups (due to low but stable retirement income, small household sizes, and so forth).

11 Thirty-five percent of the individuals in the NEET cluster in Bulgaria are between 25 to 34 years old. This share is 18 percent in Estonia, while in Greece 60 percent are in this age group. 
Retirement and disability are the main reasons for the population in these age groups to be out of the labor market. Indeed, it is possible to identify clusters of retired or disabled individuals in all the countries analyzed, and in some cases they make up an important portion of the out-of-work population. Disabled individuals, on the other hand, identified either because they declare their labor market status as disabled or otherwise declare strong limitations on daily activities due to health conditions, make up more than 20 percent of the out-of-work population in Estonia, Lithuania and Hungary. The combination of rising numbers of disabled individuals and an aging population will likely increase expenditures on disability benefits and old-age pensions that governments will have to pay in the coming decades. As the working-age population shrinks and life expectancy grows, raising the retirement age and increasing labor force participation among older individuals may prove important to counteract a shrinking workforce and the increasing fiscal costs related to aging.

Figure 2.7 Labor Force Participation as Share of Age Group, European Countries (2013)

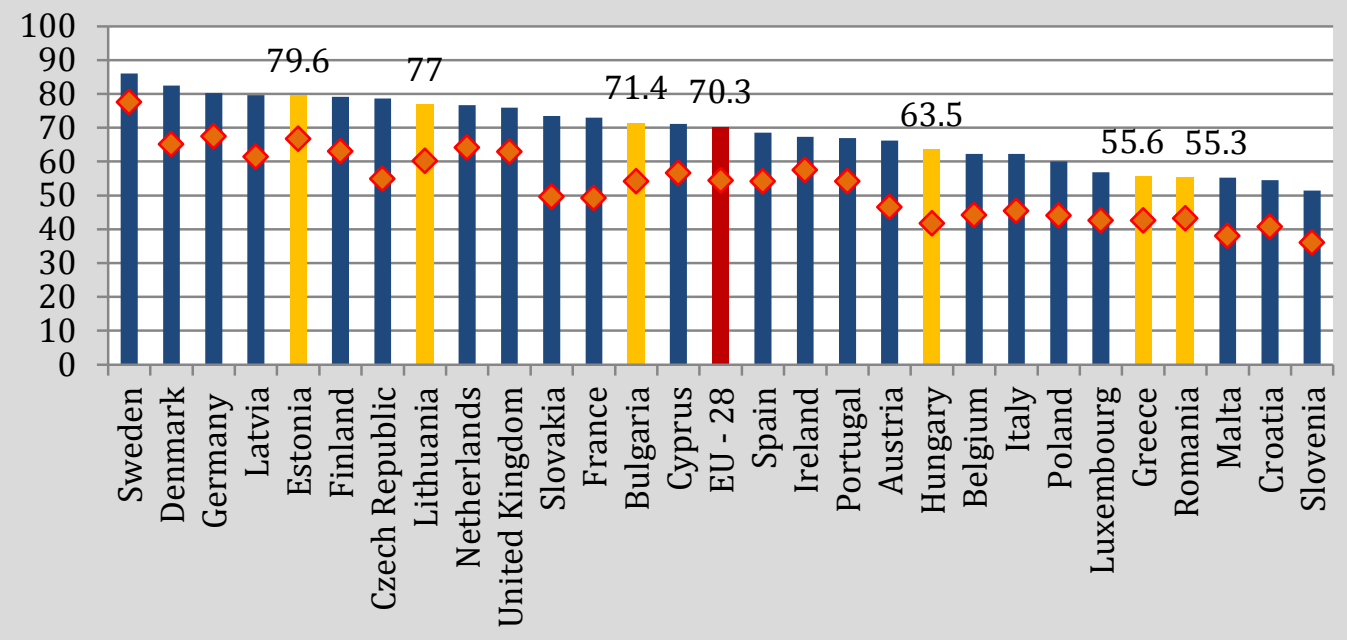

- 55 to 59 years old $\diamond 55$ to 64 years old

Source: Eurostat

Early retirees account for around half of the out-of-work population in Romania and 30 percent in Hungary. In Romania, half of these people, almost one million individuals, have not reached retirement age; in Hungary, almost 40 percent of the mostly male early retirees and retirees cluster are between 45 and 59 years old. ${ }^{12}$ In Bulgaria, two clusters contain a large number of early retirees: retired and early retired men and low-educated early retired and disabled; together they represented 16 percent of the out-of-work population in 2011. In the first cluster, almost half are between 45 and 59 years old, ${ }^{13}$ while in the second one, all of them are under 59 years old, and half of them are retired (another 40 percent are disabled).

12 Another 4 percent are 35 to 44 years old.

13 Another 6 percent are 35 to 44 years old.

Portraits of Labor Market Exclusion | 37 
A cluster of early retirees also emerged in Greece after the crisis, accounting for 6.7 percent of the out-of-work population. A striking difference is that almost 70 percent have tertiary education, unlike the early retiree clusters in the other countries, whose members mostly had only secondary educations. Also, more than half of the early retirees in Greece are in the richest income quintile; 77 percent are in the top two income quintiles. Given the dire economic situation in Greece since 2009, early retirement may be an attractive alternative in times of high unemployment.

On the other hand, clusters of mainly retired women appear in Lithuania and Hungary throughout the years analyzed, but their shares have been reduced over time. In Lithuania the married rural women with old-age pension cluster's share decreased from 25 percent in 2007 to 18 percent in 2011. Similarly, in Hungary, the urban retired women cluster's share also decreased from 20 percent in 2008 to 15 percent in 2011. Unlike the other two countries, the retired women cluster in Bulgaria emerged in 2010, separating from the retirees cluster identified the previous years. It represented a share of 20 percent of the outof-work population in 2011.

\section{Inactive women and stay-at-home mothers}

Inactive women and stay-at-home mothers can be identified as distinct categories in some countries.

The high rates of inactivity in the working-age population, particularly among women, are an issue of concern in most of the countries analyzed. Around a third of the population between 15 to 64 years of age in Hungary, Romania, Bulgaria and Greece does not participate in the labor market. On the other hand, the share of inactive women is over 40 percent for Romania, Hungary and Greece, while this share is, on average, 34.1 percent in the EU-28 countries in 2013. On average, these three countries had a gap of more than 15 percentage points between female and male participation rates (Figure 2.8).

When looking at the EU-SILC data, clusters of inactive women are clearly identified in most of the countries. In Greece, the top group of the out-of-work population is made up largely of inactive women. In Hungary, the group of inactive women accounts for 17 percent of the outof-work population, while in Romania the clusters containing inactive women make up more than 30 percent of the out-of-work population. Similarly, a stay-at-home female cluster is found in Bulgaria, Estonia and Lithuania, accounting for 12, 17 and 5 percent of the out-ofwork population in 2011, respectively.

The large groups of inactive women can be explained in part by cultural and social reasons or by the limited availability of formal child care and elder care facilities. Figure 2.9 shows that access to formal child care in all six countries is well below the 29 percent average of the EU-28. Lithuania, Hungary, Bulgaria and Romania all have less than 10 percent of children under three years of age in formal child care. For Hungary and Estonia, the percentage of women 25 to 49 years old who reported being inactive in 2013 because they were looking after children or incapacitated adults was 56.5 and 73 percent, respectively. This is much higher than the 38.5 percent average for the EU-28. Increasing the availability of affordable 
child care and elder care facilities may help address one of the main labor market barriers that the female addressing one of the main labor market barriers that the female population faces.

Figure 2.8 Labor Force Participation as a Percentage of the Total Population Aged 1564, by Gender, European Countries (2013)

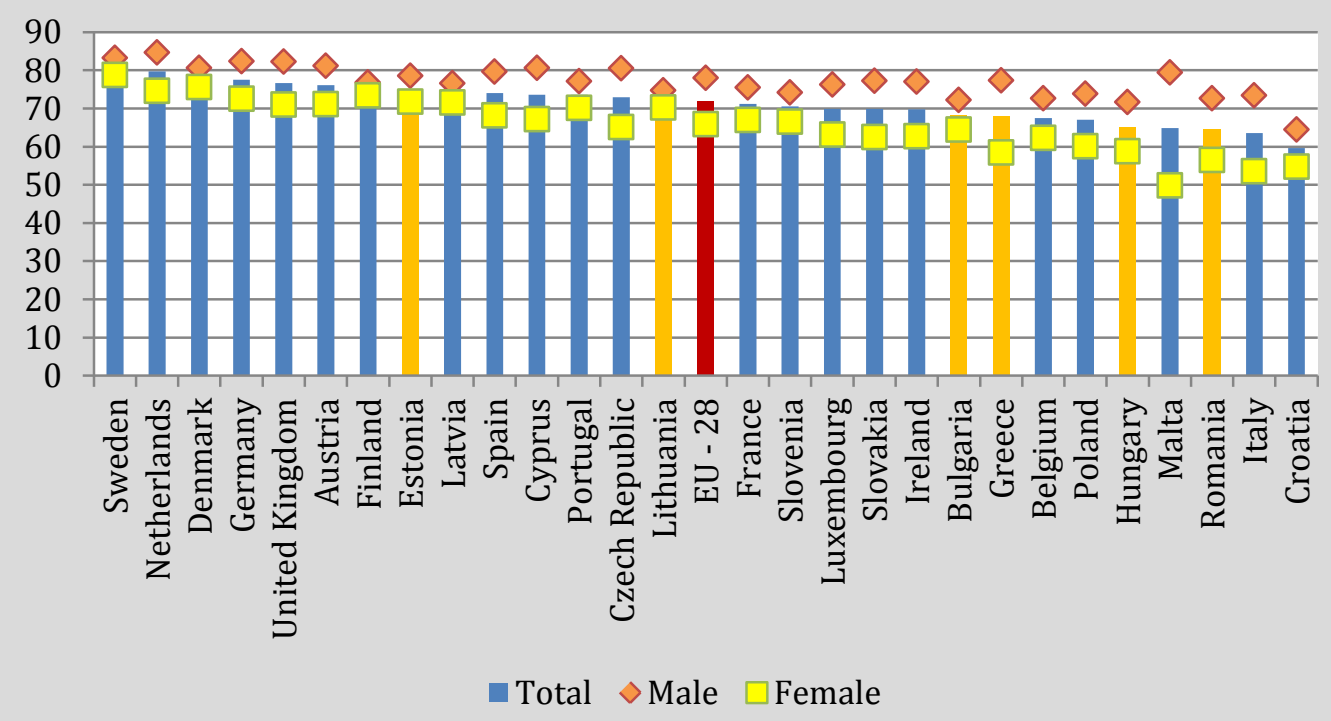

Source: Eurostat, EU-LFS

Figure 2.9 Formal Child Care as a Percentage of All Children Less than 3 Years Old, European Countries (2011)

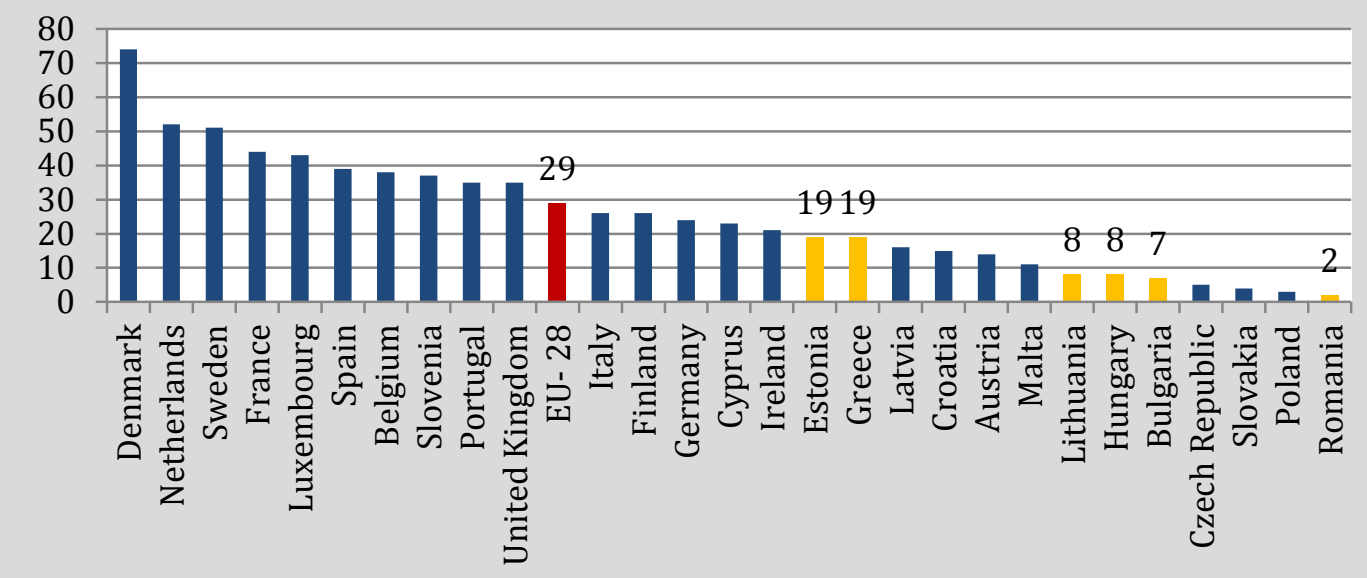

Source: Eurostat

A reduction in the inactivity of women after the crisis can also be identified when looking at the clusters of inactive stay-at-home mothers, possibly reflecting a fall in this option's 
affordability. This decline is prevalent in all the countries in terms of the stay-at-home mother clusters' share of the out-of-work population. Lithuania, Romania and Greece had the largest decrease, all falling between 8 to 9 points from 2007 to 2011. Romania had the largest decrease in absolute numbers, with its low educated rural mothers without work experience cluster decreasing by almost 332,000 individuals. It is interesting to see that the number of women within the Greek stay-at-home mothers cluster that declared themselves unemployed or long-term unemployed (versus inactive) increased from 12 to 23 percent; similarly, in Estonia 7 percent of the young inactive educated mothers with working partner declared themselves unemployed in 2011 (versus 0 percent in 2007). Notwithstanding this reduction in the inactivity of women, the clusters of stay-at-home mothers continue to represent an important share of the out-of-work population, ranging from 12 percent in Lithuania and Bulgaria to 23 percent in Greece.

\section{Long-term Unemployed}

The high share and number of long-term unemployed is another worrisome issue in all the countries analyzed. The EU-SILC data shows that across the clusters of unemployed, the share of individuals in long-term unemployment in all countries has grown. In addition, in Lithuania, Estonia, Hungary, and Romania it is possible to identify clusters of long-term unemployed that account for 12 to 28 percent of the out-of-work population. Long-term unemployment not only imposes a significant financial burden on households, but affects the long-term health status of job-seekers, negatively impacts government finances, and results in a lower overall long-term level of skills among a country's workforce, with permanent negative effects on productivity (Katz, 2010). Equally worrisome, many individuals who have been unemployed for extended periods become discouraged and drop out of the labor market altogether. Addressing the plea of the long-term unemployed should be among the policy priorities.

\section{Rural Unemployed}

Labor market participation differences and access to services between urban and rural living contexts can be distinguished as a defining feature in some countries. There is an important share of the out-of-work population that lives in rural areas, particularly in Lithuania and Romania. Although in all countries except Greece, more than half of the out-ofwork population lives in rural areas, this share is 62 percent in Romania and 69 percent in Lithuania. Additionally, the number of individuals of the out-of-work population living in a rural area grew 40 percent from 2007 to 2011 in Lithuania. In Romania half of the clusters have more than 60 percent of their members living in rural areas. Taking into account the urban/rural divide of the out-of-work population in the design of activation policies may prove critical in order to reach the desired population. 


\section{Selected Issues for Further Policy Dialogue}

The current general labor market situation, along with institutional and resource limitations, make the activation and integration of many of the identified out-of-work groups a demanding challenge. Prioritization of intervention is therefore of great importance. This section starts by presenting those groups identified in the country analysis that, given their activation need or potential, should be prioritized. We later discuss the type of activation that might best address the social or labor market barriers each prioritized group needs to overcome barriers to employment and outline the main implications for policy discussion. For this, this section draws on the recent study by the Bank, Back to Work (Arias et al. 2014), which explores more deeply policies that can lead people to jobs (Box 2.2).

The following should be considered as a starting point for further policy dialogue between the EC, the World Bank and country authorities, bearing in mind that the groups identified are heterogeneous in ways that may affect the type of support required. Accordingly these suggestions are not meant to be an exhaustive set of possible activation measures. It should also be kept in mind that the groups have been derived from the 2011 EU-SILC data. Since then, general economic development, policy actions by each government and the EC's country specific recommendations might have reflected some of these policy suggestions or rendered them obsolete.

A first step for prioritization ('activation priority') is assessing the activation need and potential of a group. Activation need refers to a group's need for inclusion in the labor market in order to achieve income and reduce or end poverty. Activation potential, on the other hand, describes the group's ability or motivation to be included in the labor market. A high activation need could be driven by high poverty risk, whereas a high activation potential could be driven by previous work experience or a relatively good educational base. Overall priority for action can also be supported by the size of the group. Table 2.1 below shows the groups with high and medium priority for action.

In general, clusters of unemployed have high priority owing to their activation need in terms of poverty risks and their potential through labor market proximity and/or education level. Clusters of youth, on the other hand, form prioritized groups because of the potential scarring effects of labor market detachment for young people at an early age. The Romanian cluster of low-educated rural mothers without work experience is the only group with low activation potential who are considered high priority due to the overall size of the cluster and strong exposure to poverty.

The groups classified with medium priority for the most part have medium activation need in that they have comparatively lower poverty risk due to having other working adults in the household or receiving social welfare benefits. Three clusters of inactive women with high activation need, driven by their high poverty risk (in Hungary, Lithuania and Romania), are considered of medium priority due to their distance from their labor market and therefore lower potential for activation. The Hungarian cluster of educated single students, although it has low activation need, is prioritized (like the other clusters of young individuals) because

Portraits of Labor Market Exclusion | 41 
of the potential effects of labor market detachment on this group. The clusters of retirees, retirees' wives and disabled are not prioritized for action owing to their lower activation need (many have reached the official retirement age or receive old-age benefits) or extreme distance (via very low educational attainment or self-declared disability) from the labor market.

\section{Table 2.1 Activation Priority: Overview of Inactive Clusters with High and Medium Priority for Action}

\begin{tabular}{|c|c|c|c|c|}
\hline Country & $\begin{array}{l}\text { Share } \\
\text { (2011) }\end{array}$ & Cluster & $\begin{array}{l}\text { Activation } \\
\text { need }\end{array}$ & $\begin{array}{l}\text { Activation } \\
\text { potential }\end{array}$ \\
\hline \multicolumn{5}{|c|}{ High priority for action } \\
\hline \multirow[t]{3}{*}{ BG $\square$} & $23 \%$ & Middle-aged unemployed & Medium & High \\
\hline & $15 \%$ & Single male NEETs & High & Medium \\
\hline & $12 \%$ & Low-educated rural long-term unemployed & High & Medium \\
\hline \multirow[t]{3}{*}{ EE } & $19 \%$ & Prime-age low income long-term unemployed & High & High \\
\hline & $13 \%$ & Prime-aged educated unemployed & High & High \\
\hline & $9 \%$ & Single NEETs without work experience & High & Medium \\
\hline \multirow[t]{2}{*}{ GR } & $18 \%$ & Highly educated single NEETs & High & Medium \\
\hline & $18 \%$ & $\begin{array}{l}\text { Middle-aged unemployed heads of } \\
\text { households }\end{array}$ & High & High \\
\hline \multirow[t]{3}{*}{ HU } & $14 \%$ & Prime-aged unemployed & High & Medium \\
\hline & $12 \%$ & Prime-aged long-term unemployed & High & Medium \\
\hline & $4 \%$ & Unemployed youth & High & Medium \\
\hline \multirow[t]{4}{*}{ LT } & $28 \%$ & $\begin{array}{l}\text { Middle-aged poor rural long-term } \\
\text { unemployed }\end{array}$ & High & Medium \\
\hline & $11 \%$ & Young educated rural unemployed & High & High \\
\hline & $9 \%$ & $\begin{array}{l}\text { Middle-aged educated unemployed family } \\
\text { men }\end{array}$ & High & High \\
\hline & $7 \%$ & Single poor rural unemployed women & High & Medium \\
\hline \multirow[t]{2}{*}{ RO } & $7 \%$ & $\begin{array}{l}\text { Long-term unemployed educated single } \\
\text { youth }\end{array}$ & High & High \\
\hline & $5 \%$ & Working-age long-term unemployed & High & Medium \\
\hline Country & $\begin{array}{l}\text { Share } \\
(2011)\end{array}$ & Cluster & $\begin{array}{l}\text { Activation } \\
\text { need }\end{array}$ & $\begin{array}{l}\text { Activation } \\
\text { potential }\end{array}$ \\
\hline \multicolumn{5}{|c|}{ Medium priority for action } \\
\hline BG & $15 \%$ & Stay-at-home young mothers & Medium & Medium \\
\hline \multirow[t]{2}{*}{ EE } & $21 \%$ & $\begin{array}{l}\text { Middle-aged educated disabled with previous } \\
\text { work experience }\end{array}$ & Medium & Medium \\
\hline & $17 \%$ & $\begin{array}{l}\text { Young inactive educated mothers with } \\
\text { working partner }\end{array}$ & Medium & High \\
\hline 星 & $23 \%$ & Stay-at-home mothers & Medium & Medium \\
\hline \multirow[t]{4}{*}{ HU } & $19 \%$ & Disabled with previous work experience & Medium & Medium \\
\hline & $13 \%$ & $\begin{array}{l}\text { Prime-aged inactive mothers with work } \\
\text { experience }\end{array}$ & Medium & High \\
\hline & $4 \%$ & $\begin{array}{l}\text { Low-educated rural inactive mothers without } \\
\text { work experience }\end{array}$ & High & Low \\
\hline & $2 \%$ & Educated single students & Low & High \\
\hline
\end{tabular}




\begin{tabular}{|c|c|c|c|c|}
\hline Country & $\begin{array}{l}\text { Share } \\
\text { (2011) }\end{array}$ & Cluster & $\begin{array}{c}\text { Activation } \\
\text { need }\end{array}$ & $\begin{array}{c}\text { Activation } \\
\text { potential }\end{array}$ \\
\hline LT & $5 \%$ & Stay-at-home poor rural women & High & Medium \\
\hline \multirow[t]{3}{*}{ RO } & $19 \%$ & $\begin{array}{l}\text { Low-educated rural mothers without work } \\
\text { experience }\end{array}$ & High & Low \\
\hline & $15 \%$ & Inactive middle-aged wives & High & Medium \\
\hline & $3 \%$ & Working-age newly unemployed & Medium & High \\
\hline
\end{tabular}

The relative severity of labor market or social obstacles to be overcome for labor market integration can also be used as an orientation for activation approaches. By mapping the respective barriers for labor market integration faced by the prioritized groups, it is possible to discern the respective types of activation that could be undertaken for each group (Figure 2.10).

Figure 2.10 Activation Types of Prioritized Clusters

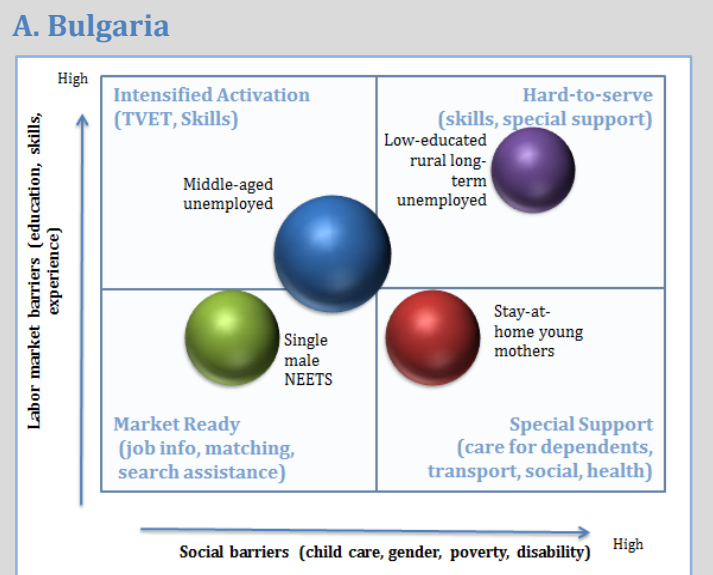

B. Estonia

\section{Greece}
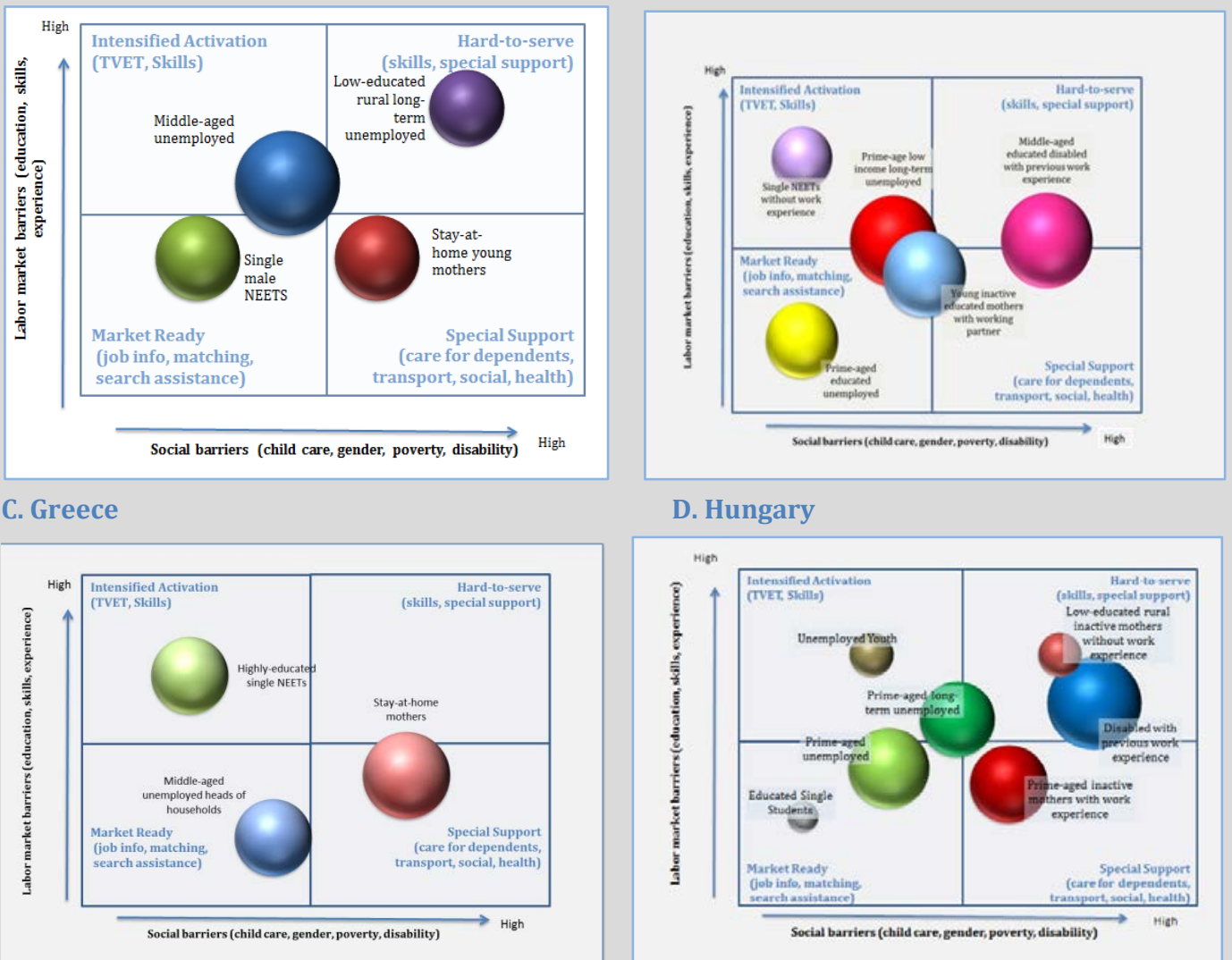

\section{Hungary}

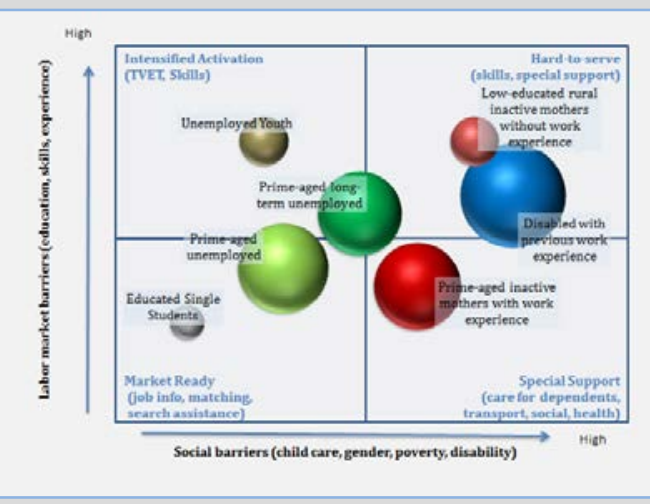


E. Lithuania

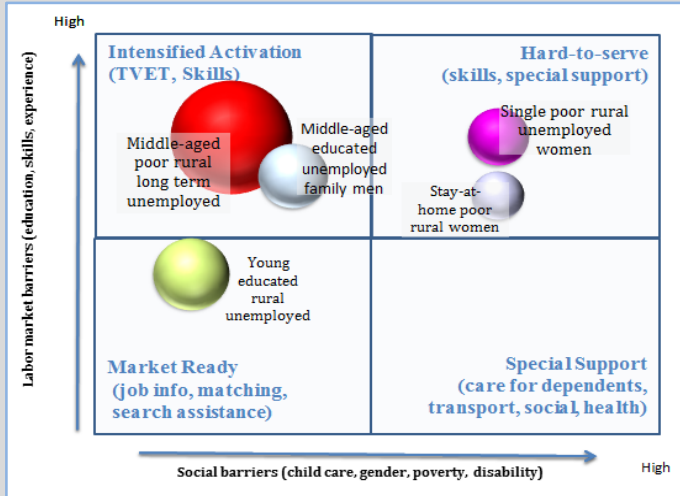

F. Romania

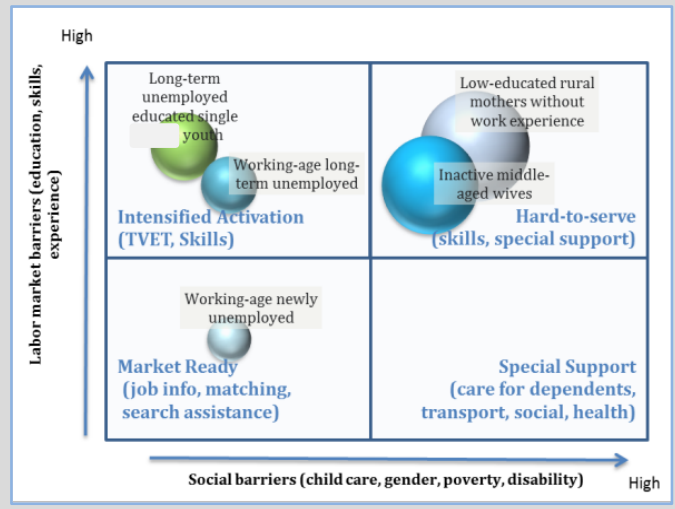

Source: World Bank staff analysis and assessment 2014

The clusters mapped near the bottom left corner have relatively lower labor market barriers and are considered "market ready" (see each one of the six country charts in Figure 2.10 above). In this category of activation type are the clusters of unemployed with work experience and/or education such as the prime-aged unemployed clusters found in Estonia, Hungary and Lithuania, the young educated rural unemployed in Lithuania, and the middle-aged unemployed heads of households in Greece. Two groups of youth without work experience are also considered for this activation type: the Hungarian educated single students and the single male NEETs in Bulgaria. Given that these clusters are still quite close to the labor market, activation measures should focus on market based types of interventions, such as providing information on job openings and assisting in job search, application and job-matching intermediation-services that could be provided through public employment services (PESs) or private employment agencies.

The upper left quadrant clusters are individuals that will require more intensified activation. Clusters whose individuals have been detached from the labor market for a longer time such as the working-age long-term unemployed and the long-term unemployed single youth in Romania, the middle-aged unemployed in Bulgaria, and both the middle-aged poor rural long-term unemployed and middle-aged educated family men in Lithuania are considered to need this type of intensified activation. The Hungarian unemployed youth cluster and the single NEET groups in Greece and Estonia are also mapped in this quadrant as they could probably benefit from adding practical skills to their education.

Among the measures to be considered in such "intensified activation" are those that help with job market re-entry, training and mobility. Taking into account the years of work experience and potential industry and trade knowledge of the individuals in these groups, reconnecting them to their previous field of employment, building on their acquired skills and upgrading missing functional or technical skills may strengthen their case with new employers. The older out-of-work population in these groups is particularly at risk of skills obsolescence as the skills demanded by employers change. Activation policies should promote effective, age-sensitive training and create the conditions for the development of a market for adult education and training services. Moreover, in order to combat any 
behavioral and attitudinal detachment from the labor market that may result after long periods of unemployment, programs that subject individuals to a (time-limited) public works requirement, combined with training, job search and skills support could also be implemented. Finally, mobility measures should also be taken into account, particularly when considering long-term unemployed in rural areas.

Additionally, linkage with regional economic development activities, self-employment and entrepreneurship support could help some of these unemployed individuals attain selfsufficient lives and improve their welfare. Broader structural reforms that improve the business climate, such as those that lower the cost of starting and closing a business, improve access to financing, and promote more favorable attitudes and social norms toward risk taking can go a long way in fostering new ventures. Tapping into the latent entrepreneurship of the out-of-work population not only helps them enter the labor market but has the potential of playing an essential role in creating new jobs for the economy.

Given the potential scarring effects of labor market detachment at an early age, special consideration should be taken to the clusters of youth. Job-start programs that offer placement through subsidized internships accompanied by professional and life-skills training could be a promising line of action, breaking the common barrier of required work experience for many entry-level positions. Another line of action is larger labor market policies that encourage flexible work schedules and part-time work. These would allow youth to combine work and study, help them gain the necessary experience, and facilitate full entry into the labor market. Job-search offerings by PESs should consider virtual platforms, since the use of mobile technology will be taken for granted by many members of these groups. Mobility support within each country and the EU (including foreign language training) could also be considered, particularly for those with higher qualifications, considering their low level of caregiving responsibility.

As Arias et al. (2014) emphasize, for younger cohorts, having the wrong set of skills (both generic and technical) is often an issue. Some educational systems still track students into vocational streams too early, neglecting generic skills that are valuable in today's workplace. Postponing this early tracking and promoting a diversified supply of courses (from traditional apprenticeships to IT skills), as well as providers that have strong linkages with employers and labor markets would be steps forward in closing the skill gap. On the other hand, while tertiary schooling has expanded quickly among youth, quality and relevance vary. Broader reforms that manage the expansion of tertiary education through quality assurance systems and which make information available about the labor prospects of various careers will also be key for new entrants to the labor market.

Clusters in the two right quadrants of the figures above have relatively higher social barriers and therefore will require additional activation support. Most of the clusters of inactive women are mapped in these two quadrants, depending on years of work experience, education level, and/or poverty. For instance, the low education and lack of work experience of the Romanian low-educated rural mothers without work experience and the inactive middle-aged wives limit their activation potential; these groups are therefore considered hard to serve. Similarly, the low-educated rural inactive mothers without work 
experience in Hungary and single poor rural unemployed women in Lithuania are also mapped in the upper right quadrant. On the other hand, the clusters of stay-at-home mothers in Greece, Hungary and Bulgaria are younger, more educated, and may have work experience, and therefore face fewer labor market barriers. Given the lower poverty risk, age and work experience of the Estonian cluster of inactive mothers, this group mapped in the border between "market ready" and "special support" activation type.

In general, women face important disincentives and barriers to work, which are reflected in the appearance of female out-of-work clusters in all the countries analyzed. Labor taxes and social protection systems create strong deterrents for second earners (generally women) to seek formal jobs. Along with these disincentives, women also face labor market barriers such as lack of services (child or elder care), limited flexibility in work schedules, and imperfect access to productive inputs, networks and information. Adverse attitudes and social norms may also limit women's access to jobs and in many cases reinforce each other (Arias et al. 2014).

Potential activation measures for all the clusters of inactive women are similar in nature, ideally with options that enable women to sort into the measure that would correspond best to their needs. In general, these groups could benefit from greater access to social and public services near their home (such as child care) as well as from job-search assistance and professional training. Those with previous work experience could build on it to gain labor market entry. Opening a "window" for mothers with children in public works programs that include child care and training opportunities might help some of these women get initial work experience and address their poverty situation. Short "second chance" schooling with a focus on professional skills tailored to the needs and skills of individuals could be offered. Another possible line of action would be offering community-based social work and entrepreneurship education to help in labor market integration. In addition to training in job hunting and basic functional skills, (temporary) mobility support for transportation and housing should also be considered to help women in these groups find employment in regional or larger cities. Improving access to child care and school after-care offerings would on their own enable many women in these clusters to better participate in the labor market or to take part in professional training or entrepreneurship offerings. Moreover, improving flexibility in work schedules - including part-time and home-based work - in order to facilitate combining work with other responsibilities would make it easier for women to hold jobs.

Finally, clusters that contain a large of share of individuals who declare their work capacity to be strongly limited (in Estonia and Hungary) and clusters of low-educated, long-term unemployed (in Estonia and Bulgaria) are also mapped to the upper right quadrant, and will require policies that address strong social and labor market barriers. Standard PES job search assistance and placement support, while also reassessing the labor market status of those who declare themselves disabled, could be a potential activation measure. For those considered fit to work, a set of support measures and continuing benefits (potentially with a phase-out period) ought to be provided to cushion the transition to labor market integration. By reconnecting individuals in these groups with previous employment 
experiences, they could be equipped with missing functional or technical skills, secondchance apprenticeship programs and upper secondary school certificates. Mobility support could be an important service. Finally, improving social inclusion benefits and linking them to activation could improve the welfare of those in low-educated, long-term unemployed clusters.

Looking at household income composition allows assessing potential cross-dependencies of the benefit system with labor market status. In general, only disability and old-age benefits contribute an important share to household income, and only in those groups where these benefit receipts correspond to the social-demographic situation of the cluster. This highlights the fact that social protection in most of these countries is largely centered upon pensions, providing little protection in terms of unemployment insurance or social assistance.

Nevertheless, in Estonia, Romania, and Hungary, the high percentage of individuals receiving disability receipts in the middle-aged educated disabled with previous work experience, early retirees, and disabled with previous experience clusters, respectively, attract attention when considering that only a small percentage in each group report strong limitations on daily activity. These countries could potentially profit from a review of the disability benefit allocation. At any rate, this significant group of out-of-work citizens needs to be followed closely and any new applications for disability benefits closely monitored and controlled. Limiting the inflow into this group (via more stringent disability benefit criteria) will be easier than forcing the activated exit of members from these groups. Prevention of long-term disability benefit dependency should also be addressed through a review of work capacity, together with early identification of people with disabilities who can work and their integration into the workforce through financial incentives for disabled workers and their employers.

Although social protection systems seem to have little impact on the household incomes of most of the out-of-work clusters in the countries studied, it is important to keep in mind that labor taxation in conjunction with these protection systems may play a role in deterring entry into the labor market, particularly for second earners (generally women) and lower wage earners (such as youth). Redesigning these systems by reducing or eliminating the abrupt withdrawal of social benefits when a person starts formal work, and eliminating filters that make a household ineligible for a benefit if one of its members is employed, should be considered part of the policy agenda. The challenge for these countries lies in expanding social protection systems without creating disincentives to work.

Retirees and early retirees, on the other hand, represent a large (and growing) share of the out-of-work population, which has important implications for fiscal expenditures. Given their overall low need and activation potential these groups are not further considered for activation policies during times of low labor demand and high unemployment. As with disability recipients, stemming the outflow of new retirees may be more effective than attempting to increase the inflows back into activity. In times of high unemployment, early retirement may become more attractive for the long-term unemployed. Policies can and should be implemented to delay early retirement, including reforms to pension systems and

Portraits of Labor Market Exclusion | 47 
the promotion of skill maintenance and life-long learning, along with flexible work schedules, adaptable work environments (for example, to health requirements) and working from home.

\section{Box 2.2 Back to Work: Growing with Jobs in Europe and Central Asia}

In early 2014, the World Bank published Back to Work: Growing with Jobs in Europe and Central Asia, a report that studies the labor markets and enterprise dynamics in the region to address how economies in Europe create more jobs, and what specific policies help workers access those jobs. The findings of Back to Work intersect with those of this report, as the policy areas that bring workers into productive jobs are the same as those that will promote inclusion in the labor market of the inactive and unemployed individuals identified by the "Portraits" analysis.

The main findings of Back to Work are: (a) market reforms pay off in terms of jobs and productivity growth, although with a time lag; (b) a small fraction of superstar high-growth firms, largely young but not necessarily small, account for most new jobs created in the region-thus, countries need to unleash the potentially high levels of latent entrepreneurship to start up new firms; (c) skill gaps hinder employment prospects, especially of youth and older workers, due to the inadequate response of the education and training systems to changes in the demand for skills; (d) employment is hindered by high implicit taxes on work for those transitioning to formal jobs from inactivity or unemployment and by barriers that especially affect women, minorities, youth and older workers; and (e) low internal labor mobility prevents labor relocation to places with greater job creation potential. 
In order for more people to access jobs, the report emphasizes that countries must carry out institutional reforms to establish the fundamentals to create jobs for all workers. A first step is taken by instituting reforms to create an auspicious environment for firms, allowing existing firms to either grow and become more productive, or exit the market and make way for new firms to emerge and succeed or fail, quickly and cheaply. A second set of policies that should be implemented are those that support workers and prepare them, in terms of skills and incentives, for the new jobs being created. These policies need to address those additional barriers to productive employability that disproportionately affect younger and older workers, women and ethnic minorities, including lack of adequate skills, low mobility, lack of child and elder care options, limited flexible work arrangements, imperfect access to productive inputs, networks and information, and adverse attitudes and social norms (Figure 2.11). These barriers not only interact with other disincentives from labor tax and social protection systems, but also reinforce each other in aggravating exclusion from labor markets. Activation policies that help overcome these employability barriers will be fundamental for the region's future prospects.

\section{Figure 2.11 Mutually Reinforcing Barriers to Employment for Younger and Older} Workers, Women and Ethnic Minorities

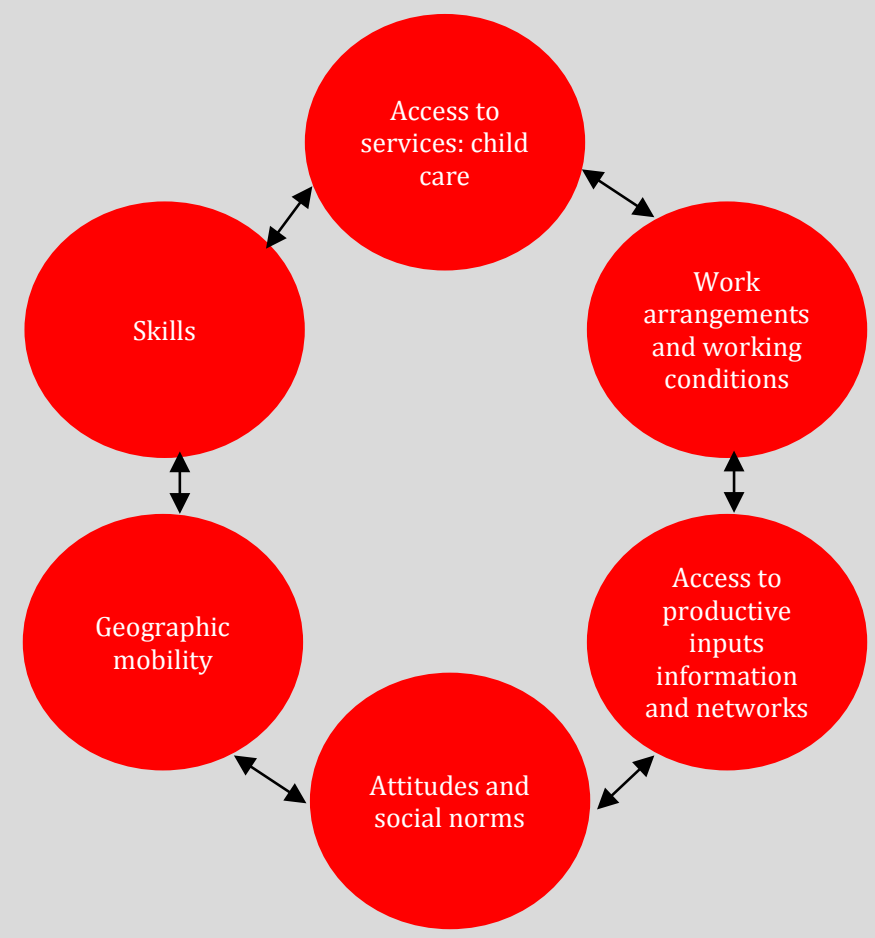




\section{Broader Policy Issues}

In general, further policy dialogue with the authorities ought to focus as much on the general level and setup of resources devoted to labor market integration and activation of the inactive and out-of-work as on the ongoing improvement of services on the national and local level.

From the potential activation policies mentioned in the previous section, there are a few areas that may transversely benefit different groups within the out-of-work population and could constitute a starting point for further policy dialogue. As stated before, the policies outlined are by no means an exhaustive set of possibilities, and their relevance will depend on the particular institutional framework of each country and the characteristics of its outof-work population.

For many out-of-work individuals, particularly youth, the older population and those who have been out-of-work for longer periods, skill deterioration or not having the adequate set for the employer's needs are important employability barriers. Policies should tackle this skill gap by prioritizing the development of a strong foundation of generic skills, ensuring quality and relevance in expanding the tertiary education system, and making the training system responsive to market needs and age-sensitive to enable life-long learning.

In parallel to broader education and training policies, activation services should build on previous work experience for training and work placement. Considering that a large share of the out-of-work population have years of work experience, training measures combined with temporary work placement in companies, nonprofits or social enterprises could help to strengthen labor market attachment. Reconnecting individuals with their previous industry or profession can build on existing ties and professional knowledge, improving re-entry into the labor market after unemployment or maternity leaves.

Meanwhile, greater coordination between social protection policies and labor market measures will allow for more effective provision and better targeting of governmental programs, particularly for individuals with disabilities or greater poverty risk. For some inactive and unemployed clusters, labor taxes, social protection systems, and labor regulation can pose strong disincentives to work. This can be particularly true in the case of second earners (generally women), older workers (nearing retirement) and those who will access low-paying or part-time jobs. Overall pension reform and improvement to the design of social assistance and unemployment benefits, particularly by removing explicit bans or penalties to (formal) work, would reduce disincentives to work. Social programs should not only provide adequate protection to the poor and vulnerable but be compatible with work and linked to job search and activation. Additionally, reforms that make labor taxation more progressive and take into account hours worked and family structure may also pay off in weakening the disincentives to work, particularly for those inactive women who are "market-ready" and youth who wish to balance work and study.

Women, youth, older population members and minorities also face additional barriers that should also be considered in the policy agenda. Lack of services, such as child or elder care, 
limited flexible work schedules, imperfect access to productive inputs, networks and information, or adverse attitudes and social norms limit their access to jobs. Extending child care and early childhood development offerings as well as alternatives for elder care will play an important role in enabling earlier labor market integration of women. Broader labor market reforms that consider more flexible work schedules and encourage age-sensitive work environments may be relevant in bringing women youth and the older population closer to the labor market. Finally, the policy agenda should also consider influencing changes in culture and social norms in favor of greater labor market participation by women, and a more positive perception of older workers and minorities.

Geographic mobility is another policy area that is relevant for many of the clusters identified. For those living in rural areas, improving regional transportation and other policies to support mobility may prove necessary for access to more dynamic labor markets and employment matching. Additionally, linking mobility to training offerings may enable some jobseekers to participate in higher-quality training in central places. Promoting labor migration within the EU, coupled with foreign language training, can be an important measure to prevent the deterioration of human capital, particularly in the younger population with higher qualifications and fewer caregiving responsibilities.

Policies that foster mobility (both internal and international) should look to remove barriers when people want to move in search of better opportunities, and make their investments and benefits portable. Arias et al. (2014) highlights several factors or barriers that can affect internal mobility. Among others barriers, such as skill and lack of information networks, underdeveloped housing and credit markets increase the cost of migration, especially for those with liquidity constraints. Moreover, social benefits, insurance, and regional development policies can either help or hinder mobility. Inasmuch as these policies help people overcome financial constraints, they will allow people to connect with better jobs in more productive regions. On the other hand, if poorly designed, social benefits (like some housing benefits) and territorial policies (such as agricultural subsidies) can end up limiting internal mobility, tying people to economically lagging regions and decreasing incentives to work.

Finally, while active labor market policies, activation and job-matching support can help smooth frictions in the labor market, they will not lead to stable, sustainable employment. Demand for jobs comes from the economic activity of firms and the social sector; therefore the integration of labor market policy with regional economic development policy is especially important. Broad economic reforms to the business climate that strengthen job creation and entrepreneurship will likely be effective in fostering the attachment to the labor market of the out-of-work population. Additionally, any mix of activation and enabling measures that help inactive or unemployed citizens reconnect to the labor market will need to take a wide-ranging approach (from training to self-employment), ensuring at all times linkage with firms (through work placements and so on), integration with efforts at regional economic development, and building on the activity and experience base of the jobseekers concerned. In this sense, all efforts need to be embedded into activities for economic growth and job demand creation.

Portraits of Labor Market Exclusion | 51 


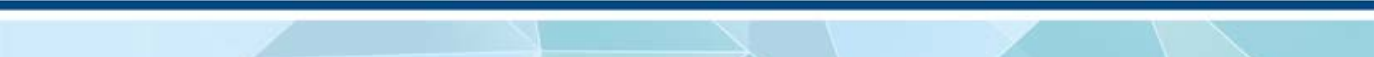

52 | Portraits of Labor Market Exclusion 


\section{Latent Class Analysis of the Out- of-Work Population in Bulgaria 2007-2011}

\section{Background}

After years of economic expansion, Bulgaria was strongly affected by the global financial crisis and has yet to recover pre-crisis growth rates. Between 2003 and 2008, the country grew at an average rate of 6.3 percent, well above the 2.2 percent average among the EU-28 Member States during the same period. Like most countries in the region, Bulgaria was hit in 2009 by the crisis, causing the economy to contract 5.5 percent. Though this contraction was larger than the EU-28 member state average (4.5 percent), it was considerably smaller than countries like Latvia and Lithuania that contracted 17.7 and 14.8 percent that year, respectively. Nevertheless, Bulgaria's recovery has been less dynamic: gross domestic product grew 1 percent on average over 2010-2013.

Following the economic downturn in 2009, and given the anemic recovery that followed, unemployment rates in Bulgaria have failed to recover to pre-crisis levels. The joblessness rate for the population aged 15 to 64 in Bulgaria had declined steadily earlier in the decade, reaching 5.7 in 2008. However, as the effects of the global financial crisis unraveled, the country suffered a large and extremely rapid increase in unemployment; by the end of 2009, joblessness had risen to 6.9 percent. Although the economy has been growing since 2009, the unemployment rate has continued to grow and has doubled since the onset of the crisis, reaching 13 percent in 2013. While the growth in unemployment is significant, such an increase is only slightly larger than those observed in the EU-28 (11 percent) or the euro area as a whole (12 percent).

As unemployment rates continue to rise, youth are among the worst affected. Unemployment for individuals aged 15 to 24 years old, independent of gender, has grown dramatically since 2009 , increasing from 12.7 percent in 2008 to 28.4 percent in 2013. High youth unemployment is also reflected in very low employment rates for youth: in 2013, this rate was astonishingly low at 21.2 percent, compared to an average of 32.3 percent for the EU.

The percentage of youth not in education, employment or training (the NEET rate) increased. The NEET rate, which measures the share of youth aged 15 to 24 not engaged in education, training or employment, rose from 17.4 percent in 2008 to 21.6 percent in 2013. However, it is noteworthy that the NEET rate has been decreasing (falling almost 9 percentage points in the last ten years), perhaps reflecting the fact that many youth, facing a tight labor market in which their lack of work experience puts them at a disadvantage, have chosen to stay longer in school and/or training.

Portraits of Labor Market Exclusion | 53 
In Bulgaria, long-term unemployment as a share of total unemployment has been usually higher than the average for the EU-28 countries. In 2013, according to Eurostat and as shown in Figure 3.1, in the average EU-28 country almost 48 percent of the unemployed have been looking for work for more than 12 months, up from 33 percent in 2009. Longterm unemployment in Bulgaria has been considerably higher than the EU-28 average during the last 10 years. In 2009, it had declined to 43.3 percent-still 10 percentage points higher than the average EU-28 country. By 2013, 57.3 percent of the unemployed were longterm unemployed.

Figure 3.1 Long-term Unemployment as a Share of Total Unemployment (2003-2013)

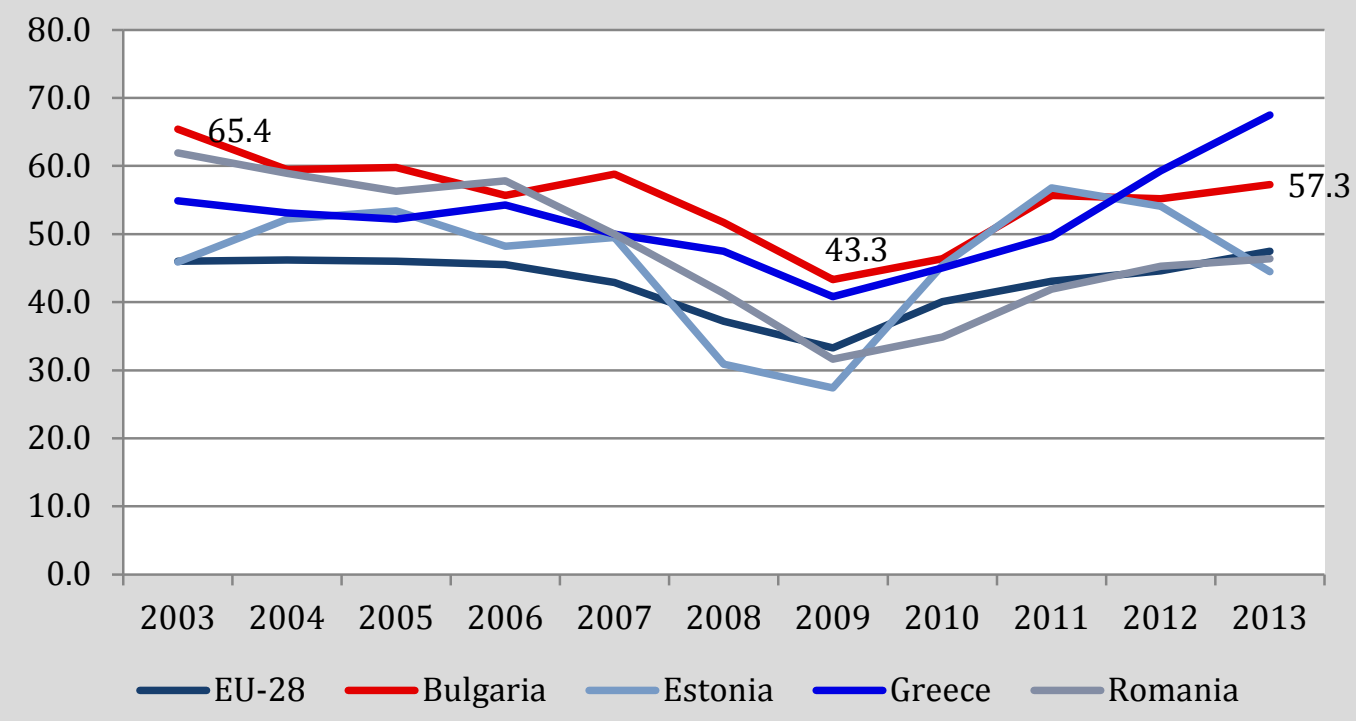

Source: Eurostat, EU-LFS

Following the crisis, low-educated individuals were especially affected by the rise in unemployment. Unemployment rates were already considerably higher for the group of less educated individuals. After the crisis hit in 2009 the gap was accentuated, reflecting structural changes that increased the demand for more-skilled workers (Figure 3.2). In fact, the difference in unemployment rates for low- and higher-educated workers grew from 12.6 percentage points in 2008 to 23.9 percentage points in 2013. However, all educational groups saw an increase in their unemployment rates from 2008 to 2013. For those with tertiary education and upper secondary and post-secondary non-tertiary education, unemployment rates more than doubled, from 2.3 to 5.9 percent and from 4.5 to 11.7 percent, respectively. 
Figure 3.2 Unemployment Among 15 to 64-year- olds by Educational Level in Bulgaria (2003-2013)

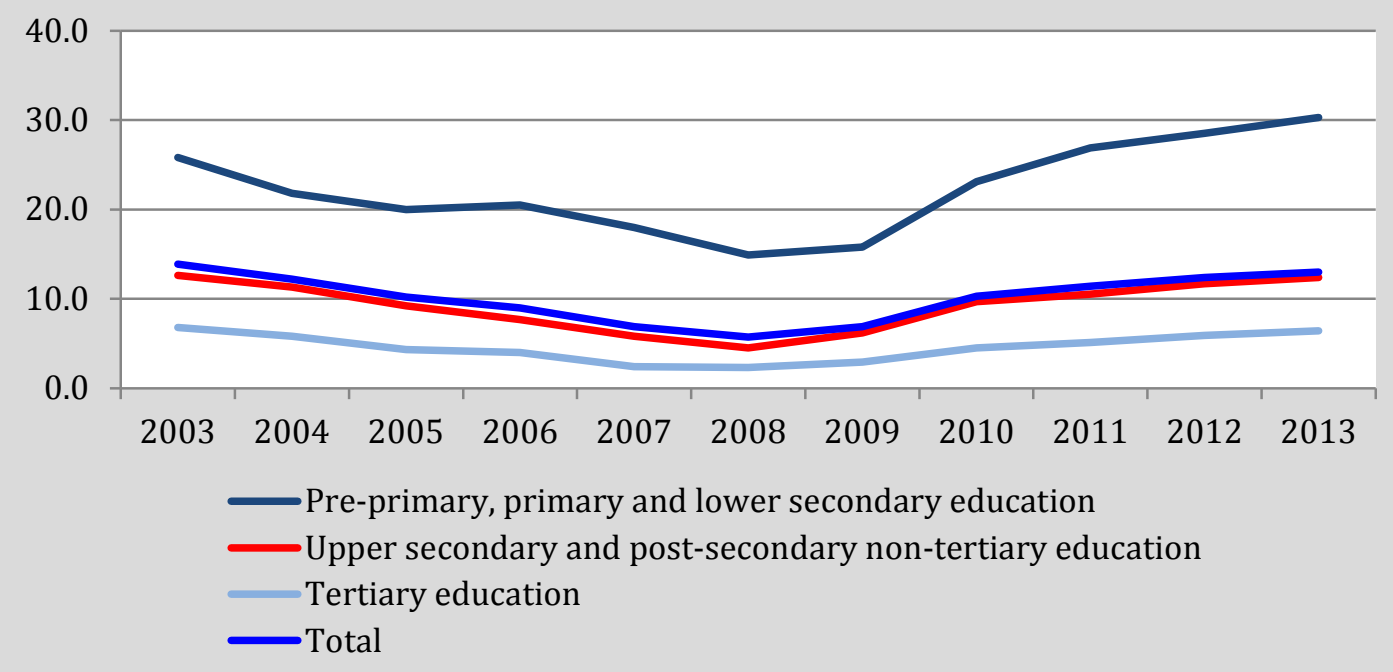

Source: Eurostat, EU-LFS

Employment levels have fallen since the onset of the crisis, but less drastically than for the highly educated. The employment rate for the population aged 15 to 64 peaked in 2008 at 64 percent; it was significantly lower in 2013 at 59.5. Employment rates have fallen across all education groups, but this fall is more pronounced for individuals with an uppersecondary education. Individuals with lower levels of education are more susceptible to seasonal volatility. Such seasonality has also affected individuals with an upper secondary degree since the crisis.

During the period from 2008 to 2011, the sample of out-of-work population considered in this note increased, from 1.49 to 1.56 million individuals. The analysis of the out-ofwork population in this note focuses on the working-age population (16 to 64 years old). Specifically, only individuals aged 25 to 64 years who are not employed, and individuals aged 16 to 24 who were neither employed nor in education nor training were considered. ${ }^{14}$ Only the working-age population (16 to 64 year olds) is analyzed, as labor activation options-the main policy focus of this note-are only viable for that segment of the population. In 2011, 1.56 million out of the 4.7 million individuals in our sample, or 33.3 percent, were out-of-work. There have also been significant increases in the number of longterm unemployed and inactive among the out-of-work population (see Figure 3.3). Moreover, the group of disabled group of disabled has more than doubled, from 13,000 in 2008 to 29,000 in 2011(Table 3.1).

\footnotetext{
14 Individuals aged 16 to 24 who are out of work and enrolled in education are excluded from the sample; they are considered to be investing in their final stages of human capital formation and therefore are not a particular target group for activation policies. Individuals enrolled in school between 25 and 64 are, however, included in the latent class analysis and will be grouped under "other inactive." It is important to note that these students (older than 24) account for less than 1 percent of total working-age population.
} 
Table 3.1 Number and Percentage of Working Age Individuals (16-64) by Labor Market Attachment in Bulgaria (2008 and 2011), in Thousands

\begin{tabular}{|l|c|c|c|}
\hline & $\mathbf{2 0 0 8}$ & $\mathbf{2 0 1 1}$ & Percent change 2008-2011 \\
\hline At work & 3,221 & 3,130 & $-2.8 \%$ \\
\hline Unemployed & $68.4 \%$ & $66.7 \%$ & $-9.9 \%$ \\
\hline & 325 & 293 & \\
\hline Long-term unemployed & $6.9 \%$ & $6.2 \%$ & $20.7 \%$ \\
\hline & 358 & 433 & \\
\hline (Early) retirement & $7.6 \%$ & $9.2 \%$ & $1.8 \%$ \\
\hline & 530 & 539 & $115.4 \%$ \\
\hline Disabled & $11.3 \%$ & $11.5 \%$ & \\
\hline & 13 & 29 & $4.9 \%$ \\
\hline Other inactive & $0.3 \%$ & $0.6 \%$ & \\
\hline & 259 & 271 & $-0.2 \%$ \\
\hline Total & $5.5 \%$ & $5.8 \%$ & \\
\hline & 4,706 & 4,695 & \\
\hline
\end{tabular}

Source: World Bank staff analysis based on EU-SILC.

Figure 3.3 Distribution of Out-of-Work Population in Bulgaria (2008 and 2011)

2008

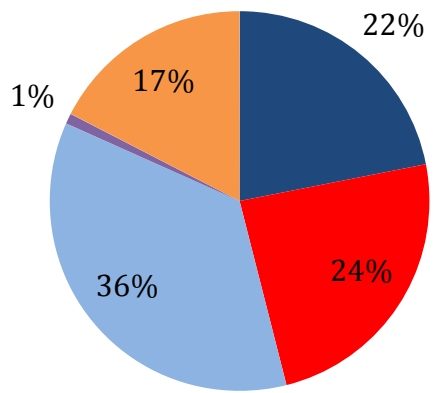

2011

- Unemployed

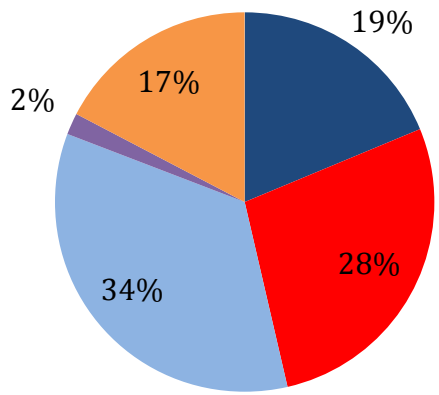

- Long-term unemployed

(Early) retirement

Disabled

- Other inactive 


\section{Methodology: Latent Class Analysis}

In Chapter 1 a general overview of the latent class analysis methodology was presented. This section explains in detail the variables and covariates used to identify classes or groups of out-of-work individuals that are as homogeneous as possible within each class according to a set of observable characteristics, and as distant as possible between classes. The emerging profiles can then be contrasted with the design and targeting of current activation policies, in order to identify the potential gaps and to enhance their design features. ${ }^{15}$

Variable selection: The definition of latent classes relies on a number of indicator variables to capture different "symptoms" of an overall latent condition (in this case, the typology of joblessness). The challenge in such models is to identify a discrete number of variables that can best explain the heterogeneity of individual outcomes. In this case, two sets of categorical variables were selected: the first set to show the extent of labor market distance and the other to capture some of the main factors that can affect employment on the supply side, such as labor supply conditions (household-level incentives to work and physical ability to work).

$\checkmark$ Distance from labor market: short-term unemployment, long-term unemployment, (early) retirement, disability, and other inactivity (largely unpaid domestic work). ${ }^{16}$

$\checkmark$ Labor supply conditions: whether the individual's household has at least one working adult, ${ }^{17}$ and perceived limitations on activities due to health problems. ${ }^{18}$

In addition to indicators, the model includes active covariates, which are used to improve the classification of individuals in each class. In this case the active covariates are the demographic variables that are normally used to disaggregate labor market outcomes:

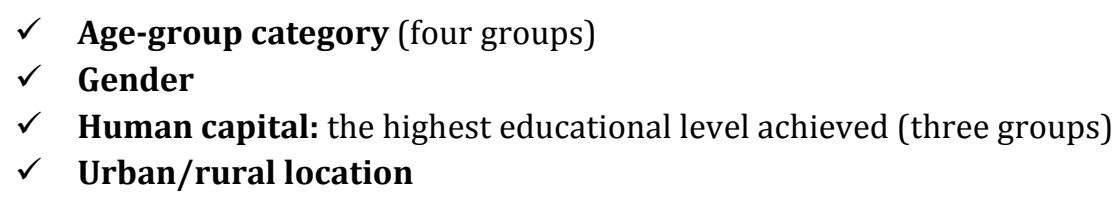

Once the latent classes have been defined, inactive covariates that were not included in the model can be used to characterize the individuals in each class and the households in which they live. The inactive covariates chosen describe those characteristics that may provide valuable information for the design of tailored policies that address barriers to employment, including income level. They include:

\footnotetext{
15 For the latest developments on active inclusion in Bulgaria, see EC (2013b).

16 This variable is constructed using the self-reported current work status in the EU-SILC survey that has four categories: at work, unemployed, retired and inactive. The unemployed are further classified into short- and long-term based on how long they have been actively looking for a job. The inactive is combined with another question to separate this group into students, disabled, military and other inactive.

17 In order to construct this variable, individuals aged 25 or older are considered adults.

18 This is a binary variable that takes the value one if an individual answered "yes, strong limitations" to whether they had been hampered in their usual activities because of health problems for at least the last six months. The value is zero if the answer is "yes, limited" or "no, not limited."
} 


\section{$\checkmark$ Household welfare conditions:}

- Income quintile (defined by equivalized disposable household income ${ }^{19,20}$ )

- Labor, benefit, and other income as share of total gross household income ${ }^{21}$

- Binary variable denoting whether at least one working adult (aged 25 and over) is present in the household

- Household ownership

- Household able to keep dwelling warm

- Partner's labor income

- Quintile of partner's labor income

- Binary variables denoting whether individuals or their households are beneficiaries of any of eight social protection benefits ${ }^{22}$

\section{$\checkmark$ Household demographics:}

- Household size

- Household composition

- Binary variable showing whether there are children under 6 in the household

- Binary variable denoting whether there are three or more under-16 children in the household

- Children under 13 receiving child care in the household: all, some or no children under 13 present

- Older person (65 and over) in the household

$\checkmark$ Other individual-level demographics:

- More refined age groups (seven groups)

- Marital status

$\checkmark$ Individual human capital:

- More refined highest educational level achieved (six groups)

- Work experience in years

- Binary variable for previous work experience

$\checkmark$ Household location:

- Degree of urbanization: ${ }^{23}$ densely populated, intermediate area, sparsely populated

19 The equivalized household income takes into account an equivalence factor to weight the number of household members used in the denominator when calculating household income per capita. The first adult aged 18 or over has a weight of 1.0 , children under 14 have a weight of 0.3 , and other individuals 14 and older have a weight of 0.5 . The sum of the weights of all household members is equal to the equivalent household size.

20 Note that income reported in EU-SILC surveys is for the year preceding the survey year.

21 Total household gross income is defined as the sum of: (at the individual level) gross employee cash or near-cash income; company car, gross cash benefits or losses from self-employment (including royalties); unemployment benefits; old-age benefits; survivor benefits; sickness benefits; disability benefits; education allowances; and (at the household level) income from rental of property or land; family/children related allowances; social exclusion not elsewhere classified; housing allowances; regular inter-household cash transfers received; interests, dividends, profit from capital investments in unincorporated business; pensions from individual private plans; and income received by people under 16. Total household net income, in turn, was calculated by subtracting from total household gross income regular taxes on wealth, taxes on income and social insurance contributions, and regular inter-household case transfers paid.

22 Social benefits are aggregated in eight branches using the European System of integrated Social PROtection Statistics (ESSPROS) definitions. For more information, see Eurostat (2011).

${ }^{23}$ According to EU-SILC guidelines, dense areas have more than 500 inhabitants per square kilometer, where the total population for the set is at least 50,000 inhabitants. Intermediate areas have more than 
- Regional breakdown: northern and eastern, southwestern and southcentral

Group labeling. The resulting groups are then labeled according to the greatest proportional characteristics within groups that also aid in distinguishing among groups. Granted, a large number of characteristics describe these groups, and only a few are taken into account for the purpose of labeling. In part, some of these characteristics may exhibit a large degree of heterogeneity and may thus not be relevant for defining a group. Additionally, some characteristics may be more relevant for the purposes of policy design than others. In short, though the labeling of groups can be considered more an art than a science, when taken together with detailed descriptions of a group's most prominent characteristics, labeling can serve as an important starting point in the design and prioritization of activation policies.

The analysis relies on cross-sectional as well as panel data from the European Union Statistics of Income and Living Conditions (EU-SILC) surveys for 2008-2011, which combine individual-level information with household characteristics. The first part of the note presents a cross-sectional analysis for the years 2008, 2009, 2010 and 2011. In particular, the latent class analysis on 2008 data shows the main characteristics of the out-of-work before the global economic crisis hit the Bulgarian economy, and thus highlight what could be considered more structural issues of the country's labor market. The 2011 latent class analysis will contrast this initial assessment with more recent developments. The second part of the note exploits longitudinal data between 2008 and $2010^{24}$ to trace the prior labor market status of individuals observed last in 2010 in various classes, and will shed light on the relative persistence in the out-of-work status among different classes of individuals. The set of variables chosen for the cross-section and the longitudinal analysis are slightly different, due to minor differences in the set of variables recorded in each of the two types of datasets.

100 inhabitants per square kilometer, and either a total population for the set of at least 50,000 inhabitants or a location adjacent to a dense area. The remaining areas are categorized as sparsely populated.

24 The EU-SILC longitudinal survey consists of a four-year rotating panel. In each year, approximately three-quarters of individuals present in the previous year are retained. The samples used in the latent class analysis include about 3,000 observations for each year in the cross-sectional analysis and 500 observations in the longitudinal analysis. The population is weighted with individual weights. 


\section{Main Findings}

\section{Out-of-Work Population: Group Profiles from Cross-Section Analysis}

The latent class analysis categorizes the out-of-work population into six major groups prior to the crisis and into seven groups in 2010 and 2011. The groups are named according to their most salient characteristics. Figure 3.4 shows the share of each of the seven classes identified in 2011, while Table 3.2 presents their summary characteristics.

Figure 3.4 Classes of Out-of-Work Individuals in Bulgaria, 2011

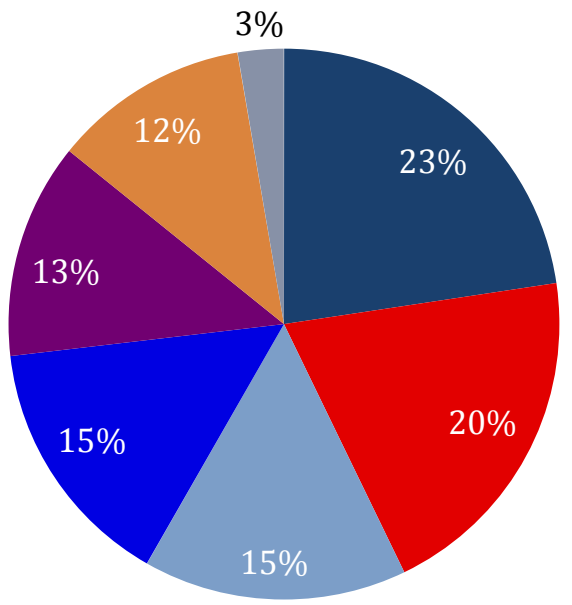

1. Middle-aged unemployed

- 2. Retired women

3. Stay-at-home young mothers

4. Single male NEETs

5. Retired and early retired men

6. Low-educated rural long-term unemployed

7. Low-educated early retired and disabled

Table 3.2 Summary Characteristics of Latent Classes of Out-of-Work Population in Bulgaria (2011)

\section{1: Middle-aged unemployed (23\%)}

\section{2: Retired women (19\%)}

- 50\% are long-term unemployed; 33\% $\quad$ - 97\% are retired unemployed

- $63 \%$ are married

- $66 \%$ have at least one working adult in the household

- $66 \%$ are 35 to 54 years old

- Mid-skilled: 67\% have secondary school

completed upper

- $85 \%$ have worked before; 18 years of experience on average

- $64 \%$ live in rural areas

- High poverty risk: $37 \%$ live in poorest quintile
- $56 \%$ have a partner who is not working; $36 \%$ do not have a partner

- 86\% are 60-64 years old

- $83 \%$ are women

- $94 \%$ worked before; 33 years of experience on average

- Low poverty risk: $22 \%$ live in poorest quintile

- $82 \%$ receive old-age benefits 
- $67 \%$ are inactive; $33 \%$ are unemployed

- $58 \%$ have a partner who is working

- $79 \%$ have at least one working adult in household

- $75 \%$ are 16 to 34 years old

- $99 \%$ are women

- $83 \%$ live with dependent children; 54\% live with children under 6

- High poverty risk $37 \%$ live in poorest quintile

- $61 \%$ receive family child benefits

5: Retired and early-retired men (13\%)
- $43 \%$ are long-term unemployed; $25 \%$ are unemployed; $31 \%$ are inactive

- 92\% have never married; $95 \%$ are without a partner

- $69 \%$ have at least one working adult in the household

- $96 \%$ are 16 to 34 years old; $61 \%$ are 16 to 24 years old

- $73 \%$ are men

- $61 \%$ have never worked before; 5 years of work experience on average

- High poverty risk: $38 \%$ live in poorest quintile

6: Low-educated rural long-term unemployed $(12 \%)$

- $86 \%$ are retired

- $65 \%$ have at least one working adult in household

- $83 \%$ are married

- $73 \%$ are 55 to 64 years old

- $88 \%$ Male

- $93 \%$ have worked before; 29 years of experience on average

- Low poverty risk: $20 \%$ live in poorest quintile

- $63 \%$ receive old-age benefits
- $61 \%$ are long-term unemployed; $31 \%$ are unemployed

- $87 \%$ have a partner who is not working; $61 \%$ have an unemployed partner

- $67 \%$ have no working adults in the household

- Low skilled: $82 \%$ have below upper secondary

- $69 \%$ are 25 to 54 years old

- $68 \%$ have worked before; 15 years of experience on average

- $70 \%$ live with dependent children; $39 \%$ live with children under 6

- $70 \%$ live in rural areas

- Very high poverty risk $69 \%$ live in poorest quintile

- $53 \%$ receive family/child benefits; $23 \%$ social exclusion benefits

7: Low-educated early-retired and disabled

(3\%)

- $50 \%$ are retired; $40 \%$ are disabled

- $77 \%$ report having a strongly limited capacity to work

- $81 \%$ are without a partner

- $89 \%$ are 25 to 59 years old; $11 \%$ are 16 to 24 years old

- $60 \%$ are men

- Low-skilled: $40 \%$ below upper secondary school; $37 \%$ have completed upper secondary

- Moderate poverty risk: $33 \%$ live in poorest quintile

- $80 \%$ receive disability benefits

Source: World Bank staff analysis based on EU-SILC.

Note: Percentages in parentheses following the group names refer to the share of the total out-of-work population. Years of work experience refer only to those individuals who have worked before. Dependent children include children under 18 and household members aged 18 to 24 who are economically inactive and living with at least one parent. Working adult refers to adults aged 25 and over. For this report's purposes, we define the at-risk-of-poverty rate as the relative risk of being in the first quintile of the income distribution. The reference period for income reported in EU-SILC surveys is the year preceding the survey year.

The seven major clusters emerging from the LCA can be characterized as follows for the year 2011 (see Annex 2: Latent class analysis profiles-Cross-sectional model for more detail): 
$\checkmark \quad$ Cluster 1: Middle-aged unemployed. This group represents 23 percent of the outof-work sample of 2011. They are mostly of prime age-35 to 59 years old. A total of 33 percent of males in this age bracket were unemployed; more worrisome, an additional 50 percent were long-term unemployed. This group is relatively educated: although only 7 percent have a tertiary degree, a significant majority (67 percent) have completed upper secondary school. In terms of the economic status of their partners, this group is fairly mixed: 52 percent have a working partner earning a relatively high income, whereas 48 percent either have an inactive partner or are without a partner altogether. In part, this explains why 37 percent of this class is in the poorest 20 percent of the income distribution. A little more than 50 percent live in households with at least one child, and 65 percent are receiving at least one type of social protection benefit.

$\checkmark$ Cluster 2: Retired women. This group made up 19 percent of the out-of-work population in 2011. It is composed of retired women aged 60 to 64, 53 percent of whom have no more than an upper secondary education, and 12 percent of whom have a tertiary education degree. They report an average of 33 years of work experience, are likely to live in relatively small households, and do not have a working partner: they are for the most part widowed (23 percent) or have a retired partner (about 50 percent). Additionally, 82 percent receive old-age benefits and 17 percent receive disability benefits. In part, the old-age benefit receipt, along with the fact that their households are relatively small (three members), may explain their relatively low risk of poverty; 22 percent of this class is in the bottom-income quintile.

$\checkmark \quad$ Cluster 3: Stay-at-home young mothers. This group, whose share of the out-ofwork population for 2011 was 15 percent, comprises young women aged 16 to 34 . A slight majority of them report having children under 6 years of age, and about 70 percent live in households with two or more children. This group consists of mostly inactive women (67 percent), although it is noteworthy that one-third are also unemployed. They are low-skilled: 47 percent have not completed upper-secondary education. Another characteristic is that 58 percent report a working partner whose average income is the highest among all the clusters in this analysis, while 79 percent report at least one working adult within the household. However, as this group's households are relatively large (5.1 members, on average) it is not surprising that despite available labor income, more than 36 percent are in the bottom 20 percent of the income distribution. A little more than 50 percent of the women in this group have no work experience and a majority (61 percent) receive family benefits at the household level (10 percent also report receiving social exclusion benefits).

$\checkmark \quad$ Cluster 4: Single male NEETs. Members of this class are predominantly male (73 percent), largely under age 35 , and concentrated among those aged 16 to $24 .{ }^{25}$ They resemble the unemployed youth who have been particularly hit by the economic crisis across Europe, as 43 percent are long-term unemployed and 25 percent are short-term unemployed, although almost one-third are also inactive. They have never been married and most (61 percent) report having never worked before. Around 17 percent have a tertiary education while another 48 percent have

25 Sixty-one percent are 16 to 24 years old, and another 35 percent are 25 to 34 years old. 
completed upper secondary school, making them relatively educated among the out-of-work population. Most may live at home with their parents, since despite being single, 69 percent report living with at least one working adult and in households with an average size of more than four members. Their income situation is nonetheless precarious, as 38 percent live in the bottom-income quintile. Like the stay-at-home young mothers, this group represented 15 percent of the out-of-work population in 2011.

$\checkmark \quad$ Cluster 5: Retired and early-retired men. This group represented 13 percent of the out-of-work population in 2011. The group is composed of early-retired men aged 45 to 59 (about 47 percent) and retired men aged 60 to 64 (about 47 percent). Although 87 percent have a partner who is not working, 65 percent do live in households where at least one adult works. They belong to households with relatively high incomes in comparison to the rest of the out-of-work groups identified, with only 20 percent living in the bottom-income quintile. Their relatively favorable economic situation is partially explained by the fact that they live in relatively small households without children (65 percent report no children in the household, the highest percentage among the groups identified). They have on average 30 years of work experience. Some 63 percent receive old-age benefits and 31 percent receive disability benefits (14 percent report being strongly limited in their activities because of health conditions).

$\checkmark \quad$ Cluster 6: Low-educated, rural, long-term unemployed. This group, representing 12 percent of the population out of work in 2011, consists of individuals of prime age (25 to 54) who are largely long-term unemployed (61 percent), although a minority are short-term unemployed (31 percent). They have very low levels of education ( 82 percent have at most completed lower secondary school) and predominantly live in rural areas (70 percent). The majority of this group (68 percent) has previous work experience, an average of 15 years. They live in households with high dependency rates, as their partners tend to also be unemployed. Only one-third report living with at least one adult who is working, and 65 percent live in households with two or more children. The majority (71 percent) receive at least one social benefit; just over half have access to family benefits and 23 percent to social exclusion benefits at the household level, but only 13 percent receive unemployment benefits. Nonetheless, the benefits received are not sufficient to take them out of poverty, as a startling 69 percent are in the poorest quintile of the income distribution.

$\checkmark \quad$ Cluster 7: Low-educated, early-retired and disabled. This group represented 3 percent of the out-of-work population in 2011, with 80 percent receiving disability benefits and 77 percent reporting a strong limitation in their daily activities due to a health condition. They are mostly of prime age (25 to 59 years old), mostly male ( 60 percent) and without a partner. Fifty percent report their labor market status as retired and another 40 percent as disabled. They are relatively low-educated: 40 percent received at most a lower-secondary education, while 37 percent completed upper secondary school. A third of this group is in the bottom quintile of the income distribution, putting them at a moderate risk for poverty.

Portraits of Labor Market Exclusion | 63 
The following tables present the main characteristics of each group in 2011. For the complete table, including inactive covariates, see Annex 2.

Table 3.3 Latent Classes of Out-of-Work Population in Bulgaria-Indicators (2011)

\begin{tabular}{|c|c|c|c|c|c|c|c|c|}
\hline & $\begin{array}{l}\text { All Out-of- } \\
\text { Work }\end{array}$ & $\begin{array}{l}\text { 1. Middle- } \\
\text { aged } \\
\text { unemployed }\end{array}$ & $\begin{array}{l}\text { 2. Retired } \\
\text { women }\end{array}$ & $\begin{array}{l}\text { 3. Stay-at- } \\
\text { home young } \\
\text { mothers }\end{array}$ & $\begin{array}{l}\text { 4. Single } \\
\text { male NEETs }\end{array}$ & $\begin{array}{l}5 . \text { Retired } \\
\text { and early- } \\
\text { retired men }\end{array}$ & $\begin{array}{l}\text { 6. Low- } \\
\text { educated } \\
\text { rural long- } \\
\text { term } \\
\text { unemployed }\end{array}$ & $\begin{array}{l}\text { 7. Low- } \\
\text { educated } \\
\text { early- } \\
\text { retired and } \\
\text { disabled }\end{array}$ \\
\hline Cluster size & $100 \%$ & $23 \%$ & $20 \%$ & $15 \%$ & $15 \%$ & $13 \%$ & $12 \%$ & $3 \%$ \\
\hline Population & $1,564,723$ & 353,940 & 315,918 & 241,906 & 232,674 & 197,937 & 180,100 & 42,248 \\
\hline
\end{tabular}

\section{Labor market attachment}

\begin{tabular}{|c|c|c|c|c|c|c|c|c|}
\hline Unemployed & $19 \%$ & $32 \%$ & $0 \%$ & $23 \%$ & $25 \%$ & $4 \%$ & $31 \%$ & $0 \%$ \\
\hline Long-term unemployed & $28 \%$ & $50 \%$ & $1 \%$ & $10 \%$ & $43 \%$ & $8 \%$ & $61 \%$ & $8 \%$ \\
\hline Retired & $34 \%$ & $11 \%$ & $97 \%$ & $0 \%$ & $1 \%$ & $86 \%$ & $0 \%$ & $50 \%$ \\
\hline Disabled & $2 \%$ & $2 \%$ & $0 \%$ & $0 \%$ & $0 \%$ & $2 \%$ & $0 \%$ & $40 \%$ \\
\hline Other inactive & $17 \%$ & $5 \%$ & $2 \%$ & $67 \%$ & $31 \%$ & $0 \%$ & $8 \%$ & $2 \%$ \\
\hline
\end{tabular}

\section{Working spouse}

\begin{tabular}{|c|c|c|c|c|c|c|c|c|}
\hline Yes & $28 \%$ & $52 \%$ & $8 \%$ & $57 \%$ & $0 \%$ & $44 \%$ & $1 \%$ & $5 \%$ \\
\hline No & $34 \%$ & $17 \%$ & $56 \%$ & $15 \%$ & $5 \%$ & $41 \%$ & $87 \%$ & $14 \%$ \\
\hline NA & $38 \%$ & $32 \%$ & $36 \%$ & $28 \%$ & $95 \%$ & $15 \%$ & $12 \%$ & $81 \%$ \\
\hline \multicolumn{9}{|c|}{ Self-assessed physical incapacity } \\
\hline Strongly limited & $94 \%$ & $1 \%$ & $8 \%$ & $1 \%$ & $1 \%$ & $14 \%$ & $2 \%$ & $77 \%$ \\
\hline None/limited & $6 \%$ & $99 \%$ & $93 \%$ & $99 \%$ & $99 \%$ & $86 \%$ & $98 \%$ & $23 \%$ \\
\hline
\end{tabular}

Source: World Bank staff analysis based on EU-SILC. 
Table 3.4 Latent Classes of Out-of-Work Population in Bulgaria-Active Covariates (2011)

\begin{tabular}{|c|c|c|c|c|c|c|c|c|}
\hline & $\begin{array}{l}\text { All Out-of- } \\
\text { Work }\end{array}$ & $\begin{array}{l}\text { 1. Middle- } \\
\text { aged } \\
\text { unemployed }\end{array}$ & $\begin{array}{l}\text { 2. Retired } \\
\text { women }\end{array}$ & $\begin{array}{l}\text { 3. Stay-at- } \\
\text { home young } \\
\text { mothers }\end{array}$ & $\begin{array}{l}\text { 4. Single } \\
\text { male NEETs }\end{array}$ & $\begin{array}{l}5 . \text { Retired } \\
\text { and early- } \\
\text { retired men }\end{array}$ & $\begin{array}{l}\text { 6. Low- } \\
\text { educated } \\
\text { rural long- } \\
\text { term } \\
\text { unemployed }\end{array}$ & $\begin{array}{l}\text { 7. Low- } \\
\text { educated } \\
\text { early- } \\
\text { retired and } \\
\text { disabled }\end{array}$ \\
\hline Cluster size & $100 \%$ & $23 \%$ & $20 \%$ & $15 \%$ & $15 \%$ & $13 \%$ & $12 \%$ & $3 \%$ \\
\hline Population & $1,564,723$ & 353,940 & 315,918 & 241,906 & 232,674 & 197,937 & 180,100 & 42,248 \\
\hline
\end{tabular}

\section{Age groups (4)}

\begin{tabular}{|c|c|c|c|c|c|c|c|c|}
\hline $16-24$ years & $15 \%$ & $1 \%$ & $0 \%$ & $25 \%$ & $61 \%$ & $0 \%$ & $10 \%$ & $11 \%$ \\
\hline $25-34$ years & $20 \%$ & $13 \%$ & $0 \%$ & $50 \%$ & $35 \%$ & $0 \%$ & $27 \%$ & $31 \%$ \\
\hline $35-59$ years & $41 \%$ & $85 \%$ & $14 \%$ & $24 \%$ & $4 \%$ & $53 \%$ & $56 \%$ & $58 \%$ \\
\hline 60-64 years & $24 \%$ & $2 \%$ & $86 \%$ & $1 \%$ & $0 \%$ & $47 \%$ & $6 \%$ & $0 \%$ \\
\hline
\end{tabular}

Gender

\begin{tabular}{|c|c|c|c|c|c|c|c|c|}
\hline Male & $45 \%$ & $51 \%$ & $17 \%$ & $1 \%$ & $73 \%$ & $88 \%$ & $53 \%$ & $60 \%$ \\
\hline Female & $55 \%$ & $49 \%$ & $83 \%$ & $99 \%$ & $27 \%$ & $12 \%$ & $47 \%$ & $40 \%$ \\
\hline
\end{tabular}

\section{Education}

Primary

Secondary

Tertiary

NA

$39 \%$

$49 \%$

$83 \%$

$99 \%$

$31 \%$

$12 \%$

$82 \%$

\begin{tabular}{|l|l|l}
\hline $48 \%$ & $25 \%$ & 33 \\
\hline
\end{tabular}

\begin{tabular}{|c|c|}
\hline $33 \%$ & $48 \%$ \\
\hline $54 \%$ & $38 \%$ \\
\hline $12 \%$ & 1 \\
\hline $1 \%$ & \\
\hline
\end{tabular}

\begin{tabular}{|c|c|c|c|c|c|c|c|c|}
\hline Urban & $44 \%$ & $36 \%$ & $48 \%$ & $53 \%$ & $45 \%$ & $53 \%$ & $30 \%$ & $47 \%$ \\
\hline Rural & $56 \%$ & $64 \%$ & $52 \%$ & $47 \%$ & $55 \%$ & $47 \%$ & $70 \%$ & $53 \%$ \\
\hline
\end{tabular}

Source: World Bank staff analysis based on EU-SILC. 
Although most of the identified out-of-work population classes have been quite stable over the last few years, they have experienced some changes in composition and in their share of the total out of work. Table 3.5 shows the evolution of the classes identified from 2008 to 2011 as a share of the total out-of-work population, while Figure 3.5 graphs the absolute numbers. From the graph, the first important observation is that the size of the outof-work population has increased only slightly, by 5 percent, between 2008 and 2011. However, some classes have changed across time; for example, classes identified in 2011 that were present in previous years changed in relative size and also in composition. The fact that the composition of the classes changes over time is particularly important to keep in mind when interpreting changes in class size. For instance, significant increases (or decreases) in class size are sometimes due to reassignments of individuals across classes, resulting in changes in class composition. Thus, although some classes may retain similar names across years due to their most salient characteristics, their composition may nonetheless vary. The evolution of particular classes' size and composition over 2008-2011 can be summarized as follows:

$\checkmark$ Across time, one of the most significant changes is the increase in size of the group of single male NEETs, which grew by 18 percent from 197,000 to 233,000. The composition of this group also changed. While 76 percent of this cluster was between 16 and 24 years old in 2007, by 2011 this share had fallen to 60 percent of the group. The proportion of males also increased, from 61 to 73 percent. Moreover, the group became more skilled as the share of individuals who had tertiary education increased from 7 to 18 percent. Although the share of this group that belonged to the lowest 20 percent of the income distribution decreased, it is worrisome that the number of long-term unemployed increased in this group, from 38 to 43 percent.

$\checkmark$ Most importantly, the previous class labeled as unemployed and early-retirees split into two groups starting in 2010: a smaller group of retired and early-retired men and a relatively large group of middle-aged unemployed, which now accounts for 23 percent of the out-of-work. The emergence of this new group of unemployed results from the increase in joblessness following the crisis.

$\checkmark$ On the other hand, although the total number of retirees also grew during the period, ${ }^{26}$ many of the individuals in the newly emerged group of retired and early-retired men may have in earlier years been grouped in the retirees cluster. Starting in 2010, these individuals are now grouped together with early retired men in the newly emerged "retired and early-retired men" cluster. The retirees group identified in 2008 and 2009 was only 65 percent female; by 2011, it had evolved to become 83 percent female and had also diminished in size. Due to its changed composition in terms of gender, it is labeled as retired women starting in 2010.

$\checkmark \quad$ The stay-at-home young mothers' cluster remained fairly stable in terms of its share of the out-of-work population during the period, although its composition varied slightly. In 2007 this cluster's population was younger: 40 percent were between 16-24 years old, compared to 25 percent in 2011. Another important difference is in the young mothers' partners. Although in 2009 the percentage of this group that had a working partner increased to 82 percent (from 77 the previous

${ }^{26}$ From 2008 to 2011, the number of (early) retired men and women in our sample rose by 2 percent; in contrast, the number of short-term and long-term unemployed increased by 6 percent. 
year), the figure decreased rapidly following the crisis to 58 percent in 2011 . This loss of income in the household meant an increased risk of poverty in this cluster; the share of those in the poorest-income quintile increased 9 points from 2007 to 2011.

$\checkmark \quad$ The low-educated, early-retired, disabled group maintained the same relative share of the out-of-work population, between 3 and 5 percent, during the period. In terms of composition, a larger share of the individuals in this group became disabled-from 15 to 40 percent-and a larger share also became long-term unemployed, up to 8 percent in 2011 compared to 0.1 percent in 2007.

$\checkmark$ Finally, the cluster of low-educated, rural, long-term unemployed was a decreasing share of the out-of-work population, falling from 15 to 12 percent from 2007 to 2011. (Note, however, that in 2009 this share went up to 17 percent before falling sharply.)

Table 3.5 Classes of Out-of-Work Population in Bulgaria (2008-2011), as Percent of Total Out-of-Work Population

\begin{tabular}{|l|c|c|c|c|}
\hline & $\mathbf{2 0 0 8}$ & $\mathbf{2 0 0 9}$ & $\mathbf{2 0 1 0}$ & $\mathbf{2 0 1 1}$ \\
\hline Middle-aged unemployed (only 2010 and 2011) & & & $31 \%$ & $23 \%$ \\
\hline Retired women (only 2010 and 2011) & & & $25 \%$ & $19 \%$ \\
\hline Stay-at-home young mothers & $16 \%$ & $15 \%$ & $12 \%$ & $15 \%$ \\
\hline Single male NEETs & $13 \%$ & $17 \%$ & $17 \%$ & $15 \%$ \\
\hline Retired and early-retired men (only 2010 and 2011) & & & $10 \%$ & $13 \%$ \\
\hline $\begin{array}{l}\text { Low-educated rural long-term unemployed } \\
\text { (not in 2010) }\end{array}$ & $15 \%$ & $17 \%$ & - & $12 \%$ \\
\hline Low-educated early-retired and disabled & $5 \%$ & $3 \%$ & $4 \%$ & $3 \%$ \\
\hline Retirees (only 2008 and 2009) & $25 \%$ & $30 \%$ & & \\
\hline Unemployed and early retirees (only 2008 and 2009) & $26 \%$ & $19 \%$ & & \\
\hline Source: World Bank staff analysis based on EU-SILC. & & & & \\
\hline
\end{tabular}


Figure 3.5 Classes of Out-of-Work Population in Bulgaria (2008-2011), Thousands of Individuals

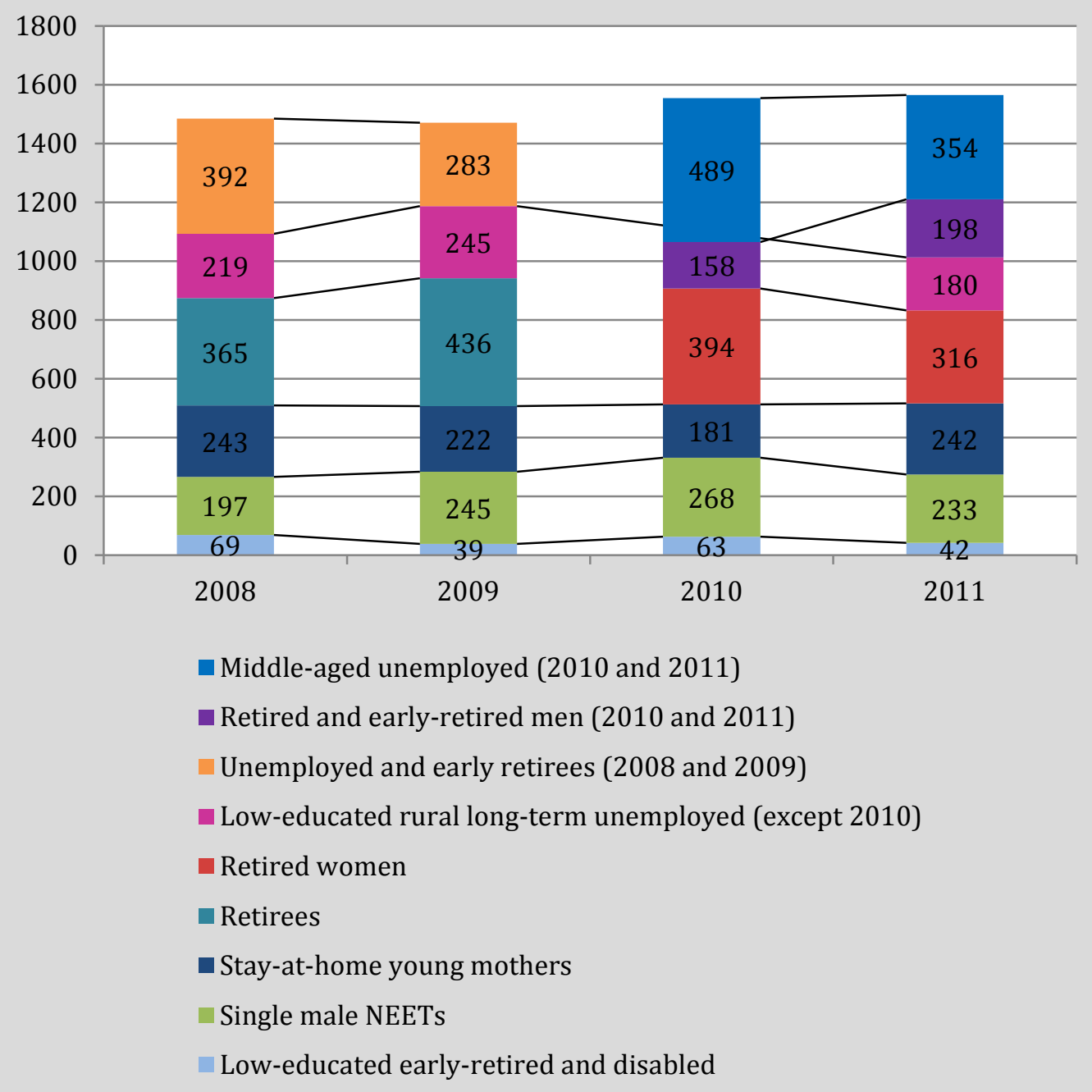

Source: World Bank staff analysis based on EU-SILC. 
The clusters identified in the out-of-work population for the 2008 -2011 period reflect both structural aspects of the Bulgarian labor market and uses cross-sectional and longitudinal analysis of clusters of the out-of-work population to further examine the effects of the crisis on the Bulgarian labor market.

Not only is unemployment high among youth and employment low, but youth labor force participation rates in Bulgaria are among the lowest in the EU. In recent years, Bulgaria's NEET rate has consistently been among the highest among the EU, while youth labor force participation rates, at only 29.6 percent in 2013, are well below the EU average of 42.2 percent (Figure 3.6). In part, low labor force participation and employment rates among youth reflect a full-time work tradition in Bulgaria. In many EU countries, youth have higher labor force participation rates because they are able combine their studies with part-time work. For example, as many as 75 percent and 40 percent, respectively, of youth in the Netherlands and Slovenia report working part time (Dimitrov and Duell, 2013). In contrast, only about 4 percent of youth in Bulgaria work part time, and this figure has remained steady in recent years (ibid).

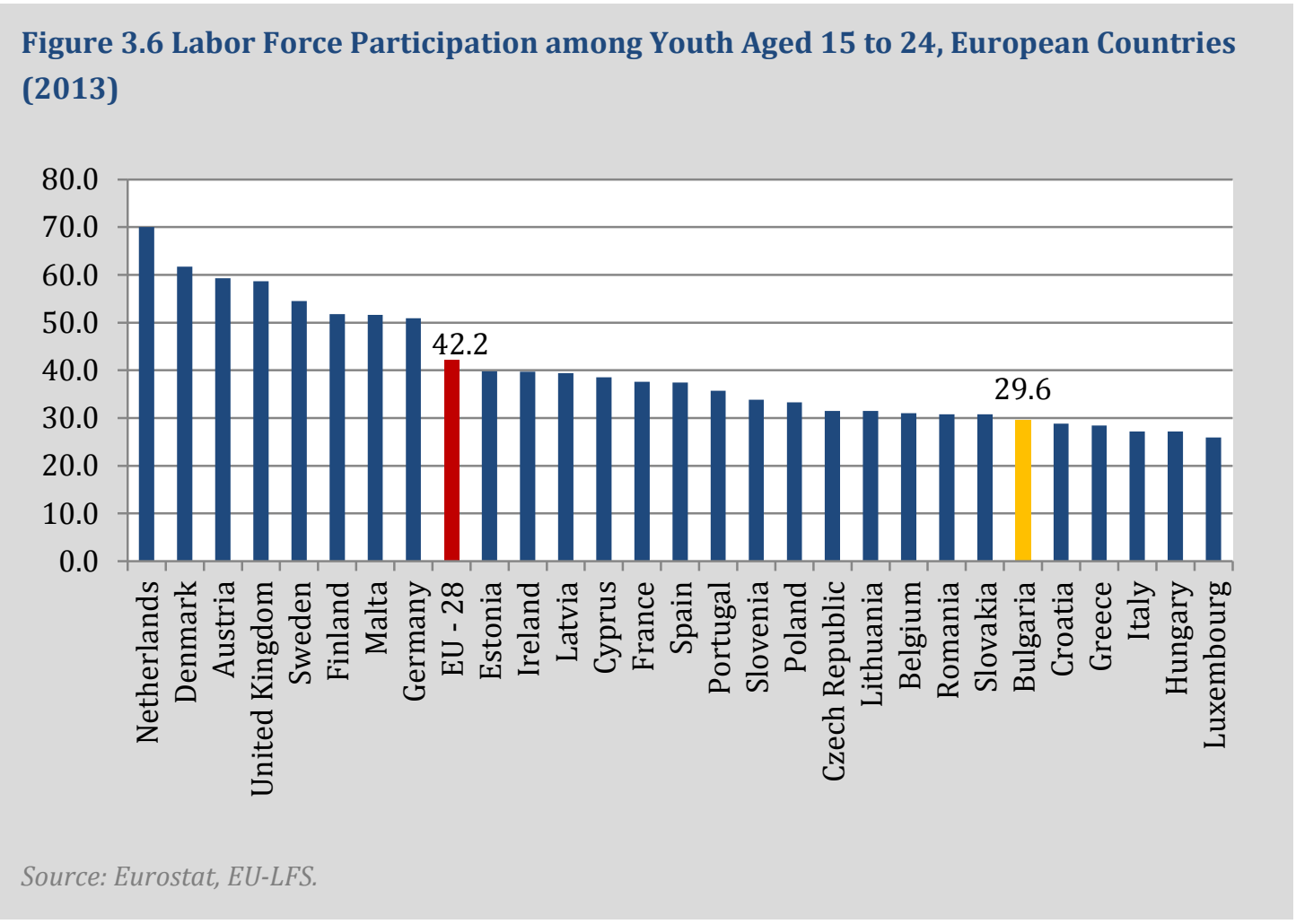

Disabled individuals face significant barriers to employment, with important consequences for spending on disability benefits. In 2011, 53 percent of individuals of working age with at least one permanent difficulty in their daily activities were inactive, and only 31 percent were employed (Dimitrov and Duell, 2013). In this analysis, the low-educated, early-retired, disabled cluster represented, on average, 4 percent of the out-of-work population (around 50,000 
individuals), and 80 percent of this group received disability benefits. Although the percentage of expenditures on disability benefits as a share of GDP in Bulgaria is among the lowest in the European Union, this proportion has been increasing and will likely continue to rise significantly in coming years, as the Bulgarian population continues to age at rapid rates. Moreover, the identified cluster is not only heavily reliant on benefits but is also relatively young, ${ }^{27}$ implying that benefit payments are likely to continue for decades to come. Low levels of education and lack of work experience, as well as an inaccessible physical environment and employer reluctance to hire individuals with disabilities, represent some of the structural barriers faced by this population.

Figure 3.7 Expenditures on Disability Benefits as a Share of GDP in Europe (2008 and 2010)

$$
\text { - } 2010 \diamond 2008
$$

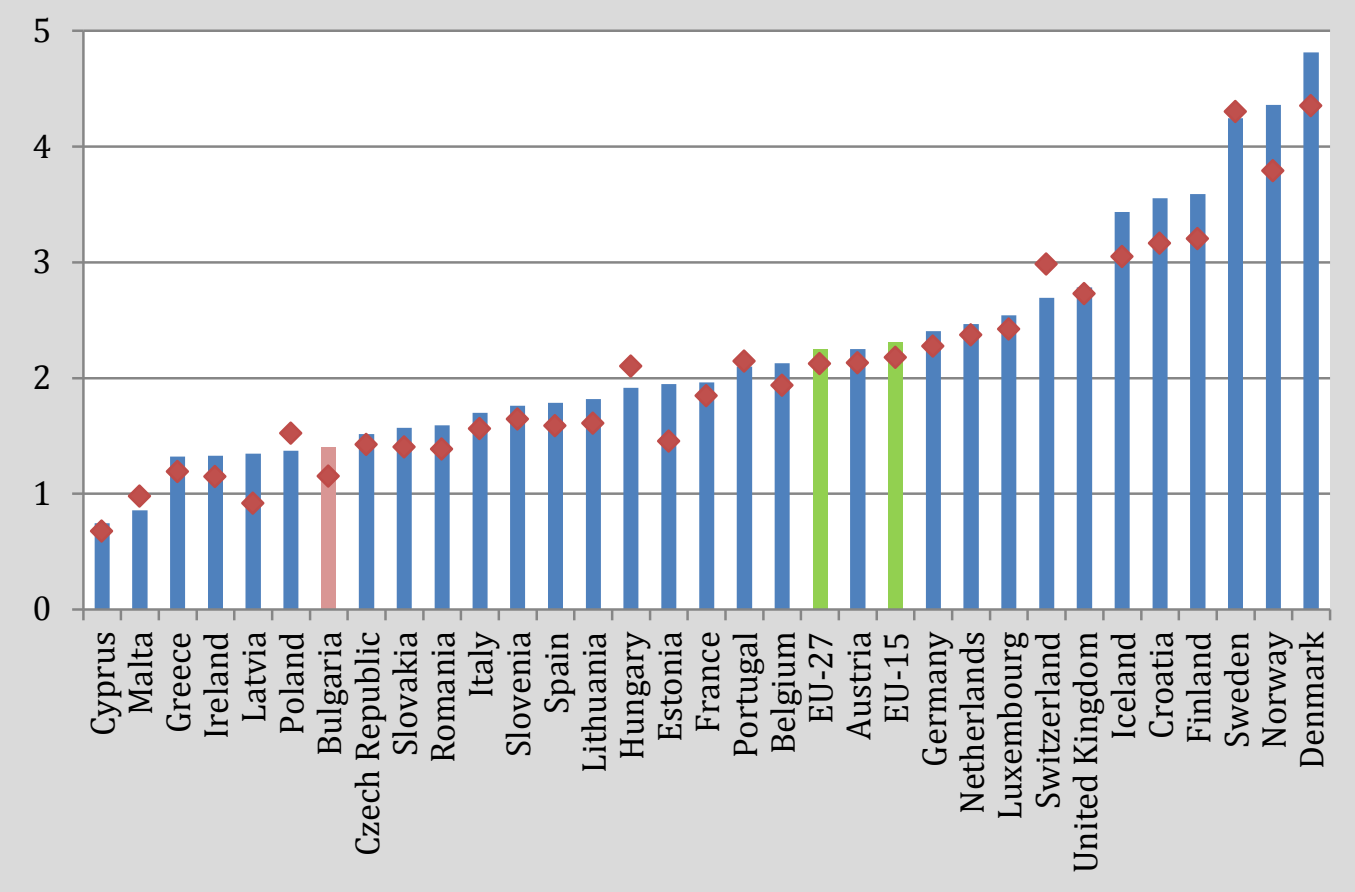

Source: Eurostat

A relatively large percentage of the working-age population is already retired. In the working-age sample used in this analysis, two main clusters of retirees emerge, representing around a third of the out-of-work population. This may partly reflect the fact that a relatively high percentage of the population aged 15 to 64 has reached retirement age. ${ }^{28}$ As shown in Figure 3.8, Bulgaria's population is expected to age dramatically in the coming years. The median age has already increased from 30.3 in 1960 to 42.7 in 2012. This presently represents the third highest median age in the EU, surpassed only by Germany and Italy. In

27 In 2011, 42 percent of this group was younger than 35, and 36 percent was between the ages of 35 and 54.

28 The current retirement age in Bulgaria is 60 for women and 63 for men. 
addition, labor force participation rates for both men and women close to retirement are lower than the EU-27 average. ${ }^{29}$ Delaying retirement and increasing labor force participation among older individuals and the general working-age population thus emerge as important policy priorities.

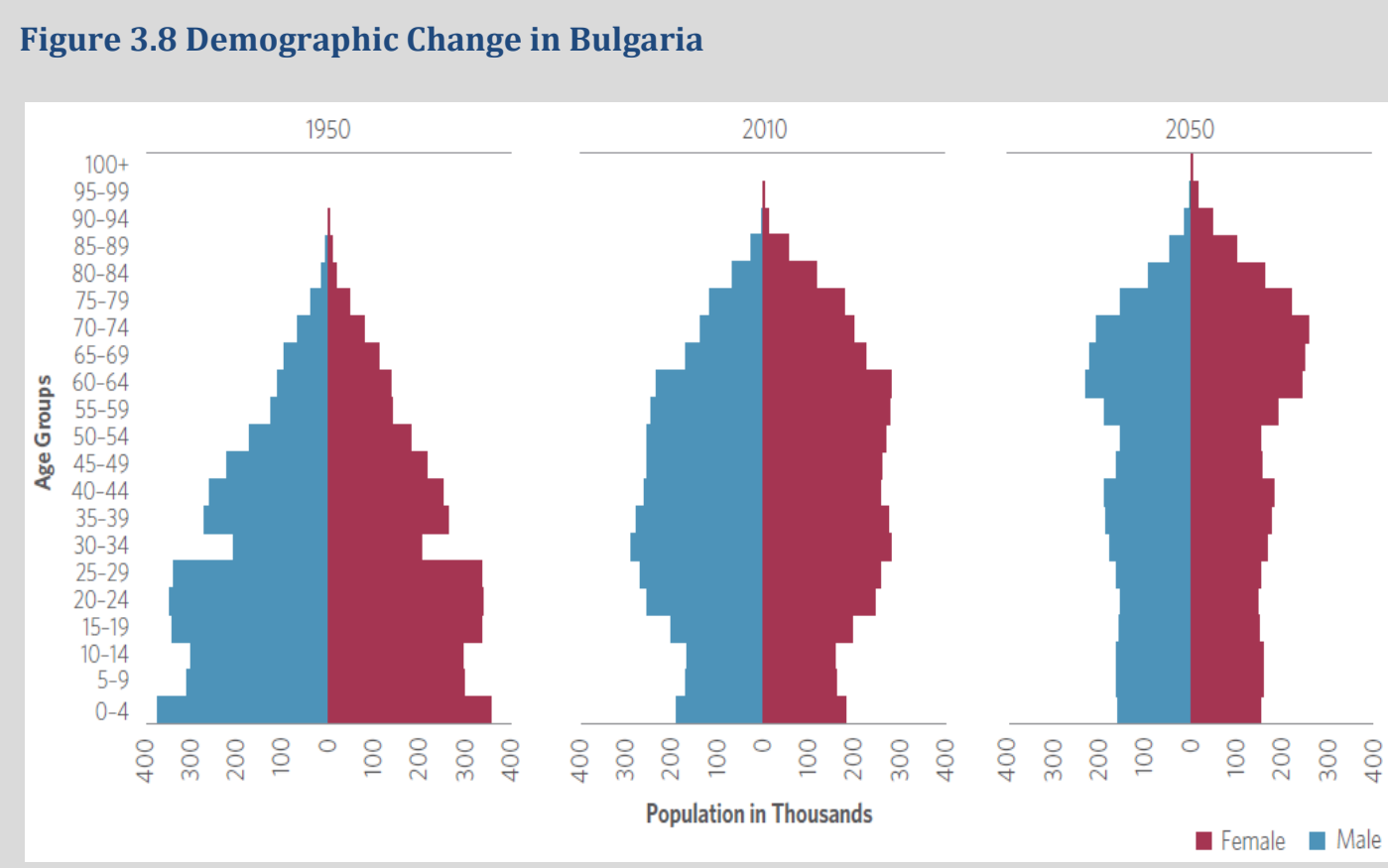

Source: World Bank 2013, based on data from the United Nations Population Division.

Not only has the number of unemployed grown with the crisis, unemployment has also changed in nature. A new distinct class of unemployed (the middle-aged unemployed) has emerged, representing 354,000 mostly-unemployed individuals, many of whom were affected by the financial crisis. The length of unemployment spells also increased following the crisis, with a resulting rise in the number of long-term unemployed individuals. It is also evident that youth - who as a group are already at a disadvantage in the labor market for structural reasons-were also affected by the crisis, as can be seen by the increasing number of single male NEETs.

Despite their high reliance on benefits, many of the unemployed and stay-at-home mothers identified in this study remain at risk for poverty. The key transmission channel of income shocks during the crisis was the labor market, with less-educated individuals, including most Roma, being the most likely to have been affected by labor market shocks. The public response, which included an increase in pensions and other social protection spending, prevented a sharp increase in poverty (World Bank, 2012). However, the stimulus underutilized Bulgaria's battery of well-targeted programs including child allowances and especially the guaranteed minimum income program, which covers a very small part of the

${ }^{29}$ The labor force participation rate for men aged 55 to 64 is about 4 percentage points lower than the EU27 average; for women aged 60 to 64, labor force participation is about 5 percentage points below the EU27 average. Source: Eurostat. 
population and of the poor. As such, inefficient targeting and low generosity have thwarted poverty reduction, even though on average more than 60 percent of the middle-aged unemployed, stay-at-home young mothers, and low-educated, rural, long-term unemployed identified in this study receive at least one form of social benefit. This is especially the case for the low-educated rural long-term unemployed, 69 percent of whom are in the poorest income quintile. The groups of retired individuals, on the other hand, are well-protected from poverty, in part due to a generous old-age benefit. 
Finally, by looking at longitudinal EU-SILC data for the 2008-2010 period, one can better understand the dynamics within clusters and notice other movements in the labor market. The latent class analysis of the out-of-work in the 2010 longitudinal dataset (which comprises a subsample of around 500 observations), yielded similar results in terms of latent classes, though in light of the reduced sample size it became necessary to combine some categories of out-of-work individuals, producing only four distinct clusters. Since there are some similarities in the size and characteristics of these four clusters compared to the cross-section analysis, the findings from the panel data can be used to understand further the dynamics of the previously described sample. The four identified classes, in order of magnitude, are:

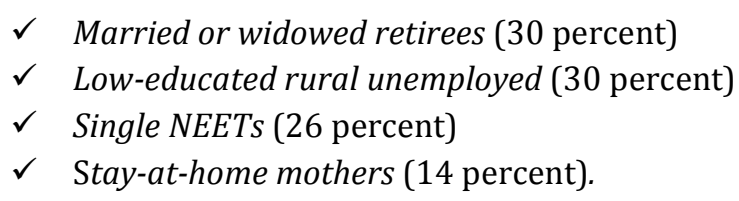

Annex 3 shows the statistical description of the latent classes in full, while Table 3.6 summarizes the most salient characteristics of the four classes.

Table 3.6 Longitudinal Analysis: Summary Characteristics of Latent Classes of Out-ofWork Population in Bulgaria, (2010)

\section{1: Married or widowed retirees $(30 \%)$}

- $96 \%$ are retired

- $43 \%$ partner is not working, while $38 \%$ is without a partner

- $\quad 60 \%$ are married , $19 \%$ widowed

- $79 \%$ are 55 to 64 years old

- $68 \%$ are female

- $48 \%$ have upper secondary, 30\% lower secondary

- 29 years of work experience on average

- 57 \% live in rural areas

- 11 percent report strongly limited capacity to work

- Low poverty risk: $20 \%$ in poorest quintile

- $\quad 55 \%$ receive old-age benefits; $46 \%$ disability benefits
2: Low-educated rural unemployed (30\%)

- $\quad 98 \%$ are unemployed

- $49 \%$ partner is not working or without a partner (26\%)

- $61 \%$ have no working adults in household

- $\quad 63 \%$ are between 35-54 years old

- Low-skilled: $60 \%$ have lower secondary education or below

- 17 years of work experience on average

- $60 \%$ live with children

- $70 \%$ live in rural areas

- Very high poverty risk: $54 \%$ in poorest quintile

- $\quad 56 \%$ receive family child benefits 
- $67 \%$ are unemployed, $33 \%$ inactive

- $\quad 93 \%$ are without a partner or never married

- $69 \%$ have at least one working adult in household

- $\quad 99 \%$ are between 16 to 34 years old

- $\quad 55 \%$ are male

- 3 years of work experience on average

- $63 \%$ live in rural areas

- High poverty risk: $43 \%$ in poorest quintile

- 6.0 household members on average
- $59 \%$ are inactive, $39 \%$ unemployed

- $\quad 96 \%$ have a working partner

- $81 \%$ are between 25 to 54 years old

- $99 \%$ are female

- 12 years of work experience on average

- $\quad 73 \%$ live with children

- Moderate poverty risk: $26 \%$ in poorest quintile

- $\quad 57 \%$ receive family child benefits

Source: World Bank staff analysis based on EU-SILC

Note: "Years of work experience" refer only to those individuals who have worked before. "Dependent children" include children under 18 and household members aged 18 to 24 who are economically inactive and living with at least one parent. "Working adult" refers to adults aged 24 and over.

An advantage of the dynamic panel analysis is that the labor market status of individuals in these four classes can be observed across time, providing information on the flows in and out of jobs two years later (Table 3.7 and Table 3.8).

Table 3.7 Composition of 2010 Clusters based on 2008 Labor Market Status-Bulgaria (Column Percentages)

\begin{tabular}{|l|l|c|c|c|c|c|}
\hline \multicolumn{2}{|c|}{} & \multicolumn{5}{|c|}{ Labor market status in 2008 } \\
\hline Cluster & $\begin{array}{l}\text { Working-age } \\
\text { population in 2010 }\end{array}$ & Unemployed & Retired & Disabled & $\begin{array}{c}\text { Other } \\
\text { Inactive }\end{array}$ & Employed \\
\hline 1 & $\begin{array}{l}\text { Married or widowed } \\
\text { retirees }\end{array}$ & 4 & 95 & 52 & 5 & 2 \\
\hline 2 & $\begin{array}{l}\text { Low-educated rural } \\
\text { unemployed }\end{array}$ & 39 & 4 & 0 & 6 & 5 \\
\hline 3 & Single NEETs & 21 & 0 & 48 & 44 & 2 \\
\hline 4 & $\begin{array}{l}\text { Stay-at-home } \\
\text { mothers }\end{array}$ & 12 & 0 & 0 & 18 & 2 \\
\hline NC & Employed & 25 & 1 & 0 & 28 & 89 \\
\hline Total & & 100 & 100 & 100 & 100 & 100 \\
\hline
\end{tabular}

Source: World Bank staff analysis based on EU-SILC.

Note: For 2010, students 16-24 years old who are inactive are excluded from the sample. Numbers referred to in the text appear shaded in blue.

The longitudinal analysis indicates that the reduction in employment between 2008 and 2010 is predominantly explained by job losses and movement into unemployment. Table 3.7 shows the flows of the 2008 working-age population, ${ }^{30}$ according to their labor market status in 2008 into any of the four latent out-of-work classes or into employment. The table shows that 11 percent of the individuals who were employed in 2008 moved into one of the four out-ofwork classes in 2010, whereas the remaining 89 percent continued in employment. The group

30 The data does not include individuals aged 62 and above in 2008, who would be dropped from the sample in 2010 because they are above 64. Also, students under 25 years old in 2010 are excluded from this analysis as they are not considered a target group for activation policies. 
of low-educated rural unemployed absorbed almost half of the job losses-around 5 percent of the previously employed, versus only 2 percent in the case of married or widowed retirees, single NEETs and stay-at-home mothers, respectively. Given that single NEETs are predominantly unemployed (68 percent), it can also be inferred that roughly 7 percent of those who were employed in 2008 moved into a largely unemployed cluster in 2010, while the remaining 4 percent predominantly moved into an inactive class.

A significant proportion of all of the out-of work groups identified in 2010 were hit by job losses, meaning that they were employed in 2008; this is especially so among low-educated rural unemployed and stay-at-home mothers. Table 3.8 allows for the identification of the groups in the 2010 population that were most affected by job losses. The group of loweducated rural unemployed is the hardest hit, with 34 percent of its members formerly employed in 2008. The second group to be affected by job losses is the class of stay-at-home mothers, 27 percent of whom lost their jobs. Comparatively, only 13 percent of single NEETs lost their jobs. However, this may explain the fact that many single NEETS who are unemployed are first-time job seekers, so few were likely to have been employed in 2008 in the first place. During economic downturns, youth are generally more likely to lose their jobs, since they tend to work in cyclically sensitive industries such as construction or hold temporary contracts (Eurofound, 2012).

Longitudinal analysis suggests a lack of flow into employment. Table 3.8 also shows that 90 percent of those employed in 2010 were already employed in 2008. In addition, from the previous table, it is clear that only 25 percent of the unemployed and 28 percent of the "other inactive" (that is, not retired or disabled) in 2008 moved into employment in 2010. This pattern might then reinforce the divide between the employed and the unemployed.

Table 3.8 Composition of 2010 Clusters Based on 2008 Labor Market Status-Bulgaria (Row Percentages)

\begin{tabular}{|l|l|c|c|c|c|c|c|}
\hline \multicolumn{2}{|c|}{} & \multicolumn{7}{c|}{ Labor market status in 2008 } \\
\hline $\begin{array}{c}\text { Clus } \\
\text { ter }\end{array}$ & $\begin{array}{c}\text { Working-age } \\
\text { population in } \\
\mathbf{2 0 1 0}\end{array}$ & $\begin{array}{c}\text { Un- } \\
\text { employed }\end{array}$ & Retired & Disabled & $\begin{array}{c}\text { Other } \\
\text { Inactive }\end{array}$ & Employed & Total \\
\hline 1 & $\begin{array}{l}\text { Married or } \\
\text { widowed retirees }\end{array}$ & 5 & 77 & 1 & 4 & 12 & 100 \\
\hline 2 & $\begin{array}{l}\text { Low-educated } \\
\text { rural unemployed }\end{array}$ & 58 & 3 & 0 & 5 & 34 & 100 \\
\hline 3 & Single NEETs & 38 & 0 & 1 & 48 & 13 & 100 \\
\hline 4 & $\begin{array}{l}\text { Stay-at-home } \\
\text { mothers }\end{array}$ & 39 & 0 & 0 & 34 & 27 & 100 \\
\hline NC & Employed & 6 & 0 & 0 & 4 & 90 & 100 \\
\hline
\end{tabular}

Source: World Bank staff analysis based on EU-SILC.

Note: For 2010, students 16-24 years old who are inactive are excluded from the sample. Numbers referred to in the text appear shaded in blue. 


\section{Box 3.1 Roma Population and Labor Market Exclusion}

Labor market exclusion in Bulgaria cannot be discussed without giving special consideration to the situation of the country's Roma population, a population that faces significant structural barriers. Because EU-SILC data does not include a differentiating indicator for Roma and non-Roma, the out-of-work population classes identified in this exercise cannot directly be linked to a Roma/non-Roma pattern.

According to national census information, there are about 370,000 citizens of Roma origin living in Bulgaria (approximately 5 percent of the total population). This number reflects the lower bound of estimates, in part because many Roma in Bulgaria also identify with the Turkish ethnicity. Members of the Roma minority achieve lower human development outcomes and are not fully integrated into economic activity. In 2011, the poverty headcount rate among Roma was 68 percent, in contrast to a poverty rate of 23 percent at the national level (see table below). In the same year the employment rate stood at 57 and 52 percent, respectively, for non-Roma men and women, while for Roma the corresponding figures were only 42 and 26 percent (World Bank (2013)). Willingness to work, as measured in the labor force participation rate (LFPR), has been shown to be relatively high among Roma, exceeding the LFPR in the majority population in the case of men: According to data from the 2007 World Bank Bulgaria Multi-Topic Survey, LFPR among non-Roma stood at 79 percent and 68 percent for men and women respectively; in contrast, among Roma, the corresponding results were 85 and 59 percent. Unemployment rates are also disproportionately high among Roma, having reached as high as 53 percent among Roma women before the crisis (data are for 2007). Unfavorable labor market outcomes among Roma population can be in part explained by a significant education gap between Roma and non-Roma population that is even higher among women. A World Bank study (2010) finds large gaps in the share of Roma and nonRoma population with a secondary education: Among Roma, only 16 and 10 percent of men and women, respectively, had completed secondary education; the corresponding figures for non-Roma men and women stood at around 87 percent. Only in recent years have educational outcomes for Roma children started to improve. Lastly, discrimination appears to be the cause of about a third of the Roma/non-Roma wage gap (World Bank 2010), and may be a further contributor to low employment rates. 
As World Bank (2010) outlined, the underperformance and exclusion of Roma carries a significant economic and fiscal cost for countries in the region. For Bulgaria, the economic and fiscal costs of Roma exclusion were estimated at EUR 0.56 billion and 0.37 billion in 2010, respectively. In light of the projected decline of the working-age population in Bulgaria, active inclusion of minority populations in education, labor markets and other areas of society is a key development challenge for the country.

\begin{tabular}{|l|ccc|ccc|ccc|}
\hline & \multicolumn{3}{|c|}{ Poverty Headcount Rate } & \multicolumn{3}{c|}{ Distribution of the Poor } & \multicolumn{3}{c|}{ Distribution of Population } \\
& Feb-10 & Oct-10 & Feb-11 & Feb-10 & Oct-10 & Feb-11 & Feb-10 & Oct-10 & Feb-11 \\
\hline Total & 21.1 & 21.2 & 23 & 100 & 100 & 100 & 100 & 100 & 100 \\
Ethnicity & & & & & & & & & \\
$\quad$ Bulgarian & 14.1 & 15.5 & 16.4 & 55.5 & 61.4 & 59.1 & 82.5 & 82.9 & 83.1 \\
$\quad$ Turkish & 41.4 & 43.4 & 50.9 & 18.7 & 21.1 & 22 & 9.5 & 10.2 & 9.9 \\
Roma & 72.5 & 64.4 & 68.4 & 23.1 & 15.1 & 15.4 & 6.7 & 4.9 & 5.2 \\
\hline
\end{tabular}

Source: Crisis Monitoring Survey OSI-WB, 2010-2011. 


\section{From Profiling to Activation}

The current general labor market situation, along with institutional and resource deficiencies, make the activation and integration of many of the identified out-of-work groups a demanding challenge. Low labor demand and sluggish growth are exacerbated by deficiencies in the institutional setup and resources of the public employment service, active labor market policies and related social services in Bulgaria. Spending on active labor market policies (ALMPs) has been drastically reduced in recent years, while the guaranteed minimum income scheme provides low coverage and is generally not associated with activation measures. Prioritizing interventions is therefore of great importance. This section will (a) give an overview of activation and inclusion policies in Bulgaria; (b) gauge the activation need and activation potential of each group of out-of-work persons; and (c) propose a focused set of interventions for the prioritized groups. It is important to keep in mind that the proposed interventions are meant only as a starting point in a discussion with country authorities on general activation policies and their respective priorities. While the latent classes identified in this exercise points generally toward certain effectively tailored policies, it would be beneficial to conduct a more detailed profiling exercise at the individual level. Latent class analysis allows for the classification of a vast population into broad meaningful categories, but variation within groups still has implications for the level of appropriate support for the purposes of activation.

\section{Activation and Inclusion Policies in Bulgaria}

After the financial crisis started to have economic and employment effects in 2009, Bulgaria responded with a further cutback of ALMP spending from 2009 onwards. In contrast to the average OECD spending on labor market policies of 1.44 percent of GDP in 2011, Bulgaria spent only 0.59 percent of GDP on Public employment service administration, active labor market policies, unemployment and early retirement benefits combined. Some of the spending from the national budget on active labor market policies has since been replaced with funding from the European Social Fund (ESF), allowing for more program flexibility, but also incurring additional administrative burdens on public employment services. 


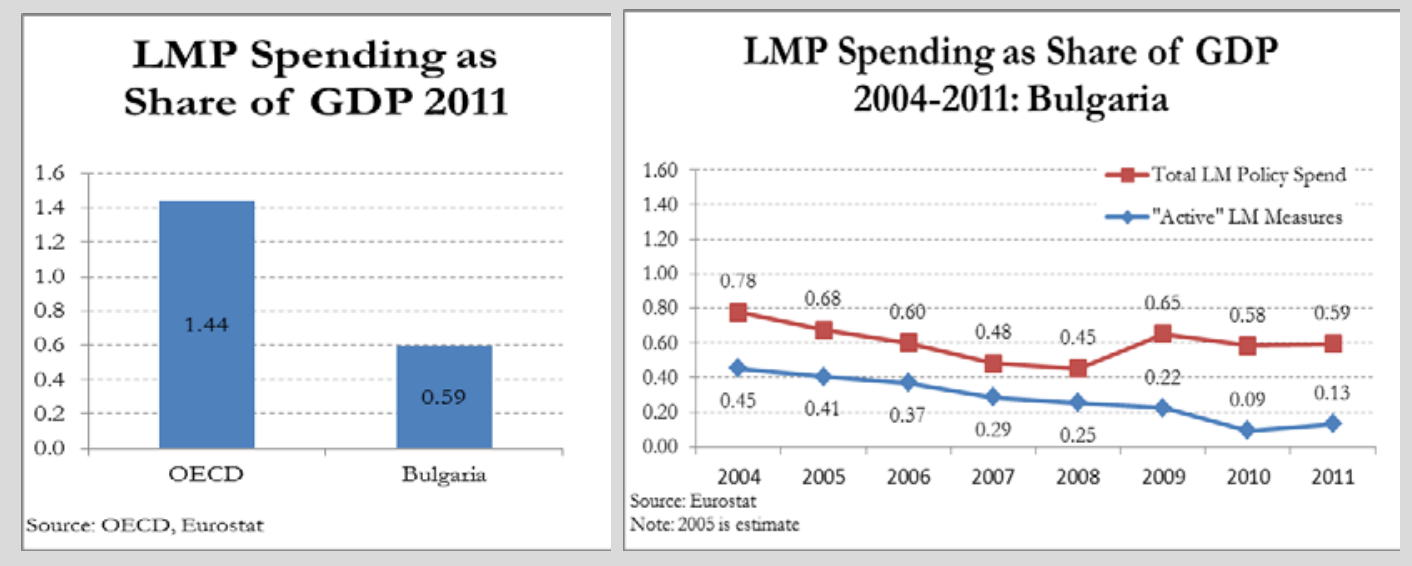

The great majority (71 percent) of labor market policy spending in Bulgaria goes to "passive" benefits, namely unemployment benefits and early retirement. Though, on average, OECD countries also allocate most labor market policy spending to these types of benefits, the proportion is considerably lower, at 60 percent.

Figure 3.10 Composition of Spending on Labor Market Policies in Bulgaria (2011)

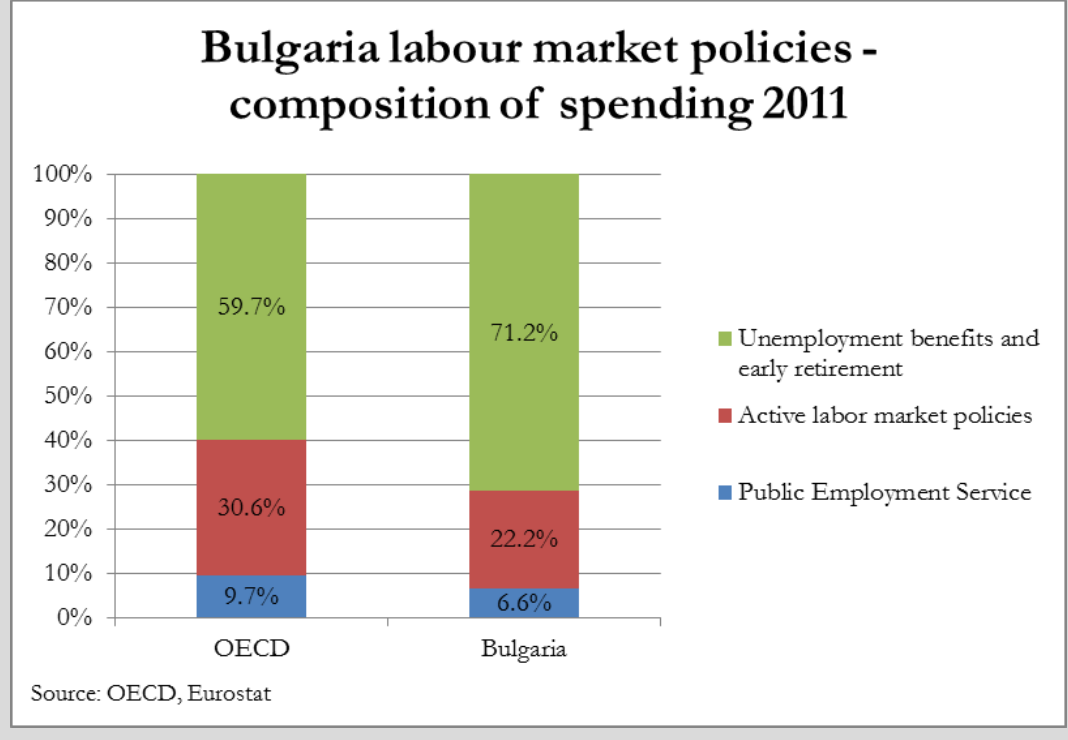

Even though a large proportion of labor market policy spending goes to passive policies, coverage of the unemployed by unemployment benefits or the guaranteed minimum income program is low. Of the registered unemployed (comprising short and long-term unemployed workers), only 14 percent received unemployment benefits and only 6 percent received guaranteed minimum income. Activity in the informal economy is high, estimated at 19.5 percent for men and 12.9 percent for women in 2008, which exacerbates the lack of access to unemployment insurance (Packard, Koettl, Montenegro, 2012: 31). 
Participation in the guaranteed minimum income program is not well linked to activation or work incentives. Recent findings from a World Bank study on the activation of vulnerable groups in Bulgaria (Dimitrov and Duell, 2013) confirmed that the participation in the guaranteed minimum income (GMI) program is generally handled in a traditional "social assistance" type way, with social workers more concerned about enforcing asset and income tests than providing activation and linkage to social services. The attractiveness of the GMI and any work incentives are further reduced by a six-month waiting period, mandatory community work (without activation, employment linkage or skill development) and the absence of earnings disregards for benefit recipients. Absence of part-time employment legislation further increases the barriers to entry-level employment for young people, parents and labor market outsiders (EC, 2013b: 24).

The institutional setup of active labor markets and services is highly fragmented. The institutional delivery structure for activating policies and services is divided between the Public Employment Service, the Social Assistance Agency, the National Security Institute and other agencies, including the Ministry of Education (1iteracy) and Medical Commissions (disability). Current collaboration between these agencies is limited, focused on rule enforcement and program crosschecks rather than on activation and job linkage. Strict, regular enforcement of asset and income tests among the GMI population further reduces the incentive for (formal) work.

Labor force participation and maternity leave. Potential concerns for female labor force participants in many countries are regulations and labor market arrangements for (paid) maternity leave and extended absences from the workplace. Bulgaria grants an OECD record of 68 weeks of maternity leave, most of it with paid benefits, for formal non-agricultural workers. While the intuitive conclusion would be to assume a lower female employment rate, the opposite is true among the active population. Female unemployment ( 9.8 percent) for $15-$ to 64-year olds is actually lower than the male unemployment rate (12.4 percent in 2011). LFPR for young women is lower (24.9 percent compared to 33.9 percent for men), but this could be explained by women's greater participation in higher education. Once women hit prime age, their labor force participation is actually quite high in Bulgaria compared to EU-27: 79.3 percent for women vs. 84.5 percent for men. The gender gap in LFPR is thus 5.2 percent in Bulgaria, compared to a 13 percent gap in the EU-27. Overall, Bulgaria could benefit from a more employment-friendly and human-capital preserving approach to maternity leave, since the overall LFPR is quite low. Women's caregiving responsibilities, combined with a lack of child care options, play a part in this.

Finally, some programs for the inclusion of inactive and marginalized groups deserve special mention. These are the program for Roma mediators in employment offices ("Activating inactive people on the labor market") and the national literacy program for adults, which help to overcome severe under-qualification and barriers to entry.

Activation Priority, Activation Type and Benefit Receipt by Group

In further considering the approach toward labor market integration, an assessment of the priorities and potentials of the identified groups is needed. Given the limited resources for

$\mathbf{8 0}$ | Portraits of Labor Market Exclusion 
programs and the low availability and difficulty coordinating staff in the Bulgarian social assistance and public employment departments, prioritization of interventions is all the more important. After the first step ("activation priority") of prioritizing interventions along activation need and activation potential, a second step ("activation type") will classify the groups according to the kind of activation intervention needed, depending on the social or labor market barriers to be overcome. Lastly, as a third step information on household income composition of the different groups will be used to assess potential crossdependencies of the benefit system with the labor market status and activation approaches.

Activation priority. The table below gives an overview of the identified inactive classes, their respective activation need, and activation potential. The total number of persons estimated in these clusters is 1.56 million, representing about 21 percent of the total population and 33 percent of the working-age (16-64) population of Bulgaria in 2011.

In the table, "activation need" refers to a group's level of need for inclusion in the labor market in order to gain income and reduce or end poverty. "Activation potential" describes that group's ability or motivation to be in the labor market. High activation need might be driven by high poverty risk (as in the case of the low-educated rural long-term unemployed), whereas high activation potential could be driven by previous work experience or a relatively good educational base (for example, the middle-aged unemployed).

\section{Table 3.9 Activation Priority: Overview of Inactive Clusters and Priority for Action- Bulgaria}

\begin{tabular}{|c|l|c|c|c|}
\hline Share & \multicolumn{1}{|c|}{ Cluster } & $\begin{array}{c}\text { Activation } \\
\text { need }\end{array}$ & $\begin{array}{c}\text { Activation } \\
\text { potential }\end{array}$ & $\begin{array}{c}\text { Priority for } \\
\text { action }\end{array}$ \\
\hline $23 \%$ & Middle-aged unemployed & Medium & High & High \\
\hline $19 \%$ & Retired women & Ledium & Medium & Medium \\
\hline $15 \%$ & Stay-at-home young mothers & High & Medium & High \\
\hline $15 \%$ & Single male NEETS & Low & Medium & Low \\
\hline $13 \%$ & Retired and early-retired men & High & Medium & High \\
\hline $12 \%$ & Low-educated rural long-term unemployed & Low & Low & Low \\
\hline $3 \%$ & Low-educated early-retired and disabled & & & \\
\hline
\end{tabular}

From this overview, an initial set of priorities arises: the middle-aged unemployed, single male NEETs and low-educated rural long-term unemployed are the highest priority for activation. Their high priority stems from their relatively large cohort sizes, high or medium activation need due to high poverty risks, and activation potential through labor market proximity given their work histories and education. Stay-at-home young mothers follow closely behind these classes as a priority, but are classified as slightly lower priority owing to their non-declared unemployment and to the significant share who have at least one working adult in their households. Retired women (86 percent of whom are over the current retirement age of 60 
years) ${ }^{31}$, retired and early-retired men (who have comparatively low poverty risk, in part due to old-age benefit income) and the low-educated early-retired and disabled, are not prioritized for activation measures or policies due to their lower activation need and potential (almost 80 percent of the low-educated early-retired and disabled report a strongly limited capacity to work).

In a less constrained environment, with more established activation and labor market integration policies for younger and middle-aged job seekers, additional consideration could be given to re-prioritizing the group of retired and early-retired men. Nearly half, 47 percent, are between ages 45 and 59, and could thus be considered to be in early retirement ${ }^{32}$ and potentially amenable to reintegration into the labor market. Given the extreme demographic pressures in Bulgaria, special attention needs to be paid to limiting inflow into this group of unemployed and avoiding further increases in the number of early retirees. Given the fact that 52 percent of this group's total household income still derives from labor and 46 percent from transfers (specifically, old-age and disability benefits for this class represent 29 percent and 11 percent, respectively, of the total spent on such benefits), all three levers need to be considered: (1) continuing labor income, (2) reducing retirements and pension payments, and (3) managing entry into disability benefits.

Activation type. As a second step, the relative severity of labor market or social obstacles to labor market integration will serve as an orientation for activation approaches.

\section{Figure 3.11 Activation Types of Prioritized Clusters-Bulgaria}

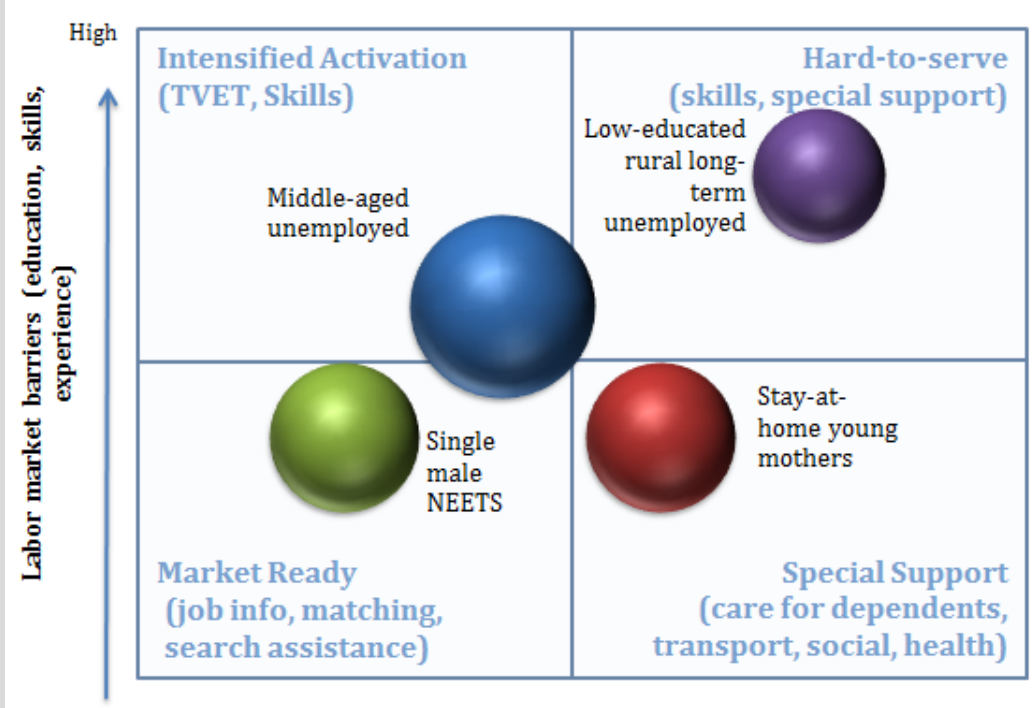

Social barriers (child care, gender, poverty, disability) High

31 http://www.ssa.gov/policy/docs/progdesc/ssptw/2012-2013/europe/bulgaria.html

32 The current retirement age for men in Bulgaria is 63. 
As a result of mapping the barriers to labor market integration faced by the four prioritized groups, we can quickly discern the respective types of activation that could be undertaken for them. Whereas the low-educated rural long-term unemployed will require activation across the labor market proximity and social inclusion axes, the single male NEETs or the stay-athome young mothers will mainly require job-search and professional training assistance on the labor market dimension. For the stay-at-home young mothers group, local social services (especially child care) will have the greatest effect on activation. The middle-aged unemployed will mainly require employability-enhancing measures.

Household income composition. When analyzing the 2011 household income of the groups, we realize that benefits are the major income source for only two of them (retired women and low-educated, early-retired, and disabled). For the large prioritized groups, no immediate benefit- or incentive-trap picture emerges from the overview. Households of middle-aged unemployed rely on pensions for 14 percent of their income, but in terms of actual numbers, only 7 percent receive old-age benefits. For retired women, old-age benefits make up 46 percent of household income, consistent with the fact that 97 percent of the group is retired and 86 percent is 60-plus years old.

Stay-at-home young mothers have the lowest benefit incidence among all groups (23 percent of household income) while single male NEETs are close behind, with 24 percent of household income. Old-age benefits make up 8 and 11 percent of the household income in these groups, an understandable fact since someone older than 64 is present in 19 and 23 percent of these households, respectively. These are interesting household composition effects, but they present no immediate labor-market participation disincentives for the young women and men in the stay-at-home young mothers and single male NEETs groups.

Retired and early-retired men receive 29 percent of old-age benefits, 40 percent if old-age and disability benefits are combined. The same figure for the low-educated early-retired and disabled is 44 percent (with disability benefits making up 26 percent of the total). Among the low-educated rural long-term unemployed, incidence of family-child benefits is rather high (13 percent of household income) and old-age benefit income comparatively low. This could reconfirm the hypothesis that many Roma and Turkish minority citizens are part of this group, as their benefit receipt patterns show greater use of family than of old-age benefits.

Given the overall picture of benefit receipt revealed by EU-SILC data, no immediate need for action emerges when looking just at these groups of inactive and out-of-work residents.

Portraits of Labor Market Exclusion | 83 
This section sets out a set of potential activation measures for each of the priority groups. Areas for further policy dialogue with respect to improving the implementation of activation policies are also outlined.

The suggestions below should be considered as a starting point for further policy dialogue between EC DG EMPL, the World Bank and the Bulgarian authorities, bearing in mind that the groups identified still have some heterogeneity that may affect the level of support required. Accordingly, these suggestions are not meant to be an exhaustive set of possible activation measures.

It should be kept in mind that the class descriptions are derived from 2011 EU-SILC data. Since then, general economic development, policy actions by the government of Bulgaria and European Commission country-specific recommendations might already have reflected some of the policy suggestions or rendered them obsolete.

Middle-aged unemployed (23 percent, Priority: High). This group is characterized by a middle-aged ( 66 percent between 35 and 54 years) and mainly rural (64 percent) profile comprising both men and women who are unemployed (83 percent). Their mid-level skill profile and average of 18 years of work experience makes them a ready-to-work group. They have an elevated need for activation, as only a small majority (52 percent) have working spouses, and with 37 percent in the poorest income quintile, their poverty risk is high. Potential activation measures for this group include the following:

$\checkmark$ Build activation on previous work experience and skills. Owing to the fact that labor market integration is as much about hard skills as it is about self-esteem and self-motivation, activation measures for the middle-aged unemployed could start by reconnecting with the job seekers' previous industry or skill profile. It will be important for employment counselors or training providers to avoid narrowly looking at the occupation held, but rather attempt to reconnect, update and extend the skills that the worker exercised during the last job. In light of the potential for informal economy employment for this group, efforts to formalize employment ought to be promoted, for example through the introduction of in-work benefits and greater use of part-time employment. Generally, however, formalized employment must be supported from a multitude of angles (taxes, labor inspection, benefit systems, and so on).

$\checkmark$ Facilitate part-time work and temporary placement in companies. In order to enable job seekers to reconnect with the labor market and with specific (new) industries or employers, part-time work experiences or temporary placements could be encouraged. This would require working arrangements through the local regional employment commissions or district development councils.

$\checkmark$ Mobility and training schemes. For individuals in households with limited family commitments (at least 48 percent do not have caregiving responsibility for 
children ${ }^{33}$ ), training combined with (regional) mobility support could enhance the labor market prospects of some jobseekers in this class, overcoming the shortage of employment in rural areas.

Single male NEETS (15 percent, Priority: High). Two-thirds of this group's members are unemployed (68 percent), 43 percent for more than one year; an additional 31 percent are inactive. The class is 73 percent male, between 16 and 34 years old, and has generally never married or is without a partner. The majority ( 61 percent) have no work experience. Their qualification level is more heterogeneous than that of the middle-aged unemployed, with close to one-third having no more than a lower secondary education and one-sixth having a tertiary degree. While the activation need for this group is high (long periods unemployment during youth can have detrimental effects on lifetime employment and earnings prospects), their activation potential is lower, owing to their lack of labor market experience and relatively high (32 percent ${ }^{34}$ ) receipt of social assistance benefits, which might not encourage job seeking. Following are some proposed activation policies for this group.

$\checkmark$ Second-chance programs. In light of the recent educational experience of some of the group's members, programs to reconnect with technical schools or professional education colleges could be attempted with this target group. For "older" candidates and those with low educational attainment, these second-chance programs would need to take the form of traditional training and work placement schemes, and be strongly complemented by basic life and occupational behavior and motivation elements.

$\checkmark$ Mobility and young-adult housing in cities. In order to provide an orderly and supported channel for rural to urban migration and professional experience, a "foyer" model could be introduced which provides low-cost housing, professional orientation and general guidance for young people moving from rural areas to live and work in major cities. This mobility support would need to be integrated with general public employment service programs and "foyers" would need to draw on a network of partner employers to place and train young people.

$\checkmark \quad$ Language skills and training for (temporary) migration. Given the low level of caregiving responsibility for this group, labor market integration could also evolve around (temporary) migration to other European Union countries and placement into jobs that have the potential to provide mid- to high-level employment in Bulgaria. Activation and training measures for jobseekers could focus on language skills and job-search skills. The government should seek agreements with receiving countries to ensure investment in qualification and adequate treatment of jobseekers during the work placement abroad. In 2014, Bulgarian nationals will enjoy freedom of movement and occupation within the European Union. Labor market policy could complement this opening of opportunities.

\footnotetext{
${ }^{33}$ Almost half of this group has no children, and the proportion without child care responsibilities could be even higher: only 19 percent live in households with children under six years of age.

34 Twenty-eight percent receive family benefits and 11 percent receive social exclusion benefits; together, 32 percent receive at least one of these two benefits.
} 
$\checkmark$ Youth volunteer mobilization programs. In light of the high proportion of inactive members and the low level of work experience in this group, another axis of activation and labor market attachment is volunteering and community organizing projects. Such programs, which provide a combination of community work, minimal remuneration and elements of training on basic skills, self-esteem and physical exercise could be supported by public employment services, municipalities, or cultural and educational NGOs.

Low-educated rural long-term unemployed (12 percent, Priority: High). This group has the highest poverty risk in the sample (69 percent fall in the poorest quintile), a very low education level, high unemployment and inactivity. The class is more rural (70 percent) and tends to belong to households with caregiving responsibility for children (70 percent live in household with at least one child). The high poverty risk coincides with a substantial selfdeclared share of social assistance receipts (64 percent ${ }^{35}$ ). While no "Roma" indicator is contained in the EU-SILC data, this profile suggests that Roma might make up a significant part of this group. Any activation policy targeted toward this group would need to be closely coordinated with national and international efforts to improve Roma integration and access to services. Among our proposed policies for this group are:

$\checkmark \quad$ Integrate basic education into training and employment programs. Given the low level of secondary educational attainment in this group, activation measures would need to include adult-learning modules and "second chance" opportunities for basic numeracy, literacy and general knowledge. If an important share of ethnic minority members (Roma) are to be found in this class, appropriate linkage with resident and embedded coordinators inside employment offices or social assistance agencies should be ensured.

$\checkmark$ Provide local employment and training. Given the high share of family-bound members in this group, wider mobility support will likely be ineffective. Instead, local employment creation and "enhanced" public works programs (for example, combined morning training modules and afternoon work modules) could maintain labor market linkage and provide support locally or regionally.

$\checkmark$ Build on existing work experience. As prime-aged (25 to 54) unemployed, many in this group can count on a relatively long tenure of work experience (15 years on average). While some of the skills gained in that work experience might have become obsolete or atrophied during extended unemployment, re-connecting with prior firms, industries and occupational communities can be an important step for this group. Active labor market programs should support this through self-help support or direct training/individual coaching.

$\checkmark$ Address discrimination. It is possible that some members of this group are subject to labor market discrimination because of their regional or ethnic origin. Discrimination in the workplace would need to be addressed as part of a wider antidiscrimination policy in the country.

35 Fifty-three percent receive a family child benefit and 23 percent receive a social exclusion benefit; together, 64 percent receive at least one of these two benefits. 
Stay-at-home young mothers (15 percent, Priority: Medium). This group of women is relatively young, with 75 percent between the ages of 16 and 34. Eighty-three percent are likely to have caregiving responsibility for children (54 percent live in households with children below six years of age). Their activation potential is gauged as slightly lower, owing to such family commitments. Although their risk of poverty is similar to that of the middleaged unemployed or single male NEETs, a great majority (79 percent) of the members of this group have at least one working adult in the household. Some possible activation policies for this group include:

$\checkmark \quad$ Linkage of child care offerings with (re)-qualifications for mothers. Given the fact that the majority of women in this group may remain inactive due to caregiving responsibilities and the fact that at least one adult in the household is already working, one of the key steps to enable activation and labor market participation is to make available sufficient good-quality child-care offerings. Provision of child care could be coupled with training and refresher education classes for women.

$\checkmark$ Volunteering, self-organization and training in social services or entrepreneurship. In light of the very high level of inactive (67 percent) women in this group, novel forms of "activity" attachment could be supported through local public employment services or municipalities. Given available free time (that is, if child care is provided), women could be encouraged to volunteer in community causes or be supported in self-organization of cooperatives or small businesses. This volunteering could be combined with on-the-job training units in the respective services (for example child care, elderly care, community work, and so on)

$\checkmark$ (Temporary) part-time employment as a first step into the labor market. Taking a part-time contract (and expanding it to full time after some years) can be an appropriate means to maintain labor market engagement for mothers. As a subject of labor law policy, this flexibility should be explored, while at the same time creating incentives for employers and employees to switch to full-time employment as soon as possible ${ }^{36}$ (given the upcoming labor shortage in the overall economy and expected shortfall in retirement income for women with a part-time work history).

$\checkmark$ General work placement and training courses. When courses are available, women from this group should be given the opportunity to receive training and qualification courses by the PES.

The latent classes of retired women (19 percent), retired and early-retired men (13 percent) and low-educated early-retired and disabled (3 percent) are not further considered for activation policies in this study. Together, these classes represent 36 percent of the out-ofwork working-age population in Bulgaria. Given the extreme demographic challenges in the country, the recently-approved increase in the retirement age to around 65 for men by 2018 and 63 for women by 2021 is a necessary step. This increase will need to be matched by policies to maintain the skills and employment of workers aged 54 and over, along with better integration of people with disabilities into the workforce, in order to counter the projected decline in the overall working-age population.

36 That is, as care-giving responsibilities start to diminish. 
In general, further policy dialogue with the Bulgarian authorities ought to focus on areas that enable the Government and its agencies, municipalities and other labor market actors to better deploy their resources, increase coordination and improve the staffing and resource situation of services. Some of the areas for future dialogue include:

$\checkmark$ Ensuring the basis for activation policies. When delivering activation policies, local and regional actors (Public Employment Service, social assistance offices, municipalities, and so on) need to be equipped and organized in a way that jobseekers and inactive citizens find the right support networks and are not facing "silos" of different public administration. Potential areas of improvement include but are not limited to (1) focusing social workers in the GMI program more on activation than on rule enforcement, (2) enhancing collaboration with non-profits and social economy organizations for delivery of community and training programs and the development of an ALMP provider ecosystem, (3) reviewing the staffing level in the public employment service.

$\checkmark$ Changing the balance between passive and active spending. Even within its current budget, Bulgaria could strengthen spending on active labor market measures and reduce spending on passive measures (benefits), setting a path for further (potential) overall increases in resources for activation policies. Given the extremely low level of benefits, there are natural limits to this strategy.

$\checkmark$ Maintaining and extending institutional anchors for disadvantaged groups. Building on the experience with Roma mediators in public employment offices, Bulgaria ought to explore other ways to improve outreach to inactive and hard-toplace groups in the labor market, either through facilitators or through collaboration with specific community organizations or social economy providers.

In summary, Bulgaria could benefit from improving the activation approach toward its out-ofwork population, especially in light of the projected demographic shift. To maintain its growth potential and ensure adequate development for all its citizens, Bulgaria must muster "all hands on deck" to increase the number and qualifications of workers. Allowing high numbers of citizens to remain inactive or unemployed and not included in the labor market will exacerbate the grave development challenges ahead. 


\section{References}

Collins, L. M., and S. T. Lanza. 2010. Latent Class and Latent Transition Analysis: With Applications in the Social, Behavioral, and Health Sciences. Hoboken, NJ: Wiley.

Dimitrov, Yordan and Nicola Duell, 2013. Activating Vulnerable Groups in Bulgaria. World Bank, Washington, DC (forthcoming)

Eurofound, 2012. NEETs-Young people not in employment, education or training: Characteristics, costs and policy responses in Europe, Publications Office of the European Union, Luxembourg.

(EC) European Commission, 2013a. EU measures to tackle youth unemployment. MEMO, Brussels, 28 May 2013.

2013b. Assessment of the implementation of the European Commission Recommendation on active inclusion: A Study of National Policies. Country Report-Bulgaria. European Union, Brussels.

Eurostat, 2011. ESSPROS Manual: The European System of integrated Social PROtection Statistics. European Union, Luxembourg.

Kaufman, L. and Rousseeuw, P. J., 1990. Finding groups in data. New York, Wiley.

Magidson, Jay and Vermunt, Jeroen (2002). Latent Class Modeling as a Probabilistic Extension of K-Means Clustering Quirk's Marketing Research Review, March, 20, 77-80. Available at: http://statisticalinnovations.com/technicalsupport/kmeans2a.htm

Packard, Truman G., Johannes Koettl, Claudio Montenegro (2012). In from the Shadow: Integrating Europe's Informal Labor. World Bank, Washington, DC.

Vermunt, J.K. and J. Magidson, 2005. Latent GOLD 4.0 User's Guide. Belmont, Massachusetts: Statistical Innovations Inc.

World Bank, 2010. Roma Inclusion. An Economic Opportunity for Bulgaria, Czech Republic, Romania and Serbia. Policy Note. Europe and Central Asia Region. Human Development Sector Unit. Washington, DC.

World Bank, 2012. Bulgaria: Household Welfare during the 2010 Recession and Recovery. Report No. 63457-BG. Washington, DC: World Bank.

World Bank, 2013a. Gender at a Glance. Bulgaria. Europe and Central Asia Region. Poverty Reduction and Economic Management Sector Unit. Washington, DC.

World Bank, 2013b. Mitigating the Economic Impact of an Aging Population: Options for Bulgaria. Washington, DC: World Bank.

Portraits of Labor Market Exclusion | 89 


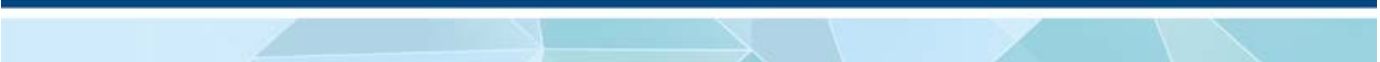

90 | Portraits of Labor Market Exclusion 


\section{Latent Class Analysis of the Out- of-Work Population in Estonia 2007-2011}

\section{Background}

Estonia entered the global financial crisis following a long period of high growth. According to the World Bank's World Development Indicators, between 2000 and 2007, the country was one of the fastest growing economies in the world, growing at an average rate of about 8 percent per year, with a peak of over 10 percent in 2006. These figures are all the more impressive if compared to the growth rates observed by the EU-28 as a whole, or the euro area (which expanded 0-3 percent per year over the same period).

Estonia saw a significant downturn associated with the global economic crisis, but it rebounded quite quickly, at least in terms of GDP growth. The cyclical downturn of the economy started earlier in Estonia than in neighboring countries. By 2008, the country had already felt the effects of the global downturn, with GDP growth for the year settling at negative 4 percent, in stark contrast to neighboring Lithuania, which displayed 3 percent GDP growth for the same year. The Estonian economy suffered its worst year in 2009, when output contracted by a staggering 14.1 percent, only slightly better than Lithuania's 14.8 percent. As with other countries in the region, this decline was mostly due to Estonia's strong dependence on exports, which collapsed in the 2008-2009 period. While neighboring Latvia fared somewhat worse, the Estonian economy's dip was much more severe than those suffered by the average EU-28 country or euro-area member, which witnessed negative growth rates in the 5 percent region in 2009. However, like nearby countries with similar income levels (for example, Lithuania and Latvia), Estonia recovered from the shock faster than its European partners. GDP growth was back into positive territory by mid-2009, settled at almost 3 percent in 2010, and reached a staggering 9.6 percent by 2011-almost twice the rates of Latvia and Lithuania - making the country the fastest growing economy in the EU. Growth rates returned to more modest levels by 2012 and 2013, at 3.9 and 0.8 respectively.

Unemployment levels, which saw a dramatic increase, are taking much longer to recover. Paralleling the developments observed in Lithuania and Latvia, unemployment in Estonia had been decreasing since the early 2000s, settling at little over 4 percent in 2007. However, as the effects of the global financial crisis unraveled, the country suffered a large and extremely rapid increase in unemployment; by the end of 2008, joblessness had risen to about 6 percent, climbing to 14 percent in 2009 and eventually peaking at 17 percent in 2010 . Such increases were considerably larger than those in the EU-28 or the Euro Area as a whole, but comparable to what other countries in the region of similar income levels witnessed. However, unemployment started decreasing in late 2010. By 2013, the average rate reached 8.9 percent, which is still above pre-crisis levels, but considerably lower than the joblessness rate observed in the region.

Portraits of Labor Market Exclusion | 91 
As in Lithuania and Latvia, young Estonians were particularly affected by the downturn. Like the overall unemployment rate, joblessness among those between the ages of 15 and 24 declined steadily in the pre-crisis period, reaching 10 percent in 2007. As the recession hit, youth unemployment skyrocketed to 29 percent in 2009 and 33 percent in 2010. However, by 2013 unemployment in the 15-24 cohort had significantly recovered, reaching 19 percent or so, still almost 10 percentage points the above the 2007 level but considerably lower that the rates observed in Lithuania and Latvia (22-24 percent).

Men were generally more affected than women by the crisis, at least in terms of unemployment. As Figure 4.1 below shows, at all age levels, Estonian men suffered larger increases than women in their rate of unemployment. Both men and women in the 25-64 age category entered the crisis with unemployment rates close or slightly below 5 percent; however, by late 2010, women in this age group displayed unemployment rates hovering around 13 percent, as opposed to the 18 percent or so registered among men of the same age. Among young Estonians, men were also affected much more than women, with the rate of joblessness among 15-to-24 year old men peaking at 35 percent, as opposed to 30 percent among women of the same cohort. Based on data from Statistics Estonia, the OECD (2012) also points to labor market discrepancies between Estonians and ethnic non-Estonians. Whereas about 10 percent of Estonians were unemployed in 2011, ethnic Non-Estonians were unemployed in about 18 percent of the cases.

Figure 4.1 Unemployment Rates by Gender and Age, Estonia (2003-2013)
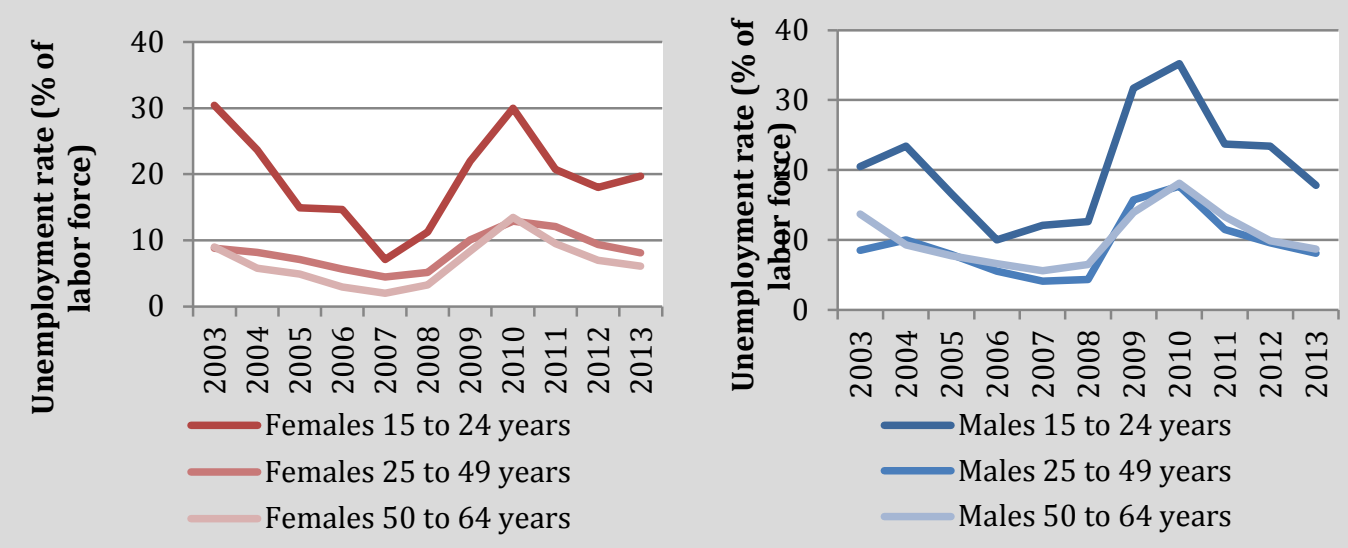

Source: Eurostat, EU-LFS. 
Figure 4.2 Long-Term Unemployment as a Share of Total Unemployment, Estonia (2003-2013)

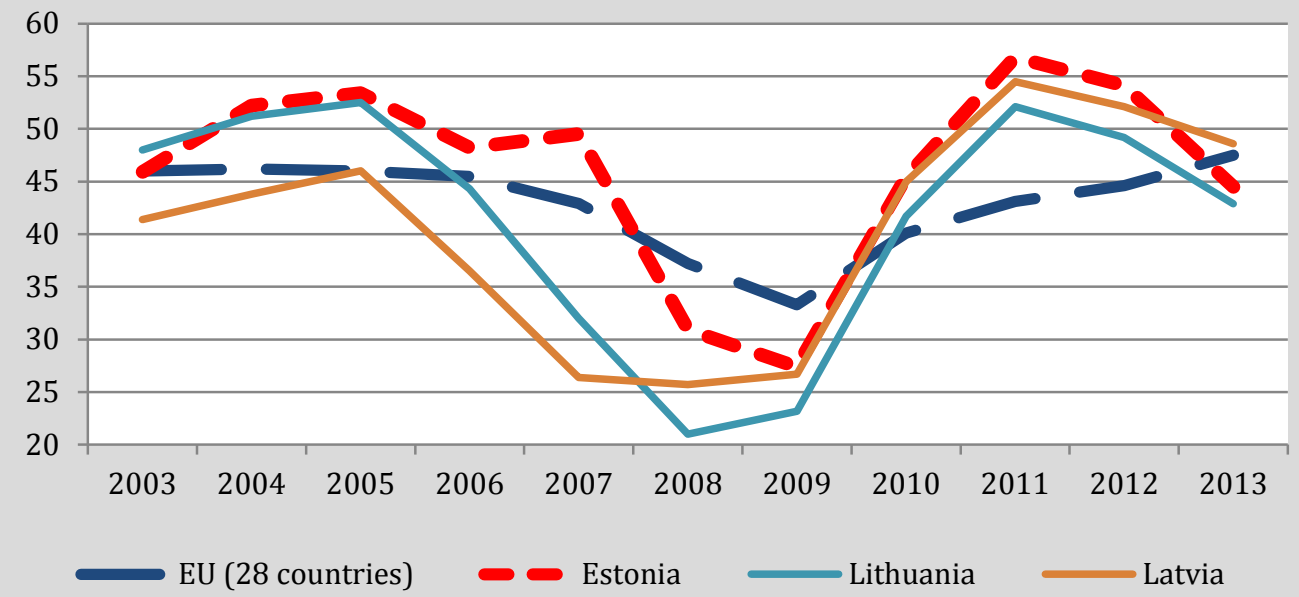

Source: Eurostat, EU-LFS

One of the most worrying developments of the crisis was the significant increase in the share of long-term unemployed. In 2013, according to Eurostat and as shown in Figure 4.2, in the average EU-28 country almost 48 percent of the unemployed had been looking for work for more than 12 months, up from 35 percent in 2009. In Estonia however, the longterm unemployment share, which had declined all the way to about 27 percent in 2009 , reached a staggering 57 percent in 2011 and settled at 54 percent in 2012, a development comparable to those observed in Latvia and Lithuania, before declining to 45 percent in 2013.

Figure 4.3 Evolution of Out-of-Work Population in Estonia (16-64),

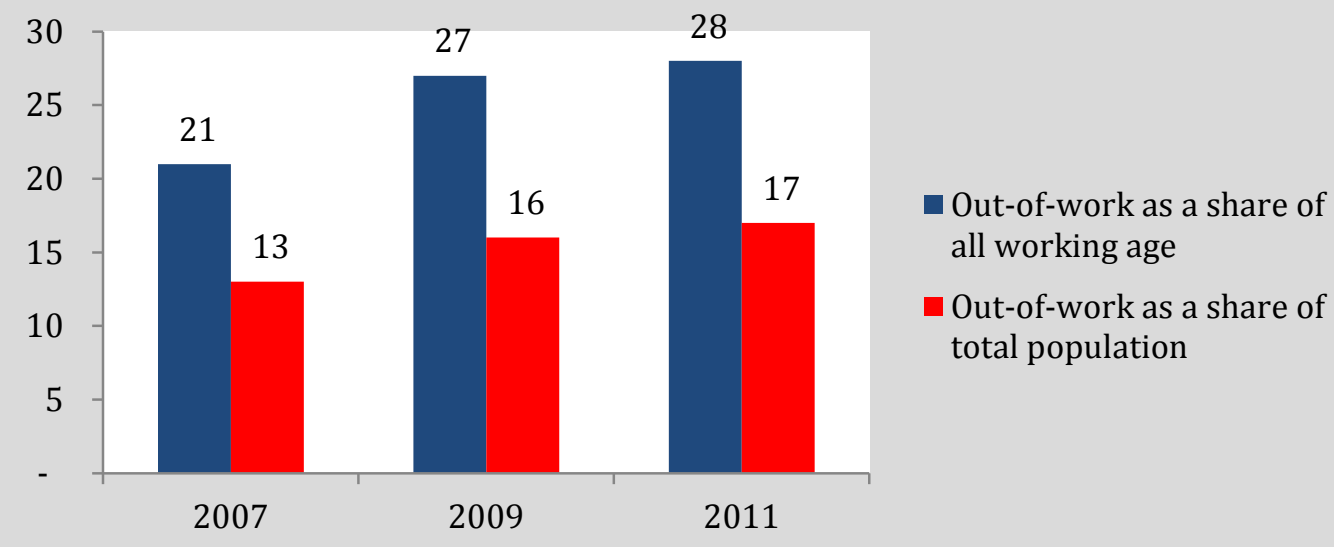

Source: World Bank staff analysis based on EU-SILC.

Another troubling change in the Estonian labor market since 2007 is the rapid increase in both the absolute number of out-of work individuals and in the share of out-of-work 
population relative to total population and working age population. EU-SILC data reveals that the number of the out-of-work population between the age of 16 and 64 (excluding students) increased steadily between 2007 and 2011, going from slightly over 167,000 to just over $224,000 .{ }^{37}$ This is all the more alarming as it occurred in a period during which both the total size of the population and the total number of working-age individuals in Estonia remained essentially unchanged (at about 1.34 million and about 0.8 million, respectively). This resulted in the share of out-of-work population relative to all working-age population increasing from 21 percent to 28 percent.

The 2007-2011 period witnessed a sizeable increase in the number and relative importance of unemployment (particularly long-term unemployment) Figure 4.4 and Figure 4.5 below show the composition of working-age and of out-of-work Estonians in 2007 and 2011, respectively. Not only, as Figure 4.3 above shows, did the size of the out-of-work population increase between 2007 and 2011 relative to working age population, but longterm unemployment represent a greater share of Estonians, with the share of those at-work losing ground. While the share of long-term unemployed relative to total working-age people was about 2 percent in 2007, the figure had increased to over 5 percent in 2007; similarly, long-term unemployed accounted for 9 percent of the out-of-work population in 2007, but for 19 percent in 2011. The share of total unemployment (long-term and otherwise) among working-age individuals (excluding students between 15 and $24^{38}$ ) also more than doubled over the period, increasing from 4 percent to 10 percent; jobless individuals accounted for 18 percent of the out-of-work population in 2007, but for 37 percent in 2011.

The developments highlighted above, in particular the increase in the size and relative weight of the out-of-work population and the unemployed, point to a deterioration in the Estonian labor market from 2007 to 2011. A deeper analysis of the out-of-work population, and understanding of its composition, is in fact key to ensuring that the right policy measures are taken and that priorities are set in an appropriate manner.

37 According to Estonian officials, in 2013 the out-of-work population accounted for less than 200,000 people. The analysis that follows is based on EU-SILC 2011 data, the most recent and the only harmonized survey across the EU at the time of publication. All the numbers are likely to have changed since.

${ }^{38}$ Individuals aged 16 to 24 who are out of work and enrolled in education are excluded from the sample; they are considered to be investing in their final stages of human capital formation and therefore are not a particular target group for activation policies. In 2011, In 2011, there were close to 88,170 youth aged 16 to 24 who were out of work and enrolled in education, representing 53 percent of the total population in this age category and 28 percent of the total out-of-work population of working age. Military personnel are included in the sample but considered "at-work," and therefore do not feature in the latent class analysis below. Individuals enrolled in school above the age of 24 and under 65 are however included in the latent class analysis and will be grouped under "other inactive." It is important to note that the two groups combined (military and students older than 24) account for less than 1 percent of total population of working age.

94 | Portraits of Labor Market Exclusion 
Figure 4.4 Composition of Working-Age Population in Estonia (16-64) by Labor Market Attachment

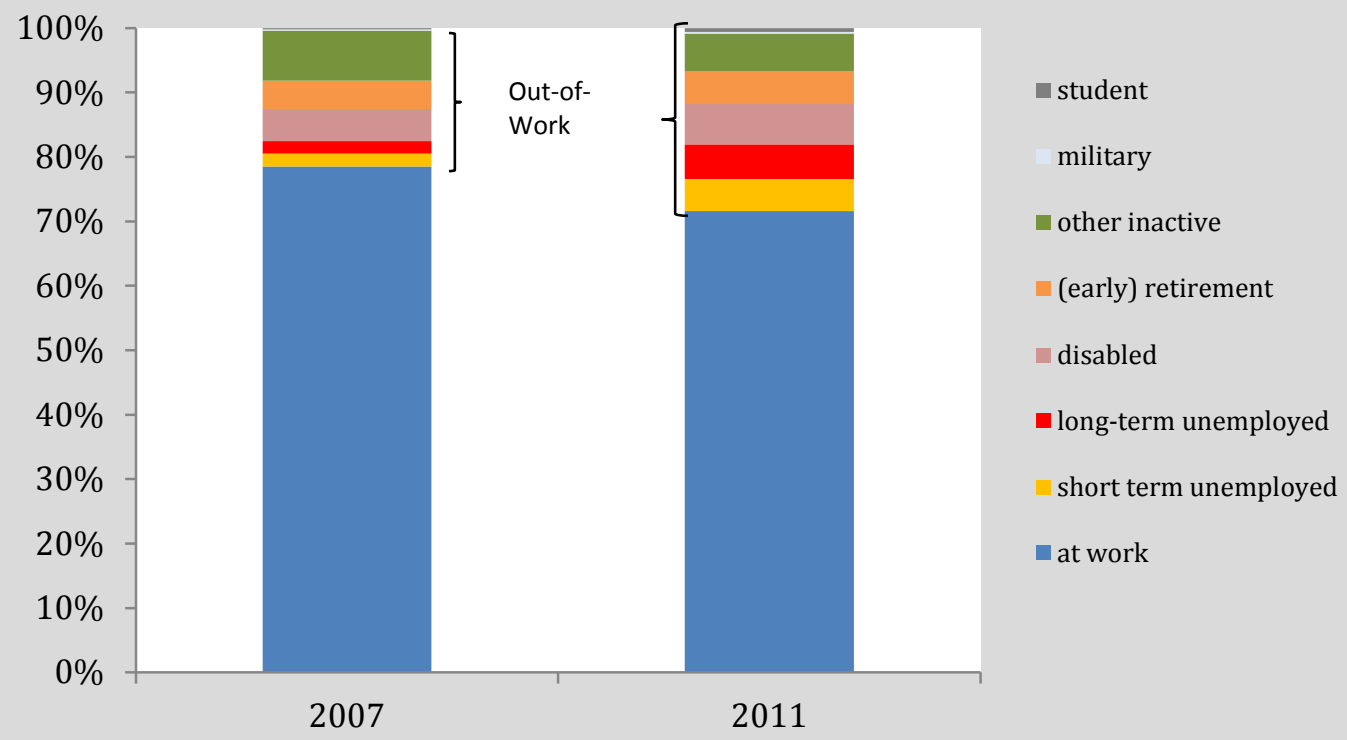

Source: World Bank staff analysis based on EU-SILC.

Figure 4.5 Distribution of Out-of-Work Population in Estonia, 2007 and 2011

2007

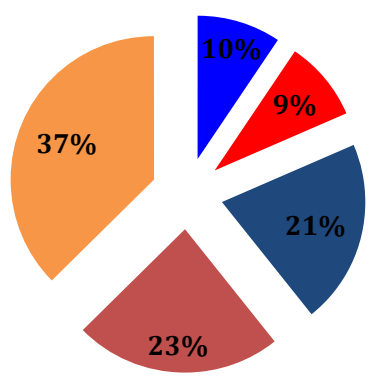

2011

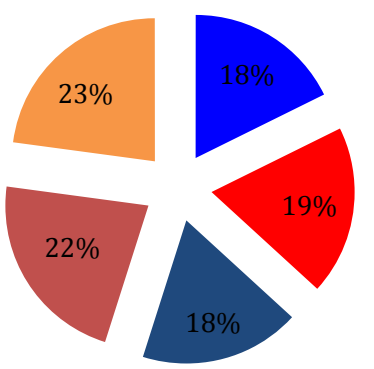

short-term

unemployed

along-term

unemployed

- (early) retirement

disabled

other inactive

Source: World Bank staff analysis based on EU-SILC. 


\section{Methodology: Latent Class Analysis}

In Chapter 1 a general overview of the latent class analysis methodology was presented. This section explains in detail the variables and covariates used to identify classes or groups of out-of-work individuals that are as homogeneous as possible within each class according to a set of observable characteristics, and as distant as possible between classes. The emerging profiles can then be contrasted with the design and targeting of current activation policies, in order to identify the potential gaps and to enhance their design features.

Variable selection: The definition of latent classes relies on a number of indicator variables to capture different "symptoms" of an overall latent condition (in this case, the typology of joblessness). The challenge in such models is to identify a discrete number of variables that can best explain the heterogeneity of individual outcomes. In this case, two sets of categorical variables were selected: the first set to show the extent of labor market distance and the other to capture some of the main factors that can affect employment on the supply side, such as labor supply conditions (household-level incentives to work and physical ability to work).

$\checkmark$ Distance from labor market: short-term unemployment, long-term unemployment, (early) retirement, disability, and other inactivity (largely unpaid domestic work)..$^{39}$

$\checkmark$ Labor supply conditions: whether the individual's household has at least one working adult, ${ }^{40}$ and perceived limitations on activities due to health problems. ${ }^{41}$

$\checkmark$ Work experience: if individual has worked before and, in this case, whether he or she worked for two or more months in the last year

In addition to indicators, the model includes active covariates, which are used to improve the classification of individuals in each class. In this case the active covariates are the demographic variables that are normally used to disaggregate labor market outcomes:

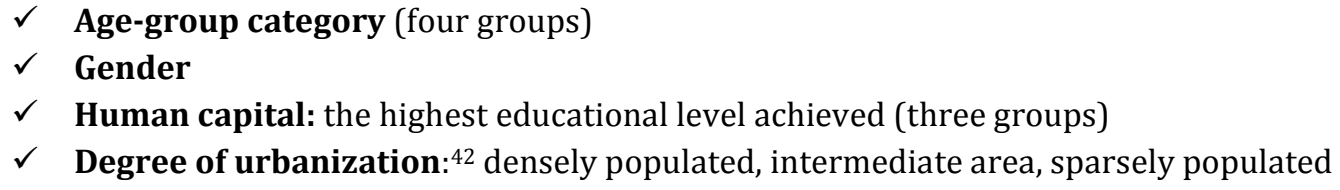

Once the latent classes have been defined, inactive covariates that were not included in the model can be used to characterize the individuals in each class and the households in which they live. The inactive covariates chosen describe those characteristics that may provide

39 This variable is constructed using the self-reported current work status in the EU-SILC survey that has four categories: at work, unemployed, retired and inactive. The unemployed are further classified into short- and long-term based on how long they have been actively looking for a job. The inactive is combined with another question to separate this group into students, disabled, military and other inactive.

40 In order to construct this variable, individuals aged 25 or older are considered adults.

41 This is a binary variable that takes the value one if an individual answered "yes, strong limitations" to whether they had been hampered in their usual activities because of health problems for at least the last six months. The value is zero if the answer is "yes, limited" or "no, not limited."

42 According to EU-SILC guidelines, dense areas have more than 500 inhabitants per square kilometer, where the total population for the set is at least 50,000 inhabitants. Intermediate areas have more than 100 inhabitants per square kilometer, and either a total population for the set of at least 50,000 inhabitants or a location adjacent to a dense area. The remaining areas are categorized as sparsely populated. 
valuable information for the design of tailored policies that address barriers to employment, including income level. They include:

\section{$\checkmark$ Household welfare conditions:}

- Income quintile (defined by equivalized disposable household income ${ }^{43,44}$ )

- Labor, benefit, and other income as share of total gross household income ${ }^{45}$

- Labor market status of partner

- Tenure status

- Household ability to keep dwelling warm

- Partner's labor income

- Quintile of partner's labor income

- Binary variables for beneficiaries of social protection benefits ${ }^{46}$

- Share of each benefit over the household's total gross income

$\checkmark$ Household demographics:

- Household size

- Household family types

- Binary variable showing whether there are children under 6 in the household

- Binary variable denoting whether there are three or more under-16 children in the household

- Children under 13 receiving child care in the household: all, some or no children under 13 present

- Older person (65 and over) in the household

$\checkmark$ Other individual-level demographics:

- More refined age groups (eight groups)

- Marital status

$\checkmark$ Individual human capital:

- More refined highest educational level achieved (six groups)

- Whether the individual is enrolled in school

- Dummy for previous work experience

$\checkmark$ Household location:

- Urban/rural status

43 The equivalized household income takes into account an equivalence factor to weight the number of household members used in the denominator when calculating household income per capita. The first adult aged 18 or over has a weight of 1.0 , children under 14 have a weight of 0.3 , and other individuals 14 and older have a weight of 0.5 . The sum of the weights of all household members is equal to the equivalent household size.

${ }^{44}$ Note that income reported in EU-SILC surveys is for the year preceding the survey year.

45 Total household gross income is defined as the sum of: (at the individual level) gross employee cash or near-cash income; company car, gross cash benefits or losses from self-employment (including royalties); unemployment benefits; old-age benefits; survivor benefits; sickness benefits; disability benefits; education allowances; and (at the household level) income from rental of property or land; family/children related allowances; social exclusion not elsewhere classified; housing allowances; regular inter-household cash transfers received; interests, dividends, profit from capital investments in unincorporated business; pensions from individual private plans; and income received by people under 16. Total household net income, in turn, was calculated by subtracting from total household gross income regular taxes on wealth, taxes on income and social insurance contributions, and regular interhousehold case transfers paid.

46 Social benefits are aggregated in eight branches using the European System of integrated Social PROtection Statistics (ESSPROS) definitions. For more information, see Eurostat (2011). 
Group labeling. The resulting groups are then labeled according to the greatest proportional characteristics within groups that also aid in distinguishing among groups. Granted, a large number of characteristics describe these groups, and only a few are taken into account for the purpose of labeling. In part, some of these characteristics may exhibit a large degree of heterogeneity and may thus not be relevant for defining a group. Additionally, some characteristics may be more relevant for the purposes of policy design than others. In short, though the labeling of groups can be considered more an art than a science, when taken together with detailed descriptions of a group's most prominent characteristics, labeling can serve as an important starting point in the design and prioritization of activation policies.

The analysis relies on cross-sectional as well as panel data from the European Union Statistics of Income and Living Conditions (EU-SILC) surveys for 2008-2011, which combine individual-level information with household characteristics. The first part of the note presents a cross-sectional analysis for the years 2008, 2009, 2010 and 2011. In particular, the latent class analysis on 2008 data shows the main characteristics of the out-of-work before the global economic crisis hit Estonia, and thus highlight what could be considered more structural issues of the country's labor market. The 2011 latent class analysis will contrast this initial assessment with more recent developments. The second part of the note exploits longitudinal data between 2008 and $2010^{47}$ to trace the prior labor market status of individuals observed last in 2010 in various classes, and will shed light on the relative persistence in the out-of-work status among different classes of individuals. The set of variables chosen for the cross-section and the longitudinal analysis are slightly different, due to minor differences in the set of variables recorded in each of the two types of datasets.

47 The EU-SILC longitudinal survey consists of a four-year rotating panel. In each year, approximately three-quarters of individuals present in the previous year are retained. The samples used in the latent class analysis include about 3,000 observations for each year in the cross-sectional analysis and 600 observations in the longitudinal analysis. The population is weighted with individual weights. 


\section{Main Findings}

\section{Out-of-Work Population: Group profiles}

The latent class analysis supports the classification of the out of work into seven main groups, some of which have remained stable over time. The groups were named according to their most salient characteristics. Figure 4.6 shows the shares of each of the seven classes identified for the year 2011 and Table 4.1 presents their most salient characteristics.

\section{Figure 4.6 Classes of Out-of-Work Individuals in Estonia (2011)}

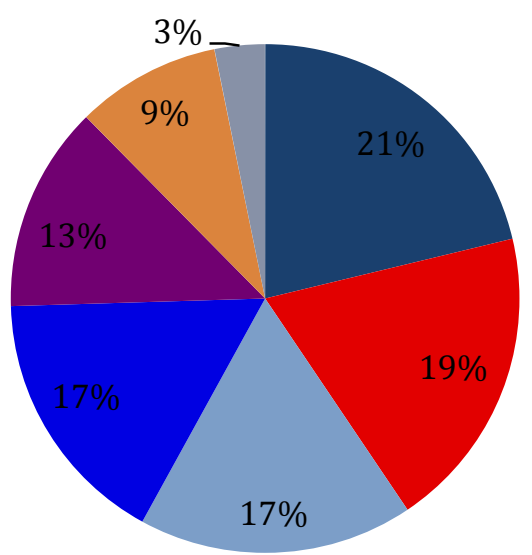

- Middle-aged educated disabled with previous work experience

- Prime-aged low income long-term unemployed

Educated retirees

- Young inactive educated mothers with working partner

- Prime-aged educated unemployed

- Single NEETs without work experience

- Young low-educated and rural disabled 
Table 4.1 Summary Characteristics of Latent Classes of Out-of-Work Population in Estonia, (2011)

\section{1: Middle-aged educated disabled with} previous work experience (21\%)

- $92 \%$ are disabled

- $86 \%$ are between 35 and 59

- Another $10 \%$ is between 60 and 64

- $64 \%$ have secondary education and another $14 \%$ tertiary education

- $62 \%$ live in rural areas

- $77 \%$ belong to the first 2 income quintiles

- $90 \%$ have prior work experience

- $\quad 93 \%$ receive disability benefits

- $\quad 98 \%$ receive some benefit

- Benefits are almost $70 \%$ of household income
2: Prime-age low income long-term unemployed $(19 \%)$

- $\quad 85 \%$ are long-term unemployed

- Two-thirds are men

- $\quad$ About $75 \%$ are between 35 and 59

- Another $25 \%$ is between 25 and 34

- $81 \%$ are in the first 2 income quintiles

- $\quad$ Only $20 \%$ receive unemployment benefits

\section{3: Educated retirees} (18\%)

- $100 \%$ are retired

- $\quad 92 \%$ are between 60 and 64

- Almost 65\% are women

- $84 \%$ have completed secondary or tertiary education

- $59 \%$ are married and another $18 \%$ are widowed

- $\quad 98 \%$ of them receive old age benefits

- $\quad 87 \%$ live in a household without dependent children

- They mostly live in small sized households

- Benefits make up almost $74 \%$ of total household income

- $60 \%$ are in the first 2 income quintiles
4: Young inactive educated mothers with working partner (17\%)

- $92 \%$ are engaged in domestic or other activities

- $94 \%$ are women

- $\quad 85 \%$ live in a household with a working adult

- $52 \%$ have tertiary education

- $97 \%$ have work experience and $26 \%$ have worked in last year

- $\quad 93 \%$ are between 25 and 55

- $69 \%$ are between 25 and 34

- $33 \%$ are in the top two quintiles

- $78 \%$ have a child below 6 in their household

- $92 \%$ receive some benefit, $84 \%$ family/child benefits

\section{5: Prime-aged educated unemployed (13\%)}

- $\quad 90 \%$ are unemployed

- $63 \%$ are men

- $\quad 84 \%$ are between 25 and 59

- $27 \%$ have tertiary education and another $56 \%$ have secondary education

- $70 \%$ receive some benefit

- $33 \%$ receive unemployment benefits

- $85 \%$ live in a household with 1 or 2 dependent children

- $36 \%$ are in the first quintile
6: Single NEETs without work experience (9\%)

- $\quad 35 \%$ are unemployed, and $25 \%$ are long-term unemployed

- $\quad$ The remaining $40 \%$ is engaged in domestic and other activities

- $\quad$ All are between 16 and 35

- $82 \%$ are between 16 and 24

- $80 \%$ have never worked

- Almost $90 \%$ are single and $60 \%$ belong to the first two income quintiles

- $\quad 51 \%$ have secondary education and $31 \%$ only primary education

- $\quad 76 \%$ of them live in a household with a working adult 
- $76 \%$ are disabled

- $\quad 96 \%$ have never worked

- $70 \%$ are below 34

- $75 \%$ are in the first two income quintiles

- $71 \%$ have only primary education

- About $75 \%$ live in urban areas

- $\quad 95 \%$ of them receive benefits, and $80 \%$ receive disability benefits

- $82 \%$ are single

Source: World Bank staff analysis based on EU-SILC

Note: Percentages in parentheses following the group names refer to the share of the total out-of-work population, Years of work experience refer only to those individuals who have worked before. Dependent children include children under 18 and household members aged 18 to 24 who are economically inactive and living with at least one parent. Working adult refers to adults aged 25 and over. For this report's purposes, we define the at-risk-of-poverty rate as the relative risk of being in the first quintile of the income distribution. The reference period for income reported in EU-SILC surveys is the year preceding the survey year.

The eight main clusters emerging from the LCA can be characterized as follows for the year 2011 (see Annex 2 for more detail):

$\checkmark \quad$ Cluster 1: Middle-aged educated disabled with previous work experience. This group represents 21 percent of the out-of-work population in 2011. Most individuals in this group report their labor market status as disabled (92 percent) and the majority are between 35 and 59 years of age ( 86 percent). However only 43 percent report having strong limitations in their ability to work. As Table 5.3 below shows, this cluster is relatively well educated as 64 percent have secondary education and another 14 percent tertiary education. About 62 percent of individuals in this group live in rural areas, which also appears to quite poor, with 51 percent of the group belonging to the first income quintile. The large majority of these individuals (93 percent) receive disability benefits ${ }^{48}$, and almost all (98 percent) of them receive at least one benefit. Finally, benefits account for a large share of these individuals' household incomes: almost 70 percent.

$\checkmark \quad$ Cluster 2: Prime-age low-income long-term unemployed. This group, accounting for 19 percent of the out-of-work population, is made up overwhelmingly (85 percent) of long-term unemployed. Two-thirds of the individuals in this cluster are men, and about 70 percent live in rural areas. Three out of four are between 35 and 59 and the remaining 25 percent are between 25 and 34 . This cluster also appears to be at very high risk of poverty, given that 66 percent of individuals belong to the lowest income quintile. Importantly, only 20 percent receive unemployment benefits; however, about 60 percent receive some form of benefit, even though benefits make up on average less than 50 percent of household income.

$\checkmark \quad$ Cluster 3: Educated retirees. This third cluster, which makes up 18 percent of the out-of-work population, is composed exclusively of retired individuals, of which

\footnotetext{
${ }^{48}$ It should be kept in mind that the EU-SILC activity status is self-reported. Therefore, the disabled population figure may not be accurate when compared to administrative data. Furthermore, in Estonia there are different benefits that are probably being captured as disability benefits: the incapacity-forwork pension and the disability benefit for people who incur additional costs due to their disability.
} 
almost 65 percent are women. More than 90 percent of those in this group are between 60 and 64 years old. Most of them hold relatively high levels of education (84 percent of them have completed secondary or tertiary education). They are mostly married (59 percent) and another 18 percent are widowed. Ninety-eight percent receive old-age benefits, which tend to be particularly generous, as benefits make up 74 percent of their total household incomes.

$\checkmark \quad$ Cluster 4: Young inactive educated mothers with a working partner. This group includes 17 percent of the out-of-work population and is for the large majority made up of women ( 94 percent), in their prime age and young ( 93 percent are between 25 and 55, and almost 70 percent are between 25 and 34), and mostly engaged in domestic or other activities ( 92 percent). About 85 percent live in a household with a working adult, and are relatively well off, as about one-third belong to the top two quintiles. This group is very well educated, as more than 50 percent have tertiary education. Almost 80 percent of the individuals in this group have a child below 6 in their household and 92 percent receive some benefit, while another 84 percent receive family/child benefits.

$\checkmark \quad$ Cluster 5: Prime-aged, educated unemployed. This group, of which 90 percent is unemployed, makes up 13 percent of the out-of-work population and includes a majority of men (63 percent). Almost two-thirds of them are between 35 and 59 and another 22 percent are between 25 and 34; like Group 4, they are well educated, as 56 percent have completed upper or post-secondary education and 27 percent tertiary. Also, most of them (85 percent) live in households with one or more children. Interestingly, 70 percent receive social benefits, but only one-third receive unemployment benefits, and, overall, benefits make up only slightly more than 20 percent of household income.

$\checkmark \quad$ Cluster 6: Single NEETs without work experience. This group accounts for 9 percent of out-of-work individuals and is mostly composed of unemployed individuals (60 percent of the cluster, with 40 percent of the unemployed being long-term unemployed). The remaining 40 percent is engaged in domestic and other activities. All individuals are between 16 and 35, and 82 percent of them are between 16 and 24 , making this cluster the youngest one by far on average. About 80 percent have never worked and almost 90 percent are single, with three out of four living in a household with a working adult. This cluster is also quite low-income, with 60 percent of it falling in the first two income quintiles. This cluster is also not particularly well educated, as 51 percent have an upper secondary education, but a sizeable portion (36 percent) have only primary education.

$\checkmark \quad$ Cluster 7: Young low-educated and rural disabled. Members of this cluster, 76 percent of which report their labor market status as disabled, account for the last 3 percent of the Estonian out-of-work population in 2011. Nearly all in this cluster, 96 percent, have never worked despite the fact that only half report a strong limitation on daily activities; 82 percent are single and 70 percent are below 35 . The individuals in this group, which is for the most part rural ( 75 percent live in rural areas), tend to be both low income (as 75 percent fall in the first two income quintile) and loweducated (with 71 percent having completed only primary education). Importantly, 80 percent of them receive disability benefits, and 95 percent receive at least one benefit. These benefits make up almost 70 percent of the average household income. 
The following tables present the main characteristics of each group in 2011. For a complete table including the inactive covariates see Annex 2.

Table 4.2 Latent Classes of Out-of-Work Population in Estonia- Indicators (2011)

\begin{tabular}{|c|c|c|c|c|c|c|c|c|}
\hline & $\begin{array}{l}\text { All Out-of - } \\
\text { Work }\end{array}$ & $\begin{array}{l}\text { 1. Middle-aged } \\
\text { educated } \\
\text { disabled with } \\
\text { previous work } \\
\text { experience }\end{array}$ & $\begin{array}{l}\text { 2. Prime-age low } \\
\text { income long- } \\
\text { term } \\
\text { unemployed }\end{array}$ & $\begin{array}{l}\text { 3. Educated } \\
\text { retirees }\end{array}$ & $\begin{array}{l}\text { 4. Young } \\
\text { inactive } \\
\text { educated } \\
\text { mothers with } \\
\text { working } \\
\text { partner }\end{array}$ & $\begin{array}{l}\text { 5. Prime-aged } \\
\text { educated } \\
\text { unemployed }\end{array}$ & $\begin{array}{c}\text { 6. Single } \\
\text { NEETs without } \\
\text { work } \\
\text { experience }\end{array}$ & $\begin{array}{l}\text { 7. Young low- } \\
\text { educated and } \\
\text { rural } \\
\text { disabled }\end{array}$ \\
\hline Cluster Size & $100 \%$ & $21 \%$ & $19 \%$ & $18 \%$ & $17 \%$ & $13 \%$ & $9 \%$ & $3 \%$ \\
\hline Population & 224,738 & 47,694 & 43,446 & 39,221 & 37,108 & 29,421 & 20,656 & 7,192 \\
\hline
\end{tabular}

\section{Labor market attachment}

\begin{tabular}{|c|c|c|c|c|c|c|c|c|}
\hline Unemployed & $18 \%$ & $3 \%$ & $4 \%$ & $0 \%$ & $7 \%$ & $90 \%$ & $35 \%$ & $4 \%$ \\
\hline Long-term unemployed & $19 \%$ & $1 \%$ & $85 \%$ & $0 \%$ & $0 \%$ & $0 \%$ & $25 \%$ & $6 \%$ \\
\hline Retired & $18 \%$ & $3 \%$ & $0 \%$ & $100 \%$ & $0 \%$ & $0 \%$ & $0 \%$ & $0 \%$ \\
\hline Disabled & $22 \%$ & $92 \%$ & $0 \%$ & $0 \%$ & $0 \%$ & $0 \%$ & $1 \%$ & $76 \%$ \\
\hline Other inactive & $13 \%$ & $1 \%$ & $11 \%$ & $0 \%$ & $92 \%$ & $10 \%$ & $39 \%$ & $14 \%$ \\
\hline
\end{tabular}

\section{Work Experience}

Never worked

\begin{tabular}{l|l}
\hline Less than 2 months in last year & $11 \%$
\end{tabular}

2 or more months in last year

\begin{tabular}{l|r}
$11 \%$ & $0 \%$ \\
\hline
\end{tabular}

Self-assessed physical incapacity

\begin{tabular}{|l|l}
\hline Strongly limited & $13 \%$
\end{tabular}

None/limited

$85 \%$

\begin{tabular}{|l|l}
\hline$\%$ & $43 \%$ \\
\hline
\end{tabular}

At least one working adult in household

\begin{tabular}{|c|c|c|c|c|c|c|c|c|}
\hline No & $48 \%$ & $3 \%$ & $4 \%$ & $0 \%$ & $7 \%$ & $90 \%$ & $35 \%$ & $4 \%$ \\
\hline Yes & $52 \%$ & $1 \%$ & $85 \%$ & $0 \%$ & $0 \%$ & $0 \%$ & $25 \%$ & $6 \%$ \\
\hline
\end{tabular}

Source: World Bank staff analysis based on EU-SILC 
Table 4.3 Latent Classes of Out-of-Work Population in Estonia-Active Covariates (2011)

\begin{tabular}{|c|c|c|c|c|c|c|c|c|}
\hline & All Out-of-Work & $\begin{array}{l}\text { 1. Middle-aged } \\
\text { educated } \\
\text { disabled with } \\
\text { previous work } \\
\text { experience }\end{array}$ & $\begin{array}{l}\text { 2. Prime- } \\
\text { age low } \\
\text { income } \\
\text { long-term } \\
\text { unemployed }\end{array}$ & $\begin{array}{l}\text { 3. Educated } \\
\text { retirees }\end{array}$ & $\begin{array}{l}\text { 4. Young } \\
\text { inactive } \\
\text { educated } \\
\text { mothers with } \\
\text { working } \\
\text { partner }\end{array}$ & $\begin{array}{l}\text { 5. Prime- } \\
\text { aged } \\
\text { educated } \\
\text { unemployed }\end{array}$ & $\begin{array}{l}\text { 6. Single } \\
\text { NEETs } \\
\text { without } \\
\text { work } \\
\text { experience }\end{array}$ & $\begin{array}{l}\text { 7. Young } \\
\text { low- } \\
\text { educated } \\
\text { and rural } \\
\text { disabled }\end{array}$ \\
\hline Cluster size & $100 \%$ & $21 \%$ & $19 \%$ & $17 \%$ & $17 \%$ & $13 \%$ & $9 \%$ & $3 \%$ \\
\hline Population & 224,738 & 47,694 & 43,446 & 39,221 & 37,108 & 29,421 & 20,656 & 7,192 \\
\hline \multicolumn{9}{|c|}{ ACTIVE COVARIATES } \\
\hline \multicolumn{9}{|l|}{ Age groups (4) } \\
\hline 16-24 years & $11 \%$ & $0 \%$ & $3 \%$ & $0 \%$ & $5 \%$ & $13 \%$ & $82 \%$ & $23 \%$ \\
\hline $25-34$ years & $23 \%$ & $4 \%$ & $25 \%$ & $0 \%$ & $69 \%$ & $22 \%$ & $18 \%$ & $46 \%$ \\
\hline $35-59$ years & $47 \%$ & $86 \%$ & $73 \%$ & $8 \%$ & $26 \%$ & $62 \%$ & $0 \%$ & $31 \%$ \\
\hline 60-64 years & $19 \%$ & $10 \%$ & $0 \%$ & $92 \%$ & $0 \%$ & $3 \%$ & $0 \%$ & $0 \%$ \\
\hline \multicolumn{9}{|l|}{ Gender } \\
\hline Male & $46 \%$ & $58 \%$ & $63 \%$ & $37 \%$ & $6 \%$ & $63 \%$ & $47 \%$ & $54 \%$ \\
\hline Female & $54 \%$ & $42 \%$ & $37 \%$ & $63 \%$ & $94 \%$ & $37 \%$ & $53 \%$ & $46 \%$ \\
\hline \multicolumn{9}{|l|}{ Education (4) } \\
\hline Primary & $20 \%$ & $21 \%$ & $22 \%$ & $16 \%$ & $7 \%$ & $15 \%$ & $36 \%$ & $71 \%$ \\
\hline Secondary & $56 \%$ & $64 \%$ & $68 \%$ & $55 \%$ & $40 \%$ & $56 \%$ & $51 \%$ & $28 \%$ \\
\hline Tertiary & $23 \%$ & $14 \%$ & $10 \%$ & $29 \%$ & $52 \%$ & $27 \%$ & $9 \%$ & $1 \%$ \\
\hline Never studied before/illiterate/NA & $1 \%$ & $0 \%$ & $0 \%$ & $0 \%$ & $1 \%$ & $2 \%$ & $4 \%$ & $0 \%$ \\
\hline Urban & $47 \%$ & $38 \%$ & $53 \%$ & $44 \%$ & $55 \%$ & $58 \%$ & $37 \%$ & $27 \%$ \\
\hline Rural & $53 \%$ & $62 \%$ & $47 \%$ & $56 \%$ & $45 \%$ & $42 \%$ & $63 \%$ & $73 \%$ \\
\hline
\end{tabular}


The composition of the classes has also experienced considerable change over the last few years. Table 4.4 shows the evolutions of the classes from 2007 to 2011 as a share of total out-of-work population, while Figure 4.7 graphs the absolute numbers. As mentioned before, one important development between 2007 and 2011 was the noticeable increase in the size of the out-of-work population, from about 167,000 to roughly 224,000 individuals. Furthermore, it is interesting how some of the clusters identified by analyzing the 2011 data could also be identified (broadly speaking) in the 2007 and 2009 data, although the relative sizes of such clusters might have changed. In particular:

$\checkmark$ The most worrying development, arguably as a result of the crisis, is the emergence in 2011 of a large cluster of young, long-term unemployed individuals. As shows in the first section, the relative weights of long-term unemployment and of overall unemployment as a share of the out-of-work population have doubled between 2007 and 2011, from 19 percent to 37 percent and from 9 to 19 percent, respectively. Within these groups, as the figures below show, by 2011 a cluster of mostly young (between 16 and 34) and long-term jobless individuals, accounting for about 19 percent of the out-of-work population in Estonia, had emerged.

$\checkmark$ Similarly, and just as worryingly, the last few years have witnessed the steady increase in the size and weight of the clusters of young Estonians who are employed in school or in training. In 2007, the NEET cluster accounted for about 11,000 individuals (or 7 percent of the out-of-work population). By 2011 this cluster had grown to include more than 20,000 people, almost doubling in size. And while it should be noted that in 2009 the cluster of NEETs was somewhat different than the clusters of NEETs observed in 2007 and 2011 (that is, it was "more rural" and "less educated"), the fact that the ranks of young NEETs with no prior work experience have grown so substantially in such a short time span is troubling from a policy and social perspective.

$\checkmark \quad$ Furthermore, at least in part as a result of the crisis, the cluster of prime-age unemployed individuals has witnessed a considerable amount of movement. Such cluster, which included roughly 22,000 people in 2007, almost tripled in size in a two-year period along, increasing to more than 61,000 people in 2009 , before declining all the way back to 29,000 by 2011 , still marking a 30 percent increase in absolute size from the 2007 figures;

$\checkmark$ The number of disabled individuals has also increased significantly over the last few years. Over the 2007-2011 period there were two clusters of disabled individuals, the combined size of which steadily increased from about 43,000 to more than 54,000 individuals. The first cluster, which increased by about 25 percent, from 38,000 individuals to 47,000 and can be observed throughout the period, was composed of middle-aged educated disabled. The second cluster changed somewhat during the period and could not be observed in 2009, but essentially included young, low-educated disabled individuals. This cluster also increased in size, from 5,000 to 7,000.

$\checkmark$ The number of adult retirees receiving benefits has been generally stable over the years, although with some changes in the features of the cluster. In 2007, the cluster including retirees numbered about 38,000 people; by 2011 this cluster had only slightly increased to about 39,000 . As a result, the share of retirees in the out-of-work population decreased from about 22 percent to 17 percent. 
Furthermore, while the cluster of retirees was mostly made of women in 2007, by 2011 this group had become more gender-balanced.

Table 4.4 Classes of Out-of-Work Individuals in Estonia, 2007, 2009 and 2011 (as percentage of total out-of-work population)

\begin{tabular}{|c|c|c|c|}
\hline Name of Cluster & 2007 & 2009 & 2011 \\
\hline Middle-aged educated disabled with previous work experience & $23 \%$ & $19 \%$ & $21 \%$ \\
\hline Prime-age low income long-term unemployed (only 2011) & - & - & $19 \%$ \\
\hline Middle-aged long-term unemployed men (2007 and 2009) & $11 \%$ & $9 \%$ & - \\
\hline Educated retirees (2009 and 2011) & - & $18 \%$ & $18 \%$ \\
\hline Educated retired women (only 2007) & $22 \%$ & - & - \\
\hline Young inactive educated mothers with working partner & $21 \%$ & $18 \%$ & $17 \%$ \\
\hline Prime-aged educated unemployed & $13 \%$ & $29 \%$ & $13 \%$ \\
\hline Single NEETs without work experience (2007 and 2011) & $7 \%$ & - & $9 \%$ \\
\hline Single uneducated and rural NEETs without work experience (only 2009) & - & $7 \%$ & - \\
\hline Young low-educated and rural disabled (only 2011) & - & - & $3 \%$ \\
\hline Low-educated and rural disabled youth (only 2007) & $3 \%$ & - & - \\
\hline Total & $100 \%$ & $100 \%$ & $100 \%$ \\
\hline
\end{tabular}

Source: World Bank staff analysis based on EU-SILC 
Figure 4.7 Classes of Out-of-Work Individuals in Estonia, 2007, 2009 and 2011 (Number of Individuals)

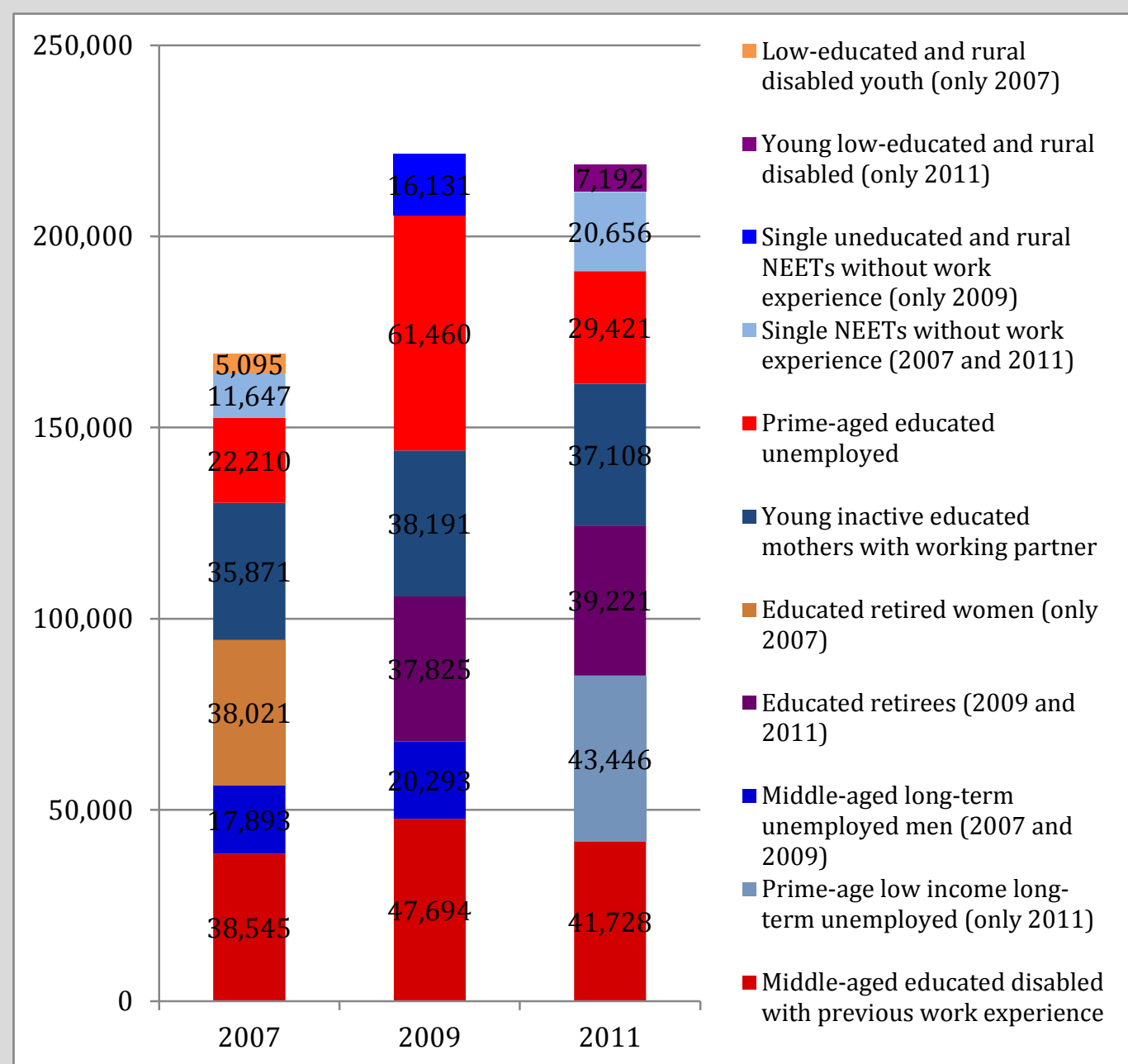

Source: World Bank staff analysis based on EU-SILC 
The analysis of the EU-SILC data using latent class methodology and the analysis of Eurostat numbers reveal the existence of a number of clusters or groups of out-of-work individuals that can be more or less clearly defined and that differ from one another in important characteristics. Some of the features that we have highlighted are more permanent in nature, while other can most likely be ascribed to the global downturn and might therefore be more cyclical.

On the structural side, first and foremost, our analysis shows that young Estonians fare quite poorly on the labor market in absolute terms, although better than youth in neighboring countries. Their performance is also in line with EU-wide averages. As per our graphs above, the unemployment rate in the 15-to-24 year old cohort was about 19 percent in 2013, after peaking at more than 35 percent among males and 30 percent among females in 2010. Noticeably, the 2013 data, while quite alarming per se, is better than that registered for the EU as a whole, and for Lithuania and Latvia (22-23 percent). Employment rates in Estonia among those aged 15 to 24 peaked, in fact, at 36 percent in 2008, before dropping to 26 percent in 2010 and recovering somewhat to 32 percent in 2013. Again, such figures are aligned with the EU-28 average (32 percent), and stand in stark contrast to those recorded in Lithuania (25 percent). Similarly, as Figure 4.8 shows, labor force participation among youth aged 15 to 24 is in line with the rest of the European Union; in 2013, youth labor force participation rates settled at about 40 percent in Estonia, considerably lower than the rate registered in some Nordic and continental European countries, but almost 10 percentage points higher than countries such as Lithuania and Bulgaria. The female participation rate for this age cohort was 38 percent in 2013, 1 percent lower than the EU-28, and more than 10 points higher than countries such as Lithuania and Bulgaria. 
Figure 4.8 Labor Force Participation among Youth aged 15 to 24, European Countries (2013)

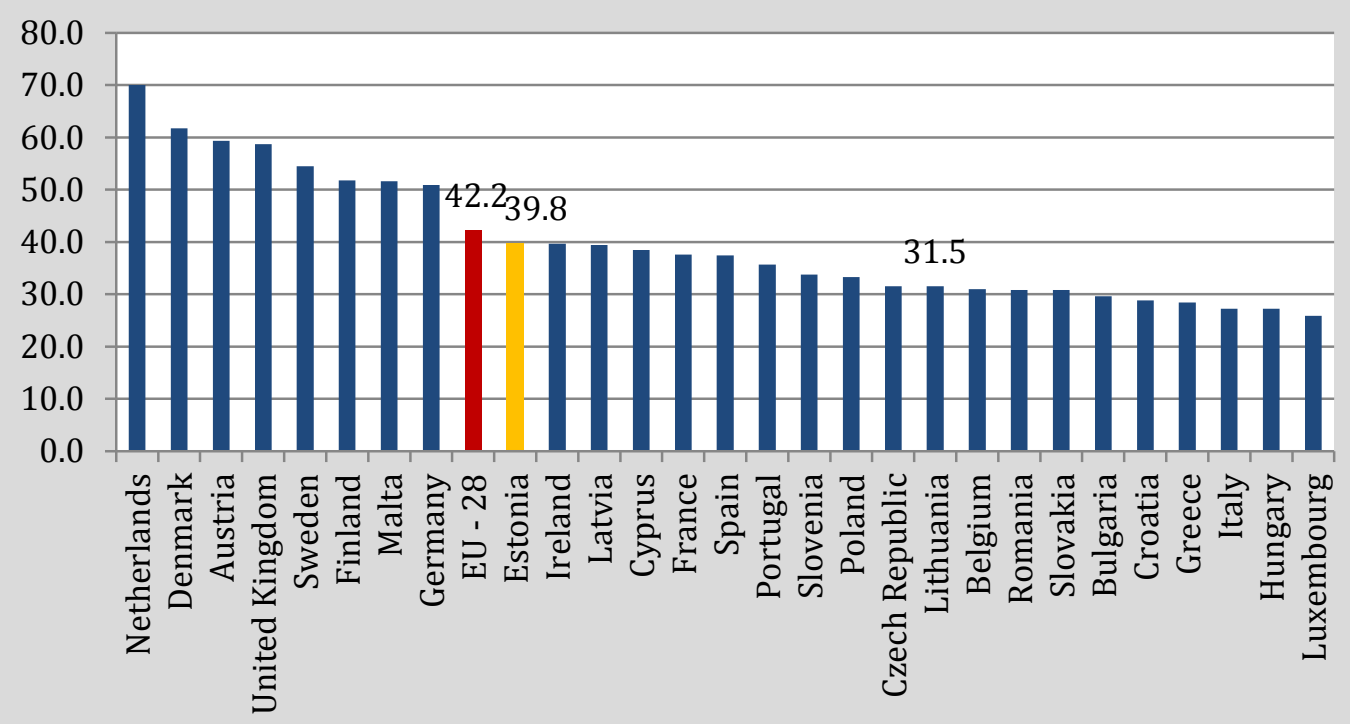

Source: Eurostat, EU-LFS

Second, disabled individuals have been and will continue to be a sizeable portion of the outof-work population, and population aging will only increase Estonia's expenditure on disability benefits. EU-SILC data shows that the number of individuals who report their labor market status as disabled (the majority of whom also receive benefits) settled at just under 50,000 in 2011, a year in which there were two distinct clusters of mostly disabled individuals. In 2007, however, the number of disabled individuals totaled less than 40,000. Thus, even though the share of disabled in the out-of-work population marginally decreased over the last few years (from 23 to 22 percent between 2007 and 2011, and mostly due to the large increase in the total out-of-work population), the absolute number of those classified as disabled increased considerably, with the increase occurring entirely between 2009 and 2011. Furthermore, as seen, disabled Estonians tend for the most part to have little or no work experience and to be above 35 years of age. The vast majority of such individuals benefit from disability or other benefits, which tend to be quite generous (making up on average 70 percent of household income). These factors combined (no work experience, age, and benefit availability) point to high (and growing) impediments for entering or re-entering the labor market, even when disabilities are not too severe. These patterns are somewhat troubling, given the rapid aging the Estonian society will undergo in the coming decades; projections based on current census data show that in the 2001-2011 decade alone, the share of Estonian permanent residents over the age of 65 rose from 15 to 18 percent. According to the Center for International Futures (CIF) at the University of Denver, this number will almost double by 2060 to about 33 percent. At the same time, the number of working-age people will decline from 66 percent to 52 percent. The most recent census (2011) also shows that over the last decade the country has lost 5.5 percent of its population 
(from 1.37 million to 1.295 million) and, using CIF data once again, by 2060 only 0.86 million people will likely live in the country, down from 1.3 million in 2011. The combination of increasing numbers of disabled individuals with an aging and shrinking population will likely increase the expenditure on disability benefits that the Government will have to undertake in the coming decades. Figure 4.9 below shows that expenditure on disability benefits as a share of GDP, while lower than the EU average, had already increased between 2008 and 2010, going from 1.4 percent to 1.9 percent.

\section{Figure 4.9 Expenditures on Disability Benefits as a Share of GDP in Europe (2008 and} 2010)

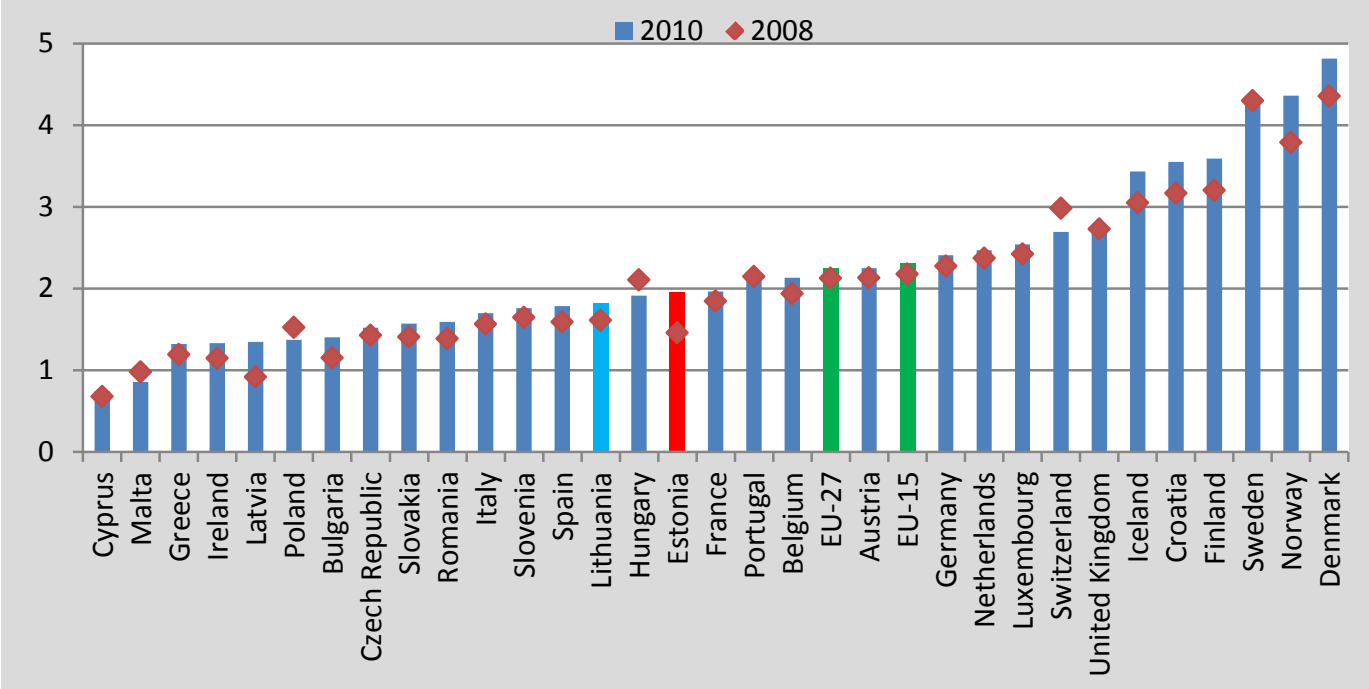

Source: Eurostat, EU-LFS

Third, a number of negative developments can be observed within the unemployed category, all of which pose significant and urgent challenges for policymakers. In particular:

As already noted above, one of the most striking developments between 2007 and 2011 is the dramatic increase in the size and share of the unemployed, especially long-term unemployed, in Estonia. Not only, as shown above, have the number of unemployed and their share of the out-of-work population increased dramatically in Estonia from 2007-2011 but, across all clusters of unemployed individuals, an extremely worrying phenomenon is the growing share of individuals in long-term unemployment, the absolute numbers of which have almost tripled over the period, according to EU-SILC data. ${ }^{49}$ Long-term unemployment not only imposes a significant financial burden on households, but affects the long-term health status of job-seekers, negatively affects Government finances, and results in a lower overall long-term level of skills among a country's workforce, with permanent negative effects on productivity

${ }^{49}$ By 2013 the number of long-term unemployed had decreased significantly. According to Estonian Labor Force Survey data, there were 48,600 long-term unemployed in 2011, but just over 26,100 in 2013. 
(Katz, 2012). Once more, addressing the plight of the long-term unemployed should be among the policy priorities for Estonian policymakers.

$\checkmark \quad$ A further concerning development is the significant increase in the size of the NEETs group, the size of which almost doubled over the last few years. About 80 percent of the individuals in this cluster have no prior work experience, and 60 percent of them belong to the first two income quintiles; activating these clusters should therefore be another policy priority for Estonian policymakers, to avoid the further depreciation of the stock of human capital among these young individuals and to promote their long-term wellbeing.

$\checkmark \quad$ In line with the first point above, the global downturn is likely at least partly responsible for the rise of a group of young long-term unemployed, a cluster that did not exist in 2007 or in 2009 but represented a staggering 19 percent of the out-ofwork population in 2011. With about two-thirds of them being men in their prime (hence many of them likely to be heads of households), and given the high risk of poverty within this group (as shown, 80 percent of these individuals fall in the first two income quintiles), facilitating the transition of this group into the labor market is key to the long-term wellbeing of these individuals and their families.

$\checkmark \quad$ The downturn is also probably responsible for at least part of the increase in the size of the group of well-educated, unemployed individuals in their prime. Despite the fact that this cluster tripled in size between 2007 and 2009, and reverted back to "only" 30 percent above its pre-crisis level by 2011, the existence of a large and increasing number of well-educated, mostly prime-aged, jobless men is now a structural feature of the Estonian labor market. 
Finally, by looking at longitudinal EU-SILC data for the period 2008-2010, one can better understand the in-cluster dynamics, as well as notice other movements in the labor market. EU-SILC allows for the tracking of a number of out-of-work individuals between 2008 and 2010. Of course, because of the difficulties in tracking people across time, the sample size of the panel dataset is considerably smaller than the cross-section surveys; the 2008-2010 longitudinal dataset includes in fact about 560 observations, as opposed to 2,400 observations for 2011. However, the panel data confirms the existence of some latent classes that emerged in the cross-sectional analysis. And even though the smaller sample size forced us to lower the number of clusters identified, some clear patterns emerged. Through longitudinal data five classes can be defined, some of which can also be found in the cross-section datasets:
$\checkmark \quad$ Prime-aged educated unemployed (38 percent)
$\checkmark$ Educated retirees (21 percent)
$\checkmark \quad$ Young inactive educated mothers with working partner(17 percent)
$\checkmark \quad$ Middle-aged low-educated and rural disabled (15 percent)
$\checkmark \quad$ Single NEETs without work experience (9)

Annex 3 shows the statistical description of the latent classes in full while Table 4.5 below summarizes the key features of each group.

Table 4.5 Longitudinal Analysis: Summary Characteristics of Latent Classes of Out-ofWork Population in Estonia (2010)

\section{1: Prime-aged educated unemployed (38\%)}

- $90 \%$ are unemployed

- $93 \%$ is between the age of 25 and 59 , and $63 \%$ is 35 to 59

- $31 \%$ have tertiary education

- $70 \%$ are men

- $50 \%$ are in the first two income quintiles

- Three out of four receive at least one benefit

\section{2: Educated retirees (21\%)}

- $85 \%$ are retired and the rest disabled

- $96 \%$ are 60 and above

- $60 \%$ are women

- $70 \%$ have upper and post-secondary education

- $60 \%$ are in the first two income quintiles

- $97 \%$ receive at least one benefit
3: Young inactive educated mothers with working partner (17\%)

- $75 \%$ are inactive and another 20\% unemployed

- $80 \%$ almost are below 34

- $97 \%$ are women

- Almost 40\% have tertiary education

- Almost 95\% receive some benefit, and about $85 \%$ receive family benefits

- $39 \%$ are in the first two income quintiles

\section{4: Middle-aged low educated and rural} disabled (15\%)

- $60 \%$ are disabled, 23\% unemployed, and another $15 \%$ inactive

- Three out of four live in a household without at least one working adult

- Over $85 \%$ reside in rural areas

- $92 \%$ are between 35 and 59

- $85 \%$ receive at least one benefit

- Almost $80 \%$ belong to the poorest two income quintiles 


\section{5: Single NEETs without work experience}

(9\%)

- $85 \%$ are unemployed

- $80 \%$ are men

- About $60 \%$ live in a household with at least one working adult

- $53 \%$ have never worked

- $80 \%$ are between the age of 16 and 24, and the remaining $20 \%$ is between 25 and 34

- $65 \%$ live in rural areas

- Almost $90 \%$ is single

- $52 \%$ are in the first two income quintiles

Source: World Bank staff analysis based on EU-SILC

Note: 'Years of work experience' refer only to those individuals who have worked before. 'Dependent children' includes children under 18 and household members aged 18 to 24 who are economically inactive and living with at least one parent. 'Working adult' refers to adults aged 24 and over.

Table 4.6 Composition of 2010 Clusters Based on 2008 Labor Status-Estonia (Column Percentages)

\begin{tabular}{|c|c|c|c|c|c|c|c|}
\hline & & & & of-Work & tus 2008 & & \\
\hline Cluster & $\begin{array}{c}\text { Working-age } \\
\text { population in } \\
2010\end{array}$ & Unemployed & Retired & Disabled & $\begin{array}{c}\text { Other } \\
\text { Inactive }\end{array}$ & Employed & Total \\
\hline 1 & $\begin{array}{l}\text { Prime-aged } \\
\text { educated } \\
\text { unemployed }\end{array}$ & 27 & 3 & 2 & 5 & 12 & 11 \\
\hline 2 & Educated retirees & 8 & 92 & 26 & 1 & 2 & 5 \\
\hline 3 & $\begin{array}{l}\text { Young inactive } \\
\text { educated mothers } \\
\text { with working } \\
\text { partner }\end{array}$ & 3 & 0 & 7 & 19 & 2 & 5 \\
\hline 4 & $\begin{array}{l}\text { Middle-aged low } \\
\text { educated and } \\
\text { rural disabled }\end{array}$ & 19 & 0 & 60 & 6 & 2 & 6 \\
\hline 5 & $\begin{array}{l}\text { Single NEETs } \\
\text { without work } \\
\text { experience }\end{array}$ & 14 & 0 & 0 & 15 & 1 & 4 \\
\hline 6 & Employed & 29 & 5 & 6 & 55 & 81 & 69 \\
\hline & Total & 100 & 100 & 100 & 100 & 100 & 100 \\
\hline
\end{tabular}

A further advantage of the panel analysis is to provide information on the movement of individuals in and out of certain clusters and in and out of jobs between 2008 and 2010. Table 4.6 below shows the flow of individuals into the different clusters as of 2010, according to their labor market status in 2008. The most interesting column is the one relative to those that were employed in 2010. According to the panel data, among those categorized as employed in 2010, 81 percent were also employed in 2008; however, and somewhat encouragingly, almost 30 percent of those unemployed in 2008 moved into 
employment by 2010 , while 55 percent of those classified as domestic workers or inactive in 2008 had become employed by 2010 . However, 19 percent of those employed in 2008 had fallen into one of the out-of-work categories by 2010 .

Table 4.7, on the other hand, shows a considerable amount of movement out of employment between 2008 and 2010. For instance, 80 percent of those in the prime-aged, educated unemployed cluster were actually employed in 2008. Similarly, 22 percent of the 2010 NEETs cluster were employed in 2008, and more than 30 percent of the young, inactive mothers had also left the ranks of the gainfully employed between 2008 and 2010.

\section{Table 4.7 Composition of 2010 Clusters Based on 2008 Labor Status-Estonia (Row Percentages)}

\begin{tabular}{|c|c|c|c|c|c|c|c|}
\hline & & \multicolumn{6}{|c|}{ Out-of-Work Status 2008} \\
\hline Cluster & $\begin{array}{c}\text { Working-age } \\
\text { population in } \\
2010\end{array}$ & Unemployed & Retired & Disabled & $\begin{array}{c}\text { Other } \\
\text { Inactive }\end{array}$ & Employed & Total \\
\hline 1 & $\begin{array}{l}\text { Prime-aged } \\
\text { educated } \\
\text { unemployed }\end{array}$ & 11 & 1 & 1 & 7 & 80 & 100 \\
\hline 2 & Educated retirees & 6 & 36 & 24 & 4 & 29 & 100 \\
\hline 3 & $\begin{array}{l}\text { Young inactive } \\
\text { educated mothers } \\
\text { with working } \\
\text { partner }\end{array}$ & 2 & 0 & 7 & 60 & 31 & 100 \\
\hline 4 & $\begin{array}{l}\text { Middle-aged low } \\
\text { educated and } \\
\text { rural disabled }\end{array}$ & 14 & 0 & 51 & 14 & 21 & 100 \\
\hline 5 & $\begin{array}{l}\text { Single NEETs } \\
\text { without work } \\
\text { experience }\end{array}$ & 17 & 0 & 0 & 61 & 22 & 100 \\
\hline 6 & Employed & 2 & 0 & 0 & 12 & 85 & 100 \\
\hline & Total & 5 & 2 & 5 & 16 & 73 & 100 \\
\hline
\end{tabular}




\section{From Profiling to Activation}

\section{Activation and Inclusion Policies in Estonia}

Expenditures on active labor market policies (ALMPs) are relatively low but have been scaled up since 2008. Up until the crisis, employment services and activation policies for the unemployed had not been a particular concern in the Estonia; in 2008, for instance, ALMP expenditures accounted for 0.1 percent of GDP, half of which was covered through EU funds (OECD, 2010). More than half of that amount was spent on employment services, counseling, and job-search activities, and no more than 0.5 percent of the total workforce benefited from labor market policies. Few of the unemployed received benefits, either contributory or non-contributory. The effects of the financial crisis underlined the need for labor market reforms, for greater resources to support the unemployed; accordingly, in 2009, the country underwent an extensive reform process that affected labor market regulations, contractual agreements, labor compensation and wage policies, unemployment insurance, social protection and insurance schemes, and so on.

In the post-2009 scenario, the main agency in charge of employment services and unemployment benefits is the Unemployment Insurance Fund (UIF). Until 2009 the country had a self-standing public employment service under the Ministry of Social Affairs; however, with the advent of the crisis and the increasing need to tighten the link between unemployment assistance, unemployment insurance, and employment services, the public employment service was merged with the UIF. After the merge, the UIF, a public agency fully financed by employers' and employees' contributions, became a "tripartite" organization in charge of all active and passive labor market policies. The merged UIF, which remained under the supervision of the Ministry of Social Affairs, maintained its 15 regional and 26 local labor offices, 80 percent of which provide information and job counseling and manage jobseekers and employers' cases through their front-line staff (OECD, 2010).

As a result of the crisis, the range of active and passive labor market policies and employment services offered by the UIF is now wide. In particular, examples of services and programs offered by UIF include (OECD, 2010):

$\checkmark \quad$ Supported Employment Programs/Measures. These include career counseling, job-search assistance, job-broking services, measures for disabled jobseekers, and public works in selected municipalities;

$\checkmark \quad$ Training Schemes in the form of benefits for both employers and employees, workplace trainings, and so on;

$\checkmark \quad$ Support Schemes for Job Creation, such as start-up incentives, support to employers in finding suitable workers;

$\checkmark \quad$ Passive measures such as unemployment benefits.

Estonia traditionally spends much less on labor market policies (LMPs) than other OECD countries; this pattern still holds despite the fact that the crisis resulted in a notable increase in such expenditures. As Figure 4.10 below shows, in 2011 Estonia spent little more than 0.6 percent of GDP on LMPs, two-thirds of which was devoted to unemployment benefits and early retirement. The average OECD country, on the other hand, spent over 1.4 percent of 
GDP in LMPs, almost two and a half times the Estonian figure. Looking at the evolution of such expenditures between 2003 and 2011, it is immediately noticeable that the downturn was associated with a massive increase in unemployment and early retirement benefits. In the pre-crisis period, total LMP expenditure was extremely low; it ranged between 0.1 and 0.2 percent of national GDP, with unemployment and early benefits absorbing about threequarters of the expenditures (0.07-0.15 percent of GDP). By 2009, at the peak of the crisis, the share of these benefits had increased more than tenfold, reaching 1.6 and 1.3 percent of GDP, respectively. By 2012, unemployment and early retirement benefits as a share of GDP were still three times as much as the pre-crisis level (Eurostat and OECD data). It should be noted as a positive that Estonia did not respond to the crisis with a decrease in relative activation spending, but rather increased such expenditures; the share of ALMP spending in GDP quadrupled between 2007 and 2012 (from about 0.05 to 0.2 percent of GDP). Overall, then, even though the range of labor market policies offered by the UIF is now quite wide and comparable to the packages offered by the LMP systems of other OECD countries, the scale of such programs is much more limited.

The large increase (and then decrease) in the share of total LMP costs that went toward unemployment benefits was matched by a dramatic rise (and then fall) in the number of beneficiaries. As Figure 4.11 shows, while the 2003-2011 period did witness an increase (although from a very low basis) in the number of active labor market policies' beneficiaries from about 1,000 in 2003 to 6,000 in 2011, the downturn was clearly linked to a spike in the number of those receiving unemployment or early retirement benefits, with almost 30,000 individuals joining the ranks of the beneficiaries between 2008 and 2009 alone. 
Figure 4.10 Labor Market Policy (LMP) Spending in Estonia as a Share of GDP
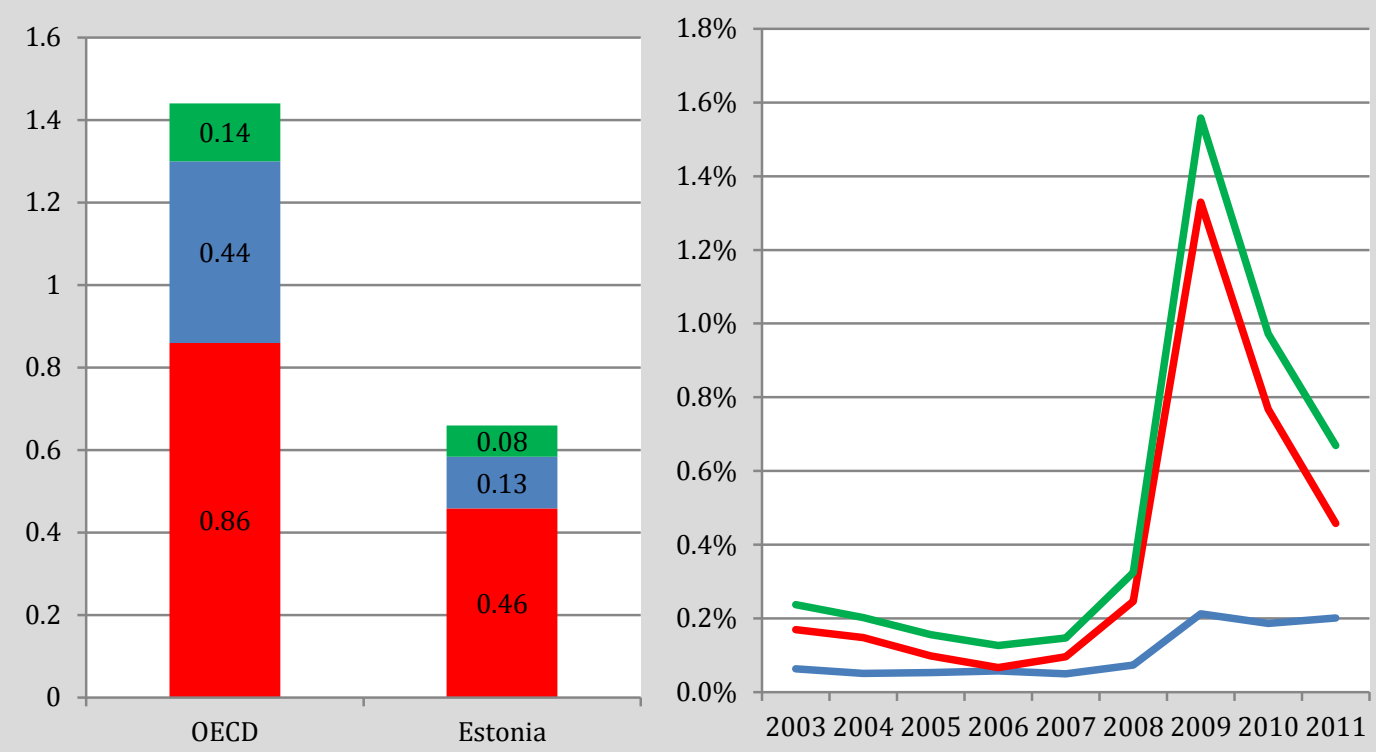

— Public Empl. Services

- Active Labor Market Policies

Active LMP

- Unemp. Benefits and Early Retirement

Unemp. Benefits and Early Retirement

Total LMP

Source: Eurostat and OECD

Figure 4.11 Labor Market Policy Beneficiaries in Estonia (Annual)

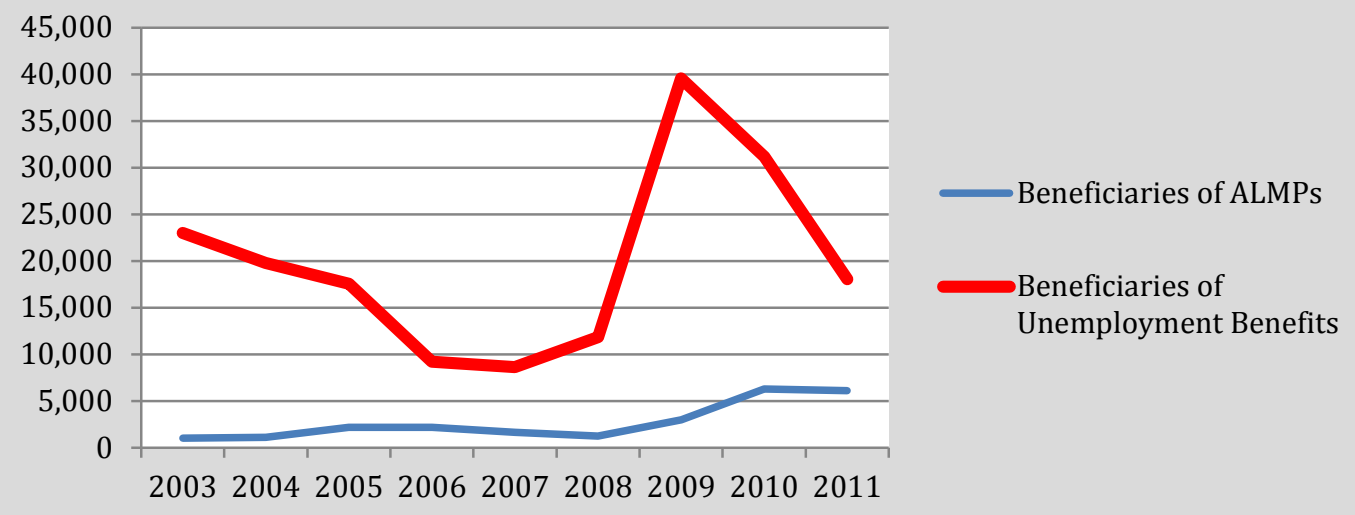

Source: Eurostat, OECD

As mentioned above, the level of ALMP spending has increased considerably as a result of the global financial crisis, albeit from a very low base; furthermore, the composition and source of such expenditures have changed. As depicted on Figure 4.12, spending on training, which made up virtually all of ALMPs expenditures in 2008, increased threefold. On the 
other hand, spending on employment incentives became a sizeable budget item in 2001, but was almost negligible in 2008 (Eurostat, 2010). In addition to the new composition of LMP spending, the crisis also led to a change in the financing of the inclusion measure: after 2009, a major funding source has in fact now become the EU structural funds, which currently support projects that provide vocational training, improve the quality of working life, facilitate job creation, and so on.

Figure 4.12 Composition of Spending on ALMPs in Estonia (Euro Millions), 2008 and 2011

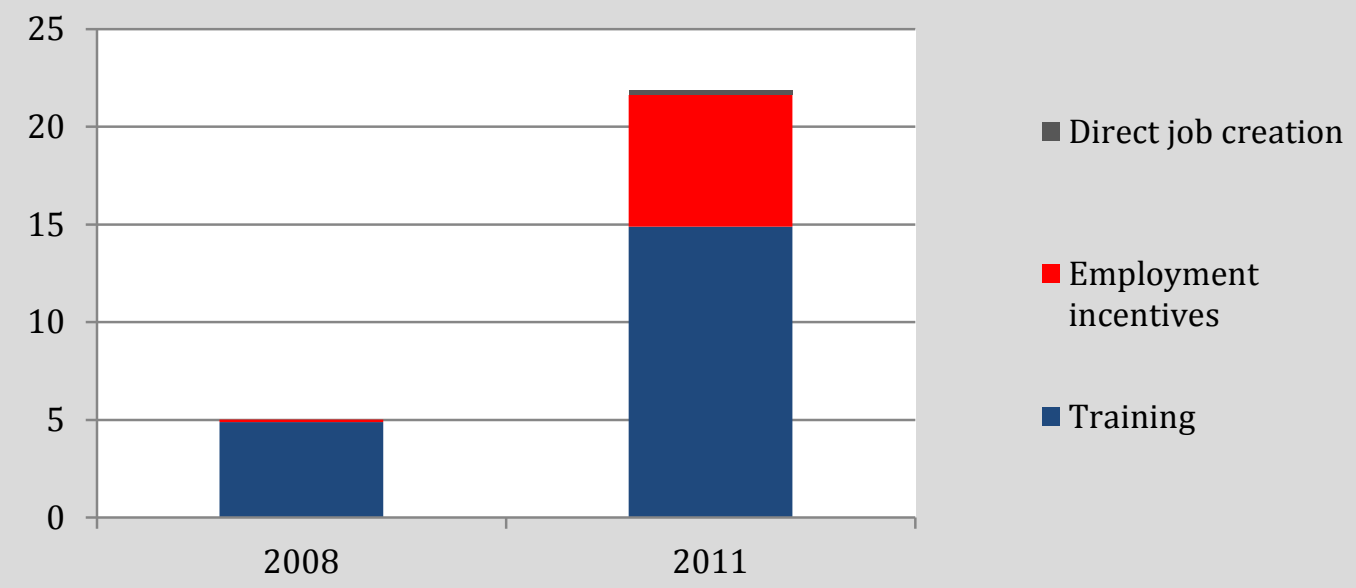


When further considering the approach to labor market integration, an assessment of the priorities and potential of the identified groups needs to be undertaken. Given the cautious increase in nominal resources for activation programs, further prioritization of intervention is all the more important. After a first step ("activation priority") of prioritizing the intervention along activation need and activation potential, a second step ("activation type") will attempt to classify the groups according to the kind of activation intervention needed, depending on social or labor market barriers to be overcome. Lastly, as a third step, information on the household income composition of the different groups will be used to assess potential cross-dependencies of the benefit system with the labor market status and activation approaches

Activation Priorities. The table below gives an overview of the identified out-of-work classes and their respective activation need and activation potential. The total number of persons estimated in these clusters was about 224,000 in 2011, representing 28 percent of the working-age (16-64-year-old) population of Estonia in 2011.

In the table, "activation need" refers to a group's level of need for inclusion in the labor market in order to achieve income and reduce or end poverty. "Activation potential" describes that group's ability or motivation to be included in the labor market. A high activation need could be driven by high poverty risk (as in the case of the prime-age low income long-term unemployed) whereas a high activation potential could be driven by previous work experience or a relatively good educational base (for example, the prime-aged educated unemployed). Overall priority for action can also be supported by the size of the group.

Table 4.8 Activation Need and Potential of Different Clusters-Estonia

\begin{tabular}{|c|c|c|c|c|}
\hline $\begin{array}{l}\text { Share } \\
(2011)\end{array}$ & Cluster & $\begin{array}{l}\text { Activation } \\
\text { need }\end{array}$ & $\begin{array}{c}\text { Activation } \\
\text { potential }\end{array}$ & $\begin{array}{l}\text { Priority for } \\
\text { action }\end{array}$ \\
\hline $21 \%$ & $\begin{array}{l}\text { Middle-aged educated disabled with } \\
\text { previous work experience }\end{array}$ & Medium & Medium & Medium \\
\hline $19 \%$ & $\begin{array}{l}\text { Prime-age low-income long-term } \\
\text { unemployed }\end{array}$ & High & High & High \\
\hline $18 \%$ & Educated retirees & Low & Low & Low \\
\hline $17 \%$ & $\begin{array}{l}\text { Young inactive educated mothers with } \\
\text { working partner }\end{array}$ & Medium & High & Medium \\
\hline $13 \%$ & Prime-aged educated unemployed & High & High & High \\
\hline $9 \%$ & $\begin{array}{l}\text { Single NEETs without work } \\
\text { experience }\end{array}$ & High & Medium & High \\
\hline $3 \%$ & Young low-educated rural disabled & Medium & Low & Low \\
\hline
\end{tabular}

From this prioritization exercise, a set of five groups emerges with "high" or "medium" priority for action. Middle-aged disabled with previous work experience are a large group with a relatively high share of benefit receipts and prima-facie work limitations. At the same time, 
they have previous work experience and a relatively high educational status (14 percent even have tertiary degrees). Prime-age low-income long-term unemployed have a high activation need among other factors, owing to their high exposure to poverty. At the same time, they report almost no work limitation due to physical disabilities and have a good education status. Young, inactive, educated mothers with working partner show a medium activation need, less so because of their poverty risk but more because of their labor market contribution potential (52 percent have tertiary education!). Their activation potential is high but their overall priority should be set to "medium" in light of their households' relatively secure position. Prime-aged, educated unemployed and single NEETs without work experience are both rated as "high priority" because of either good work experience and maintenance of human capital or young age and avoidance of "scarring" effects.

Educated retirees and young low-educated rural disabled are not prioritized for further action owing respectively to their officially achieved retirement status and extreme distance (via very low educational attainment and self-declared disability) from the labor market.

Activation type. As a second step, the relative severity of labor market or social obstacles to be overcome for labor market integration will serve as an orientation for activation approaches.

\section{Figure 4.13 Activation Types of Prioritized Clusters in Estonia}

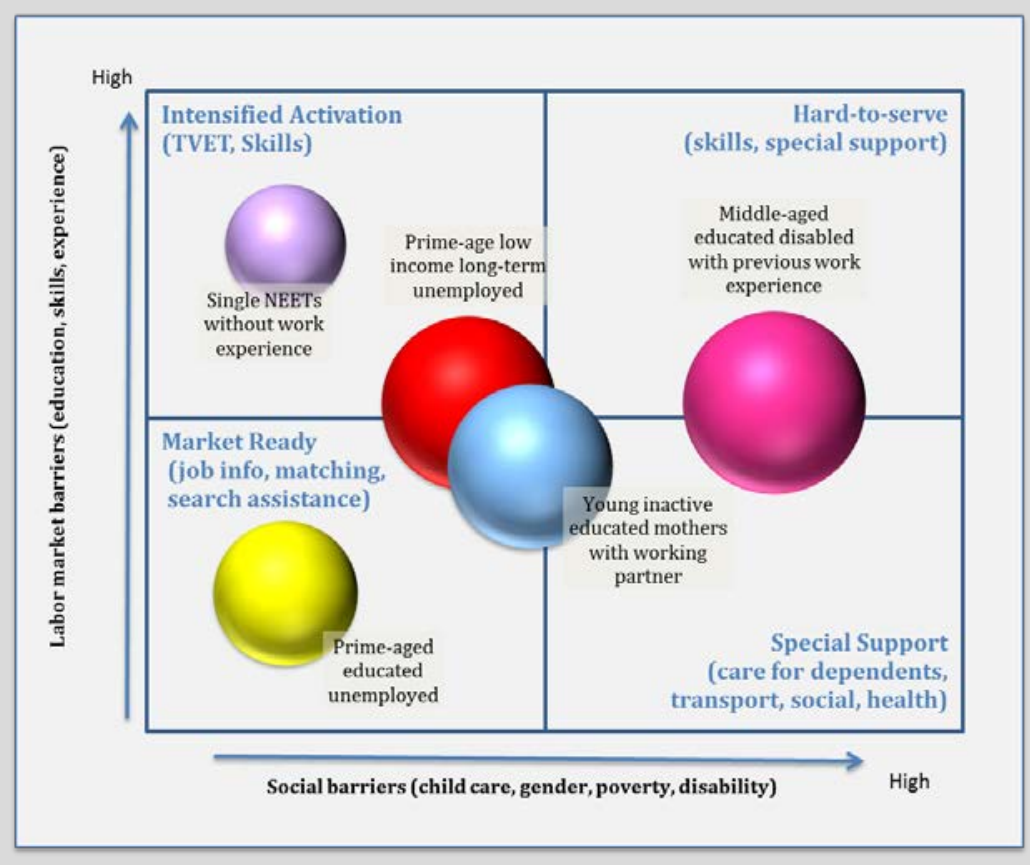

Source: World Bank staff analysis and assessment 2014

When mapping the respective barriers for labor market integration faced by the five prioritized groups, we can see that while many of them have severe labor market distance and attachment challenges, only the middle-aged educated disabled with previous work experience emerge as a group that will face severe social barriers owing to the high share of 
disability within the group. The young inactive educated mothers with working partner could be described as facing a "social" barrier because of the relative importance of paid maternity leave compared with the availability of public child care offerings in Estonia. On the other hand, their excellent household welfare situation (only 19 percent in bottom income quintile) could lead to the conclusion that their social situation might be in part self-chosen or driven by "cultural norms," if not that potential combined household income will not be perceived as sufficient to cover eventual private child care costs. Nevertheless it should be kept in mind that Estonia has higher female labor market participation than Europe as a whole (71.5 percent versus 65.5 percent for EU-28 for 2012). The female participation is even greater in the 25 -to-64-year-old cohort at almost 80 percent, 10 points higher than the region's average.

Finally, the three groups of single NEETs without work experience, prime-age lo-income longterm unemployed and prime-aged educated unemployed can be distinguished by their relative distance from the labor market (in terms of qualification and work experience). However, the prime-age low-income long-term unemployed face significantly higher poverty.

Household income composition. When analyzing the 2011 household income of the prioritized groups, it is a striking feature that most households have a relatively high share of labor income. This is related to the low level and degree of coverage of unemployment and social assistance benefits in Estonia (EU, 2013). Among the prioritized groups, only the middle-aged educated disabled with previous work experience (29 percent) have a low share of labor income, a fact certainly corresponding to the 62 percent of household income stemming from disability and old-age benefits. With 92 percent of this group's individuals reporting their labor market status as "disabled," but only 43 percent strongly limited in their capacity to work because of their physical or mental condition, there appears to be some potential for labor market mobilization and benefit rationalization in this group.

Apart from this observation, the general level of benefit receipt in the prioritized groups is small to non-existent. The single NEETs without work experience are the only group with a noticeable amount (1 percent (!)) of household income stemming from social exclusion benefits. In light of the fact that, with the exception of the young, educated mothers with working partner, all of the groups are severely overrepresented in the two bottom-income quintiles, this pattern of benefit receipts certainly falls short on any social inclusion target.

Given the overall picture of benefit receipt revealed by EU-SILC data, a key need for action emerges around a potential review of disability benefit allocation among middle-aged educated disabled with previous work experience and on the coverage and generosity of the unemployment and social exclusion benefits in general.

Portraits of Labor Market Exclusion | 121 
This section sets out a set of potential activation measures for each of the priority groups. Areas for further policy dialogue are also outlined. Any suggestion or policy discussion around concrete measures will need to take into account that the Estonian authorities have introduced a recent set of reforms and changes to existing programs in the field of employment and labor market inclusion (EU 2013).

The suggestions below should be considered as a starting point for further policy dialogue between the EC, the World Bank and Estonia, bearing in mind that the groups identified still carry heterogeneity that may affect the type of support required. Accordingly, these suggestions are also not meant to be an exhaustive set of possible activation measures.

It is important to keep in mind that the groups have been derived from EU-SILC data from the year 2011. Since then, general economic development, policy actions by the Government of Estonia and European Commission Country-specific recommendations" might reflect some of these policy suggestions or render them obsolete. Among the policy changes that the government of Estonia has initiated since 2011 that ought to improve the labor market integration or activation of some of the groups is a major reform of the incapacity-for-work scheme and the implementation of measures to prevent youth unemployment, support youth who are NEET, and include a wage subsidy for the employer and reimbursement of training costs for people aged 17 to 29 .

Middle-aged educated disabled with previous work experience (21 percent, Priority: Medium). This is the largest group among the identified and prioritized groups. Its almost 48,000 members make up about 5 percent of the total working-age population in Estonia. Forty-three percent of this group report severe limitations in their capacity to work. While this is significantly lower than the share of individuals reporting their activity status as disabled (93 percent), any improved labor market integration of this group is likely going to require a complex set of social, medical and therapeutic support actions.

At any rate, this significant group of out-of-work citizens needs to be followed more closely, and any new applicants for disability benefits closely monitored and controlled. Limiting the inflows into this group (via more stringent disability benefit criteria) will be easier than forcing the activated exit from members of this group. Potential activation measures for the inactive who remain in this group will largely depend on the ability of local governments to provide and finance services for disabled (transport, social and medical care, and so on), but also on the integration of national policies with local service standards and adequate financing. In light of the potentially high integration cost for and potential discrimination against disabled workers, local social services cannot be expected to finance these approaches without support from central government. Potential activation measures include:

$\checkmark$ Review disability status but continue benefits (for now). While continuing to provide current benefits, the government could make the members of this group eligible for a review of their disability and work-ability status. When considered "fit to work" in this review, a set of support measures and continuing benefits 
(potentially with a phase-out period) ought to be provided to cushion the transition to labor market integration. According to Estonian officials, measures along these lines are currently under consideration and changes in the way the country supports and integrates disabled individuals will be introduced.

$\checkmark$ Mobility support. Given the fact that the majority of this population lives in rural contexts, support for labor market access and mobility could be an important service. When providing transport or mobility solutions, local authorities could draw on social enterprises or cooperatives, providing additional opportunities for local employment.

$\checkmark \quad$ Standard PES job search assistance and placement support. Building on the strong previous work experience of this group and starting with the "non-disabled" members, integration into the standard (or emerging) activation regime of the Estonian Unemployment Insurance Fund (UIF), the Public Employment Service (PES) in Estonia.

$\checkmark$ Social economy support and sheltered employment as time-limited transition offerings. For members of this group who subjected to transition from "disabled" to "unemployed" labor market status, temporary placement in social economy enterprises or "sheltered" employment could provide a first step back into a fully competitive labor market. Special care needs to be taken that these offerings are time-limited and linked to clear activation regimes.

Prime-age low-income long-term unemployed (19 percent, Priority: High). This middle-aged group shows strong work availability, is majority male and has a nearly 50/50 urban-rural split. It has the highest poverty risk among all the groups identified.

$\checkmark$ Improve social inclusion benefit and link to activation. In light of the extremely high poverty faced by this group, a targeted expansion of coverage and generosity of an activating social inclusion benefit (conditional on job search) could improve the household welfare condition. This would require improved collaboration of the EUIF and municipal social welfare offices.

$\checkmark$ Reconnect with previous employment experience. Building on previous employment experience, this group could be equipped with missing functional or technical skills, second-chance apprenticeship programs and higher secondary school certificates. Ideally, these programs would relate to industry experience already gained in previous employment spells.

$\checkmark$ Combined professional training and public works. In order to combat any behavioral and attitudinal detachment from the labor market that may result after long periods of unemployment, it may be warranted to subject some of the members of this group to a (time-limited) public works requirement, combining this offering with training, job search and skills support.

$\checkmark \quad$ Mobility and training. Questions of geographic mobility are of great importance for this group of unemployed. Linking mobility to training offerings, enabling some of these jobseekers to participate in higher-quality training in central places can be an important addition to the menu of labor market policies locally. Encouragingly, training needs are already assessed individually by local PESs, and transportation costs related to training will be reimbursed up to EUR 26 per day.

Young inactive educated mothers with working partner (17 percent, Priority: Medium). Given their excellent educational status, relatively low poverty, and the high 
income of their working partners, some of these women could be more or less voluntarily inactive. In terms of their labor market status, they could be regarded as "market" type customers for the EUIF, needing limited and self-driven forms of job search support and reconnection with previous employment and education experience, as long as any service needs (child care, elderly care in family, and so on) are taken care of.

$\checkmark$ Child care and early childhood development. Extension of accessible child care offerings will play an important role in enabling earlier labor market integration for these women. Given their above-average household income, an income-graded cost for participation could pay for the necessary child care services. It is likely that such policies will be supported by European Social Funds during the 2014-2020 period.

$\checkmark$ Reconnection with previous employment. With 93 percent of the women having worked before, linking women to their previous industry or profession after maternity leave or family time can build on existing ties and professional knowledge. These interventions should ideally be employer-driven and only marginally supported by public intervention (for example, voucher systems), and focus on women who have been detached from their industry or employer for many years and have difficulties reconnecting. 50

$\checkmark$ Group-specific job search support. Support from PES counselors in job search techniques, soft skills, self-presentation and update of certain functional skills may help members of this group reconnect with the labor market and attack the necessary challenges in a group-specific support network (for example, "young mothers job club," and so on)

Prime-aged educated unemployed (13 percent, Priority: High). This group should be among the highest priority customers of the Public Employment Service since they boast a very good education level and relatively recent work experience. Building on these assets, this group's integration in the benefit and activation system of the Unemployment Insurance Fund should be strengthened. Currently, this group receives very limited social assistance benefits.

$\checkmark \quad$ Job search support through PES. Standard measures of job search support, regular updates on personal progress, and personal action plans need to be the central pillar of activation support. Nevertheless, these should be seen as a "second level" option, to be used after a self-driven job search fails. As evidenced in EU (2013), Estonia has already taken important steps in this direction with recent changes to unemployment and labor market programs.

$\checkmark$ Placement in private enterprises. Job placement and training that occur within labor market activation programs need to be linked to employers' needs for skills and workers. Given the good educational endowment of these unemployed, supporting employers with skills upgrades for their existing workforces, together with these unemployed, could facilitate their access to companies.

$\checkmark$ Mobility and training. Questions of geographic mobility are of great importance for this group of unemployed. Linking mobility to training offerings, enabling some of these jobseekers to participate in higher-quality trainings in central places can be an important addition to the menu of labor market policies locally.

${ }^{50}$ Currently, parents retain the right to rejoin their employer for up to 3 years after the birth of a child, with access to same job. 
Single NEETs without work experience ( 9 percent, Priority: High). This group is mainly challenged with getting its first foothold in the labor market and building on recent educational experience.

$\checkmark \quad$ Internet and social network-based activation and information offerings. Promotion of online job portals, potentially linked with "game-ification" of job search offerings, mobile CV submission, application, and so on

$\checkmark$ Group job search. Mobilizing young people to continue job searching and not retreat to their homes can be an important measure to keep NEETs "engaged."

$\checkmark$ Reconnect programs with educational history. Building on educational history, training and job search offerings could help to build the functional skills necessary for related industries.

$\checkmark$ School-to-work transition, first work experience. Estonia has already taken initial steps to strengthen this critical area.

$\checkmark$ Youth guarantee programs. Importantly, these programs are set to be introduced in 2015. The services, which will combine training and wage subsidies, aim to increase the number of active young people in the labor market.

In general, further policy dialogue with the Estonian authorities ought to focus as much on the general level and setup of resources devoted to labor market integration and activation of the inactive and out-of-work, as on the ongoing improvement of services on the national and local level. Within this discussion, a dialogue around specific measures for specific groups could be deepened. The following items appear especially important:

$\checkmark$ Consistent local service delivery. According to EU (2013), Estonia is intending to take steps to ensure consistent service delivery levels across the country. Given the fact that the majority of the country's out-of-work population is situated in rural areas and many members of these groups require social and other public services for improved labor market integration, the adequate financing and equipment of local services (for example support to disabled, child care, and so on) can be an important prerequisite and complement to any activation policy.

$\checkmark$ Labor market (re-)entry policies. Several groups face barriers to labor market entry post-school or post-work interruption. Giving special attention to school-towork transitions and supporting fast re-entry into the labor market after unemployment or maternity spells will address the activation needs of many prioritized groups (young mothers as well as NEETs.)

In summary, Estonia could benefit from accompanying the ongoing improvement of its labor market services and social inclusion policies with an enhanced knowledge about the composition and socio-economic situations of the different groups of out-of-work citizens. This notably relates to a unified view across traditional labor market categories (employed/unemployed) and social inclusion dimensions (poverty, living conditions, and access to services) because the two are intrinsically linked, especially for the labor market's most marginalized participants. 


\section{References}

Brixiova, Zuzana and Balazs Egert, 2012. Labour Market Reforms and Outcomes in Estonia. IZA Discussion Paper No. 6336. February.

Collins, L. M., and S. T. Lanza, 2010, Latent Class and Latent Transition Analysis: With Applications in the Social, Behavioral, and Health Sciences. Hoboken, NJ: Wiley.

Eurofound, 2012, NEETs-Young people not in employment, education or training: Characteristics, costs and policy responses in Europe, Publications Office of the European Union, Luxembourg.

EC, European Commission, European Community Programme for Employment and Social Solidarity, 2013, "Assessment of the implementation of the European Commission Recommendation on active inclusion: A study of national policies-Estonia," January 2013.

EC, European Commission, 2013a, EU measures to tackle youth unemployment. MEMO, Brussels, 28 May 2013.

Eurostat, 2011, ESSPROS Manual: The European System of integrated Social Protection Statistics. European Union, Luxembourg.

Katz, L., 2010, "Long-Term Unemployment in the Great Recession," Testimony for the Joint Economic Committee, U.S. Congress Hearing on "Long-Term Unemployment: Causes, Consequences and Solutions," April 29, 2010.

Kaufman, L. and Rousseeuw, P. J., 1990, Finding groups in data. New York, Wiley.

Magidson, Jay and Vermunt, Jeroen, 2002, Latent Class Modeling as a Probabilistic Extension of K-Means Clustering Quirk's Marketing Research Review, March, 20, 77-80. Available at:

http://statisticalinnovations.com/technicalsupport/kmeans2a.htm

Masso, Jaan; Raul Eamets and Pille Motsmees. "The Effect of Migration Experience on Occupational Mobility in Estonia." IZA Discussion Paper No. 7482. June 2013

OECD, 2010, OECD Reviews of Labor Market and Social Policies: Estonia.

http://www.oecd-ilibrary.org/docserver/download/8110061e.pdf?expires=1387213871\& id=id\&accname=ocid195787\&checksum=9F87DC8BFF74755DC339F9D137FEF4A3 OECD, 2012, OECD Economic Surveys: Estonia. October 2012

Vermunt, J. K. and J. Magidson, 2005, Latent GOLD 4.0 User's Guide. Belmont, Massachusetts: Statistical Innovations Inc. 


\section{Latent Class Analysis of the Out- of-Work Population in Greece 2007-2011}

\section{Background}

While most countries in the region have been able to recover after the global financial crisis, Greece is still in a recession. Greece had a moderate growth rate of over 4.3 percent from 2003 to 2007, above the 2.2 percent average among the EU-28 Member States during the same period. Like most of Europe, in 2009 the country was hit by the crisis and the economy contracted 3.1 percent. Nevertheless, unlike other European countries, whose growth started recovering soon afterward, Greece's economy continued its downturn, contracting 4.9, 7.1, 6.4 and 3.9 percent during 2010, 2011, 2012 and 2013, respectively.

As it enters its sixth year of recession in 2013, Greece has also witnessed a steady deterioration of employment outcomes, particularly since 2010. From 2004 to 2008, unemployment of 15-to-64-year-olds slowly decreased, reaching 7.8 percent. Following the onset of the crisis, unemployment rose rapidly, increasing more than 16 percentage points to 27.5 percent in 2013. This is more than twice the average rate that EU-28 countries had in 2013. Labor force participation is also low by European standards. In 2013, 32 percent of Greece's working-age population was inactive, compared to a 28.1 percent average for the EU-28 countries.

Conversely, unemployment rates rose steadily and disproportionately affected those segments of the working-age population traditionally at higher labor market risk in Greece. ${ }^{51}$ In 2013, a staggering 68.3 percent of young people 15 to 24 of the working age population were unemployed, and among them, more than 60 percent were long-term unemployed (12 months or more), compared to about a third in 2008. Perhaps more tellingly, the share of youth not in education, employment or training (NEET rate) nearly doubled, from 11.7 percent in 2008 to 20.6 percent in 2013. It is among the highest NEET rates in the EU. Another telling example of the social consequences of the employment crisis is that the share of children 0-17 who live in households with no employed member increased from 3.6 percent in 2008 to 12.9 percent in 2012.

A look at unemployment rates disaggregated by gender shows that women were particularly affected by the crisis. As Figure 5.1 shows, unemployment rates are generally higher for women, independent of age. While men in the 25-64 age category entered the crisis with unemployment rates close to 4.3 percent, the share of unemployed women in this same age group was close to 10.1 percent. By 2013 these rates had jumped to 19.9 and 25.7 percent, respectively. Among young Greeks, women were also affected more than men, with

51 OECD (2013). 
the rate of joblessness among 15-24-year-old-men reaching 53.6 percent in 2013, as opposed to 64.2 percent of women of the same cohort.

\section{Figure 5.1 Unemployment Rates by Age and Gender (2007-2013)}

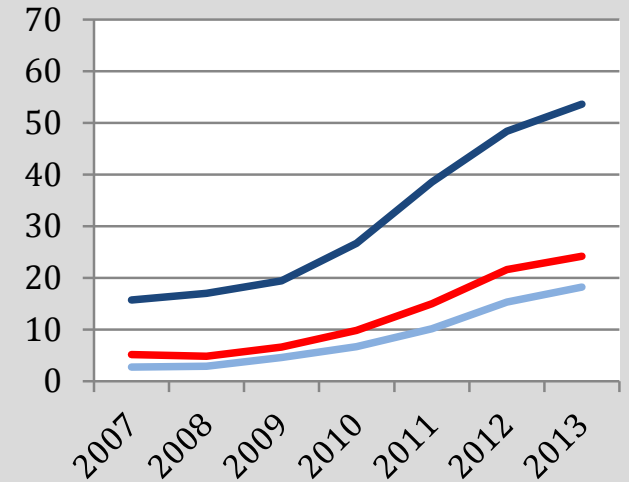

Males 15 to 24 years

Males 25 to 49 years

Males 50 to 64 years

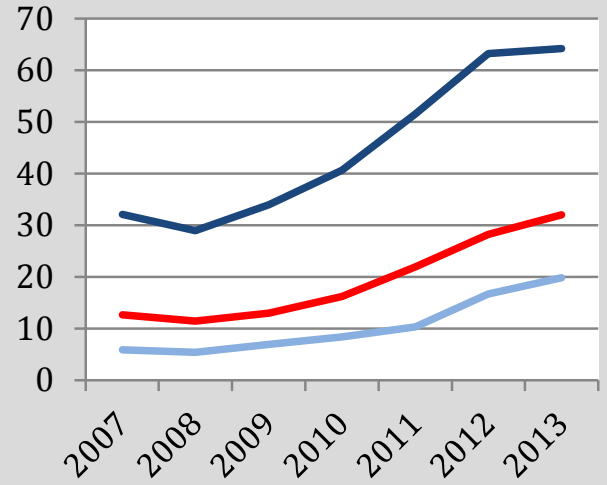

Females 15 to 24 years

Females 25 to 49 years

Females 50 to 64 years

Source: Eurostat, EU-LFS

In Greece, long-term unemployment as a share of total unemployment has usually been higher than the average for the EU-28 countries. In 2013, according to Eurostat and as shown in Figure 5.2, in the average EU-28 country 47.5 percent of the unemployed have been looking for work for more than 12 months, up from 33 percent in 2009. The long-term unemployment in Greece has been considerably higher than that during the last 10 years. In 2009, it declined to 41 percent-still 6 point higher than the average EU-28 country-but by 201367.5 percent of the unemployed were long-term. 
Figure 5.2 Long-Term Unemployment as a Share of Total Unemployment (2003-2013)

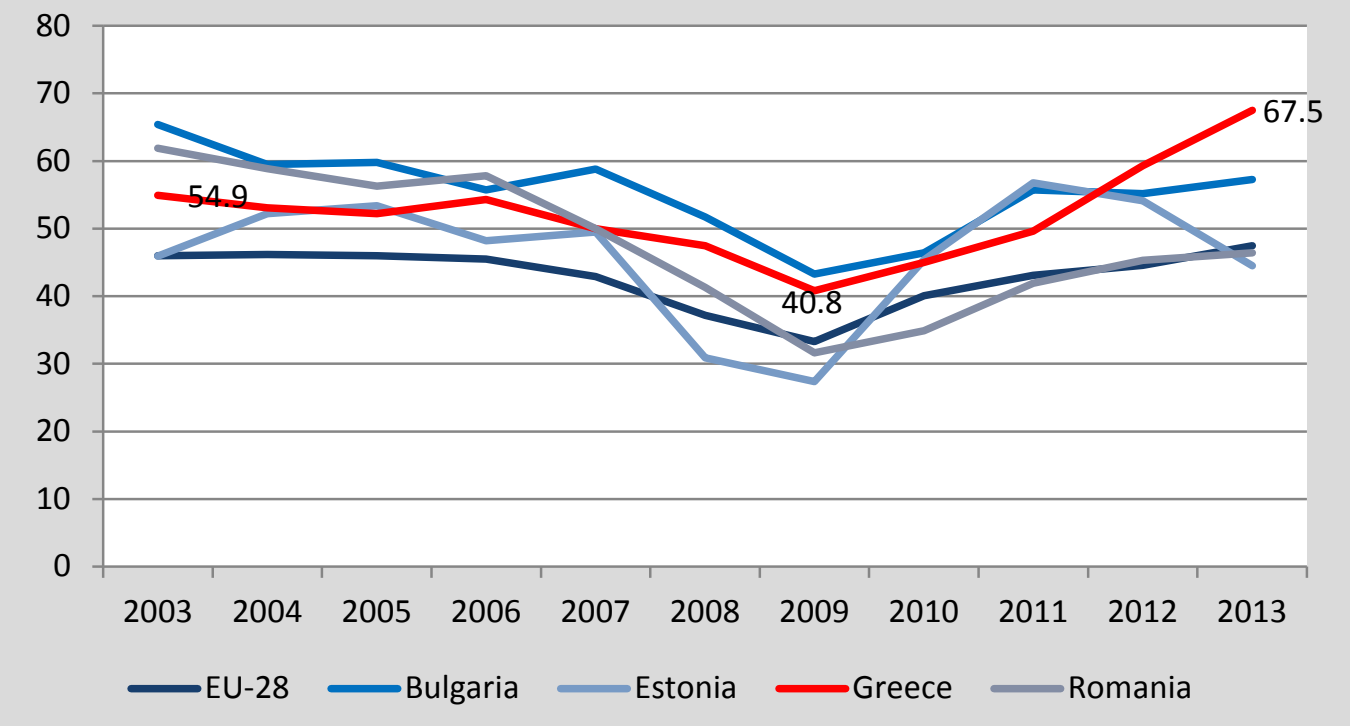

Source: Eurostat, EU-LFS

Following the crisis, low-educated individuals were especially affected by the rise in unemployment. Unemployment rates were already increasing for the group of lesseducated individuals. After the crisis hit in 2009 this trend was somewhat accentuated. However, all educational groups saw an increase in unemployment rates during the period from 2008 to 2013. For those with a tertiary education, unemployment more than tripled, from 6.3 to 20.3 percent of the working-age population. Those with lower educational levels witnessed a greater increase in their unemployment rate, making the gap between low- and high-educated groups bigger during the period. The gap also reflects structural changes that increased the demand for more skilled workers. The difference in unemployment rates for low- and high-educated workers grew from 1.3 percentage points in 2008 to 9.8 percentage points in 2013.

As a result of the crisis, employment rates also deteriorated. The employment rate of individuals aged 15 to 64 years, which peaked in 2008 at 61.9 percent, reached their lowest level in 2013 at 49.3 percent, notably with no major distinction across educational categories.

Although Greeks with lower educational levels suffered the most as a result of the crisis, their share of the active population has been decreasing over time. The percentage of people that only have lower secondary education or less has fallen almost 10 points since 2003, reaching 28.2 percent in 2013. Similarly, those with tertiary education have increased from 21 percent in 2003 to 30.5 percent 2013.

During the period from 2007 to 2011, the size of the out-of-work population considered in this note increased, from 2.139 to 2.695 million individuals. The analysis 
of the out-of-work population in this note focuses on the working-age population (16 to 64 years old). Specifically, only individuals aged 25 to 64 years who are not employed and individuals aged 16 to 24 who were neither employed nor in education or training were considered. ${ }^{52}$ Only the working-age population (16-64-year-olds) is analyzed, as labor activation options-the main policy focus of this note-are only viable for that segment of the population. The group in need of opportunities has substantially increased since 2007, as the profiles of working-age population by labor market status show (see Figure 5.3). Table 5.1 shows that the groups of unemployed (short and long term), and even of early retirees, have increased, while the share of disabled individuals and other inactive has decreased. Non-employment, ${ }^{53}$ defined here as neither at work nor in military service, rose from 33 percent in 2007 to 41 percent in 2011.

Table 5.1 Number and Percentage of Working-Age Individuals (16-64) by Labor Market Attachment in Greece (2007 and 2011), in Thousands

\begin{tabular}{|l|c|c|c|}
\hline & $\mathbf{2 0 0 7}$ & $\mathbf{2 0 1 1}$ & $\begin{array}{c}\text { Percent change } \\
\mathbf{2 0 0 7 - 2 0 1 1}\end{array}$ \\
\hline At work & 4,379 & 3,871 & $-11.6 \%$ \\
\hline Unemployed & $67.2 \%$ & $59.0 \%$ & \\
\hline & 204 & 435 & $113.1 \%$ \\
\hline Long-term unemployed & $3.1 \%$ & $6.6 \%$ & \\
\hline & 275 & 588 & $113.8 \%$ \\
\hline (Early) retirement & $4.2 \%$ & $9.0 \%$ & \\
\hline & 477 & 670 & $40.3 \%$ \\
\hline Disabled & $7.3 \%$ & $10.2 \%$ & $-54.7 \%$ \\
\hline & 134 & 61 & \\
\hline Other inactive & $2.1 \%$ & $0.9 \%$ & $-10.3 \%$ \\
\hline & 1,048 & 941 & \\
\hline Total & $16.1 \%$ & $14.3 \%$ & $0.7 \%$ \\
\hline & 6,518 & 6,565 & \\
\hline
\end{tabular}

Source: World Bank staff analysis based on EU-SILC

52 Individuals aged 16 to 24 who are out of work and enrolled in education are excluded from the sample; they are considered to be investing in their final stages of human capital formation and therefore are not a particular target group for activation policies. Individuals enrolled in school between 25 and 64 are, however, included in the latent class analysis and will be grouped under "other inactive." It is important to note that the group of students older than 24 account for only 1 percent of total population of working age.

53 Throughout this report, this population is also referred to as the out-of-work population. 
Figure 5.3 Distribution of Working-Age Population (16-64) by Labor Market Attachment in Greece (2007 and 2011)

2007

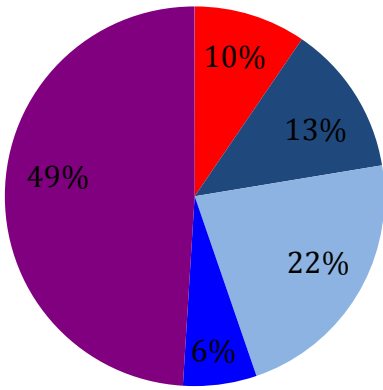

2011

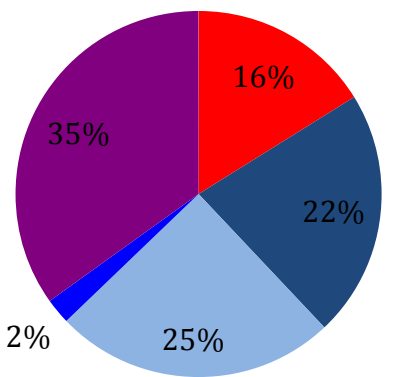

- Unemployed

- Long-term unemployed

(Early) retirement

- Disabled

Other inactive 


\section{Methodology: Latent Class Analysis}

In Chapter 1 a general overview of the latent class analysis methodology was presented. This section explains in detail the variables and covariates used to identify classes or groups of out-of-work individuals that are as homogeneous as possible within each class according to a set of observable characteristics, and as distant as possible between classes. The emerging profiles can then be contrasted with the design and targeting of current activation policies, in order to identify the potential gaps and to enhance their design features. ${ }^{54}$

Variable selection: The definition of latent classes relies on a number of indicator variables to capture different "symptoms" of an overall latent condition (in this case, the typology of joblessness). The challenge in such models is to identify a discrete number of variables that can best explain the heterogeneity of individual outcomes. In this case, two sets of categorical variables were selected: the first set to show the extent of labor market distance and the other to capture some of the main factors that can affect employment on the supply side, such as labor supply conditions (household-level incentives to work and physical ability to work).

$\checkmark$ Distance from labor market: short-term unemployment, long-term unemployment, (early) retirement, disability, and other inactivity (largely unpaid domestic work)..$^{55}$

$\checkmark$ Labor supply conditions: whether the individual's household has at least one working adult, ${ }^{56}$ and perceived limitations on activities due to health problems. ${ }^{57}$

In addition to indicators, the model includes active covariates, which are used to improve the classification of individuals in each class. In this case the active covariates are the demographic variables that are normally used to disaggregate labor market outcomes:

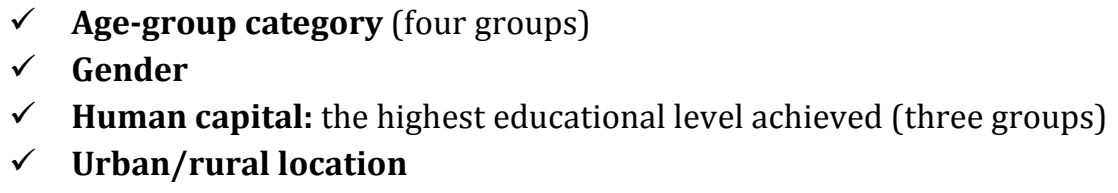

Once the latent classes have been defined, inactive covariates that were not included in the model can be used to characterize the individuals in each class and the households in which they live. The inactive covariates chosen describe those characteristics that may provide valuable information for the design of tailored policies that address barriers to employment, including income level. They include:

${ }^{54}$ For the latest developments on active inclusion in Greece, see EC (2013b).

${ }^{55}$ This variable is constructed using the self-reported current work status in the EU-SILC survey that has four categories: at work, unemployed, retired and inactive. The unemployed are further classified into short- and long-term based on how long they have been actively looking for a job. The inactive is combined with another question to separate this group into students, disabled, military and other inactive.

56 In order to construct this variable, individuals aged 25 or older are considered adults.

${ }^{57}$ This is a binary variable that takes the value one if an individual answered "yes, strong limitations" to whether they had been hampered in their usual activities because of health problems for at least the last six months. The value is zero if the answer is "yes, limited" or "no, not limited." 


\section{$\checkmark$ Household welfare conditions:}

- Income quintile (defined by equivalized disposable household income ${ }^{58,59}$ )

- Labor, benefit, and other income as share of total gross household income ${ }^{60}$

- Binary variable denoting whether at least one working adult (aged 25 and over) is present in the household

- Tenure status

- Household able to keep dwelling warm

- Partner's labor income

- Quintile of partner's labor income

- Binary variables denoting whether individuals or their households are beneficiaries of any of eight social protection benefits ${ }^{61}$

\section{$\checkmark$ Household demographics:}

- Household size

- Household composition

- Binary variable showing whether there are children under 6 in the household

- Binary variable denoting whether there are three or more under-16 children in the household

- Children under 13 receiving child care in the household: all, some or no children under 13 present

- Older person (65 and over) in the household

$\checkmark$ Other individual-level demographics:

- More refined age groups (seven groups)

- Marital status

$\checkmark$ Individual human capital:

- More refined highest educational level achieved (six groups)

- Work experience in years

- Binary variable for previous work experience

\section{$\checkmark$ Household location:}

- Degree of urbanization: ${ }^{62}$ densely populated, intermediate area, sparsely populated

\footnotetext{
58 The equivalized household income takes into account an equivalence factor to weight the number of household members used in the denominator when calculating household income per capita. The first adult aged 18 or over has a weight of 1.0 , children under 14 have a weight of 0.3 , and other individuals 14 and older have a weight of 0.5 . The sum of the weights of all household members is equal to the equivalent household size.

${ }^{59}$ Note that income reported in EU-SILC surveys is for the year preceding the survey year.

${ }^{60}$ Total household gross income is defined as the sum of: (at the individual level) gross employee cash or near-cash income; company car, gross cash benefits or losses from self-employment (including royalties); unemployment benefits; old-age benefits; survivor benefits; sickness benefits; disability benefits; education allowances; and (at the household level) income from rental of property or land; family/children related allowances; social exclusion not elsewhere classified; housing allowances; regular inter-household cash transfers received; interests, dividends, profit from capital investments in unincorporated business; pensions from individual private plans; and income received by people under 16. Total household net income, in turn, was calculated by subtracting from total household gross income regular taxes on wealth, taxes on income and social insurance contributions, and regular inter-household case transfers paid.

${ }^{61}$ Social benefits are aggregated in eight branches using the European System of integrated Social PROtection Statistics (ESSPROS) definitions. For more information, see Eurostat (2011).
} 
- Regional breakdown: northern and eastern, southwestern and southcentral

Group labeling. The resulting groups are then labeled according to the greatest proportional characteristics within groups that also aid in distinguishing among groups. Granted, a large number of characteristics describe these groups, and only a few are taken into account for the purpose of labeling. In part, some of these characteristics may exhibit a large degree of heterogeneity and may thus not be relevant for defining a group. Additionally, some characteristics may be more relevant for the purposes of policy design than others. In short, though the labeling of groups can be considered more an art than a science, when taken together with detailed descriptions of a group's most prominent characteristics, labeling can serve as an important starting point in the design and prioritization of activation policies.

The analysis relies on cross-sectional as well as panel data from the European Union Statistics of Income and Living Conditions (EU-SILC) surveys for 2008-2011, which combine individual-level information with household characteristics. The first part of the note presents a cross-sectional analysis for the years 2008, 2009, 2010 and 2011. In particular, the latent class analysis on 2008 data shows the main characteristics of the out-of-work before the global economic crisis hit Greece, and thus highlight what could be considered more structural issues of the country's labor market. The 2011 latent class analysis will contrast this initial assessment with more recent developments. The second part of the note exploits longitudinal data between 2008 and $2010^{63}$ to trace the prior labor market status of individuals observed last in 2010 in various classes, and will shed light on the relative persistence in the out-of-work status among different classes of individuals. The set of variables chosen for the cross-section and the longitudinal analysis are slightly different, due to minor differences in the set of variables recorded in each of the two types of datasets.

62 According to EU-SILC guidelines, dense areas have more than 500 inhabitants per square kilometer, where the total population for the set is at least 50,000 inhabitants. Intermediate areas have more than 100 inhabitants per square kilometer, and either a total population for the set of at least 50,000 inhabitants or a location adjacent to a dense area. The remaining areas are categorized as sparsely populated.

63 The EU-SILC longitudinal survey consists of a four-year rotating panel. In each year, approximately three-quarters of individuals present in the previous year are retained. The samples used in the latent class analysis include about 3,000 observations for each year in the cross-sectional analysis and 600 observations in the longitudinal analysis. The population is weighted with individual weights. 


\section{Main Findings}

\section{Out-of-Work Population: Group Profiles from Cross-Sectional Analysis}

The latent class analysis supports the categorization of the out of work into seven major groups, some of which have remained stable over time. Figure 5.4 shows the shares of each of these seven classes in the year 2011 while Table 5.2 presents their most salient characteristics.

\section{Figure 5.4 Classes of Out-of-Work Individuals in Greece (2011)}

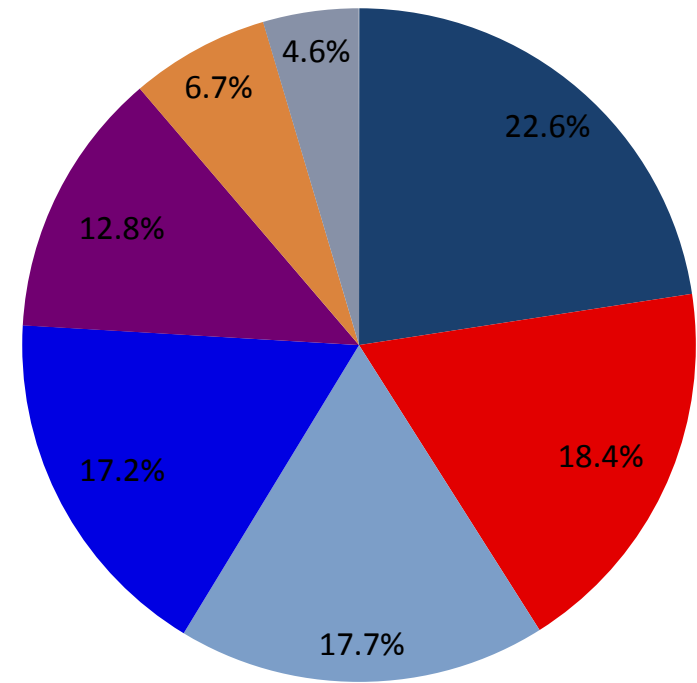

$$
\begin{aligned}
& \text { - Stay-at-home mothers } \\
& \text { — Highly educated single } \\
& \text { NEETs } \\
& \text { Middle-aged unemployed } \\
& \text { heads of households } \\
& \text { - Retirees' inactive wives } \\
& \text { - Low-educated retirees } \\
& \text { Highly educated early } \\
& \text { retirees } \\
& \text { Low-educated mostly } \\
& \text { rural disabled }
\end{aligned}
$$

Source: World Bank staff analysis based on EU-SILC

The seven main groups emerging from the LCA analysis in 2011 can be characterized as follows (see Annex 2: Latent class analysis profiles-Cross-sectional model for more detail, including the full list of inactive covariates):

$\checkmark \quad$ Cluster 1: Stay-at-home mothers. This group, representing 23 percent of the outof-work sample in 2011, consists largely of out-of-the-labor-force women (77 percent) in their prime-age (35 to 54 years). Two-thirds of this group have children (almost one-third have children under 6 years of age), more than half have an upper secondary education, and only 56 percent claim to have worked before. Another robust characteristic of this group is a working partner who earns, on average, a medium level of annual income (EUR 17,000). This group has the lowest share of the "no working adult in the household" indicator (11 percent). However, as these women's households tend to be relatively large (3.5 members on average), it is not surprising that in terms of welfare, more than 50 percent of the class members live in the bottom 40 percent of the income distribution. Overall, although some individuals in this group receive family/child benefits, this group can least rely on public transfers, owing to the fact that their partners are employed. 
Table 5.2 Summary Characteristics of Latent Classes of Out-of-Work Population in Greece (2011)

\section{1: Stay-at-home mothers (23\%)}

- $76 \%$ are inactive

- $86 \%$ have a working partner

- $\quad 99 \%$ are married

- $\quad$ Mid-skilled: $48 \%$ have completed upper secondary while only $21 \%$ have completed tertiary or post-secondary education

- $11 \%$ have no working adult in household

- $\quad 63 \%$ are $35-54$ years old

- $\quad$ They are all female

- $56 \%$ have worked before, 11 years of experience on average

- $\quad 67 \%$ live with children, $29 \%$ with children under 6

- Moderate poverty risk: $28 \%$ in poorest quintile

\section{3: Middle-aged unemployed heads of} households (18\%)

- $\quad 29 \%$ are unemployed, $54 \%$ are long-term unemployed,

- $\quad 67 \%$ don't have a partner or partner not working

- $\quad 56 \%$ have no working adult in household

- $\quad 69 \%$ are married

- Mid-skilled: 38\% have upper secondary education; $25 \%$ tertiary or post-secondary

- $\quad 71 \%$ are $35-54$ years old

- $61 \%$ are male

- $93 \%$ have worked before, 17 years of experience on average

- $\quad 71 \%$ live in urban areas

- Very high poverty risk: $44 \%$ in poorest quintile

- $19 \%$ receive unemployment benefits

\section{5: Low-educated retirees (13\%)}

- $\quad 90 \%$ are retired

- $72 \%$ live in households without a working partner

- $\quad 90 \%$ are married

- Low-skilled: $52 \%$ have below upper secondary

- $\quad 58 \%$ have no working adult in household

- $\quad 59 \%$ are $60-64$ years old

- $86 \%$ are male

- $97 \%$ have worked before, 34 years of experience on average

- $62 \%$ live in urban areas

- Low poverty risk, $19 \%$ in poorest quintile

- $71 \%$ receive old-age benefits

\section{2: Highly educated single NEETs (18\%)}

- $\quad 43 \%$ are long-term unemployed, unemployed (29\%)

- $\quad 94 \%$ have never married (94\%)

- High-skilled: 55\% have completed tertiary or post-secondary

- $\quad 40 \%$ have no working adult in household

- $60 \%$ are 25-34 years old

- $59 \%$ are male

- $53 \%$ have worked before, 5 years of experience on average

- $\quad 63 \%$ live in urban areas

- Moderate poverty risk: $29 \%$ in poorest quintile

\section{4: Retirees' inactive wives (17\%)}

- $\quad 69 \%$ are inactive $(69 \%)$

- $76 \%$ are married (76\%), 62\% have a retired partner

- Low-skilled: $64 \%$ have below upper secondary education

- $68 \%$ have no working adult in household

- $71 \%$ are $55-64$ years old (71\%)

- $100 \%$ are female

- $55 \%$ have worked before, 21 years of experience on average

- $\quad 58 \%$ live in urban areas

- Moderate poverty risk: $27 \%$ in poorest quintile

\section{6: Highly educated early retirees (7\%)}

- $\quad 99 \%$ are retired

- $\quad 61 \%$ live in a household without a working partner

- $\quad 85 \%$ are married

- High-skilled: $76 \%$ have tertiary or postsecondary education

- $\quad 44 \%$ have no working adult in household

- $82.5 \%$ are $45-59$ years old

- $61 \%$ are female

- $98 \%$ have worked before, 29 years of experience on average

- $71 \%$ live in urban areas

- Very low poverty risk: $4 \%$ in poorest quintile

- $79 \%$ receive old-age benefits 


\section{7: Low-educated mostly rural disabled (5\%)}

- $\quad 44 \%$ are disabled, $25 \%$ are retired

- $67 \%$ have strongly-limited capacity to work

- $\quad 86 \%$ live in a household without a working partner

- $\quad 61 \%$ have never married

- Low-skilled: 68\% have below upper secondary

- $64 \%$ have no working adult in household

- $\quad 35-59$ years old (72\%)

- $\quad$ Male (63\%)

- Worked before (59\%), 20 years of experience on average

- $\quad$ Rural (58\%)

- High poverty risk: $34 \%$ in poorest quintile

- $51 \%$ receive disability benefits, $26 \%$ family/child benefits

Source: World Bank staff analysis based on EU-SILC

Note: Percentages in parentheses following the group names refer to the share of the total out-of-work population. "Years of work experience" refers only to individuals who have worked before. "Dependent children" include children under 18 and household members aged 18 to 24 who are economically inactive and living with at least one parent. "Working adult" refers to adults aged 25 and over. For this report's purposes, we define the at-risk-of-poverty rate as the relative risk of being in the first quintile of the income distribution. The reference period for income reported in EU-SILC surveys is the year preceding the survey year.

$\checkmark \quad$ Cluster 2: Highly educated single NEETs. This group represented 18 percent of the out-of-work population in 2011. Members of this class are largely under the age of 35 and resemble other unemployed youth who have been particularly hit by the economic crisis across the EU, as 40 percent of them are long-term unemployed and another 30 percent short-term unemployed. The protracted employment crisis is also evident through a relatively high (and rising) average age. In 2010 less than a third of this group was below 25 years old, while more than 60 percent was between 25 and 34 years of age. In 40 percent of these group's households, there is no working adult. Moreover, this group is relatively highly educated; more than half have either higher education or a post-secondary degree. Another defining characteristic of the highly educated single NEETs is that they have never been married and live in large households without children (probably their household of origin). Overall this group has a moderate poverty risk; 27 percent of them are in the poorest income quintile.

$\checkmark \quad$ Cluster 3: Middle-aged unemployed heads of households. This group made up 18 percent of the out-of-work in 2011. This group comprises individuals who are almost entirely middle-aged (35-59), majority male (61 percent), unemployed (more than half long-term, that is, unemployed for more than 12 months). Together with the highly educated single NEETs they constitute over 80 percent of the unemployed in the country. ${ }^{64}$ Unlike their younger counterparts, however, this group comprises individuals who have left their birth households, made the

\footnotetext{
${ }^{64}$ As shown in Table 5.1, there were 1.023 million unemployed individuals in our sample of the working-age population in 2011. As many as 98 percent of the middle-aged unemployed heads of households and 71 percent of the highly educated single NEETs are reported to be unemployed; together, these two clusters are a concentration of 80 percent of the unemployed.
} 
transition to marriage and largely have children. They are also fairly heterogeneous in terms of educational attainment: 36 percent have not completed upper secondary and 25 percent have completed post-secondary or tertiary education. And while half of the NEETs never worked before, this group is composed almost entirely of joblosers, with 17 years of experience on average. Their joblessness and family status explain why they are by far the worst-off in the whole sample of the out-of-work in terms of welfare (44 percent belonged to the bottom income quintile in 2011). In this context, it is noteworthy that only one-fifth of them receive unemployment benefits and only a small fraction receive the child allowance. In 56 percent of these group's households, there is no working adult, the second-highest share among the non-retiree groups.

$\checkmark$ Cluster 4: Retirees' inactive wives. Representing 17 percent of the out-of-work population of 2011, this group consists of low-educated, inactive women, mostly close to or at retirement age, who live in small households and are married to retired men. Just over half of this group reports having worked in the past, but only 30 percent describe themselves as retired. Over all, this group has a moderate poverty risk; 27 percent of them live in the poorest quintile.

$\checkmark$ Cluster 5: Low-educated retirees. The fifth-largest group can be considered the male counterpart of the previous one, sharing similar household characteristics. They have low educational attainment; more than half did not finish upper secondary school. Interestingly, a third of the members in this group are less than 60 years old, but almost all of them (84 percent) receive either a permanent (pension, disability pension) or unemployment-related income replacement benefit. In fact, this group figures among those least likely to be in poverty or near poverty, with only 19 percent in the bottom quintile. Their retirement status and previous work experience make them likely to be the main owners of pension rights for their households. Thirteen percent of them claim to be unable to work due to illness or disability, a rather high share compared to most groups.

$\checkmark \quad$ Cluster 6: Highly educated early retirees. This group represented 7 percent of the out-of-work population in 2011. Its members are characterized by a relatively low age for people in retirement ( 29 percent between 45 and 54 , and another 53 percent between 55 and 59), all of them self-defining as retired, and about 85 percent of them receiving either old-age or disability benefits. They are by far the most highly educated (69 percent have tertiary education), urbanized (60 percent live in the capital of Athens), and highest-income group, with 54 percent in the top income quintile and only 4 percent in the bottom.

$\checkmark \quad$ Cluster 7: Low-educated, mostly rural disabled. This group, representing from 4 to 5 percent of the out-of-work population, reports its labor market status as disabled (44 percent) or retired (25 percent), with very low education levels. A majority (67 percent) also report strongly limited to work ability due to a health condition. In 65 percent of this group's households, there is no working adult, the highest share among the non-retiree groups. Most of these individuals receive at least one social benefit: the most common are disability benefits (51 percent) and family/child benefits (26 percent). The members of this group are also characterized by the absence of a partner and live in households without a working adult. They are the group next at risk of falling into poverty after the unemployed heads of households, with 34 percent belonging to the poorest income quintile. A majority live in rural areas. 
The following two tables present the main characteristics of each group in 2011. Annex 2 provides tables with the full characteristics of the identified groups for the years 2007, 2009, and 2011

Table 5.3 Latent Classes of Out-of-Work Population in Greece-Indicators (2011)

\begin{tabular}{|c|c|c|c|c|c|c|c|c|}
\hline & $\begin{array}{l}\text { All Out-of- } \\
\text { Work }\end{array}$ & $\begin{array}{c}\text { 1. Stay-at- } \\
\text { home mothers }\end{array}$ & $\begin{array}{l}\text { 2. Highly } \\
\text { educated single } \\
\text { NEETs }\end{array}$ & $\begin{array}{l}\text { 3. Middle-aged } \\
\text { unemployed } \\
\text { heads of } \\
\text { households }\end{array}$ & $\begin{array}{l}\text { 4. Retirees' } \\
\text { inactive wives }\end{array}$ & $\begin{array}{l}\text { 5. Low-educated } \\
\text { retirees }\end{array}$ & $\begin{array}{l}\text { 6. Highly } \\
\text { educated early } \\
\text { retirees }\end{array}$ & $\begin{array}{l}\text { 7. Low-educated } \\
\text { mostly rural } \\
\text { disabled }\end{array}$ \\
\hline Cluster size & $100 \%$ & $22.6 \%$ & $18.4 \%$ & $17.7 \%$ & $17.2 \%$ & $12.8 \%$ & $6.7 \%$ & $4.6 \%$ \\
\hline Population & $2,694,563$ & 608,102 & 496,828 & 476,621 & 464,496 & 345,139 & 179,709 & 123,668 \\
\hline \multicolumn{9}{|c|}{ INDICATORS } \\
\hline \multicolumn{9}{|c|}{ Labor market attachment } \\
\hline Unemployed & $16 \%$ & $11 \%$ & $29 \%$ & $45 \%$ & $0 \%$ & $3 \%$ & $0 \%$ & $2 \%$ \\
\hline Long-term unemployed & $22 \%$ & $13 \%$ & $43 \%$ & $54 \%$ & $0 \%$ & $4 \%$ & $0 \%$ & $21 \%$ \\
\hline Retired & $25 \%$ & $0 \%$ & $2 \%$ & $0 \%$ & $30 \%$ & $90 \%$ & $99 \%$ & $25 \%$ \\
\hline Disabled & $2 \%$ & $0 \%$ & $0 \%$ & $0 \%$ & $0 \%$ & $2 \%$ & $0 \%$ & $44 \%$ \\
\hline Domestic tasks/other & $35 \%$ & $76 \%$ & $27 \%$ & $1 \%$ & $69 \%$ & $2 \%$ & $0 \%$ & $8 \%$ \\
\hline \multicolumn{9}{|l|}{ Education } \\
\hline Primary & $36 \%$ & $32 \%$ & $5 \%$ & $37 \%$ & $68 \%$ & $52 \%$ & $1 \%$ & $74 \%$ \\
\hline Secondary & $44 \%$ & $56 \%$ & $54 \%$ & $48 \%$ & $32 \%$ & $37 \%$ & $30 \%$ & $26 \%$ \\
\hline Tertiary & $19 \%$ & $13 \%$ & $41 \%$ & $16 \%$ & $1 \%$ & $11 \%$ & $69 \%$ & $0 \%$ \\
\hline \multicolumn{9}{|l|}{ Working partner } \\
\hline Yes & $32 \%$ & $86 \%$ & $0 \%$ & $33 \%$ & $5 \%$ & $19 \%$ & $39 \%$ & $15 \%$ \\
\hline No & $34 \%$ & $14 \%$ & $0 \%$ & $35 \%$ & $71 \%$ & $71 \%$ & $46 \%$ & $7 \%$ \\
\hline NA & $34 \%$ & $0 \%$ & $100 \%$ & $32 \%$ & $25 \%$ & $10 \%$ & $15 \%$ & $78 \%$ \\
\hline \multicolumn{9}{|c|}{ Self-assessed physical incapacity } \\
\hline None/limited & $92 \%$ & $99 \%$ & $99 \%$ & $97 \%$ & $90 \%$ & $87 \%$ & $99 \%$ & $33 \%$ \\
\hline Strongly limited & $8 \%$ & $1 \%$ & $1 \%$ & $3 \%$ & $10 \%$ & $13 \%$ & $1 \%$ & $67 \%$ \\
\hline
\end{tabular}


Table 5.4 Latent Classes of Out-of-Work Population in Greece-Covariates (2011)

\begin{tabular}{|c|c|c|c|c|c|c|c|c|}
\hline & $\begin{array}{l}\text { All Out-of- } \\
\text { Work }\end{array}$ & $\begin{array}{l}\text { 1. Stay-at-home } \\
\text { mothers }\end{array}$ & $\begin{array}{l}\text { 2. Highly educated } \\
\text { single NEETs }\end{array}$ & $\begin{array}{l}\text { 3. Middle-aged } \\
\text { unemployed heads } \\
\text { of households }\end{array}$ & $\begin{array}{l}\text { 4. Retirees' } \\
\text { inactive wives }\end{array}$ & $\begin{array}{l}\text { 5. Low- } \\
\text { educated } \\
\text { retirees }\end{array}$ & $\begin{array}{l}\text { 6. Highly } \\
\text { educated early } \\
\text { retirees }\end{array}$ & $\begin{array}{l}\text { 7. Low-educated } \\
\text { mostly rural } \\
\text { disabled }\end{array}$ \\
\hline Cluster size & $100 \%$ & $22.6 \%$ & $18.4 \%$ & $17.7 \%$ & $17.2 \%$ & $12.8 \%$ & $6.7 \%$ & $4.6 \%$ \\
\hline Population & $2,694,563$ & 608,102 & 496,828 & 476,621 & 464,496 & 345,139 & 179,709 & 123,668 \\
\hline \multicolumn{9}{|c|}{ COVARIATES } \\
\hline \multicolumn{9}{|l|}{ Age group } \\
\hline $16-24$ years & $7 \%$ & $3 \%$ & $32 \%$ & $4 \%$ & $0 \%$ & $0 \%$ & $0 \%$ & $1 \%$ \\
\hline $25-34$ years & $20 \%$ & $25 \%$ & $60 \%$ & $15 \%$ & $0 \%$ & $0 \%$ & $0 \%$ & $19 \%$ \\
\hline $35-59$ years & $55 \%$ & $72 \%$ & $8 \%$ & $81 \%$ & $57 \%$ & $31 \%$ & $86 \%$ & $72 \%$ \\
\hline 60-64 years & $18 \%$ & $1 \%$ & $0 \%$ & $0 \%$ & $43 \%$ & $69 \%$ & $14 \%$ & $7 \%$ \\
\hline \multicolumn{9}{|l|}{ Gender } \\
\hline Female & $62 \%$ & $100 \%$ & $41 \%$ & $39 \%$ & $100 \%$ & $14 \%$ & $61 \%$ & $37 \%$ \\
\hline Male & $38 \%$ & $0 \%$ & $59 \%$ & $61 \%$ & $0 \%$ & $86 \%$ & $39 \%$ & $63 \%$ \\
\hline \multicolumn{9}{|c|}{ Urbanization degree } \\
\hline Densely populated & $46 \%$ & $35 \%$ & $49 \%$ & $55 \%$ & $48 \%$ & $51 \%$ & $37 \%$ & $35 \%$ \\
\hline Intermediate areas & $15 \%$ & $18 \%$ & $14 \%$ & $16 \%$ & $10 \%$ & $11 \%$ & $34 \%$ & $7 \%$ \\
\hline Sparsely populated & $39 \%$ & $47 \%$ & $37 \%$ & $29 \%$ & $42 \%$ & $38 \%$ & $29 \%$ & $58 \%$ \\
\hline \multicolumn{9}{|c|}{ At least one working adult in household } \\
\hline No & $45 \%$ & $12 \%$ & $40 \%$ & $56 \%$ & $68 \%$ & $58 \%$ & $45 \%$ & $65 \%$ \\
\hline Yes & $55 \%$ & $88 \%$ & $60 \%$ & $44 \%$ & $32 \%$ & $42 \%$ & $55 \%$ & $35 \%$ \\
\hline
\end{tabular}


Although a small number of the identified classes of out-of-work have been quite stable over the last few years, most of the identified classes experienced changes in composition and also in the share they represent of the total out-of-work. Table 5.5 shows the evolution of the groups' classifications from 2007 to 2011 as a share of total outof-work population, while Figure 5.5 shows the absolute numbers. From the graph, the first important observation is that the size of the out-of-work population has increased from 2.142 million to 2.695 million individuals, almost a 27 percent increase. Some clusters have changed across time; for example, clusters identified in 2011 that were present in previous years underwent changes in relative size and also in composition. The fact that the composition of the groups change over time is particularly important to keep in mind when interpreting changes in group size. For instance, significant increases (decreases) in group size are sometimes due to reassignments of individuals across groups, resulting in changes in group composition. Thus, although some groups may retain similar names across years due to their most salient characteristics, they may nonetheless vary in composition across years. The evolution in terms of group size and group composition over the 2007-2011 period can be summarized as follows:

$\checkmark$ The major difference across time is the division of early retirees/poor unemployed cluster into two parts in 2011. Up until 2009 this group represented almost 13 percent of the out-of-work population. In 2011, this group splits into a smaller group of highly educated early retirees and a new, relatively large group comprising middle-aged unemployed heads of households. This new group captures the increase in unemployment among prime-aged individuals following the crisis.

$\checkmark$ The highly educated single NEETs cluster share of the total out-of-work population remained stable at around 18 percent during the 2007-2010 period. Nevertheless, the group had absolute growth of 25 percent in the same period (the population in this group was around 394,000 in 2007 and grew to 497,000 in 2011). The composition of the group also experienced some changes from 2007 to 2010. In 2011 this cluster had more males than in previous years, increasing from 46 to 59 percent. Also, the share of people with tertiary or postsecondary education increased to 57 percent in 2011, up from 33 percent in 2007.

$\checkmark \quad$ There has been a slight decrease in the absolute size of the group of stay-athome mothers. It is notable that this group represented 30 percent of the out-ofwork in 2007, but due to the growth in other groups as a direct result of the crisis, its relative size shrank to 23 percent after the crisis. Interestingly, the group also decreased in absolute size, possibly because of changes in incentives for labor supply due to the loss of income of the partner, along with a general trend toward higher female labor force participation. Indeed, while in 200788 percent declared themselves to be inactive, in 2010 only 76 percent did so. Conversely, the group of stay-at-home mothers that claimed to be unemployed grew 11 percent. This group also became slightly more educated. In 2010, 17 percent had only a primary education (compared to 29 percent in 2008), and 48 percent had upper secondary (compared to 39 percent).

$\checkmark$ The retirees' inactive wives share of the out-of-work population oscillated between 17 and 22 percent from 2007 to 2009. Although the share of this cluster in 2011 with respect to that of 2007 did not vary significantly (17 percent), in absolute numbers this group grew almost 29 percent, an additional 103,000 people.

Portraits of Labor Market Exclusion | 141 
In terms of composition there were also considerable changes. First, the percentage of individuals that were classified as retired increased from 3 percent to 30 percent between 2007 and 2011. The share of inactive decreased from 96 to 69 percent during the same period. In addition, the members of this group became more likely to have worked before -43 to 55 percent —and the share of them that received oldage benefits increased from 4 to 21 percent.

$\checkmark$ The low-educated retirees and low-educated, mostly rural disabled groups remained stable in terms of absolute size. Although the relative size of both groups fell over time, the absolute numbers varied very little. The share of the outof-work population for low-educated retirees decreased from 16 to 13 percent while growing 14 percent in absolute numbers. In terms of composition, the share of individuals with secondary education increased 13 percent, and were more likely to be male-86 percent in 2011 compared to 72 percent in 2007. On the other hand, the low-educated mostly rural disabled group reduced its share from 6 to 4 percent, which in absolute numbers represented a 6 percent decrease. The share of individuals in the low-educated mostly rural disabled who were between 35 to 54 years old increased from 63 to 72 percent, and 65 percent said there was no working adult in the household in 2011, compared with 46 percent in 2007. A larger share of this group have never married-the percentage increased from 44 to 61and is more likely to be living in urban areas than before.

Table 5.5 Classes of Out-of-Work Population in Greece, 2007, 2009 and 2011, as Percent of Total Out-of-Work Population

\begin{tabular}{|l|c|c|c|}
\hline Name of Cluster & $\mathbf{2 0 0 7}$ & $\mathbf{2 0 0 9}$ & $\mathbf{2 0 1 1}$ \\
\hline Stay-at-home mothers & $31 \%$ & $28 \%$ & $23 \%$ \\
\hline Highly educated single NEETs & $18 \%$ & $19 \%$ & $18 \%$ \\
\hline Retirees' inactive wives & $17 \%$ & $22 \%$ & $17 \%$ \\
\hline Low-educated retirees & $16 \%$ & $12 \%$ & $13 \%$ \\
\hline Low-educated mostly rural disabled & $6 \%$ & $6 \%$ & $5 \%$ \\
\hline Early retirees/Poor unemployed (2007 and 2009) & $13 \%$ & $13 \%$ & - \\
\hline Highly educated early retirees (only 2011) & - & - & $7 \%$ \\
\hline Middle-aged unemployed heads of households (only 2011) & - & - & $18 \%$ \\
\hline Source: World Bank staff analysis based on EU-SILC & & & \\
\hline
\end{tabular}


Figure 5.5 Classes of Out-of-Work Population in Greece, 2007, 2009 and 2011 (Thousands of Individuals)

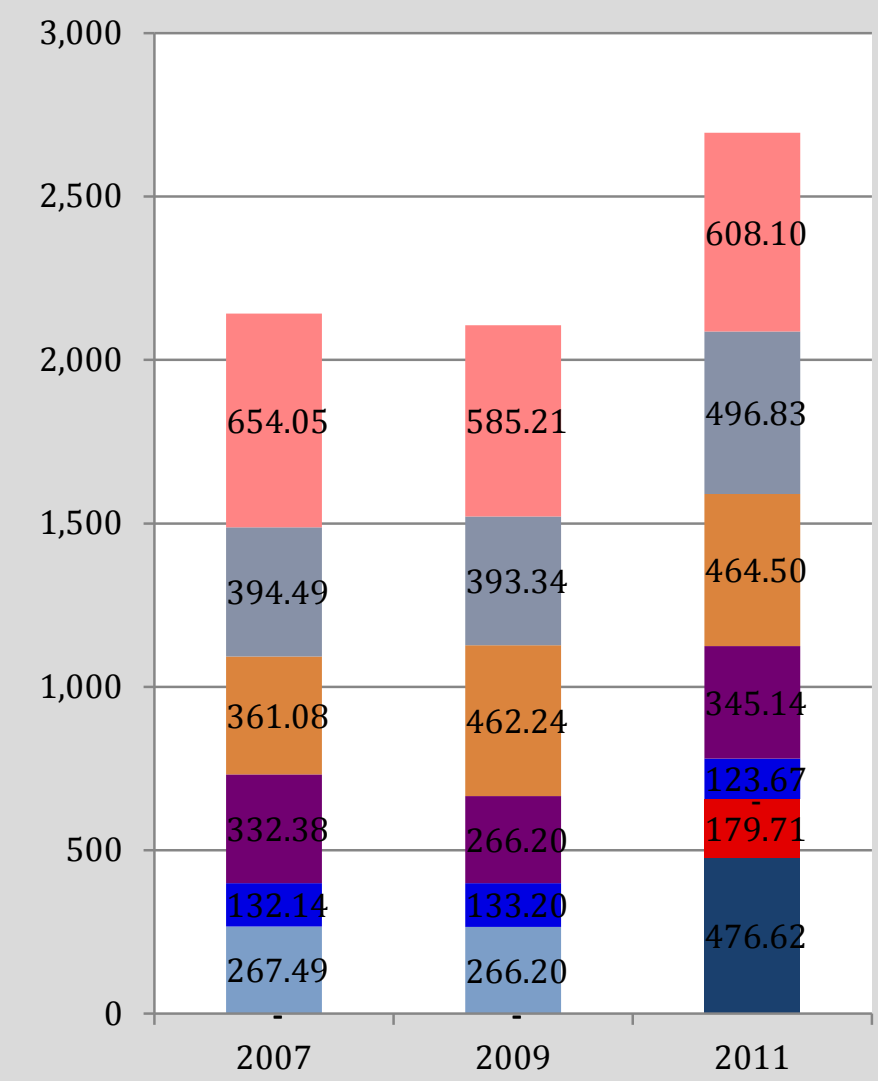

Stay-at-home mothers

- Highly educated single NEETs

Retirees' inactive wives

— Low-educated retirees

- Low-educated mostly rural disabled

Early retirees/Poor unemployed (2007 and 2009)

- Highly educated early retirees (only 2011)

- Middle-aged unemployed heads of households (only 2011)

Source: World Bank staff analysis based on EU-SILC 
The clusters identified in the out-of-work population for the period from 2007 to 2011 reflect both structural and cyclical aspects of the labor market. This section identifies some of the key structural aspects of the Greek labor market and uses crosssectional and longitudinal analysis of clusters of the out-of-work population to further examine the effects of the crisis.

Even in time of protracted economic crisis, only just over one third of the out-of-work population reports being actively searching for work. Out of the seven classes identified in 2011, the first (largest) class, together with the last four (smallest) classes, comprise individuals with either low or no labor force participation, and with limited incentives to join the labor force. Limited incentives to work are found especially among the four smallest classes, all of which are made up of retired individuals and their wives or individuals on disability. The first (largest) group is composed of stay-at-home mothers who could potentially be pushed into the labor market in the case of loss of income from their partners, as well as if barriers, such as lack of child care, were removed. The two middle-sized groups of largely unemployed individuals (highly educated single NEETs and middle-aged unemployed heads of households) are only just above a third of the total unemployed (36 percent).

Figure 5.6 Female Labor Force Participation Rate for 15-64-Year-Olds (2013)

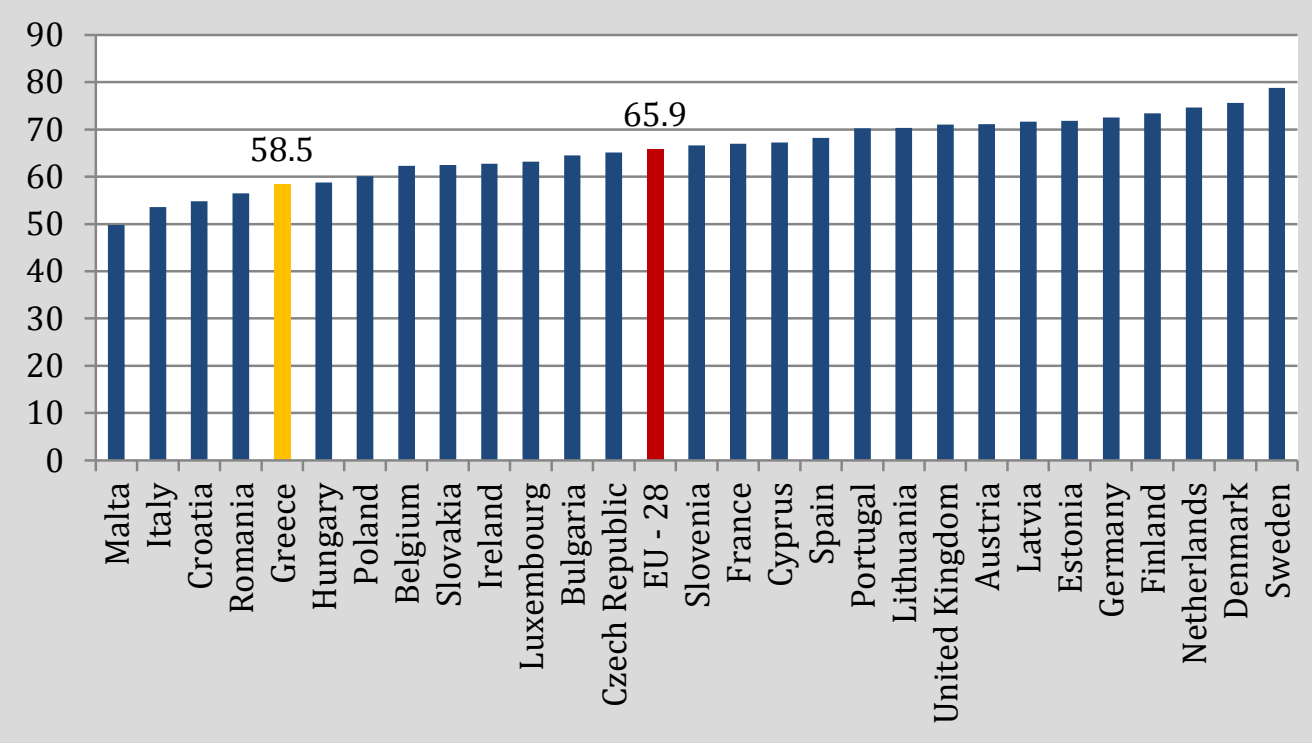

Source: Eurostat, EU-LFS

The low activity rates of some latent classes are associated with structural aspects of the labor market that preceded the crisis. The first issue relates to very limited female labor force participation, highlighted by the fact that the top group of the out-of-work population is made up of largely inactive women. In fact, the labor force participation rate 
for women of working age in Greece is 7 percentage points below that of the European Union average (see Figure 5.7). The stay-at-home mothers depend on their partner's income, and nearly half of them have never worked before despite being of prime working age. As noted below, however, their absolute number fell after the crisis, consistent with the fact that the female labor force participation rate has been rising in recent years.

The structure of social protection benefits, particularly pensions, is directly linked with the very high levels of inactivity in the working-age population, especially among those aged 55 to 64. Low-educated retirees, highly educated early retirees, retirees' inactive wives, and the low-educated mostly rural disabled make up 42 percent of the out-of-work population. Interestingly, their absolute number has been increasing since the crisis, probably as the low labor demand drove down incentives for remaining in the labor force and increased pressure to enter the pension system at an early age. As a relative number, these groups of retired individuals shrank compared to earlier years because of the large inflows of job losers in the out-of-work population. It is noteworthy that retirees and their wives are the groups that are best protected from the risk of poverty in the out-of-work population. In fact, the labor force participation rate for the population aged 55 to 64 , at 42.5 percent in 2013, is almost 12 percentage points lower than the average for the European Union (Figure 5.7). In contrast, the low-educated mostly rural disabled are at the highest risk of poverty, but make up only 5 percent of the out-of-work, versus 37 percent in the case of (early) retirees and their inactive wives.

Figure 5.7 Labor Force Participation Rate (ages 55-64), 2013

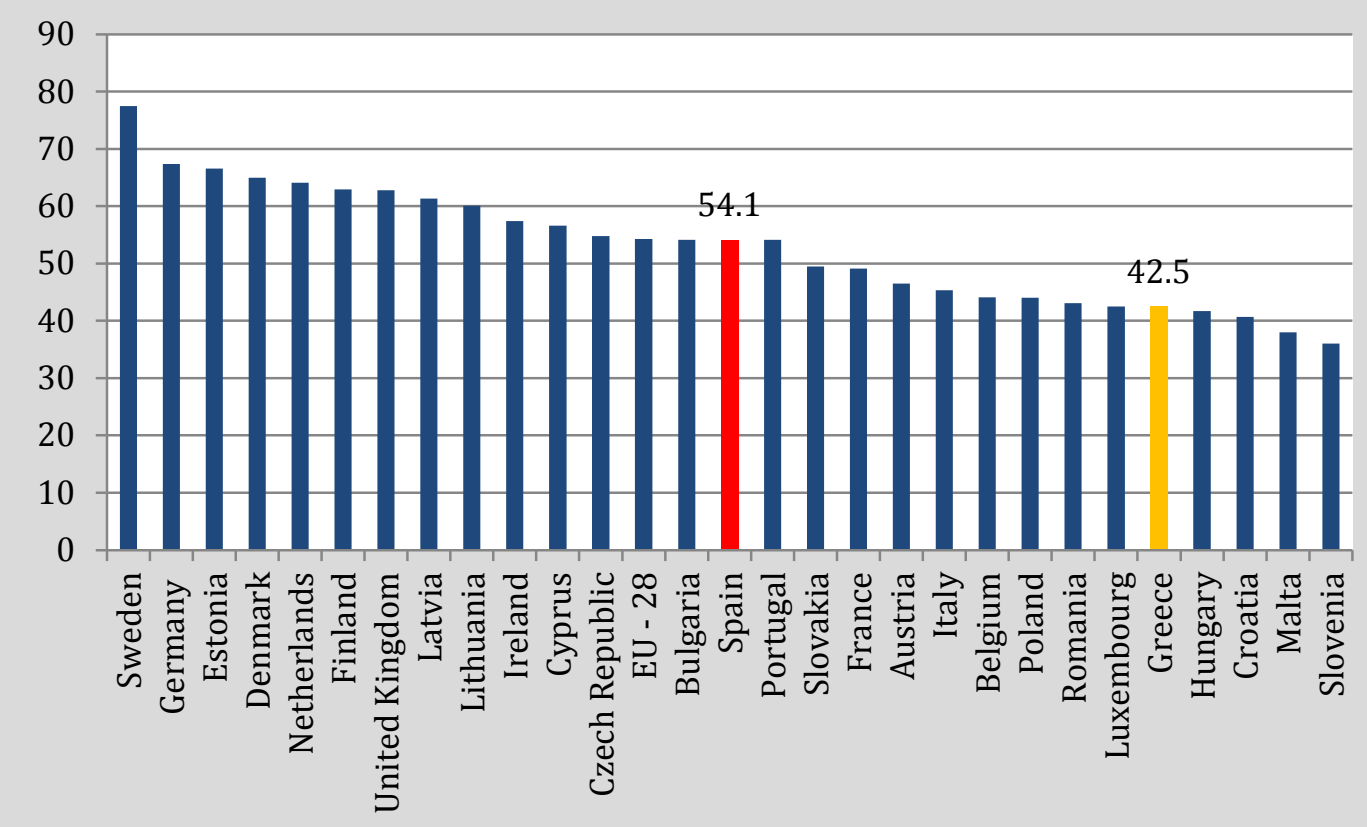

Source: Eurostat, EU-LFS

Unemployment has changed in nature and size as a result of the crisis, with middleaged job losers acquiring new importance. Almost all of the groups of out-of-work 
individuals remained largely stable over time, though the crisis saw a rise in unemployed, middle-aged poor. The population comprised six similar groups in 2007 and 2009, expanding to seven well-defined groups in 2011, due to the increase in the size and the nature of joblessness. The crisis also reduced the affordability of inactivity among middleclass inactive mothers, and saw a significant reduction in the share of stay-at-home mothers.

Middle-aged unemployed heads of households appear to be at highest risk of falling into poverty. The significant share of inactive in this group that receive retirement benefits at a relatively young age appear to be at less risk of poverty than those who are out of work but staying in the labor market. In the middle lie stay-at-home mothers and highly educated single NEETs, who, although not as protected from poverty as retirees and their wives, are at less relative risk of poverty.

Household composition patterns appear to be endogenous products of the protracted employment crisis. Across groups, with the exception of stay-at-home mothers and middleaged unemployed heads of households, households mainly comprise at least two adults and no children, even in the case of highly educated single NEETs. Of these, about 32 percent still live with their parents. This suggests that out-of-work individuals live with their families, which play the role of a safety net. In the case of stay-at-home mothers, although the great majority (67 percent) live in households with children, an even larger proportion (86 percent) have a working partner. This is in contrast with middle-aged unemployed heads of households, for whom living with their families largely implies having dependents (only one third have a working spouse and a majority live in households with children) and thus a higher risk of falling into poverty.

The most discernible change between 2007 and 2011 is the emergence of the middleaged unemployed heads of households and the large growth of highly educated single NEETS (Figure 5.5). Models for 2007 and 2009 indicated the existence of six latent classes, while in 2011 the most fitting model supported seven classes. The main difference resulted from the clear growth in size of a new class of middle-aged unemployed heads of households, who represent the main departure from existing structural issues in the labor marketwhich especially penalized youth and women. The size of the highly educated single NEETs group also increased substantially during the period. 
The analysis of longitudinal data for the period 2008-2010 can shed further light on the dynamics within clusters in the labor market. The latent class analysis on the out-ofwork in the 2010 longitudinal dataset (which comprises 600 observations, a subsample of the total) yielded similar results in terms of latent classes, though in light of the reduced sample size, some categories of out-of-work were combined into one class: early retirees were put together with retirees, and the unemployed (non-single NEET) together with the disabled. Given the qualitative similarity between the size and characteristics of these five clusters compared to those found in the cross-sectional analysis, the findings from the panel data are here used to understand further the dynamics of the previously described sample. Overall the five classes include, in order of magnitude:

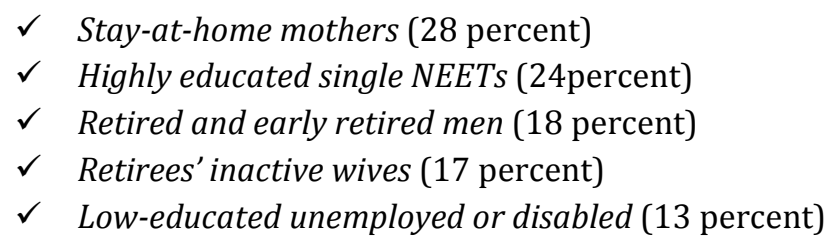

Annex 3 shows the statistical description of the latent classes in full while Table 5.6 below summarizes the main key characteristics of the five classes.

Table 5.6 . Longitudinal Analysis: Summary Characteristics of Latent Classes of the Out-of-Work Population in Greece (2010)

1: Stay-at-home mothers (28\%)

- $86 \%$ are inactive

- $\quad 94 \%$ have a working partner

- Low-to-mid-skilled: $44 \%$ have primary education; $44 \%$ have upper secondary

- $\quad 88 \%$ are 25-54 years old

- All are female

- 10 years of work experience on average

- $63 \%$ live in households with children; $29 \%$ with children under 6

- $64 \%$ live in rural areas

- High poverty risk: $36 \%$ in poorest quintile 3: Retired and early retired men (18\%)

- $76 \%$ are retired; $20 \%$ are unemployed

- $54 \%$ have a partner that is not working

- $\quad 90 \%$ are married

- Low-to-mid-skilled: 52\% have below upper secondary education; $23 \%$ have tertiary

- 47\% are 45-59 years old; $17 \%$ are $60-64$ years old

- $73 \%$ are male

- 29 years of work experience on average

- $53 \%$ live in urban

- Low poverty risk: $22 \%$ in poorest quintile

- $59 \%$ receive old-age benefits; $42 \%$ social assistance benefits

\section{2: Highly educated single NEETs (24\%)}

- $64 \%$ are unemployed ; $36 \%$ inactive

- $\quad 99 \%$ do not have a partner

- High-skilled: 25\% have completed tertiary education; $44 \%$ have upper secondary or post-secondary

- $\quad 89 \%$ are $20-34$ years old

- $56 \%$ are female

- 4 years of work experience on average

- $54 \%$ live in urban areas

- Low poverty risk: $24 \%$ in poorest quintile

\section{4: Retirees' inactive wives (17\%)}

- $82 \%$ are inactive

- $\quad 97 \%$ do not have a working partner, $63 \%$ have a retired partner

- $76 \%$ are married

- Low-skilled: $79 \%$ have below upper secondary education

- $\quad 75 \%$ are 55-64 years old

- $\quad$ All are female

- 18 years of work experience on average

- $59 \%$ live in rural areas

- Moderate poverty risk; $28 \%$ in poorest quintile 
5: Low-educated unemployed or disabled (13\%)

- $\quad 57 \%$ are unemployed; $35 \%$ are disabled

- $\quad 29 \%$ have strongly-limited capacity to work

- $74 \%$ do not have a working partner

- $\quad 57 \%$ have never married

- Low-skilled: 59 have below upper secondary

- $75 \%$ are $35-54$ years old

- $73 \%$ are male

- 18 years of experience on average

- $61 \%$ live in rural

- High poverty risk: $40 \%$ in poorest quintile

- $\quad 49 \%$ receive social assistance; $26 \%$ sickness benefits

Source: World Bank staff analysis based on EU-SILC

Note: Years of work experience refer only to those individuals who have worked before. Dependent children include children under 18 and household members aged 18 to 24 who are economically inactive and living with at least one parent. Working adult refers to adults aged 24 and over.

A further advantage of the panel analysis is to provide information on the flow of individuals among clusters and in and out of employment. Table 5.7 shows the flow of individuals into each cluster of the out-of-work population or into employment in 2010 according to their labor market status in 2008. Between 2008 and 2010, 88 percent of the employed remained at work. About 6 percent moved into unemployment, either to the group of the highly educated single NEETs or to the low-educated unemployed or disabled, while another 7 percent moved into inactivity: 3 percent into retirement, 1 percent into the retirees' inactive wives group, and an additional 3 percent into the stay-at-home mothers group. There is also an interesting flow into employment among those who were unemployed or inactive in 2008. In 2010, 34 percent of those who were classified as unemployed and 21 percent who were classified as inactive in 2008 were found to be employed. The sample size of individuals who were inactive in 2010 and for whom we had information in 2008 is about 600 .

Job losses hit all identified groups to some extent, but they were more pronounced among the low-educated unemployed or disabled and highly educated single NEETs. Table 5.7 shows the labor market status in 2008 for each cluster and at-work population in 2010. Table 5.8 identifies the 2010 population groups that were most affected by job loss. The fifth (and smallest) class of low-educated unemployed or disabled were those that were hardest hit, as close to half of them changed status from employment to non-employment during this period. Young people were the second hardest-hit group, as one-third of highly educated single NEETs lost their jobs. 
Table 5.7 Composition of 2010 Clusters Based on 2008 Labor Market Status-Greece (Column Percentages)

\begin{tabular}{|c|c|c|c|c|c|c|}
\hline \multirow[b]{2}{*}{ Cluster } & \multirow[b]{2}{*}{$\begin{array}{c}\text { Working-age } \\
\text { population in } 2010\end{array}$} & \multicolumn{5}{|c|}{ Labor market status 2008} \\
\hline & & Unemployed & Retired & Disabled & $\begin{array}{c}\text { Other } \\
\text { Inactive }\end{array}$ & Employed \\
\hline 1 & Stay-at-home mothers & 18 & 0 & 0 & 33 & 3 \\
\hline 2 & $\begin{array}{l}\text { Highly educated single } \\
\text { NEETs }\end{array}$ & 29 & 1 & 0 & 17 & 3 \\
\hline 3 & $\begin{array}{l}\text { Retired and early } \\
\text { retired men }\end{array}$ & 3 & 71 & 17 & 1 & 3 \\
\hline 4 & Retirees' inactive wives & 0 & 21 & 4 & 27 & 1 \\
\hline 5 & $\begin{array}{l}\text { Low-educated } \\
\text { unemployed or } \\
\text { disabled }\end{array}$ & 16 & 5 & 79 & 1 & 3 \\
\hline \multirow[t]{2}{*}{ NC } & Employed & 34 & 2 & 0 & 21 & 88 \\
\hline & Total & 100 & 100 & 100 & 100 & 100 \\
\hline
\end{tabular}

Source: World Bank staff analysis based on EU-SILC

Note: For the year 2010, inactive individuals aged 16-24 enrolled in education are excluded from the analysis. Numbers referred to in the text appear shaded in blue.

Table 5.8 Composition of 2010 Clusters Based on 2008 Labor Market Status, (row percentages)

\begin{tabular}{|c|l|c|c|c|c|c|c|}
\hline & \multicolumn{5}{|c|}{ Labor market status in 2008 } \\
\hline Cluster & $\begin{array}{l}\text { Working-age } \\
\text { population in } \\
\mathbf{2 0 1 0}\end{array}$ & Unemployed & Retired & Disabled & $\begin{array}{c}\text { Other } \\
\text { Inactive }\end{array}$ & Employed & Total \\
\hline 1 & $\begin{array}{l}\text { Stay-at-home } \\
\text { mothers }\end{array}$ & 8 & 0 & 0 & 72 & 20 & 100 \\
\hline 2 & $\begin{array}{l}\text { Highly } \\
\text { educated } \\
\text { single NEETs }\end{array}$ & 16 & 0 & 0 & 49 & 34 & 100 \\
\hline 3 & $\begin{array}{l}\text { Retired and } \\
\text { early retired } \\
\text { men }\end{array}$ & 2 & 58 & 3 & 2 & 35 & 100 \\
\hline 4 & $\begin{array}{l}\text { Retirees' } \\
\text { inactive wives }\end{array}$ & 0 & 15 & 1 & 77 & 8 & 100 \\
\hline 5 & $\begin{array}{l}\text { Low-educated } \\
\text { unemployed } \\
\text { or disabled }\end{array}$ & 16 & 7 & 22 & 8 & 47 & 100 \\
\hline NC & Employed & 2 & 0 & 0 & 6 & 92 & 100 \\
\hline
\end{tabular}

Source: World Bank staff analysis based on EU-SILC

Note: Students aged 16 to 24 who were inactive or unemployed are excluded from the sample. Numbers referred to in the text appear shaded in blue.

On the other hand, the lack of flow into employment was pronounced. Table 5.8 also shows that of those employed in 2010, only 8 percent had been out of work in 2008. In addition, from the previous table it is clear that only one-third of the unemployed and one-fifth of the inactive moved into a job between 2008 and 2010. This suggests that the lack of job creation and the structural rigidities of the labor market reinforced the divide between the employed and the non-employed during this period. 
Self-employment and the "informal economy." Any discussion of the Greek economy and its labor market will need to take into account the presence of high self-employment and a variety of informal activities. For the purpose of the segmentation of the out-of-work and inactive population, EU-SILC data should be indifferent to the formality or informality of work performed or income received. In an OECD working paper on the subject, Andrews et al. (2011) give an overview of different measures for informality in EU and OECD countries and report the share of employees not covered by social security contributions in Greece to be 37.3 percent in 2008 (with an OECD average of 32 percent). At the same time, the authors question the reliability of the data in terms of the question design in the EU-SILC questionnaire. In a 2007 Eurobarometer Study on "Undeclared Work," Greece reported the highest number (16 hours) of undeclared hours per week in the European OECD sample. The high prevalence of non-agricultural self-employment in Greece (higher than 35 percent) and the almost 40 percent of workers without an employment contract (ibid, pp. 17 and 18, respectively) indicate the main driver of informality in Greece, self-employment. 


\section{From Profiling to Activation}

Overall, the profiles of the out-of-work resulting from this analysis indicate that an important share of this population has very low activation potential, especially in the current dire labor market situation. Many of the groups that are not working now are inactive either from choice or from a combination of choice and labor market conditions. This section will start with (a) a short overview of the current state of activation and inclusion policies and programs in Greece, then (b) gauge the activation need and potential of the different groups, and conclude with (c) a focused set of suggestions for further analysis, policy approaches and activation opportunities for the different groups. The suggested interventions are meant only as a starting point in a discussion with country authorities on general activation policies and their respective priorities. While the latent classes identified in this exercise can point to a general direction in terms of effective tailored policies, it would be beneficial to conduct a more detailed profiling exercise at the individual level. Latent class analysis allows for the classification of a vast population into broad meaningful categories, but there is still variation within groups, with resulting implications for the appropriate level of support required for activation.

\section{Activation and Inclusion Policies in Greece}

The current state of social inclusion and activation policies in Greece can best be described as fragmentary (EU 2013b). Without a general minimum income scheme for social assistance and a very limited and uncoordinated set of active labor market policies, the country is ill equipped to withstand the current social crisis by means of formal state intervention (Matsaganis, 2012: 4). According to the OECD database on active labor market policies (ALMPs), Greece spent 0.22 percent of GDP on ALMPs in 2010, vs. an OECD average of 0.49 percent (excluding public employment services (PES) operation respectively). The ALMPs offered by the Greek public employment service (Organismou Apascholisis Ergatikou Dynamikou, or OAED) are in many cases funded from the European Social Fund (EU 2013b: 18) but can provide help for some unemployed (Table 5.9).

According the EC DG EMPL, since 2010, about 1.2 million persons have benefited from OAED training and placement schemes at a total budget of EUR 3.87 billion. Evaluation of the programs by OAED finds that they have resulted in the retention of approximately 340,000 jobs, vocational training for 625,000 persons and initial vocational training for 42,000 young people. It should be noted that the majority of vocational training institutions in the country are in fact run by the OAED organization. At the same time, the provider landscape for training, placement and accompanying activation work is clearly underdeveloped.

Moreover, the Greek social protection model has at its core always relied on maintenance of primary breadwinner employment, family-based solidarity patterns (Amitsis, 2012: 6) and a strong role for social insurance benefits, while granting generous payments and treatments to privileged insider groups (bankers, senior civil servants, certain professions, and so on).

Much like the entire country and its budgets, the current social protection system is under severe financial stress, contributing to the fiscal contraction agreed upon with EU authorities

Portraits of Labor Market Exclusion | 151 
(Amitsis, 2012: 5). At the same time, the crisis has forced changes in many social programs in Greece, especially in the field of social insurance (pensions, health) and the related general budget subsidies for these programs. Given these fiscal constraints, many of the proposed activation and support measures must be designed in a very cost-conscious way, giving initial preference to group interventions, self-help approaches and self-service online services, rather than customized and individual case manager approaches.

Table 5.9 Number of Beneficiaries and Budget of Selected ALMP Interventions of OAED (2013)

\begin{tabular}{|c|c|c|}
\hline Program & $\begin{array}{c}\text { No. of } \\
\text { beneficiaries }\end{array}$ & $\begin{array}{l}\text { Total } \\
\text { budget (m } \\
\text { EUR) }\end{array}$ \\
\hline Subsidy program for social security contributions (2 years) & 25,000 & 170.9 \\
\hline Subsidy program for social security contributions (4 years) & 40,000 & 501.4 \\
\hline $\begin{array}{l}\text { Work experience program for } 16-24 \text { yo labor market entrants. } \\
\text { Traineeships of } 6-12 \text { months at } 80 \% \text { of National Minimum Wage. } \\
100 \% \text { subsidy of social security contributions. }\end{array}$ & 5,000 & 1.4 \\
\hline $\begin{array}{l}\text { Hiring subsidy for university and technical HE graduates up to } 35 \\
\text { years of age. } 24 \text { months part of wage subsidized. }\end{array}$ & 7,200 & 40.1 \\
\hline $\begin{array}{l}\text { Labor market entry voucher for training and work experience (up to } \\
5 \text { months) up to } 29 \text { years of age. }\end{array}$ & 35,000 & 130.0 \\
\hline $\begin{array}{l}\text { Public Works Program. Jobs in local institutions and NGOs. } 625 \text { EUR } \\
\text { / month allowance for max. } 5 \text { months. Payroll and insurance } \\
\text { contributions covered. }\end{array}$ & 57,400 & 188.3 \\
\hline Training program for the unemployed in the tourism sector & $\mathrm{n} / \mathrm{a}$ & $\mathrm{n} / \mathrm{a}$ \\
\hline $\begin{array}{l}\text { Wage subsidy for older people, between } 1 \text { and } 60 \text { months for approx. } \\
40 \text { percent of wage bill. }\end{array}$ & $\mathrm{n} / \mathrm{a}$ & $\mathrm{n} / \mathrm{a}$ \\
\hline Placement program for older workers in local authority enterprises & 5,000 & 75.0 \\
\hline
\end{tabular}

Over the next two years, the Government of Greece has committed to the introduction of a pilot program for a means-tested minimum income benefit (European Commission 2013c: 40). If successfully rolled out on a national scale to low-income individuals and households, this benefit could provide effective poverty relief and be a backstop against the deprivation currently experienced by some of the out-of-work groups identified in this note. 65 With a benefit of this type, Greece would close its gap with the European standard for inclusion policies, providing generalized income support instead of insurance-based and categorical payments.

Concurrently, the Government of Greece has announced an emergency public works program, the details of which are still being negotiated with EU authorities. Owing to the fact that this program will be limited in run time and volume, it will be considered only as a part of the policy approaches to address specific activation needs of the inactive groups in this survey, and not as a main line of policy response.

65 The means-tested minimum income benefit will not necessarily be exclusively targeted toward the out-of-work population; it will be targeted toward individuals and households living in extreme poverty in general. 
When further considering the approach toward labor market integration, an assessment of the priorities and potential of the identified groups needs to be undertaken. In the current context in Greece, a prioritization of intervention is very important. After a first step ("activation priority") of prioritizing the intervention along activation need and activation potential, a second step ("activation type") will attempt to classify the groups according to the kind of activation intervention needed, depending on social or labor market barriers to be overcome. Lastly, as a third step, information on household income composition of the different groups will be used to assess potential cross-dependencies of the benefit system with groups' labor market status and activation approaches

Activation priority. Table 5.10 below provides an overview of the seven primary groups of out-of-work persons among the population of working age according to their activation need and potential. The total number of individuals included is 2.695 million, representing 25 percent of the total population in Greece in 2011, and 46 percent of the population of working age.

"Activation need" describes a group's need for inclusion in the labor market to achieve income and dampen or end poverty. "Activation potential" describes that group's ability or motivation to be included in the labor market again. A high activation potential could indicate good qualifications and labor market experience (as in the case of the highly educated early retirees) or previous work experience and high household-level incentives to work (due to low employment) (as is the case of middle-aged unemployed heads of households).

Table 5.10 Activation Need and Potential of Different Clusters-Greece

\begin{tabular}{|c|l|c|c|c|}
\hline Share & \multicolumn{1}{|c|}{ Cluster } & $\begin{array}{c}\text { Activation } \\
\text { need }\end{array}$ & $\begin{array}{c}\text { Activation } \\
\text { potential }\end{array}$ & $\begin{array}{c}\text { Priority } \\
\text { for } \\
\text { action }\end{array}$ \\
\hline $23 \%$ & Stay-at-home mothers & Medium & Medium & Medium \\
\hline $18 \%$ & Highly educated single NEETs & High & Medium & High \\
\hline $18 \%$ & Middle-aged unemployed heads of households & High & High & High \\
\hline $17 \%$ & Retirees' inactive wives & Low & Low & Low \\
\hline $13 \%$ & Low-educated retirees & Low & Medium & Low \\
\hline $7 \%$ & Highly educated early retirees & Low & High & Low \\
\hline $5 \%$ & Low-educated, mostly rural disabled & & Low & Low \\
\hline \multicolumn{2}{|l|}{ Source: World Bank staff analysis and assessment 2014} & & \\
\end{tabular}

From this simple overview of need and potential, a clear set of prioritizations arises. The groups highly educated single NEETs and middle-aged unemployed heads of households emerge as the top priority target groups for potential activation measures. The latter group is considered a particular priority due to its income situation and potential for activation. While highly educated single NEETs largely rely on other household members as a safety net, they are also considered a priority because their current unemployment status and difficulty in acquiring work experience could have long-lasting societal consequences, 
including negative effects on future employment outcomes and earnings for the economy as a whole. Stay-at-home mothers represent the largest group among the out-of-work population and are largely inactive, with the presence of a working member/partner reducing their incentive to join the labor force. The presence of children also implies caregiving responsibilities that may serve as a barrier to labor force participation. Because activation is thus more difficult in an environment of labor-demand shortage, they are considered second in line in terms of activation priorities.

Lastly, non-activation target groups in the current state (thus considered as priority C) include retirees' inactive wives, low-educated retirees, highly educated early retirees, and loweducated, mostly rural disabled. As a whole, these groups will likely lack incentives to return to work. Nonetheless, they have also grown in size over the last four years and the majority of their members receive old age or disability benefits, resulting in fiscal pressures on the pension system. Reducing the inflow of individuals into these groups is thus also a policy priority for Greece.

When looking at these groups in greater detail, special consideration needs to be given to the significant shares of early retirees in the groups of low-educated retirees and highly educated early retirees. The highly educated early retirees pose an especially striking example, with 83 percent of them 45 to 59 years old. This effect is less pronounced for the low-educated retirees, of whom 29 percent are in this age group. As discussed below, this pattern is a clear cause for concern because significant numbers of potential workers have been allowed to enter old-age benefit systems during their productive work years. While activating these groups out of the retirement status will be difficult, special care needs to be taken to limit further inflow into these groups.

Activation type. As a second step, the relative severity of labor market or social obstacles to labor market integration will serve as an orientation for activation approaches of the prioritized groups of stay-at-home mothers, highly educated single NEETs and middle-aged unemployed heads of household. 
Figure 5.8 Activation Types of Prioritized Clusters-Greece

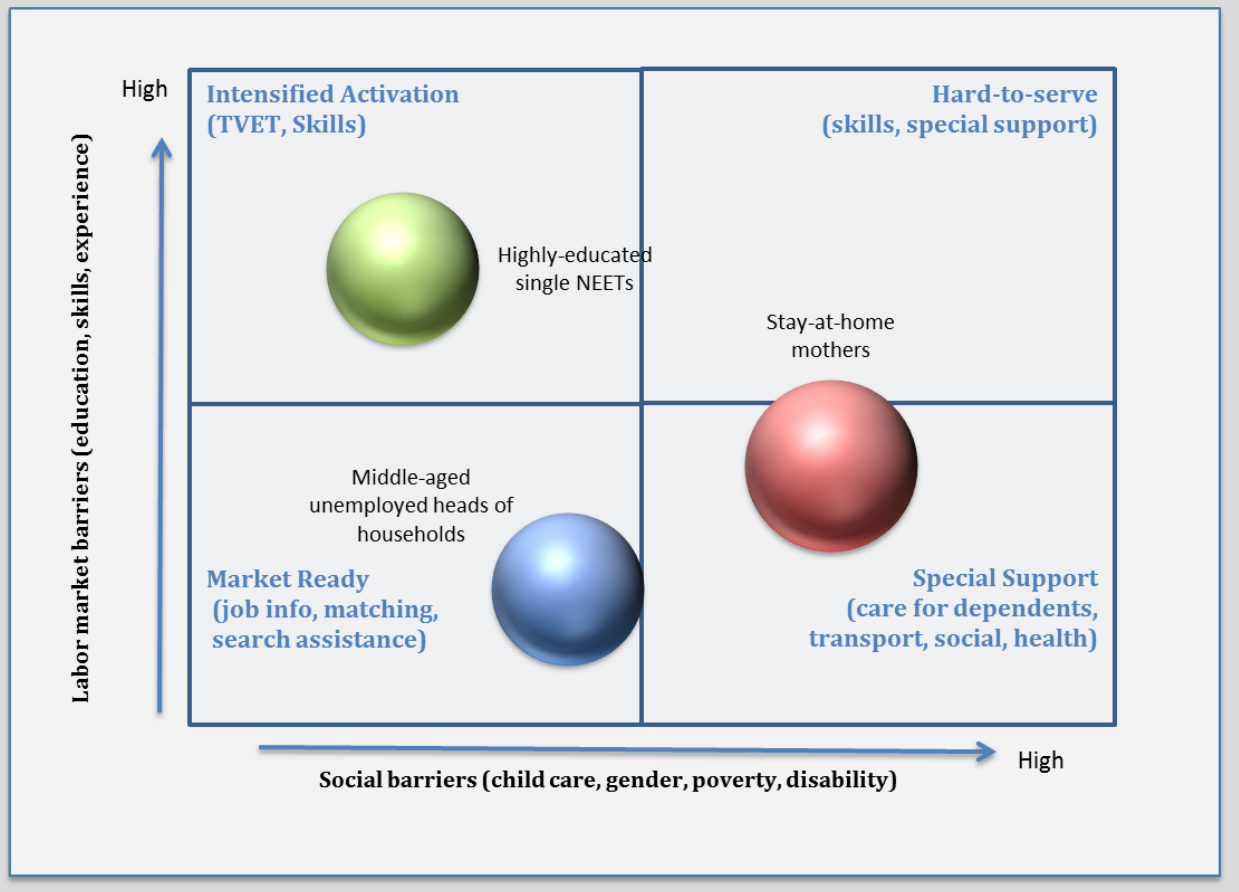

Source: World Bank staff analysis and assessment 2014

By mapping the respective barriers for labor market integration faced by the three prioritized groups, we can quickly discern the respective types of activation that could be undertaken for them. The areas of activation are very broad and will need to be refined more narrowly when considering individual or group-based intervention patterns for the different groups. Whereas the middle-aged unemployed heads of households probably require more "market-based" types of interventions because of their work experience, the highly educated single NEETs will need more intensified labor market entry support, adding practical and usable skills to their (often academic) education. Stay-at-home mothers require more social support (for child care, care of other dependents, and so on) but can build on previous work experience to gain labor market entry.

Household income composition. In the third step, planning and consideration of activation approaches, an overview of the 2011 household income of the groups can be conducted. In the first three groups (stay-at-home mothers, highly educated single NEETs and middle-aged unemployed heads of households), labor income represents the majority of household income. The situation reverses for the remaining four groups, with old-age and disability benefit payments consistently contributing between 50 and 65 percent of household income. 
The striking feature of the receipt of benefits for groups four through seven is the high prevalence of old-age benefits. In the group of the low-educated mostly rural disabled, disability benefits come into play (representing 25 percent of total household income), but for the retirees' inactive wives, the low-educated retirees and the highly educated early retirees, old-age benefits contribute to 51,55 and 51 percent of household income respectively. As briefly discussed before, this type of income will also fall to many of the below-64 years of age members in these groups, and will in fact act as a disincentive to labor market participation.

In the prioritized groups, old-age benefits play a significant role only for the households of the highly educated single NEETs (representing close to one fourth of total household income), implicitly suggesting the use of them as retirement income for older household members $(20$ percent of this group live in households with at least one 64-plus aged member). While this benefit income helps to stabilize household welfare, it can take away from job search or work incentives for younger household members (the identified highly educated single NEETs).

Lastly, it is striking that all other forms of benefits, that is, those not associated with old age or disability, contribute an almost negligible proportion to the total household incomes of the identified groups. This highlights the fact that social protection in Greece is largely centered upon pensions, providing little protection in terms of unemployment insurance or social assistance. 
The following sections set out a short set of potential activation measures for each of the priority groups. All of the suggestions below should be considered as a starting point for further policy dialogue between EC DG EMPL, the World Bank and the Greek authorities, bearing in mind that the groups identified still carry some heterogeneity that may affect the level of support required. Accordingly, these suggestions are also not meant to be an exhaustive set of possible activation measures.

It should also be kept in mind that the recommendations are based on clusters derived from 2011 EU-SILC data. Since then, policy actions by the government of Greece and the European Commission's country-specific recommendations" might have reflected some of these policy suggestions or rendered them obsolete.

Highly educated single NEETs (18 percent, Priority: High). This group is characterized by a relatively high education standard and lack of independence (most are still living at home). The majority are unemployed, although a non-negligible 29 percent are inactive. Potential activation measures for this group include the following:

$\checkmark$ Assist in developing a qualification in a field related to the one studied, but promote technical or professional skills rather than further acquisition of academic qualifications.

$\checkmark \quad$ Support skill development through work experience for post-secondary or tertiary degree holders. Examples include internship and "second-chance" programs that enable youth to enhance and make use of analytical skills, while facilitating the transition between school and work.

$\checkmark$ Support mobility within Greece and the EU (including foreign language training) that is aimed at placing highly qualified individuals.

$\checkmark$ Enable participation in the intended public works program for the 45 percent of NEETs who only have an upper secondary education or below, or for the 40 percent who do not have at least one working adult in their household.

Middle-aged unemployed heads of households (18 percent, Priority: High). This group represents probably the most traditional group of activation-policy clients, having formed families and gained work experience, and having now lost their jobs in the crisis. Given the lack of other income support, it is here that the threat to welfare is especially severe. As an emergency backstop, this group will need to be made aware of its right to family benefits (by entering a tax return and applying for the reformed family benefit). Their high poverty risk also implies that members of this group might also participate in the planned public works program, or apply for a yet-to-be-introduced minimum income benefit in 2015 or later. When considering integration of this group with a new version of the public works program, the public works engagements could be combined with short training seminars, job-search clubs or seminar offerings for participants. Focusing these complimentary offerings on participants with recent work experience will help to self-select "market-type" clients into the offers. Potential activation measures for this group include the following:

Portraits of Labor Market Exclusion | 157 
$\checkmark$ OAED training measures (opening OAED-run vocational schools to adults and "second chance" candidates)

$\checkmark$ "Job search club" group interventions for men from different professions

$\checkmark$ Update of formal professional skills (certificates, new qualifications), including foreign language skills training aimed toward employment in the tourism industry

$\checkmark \quad$ Limited offer of self-employment training/startup support (making this highly selective of clients with a good chance for success)

$\checkmark$ Mobility support within Greece and within the EU (including foreign language training)

Stay-at-home mothers (23 percent, Priority: Medium). This group presents a heterogeneous picture and would most likely need further analysis through a more qualitative approach. Activation should focus on the 50 percent of women in this group who have previous work experience. The respective pathways of women who successfully transitioned from inactivity to contingent breadwinner in response to partner job loss during the crisis might yield clues as to activation strategies for other women in this cohort. In general, potential activation measures could include:

$\checkmark$ "Reconnection" programs to seek contact with previous employer, industry or colleagues and assess skill needs, availability, and so on for re-entry.

$\checkmark$ "Family enterprise and self-employment" programs to explore self-employment or joint employment with other family members.

$\checkmark$ "Job club for experienced women": multi-session group activity for teaching job search skills, resume and job interview training, and so on.

$\checkmark$ Provision of free or subsidized child care for mothers of young children, using a means-tested approach targeted toward low-income households and low-skilled women who engage in work or a job search.

Retirees' inactive wives (17 percent, Priority: Low). This group is characterized by very low activation needs and potential, due to their low education levels and close-to-retirement age.

$\checkmark \quad$ Offer self-help portal on OAED website to assist in restarting their careers (but only opportunistically and without new resources).

Low-educated retirees (13 percent, Priority: Low). This group is also a low priority for current activation-policy planning. Their retirement income is mostly sufficient to make any public transfers beyond the pension payment nonessential.

Highly educated early retirees (7 percent, Priority: Low). Although their high educational attainment and work experience drive up its activation potential, this group is also very unlikely to have an interest in activation policies. Over 50 percent are in the richest household income quintile and only 4 percent are in the bottom quintile.

Low-educated mostly rural disabled (5 percent, Priority: Low). While the welfare of this group could certainly be enhanced by strengthening mobile and decentralized assistance services to disabled citizens (67 percent report "severe limitations" on taking up 
employment), the current focus on out-of-work groups does not mesh with the lack of employment prospects for this group.

Retirees' inactive wives (17 percent), low-educated retirees (13 percent), highly educated early retirees (7 percent), and the low-educated mostly rural disabled (5 percent) are not further considered for activation policies for the purposes of this study. Together, these clusters together represent more than a third of the out-of-work and their absolute size has been growing over time, with implications for fiscal expenditures. As mentioned above, however, given their overall low need and potential for activation, these groups are not considered a priority for activation during times of low labor demand and high unemployment. Moreover, international experience shows that stemming the outflow of new retirees and disability benefit recipients from work into inactivity may be more effective than attempting to increase inflows into activity. ${ }^{66}$ Stanching outflows is especially important in times of high unemployment if long-term disability or early retirement have become more attractive than work for the long-term unemployed. Policies can and should be implemented to delay early retirement, including the promotion of skill maintenance and lifelong learning, along with flexible work schedules and the ability to work from home. Prevention of long-term disability benefit dependency should also be addressed through a review of work capacity assessment, together with the early identification of people with disabilities who can work and their integration into the workforce through financial incentives for disabled workers and their employers. Greek authorities note that there is a limited culture of workplace integration of disabled or (partly) incapacitated workers. Setting out to change this would require a long-term and very difficult effort in the current economic situation.

In summary, while each cluster of the out-of-work has particular characteristics that need to be considered in the activation policy design, there are some overarching policy options that could cater to several groups at once. All poor households or individuals among the currently identified groups of out-of-work citizens are likely to benefit from the Minimum Income Benefit program to be introduced in 2015 or later. The program is being piloted in 2014, and will potentially be taken to a national scale in the following years. LCA analysis has shown that the groups of out-of-work individuals most at risk of falling into poverty are middle-aged unemployed heads of households (of which 56 percent don't have another working adult in the household) and the low-educated mostly rural disabled, whereas (early) retirees are in least need of social assistance.

In general, current and future policy discussions between the Government of Greece and international partners could focus on a set of policy areas where potential activation linkages can emerge. These include, but are not limited to:

$\checkmark$ Emergency public works program. Responsible authorities ought to provide more details on the planned size, scope and target groups of the program. If possible, the targeting mechanism for enrollment in the program ought to focus on the group of middle-aged unemployed heads of households but should also be open to highly educated single NEETs and stay-at-home mothers. The inherent self-targeting

${ }^{66}$ For the case of disability benefit recipients, see, for example, OECD (2010). 
mechanism (effort, stigma, crowding-out of informal employment) of a wellmanaged public works program will most likely help to focus program participation on the truly needy (bottom quintiles) among the identified inactive groups

$\checkmark$ Reform of the public employment service (PES) and the unemployment insurance agency OAED. In 2011, Greece initiated a reform of its PES, supported by technical assistance from EU partner countries. Currently, OAED offers only limited activation support in form of active 1abor market programs and is focusing many of its resources on administering the unemployment insurance benefit, which is limited to one year (OECD 2013: 50). Work-streams 4 through 6 of the current OAED reform ("Active labor market measures design, adjusted to market needs"; "Service provision related to the needs of jobseekers"; and "Support of young apprentices") can form a central piece of the activation response for the group of excluded and out-of-work identified in this note.

$\checkmark$ Integration with employment demand generation and competitiveness policies. While active labor market policies, activation and job-matching support can help smooth frictions in the labor market, they will not lead to stable and sustainable employment. Demand for jobs comes from the economic activity of firms and the social sector. This integration with regional economic development policy is especially important and has been recognized by the authorities.

In summary, Greece could benefit from focusing activation policies on the target groups identified, enhancing the opportunity for labor market inclusion and stabilizing welfare for poor and inactive households. 


\section{References}

Amitsis, Gabriel, 2012. "Developing activation discourses in an era of fiscal constraintsPolicy challenges for the rudimentary Greek Welfare State." Paper for the 10th Annual Conference of the European Social Policy Network, Edinburgh, 2012 [accessed at www.espanet2012.info/_data/assets/word .../Amitsis_-_Stream_7.doc (9-Aug 2013)]

Andrews, D., A. Caldera Sánchez and Å. Johansson, 2011. “Towards a Better Understanding of the Informal Economy," OECD Economics Department Working Papers, No. 873, OECD Publishing. http://dx.doi.org/10.1787/5kgb1mf88x28-en

Collins, L. M., and S. T. Lanza. 2010. Latent Class and Latent Transition Analysis: With Applications in the Social, Behavioral, and Health Sciences. Hoboken, NJ: Wiley.

Eurofound, 2012. NEETs-Young people not in employment, education or training: Characteristics, costs and policy responses in Europe, Publications Office of the European Union, Luxembourg.

(EC) European Commission, 2013a. EU measures to tackle youth unemployment. MEMO, Brussels, 28 May 2013.

2013b. Assessment of the implementation of the European Commission Recommendation on active inclusion: A Study of National Policies. Country Report-Greece. European Union, Brussels.

2013c. The second economic adjustment program for Greece. Second Review. May 2013. Directorate General for Economic and Financial Affairs. Occasional Paper No. 148. European Commission, Brussels.

Eurostat, 2011. ESSPROS Manual: The European System of Integrated Social PROtection Statistics. European Union, Luxembourg.

Kaufman, L. and Rousseeuw, P. J., 1990. Finding groups in data. New York, Wiley.

Magidson, Jay and Vermunt, Jeroen, 2002. Latent Class Modeling as a Probabilistic Extension of K-Means Clustering Quirk's Marketing Research Review, March, 20, 77-80. Available at: http://statisticalinnovations.com/technicalsupport/kmeans2a.htm

Matsaganis, Manos, 2012. Social policy in hard times: The case of Greece. Critical Social Policy, vol. 32(3), pp. 406-421.

Moschou, Angeliki (2012). Country sheet on youth policy in Greece. Youth Partnership, EU.

OECD, 2013. OECD Employment Outlook 2013, OECD Publishing. Available at: http://dx.doi.org/10.1787/empl_outlook-2013-en

OECD, 2010. Sickness, Disability and Work: Breaking the Barriers. OECD, Paris.

OECD, 2013. Greece: Reform of Social Welfare Programmes, OECD Public Governance Reviews, OECD Publishing.

Vermunt, J. K. and J. Magidson, 2005. Latent GOLD 4.0 User's Guide. Belmont, Massachusetts: Statistical Innovations Inc. 


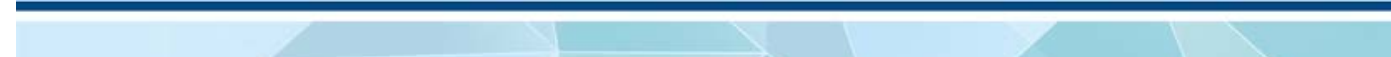

162 | Portraits of Labor Market Exclusion 


\section{Latent Class Analysis of the Out- of-Work Population in Hungary 2007-2011}

\section{Background}

Following the world financial crisis, Hungary's economy underwent severe economic contraction in 2009, and it has not fully recovered since then. Over the 2003-2008 period, the Hungarian economy grew by an annual average of 2.9 percent, not too far from the 2.2 percent average among EU-28 Member States during this same period. And as in other countries in the region, in 2009 the crisis hit hard and output contracted by 6.8 percent. By the end of 2011 Hungary was one of the most financially vulnerable countries in Europe outside the euro area (EEAG, 2012) and growth has not recovered yet, as GDP declined 1.7 in 2012 and grew 1.1 percent in 2013.

Unemployment started rising during the mid-2000s with a sharper increase in 2009, following the fall in output. In 2003 and 2004, unemployment (for those between 15 and 64 years old) was slightly below 6 percent. From 2005 to 2008, it rose to an average of 7.5 percent. After the crisis hit the Hungarian economy in 2009, unemployment increased by 2.2 percentage points, reaching a high of 11.2 percent in 2010. It has remained steady at 11 percent till 2012, and fell to 10.3 percent in 2013. Unemployment in Hungary can be considered moderate when compared to the average of 11 percent for the EU-28 countries in 2013. And despite the fact that labor force participation is low by European standards-in 2013, the working age population in the EU-28 countries was on average 71.9 percent - it remained fairly constant during the crisis, at 61.6 percent in 2009. ${ }^{67}$ By 2013, it had slightly increased to 65.1 percent.

Young workers experienced a sharp rise in unemployment when compared to the overall working-age population. In 2003 unemployment rates were 7.1 percentage points higher for individuals aged 15 to 24 years old than for individuals aged 15 to 64 . Youth were clearly disproportionately affected by the increase in unemployment. In 2012, the gap in the unemployment rates observed for these two groups reached 17.1 percentage points, when youth unemployment reached 28.1 percent. In 2013 the gap fell to 16.9 as youth unemployment fell slightly to 27.2 percent. The percentage of young individuals aged 15 to 24 that were not in employment, education, or training (the NEET rate) reached its lowest level for the decade in 2007-11.3 percent. After a downward trend between 2003 and 2008, the NEET rate also increased, reaching 15.4 percent in 2013.

A look at unemployment rates disaggregated by age and gender shows that young men were generally more affected by the crisis. As shown in Figure 6.1, the economic downturn of 2009 also affected men the most, especially those in the 15-to-24-year-old

67 Prior to the crisis, the labor force participation rate in 2008 was 61.5 percent. 
group, whose unemployment rate grew from 19 to 28 percent between 2008 and 2009, representing an increase of 48 percent. In contrast, unemployment for women in this age group only increased by 16 percent. Men aged 25 to 49 and 50 to 64 also experienced higher proportional increases in unemployment than women in the same age group.

Figure 6.1 Unemployment Rate by Gender and Age (2007-2013)
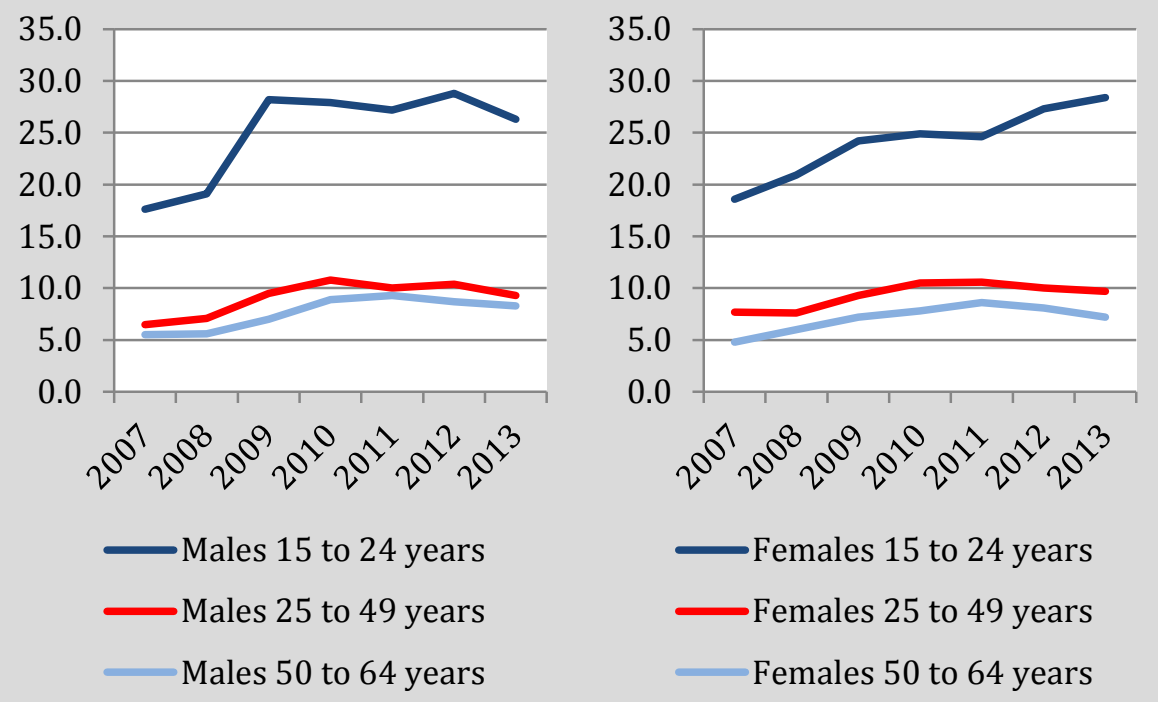

Source: Eurostat, EU-LFS

In Hungary, long-term unemployment as a share of total unemployment has usually been higher than the average for the EU-15 countries. In 2010, it peaked at 49.3 percent but has decreased again to the same level as in 2005, around 45 percent. Unfortunately, in 2013 the percentage of long-term unemployed increased once more, reaching 48.6 percent. Even if there was no sharp increase in the share of long-term unemployment in the economy during the decade (on average), there is still a concern due to the high share of individuals that have been without a job for at least 12 months. 
Figure 6.2 Long-Term Unemployment as a Share of Total Unemployment (2003-2013)

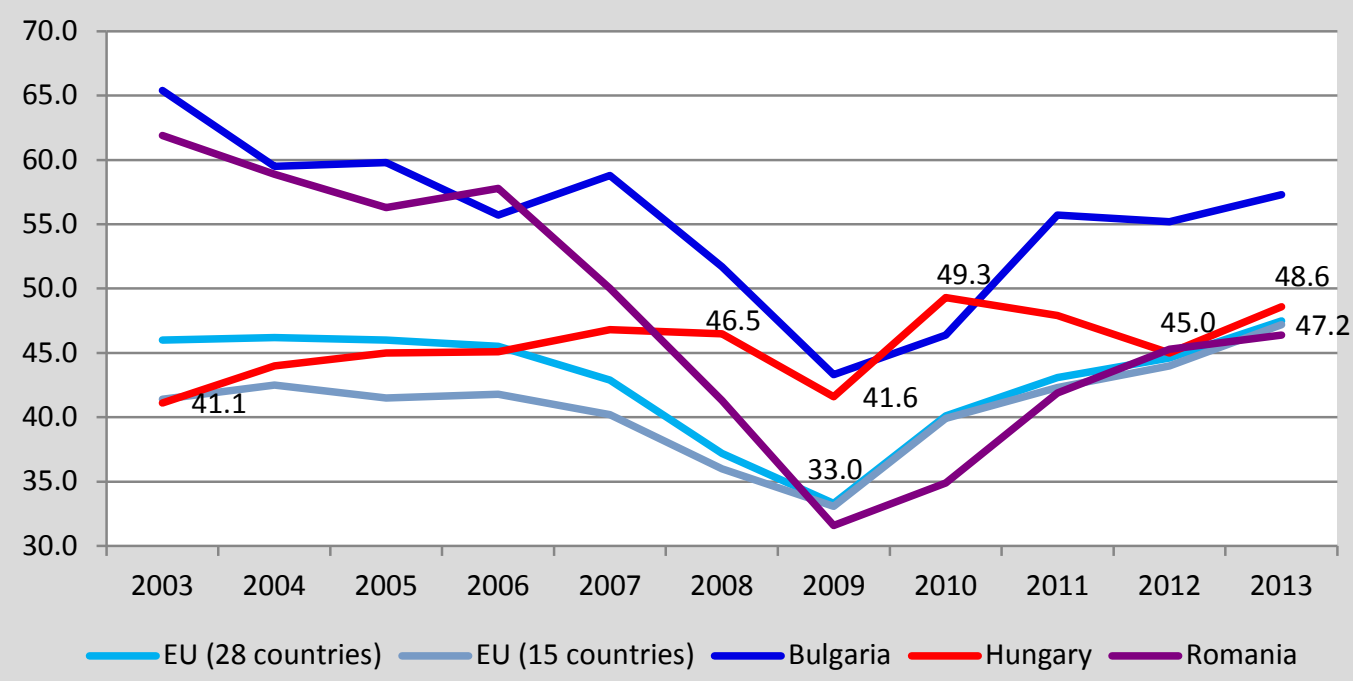

Source: Eurostat, EU-LFS

Following the crisis, low-educated individuals were especially affected by the rise in unemployment. Unemployment rates were already increasing for the group of lesseducated individuals; after the crisis hit in 2009 this trend was rather accentuated. However, all educational groups saw an increase in unemployment rates during the period from 2008 to 2013. For those with tertiary education, the unemployment rate increased 50 percent, from 2.8 to 4.1. But the gap between the groups became bigger during the period, which reflects structural changes that increased the demand for more skilled workers. The difference in unemployment rates for low- and higher-educated workers grew from 16.1 percentage points in 2008 to 20.1 percentage points in 2013.

Overall employment levels remained relatively stable before and following the crisis, slightly decreasing during the period for individuals in all educational levels. Employment levels have decreased slightly for all educational levels, not only after the crisis in 2009, but this trend had been in place since the mid-2000s. The educational composition of the working-age population in Hungary, on the other hand, has changed during the last decade. The share of the working-age population with less than an upper-secondary education fell from 30.3 in 2003 to 22.6 percent in 2013, while the share with tertiary education increased from 12.9 percent to 19.5 during the same period.

During the period from 2008 to 2011, the sample of the out-of-work population considered in this note increased, from 2.25 to 2.28 million individuals. The analysis of the out-of-work population in this note focuses on the working-age population (16-64 years old). Specifically, only individuals aged 25 to 64 years who are not employed, and individuals aged 16 to 24 who were neither employed nor in education nor training were considered. ${ }^{6}$

${ }^{68}$ Individuals aged 16 to 24 who are out of work and enrolled in education are excluded from the sample; they are considered to be investing in their final stages of human capital formation and 
Only the working-age population (16-64 year olds) is analyzed, as labor activation optionsthe main policy focus of this note-are only viable for that segment of the population. As a percentage of the population of working age under analysis, the out-of-work population rose from 37 percent to 38.1 percent. The two groups of the out-of-work population that became smaller during this period were the groups of disabled and other inactive, which decreased in size by 32 and 23 percent, respectively. On the other hand, the groups of (short-term) unemployed, long-term unemployed and (early) retired grew by 99, 58 and 14 percent, respectively (see Table 6.1). Figure 6.3 shows the composition of the out-of-work population in Hungary in 2008 and 2011.

Table 6.1 Number and Percentage of Working Age Individuals (16-64) by Labor Market Attachment in Hungary, 2008 and 2011 (Number in Thousands)

\begin{tabular}{|l|c|c|c|}
\hline & & \multicolumn{2}{|c|}{ Percent change 2008- } \\
\hline At work & $\mathbf{2 0 0 8}$ & $\mathbf{2 0 1 1}$ & $-3.4 \%$ \\
\hline Unemployed & 3,834 & 3,702 & \\
\hline & $63 \%$ & $62 \%$ & $99.2 \%$ \\
\hline Long-term unemployed & 184 & 367 & \\
\hline & $3 \%$ & $6 \%$ & $57.9 \%$ \\
\hline (Early) retirement & 194 & 307 & $13.7 \%$ \\
\hline & $3 \%$ & $5 \%$ & \\
\hline Disabled & 599 & 681 & $-31.6 \%$ \\
\hline & $10 \%$ & $11 \%$ & \\
\hline Other inactive & 664 & 454 & $-23.2 \%$ \\
\hline & $11 \%$ & $8 \%$ & $-1.7 \%$ \\
\hline Total & 610 & 469 & \\
\hline & $10 \%$ & $8 \%$ & \\
\hline
\end{tabular}

Source: World Bank staff analysis based on EU-SILC

Note: Individuals aged 16 to 24 who are out of work and enrolled in education (0.75 million individuals) are excluded from the sample.

therefore are not a particular target group for activation policies. In 2011, there were 741,817 youth aged 16 to 24 who were out of work and enrolled in education, representing 62 percent of the total population in this age category and 25 percent of the total out-of-work population of working age. Individuals between 25 and 64 who are enrolled in school are included in the latent class analysis, and will be grouped under "other inactive." It is important to note that this group of students (older than 24 ) accounts for only 1 percent of total population of working age. 
Figure 6.3 Distribution of Out-of-Work Population in Hungary (2008 and 2011)

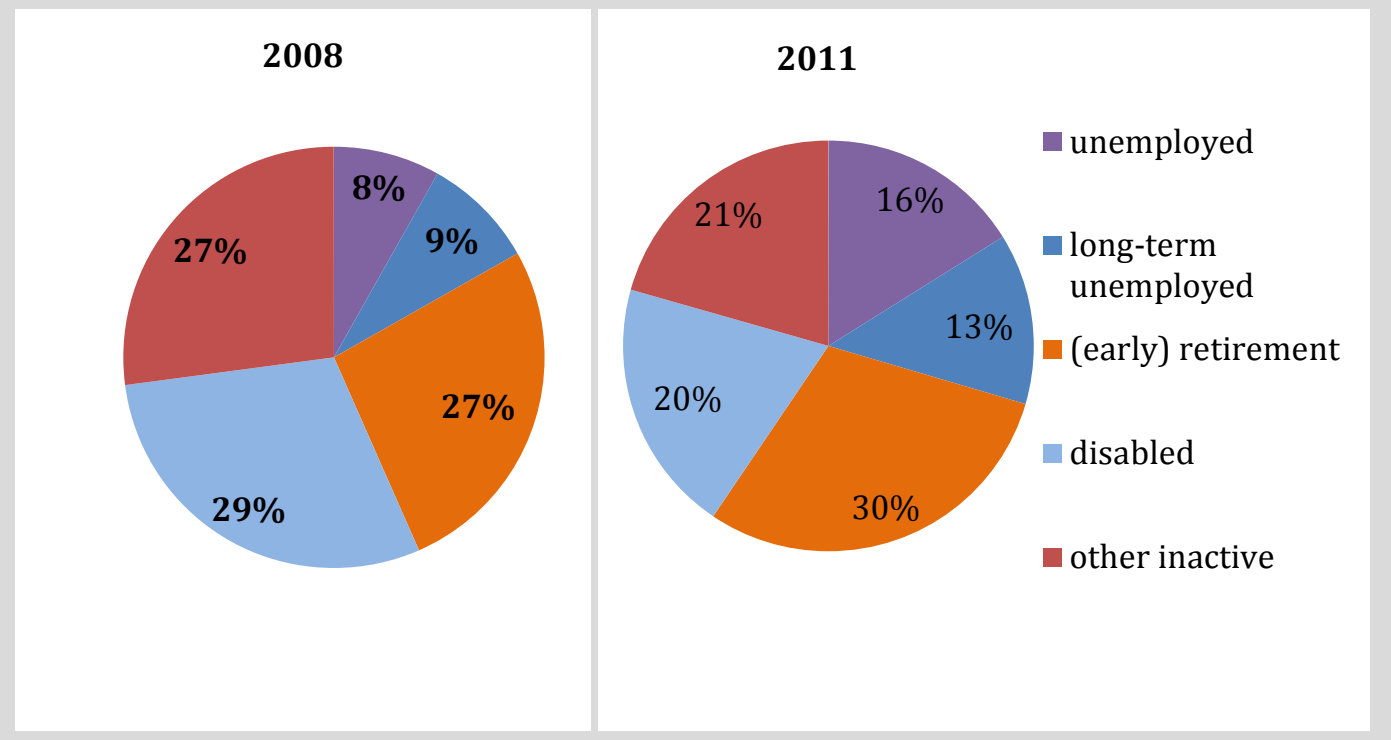

Source: World Bank staff analysis based on EU-SILC

\section{Box 6.1 Retirement-Income Systems in Hungary}

The following provides details about some recent changes in the retirement system in Hungary.

\section{Old-age pensions}

In Hungary, the retirement age was equalized at 62 for both men and women (from 60 and 55, respectively). The age for men reached 62 in 2000; for women, it occurred in the beginning of 2009. After 2010, the statutory unisex retirement age is being increased gradually, reaching 65 by 2022 .

In addition, 20 years of service are required for both the earnings-related pension and the minimum pension. Fifteen years of service are required to receive a partial pension.

The pension payment has been indexed, half to wages and half to prices, since 2001, but further ad hoc increases were applied. As of 2010 indexation will be linked to GDP growth.

From 2006 to 2009, all pensioners received an additional month's (13 ${ }^{\text {th }}$-month) pension. In January 1, 2009, the rules on eligibility to 13 th month pension changed. As of 2010, the 13th month pension was totally abolished. 


\section{Early retirement:}

In 2008, early retirement was possible for men at age 60 and for women at age 57 without actuarial reduction. When pension ages were equalized at 62 in 2009, early retirement became available at 59 for women and 60 for men. According to newly adopted legislation, the retirement age will gradually increase to 65 years. And, as of 2010, advanced pension rules were also tightened along with the increase in standard retirement age.

\section{Unemployment:}

Older unemployed people can receive special pre-retirement benefits if they have received unemployment insurance benefits for 140 days, will reach pensionable age within five years, have exhausted their unemployment benefit entitlement within eight years of pensionable age, and have contributed to the pension scheme for at least 20 years.

\section{Source: World Bank staff analysis 2014}

\section{Box 6.2 Child Benefit Systems in Hungary}

The following provides details about some recent changes occurring in other benefits such as maternity leave.

\section{Child care:}

People can take the following benefits: pregnancy confinement, child care fee, child care allowance and child-raising support.

The pregnancy confinement benefit is for women who are pregnant or giving birth, for 24 weeks (168 days). The benefit is 70 percent of the daily average gross earnings of the previous year.

The child care fee may be claimed by one parent the day after the pregnancy confinement benefit expires. The entitlement runs to the second birthday of the child (maximum 24 months). The benefit amount is 70 percent of the daily average gross earnings of the previous year, up to a maximum of twice the minimum wage.

The child-care allowance is for a parent who cares for the child until the child's third birthday (maximum 36 months); or in the case of twin children, until the end of the year they reach school age; or in the case of a permanently ill or seriously disabled child, until the child is ten years of age (maximum 120 months). The monthly amount is equal to the minimum old-age pension, irrespective of the number of children in the family; and in the case of twins, the amount is twice the minimum old-age pension. After a child's first birthday, a grandparent may claim the benefit. 
Child-raising support is for a parent who raises three or more underage children in the period between the third and eighth birthday of the youngest child (maximum 60 months).

The monthly amount is equal to the minimum old-age pension, irrespective of the number of children

Source: OECD 2011

Portraits of Labor Market Exclusion | 169 


\section{Methodology: Latent Class Analysis}

In Chapter 1 a general overview of the latent class analysis methodology was laid out. This section explains in detail the variables and covariates used to identify classes or groups of out-of-work individuals that are as homogeneous as possible within each class according to a set of observable characteristics, and as distant as possible between classes. The emerging profiles can then be contrasted with the design and targeting of current activation policies, in order to identify the potential gaps and to enhance their design features. ${ }^{69}$

Variable selection: The definition of latent classes relies on a number of indicator variables to capture different "symptoms" of an overall latent condition (in this case, the typology of joblessness). The challenge in such models is to identify a discrete number of variables that can best explain the heterogeneity of individual outcomes. In this case, two sets of categorical variables were selected: the first set to show the extent of labor market distance and the other to capture some of the main factors that can affect employment on the supply side, such as labor supply conditions (household-level incentives to work and physical ability to work).

$\checkmark$ Distance from labor market: short-term unemployment, long-term unemployment, (early) retirement, disability, and other inactivity (largely unpaid domestic work)..$^{70}$

$\checkmark$ Work experience: if individual has worked before and, in this case, whether he or she worked for two or more months in the last year.

$\checkmark$ Labor supply conditions: whether the individual's household has at least one working adult, ${ }^{71}$ and perceived limitations on activities due to health problems. ${ }^{72}$

In addition to indicators, the model includes active covariates, which are used to improve the classification of individuals in each class. In this case the active covariates are the demographic variables that are normally used to disaggregate labor market outcomes:

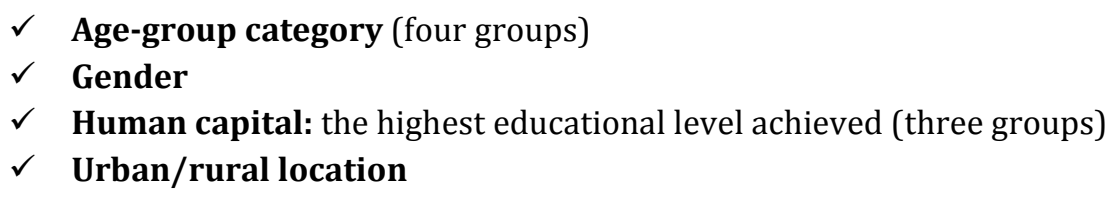

Once the latent classes have been defined, inactive covariates that were not included in the model can be used to characterize the individuals in each class and the households in which they live. The inactive covariates chosen describe those characteristics that may provide

\footnotetext{
${ }^{69}$ For the latest developments on active inclusion in Hungary, see EC (2013b).

70 This variable is constructed using the self-reported current work status in the EU-SILC survey that has four categories: at work, unemployed, retired and inactive. The unemployed are further classified into short- and long-term based on how long they have been actively looking for a job. The inactive is combined with another question to separate this group into students, disabled, military and other inactive. In the case of Hungary, the retired category also includes disabled.

${ }^{71}$ In order to construct this variable, individuals aged 25 or older are considered adults.

72 This is a binary variable that takes the value one if an individual answered "yes, strong limitations" to whether they had been hampered in their usual activities because of health problems for at least the last six months. The value is zero if the answer is "yes, limited" or "no, not limited."
} 
valuable information for the design of tailored policies that address barriers to employment, including income level. They include:

\section{$\checkmark$ Household welfare conditions:}

- Income quintile (defined by equivalized disposable household income ${ }^{73,74}$ )

- Labor, benefit, and other income as share of total gross household income ${ }^{75}$

- Working status of the partner

- Household ability to keep dwelling warm

- Partner's labor income

- Quintile of partner's labor income

- Tenure status

- Binary variables denoting whether individuals or their households are beneficiaries of any of eight social protection benefits ${ }^{76}$

- Share of benefits over the total household gross income

$\checkmark$ Household demographics:

- Household size

- Household composition

- Binary variable showing whether there are children under 6 in the household

- Binary variable denoting whether there are three or more under-16 children in the household

- Children under 13 receiving child care in the household: all, some or no children under 13 present

- Older person (65 and over) in the household

- Presence of individual's parents in the household

$\checkmark$ Other individual-level demographics:

- More refined age groups (eight groups)

- Marital status

$\checkmark$ Individual human capital:

- More refined highest educational level achieved (six groups)

- Work experience in years

\section{$\checkmark$ Household location:}

73 The equivalized household income takes into account an equivalence factor to weight the number of household members used in the denominator when calculating household income per capita. The first adult aged 18 or over has a weight of 1.0 , children under 14 have a weight of 0.3 , and other individuals 14 and older have a weight of 0.5 . The sum of the weights of all household members is equal to the equivalent household size.

${ }^{74}$ Note that income reported in EU-SILC surveys is for the year preceding the survey year.

75 Total household gross income is defined as the sum of: (at the individual level) gross employee cash or near-cash income; company car, gross cash benefits or losses from self-employment (including royalties); unemployment benefits; old-age benefits; survivor benefits; sickness benefits; disability benefits; education allowances; and (at the household level) income from rental of property or land; family/children related allowances; social exclusion not elsewhere classified; housing allowances; regular inter-household cash transfers received; interests, dividends, profit from capital investments in unincorporated business; pensions from individual private plans; and income received by people under 16. Total household net income, in turn, was calculated by subtracting from total household gross income regular taxes on wealth, taxes on income and social insurance contributions, and regular inter-household case transfers paid.

${ }^{76}$ Social benefits are aggregated in eight branches using the European System of integrated Social PROtection Statistics (ESSPROS) definitions. For more information, see Eurostat (2011). 
- Degree of urbanization: ${ }^{77}$ densely populated, intermediate area, sparsely populated

- Regional breakdown

Group labeling. The resulting groups are then labeled according to the greatest proportional characteristics within groups that also aid in distinguishing among groups. Granted, a large number of characteristics describe these groups, and only a few are taken into account for the purpose of labeling. In part, some of these characteristics may exhibit a large degree of heterogeneity and may thus not be relevant for defining a group. Additionally, some characteristics may be more relevant for the purposes of policy design than others. In short, though the labeling of groups can be considered more an art than a science, when taken together with detailed descriptions of a group's most prominent characteristics, labeling can serve as an important starting point in the design and prioritization of activation policies.

The analysis relies on cross-sectional as well as panel data from the European Union Statistics of Income and Living Conditions (EU-SILC) surveys for 2008-2011, which combine individual-level information with household characteristics. The first part of the note presents a cross-sectional analysis for the years 2008, 2009, 2010 and 2011. In particular, the latent class analysis on 2008 data shows the main characteristics of the out-of-work before the global economic crisis hit Hungary, and thus highlight what could be considered more structural issues of the country's labor market. The 2011 latent class analysis will contrast this initial assessment with more recent developments. The second part of the note exploits longitudinal data between 2008 and $2010^{78}$ to trace the prior labor market status of individuals observed last in 2010 in various classes, and will shed light on the relative persistence in the out-of-work status among different classes of individuals. The set of variables chosen for the cross-section and the longitudinal analysis are slightly different, due to minor differences in the set of variables recorded in each of the two types of datasets.

${ }^{77}$ According to EU-SILC guidelines, dense areas have more than 500 inhabitants per square kilometer, where the total population for the set is at least 50,000 inhabitants. Intermediate areas have more than 100 inhabitants per square kilometer, and either a total population for the set of at least 50,000 inhabitants or a location adjacent to a dense area. The remaining areas are categorized as sparsely populated.

78 The EU-SILC longitudinal survey consists of a four-year rotating panel. In each year, approximately three-quarters of individuals present in the previous year are retained. The samples used in the latent class analysis include about 6,000 observations for each year in the cross-sectional analysis and 1,150 observations in the longitudinal analysis. The population is weighted with individual weights. 


\section{Main Findings}

\section{Out-of-Work Population: Group Profiles from Cross-Section Analysis}

The latent class analysis supports the classification of the out-of-work into ten major groups, some of which have remained stable over time. The groups were named according to their most salient characteristics. Figure 6.4 shows the shares of each of the ten classes identified for the year 2011 while Table 6.2 presents their most salient characteristics.

\section{Figure 6.4 Classes of Out-of-Work Population in Hungary, 2011}

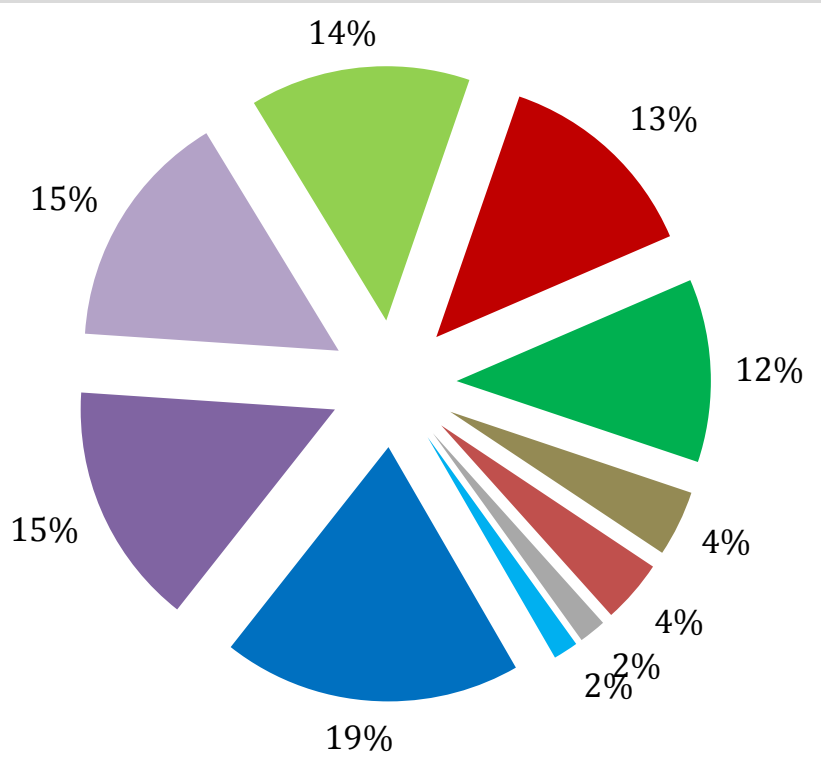

1. Disabled with previous work experience

2. Mostly male early retirees and retirees

- 3. Urban retired women

4. Prime-aged unemployed

घ. Prime-aged inactive mothers with work experience

6. Prime-aged long-term unemployed

7. Unemployed youth

n. Low-educated rural inactive mothers without work experience

-9. Educated single students

10. Low-educated disabled without work experience 


\begin{tabular}{|c|c|}
\hline $\begin{array}{l}\text { 1: Disabled with previous work experience } \\
\qquad(19 \%)\end{array}$ & $\begin{array}{l}\text { 2: Mostly male early retirees and retirees } \\
\qquad(15 \%)\end{array}$ \\
\hline $\begin{array}{l}\text { - } 94 \% \text { are disabled } \\
\text { - } \quad 50 \% \text { are men, } 50 \% \text { are women } \\
\text { - } \quad 60 \% \text { are } 45-59 \text { years old } \\
\text { partner } \\
\text { - } 35 \% \text { report strongly limited capacity to } \\
\text { work } \\
\text { - } 55 \% \text { have no working adults in household } \\
\text { - } \quad \text { Low-to-mid-skilled: } 37 \% \text { have not } \\
\text { completed upper secondary; } 58 \% \text { have } \\
\text { complete upper or post-secondary } \\
100 \% \text { worked before; } 98 \% \text { worked less } \\
\text { than } 2 \text { months in the last year; } 25 \text { years of } \\
\text { experience on average } \\
72 \% \text { live in households without dependent } \\
\text { children; } 11 \% \text { live alone } \\
\text { - } 63 \% \text { live in rural areas } \\
\text { High poverty risk: } 36 \% \text { are in poorest } \\
\text { quintile } \\
89 \% \text { receive disability benefits } \\
\text { Total household benefits represent } 64 \% \text { of } \\
\text { gross household income }\end{array}$ & $\begin{array}{l}\text { - } 100 \% \text { are retired } \\
\text { - } 62 \% \text { are men } \\
\text { - } 57 \% \text { are } 60-64 \text { years old; } 31 \% \text { are } 55-59 \\
\text { years old } \\
\text { - } 70 \% \text { are married } \\
12 \% \text { report strongly limited capacity to } \\
\text { work } \\
\text { - } \text { Low-to-mid-skilled: } 29 \% \text { have not } \\
\text { completed upper secondary; } 59 \% \text { have } \\
\text { complete upper or post-secondary } \\
\text { - } 99 \% \text { have worked before, } 90 \% \text { worked less } \\
\text { than } 2 \text { months in the last year; } 36 \text { years of } \\
\text { experience on average } \\
\text { - } 79 \% \text { live in households without dependent } \\
\text { children } \\
\text { - } 54 \% \text { live in rural areas } \\
\text { Very low poverty risk: } 13 \% \text { are in poorest } \\
\text { quintile } \\
\text { - } 90 \% \text { receive old-age benefits } \\
\text { Total household benefits represent } 67 \% \text { of } \\
\text { gross household income }\end{array}$ \\
\hline 3: Urban retired women (15\%) & 4: Prime-aged unemployed (14\%) \\
\hline $\begin{array}{l}\text { - } \quad 95 \% \text { are retired; } 5 \% \text { are disabled } \\
\text { - } \quad 80 \% \text { are women } \\
\text { - } \quad 96 \% \text { are } 60-64 \text { years old } \\
\text { - } \quad 60 \% \text { are married; } 21 \% \text { are widowed } \\
\text { - } \quad 79 \% \text { have no working adults in household } \\
\text { - } \quad \text { Low-to-mid-skilled: } 21 \% \text { have not } \\
\text { completed upper secondary; } 62 \% \text { have } \\
\text { complete upper or post-secondary } \\
\text { - } 98 \% \text { have worked before, but less than } 2 \\
\text { months in last year; } 36 \text { years of experience } \\
\text { on average } \\
\text { - } 91 \% \text { live in households without dependent } \\
\text { children; } 23 \% \text { live alone } \\
\text { - } 64 \% \text { live in urban areas } \\
\text { Very low poverty risk: } 12 \% \text { in poorest } \\
\text { quintile } \\
\text { - } 94 \% \text { receive old-age benefits } \\
\text { Total household benefits represent } 83 \% \text { of } \\
\text { gross household income }\end{array}$ & $\begin{array}{l}\text { - } 97 \% \text { are unemployed } \\
\text { - } \quad 60 \% \text { are men } \\
\text { - } \quad 76 \% \text { are } 25-54 \text { years old } \\
\text { - } 55 \% \text { have no working adults in household } \\
\text { - } \quad \text {-ow-to-mid-skilled: } 36 \% \text { have not } \\
\text { completed upper secondary; } 59 \% \text { have } \\
\text { complete upper or post-secondary } \\
\text { - } 100 \% \text { have worked before, } 93 \% 2 \text { or more } \\
\text { months in last year; } 16 \text { years of experience } \\
\text { on average } \\
\text { - } 51 \% \text { live in households with dependent } \\
\text { children; } 18 \% \text { live in households with } \\
\text { children under } 6 \\
\text { - } 59 \% \text { live in rural areas } \\
\text { Very high poverty risk: } 49 \% \text { in poorest } \\
\text { quintile } \\
\text { - } 5 \% \text { receive unemployment benefits; } 50 \% \\
\text { receive family/child benefits } \\
\text { Total household benefits represent 35\% of } \\
\text { gross household income }\end{array}$ \\
\hline
\end{tabular}


- $94 \%$ are inactive

- $100 \%$ are women

- $91 \%$ are 25-54 years old

- $82 \%$ have at least one working adult in household

- $73 \%$ have a working partner

- Mid-to-high-skilled: $57 \%$ with complete upper or post-secondary; $24 \%$ with complete tertiary

- $100 \%$ have worked before, $89 \%$ have worked less than 2 months in last year; 11 years of experience on average

- $91 \%$ live in households with dependent children; $72 \%$ live in households with children under 6

- High poverty risk: $32 \%$ in poorest quintile

- $92 \%$ receive family/child benefits

- Total household benefits represent $40 \%$ of gross household income
- $86 \%$ are long-term unemployed; $14 \%$ are inactive

- $57 \%$ are men

- $75 \%$ are $25-54$ years old ; $18 \%$ are 54 to 59 years old

- $59 \%$ have no working adults in household

- Low-to-mid-skilled: $38 \%$ have not completed upper secondary; $56 \%$ have complete upper or post-secondary

- $99 \%$ worked before, but less than 2 months in last year; 18 years of experience on average

- $50 \%$ live in households with dependent children; $19 \%$ live in households with children under 6

- $50 \%$ live in rural areas

- Extreme poverty risk: $65 \%$ in poorest quintile

- $49 \%$ receive unemployment benefits; $49 \%$ receive family/child benefits

- Total household benefits represent $56 \%$ of gross household income
7: Unemployed youth (4\%)

- $47 \%$ are long-term unemployed; $43 \%$ are unemployed

- $56 \%$ are men

- $91 \%$ are $16-24$ years old

- $78 \%$ have at least one working adult in household

- $57 \%$ are married

- Mid-skilled: $66 \%$ have complete upper or post-secondary

- $18 \%$ have worked before, but less than 2 months in last year; 2 years of experience on average

- $89 \%$ live with at least one parent

- High poverty risk: $44 \%$ in poorest quintile

- Total household benefits represent $33 \%$ of gross household income
8: Low-educated rural inactive mothers without work experience (4\%)

- $88 \%$ are inactive; $12 \%$ are long-term unemployed

- $90 \%$ are women

- $84 \%$ are $16-34$ years old

- $62 \%$ are never married; $63 \%$ have a partner

- $53 \%$ have at least one working adult in household

- Low-skilled: 78\% have not completed upper secondary

- $78 \%$ have never worked before

- $88 \%$ live in households with dependent children; $62 \%$ live in households with children under 6

- $70 \%$ live in rural areas

- Extreme poverty risk: $77 \%$ in poorest quintile

- $86 \%$ receive family/child benefits; $38 \%$ receive housing allowance; $29 \%$ receive social exclusion benefits

- Total household benefits represent $57 \%$ of gross household income 
- $90 \%$ are inactive

- $63 \%$ are men

- $\quad 91 \%$ are 25 to 29 years old

- $79 \%$ have at least one working adult in household

- Mid-to-high-skilled: $68 \%$ with complete upper or post-secondary; $32 \%$ with complete tertiary

- $\quad 99 \%$ have never worked before

- $81 \%$ are enrolled in education

- $82 \%$ live with at least one parent

- $94 \%$ are single

- $77 \%$ live in urban areas

- $\quad$ Moderate poverty risk: $23 \%$ in poorest quintile

- $\quad 23 \%$ receive education allowance

- Total household benefits represent $22 \%$ of gross household income
- $85 \%$ are disabled

- $52 \%$ are women

- $88 \%$ are 20 to 54 years old

- $67 \%$ report strongly limited capacity to work

- $58 \%$ have no working adults in the household

- $100 \%$ have never worked before

- Low skilled: $60 \%$ have not completed upper secondary; an additional $15 \%$ have never studied before

- $\quad 76 \%$ live with at least one parent

- High poverty risk: $46 \%$ in poorest quintile

- $74 \%$ receive disability benefits; $59 \%$ receive family/child benefits; $45 \%$ receive old-age benefits at household level

- Total household benefits represent $71 \%$ of gross household income

Source: World Bank staff analysis based on EU-SILC

Note: Percentages in parentheses following the group names refer to the share of the total out-of-work population. "Years of work experience" refer only to those individuals who have worked before.

"Dependent children" include children under 18 and household members aged 18 to 24 who are economically inactive and living with at least one parent. "Working adult" refers to adults aged 25 and over. For this report's purposes, we define the at-risk-of-poverty rate as the relative risk of being in the first quintile of the income distribution. The reference period for income reported in EU-SILC surveys is the year preceding the survey year.

The ten main groups emerging from the LCA analysis in 2011 can be characterized as follows (see Annex 2 for more detail, including the full list of inactive covariates):

$\checkmark \quad$ Cluster 1: Disabled with previous work experience. This group, representing almost one fifth of our sample of out-of-work in 2011, reports its economic status as disabled and most of them (89 percent) receives disability benefits ${ }^{79}$, despite the fact that only 35 percent report strong physical limitations on their ability to work. A majority (63 percent) live in rural areas. It is likely that many in this group could be work-ready: most has worked before, with 25 years of work experience on average, and educational attainment is in the low to mid-range: 37 percent have not completed upper secondary, while 58 percent have complete upper secondary or post-secondary. The group is equal parts men and women and most (78 percent) are between 45 and 59 years of age. Just over half do not report at least one adult working in the household, and overall benefits amount to 64 percent of total gross household income. ${ }^{80}$ Their risk of poverty ${ }^{81}$ is high, with 36 percent living in the first income quintile.

\footnotetext{
${ }^{79}$ It should be kept in mind that the EU-SILC activity status is self-reported; therefore the disabled population count may not be accurate when compared with administrative data.

${ }^{80}$ Disability benefits amount to 38 percent of total gross household income.

81 Risk of poverty is here understood as the relative probability of living in the poorest income quintile. By definition, 20 percent of the population lives in this quintile; risk is thus gauged relative to a benchmark of 20 percent.
} 
$\checkmark \quad$ Cluster 2: Mostly male early retirees and retirees. This group represented 15 percent of the out-of-work population in 2011. It comprises mostly men (62 percent), and all of its members are retired, with 90 percent receiving old-age benefits. A slim majority ( 57 percent) are 60 to 64 years old, meaning that they are likely to have reached the retirement age of 62 . The remaining 43 percent can be considered early retired, of which the majority are in the 55- to 59-age range. Because they are retired, this group's members all have work experience, but only 9 percent report having worked for two or more months during the last year. They are low to mid-skilled: almost one-third have not completed upper secondary school; the majority (59 percent) have completed upper or post-secondary education. Just over one-half do not report any working adults in the household. The benefit levels received by this group and their households appear to be generous: benefits represent 67 percent of total gross household income, and only 13 percent of households are in the poorest income quintile.

$\checkmark$ Cluster 3: Urban retired women. Like cluster 2 (mostly male early retirees and retirees), this group of retirees represented 15 percent of the out-of-work sample in 2011. In contrast to that group, however, nearly all the retirees in this group have reached retirement age, as 96 percent are 60 to 64 years old. They are also predominantly female ( 80 percent) and mostly live in urban areas (64 percent). Another characteristic that distinguishes them from cluster 2 is that 79 percent do not have any working adults in their households. As such, total benefits represent 83 percent of gross household income, the highest share among all identified groups. Benefits also appear to be sufficiently generous, as only 12 percent of this group lives among the poorest quintile.

$\checkmark$ Cluster 4: Prime-aged unemployed. This group made up 14 percent of the out-ofwork in 2011. Its members are newly unemployed individuals who worked for two or more months during the last year, and who, on average, have 16 years of work experience. They are mostly men (60 percent) in their prime age and are concentrated in rural areas (59 percent). Over one-third have not completed upper secondary school, and 59 percent have completed upper or post-secondary studies, making this a low-to-mid skilled group. Half of this group live in households with dependent children. One-half also receive family/child benefits, and a small majority receive unemployment benefits. One-half of the group's members (55 percent) do not have any working adults in the household, and over all, benefits make up just over a third of their total household income. The group has a very high risk of poverty, as 49 percent live in the poorest quintile.

$\checkmark$ Cluster 5: Prime-aged inactive mothers with work experience. This group of prime-aged (25 to 54) women represented 13 percent of the out-of-work in 2011. Given that 91 percent live in households with dependent children (72 percent live in households with children under six), and that, for the most part, these inactive women have working partners, they are likely to be stay-at-home mothers. However, their work experience and relatively high educational attainment-24 percent of them have completed a tertiary degree — make the members of this group labor- market ready. Ninety-two percent receive family-child benefits, and, on average, total household benefits represent 40 percent of gross household income. Perhaps due to a relatively large average household size of 4.2 members, this group has a high risk of poverty, with 32 percent in the poorest income quintile.

Portraits of Labor Market Exclusion | 177 
$\checkmark \quad$ Cluster 6: Prime-aged long-term unemployed. This group represented 12 percent of the out-of-work in 2011 and resembles the larger group of prime-aged unemployed. Like its newly unemployed counterparts, the long-term unemployed members of this group comprise mostly men (57 percent) who for the most part are in their prime (25 to 54). This group, however, is somewhat skewed toward older individuals, and a non-negligible 18 percent are 54 to 59 years old. Furthermore, the group is less rural, with a 50/50 urban/rural split, and a slightly larger majority (59 percent) of households are without any working adults. However, the educational attainment of this group is very similar, with 36 percent having not completed an upper secondary education and 59 percent having completed upper or postsecondary school. The members of this group are just as likely as the larger group to have dependent children in their households (50 percent), as well as to receive family/child benefits. Interestingly, they are only marginally less likely to receive unemployment benefits ( 49 percent), despite the fact that they have been unemployed for at least 12 months. Again, total household benefits make up a very similar percentage of total household income (57 percent). Nonetheless, despite having slightly smaller households (3.4 members, versus 3.5 for their newly unemployed counterparts) this group is more likely to be living in poverty. With 65 percent in the poorest quintile, this group has the second highest risk of poverty among the ten identified groups.

$\checkmark \quad$ Cluster 7: Unemployed youth. Making up just 4 percent of the out-of-work in 2011, this group comprises both long-term and newly unemployed youth aged 16 to 24 and resembles the unemployed youth who have been largely affected by the crisis in Europe. Owing to their young age, this group has very little work experience, with only 18 percent having worked before. They are for the most part mid-skilled, as 66 percent have completed upper or post-secondary education. More than half are also in households that receive family/child benefits and one-fifth receive unemployment benefits. Despite the fact that these never-married individuals are still living in their birth households - 78 percent of which have at least one working adult - they remain at a high risk for poverty: 44 percent live in the poorest income quintile. With benefits making up 33 percent of total household income, their benefit dependence is low in comparison to most other groups.

$\checkmark \quad$ Cluster 8: Low-educated rural inactive mothers without work experience. This group, amounting to about 4 percent of the out-of-work population in 2011, is composed of relatively young, inactive women (16 to 34 years old) living in rural areas. They are likely to be mothers, as 88 percent live in households with dependent children (62 percent with children under six). In contrast to the larger group of prime-aged inactive mothers with work experience, this group has lower prospects for labor market insertion, as they do not have previous work experience and have low educational attainment, with the great majority (78 percent) not finishing upper secondary school. Another distinguishing feature of this group is that the majority (62 percent) has never been married and just over half do not have a working adult in their households. Like their counterparts with work experience, the great majority receive family/child benefits. However, 29 percent also receive social exclusion benefits and 38 percent receive housing allowances, perhaps reflecting their lower socioeconomic status. Benefits make up more than half (57 
percent) of household income. Nonetheless, this group has the highest risk of poverty among the ten identified groups: 77 percent live in the poorest quintile.

$\checkmark \quad$ Cluster 9: Educated single students. This group only amounted to 2 percent of the out-of-work in 2011 and comprises students ( 81 percent) who are aged 25 to 29 (91 percent). This group is the most educated of the ten, with close to one-third having completed tertiary education; an additional 68 percent have completed upper or secondary education. Despite being over 24 years of age, the members of this group have never worked before. Like the unemployed youth, they have also never married and for the most part are still living with their parents, in households that predominantly have at least one working adult. However, unlike their unemployed youth counterparts, they tend to live in urban areas, where educational opportunities are likely to be more abundant. Twenty-three percent of them receive an educational allowance, and benefits make up 22 percent of total gross income, the lowest share among all groups. With 23 percent in the poorest income group, this group has a moderate risk of poverty.

$\checkmark \quad$ Cluster 10: Low-educated disabled without work experience. Like the group of young students, this group represented only 2 percent of the out-of-work in 2011. Its members report their labor market status as disabled, but unlike the larger group of disabled (disabled with previous work experience), none have ever worked before and most (67 percent) report that their capacity to work is strongly limited. Nonetheless, the percentage that reports receiving disability benefits ( 74 percent) is lower than that of the disabled with previous work experience (89 percent). Just over half are women, and their ages span a larger range, with 80 percent between 20 and 54 years of age. Likely due to their disability status, their educational attainment is low: 15 percent have never attended school, 22 percent have never finished primary school, and another 38 percent have never finished lower secondary. Another characteristic that distinguishes this group from their disabled counterparts with work experience is that they have never married and are still living with their parents. Just over half report having at least one working adult in their households, and benefit dependency is high: 71 percent of total gross household income is composed of benefits, second only to the group of urban retired women. This group is also at a high risk for poverty, as 46 percent of them live among the poorest quintile. 
The following two tables present the main characteristics of each group in 2011. For the complete table, including inactive covariates, see Annex 2.

Table 6.3 Latent Classes of Out-of-Work Population in Hungary-Indicators (2011)

\begin{tabular}{|c|c|c|c|c|c|c|c|c|c|c|c|}
\hline & $\begin{array}{l}\text { All Out-of- } \\
\text { Work }\end{array}$ & $\begin{array}{l}\text { 1. Disabled } \\
\text { with } \\
\text { previous } \\
\text { work } \\
\text { experience }\end{array}$ & $\begin{array}{l}2 . \\
\text { Mostly } \\
\text { male } \\
\text { early } \\
\text { retirees } \\
\text { and } \\
\text { retirees }\end{array}$ & $\begin{array}{c}3 . \\
\text { Urban } \\
\text { retired } \\
\text { women }\end{array}$ & $\begin{array}{l}\text { 4. Prime- } \\
\text { aged un- } \\
\text { employed }\end{array}$ & $\begin{array}{l}\text { 5. Prime- } \\
\text { aged } \\
\text { inactive } \\
\text { mothers } \\
\text { with work } \\
\text { experience }\end{array}$ & $\begin{array}{l}\text { 6. Prime- } \\
\text { aged long- } \\
\text { term } \\
\text { unemployed }\end{array}$ & $\begin{array}{l}\text { 7. Un- } \\
\text { employed } \\
\text { youth }\end{array}$ & $\begin{array}{l}\text { 8. Low- } \\
\text { educated } \\
\text { rural } \\
\text { inactive } \\
\text { mothers } \\
\text { without } \\
\text { work } \\
\text { experience }\end{array}$ & $\begin{array}{c}9 . \\
\text { Educated } \\
\text { single } \\
\text { students }\end{array}$ & $\begin{array}{l}\text { 10. Low- } \\
\text { educated } \\
\text { disabled } \\
\text { without } \\
\text { work } \\
\text { experience }\end{array}$ \\
\hline Cluster size & $100 \%$ & $19 \%$ & $15 \%$ & $15 \%$ & $14 \%$ & $13 \%$ & $12 \%$ & $4 \%$ & $4 \%$ & $2 \%$ & $2 \%$ \\
\hline Population & $2,277,342$ & 432,012 & 351,394 & 346,839 & 318,600 & 301,065 & 265,310 & 95,648 & 91,094 & 39,170 & 36,210 \\
\hline
\end{tabular}

\section{Labor market attachment}

\begin{tabular}{|c|c|c|c|c|c|c|c|c|c|c|c|}
\hline Unemployed & $16 \%$ & $1 \%$ & $0 \%$ & $0 \%$ & $97 \%$ & $3 \%$ & $0 \%$ & $43 \%$ & $0 \%$ & $6 \%$ & $1 \%$ \\
\hline $\begin{array}{l}\text { Long-term } \\
\text { unemployed }\end{array}$ & $13 \%$ & $3 \%$ & $0 \%$ & $0 \%$ & $0 \%$ & $3 \%$ & $86 \%$ & $47 \%$ & $12 \%$ & $3 \%$ & $6 \%$ \\
\hline Retired & $30 \%$ & $0 \%$ & $100 \%$ & $95 \%$ & $0 \%$ & $0 \%$ & $0 \%$ & $0 \%$ & $0 \%$ & $0 \%$ & $2 \%$ \\
\hline Disabled & $20 \%$ & $94 \%$ & $0 \%$ & $5 \%$ & $0 \%$ & $0 \%$ & $0 \%$ & $0 \%$ & $0 \%$ & $1 \%$ & $85 \%$ \\
\hline Other inactive & $21 \%$ & $2 \%$ & $0 \%$ & $0 \%$ & $3 \%$ & $94 \%$ & $14 \%$ & $11 \%$ & $88 \%$ & $90 \%$ & $6 \%$ \\
\hline
\end{tabular}

\section{At least one working adult in household}

\begin{tabular}{|c|c|c|c|c|c|c|c|c|c|c|c|}
\hline No & $51 \%$ & $55 \%$ & $52 \%$ & $79 \%$ & $55 \%$ & $18 \%$ & $59 \%$ & $22 \%$ & $47 \%$ & $21 \%$ & $58 \%$ \\
\hline Yes & $49 \%$ & $45 \%$ & $48 \%$ & $21 \%$ & $45 \%$ & $82 \%$ & $41 \%$ & $78 \%$ & $53 \%$ & $79 \%$ & $42 \%$ \\
\hline \multicolumn{12}{|l|}{ Work experience } \\
\hline Never worked & $10 \%$ & $0 \%$ & $0 \%$ & $1 \%$ & $0 \%$ & $0 \%$ & $1 \%$ & $82 \%$ & $78 \%$ & $99 \%$ & $100 \%$ \\
\hline $\begin{array}{l}\text { Less than } 2 \text { months } \\
\text { in last year }\end{array}$ & $73 \%$ & $98 \%$ & $90 \%$ & $98 \%$ & $7 \%$ & $89 \%$ & $99 \%$ & $18 \%$ & $21 \%$ & $1 \%$ & $0 \%$ \\
\hline $\begin{array}{l}2 \text { or more months } \\
\text { in last year }\end{array}$ & $16 \%$ & $2 \%$ & $9 \%$ & $1 \%$ & $93 \%$ & $11 \%$ & $0 \%$ & $0 \%$ & $2 \%$ & $0 \%$ & $0 \%$ \\
\hline \multicolumn{12}{|c|}{ Self-assessed physical incapacity } \\
\hline Strongly limited & $12 \%$ & $35 \%$ & $12 \%$ & $8 \%$ & $3 \%$ & $2 \%$ & $3 \%$ & $0 \%$ & $0 \%$ & $0 \%$ & $67 \%$ \\
\hline None/limited & $88 \%$ & $65 \%$ & $88 \%$ & $92 \%$ & $97 \%$ & $98 \%$ & $97 \%$ & $100 \%$ & $100 \%$ & $100 \%$ & $33 \%$ \\
\hline
\end{tabular}

Source: World Bank staff analysis based on EU-SILC 
Table 6.4 Latent Classes of Out-of-Work Population in Hungary-Active Covariates (2011)

\begin{tabular}{|c|c|c|c|c|c|c|c|c|c|c|c|}
\hline & $\begin{array}{l}\text { All Out-of- } \\
\text { Work }\end{array}$ & $\begin{array}{l}\text { 1. Disabled } \\
\text { with } \\
\text { previous } \\
\text { work } \\
\text { experience }\end{array}$ & $\begin{array}{c}2 . \\
\text { Mostly } \\
\text { male } \\
\text { early } \\
\text { retirees } \\
\text { and } \\
\text { retirees }\end{array}$ & $\begin{array}{c}3 . \\
\text { Urban } \\
\text { retired } \\
\text { women }\end{array}$ & $\begin{array}{l}\text { 4. Prime- } \\
\text { aged un- } \\
\text { employed }\end{array}$ & $\begin{array}{l}\text { 5. Prime- } \\
\text { aged } \\
\text { inactive } \\
\text { mothers } \\
\text { with work } \\
\text { experience }\end{array}$ & $\begin{array}{l}\text { 6. Prime- } \\
\text { aged long- } \\
\text { term un- } \\
\text { employed }\end{array}$ & $\begin{array}{l}\text { 7. Un- } \\
\text { employed } \\
\text { youth }\end{array}$ & $\begin{array}{l}\text { 8. Low- } \\
\text { educated } \\
\text { rural } \\
\text { inactive } \\
\text { mothers } \\
\text { without } \\
\text { work } \\
\text { experience }\end{array}$ & $\begin{array}{c}9 . \\
\text { Educated } \\
\text { single } \\
\text { students }\end{array}$ & $\begin{array}{l}\text { 10. Low- } \\
\text { educated } \\
\text { disabled } \\
\text { without } \\
\text { work } \\
\text { experience }\end{array}$ \\
\hline Cluster size & $100 \%$ & $19 \%$ & $15 \%$ & $15 \%$ & $14 \%$ & $13 \%$ & $12 \%$ & $4 \%$ & $4 \%$ & $2 \%$ & $2 \%$ \\
\hline Population & $2,277,342$ & 432,012 & 351,394 & 346,839 & 318,600 & 301,065 & 265,310 & 95,648 & 91,094 & 39,170 & 36,210 \\
\hline \multicolumn{12}{|c|}{ ACTIVE COVARIATES } \\
\hline \multicolumn{12}{|l|}{ Age groups (4) } \\
\hline $16-24$ years & $9 \%$ & $0 \%$ & $0 \%$ & $0 \%$ & $14 \%$ & $3 \%$ & $5 \%$ & $91 \%$ & $52 \%$ & $0 \%$ & $31 \%$ \\
\hline $25-34$ years & $17 \%$ & $2 \%$ & $0 \%$ & $0 \%$ & $25 \%$ & $50 \%$ & $20 \%$ & $9 \%$ & $32 \%$ & $100 \%$ & $33 \%$ \\
\hline $35-59$ years & $48 \%$ & $88 \%$ & $43 \%$ & $4 \%$ & $60 \%$ & $45 \%$ & $73 \%$ & $0 \%$ & $15 \%$ & $0 \%$ & $34 \%$ \\
\hline 60-64 years & $26 \%$ & $10 \%$ & $57 \%$ & $96 \%$ & $1 \%$ & $1 \%$ & $2 \%$ & $0 \%$ & $1 \%$ & $0 \%$ & $2 \%$ \\
\hline \multicolumn{12}{|l|}{ Gender } \\
\hline Male & $42 \%$ & $50 \%$ & $62 \%$ & $20 \%$ & $60 \%$ & $0 \%$ & $57 \%$ & $56 \%$ & $10 \%$ & $63 \%$ & $48 \%$ \\
\hline Female & $58 \%$ & $50 \%$ & $38 \%$ & $80 \%$ & $40 \%$ & $100 \%$ & $43 \%$ & $44 \%$ & $90 \%$ & $37 \%$ & $52 \%$ \\
\hline \multicolumn{12}{|l|}{ Education (4) } \\
\hline Primary & $32 \%$ & $37 \%$ & $29 \%$ & $21 \%$ & $36 \%$ & $19 \%$ & $38 \%$ & $20 \%$ & $78 \%$ & $0 \%$ & $60 \%$ \\
\hline Secondary & $57 \%$ & $58 \%$ & $59 \%$ & $62 \%$ & $59 \%$ & $57 \%$ & $56 \%$ & $60 \%$ & $21 \%$ & $68 \%$ & $23 \%$ \\
\hline Tertiary & $11 \%$ & $5 \%$ & $12 \%$ & $17 \%$ & $5 \%$ & $24 \%$ & $6 \%$ & $20 \%$ & $2 \%$ & $32 \%$ & $1 \%$ \\
\hline $\begin{array}{l}\text { Never studied } \\
\text { before/illiterate/NA }\end{array}$ & $0 \%$ & $0 \%$ & $0 \%$ & $1 \%$ & $0 \%$ & $0 \%$ & $0 \%$ & $1 \%$ & $0 \%$ & $0 \%$ & $15 \%$ \\
\hline Urban & $48 \%$ & $37 \%$ & $46 \%$ & $64 \%$ & $41 \%$ & $52 \%$ & $50 \%$ & $45 \%$ & $30 \%$ & $77 \%$ & $47 \%$ \\
\hline Rural & $52 \%$ & $63 \%$ & $54 \%$ & $36 \%$ & $59 \%$ & $48 \%$ & $50 \%$ & $55 \%$ & $70 \%$ & $23 \%$ & $53 \%$ \\
\hline
\end{tabular}


Although a small number of the identified classes of the out-of-work population have been quite stable over the last few years, most of the identified classes experienced changes in their composition and also in the share they represent among the out-ofwork. In Table 6.5, clusters are compared over time between 2008 and 2011 as a share of the total out-of-work population, while Figure 6.5 shows the absolute numbers. From the graph, the first important observation is that the size of the out-of-work population has just slightly increased-by 1 percent-between 2008 and 2011. However, some clusters have changed across time; for example, clusters identified in 2011 that were present in previous years underwent changes in relative size and also in composition. The fact that the composition of the groups changes over time is particularly important to keep in mind when interpreting changes in group size. For instance, significant increases (decreases) in group size are sometimes due to reassignments of individuals across groups, resulting in changes in group composition. Thus, although some groups may retain similar names across years due to their most salient characteristics, they may nonetheless vary in their composition across years. The evolution in terms of group size and group composition over the 20082011 period can be summarized as follows:

$\checkmark \quad$ The composition of the group of disabled with previous work experience has been quite stable over time, but its relative and absolute size has decreased. The share of this cluster in the out-of-work population was 29 percent in 2008. In 2011, it reached 19 percent (although it was still the largest cluster). This represented an approximate 33 percent decline in absolute numbers. More than 90 percent of the individuals in this cluster reported being disabled and around 35 percent of them claimed to have a strong limitation on work capacity due to their health. Indeed, 84 and 89 percent of them were receiving disability benefits in 2008 and 2011, respectively. Among the characteristics that have been quite stable, more than 80 percent are between 35 and 59 years old, around 40 percent live in urban areas and a minimum of 60 percent have at least an upper secondary education.

$\checkmark \quad$ The early retirees and retirees were a single group from 2008 to 2009. In 2011, retirees were classified as either mostly male early retirees and retirees or urban retired women. Taken together, they represent an absolute size increase of $\mathbf{1 1}$ percent when compared to the original group in 2008. The cluster of early retirees and retirees changed in size and composition over time. In 2011, it was called mostly male early retirees and retirees because the female share fell from 62 percent in 2008 to only 38 percent in 2011. This group also became less urban - the share of individuals living in urban areas fell from 59 to 46 percent over the period. It also became relatively younger-in 2008, 28 and 70 percent were 45 to 59 and 60 to 64 years old, respectively; in 2011 these shares changed to 39 and 57 percent. Despite those differences in composition over time, around 90 percent of the individuals in this cluster are receiving old-age benefits and have on average more than 35 years of work experience.

$\checkmark \quad$ In its turn, the cluster of urban retired women-which appeared as a separate group beginning in 2009-became more urban, female and 
older. From being 18 percent of the out-of-work population in 2009, this cluster lost almost 50,000 individuals, reducing its share to 15 percent in 2011. Not only has its size changed, but individuals classified in this cluster became older-in 2011, 96 percent of them were between 60 and 64 years old, against 76 percent in 2009- the share of women increased from 68 to 80 percent during the same period, and they are more likely to be living in urban areas than before.

$\checkmark \quad$ One important change observed is the increase in unemployment among prime-aged individuals. Two clusters of prime-aged unemployed were identified in all the years, one of newly unemployed and the other representing those who have been unemployed for more than 12 months. Regardless of the year of analysis, the group of long-term unemployed comprises older individuals who are also more likely to be living in poverty. And from 2008 to 2011 , both of these clusters increased in size. The prime-aged unemployed faced an increase of 37 percent during this period, while the prime-aged long-term unemployed grew around 35 percent. However, not only did these clusters increase in size, but the composition of their members' labor market status changed. Among the prime-aged unemployed, the share of individuals who reported being inactive fell from 31 to 3 percent, while the share of unemployed grew from 64 to 97 percent. Among the prime-aged long-term unemployed the share of inactive fell from 27 to 14 percent, while the share of long-term unemployed increased from 70 to 86 percent.

$\checkmark$ Across time, different clusters of young individuals were found. It can be noticed that they have become relatively more likely to be unemployed and less likely to be inactive. Until 2009, 8 percent of the out-of-work population was represented by the low-educated inactive young women without work experience, but in the next years the composition of the clusters of younger individuals would become more defined and new clusters could be identified. Indeed, in 2010, this cluster of inactive young women itself represented a higher percentage of females, increasing from 69 to 81 percent of the total. In 2011, this cluster was replaced by the low-educated rural inactive mothers without work experience. Women represented 90 percent of this group, whose members were more likely to be living in rural areas. Sixty-three percent had a partner (regardless of marital status). This group was also less likely to report living with parents in the same household, and was less educated (78 percent had completed up to lower secondary education). In 2010, the cluster of unemployed youth appeared, representing 3 percent of the out-of-work population. In 2011, more than 20,000 young individuals were added to this cluster, an increase of more than 30 percent. So, in the last year analyzed, three clusters of young individuals were identified: unemployed youth (4 percent), low-educated rural inactive mothers without work experience (4 percent) and educated single youth ( 2 percent). Even accounting for the presence of inactive youth in the cluster of unemployed and for the unemployed youth in the cluster of inactive, the percentage of young individuals that were classified as unemployed increased from 25 percent to 44 percent from 2008 to 2011. In addition, the absolute size of these youth clusters has become 22 percent larger during this same period. 
$\checkmark \quad$ Finally, the prime-aged inactive mothers with work experience and the loweducated disabled without work experience clusters remained most stable during the period in analysis, both in size and composition. The cluster of inactive mothers with work experience represented around 13 percent of the out-of-work individuals between 2008 and 2011, which in absolute numbers accounted for a slight decrease of 7 percent in its size-a reduction of around 23,000 people. Not only has its share been maintained, its composition also has not experienced considerable changes. For the group of disabled without work experience, which represented only 2 percent of the out-of-work population during these four years, characteristics have only changed slightly. This group reported an increase in the share of people with a strong limitation on ability to work, from 61 to 67 percent; its members became more likely to be living in urban areas-from 37 percent in 2008 to 47 percent in 2011-and the share of women also rose, from 41 to 52 percent.

\begin{tabular}{|c|c|c|c|c|}
\hline Name of Cluster & 2008 & 2009 & 2010 & 2011 \\
\hline Disabled with previous work experience & $29 \%$ & $25 \%$ & $17 \%$ & $19 \%$ \\
\hline Mostly male early retirees and retirees (only 2011) & & & & $15 \%$ \\
\hline Early retirees and retirees (except 2011) & $28 \%$ & $13 \%$ & $19 \%$ & \\
\hline Urban retired women (except 2008) & & $18 \%$ & $15 \%$ & $15 \%$ \\
\hline Prime-aged unemployed & $10 \%$ & $10 \%$ & $13 \%$ & $14 \%$ \\
\hline Prime-aged inactive mothers with work experience & $14 \%$ & $14 \%$ & $13 \%$ & $13 \%$ \\
\hline Prime-aged long-term unemployed & $9 \%$ & $10 \%$ & $11 \%$ & $12 \%$ \\
\hline Unemployed youth (2010 and 2011) & & & $3 \%$ & $4 \%$ \\
\hline $\begin{array}{l}\text { Low-educated rural inactive mothers without work } \\
\text { experience (only 2011) }\end{array}$ & & & & $4 \%$ \\
\hline $\begin{array}{l}\text { Low-educated inactive young women without work } \\
\text { experience (except 2011) }\end{array}$ & $8 \%$ & $8 \%$ & $7 \%$ & \\
\hline Educated single students (only 2011) & & & & $2 \%$ \\
\hline Low-educated disabled without work experience & $2 \%$ & $2 \%$ & $2 \%$ & $2 \%$ \\
\hline
\end{tabular}


Figure 6.5 Classes of Out-of-Work Population in Hungary, 2008- 2011 (Number of Individuals)

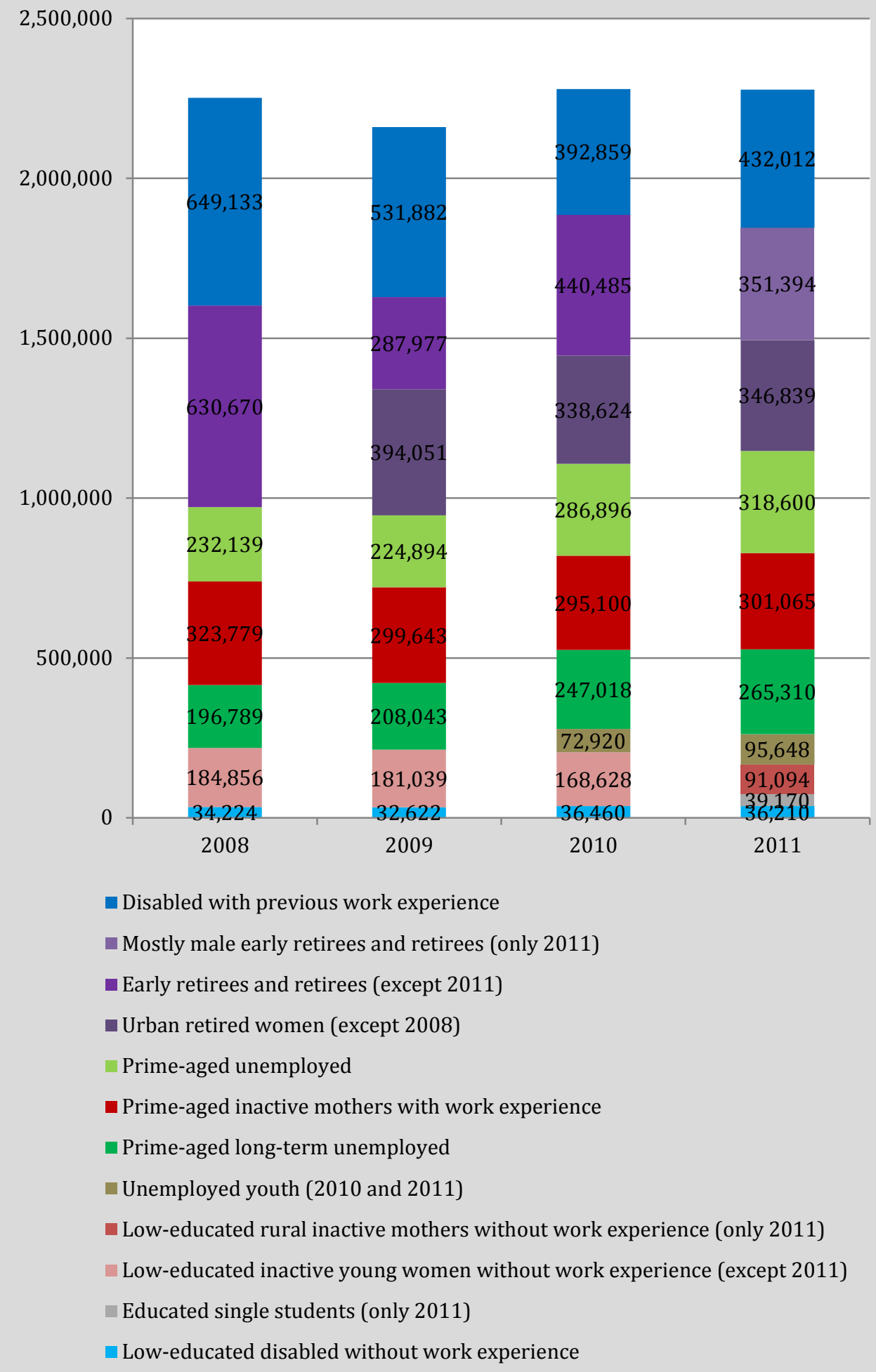

Source: World Bank staff analysis based on EU-SILC 
The clusters identified in the out-of-work population for the period from 2008 to 2011 reflect both structural and cyclical aspects of the labor market. This section identifies some of the key structural aspects of the Hungarian labor market and uses cross-sectional and longitudinal analysis of clusters of the out-of-work population to further examine the effects of the crisis.

The youth labor force participation rate in Hungary was the second lowest in Europe in 2013. Since 2007, Hungary's NEET rate has increased, reaching 15.4 percent in 2013. The youth labor force participation rate, at only 27.2 percent in 2013, is the second lowest among the countries in the region (Figure 6.6), and pales in comparison to the EU average of 42.2 percent. Two aspects might account for the low activity rate among the youth. In many EU countries, youth have higher labor force participation rates partly because they are able to combine their studies with part-time work. For example, as many as 75 percent and 40 percent of youth in the Netherlands and Slovenia, respectively, reported working part-time (Dimitrov and Duell, 2013). However, in 2013, only about 10 percent of the youth in Hungary (15 to 24 years old) reported working part-time (Eurostat). Also, the labor tax wedge $^{82}$ is one of the highest in the European Union (Figure 6.7). Lower take-home wages reduce labor supply at the extensive margin, primarily for younger and older workers (EEAG, 2012).

Figure 6.6 Labor Force Participation Among Youth Aged 15 to 24, European Countries (2013)

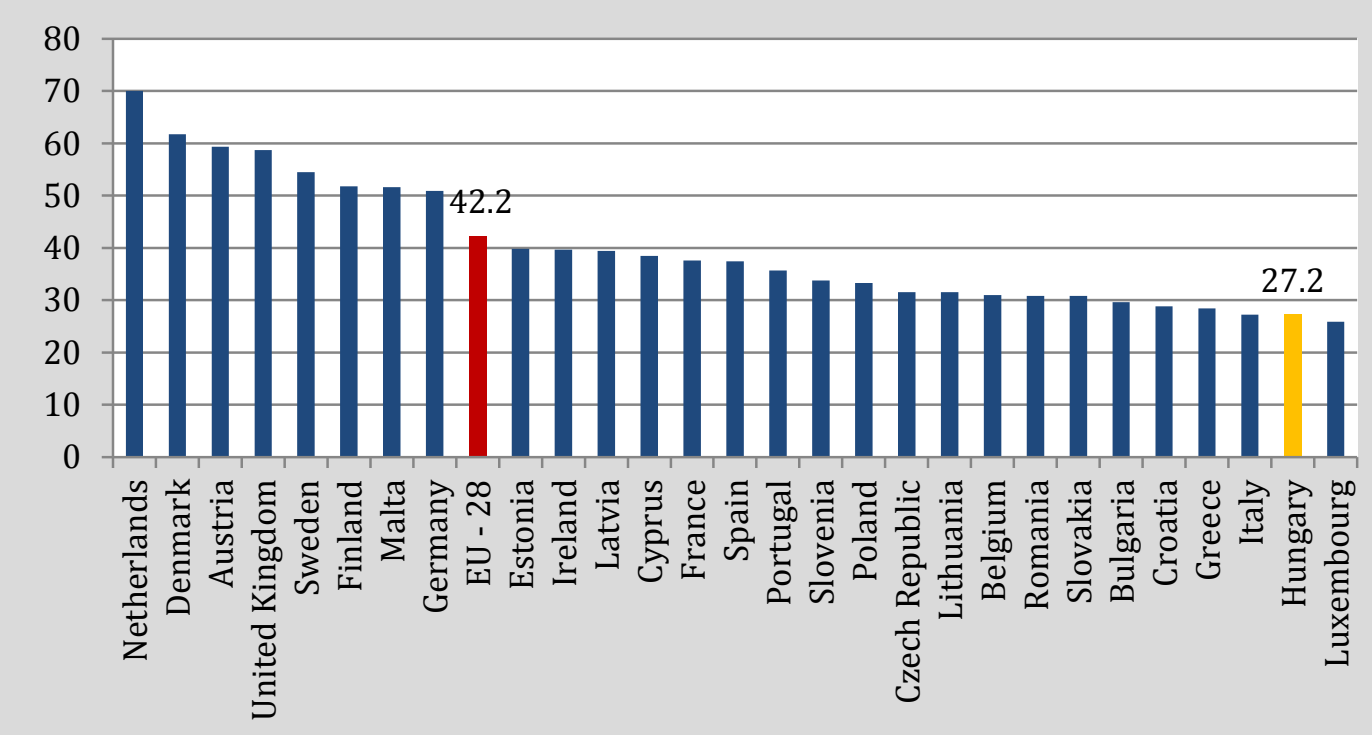

Source: Eurostat, EU-LFS

82 The tax wedge is defined as the difference between labor's cost to the employer and the corresponding net take-home pay of the employee. 


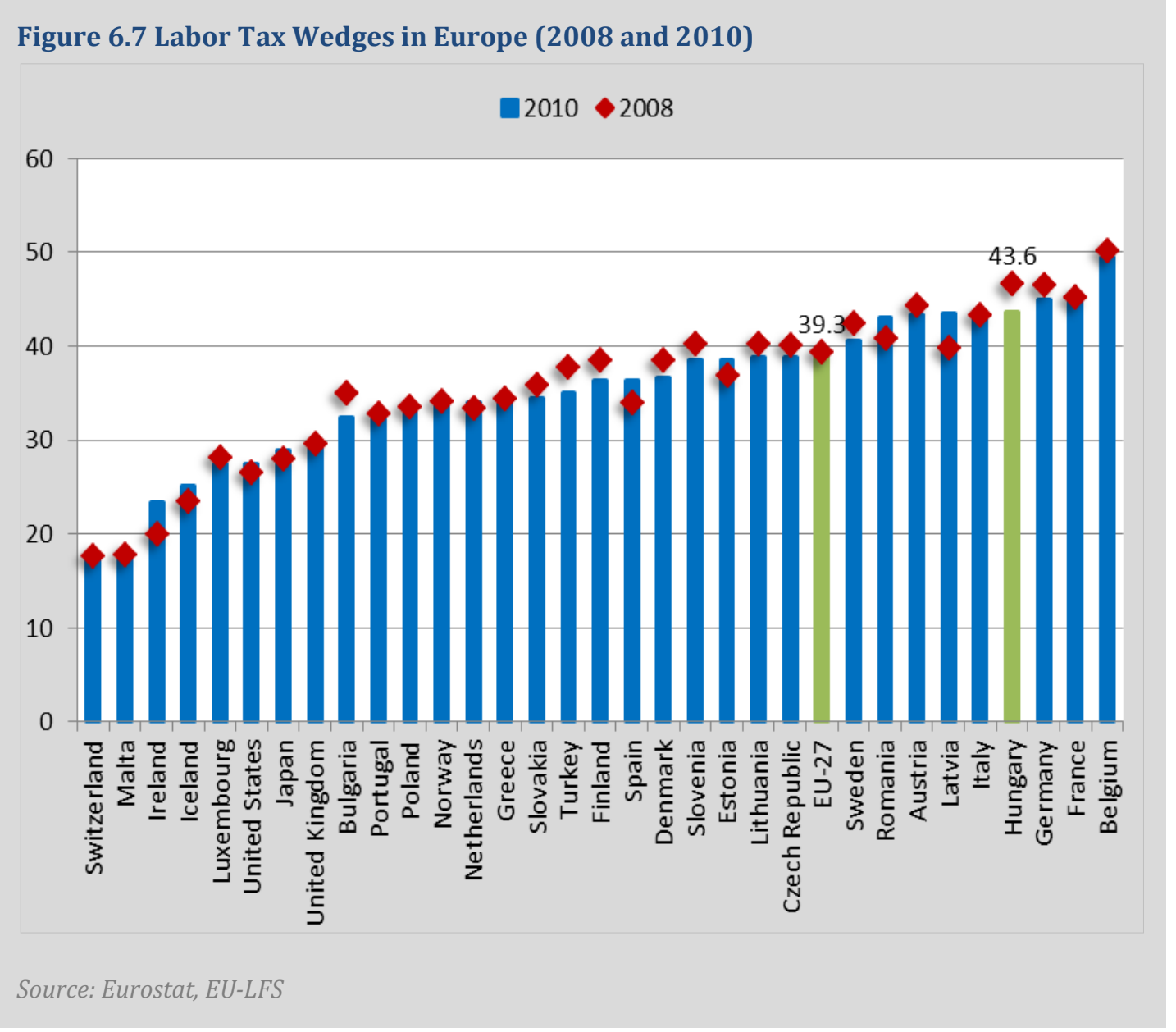

Low participation rates among the older working-age population in Hungary can be explained by changes in both the demand for and supply of labor in the economy. The transition to a market economy and privatization schemes that led to increased competition among firms generated the restructuring and reallocation of resources in the economy. There was a decline in employment, particularly in the agricultural and industrial sectors, and a shift in the labor demand toward more skilled workers. From the supply side, a relatively low retirement age ${ }^{83}$ and the possibility of retiring earlier than the legal age with little or no penalty in terms of a lower pension, also contributes to explaining the low participation rates observed among older workers (EEAG, 2012).

Retired and disabled individuals make up more than half of the out-of-work population analyzed in this note. In the working-age sample used in this analysis, three clusters of retirees or disabled individuals with previous work experience emerge, representing almost half of the out-of-work population-or more than 50 percent if we consider a small group of disabled without work experience. However, about half of them are under the age of 60; in other words, they are under the legal retirement age. If we consider the two main clusters found-and exclude the cluster of urban retired women-this share reaches almost 70 percent. In the cluster of disabled with previous work experience,

83 The legal retirement age is 62 for both men and women. 
which represents almost one fifth of the out-of-work sample analyzed, 88 percent are between 35 and 59 years old, and 35 percent of them reported being strongly limited in work capacity due to a health condition. The second cluster-mostly male early retirees and retirees-represents 15 percent of the out-of-work population sample; 43 percent of the individuals in this group are between ages 35 and 59.

Labor force participation rates for older people are among the lowest in Europe. In 2013, Hungary showed a labor force participation rate of only 63.5 percent among the group of people aged 55 to 59 years old (Figure 6.8). In the case of individuals 55 to 64 years old, rates are only 41.7 percent, much lower than the EU-28 average of 54.3 percent. Nevertheless, this difference has been decreasing over time, since in 2008 activity rates were only 33 and 48 percent in Hungary and the EU-28, respectively. Figure 6.9 shows that for other European countries, expenditures on old-age pensions as a share of the GDP have been increasing. As the working-age population shrinks and life expectancy rises, raising the retirement age and increasing labor force participation among older individuals may counteract a shrinking workforce and rising old-age benefit outlays.

Figure 6.8 Labor Force Participation, ages 55 to 59, European Countries (2013)

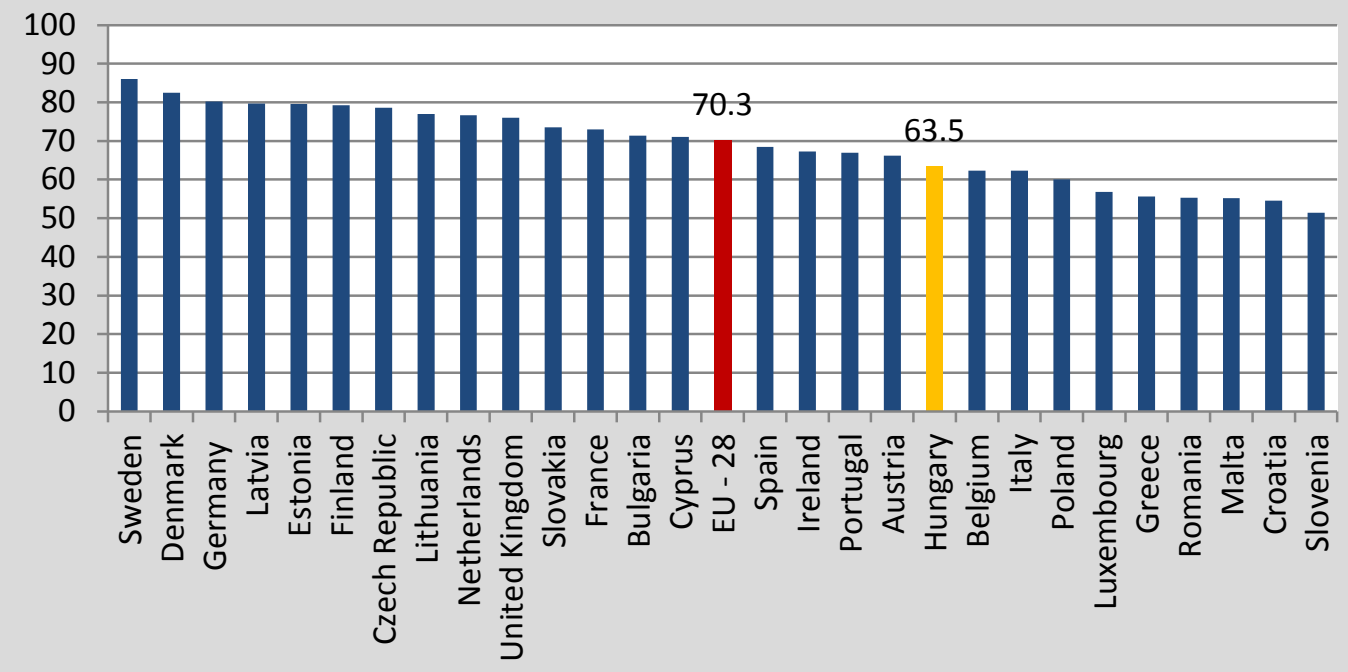

Source: Eurostat, EU-LFS 
Figure 6.9 Expenditures on Old-Age Benefits as a Share of GDP in Europe (2008 and 2010)

$2010 \diamond 2008$

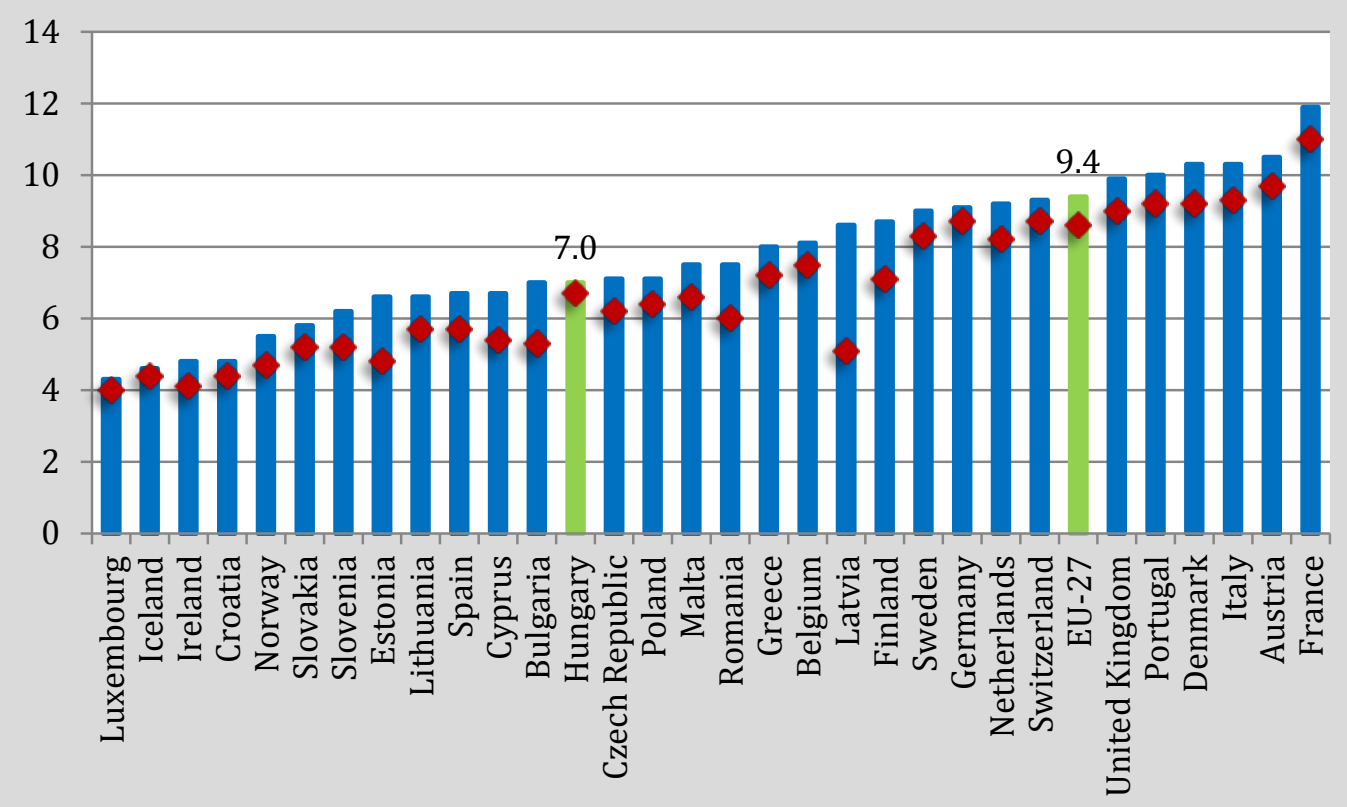

Source: Eurostat

Inactive women account for 17 percent of the out-of-work population, and 84 percent of them are in their prime age. High inactivity rates are an issue in Hungary, and this is no different for women of working age. Labor force participation rates for women between 15 and 64 years old have increased 3 points, from around 56 percent since before the crisis. Data from Eurostat show that in Hungary the percentage of children with access to formal child care is one of the lowest among European countries (Figure 6.10). Indeed, in comparison to the average in the EU-28, in Hungary the percentage of women who report being inactive because they are looking after children or incapacitated adults is 11 and 18 percentage points higher, for the groups of inactive women aged 15 to 39 and 25 to 49 years old, respectively (Figure 6.11). 
Figure 6.10 Formal Child Care as a Percentage of all Children less than 3 years old, European Countries (2011)

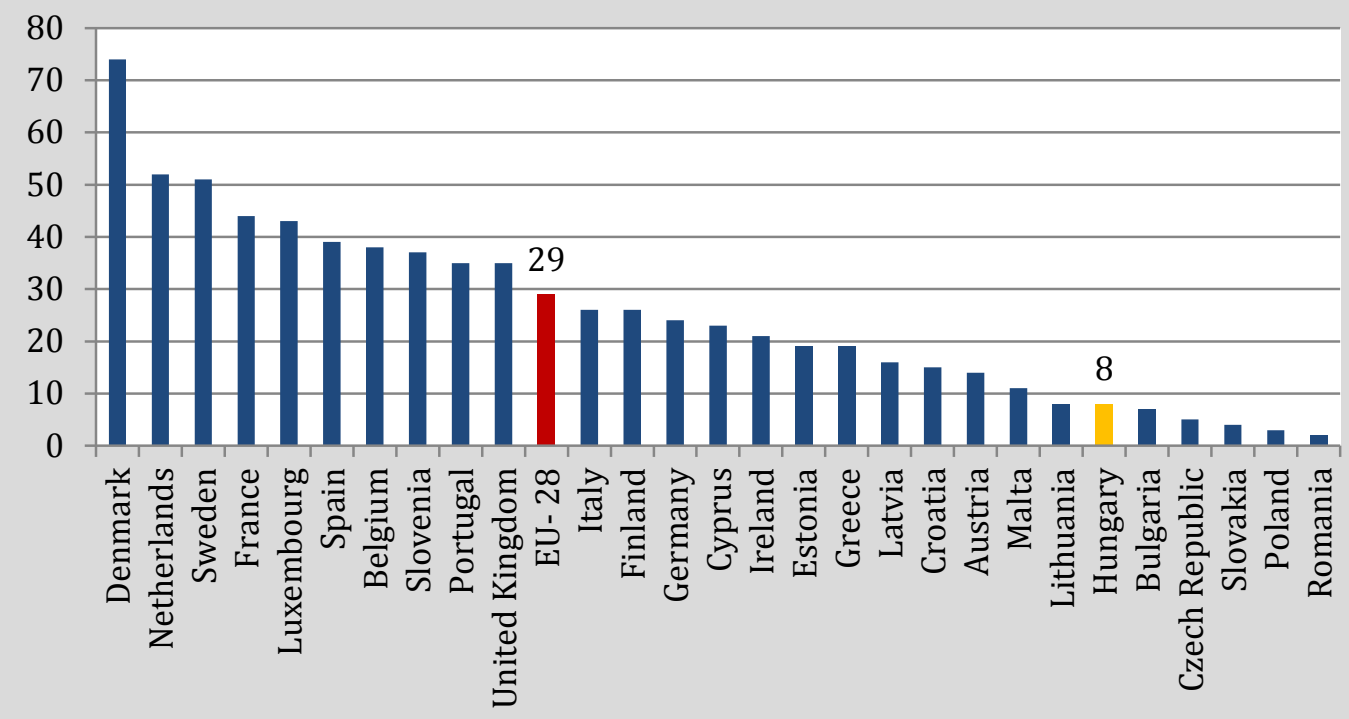

Source: Eurostat, EU-LFS

Figure 6.11 Percentage of Inactive Women that Report Looking after Children or Incapacitated Adults as the Main Reason for Not Seeking Employment, European Countries (2013)

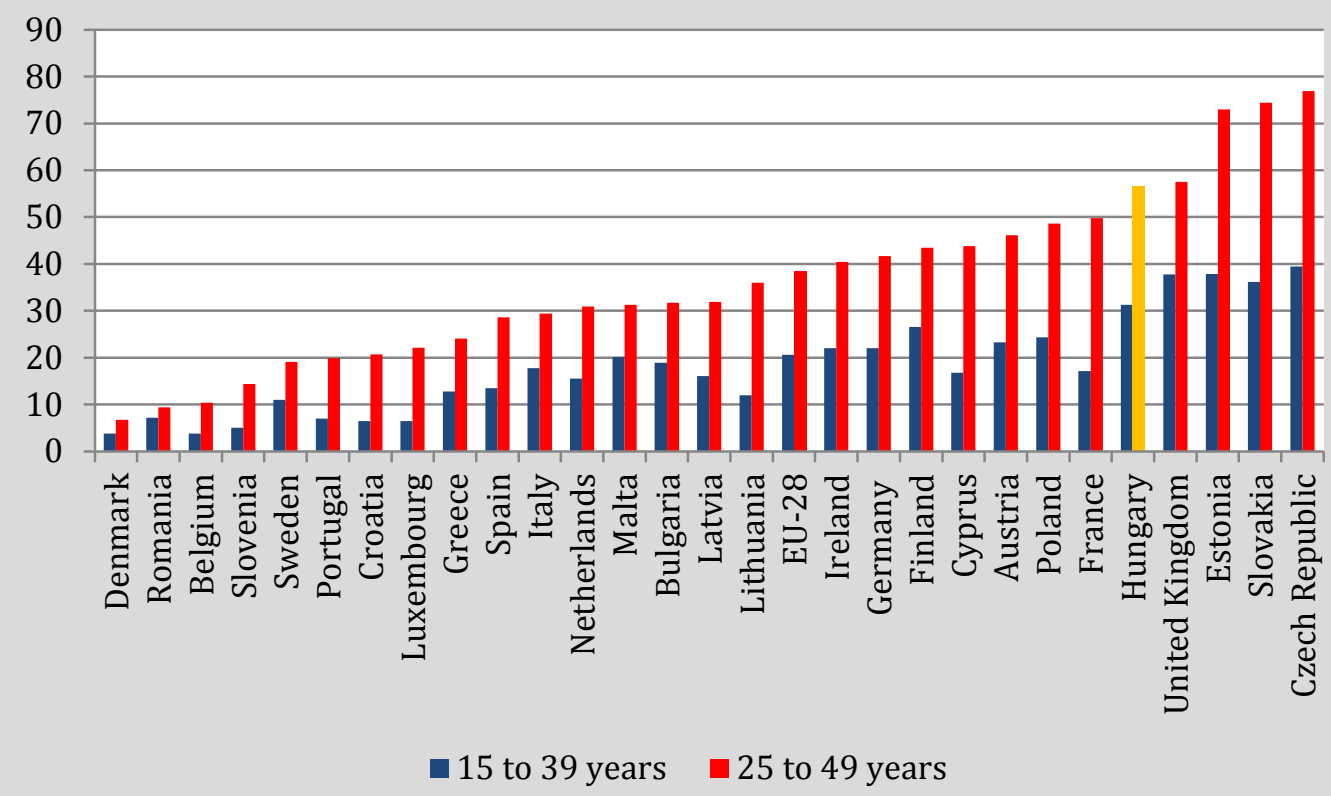

Source: Eurostat 
In order to better understand the dynamics within clusters and other labor market movements, latent class analysis was also applied to longitudinal EU-SILC data for the period 2008-2010. The EU-SILC survey allows the tracking of individuals in both 2008 and 2010, albeit with a smaller sample size than that available in the cross-section surveys. The latent class analysis of the out-of-work population in 2010 yielded similar results in terms of clusters, although due to the reduced sample size, the number of clusters was also smaller. For a sample of around 1,150 observations, six classes were defined:

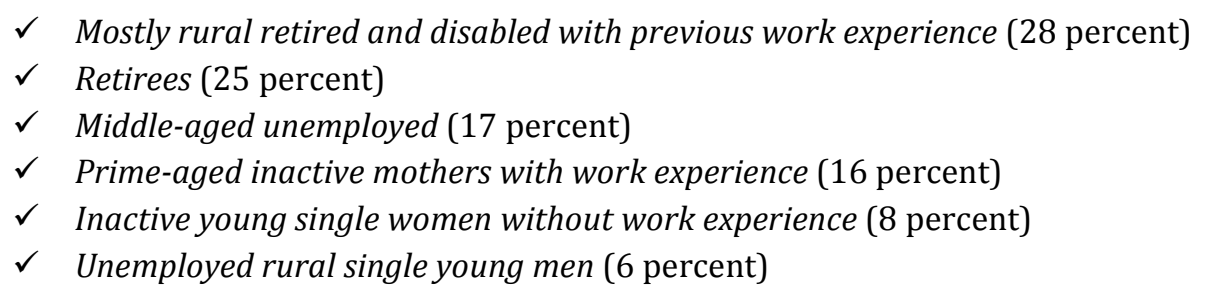

Annex 3 shows the full statistical description of the latent classes, while Table 6.6 below summarizes the key features of each cluster.

Table 6.6 Longitudinal Analysis: Summary Characteristics of Latent Classes of Out-ofWork Population in Hungary (2010)

\section{1: Mostly rural retired and disabled with} previous work experience $(28 \%)$

- $70 \%$ are disabled, $27 \%$ are retired

- $55 \%$ are women

- $85 \%$ are $45-64$ years old

- $64 \%$ are married; $34 \%$ are without a partner

- $33 \%$ report strongly limited capacity to work

- $54 \%$ have no working adults in household

- Low-to-mid-skilled: $35 \%$ have not completed upper secondary; 59\% have complete upper or post-secondary

- $99 \%$ worked before; 91\% worked less than 2 months in the last year; 26 years of experience on average

- $82 \%$ live in households without dependent children; $11 \%$ live alone

- $66 \%$ live in rural areas

- High poverty risk: $28 \%$ are in poorest quintile

- $71 \%$ receive disability benefits

- Total household benefits represent $67 \%$ of gross household income
2: Retirees (25\%)

- $98 \%$ are retired

- $63 \%$ are women

- $88 \%$ are 60-64 years old

- $67 \%$ are married; $31 \%$ without a partner

- $11 \%$ report strongly limited capacity to work

- Low-to-high-skilled: $23 \%$ have not completed upper secondary; $61 \%$ have complete upper or post-secondary; $16 \%$ have complete tertiary

- $100 \%$ have worked before, $97 \%$ worked less than 2 months in the last year; 36 years of experience on average

- $96 \%$ live in households without dependent children, $18 \%$ live alone

- $62 \%$ live in urban areas

- Very low poverty risk: $12 \%$ are in poorest quintile

- $92 \%$ receive old-age benefits

- Total household benefits represent $77 \%$ of gross household income 
3: Middle-aged unemployed (17\%)

- $84 \%$ are unemployed

- $60 \%$ are men

- $76 \%$ are 35-59 years old

- $53 \%$ are married; $38 \%$ are without a partner

- 59\% have no working adults in household

- Low-to-mid-skilled: 32\% have not completed upper secondary; $63 \%$ have complete upper or post-secondary

- $100 \%$ have worked before; $63 \%$ have worked 2 or more months in last year; 20 years of experience on average

- $57 \%$ live in households without dependent children

- $66 \%$ live in rural areas

- Very high poverty risk: $50 \%$ in poorest quintile

- $48 \%$ receive unemployment benefits

- Total household benefits represent $45 \%$ of gross household income

5: Inactive young single women without work experience $(8 \%)$

- $81 \%$ are inactive

- $76 \%$ are women

- $79 \%$ are $16-29$ years old

- $73 \%$ are never married, $60 \%$ are without a partner

- $54 \%$ have at least one working adult in household

- Low-to-mid-skilled: $42 \%$ have not completed upper secondary; $46 \%$ with complete upper or post-secondary

- $91 \%$ have never worked before; 6 years of experience on average

- $53 \%$ live in households with dependent children; $43 \%$ live in households with children under 6

- $60 \%$ live with at least one parent

- Very high poverty risk: $43 \%$ in poorest quintile

- $66 \%$ receive family/child benefits; $39 \%$ receive housing allowance

- Total household benefits represent $51 \%$ of gross household income
4: Prime-aged inactive mothers with work experience $(16 \%)$

- $88 \%$ are inactive

- $99 \%$ are women

- $82 \%$ are 25-54 years old

- $76 \%$ are married; $14 \%$ are without a partner

- $82 \%$ have at least one working adult in household

- Mid-to-high-skilled: 59\% have complete upper or post-secondary; $28 \%$ have complete tertiary

- $100 \%$ have worked before; $83 \%$ less than 2 months in last year; 11 years of experience on average

- $87 \%$ live in households with dependent children; $60 \%$ live in households with children under 6

- $57 \%$ live in rural areas

- High poverty risk: $31 \%$ in poorest quintile

- $95 \%$ receive family/child benefits

- Total household benefits represent $36 \%$ of gross household income

6: Unemployed rural single young men (6\%)

- $100 \%$ are unemployed

- $77 \%$ are men

- $94 \%$ are 20-24 years old

- $98 \%$ are never married

- $76 \%$ have no working adults in household

- Low-to-mid-skilled: $24 \%$ have not completed upper secondary; $71 \%$ have complete upper or post-secondary

- $51 \%$ have never worked before; $45 \%$ worked 2 or more months in last year; 2 years of experience on average

- $71 \%$ live in households without dependent children

- $98 \%$ live with at least one parent

- $73 \%$ live in rural areas

- Very high poverty risk: $49 \%$ in poorest quintile

- $65 \%$ receive family/child benefits; $22 \%$ receive unemployment benefits

- Total household benefits represent $35 \%$ of gross household income

Source: World Banks staff analysis based on EU-SILC

Note: Percentages in parentheses following the group names refer to the share of the total out-of-work population. "Years of work experience" refers only to those individuals who have worked before.

"Dependent children" includes children under 18 and household members aged 18 to 24 who are economically inactive and living with at least one parent. "Working adult" refers to adults aged 24 and over.

A further advantage of the panel analysis is to provide information on the flow of individuals among clusters and in and out of employment. Table 6.7 shows the flow of individuals into each cluster of the out-of-work population or into employment in 2010 according to their labor market status in 2008. Between 2008 and 2010, 85 percent of the employed remained 
at work. Indeed, there is also an interesting flow into employment among those who were unemployed or inactive in 2008. In 2010, 41 percent of those who were classified as unemployed and 53 percent who were classified as inactive in 2008 were found to be employed. In other words, more than half of the inactive individuals in 2008 were reported as employed in 2010. An additional 15 percent of those inactive in 2008 moved to a cluster of unemployed individuals in 2010, meaning that around 68 percent left inactivity.

\section{Table 6.7 Composition of 2010 Clusters based on 2008 Labor Status-Hungary (Column Percentages)}

\begin{tabular}{|c|c|c|c|c|c|c|c|}
\hline \multirow[b]{2}{*}{$\begin{array}{l}\text { Clus- } \\
\text { ter }\end{array}$} & \multirow[b]{2}{*}{$\begin{array}{c}\text { Working-age } \\
\text { population in } 2010\end{array}$} & \multicolumn{6}{|c|}{ Labor market status in 2008} \\
\hline & & $\begin{array}{l}\text { Unem- } \\
\text { ployed }\end{array}$ & Retired & Disabled & $\begin{array}{l}\text { Other } \\
\text { inactive }\end{array}$ & $\begin{array}{c}\text { Em- } \\
\text { ployed }\end{array}$ & Total \\
\hline 1 & $\begin{array}{l}\text { Mostly rural retired } \\
\text { and disabled with } \\
\text { previous work } \\
\text { experience }\end{array}$ & 5 & 15 & 66 & 3 & 3 & 11 \\
\hline 2 & Retirees & 3 & 76 & 24 & 1 & 4 & 10 \\
\hline 3 & $\begin{array}{l}\text { Middle-aged } \\
\text { unemployed }\end{array}$ & 32 & 1 & 2 & 8 & 6 & 7 \\
\hline 4 & $\begin{array}{l}\text { Prime-aged inactive } \\
\text { mothers with work } \\
\text { experience }\end{array}$ & 11 & 0 & 0 & 17 & 2 & 5 \\
\hline 5 & $\begin{array}{l}\text { Inactive young } \\
\text { single women } \\
\text { without work } \\
\text { experience }\end{array}$ & 3 & 0 & 3 & 10 & 0 & 2 \\
\hline 6 & $\begin{array}{l}\text { Unemployed rural } \\
\text { single young men }\end{array}$ & 5 & 0 & 0 & 7 & 0 & 2 \\
\hline $\mathrm{NC}$ & Employed & 41 & 8 & 5 & 53 & 85 & 63 \\
\hline & Total & 100 & 100 & 100 & 100 & 100 & 100 \\
\hline $\begin{array}{l}\text { Sourc } \\
\text { Notes } \\
\text { referr }\end{array}$ & $\begin{array}{l}\text { World Bank staff analy } \\
\text { udents aged } 16 \text { to } 24 \text { u } \\
\text { to in the text appear sh }\end{array}$ & $\begin{array}{l}\text { ased on } \\
\text { vere ina } \\
\text { d in blue }\end{array}$ & $\begin{array}{l}\text { LC } \\
\text { or unemp }\end{array}$ & d are excl & d from th & imple. $N$ & ers \\
\hline
\end{tabular}

On the other hand, Table 6.8 shows the labor market status in 2008 for each cluster and atwork population in 2010. Three main results emerge from the dynamics presented. First, for the cluster of middle-aged unemployed, 50 percent were employed in 2008, which makes them the most affected by employment losses. Second, the group of prime-aged inactive mothers with work experience was the second most likely to have been employed in 2008. This may be reflecting incentives for women of child-bearing age to drop out of the labor force. Finally, 71 percent of the individuals in the group of unemployed rural single young men were inactive in 2008, a reflection of the fact that youth tend to be new to the labor market and lack work experience (in contrast, only 21 percent of the middle-aged unemployed were inactive in 2008). 


\begin{tabular}{|c|c|c|c|c|c|c|c|}
\hline \multirow[b]{2}{*}{$\begin{array}{l}\text { Clus- } \\
\text { ter }\end{array}$} & \multirow[b]{2}{*}{$\begin{array}{c}\text { Working-age } \\
\text { population in } 2010\end{array}$} & \multicolumn{6}{|c|}{ Labor market status in 2008} \\
\hline & & $\begin{array}{l}\text { Unem- } \\
\text { ployed }\end{array}$ & Retired & Disabled & $\begin{array}{l}\text { Other } \\
\text { inactive }\end{array}$ & $\begin{array}{c}\text { Em- } \\
\text { ployed }\end{array}$ & Total \\
\hline 1 & $\begin{array}{l}\text { Mostly rural retired } \\
\text { and disabled with } \\
\text { previous work } \\
\text { experience }\end{array}$ & 3 & 9 & 65 & 5 & 18 & 100 \\
\hline 2 & Retirees & 2 & 50 & 25 & 2 & 22 & 100 \\
\hline 3 & $\begin{array}{l}\text { Middle-aged } \\
\text { unemployed }\end{array}$ & 25 & 1 & 3 & 21 & 50 & 100 \\
\hline 4 & $\begin{array}{l}\text { Prime-aged inactive } \\
\text { mothers with work } \\
\text { experience }\end{array}$ & 12 & 0 & 1 & 61 & 26 & 100 \\
\hline 5 & $\begin{array}{l}\text { Inactive young single } \\
\text { women without work } \\
\text { experience }\end{array}$ & 6 & 0 & 12 & 79 & 3 & 100 \\
\hline 6 & $\begin{array}{l}\text { Unemployed rural } \\
\text { single young men }\end{array}$ & 13 & 0 & 0 & 71 & 15 & 100 \\
\hline NC & Employed & 3 & 1 & 1 & 15 & 80 & 100 \\
\hline \multicolumn{2}{|l|}{ Total } & 5 & 7 & 11 & 18 & 60 & 100 \\
\hline
\end{tabular}




\section{From Profiling to Activation}

\section{Activation and Inclusion Policies in Hungary}

Active labor market policies (ALMPs) are not a strategy per se in Hungary, but their elements are integrated into national policy making and should be further enhanced. The Hungarian employment level is low when compared to other European countries. The main challenge has been to increase the labor market participation of specific disadvantaged groups, such as low-skilled, older workers, young career starters, women with small children and the disabled (EU, 2013). Therefore, several reforms have been introduced in order to make work attractive to the inactive and promote employment.

In 2011, expenditures on labor market policies (LMPs) in Hungary corresponded to 70 percent of the total for the OECD countries, and unemployment and early retirement benefits accounted for more than half of these expenditures. Figure 6.12 shows the spending on different LMPs as a share of GDP in Hungary and compared to OECD countries (in 2011). From 2008 and 2010, there was an increase of 112 percent in the amount spent on ALMPs as a share of GDP. Unemployment and early retirement benefit values rose by 95 percent in the same period. And, while ALMPs represented around one-third of the total LMPs in 2011, unemployment and early retirement benefits accounted for 65 percent, an increase in comparison with a share of 51 percent in 2008.

Figure 6.12 Labor Market Policy (LMP) Spending in Hungary as a Share of GDP
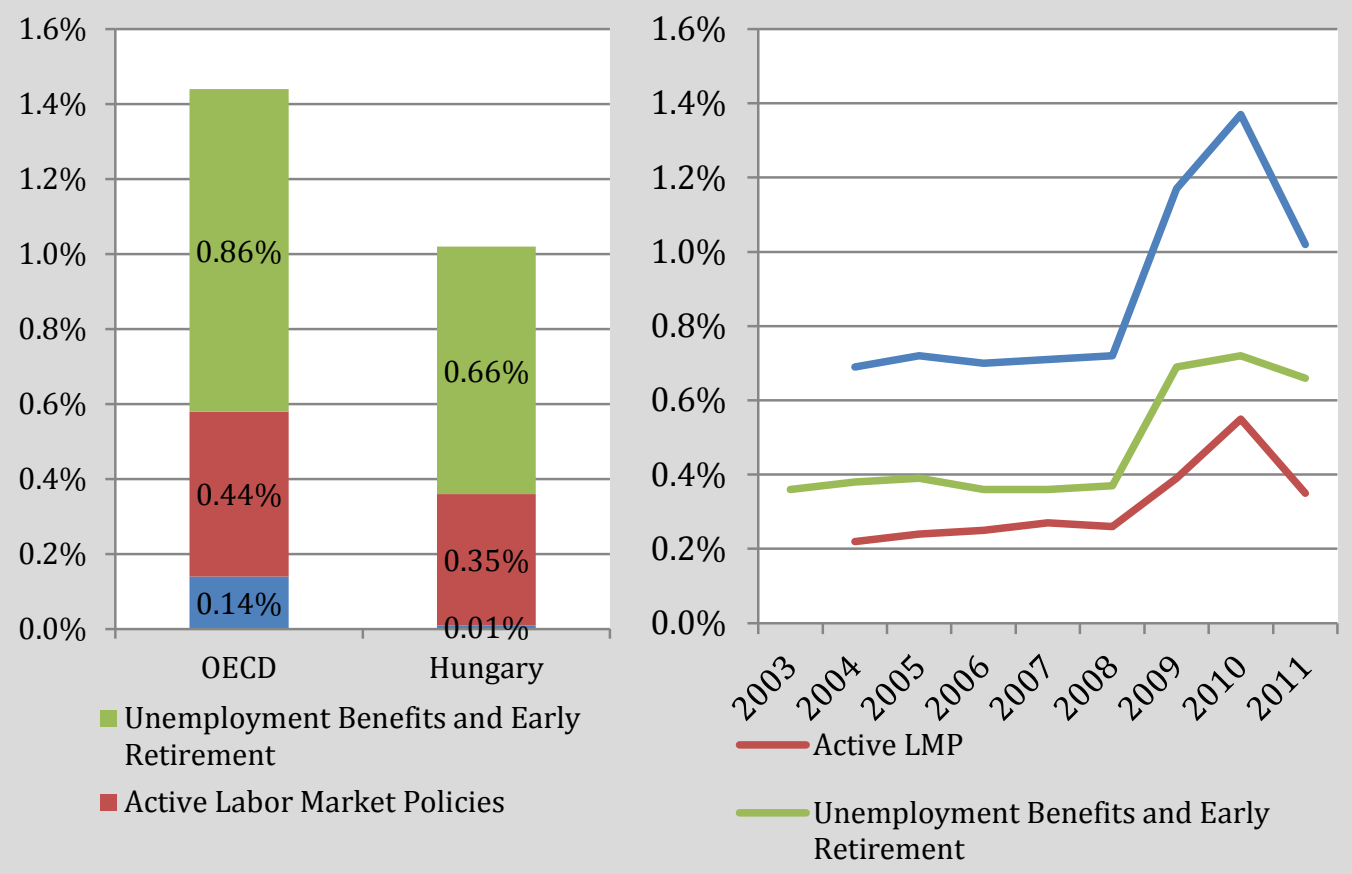

Source: Eurostat, OECD

Structural reforms have been introduced to raise the effective retirement age, increase employment and promote sustainability. As a response to a high inflow into 
disability schemes and a widespread use of early retirement options, reforms affecting the pension, disability and social benefit systems were introduced. The value of benefits is decreasing while the criteria for accessing them has become stricter and more workoriented (EC, 2013). Furthermore, in order to activate those capable of work, some measures listed in the Hungarian Work Plan include:

$\checkmark$ Strengthen ALMPs, reinforcing services and supports available to job-seekers;

$\checkmark$ Increase labor market flexibility through the promotion of flexible forms of employment and flexible workplaces, ease return of young parents and support companies in adjusting working hours for flexibility;

$\checkmark$ Continue targeted tax allowance for employers who employ young career starters, and support their acquisition of work experience;

$\checkmark$ Modernize the education and training system to improve the skills of the labor force;

$\checkmark$ Strengthen the social economy and social cooperatives;

$\checkmark$ Promote public works.

Figure 6.13 Composition of Spending on ALMPs in Hungary (in millions of Euros), 2008 and 2011

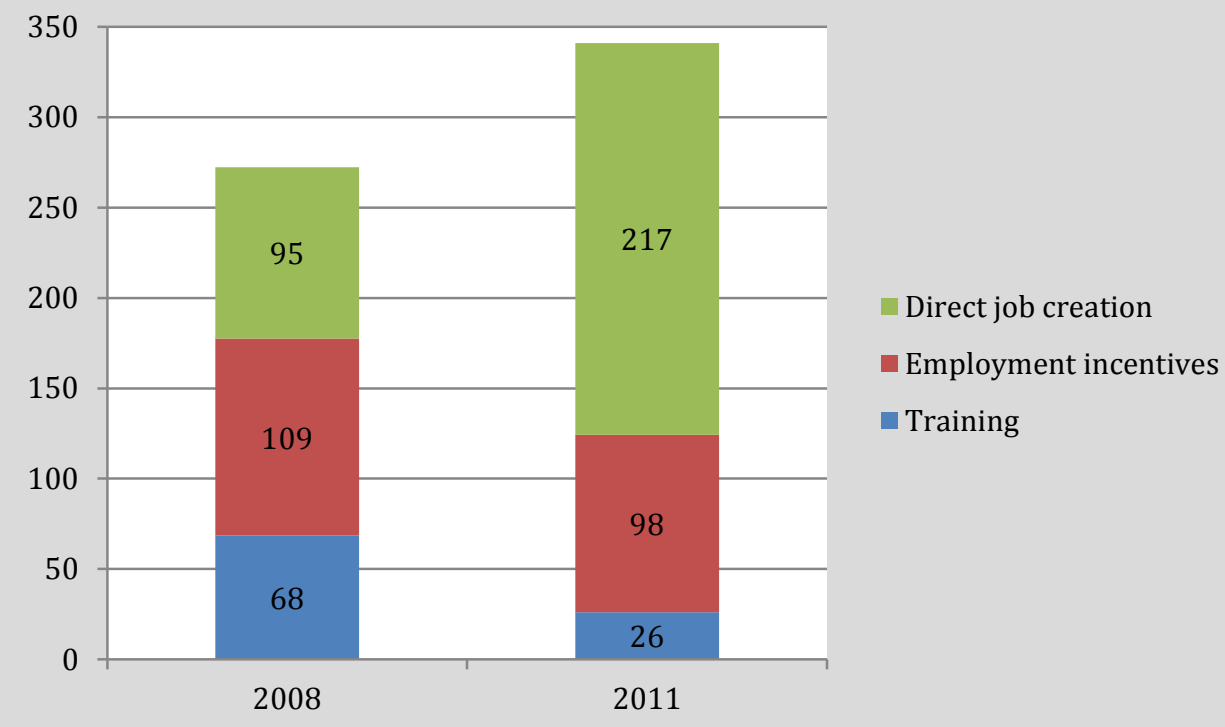




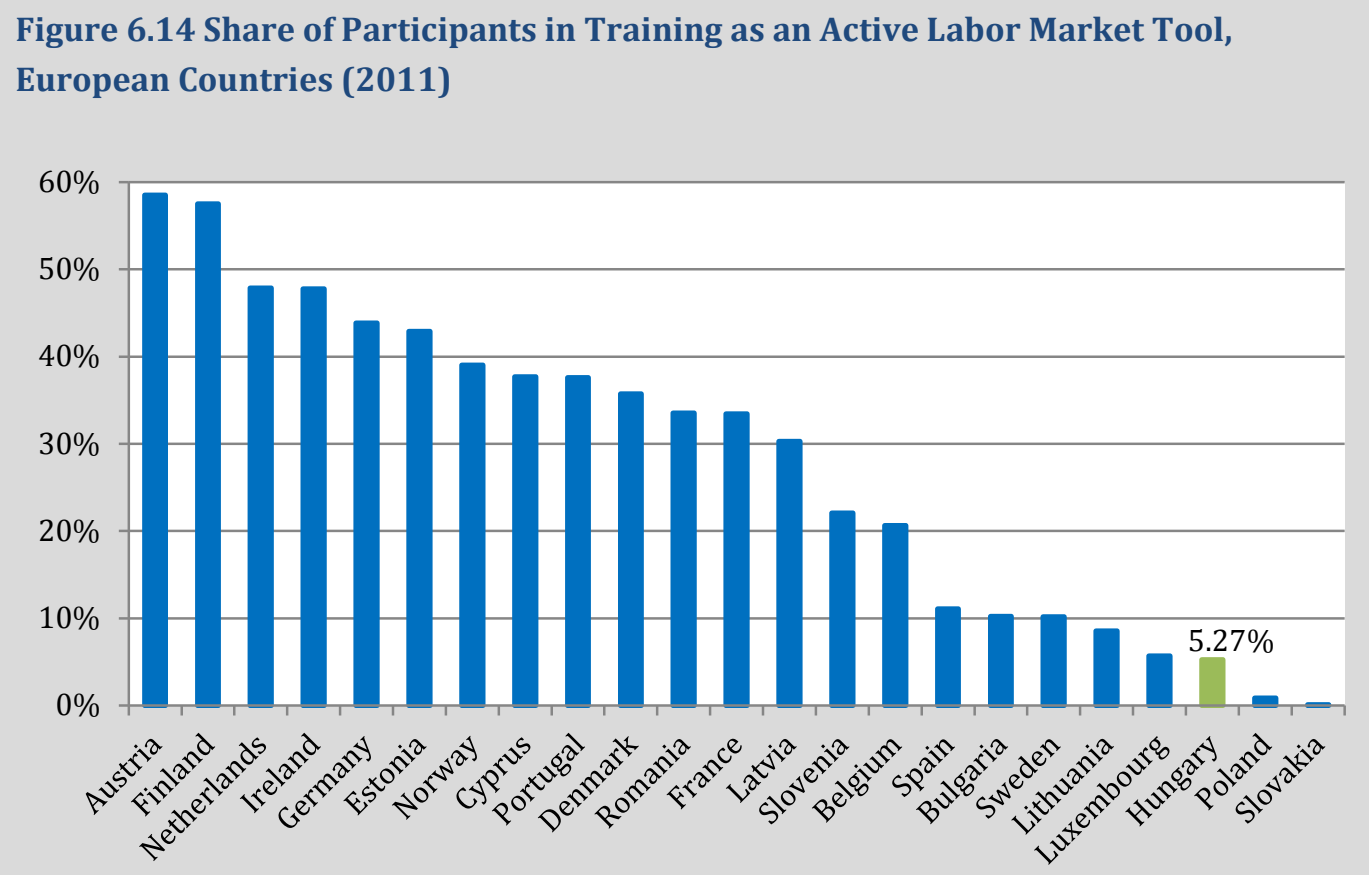

Source: Eurostat

Public work became an important activation measure in 2009 with the launch of the "Pathway to work" program. The idea was to assist those capable of work to find some form of public employment, reducing the duration of unemployment and breaking long-term benefit dependency, while making easier for them to find a job on the open labor market through the improvement in their skills. Figure 6.13 shows the composition of spending on ALMPs in Hungary and how direct job creation was almost two times more expensive than employment incentives and training together. Indeed, among different labor market policy measures available, the share of participants in training activities, for example, is one of the lowest in Europe (Figure 6.14). Therefore, while the majority of financial resources is spent on public work, there is less left for training, rehabilitation programs, or significant contribution allowances, although these latter are proved to be efficient in promoting labor market participation (EC, 2013). In the case of Hungary, the low effectiveness, high selectivity of inclusion and sometimes discriminating practices by local authorities have been outlined by OECD (2014) and Kierzenkowski (2012). The Government of Hungary has signaled its response to these observations by better combining the public works program with training offerings. 
When further considering the approach toward labor market integration, an assessment of the priorities and potentials of the identified groups needs to be undertaken. Given the limited increase in nominal resources for activation programs, further prioritization of intervention is all the more important. After a first step ("activation priority") of prioritizing the intervention along activation need and activation potential, a second step ("activation type") will attempt to classify the groups according to the kind of activation intervention needed, depending on social or labor market barriers to be overcome. Lastly, as a third step, information on household income composition of the different groups will be used to assess potential cross-dependencies of the benefit system with the labor market status and activation approaches.

Activation Priorities. The table below gives an overview of the identified out-of-work classes and their respective activation need and activation potential. The total number of persons estimated in these clusters was about 2.28 million in 2011, representing about 38 percent of the working-age (16-64) population of Hungary in 2011.

In the table, "activation need" refers to a group's level of need for inclusion in the labor market in order to achieve income and reduce or end poverty. "Activation potential" describes that group's ability or motivation to be included in the labor market. A high activation need could be driven by high poverty risk (as in the case of the prime-aged longterm unemployed), whereas a high activation potential could be driven by previous work experience or a relatively good educational base (for example, the educated single students). Overall priority for action can also be supported by the size of the group.

\section{Table 6.9 Activation Need and Potential of Different Clusters}

\begin{tabular}{|c|l|c|c|c|}
\hline $\begin{array}{c}\text { Share } \\
\mathbf{2 0 1 1}\end{array}$ & \multicolumn{1}{|c|}{ Cluster } & $\begin{array}{c}\text { Activation } \\
\text { need }\end{array}$ & $\begin{array}{c}\text { Activation } \\
\text { potential }\end{array}$ & $\begin{array}{c}\text { Priority } \\
\text { for } \\
\text { action }\end{array}$ \\
\hline $19 \%$ & Disabled with previous work experience & medium & medium & medium \\
\hline $15 \%$ & Mostly male early retirees and retirees & low & medium & low \\
\hline $15 \%$ & Urban retired women & low & low & low \\
\hline $14 \%$ & Prime-aged unemployed & high & medium & high \\
\hline $13 \%$ & $\begin{array}{l}\text { Prime-aged inactive mothers with work } \\
\text { experience }\end{array}$ & medium & high & medium \\
\hline $12 \%$ & Prime-aged long-term unemployed & high & medium & high \\
\hline $4 \%$ & Unemployed youth & medium & high \\
\hline $4 \%$ & $\begin{array}{l}\text { Low-educated rural inactive mothers } \\
\text { without work experience }\end{array}$ & low & high & medium \\
\hline $2 \%$ & Educated single students & medium & low & low \\
\hline $2 \%$ & $\begin{array}{l}\text { Low-educated disabled without work } \\
\text { experience }\end{array}$ & & & \\
\hline
\end{tabular}


From this prioritization exercise, a set of seven groups emerges with a "high" or "medium" priority for action. Disabled with previous work experience have a medium priority because their potential reinsertion into the labor market will most probably have to be achieved via a forced reassessment of their disability status. This can be a protracted process. Prime-aged unemployed and prime-aged long-term unemployed are considered high priority for further activation. Prime-aged inactive mothers with work experience and low-educated rural inactive mothers without work experience are both ranked "medium" priority but should still be included in the roster of prioritized groups. They present very different socio-economic challenges. Unemployed youth and educated single students form prioritized groups because of the potential scarring effects of labor market detachment for young people at an early age. From the view of the Hungarian authorities, "educated single students" do not constitute a prioritized group for further action in 2014 or later, because one of their main labor market barriers (language completion requirement) was addressed through dedicated programs after 2011.

Mostly male early retirees and retirees, urban retired women and low-educated disabled without work experience are not prioritized for further action owing, respectively, to their officially achieved retirement status and extreme distance (via very low educational attainment and self-declared disability) from the labor market.

\section{Figure 6.15 Activation Types of Prioritized Clusters in Hungary}

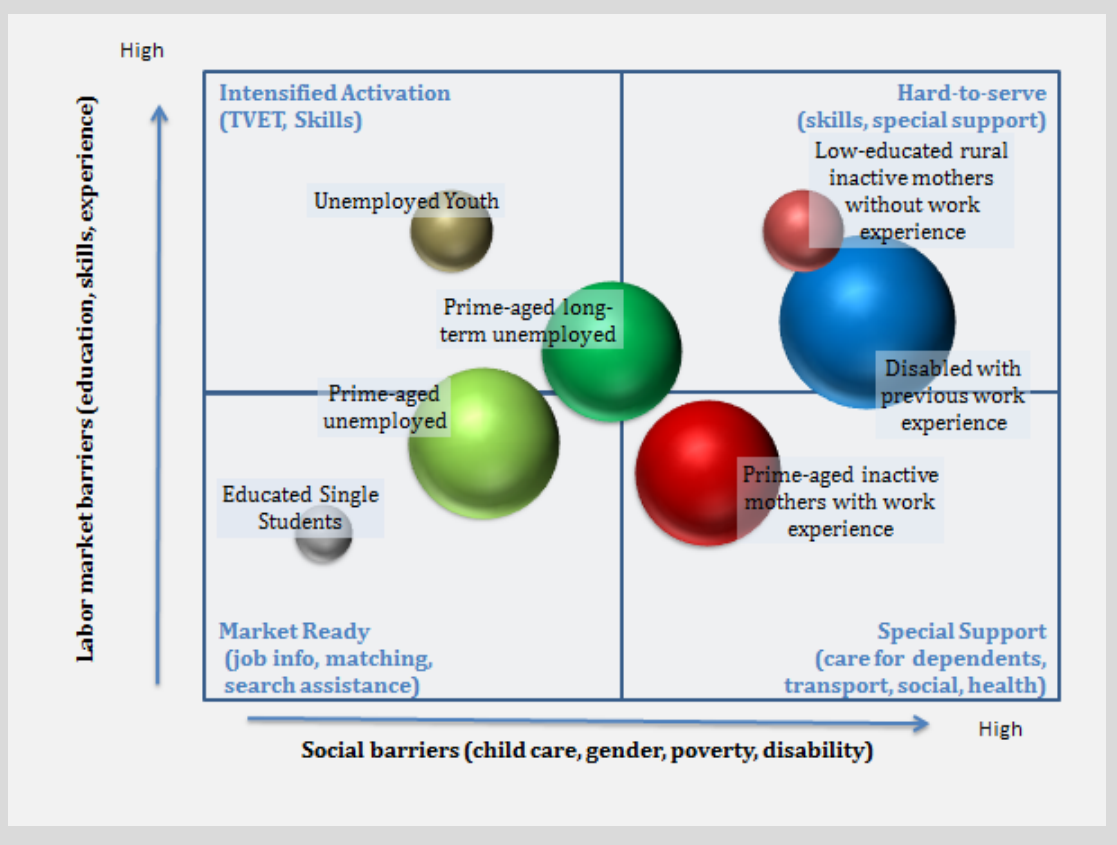

Source: World Bank analysis and assessment 2014

Activation type. As a second step, the relative severity of labor market or social obstacles to be overcome for labor market integration will serve as an orientation for activation approaches. 
When mapping the respective barriers for labor market integration faced by the seven prioritized groups, we can see that their challenges are quite evenly distributed across the matrix. Unemployed youth and educated single students have similar social barriers but differ in their potential labor market proximity, the students being much closer to a job start. The two groups of the prime-aged long-term unemployed and the prime-aged unemployed face similar social barriers. The same can be said for the two groups of the inactive mothers, with the prime-aged inactive mothers with work experience being much closer to the labor market. The large group of the disabled with previous work experience probably faces the strongest social hurdles for labor market integration: overcoming their disability status and reintegrating in mid-life.

Household income composition. When analyzing the 2011 household income of the prioritized groups, one notices a relatively high share of benefit income among many groups. For the three non-prioritized groups (mostly male early retirees and retirees, urban retired women and low-educated disabled without work experience) this does not present a major problem because their pattern of benefit receipt corresponds to their socio-demographic situation. The prime-aged unemployed and prime-aged long-term unemployed each have about 50 percent of income from unemployment benefits. Following recent policy changes to reduce the unemployment benefit payment to only three months, this figure may be lower.

As already mentioned, the disabled with previous work experience ought to be examined again as to their disability status. With only 35 percent reporting any limitation on daily activities, yet 89 percent receiving disability benefits, there appears to be some potential for labor market mobilization and benefit rationalization in this group.

Given the overall picture of benefit receipt revealed by EU-SILC data, the key need for action emerges around a potential review of disability benefit allocation. 
This section sets out a set of potential activation measures for each of the priority groups. Areas for further policy dialogue are also outlined. Any suggestion or policy discussion around concrete measures will need to take into account that the Hungarian authorities have introduced a set of reforms since 2012, and changes to existing programs in the field of employment and labor market inclusion (EU 2012 and OECD 2014).

The suggestions below should be considered as a starting point for further policy dialogue between the EC, the World Bank and Hungary, bearing in mind that the groups identified still may have heterogeneities that affect the type of support required. Accordingly, these suggestions are not meant to be an exhaustive set of possible activation measures.

When discussing potential activation approaches for the identified groups, it is important to keep in mind that the groups have been derived from EU-SILC data from the year 2011. Since then, general economic development, policy actions by the government of Hungary and European Commission "Country Specific Recommendations" might have reflected some of the policy suggestions or rendered them obsolete.

More concretely, since 2011 the government of Hungary has taken a number of steps and has initiated policy changes that ought to improve the labor market integration or activation of some of the groups. Notably, these reforms were taken in the fields of (1) access to disability insurance-with a change from disability pensions to rehabilitation benefits and the revision of the health status of the recipients, emphasizing working capacity rather than loss of skills; (2) early retirement-where rules of early retirement were tightened and the retirement age will be raised from 62 to 65 years (Box 6.1); (3) linkage of social assistance beneficiaries with activation services-eligibility rules for unemployment assistance became stricter and recipients were obliged to participate in public works or other activation programs for at least 30 days a year; and (4) reconciliation of work and family life, allowing parents who receive child care benefits to pursue gainful activity without time limitation (Box 6.2), and by the development of daycare services. When discussing the results of the LCA segmentation analysis, the potential impact of these reforms on current $(2013 / 2014)$ inactivity figures will need to be discussed.

Disabled with previous work experience (19 percent, Priority: Medium). This is the largest group among the identified and prioritized groups, with 432,000 members in 2011. On the face of things, the group does have strong work experience in light of middle to low educational achievement. The large majority of them live in rural areas and about 35 percent of them report strong physical limitations on their ability to work, a much lower rate than the 89 percent claiming a disability benefit.

At any rate, this significant group of out-of-work citizens needs to be followed more closely and any new applicants for disability benefits closely monitored and controlled (as recent policy changes by the Hungarian authorities suggest). Limiting the inflows into this group (via more stringent disability benefit criteria) will be easier than forcing the activated exit of members from this group. Nevertheless, this effort ought to be undertaken in light of the

Portraits of Labor Market Exclusion | 201 
demographic profile of the group (many members are still in their forties). Potential activation measures for the inactive who remain in this group will largely depend on the ability of local governments to provide and finance services for the (formerly) disabled (rehabilitation, transport, social and medical care, and so on), but also on the integration of national policies with local service standards and adequate financing. In light of the potentially high integration cost for and potential discrimination against disabled workers, local social services cannot be expected to finance these approaches without support from central government. Potential activation measures include:

$\checkmark$ Review disability status but continue benefits (for now). Continuing to provide the current benefits, the members of this group could be made eligible for a review of their disability and work-ability status. When considered "fit to work" in this review, a set of support measures and continuing benefits (potentially with a phaseout period) ought to be provided to cushion the transition toward labor market integration. Since 2012, the incapacity benefit administration has been reformed; it is more focused on "work ability" checks and is supposed to tighten the access to the program.

$\checkmark \quad$ Integration into standard PES offerings. After reassessment of their labor market status, the members of the group ought to be made part of the normal client base of the public employment service (at medium priority), offering training and job placement experience.

$\checkmark$ Participation in (reformed!) public works program. In light of the strong rural living pattern of the group, a participation in the (reformed! more training!) public works program could be an option to supplement potential social assistance income levels after withdrawal of the disability pension.

$\checkmark$ PES does provide a mobility subsidy to job seekers who have found a job outside of their home city. However, this does not address the general lack of public transportation in the country nor its high cost.

$\checkmark$ Enhanced and cheaper mobility in rural and peri-urban areas. Given the relative high cost of mobility using public transport in Hungary (OECD 2014), this group might find itself at a disadvantage owing to its rural living pattern. Any progress in that field of public transport could certainly help to improve regional mobility and labor matching.

$\checkmark$ The "Rehabilitation card" issued for persons with health problems by the national tax authority, which provides support to employers for the employment of disabled/incapacitated workers. In February 2014 more than 23 thousand employees in almost 6,000 companies benefited from this program,

Prime-aged unemployed (14 percent, Priority: High). These newly unemployed have solid work experience (16 years on average) and mainly live in rural areas. Many of them have dependent children, reducing their geographic mobility. Their risk of poverty is high, with 49 percent living in the poorest quintile.

Prime-aged long-term unemployed (12 percent, Priority: High). This group resembles the previous group but is slightly older and less rural. Potential activation measures for the two groups include: 
$\checkmark$ Availability of public transportation and rental offers. Increasing the availability of public transportation can improve the quality of life and people's chances of finding a job and staying employed-for example, taking advantage of opportunities in particular geographic areas. The Hungarian authorities noted that many rental offers and incomes are in fact part of the "grey" economy, so the real availability of rental offers in the market might be higher than perceived but might be unsuitable for any type of mobility support due to lack of documentation. Nevertheless the Government of Hungary introduced in 2012 a housing allocation for job seekers who cannot find jobs locally, to be used to rent accommodations for up to 18 months in the case of employment.

$\checkmark$ Enhanced and cheaper mobility in rural and peri-urban areas. Given the relative high cost of mobility using public transport in Hungary (OECD 2014), this group might find itself at a disadvantage owing to its rural living pattern. Any progress in that field of public transport could certainly help to improve regional mobility and labor matching.

$\checkmark$ Job-to-job matching by PES. The rather recent fall into unemployment by this group (prime-aged unemployed), underlines the necessity for the PES to take customers in charge early on, ideally when they are still employed in their previous job, and help with "job-to-job" transitions to avoid long spells of unemployment in the first place. This requires immediate notification on the part of the (future) job seeker and immediate action by the PES when it learns about the upcoming joblessness of a potential client.

$\checkmark$ Reconnection with previous field of employment. Given the strong work experience of this group, building any future development on their acquired skills can strengthen their case with new employers.

$\checkmark$ Linkage with regional economic development activities. For both groups, a linkage with regional economic development activities (investment, selfemployment promotion, enhanced public works schemes, and so on) will be important, regardless of urban or rural living pattern.

Prime-aged inactive mothers with work experience (13 percent, Priority: Medium). This group of women could certainly benefit from improved child care offerings and reconnection programs with their fields of previous employment or study. Potential and current activation measures include:

$\checkmark \quad$ Standard PES job search assistance. Given their good work experience and (on average) high educational attainment, job searches by this group could be expected to be conducted independently, with little supervision and support from the PES authorities.

$\checkmark \quad$ Linkage of PES job search assistance with child care offerings. Linking any activation attempt to provision of child care will be critical.

$\checkmark$ Continue to expand child care facilities. 75 percent of children aged three to six were enrolled in formal child care in 2011, which was below the EU average of 83 percent. During the joint country mission, the Hungarian authorities noted that child care offerings had been expanded since 2011. More challenging is child care for younger children, which according to Eurostat is provided to around 8 percent of children under three, compared to 30 percent of children in the EU in 2011. In 
2009-2010 an action plan was launched to increase the capacity of day care by 3,200-3,500 new places before 2013.84,85

$\checkmark$ Greater flexibility in parental leave and benefit policies. In January 2014, parents were allowed to return to work more quickly while still receive their benefit for the full two years. At the same time, low-income mothers were able to receive a "child care allowance" for three years. There are fears that this last might act as a work disincentive, a view not shared by the Hungarian authorities due to the very low level of the benefit, at about one-fourth of the minimum wage.

$\checkmark$ The "Job Protection Act" introduced an employment subsidy for disadvantaged job seekers, including those returning from child care and those without qualifications, among others.

Unemployed youth ( 4 percent, Priority: High). This group urgently needs to be connected to the labor market to avoid any "scarring" effect on their life chances. Very few of them have initial work experience, but the group has medium-level educational attainment. Potential activation measures include:

$\checkmark \quad$ Job placement and job-start programs. Placement through subsidized internships with accompanying professional and life-skills training could be a promising line of action, breaking the common barrier of required work experience for many entrylevel positions.

$\checkmark \quad$ Job-search offerings by PES and via virtual platforms. Any PES offering for this group will have to take into account that the use of mobile technology (for localized job search, initiation of employer contact), and so on, will be taken for granted by many members of this group.

$\checkmark$ The "Job Protection Act" introduced an employment subsidy for young people. The subsidy is time-limited and targeted to younger-than-25-year-olds to incentivize sustainable employment.

Low-educated rural inactive mothers without work experience (4 percent, Priority: Medium). This group presents much greater integration challenges than the larger group of inactive mothers. They are a group of much younger women who mainly live in rural areas. They have almost no work experience and much lower educational attainment. Potential activation measures include:

$\checkmark$ (Reformed!) Public-works "window" for mothers. Opening a "mothers" window in a reformed public works program that includes child-care offerings and training opportunities might help some of these women get initial work experience and address their dire poverty situation. Most likely, this will call for reform of the local selection practices of the public works program by municipalities.

$\checkmark \quad$ Remedial education. In light of the extremely low educational attainment among this group, offerings of remedial secondary education could be quite well placed for

${ }^{84}$ European Union. European Platform for Investing in Children. Country Profile (last updated in February 2014). Hungary: Developing child care services to help parents back to work. Available at: http://europa.eu/epic/countries/hungary/index_en.htm

85 Furthermore, the government has installed "sure start" centers for vulnerable communities (modeled after a UK example) that provide additional social support for poor children and their families. 
this group. Again, these offerings would probably have to be accompanied by child care offerings.

Educated single students (2 percent, Priority: Medium). This group has a high educational standard but no work experience and will, in the coming years, leave school and enter either unemployment or inactivity. Similar to the unemployed youth, they will need a quick start and work attachment to avoid any "scarring." Potentially, programs for the unemployed youth and the educated single students could be offered along the same program lines (in the same ESF OP or the like), with participants self-selecting into specific courses or programs based on educational background or living area (rural/urban). Potential activation measures include:

$\checkmark$ Promotion of part-time work during studies. Allowing students to gain first-hand work experience during their studies might help with initial labor market insertion upon graduation.

$\checkmark$ Standard job search support. Helping the members of this group with basic job search skills could already be helpful.

$\checkmark$ Offer support to students in order to comply with language requirements needed to receive their university diplomas (already addressed). In order to get their university degree, students in Hungary must pass an intermediate level language exam in the foreign language of their choice. Offering more support for these language requirements could help provide many students with the necessary formal credentials for labor market entry. In March 2014, the government of Hungary launched the Diploma Rescue Program, which supports those who have completed their tertiary education and only require a certificate of foreign language to get their degree, by covering their language course cost and, for registered job seekers, the cost of the (first) language exam.

In summary, Hungary could benefit from accompanying the ongoing improvement of its labor market services and social inclusion policies with enhanced knowledge about the composition and socio-economic situation of the different groups of out-of-work citizens. 


\section{References}

Collins, L. M., and S. T. Lanza, 2010, Latent Class and Latent Transition Analysis: With Applications in the Social, Behavioral, and Health Sciences. Hoboken, NJ: Wiley.

EEAG, 2012, The EEAG Report on the European Economy, "The Hungarian Crisis," CESifo, Munich 2012, pp. 115-130.

Eurofound, 2012, NEETs-Young people not in employment, education or training: Characteristics, costs and policy responses in Europe, Publications Office of the European Union, Luxembourg.

(EC), European Commission, European Community Programme for Employment and Social Solidarity, 2013, "Assessment of the implementation of the European Commission Recommendation on active inclusion: A study of national policies. Hungary," 2012

(EC) European Commission, 2013a, EU measures to tackle youth unemployment. MEMO, Brussels, 28 May 2013.

Eurostat, 2011, ESSPROS Manual: The European System of integrated Social PROtection Statistics. European Union, Luxembourg.

Katz, L., 2010, “Long-Term Unemployment in the Great Recession,” Testimony for the Joint Economic Committee, U.S. Congress Hearing on "Long-Term Unemployment: Causes, Consequences and Solutions," April 29, 2010.

Kaufman, L. and Rousseeuw, P. J., 1990, Finding groups in data. New York, Wiley.

Kierzenkowski, Rafal, 2012, "Towards a More Inclusive Labour Market in Hungary," OECD Economics Department Working Papers, No. 960, Paris: OECD

Magidson, Jay and Vermunt, Jeroen, 2002, Latent Class Modeling as a Probabilistic Extension of K-Means Clustering Quirk's Marketing Research Review, March, 20, 77-80. Available at: http://statisticalinnovations.com/technicalsupport/kmeans2a.htm

OECD, 2011, "Hungary," in Pensions at a Glance 2011: Retirement-income Systems in OECD and G20 Countries, OECD Publishing. Available at: http://dx.doi.org/10.1787/pension glance-2011-58-en

OECD, 2014, Economist Surveys: Hungary. January 2014, OECD: Paris

Vermunt, J. K. and J. Magidson, 2005, Latent GOLD 4.0 User's Guide. Belmont, Massachusetts: Statistical Innovations Inc. 


\section{Latent Class Analysis of the Out- of-Work Population in Lithuania 2007-2011}

\section{Background}

Lithuania approached the global financial crisis following a decade of high growth. According to the World Bank's World Development Indicators, between 1998 and 2008, the country was one of the fastest growing economies in the world, displaying an average GDP growth rate of about 7 percent per year. In the 2003-2008 period, the country grew between 6 and 10 percent per year, in sharp contrast to the anemic growth rates observed by the EU-28, or the euro area (which expanded between 0 and 3 percent per year).

Lithuania was hit hard by the downturn but appears to have recovered fairly rapidly, at least as far as output growth is concerned. Even though the country entered the storm later compared to many other countries (GDP growth in 2008 still settled at an acceptable 3 percent), the Lithuanian economy suffered a severe recession in 2009, when output contracted by a staggering 14.8 percent. This was mostly due to the country's strong dependence on exports, which collapsed in the 2008-2009 period. While neighboring Latvia fared somewhat worse, the dip witnessed by the Lithuanian economy was much more severe than the one suffered by the average EU-28 country or Euro-area member, which witnessed negative growth rates in the 5 percent region in 2009. However, like neighboring countries with similar income levels (for example Estonia and Latvia), Lithuania recovered from the shock faster than its European partners; GDP growth was back into positive territory by mid-2009 and remained comfortably positive throughout 2010, before settling at about 6 percent in 2011. Growth rates returned to more modest levels by 2012 and 2013, at about 3-4 percent.

While GDP growth resumed quite rapidly, unemployment deteriorated sharply as a result of the downturn and is struggling to revert to pre-crisis levels. The rate of joblessness in Lithuania had declined steadily since the early 2000s, settling at little over 4 percent in 2007. However, as the effects of the global financial crisis unraveled, the country suffered a large and extremely rapid increase in unemployment; by the end of 2008, joblessness had risen to about 6 percent, climbing to 14 percent in 2009 and eventually peaking at 18 percent in 2010. Such increases are considerably larger than those observed in the EU-28 or the euro area as a whole, but comparable to what other countries in the region of similar income levels witnessed. Unemployment began to slowly decrease in late 2010, but the average rate in 2013 was still 12 percent, about 8 percentage points above the precrisis levels.

Young Lithuanians were particularly affected by the global downturn. Like the overall unemployment rate, the joblessness rate among Lithuanians between the age of 15 and 24

Portraits of Labor Market Exclusion | 207 
had declined steadily in the pre-crisis period, reaching 8 percent in 2007. As the global recession hit, youth unemployment skyrocketed to 29 percent in 2009 and then 35 percent in 2010. Encouragingly, however, as unemployment started to fall in 2010, the rate of joblessness among young Lithuanians followed suit; by 2012, unemployment in the 15-24 cohort had recovered somewhat to 26 percent-still more than 15 percentage points above the 2007 pre-crisis level. However, youth unemployment declined somewhat to 22 percent, and was slightly lower than the rate registered for the EU-28 as a whole (23 percent).

As far as joblessness goes, men were generally more affected than women. As Figure 7.1 below shows, at all age levels, Lithuania men suffered larger increases in their rate of unemployment relative to women. Both men and women in the 25-64 age category entered the crisis with unemployment rates close to 5 percent; however, by late 2010, women in this age group displayed unemployment rates in the 12-15 percent range, as opposed to 15 to 20 percent among men of the same age. Among young Lithuanians, men were also affected much more than women, with the rate of joblessness among 15-to-24-year-old men peaking at 45 percent, as opposed to 35 percent among women of the same cohort.

Figure 7.1 Unemployment Rates by Gender and Age (2007-2013)
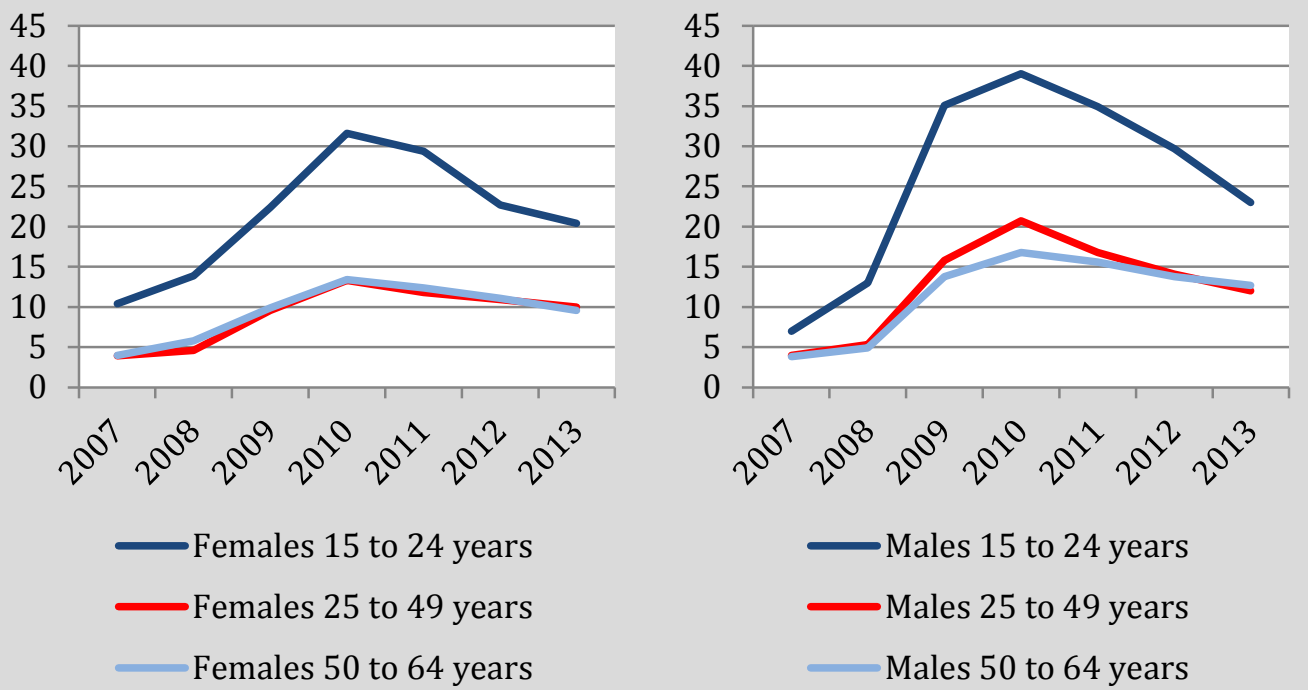

Source: Eurostat, EU-LFS 
Figure 7.2 Long-Term Unemployment as a Share of Total Unemployment (2003-2013)

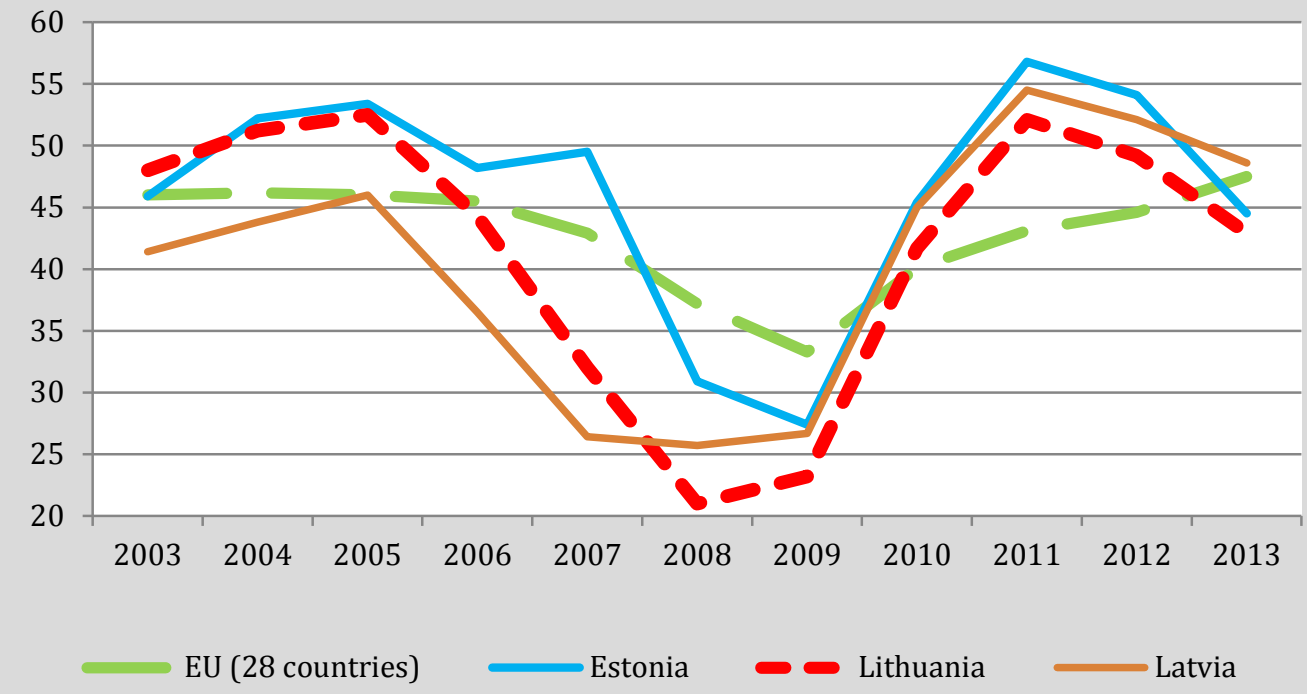

Source: Eurostat

One of the most worrying developments as a result of the crisis was the significant increase in the share of long-term unemployed. In 2013, according to Eurostat and as shown in Figure 7.2 in the average EU-28 country almost 48 percent of the unemployed have been looking for work for more than 12 months, up from 35 percent in 2009. In Lithuania, where the long-term unemployment rate had declined all the way to just over 20 percent in 2009, the figure reached 52 percent in 2011 and settled at 50 percent in 2012, a development comparable to those observed in Latvia and Estonia, before declining to 43 percent in 2013.

Figure 7.3 Evolution of Out-of-Work Population in Lithuania (16-64)

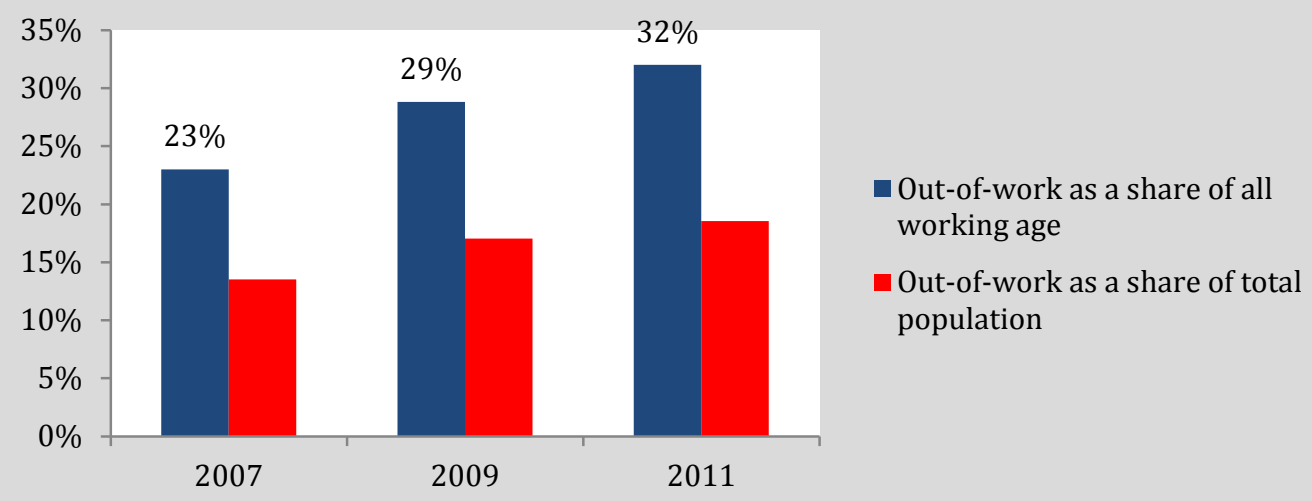

Source: World Bank staff analysis based on EU-SILC

A further troubling change in the Lithuanian labor market since 2007 is the rapid increase in both the absolute number of out-of work individuals and in the share of 
the out-of-work population relative to total population and working-age population. EU-SILC data reveals that the number of the out-of-work population between the age of 16 and 64 (excluding students) had been increasing steadily between 2007 and 2011, going from slightly over 450,000 to just under 610,000 . This is all the more alarming as it occurred during a period in which both the total size of the population and the total number of working-age individuals in Lithuania actually shrank (from about 3.375 to about 3.285 million and from 1.985 to 1.9 million, respectively). This resulted in the share of out-of-work population relative to the total working-age population increasing from 23 percent to 32 percent.

The 2007-2011 period witnessed a sizeable increase in the number and relative importance of unemployment (particularly long-term unemployment), at the expenses of employment. Figure 7.4 and Figure 7.5 below show the composition of working-age and of out-of-work Lithuanians in 2007 and 2011, respectively. Not only, as Figure 7.3 above shows, did the size of out-of-work population increase between 2007 and 2011 relative to the working-age population, but long-term unemployment became relatively more common among Lithuanians, while the share of those at work has been losing ground. While the share of long-term unemployed relative to total working-age people was about 2.5 percent in 2007, the figure had increased to over 8 percent in 2011; similarly, long-term unemployed accounted for 11 percent of the out-of-work population in 2007, but for 26 percent in 2011. The share of total unemployment (long-term and non) among working-age individuals (excluding students ${ }^{86}$ ) also more than doubled over the period, increasing from 6 percent to 15 percent; jobless individuals accounted for 25 percent of the out-of-work population in 2007, but for 46 percent in 2011.

The developments highlighted above, in particular the increase in the size and relative weight of the out-of-work population and the unemployed, point to a deterioration in the Lithuanian labor market over the last few years. A deeper analysis of the out-of-work population is therefore urgently needed; understanding the composition of these groups is in fact key to ensuring that the right policy measures are taken and that priorities are set in an appropriate manner.

\footnotetext{
86 Individuals aged 16 to 24 who are out of work and enrolled in education are excluded from the sample; they are considered to be investing in their final stages of human capital formation and therefore also not a particular target group for activation policies. In 2011, this population amounted to about 257,400 individuals, representing 59.5 percent of the total population aged 16 to 24 and 30 percent of the total out-of-work population of working age. Individuals enrolled in school between 25 and 64 are however included in the latent class analysis and will be grouped under "other inactive." It is important to note that the group of students (older than 24) account for less than 1 percent of total population of working age.
} 
Figure 7.4 Composition of Working-Age Population (16-64) by Labor Market Attachment in Lithuania

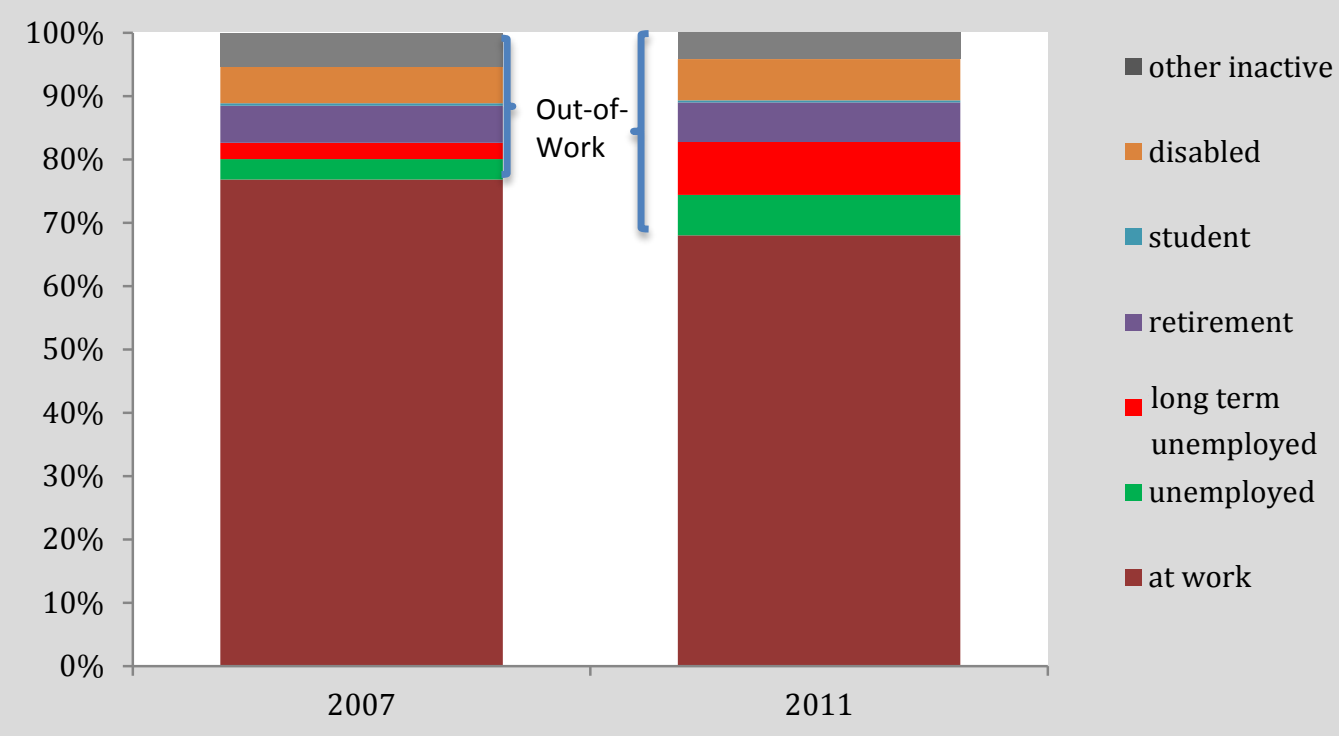

Source: World Bank staff analysis based on EU-SILC

Figure 7.5 Distribution of Out-of-Work Population in Lithuania (2007 and 2011)

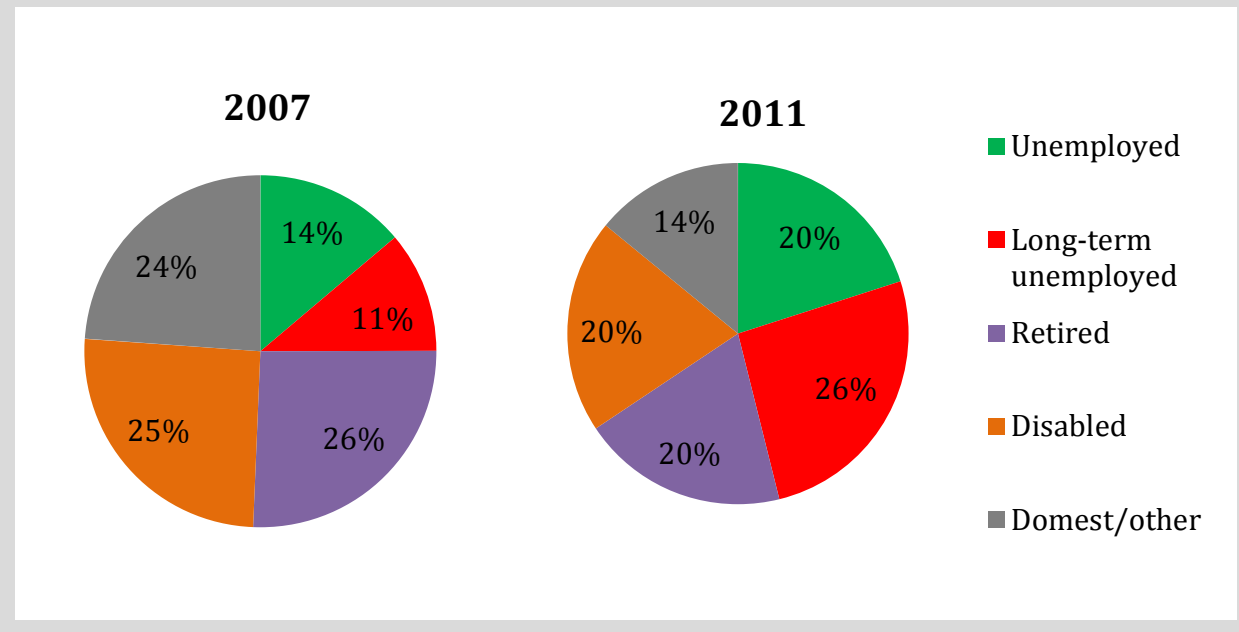

Source: World Bank staff analysis based on EU-SILC 


\section{Methodology: Latent Class Analysis}

In Chapter 1 a general overview of the latent class analysis methodology was presented. This section explains in detail the variables and covariates used to identify classes or groups of out-of-work individuals that are as homogeneous as possible within each class according to a set of observable characteristics, and as distant as possible between classes. The emerging profiles can then be contrasted with the design and targeting of current activation policies, in order to identify the potential gaps and to enhance their design features.

Variable selection: The definition of latent classes relies on a number of indicator variables to capture different "symptoms" of an overall latent condition (in this case, the typology of joblessness). The challenge in such models is to identify a discrete number of variables that can best explain the heterogeneity of individual outcomes. In this case, two sets of categorical variables were selected: the first set to show the extent of labor market distance and the other to capture some of the main factors that can affect employment on the supply side, such as labor supply conditions (household-level incentives to work and physical ability to work).

$\checkmark$ Distance from labor market: short-term unemployment, long-term unemployment, (early) retirement, disability, and other inactivity (largely unpaid domestic work). ${ }^{87}$

$\checkmark$ Labor supply conditions: whether the individual's household has at least one working adult, 88 and perceived limitations on activities due to health problems. ${ }^{89}$

In addition to indicators, the model includes active covariates, which are used to improve the classification of individuals in each class. In this case the active covariates are the demographic variables that are normally used to disaggregate labor market outcomes:

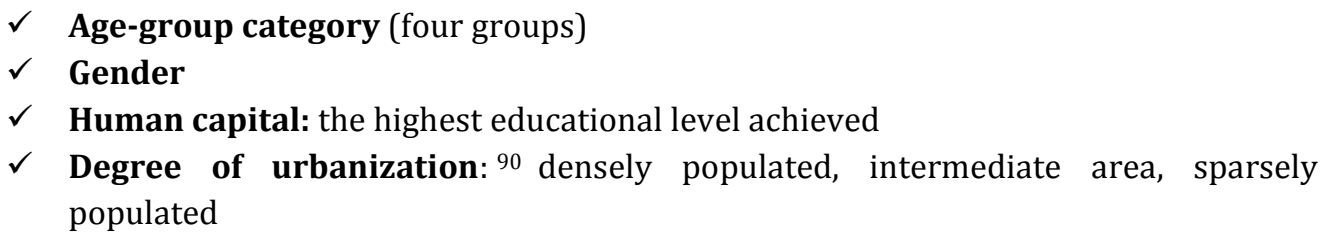
populated

Once the latent classes have been defined, inactive covariates that were not included in the model can be used to characterize the individuals in each class and the households in which

\footnotetext{
87 This variable is constructed using the self-reported current work status in the EU-SILC survey that has four categories: at work, unemployed, retired and inactive. The unemployed are further classified into short- and long-term based on how long they have been actively looking for a job. The inactive is combined with another question to separate this group into students, disabled, military and other inactive.

88 In order to construct this variable, individuals aged 25 or older are considered adults.

89 This is a binary variable that takes the value one if an individual answered "yes, strong limitations" to whether they had been hampered in their usual activities because of health problems for at least the last six months. The value is zero if the answer is "yes, limited" or "no, not limited."

${ }^{90}$ According to EU-SILC guidelines, dense areas have more than 500 inhabitants per square kilometer, where the total population for the set is at least 50,000 inhabitants. Intermediate areas have more than 100 inhabitants per square kilometer, and either a total population for the set of at least 50,000 inhabitants or a location adjacent to a dense area. The remaining areas are categorized as sparsely populated.
} 
they live. The inactive covariates chosen describe those characteristics that may provide valuable information for the design of tailored policies that address barriers to employment, including income level. They include:

\section{$\checkmark$ Household welfare conditions:}

- Income quintile (defined by equivalized disposable household income ${ }^{91,92}$ )

- Labor, benefit, and other income as share of total gross household income ${ }^{93}$

- Working status of the partner

- Tenure status

- Household ability to keep dwelling warm

- Partner's labor income

- Quintile of partner's labor income

- Binary variables denoting whether individuals or their households are beneficiaries of any of eight social protection benefits ${ }^{94}$

- Share of each benefit over the household's gross income

\section{$\checkmark$ Household demographics:}

- Household size

- Household composition

- Binary variable showing whether there are children under 6 in the household

- Binary variable denoting whether there are three or more under-16 children in the household

- Children under 13 receiving child care in the household: all, some or no children under 13 present

- Older person (65 and over) in the household

\section{$\checkmark$ Other individual-level demographics:}

- More refined age groups (eight groups)

- Marital status

\section{$\checkmark$ Individual human capital:}

- More refined highest educational level achieved (six groups)

- Work experience in years

- Binary variable for previous work experience

91 The equivalized household income takes into account an equivalence factor to weight the number of household members used in the denominator when calculating household income per capita. The first adult aged 18 or over has a weight of 1.0 , children under 14 have a weight of 0.3 , and other individuals 14 and older have a weight of 0.5 . The sum of the weights of all household members is equal to the equivalent household size.

92 Note that income reported in EU-SILC surveys is for the year preceding the survey year.

93 Total household gross income is defined as the sum of: (at the individual level) gross employee cash or near-cash income; company car, gross cash benefits or losses from self-employment (including royalties); unemployment benefits; old-age benefits; survivor benefits; sickness benefits; disability benefits; education allowances; and (at the household level) income from rental of property or land; family/children related allowances; social exclusion not elsewhere classified; housing allowances; regular inter-household cash transfers received; interests, dividends, profit from capital investments in unincorporated business; pensions from individual private plans; and income received by people under 16. Total household net income, in turn, was calculated by subtracting from total household gross income regular taxes on wealth, taxes on income and social insurance contributions, and regular inter-household case transfers paid.

${ }^{94}$ Social benefits are aggregated in eight branches using the European System of integrated Social PROtection Statistics (ESSPROS) definitions. For more information, see Eurostat (2011). 


\section{$\checkmark$ Household location:}

- Urban/rural status

The analysis relies on cross-sectional as well as panel data from the European Union Statistics of Income and Living Conditions (EU-SILC) surveys for 2008-2011, which combine individual-level information with household characteristics. The first part of the note presents a cross-sectional analysis for the years 2008, 2009, 2010 and 2011. In particular, the latent class analysis on 2008 data shows the main characteristics of the out-of-work before the global economic crisis hit Lithuania, and thus highlight what could be considered more structural issues of the country's labor market. The 2011 latent class analysis will contrast this initial assessment with more recent developments. The second part of the note exploits longitudinal data between 2008 and $2010^{95}$ to trace the prior labor market status of individuals observed last in 2010 in various classes, and will shed light on the relative persistence in the out-of-work status among different classes of individuals. The set of variables chosen for the cross-section and the longitudinal analysis are slightly different, due to minor differences in the set of variables recorded in each of the two types of datasets.

95 The EU-SILC longitudinal survey consists of a four-year rotating panel. In each year, approximately three-quarters of individuals present in the previous year are retained. The samples used in the latent class analysis include about 3,000 observations for each year in the cross-sectional analysis and 600 observations in the longitudinal analysis. The population is weighted with individual weights. 


\section{Main Findings}

\section{Out-of-Work Population: Group Profiles}

The latent class analysis supports the classification of the out-of-work into eight major groups, some of which have remained stable over time. The groups were named according to their most salient characteristics. Figure 7.6 shows the shares of each of the eight classes identified for the year 2011 while Table 7.1 presents their most salient characteristics.

Figure 7.6 Classes of Out-of-Work Individuals in Lithuania (2011)

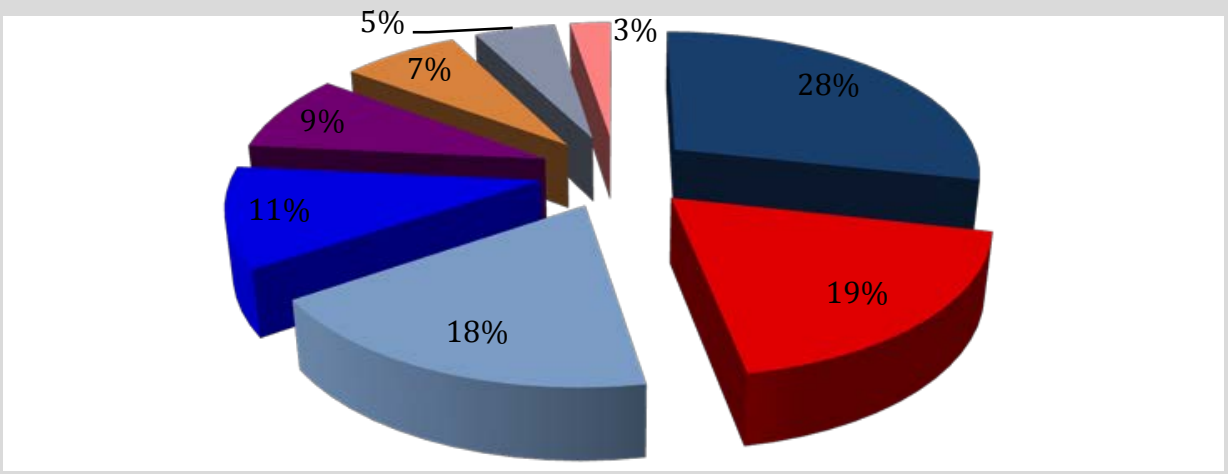

- Middle-aged poor rural long term unemployed

- Rural disabled adults with benefits

- Married rural women with old age pension

- Young educated rural unemployed

- Middle-aged educated unemployed family men

- Single poor rural unemployed women

- Stay-at-home poor rural women

- Disabled and low-educated urban young men

Source: World Bank staff analysis based on EU-SILC

Table 7.1 Summary Characteristics of Latent Classes of the Out-of-Work Population in Lithuania (2011)

\section{1: Middle-aged poor rural long-term unemployed (28\%)}

- Almost all are unemployed

- High proportion of long-term of unemployed (over $70 \%$ of all the cluster or $3 / 4$ of the unemployed in the cluster)

- $\quad 45 \%$ have upper secondary education, and almost $25 \%$ lower secondary

- Almost 70\% live in rural areas

- About 65\% are between 35 and 59

- Another $24 \%$ is between 25 and 34

- Almost $80 \%$ are in the first 2 income quintiles

- Almost $60 \%$ are men

\section{2: Rural disabled adults with benefits $(19 \%)$}

- $\quad 90 \%$ are disabled

- $85 \%$ are between 35 and 59

- Another $11 \%$ is between 60 and 64

- $75 \%$ reside in rural areas

- $84 \%$ of them receive disability benefits

- $\quad 96 \%$ of them receive some benefit

- Benefits make up almost $75 \%$ of total household income 


\begin{tabular}{|c|c|}
\hline $\begin{array}{l}\text { 3: Married rural women with old age } \\
\text { pensions }(18 \%)\end{array}$ & $\begin{array}{l}\text { 4: Young educated rural unemployed } \\
\qquad(11 \%)\end{array}$ \\
\hline $\begin{array}{l}\text { - } 99 \% \text { are retired } \\
\text { - } 91 \% \text { are between } 60 \text { and } 64 \\
\text { - } \quad \text { Almost } 70 \% \text { are women } \\
\text { - } 65 \% \text { live in rural areas } \\
\text { - } \quad 60 \% \text { are married and another } 20 \% \text { is } \\
\text { widowed } \\
\text { - } 77 \% \text { of them receive old age benefits } \\
\text { - } 85 \% \text { live in a household without children } \\
\text { - } \quad \text { They mostly live in small sized households } \\
\text { - } \quad \text { Benefits make up almost } 75 \% \text { of total } \\
\text { household income }\end{array}$ & $\begin{array}{l}\text { - } 77 \% \text { are unemployed } \\
\text { - } \quad \text { All are between } 16 \text { and } 35 \\
\text { - } 53 \% \text { are between } 16 \text { and } 24 \\
\text { - } \quad 44 \% \text { lmost } 60 \% \text { are single } \\
\text { - } 44 \% \text { have tertiary education and } 10 \% \text { post- } \\
\text { Almost } 90 \% \text { of them live in a household } \\
\text { with a working adult }\end{array}$ \\
\hline $\begin{array}{l}\text { 5: Middle-aged educated } \\
\text { unemployed family men (9\%) }\end{array}$ & $\begin{array}{l}\text { 6: Single poor rural } \\
\text { unemployed women (7\%) }\end{array}$ \\
\hline $\begin{array}{ll}\text { - } & 66 \% \text { are unemployed } \\
\text { - } & 61 \% \text { are men } \\
\text { - } & \text { Two thirds live in rural areas } \\
\text { - } & 99 \% \text { are between } 35 \text { and } 59 \\
\text { - } & 30 \% \text { have tertiary education } \\
\text { - } & 87 \% \text { are married } \\
\text { - } & 81 \% \text { have a working spouse } \\
\text { - } & 70 \% \text { receive some benefit } \\
\text { - } & \text { Almost } 60 \% \text { live in a household with } 1 \text { or } 2 \\
\text { kids }\end{array}$ & $\begin{array}{l}\text { - } 40 \% \text { are unemployed and } 60 \% \text { are engaged } \\
\text { in domestic activities } \\
\text { - } \quad \text { None live in a household with a working } \\
\text { adult } \\
\text { - } 62 \% \text { are women } \\
\text { - } 86 \% \text { live in rural areas } \\
\text { - } 80 \% \text { are in the first two income quintiles } \\
\text { - } \quad 60 \% \text { are single, divorced, or widowed } \\
\text { - } \quad \text { Almost a third of them has no previous } \\
\text { work experience }\end{array}$ \\
\hline 7: Stay-at-home poor rural women (5\%) & $\begin{array}{l}\text { 8: Disabled and low-educated urban young } \\
\text { men (3\%) }\end{array}$ \\
\hline 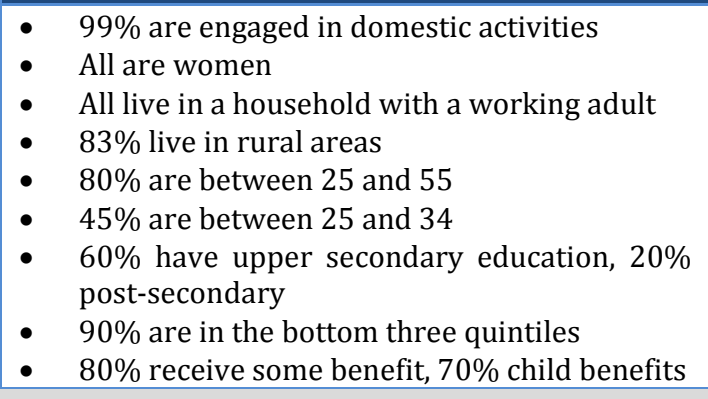 & $\begin{array}{l}\text { - } 95 \% \text { are disabled } \\
\text { - } 95 \% \text { suffer from severe disabilities } \\
\text { - } 99 \% \text { are below } 34 \\
\text { - } \quad \text { More than } 80 \% \text { are male } \\
\text { - } \quad \text { About } 77 \% \text { live in urban areas } \\
\text { - } \quad \text { Almost all of them receive benefits, and } \\
\text { - } \quad 96 \% \text { receive disability benefits } \\
\text { - } 96 \% \text { are single }\end{array}$ \\
\hline \multicolumn{2}{|c|}{$\begin{array}{l}\text { Source: World Bank staff analysis based on EU-SILC } \\
\text { Note: Percentages in parentheses following the group names refer to the share of the total out-of-work } \\
\text { population. "Years of work experience" refers only to those individuals who have worked before. } \\
\text { "Dependent children" includes children under } 18 \text { and household members aged } 18 \text { to } 24 \text { who are } \\
\text { economically inactive and living with at least one parent. "Working adult" refers to adults aged } 25 \text { and } \\
\text { over. For this report's purposes, we define the at-risk-of-poverty rate as the relative risk of being in the } \\
\text { first quintile of the income distribution. The reference period for income reported in EU-SILC surveys is the } \\
\text { year preceding the survey year. }\end{array}$} \\
\hline
\end{tabular}

The eight main clusters emerging from the latent class analysis can be characterized as follows (see Annex 2 for more detail):

Cluster 1: Middle-aged poor rural long-term unemployed. This group represents 28 percent of the out-of-work population in 2011. The increase of the out-of-work population from 2007 to 2011 can be mainly ascribed to the increase in the size of this particular cluster of people. Individuals in this group are mostly between 25 and 59 
years of age, and more than 60 percent are between 35 and 59. About 29 percent of them are unemployed while, most worryingly, the majority of them (71 percent) are long-term unemployed. 66 percent of the members of this group live in rural areas and they tend to be low-income, as almost 80 percent of them belong to the first two income quintiles. About 45 percent have upper secondary education, and almost 25 percent lower secondary. This group is composed of both men and women (58 and 42 percent, respectively), and almost 70 percent have completed secondary education.

$\checkmark \quad$ Cluster 2: Rural disabled adults with benefits. This group, accounting for 19 percent of out-of-work population, is almost completely (90 percent) made up of disabled people who receive benefits: 84 percent of them receive a disability benefit; 96 percent receive some sort of benefit. The benefits also appear quite generous, as they comprise over 70 percent of total household income. However, surprisingly, only 42 percent of the individuals in this group claimed to have strong limitations on their daily activities due to health conditions. This cluster comprises few young individuals, as 99 percent are between 25 and 64 years old. Similarly to the first and third groups, the level of education attained is mainly secondary (71 percent), and most live in rural areas (76 percent). The individuals in this cluster are in the middle of the income distribution, as 70 percent of them have an income belonging to the second to fourth quintiles.

$\checkmark \quad$ Cluster 3: Married rural women with old age pensions. This third cluster, which makes up 18 percent of the out-of-work population, is composed almost exclusively of retired individuals, of whom almost 70 percent are women. More than 90 percent of those in this group are between 60 and 64 years old, and almost 55 percent belong to the first two quintiles of the income distribution. Most of them live in rural areas (65 percent) and hold relatively high levels of education (71 percent of them have completed secondary or tertiary education). They are mostly married (61 percent) and about 40 percent of them live with a retired spouse. Most of them receive generous (75 percent of total household income) benefits: 91 percent receive at least one assistance benefit, 77 percent receive some form of old-age payment, and 13 percent receive survivor benefits.

$\checkmark \quad$ Cluster 4: Young educated rural unemployed. This group, which emerged in 2011 probably as a result of the crisis, includes 11 percent of the out-of-work population and comprises young individuals, as all are between 16 and 35, and 53 percent are between 16 and 24. Most of the individuals in this cluster are unemployed (45 percent), while 22 percent are long-term unemployed. However, this group tends to be quite evenly distributed among income quintiles. Almost two out of three live in rural areas and almost 90 percent of them live in a household with a working adult. Compared to the first three groups, individuals in this class have a relatively high level of education: 44 percent have completed tertiary education and 44 percent have completed upper or post-secondary. When it comes to their marital status, almost 60 percent of them are single. While family and social exclusion benefits make up 13 percent of their household income, unemployment benefits only contribute 2 percent.

$\checkmark \quad$ Cluster 5: Middle-aged educated unemployed family men. This group, of which 66 percent is unemployed, makes up 9 percent of the out-of-work population and includes a majority of men (61 percent). Twenty-two percent of those in this cluster are long-term unemployed and two-thirds live in rural areas. Almost all of them are between 35 and 59 and, like Cluster 4, they are well educated: 64 percent have completed upper or postsecondary education and 30 percent tertiary. Their income status does not appear to be 
very informative, as this groups is relatively evenly distributed among quintiles. Also, most of them live in households composed of two adults and one or more children (60 percent). Interestingly, 70 percent receive social assistance benefits and 45 percent receive child or family benefits.

$\checkmark \quad$ Cluster 6: Single poor rural unemployed women. This group accounts for 7 percent of out-of-work individuals and the majority are women ( 62 percent). Forty 40 percent are unemployed while 60 percent are engaged in domestic activities. They are of prime working age, as 90 percent are between 25 and 59 years old. Similarly to most of the other clusters, they mainly live in rural area (86 percent); however, more than a third hold only a primary education, and 70 percent are in the first income quintile. In fact, 80 percent fall within the first two income quintiles. About 60 percent are either single, divorced or widowed, and around one-fifth have no prior work experience. Importantly, more than 70 percent receive at least one benefit, and 64 percent of the total income of the households in this group is derived from benefits.

$\checkmark \quad$ Cluster 7: Stay-at-home poor rural women. Members of this cluster, covering about 5 percent of the out-of-work population, are all women, engaged in domestic activities and predominantly living in rural areas ( 83 percent). 80 percent are between 25 and 54 years old, but 40 percent are between 25 and 34 . Almost all women in this group have at least a secondary education (15 percent at the lower level, 59 percent at the uppersecondary level, and 19 percent at the post-secondary level). About 65 percent of them fall in the first two income quintiles. All of them live in households with a working adult, and more than 80 percent in households with at least one child. Like Cluster 1, though, the other important characteristic of this group is its low income level: in fact, 66 percent of them have incomes in the two lowest quintiles of the income distribution. Eighty percent receive at least one benefit, and 70 percent benefit from child-support programs. The main difference between this cluster and the previous one lies in two variables: first, this cluster is made up exclusively of women, as opposed to Group 6, which is made mostly of women. Second, this cluster includes stay-at-home women, while the previous one includes unemployed individuals as well.

$\checkmark \quad$ Cluster 8; Disabled and low-educated urban young men. The last group emerged in 2011. It represents 3 percent of the out-of-work population. It is composed of single men between 16 and 34 years old, most of whom are extremely disabled. Almost all are single and live with other family members. Unlike the other seven groups, the individuals in this cluster live mostly in urban areas ( 77 percent) and have very low levels of education (only one-third have completed at least lower secondary school), but seem to live in better-off households (as almost 60 percent of these households belong to the top two income quintiles). In addition, 96 percent of the disabled have never worked. As said previously, their main characteristic is that they are all disabled and, as opposed to Cluster 3, 94 percent of them claim to suffer from strong limitations on daily activity due to health conditions. Even though almost all individuals in this group receive at least one benefit, just 81 percent of individuals in this group receive a disability benefit, as opposed to 84 percent of individuals in group 2 . 
The following tables present the main characteristics of each group in 2011. For the complete table, including inactive covariates, see Annex 2.

Table 7.2 Latent Classes of the Out-of-Work Population in Lithuania-Indicators (2011)

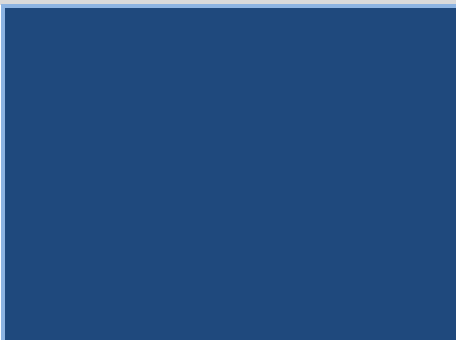

Cluster Size

Population

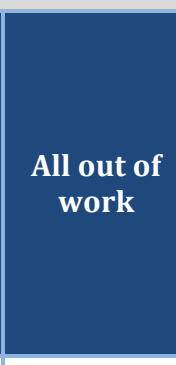

100

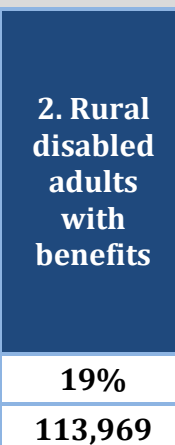

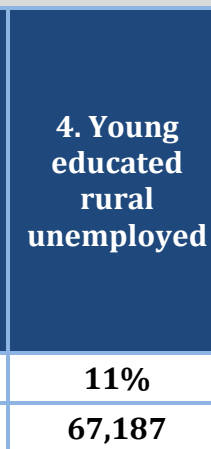

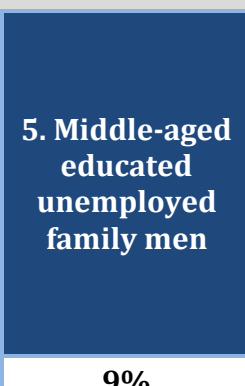

$9 \%$

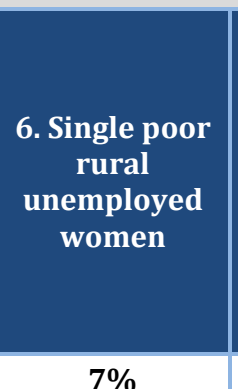

44,345

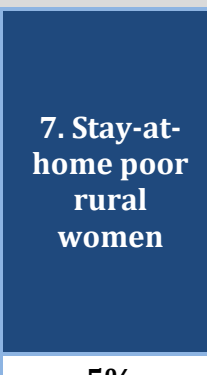

8. Disabled and loweducated

urban young men INDICATORS
$5 \%$

30,639
$3 \%$

15,472

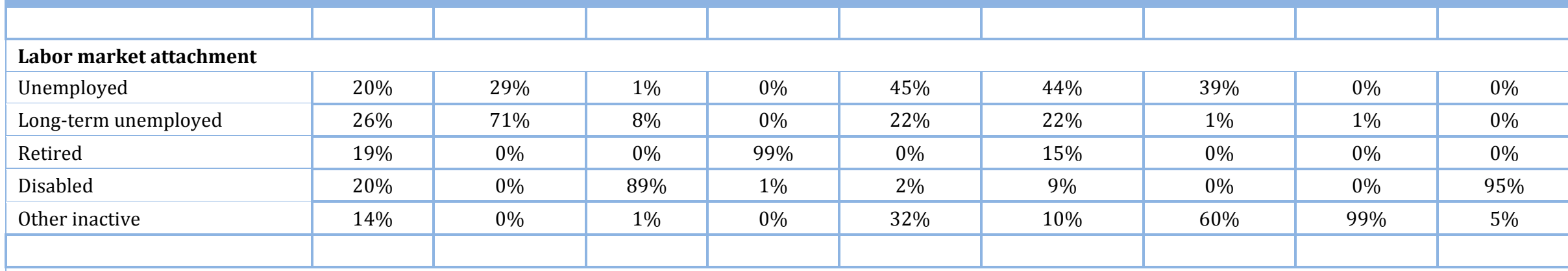

\section{Self-assessed physical incapacity}

Strongly limited

None/limited

\begin{tabular}{|c|c|c|}
\hline $13 \%$ & $2 \%$ & \\
\hline $87 \%$ & $98 \%$ & \\
\hline & & \\
\hline
\end{tabular}

$42 \%$

\begin{tabular}{|c|c|c|c|c|}
\hline $0 \%$ & $1 \%$ & $0 \%$ & $0 \%$ & $94 \%$ \\
\hline $100 \%$ & $99 \%$ & $100 \%$ & $100 \%$ & $6 \%$ \\
\hline & & & & \\
\hline
\end{tabular}

\section{At least one working adult in household}

\begin{tabular}{|c|c|c|c|c|c|c|c|c|c|}
\hline No & $52 \%$ & $61 \%$ & $67 \%$ & $68 \%$ & $13 \%$ & $2 \%$ & $100 \%$ & $1 \%$ & $40 \%$ \\
\hline Yes & $48 \%$ & $39 \%$ & $33 \%$ & $32 \%$ & $87 \%$ & $98 \%$ & $0 \%$ & $99 \%$ & $60 \%$ \\
\hline
\end{tabular}

Source: World Bank staff analysis based on EU-SILC 
Table 7.3 Latent Classes of Out-of-Work Population in Lithuania-Active Covariates (2011)

\begin{tabular}{|c|c|c|c|c|c|c|c|c|c|}
\hline & $\begin{array}{l}\text { All out of } \\
\text { work }\end{array}$ & $\begin{array}{l}\text { Middle-aged } \\
\text { poor rural } \\
\text { long-term } \\
\text { unemployed }\end{array}$ & $\begin{array}{c}\text { Rural } \\
\text { disabled } \\
\text { adults with } \\
\text { benefits }\end{array}$ & $\begin{array}{l}\text { Married } \\
\text { rural } \\
\text { women } \\
\text { with old } \\
\text { age } \\
\text { pensions }\end{array}$ & $\begin{array}{l}\text { Young } \\
\text { educated } \\
\text { rural } \\
\text { unemployed }\end{array}$ & $\begin{array}{l}\text { Middle-aged } \\
\text { educated } \\
\text { unemployed } \\
\text { family men }\end{array}$ & $\begin{array}{l}\text { Single poor } \\
\text { rural } \\
\text { unemployed } \\
\text { women }\end{array}$ & $\begin{array}{c}\text { Stay-at- } \\
\text { home } \\
\text { poor } \\
\text { rural } \\
\text { women }\end{array}$ & $\begin{array}{l}\text { Disabled } \\
\text { and low- } \\
\text { educated } \\
\text { urban } \\
\text { young } \\
\text { men }\end{array}$ \\
\hline Cluster Size & $100 \%$ & $28 \%$ & $19 \%$ & $18 \%$ & $11 \%$ & $9 \%$ & $7 \%$ & $5 \%$ & $3 \%$ \\
\hline Population & 609,134 & 173,299 & 113,969 & 111,715 & 67,187 & 52,446 & 44,345 & 30,639 & 15,472 \\
\hline \multicolumn{10}{|c|}{ ACTIVE COVARIATES } \\
\hline \multicolumn{10}{|l|}{ Age Group } \\
\hline 16-24 years & $12 \%$ & $11 \%$ & $1 \%$ & $0 \%$ & $53 \%$ & $0 \%$ & $7 \%$ & $16 \%$ & $52 \%$ \\
\hline 25-34 years & $18 \%$ & $24 \%$ & $3 \%$ & $0 \%$ & $47 \%$ & $0 \%$ & $32 \%$ & $40 \%$ & $46 \%$ \\
\hline 35-59 years & $51 \%$ & $65 \%$ & $85 \%$ & $9 \%$ & $0 \%$ & $99 \%$ & $58 \%$ & $44 \%$ & $0 \%$ \\
\hline 60-64 years & $19 \%$ & $1 \%$ & $11 \%$ & $91 \%$ & $0 \%$ & $1 \%$ & $3 \%$ & $0 \%$ & $1 \%$ \\
\hline \multicolumn{10}{|l|}{ Gender } \\
\hline Male & $48 \%$ & $58 \%$ & $52 \%$ & $32 \%$ & $48 \%$ & $61 \%$ & $38 \%$ & $0 \%$ & $81 \%$ \\
\hline Female & $52 \%$ & $42 \%$ & $48 \%$ & $68 \%$ & $52 \%$ & $39 \%$ & $62 \%$ & $100 \%$ & $19 \%$ \\
\hline \multicolumn{10}{|l|}{ Education Level } \\
\hline Primary & $23 \%$ & $27 \%$ & $22 \%$ & $29 \%$ & $0 \%$ & $2 \%$ & $35 \%$ & $18 \%$ & $67 \%$ \\
\hline Secondary & $63 \%$ & $67 \%$ & $71 \%$ & $58 \%$ & $44 \%$ & $64 \%$ & $50 \%$ & $78 \%$ & $3 \%$ \\
\hline Tertiary & $14 \%$ & $5 \%$ & $5 \%$ & $13 \%$ & $44 \%$ & $30 \%$ & $11 \%$ & $3 \%$ & $4 \%$ \\
\hline Never studied before/illiterate/NA & & $1 \%$ & $2 \%$ & $1 \%$ & $12 \%$ & $4 \%$ & $5 \%$ & $1 \%$ & $26 \%$ \\
\hline \multicolumn{10}{|l|}{ Urban or Rural } \\
\hline Urban & $31 \%$ & $34 \%$ & $24 \%$ & $35 \%$ & $37 \%$ & $34 \%$ & $14 \%$ & $17 \%$ & $77 \%$ \\
\hline Rural & $69 \%$ & $66 \%$ & $76 \%$ & $65 \%$ & $63 \%$ & $66 \%$ & $86 \%$ & $83 \%$ & $23 \%$ \\
\hline
\end{tabular}


Table 7.4 Classes of Out-of-Work Population in Lithuania (2007, 2009 and 2011), as Percent of Total Out-of-Work Population

Name of Cluster

\begin{tabular}{|l|l|l|l}
2007 & 2009 & 2011
\end{tabular}

Married rural women with old age pensions

Middle-aged educated unemployed family men

Young educated rural unemployed

Stay-at-home (or unemployed) rural married-with-kids young women

Rural disabled adults with benefits

Single poor rural unemployed women

Middle-aged poor rural long-term unemployed

Middle-aged mostly urban low educated low income (mostly long-term) unemployed men

Stay-at-home poor rural women

Unemployed urban young women

Stay-at-home (or unemployed) well-educated rural married-with-kids young women

Stay-at-home low income young women with children

Disabled and low-educated urban young men

Total

\begin{tabular}{|c|c|c|}
\hline $25 \%$ & $17 \%$ & $18 \%$ \\
\hline $8 \%$ & $28 \%$ & $9 \%$ \\
\hline $13 \%$ & $6 \%$ & - \\
\hline $21 \%$ & $17 \%$ & $19 \%$ \\
\hline $9 \%$ & $14 \%$ & $7 \%$ \\
\hline $11 \%$ & $5 \%$ & $28 \%$ \\
\hline $4 \%$ & - & - \\
\hline & - & $5 \%$ \\
\hline- & $9 \%$ & - \\
\hline $9 \%$ & - & - \\
\hline- & $4 \%$ & - \\
\hline- & - & $3 \%$ \\
\hline $100 \%$ & $100 \%$ & $100 \%$ \\
\hline
\end{tabular}

Source: Staff Calculation based on EU-SILC

The composition of the classes has experienced considerable changes over the last few years. Table 7.4 and Figure 7.7 show the evolutions of the classes from 2007 to 2011, as a share of total out-of-work population and in absolute numbers. As mentioned before, one important development between 2007 and 2011 was the noticeable increased in the size of the out-of-work population, from less than 460,000 to just under 610,000 individuals. Furthermore, it is interesting how some of the clusters identified by analyzing the 2011 data could also be (broadly speaking) identified in the 2007 and 2009 data, although the relative sizes of such clusters might have changed. In particular:

$\checkmark \quad$ The most striking and worrying change is the increase in the size of the middle-aged poor rural long-term unemployed group, the size of which more than tripled in absolute numbers over the period (going from just over 50,000 individuals to almost 175,000); this cluster represented 11 percent of the out-of-work population in 2007, but 28 percent in 2011. Interestingly, in 2011 this group was composed of men and women in almost equal shares, while by 2009,86 percent were men.

$\checkmark \quad$ A further significant and negative development was the increase in the number of middle-aged educated unemployed family men. This group represented only 8 percent of the work population in 2008, but reached 28 percent in 2009, before returning to 9 percent in 2011. In absolute terms, this group increased from over 36,000 in 2007 to 52,000 in 2011.

$\checkmark \quad$ The group of single poor rural unemployed women also witnessed significant changes over the period, increasing from fewer than 42,000 individuals in 2007 to 82,000 in 2009 , but decreasing all the way back to 44,000 by 2011 . Somewhat encouragingly, this group's share of the out-of-work population was lower in 2011 than in 2007.

Portraits of Labor Market Exclusion | 221 
$\checkmark \quad$ The cluster of young educated unemployed emerged only in 2011, possibly as a result of the crisis. This group was not present in the data from previous years, but represented 11 percent of the out-of-work population in 2011 (67,000 individuals).

$\checkmark$ The group of rural disabled adults with benefits has been generally stable over the years in relative terms, but has increased in absolute terms. This group represented 21 percent of the out-of-work population in 2007, 17 percent in 2009 and 19 percent in 2011. However, the total size of this group increased from 96,000 in 2007 to 114,000 in 2011.

$\checkmark \quad$ The well-established group of married rural women with old-age pensions did not move much in absolute terms. The absolute number of individuals in this group has in fact been stable over the period at about 110,000; however, its relative size has declined from 25 percent in 2007 to 18 percent in 2011.

Figure 7.7 Classes of Out-of-Work Population in Lithuania (2007, 2009 and 2011), Number of Individuals

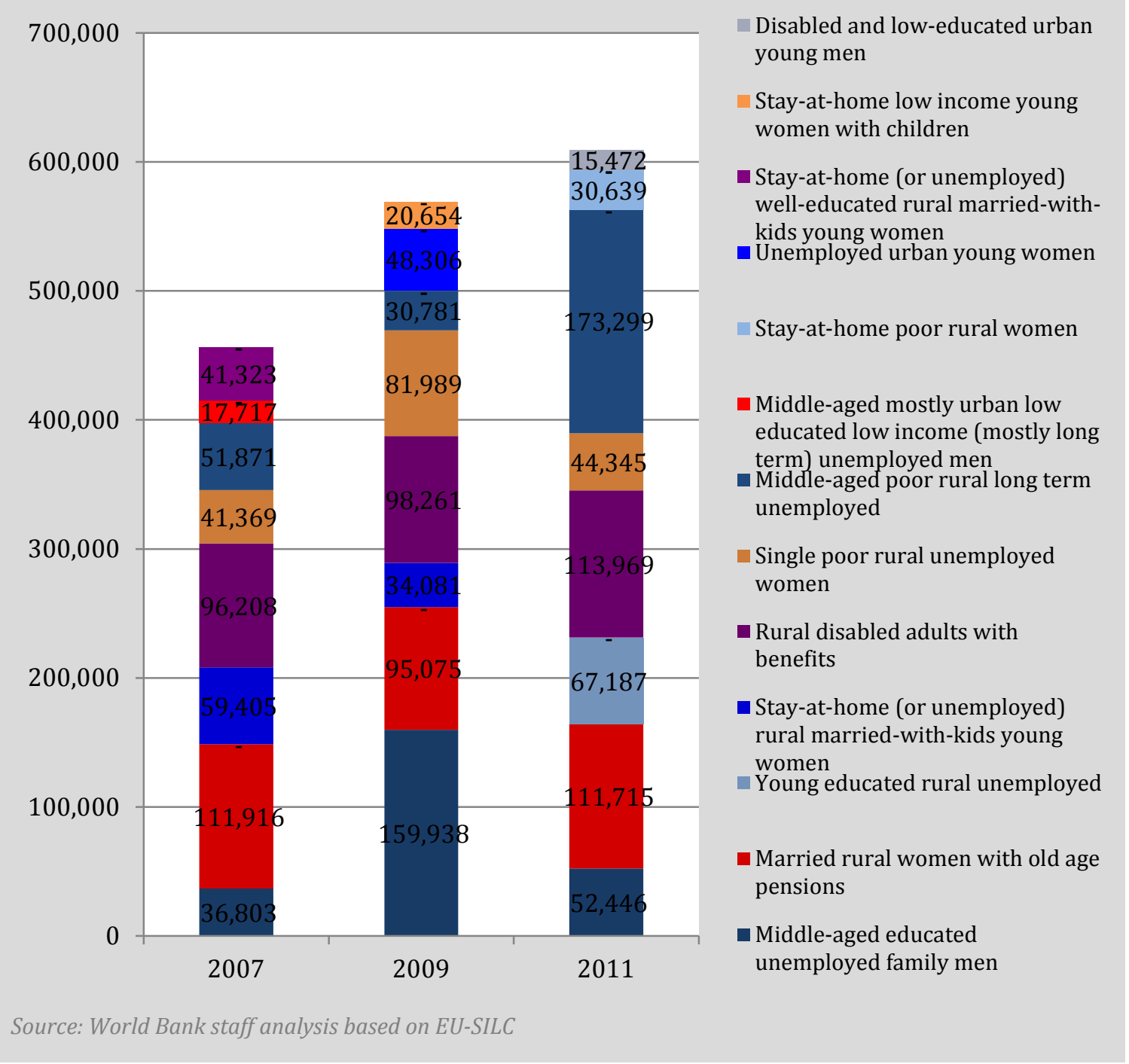


The analysis of the EU-SILC data using latent class methodology, and of Eurostat numbers, reveal the existence of a number of clusters or groups of out-of-work individuals that can be more or less clearly defined and that differ from one another in important characteristics. Some of the features that we have highlighted are more permanent in nature, while others can most likely be ascribed to the global downturn and might therefore be more cyclical.

On the structural side, first and foremost, our analysis shows that young Lithuanians have fared-and fare-particularly badly on the labor market. As per the graphs above, the unemployment rate in the 15-to-24 year old cohort was 22 percent in 2013, after peaking at more than 39 percent among males and 32 percent among females in 2010. Although youth unemployment in Lithuania is worrisome, it is in line with the average unemployment rate in the EU-28 among young people in 2013 (23 percent). At the same time, according to Eurostat data, Lithuanian youth display much worse employment rates than their European counterparts. Employment rates in Lithuania among those aged 15 to 25 peaked, in fact, at 27 percent in 2008, before dropping to 18 percent in 2010 and recovering somewhat to 25 percent in 2013; Latvia and Estonia, on the other hand, closed 2013 at 30 and 32 percent, respectively, after peaking at 37 percent in 2008. Similarly, employment rates in the average EU-28 or Euro Area country are currently 7 percentage points higher than the Lithuanian ones. Finally, as Figure 7.8 shows, labor force participation among youth aged 15 to 24 is also considerably lower in Lithuania relative to the rest of the European Union; in 2013, youth labor force participation rates reached 30 percent in Lithuania, one of the lowest rates in the European Union, and about 10 percentage points lower than countries such as Latvia, Estonia, and the EU average. 
Figure 7.8 Labor Force Participation among Youth Aged 15 to 24, European Countries (2013)

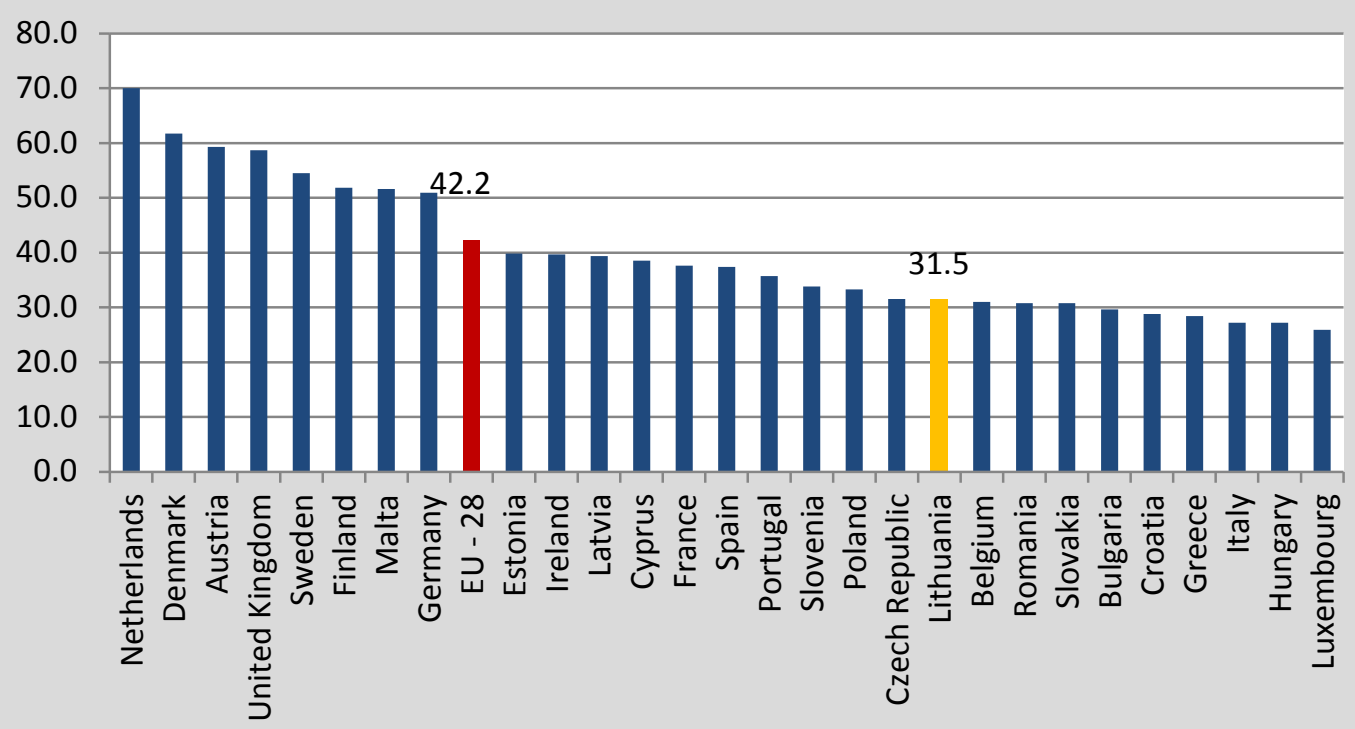

Source: Eurostat, EU-LFS

Second, disabled individuals have been and will continue to be a sizeable portion of the out-of-work population, and population aging will only increase the expenditures on disability benefits. The cluster of rural disabled adults with benefits included almost 114,000 people in 2011, while a second cluster that emerged in the same year made of disabled and loweducated urban young men accounted for another 15,000 individuals. In 2007, the cluster of rural disabled adults with benefits accounted for slightly more than 96,000 people. EU-SILC data also shows that those classified as disabled, while decreasing as a share of the out-of-work population from 2007 to 2011 (from 25 to 20 percent), have actually increased in absolute term, from about 114,000 in 2007 to almost 124,000 in 2011 (a 6 percent increase in four years). Furthermore, disabled Lithuanians tend to be relatively old ( 85 percent of them were more than 35 years old in 2011 according to EU-SILC data, and 65 percent more than 45). As many as 25 percent of them have no previous work experience, and thereby face high (and growing) impediments to entering or re-entering the labor market. Finally, the same data reveals that approximately 24 percent of all out-of-work population, or about 147,000 individuals, receive disability benefits, up from 123,000 people in 2007 (a 20 percent increase over four years). These patterns are somewhat concerning given the rapid aging that the Lithuanian society will undergo in the coming decades; Eurostat data shows that the share of Lithuanian residents over the age of 65 is currently 16 percent of total population, but this number will double by 2060. At the same time, the number of working age people will decline from 67 percent to 55 percent. The most recent census also shows that over the last decade the country has lost 13 percent of its population and, using Eurostat data once again, by 2060 only 2.76 million people will likely live in the country, down from 3.29 million in 2011. The combination of increasing numbers of disabled individuals and the aging of the population will likely increase the expenditures on disability benefits that the Government will have to undertake in the coming decades. Figure 7.9 below shows that 
expenditure on disability benefits as a share of GDP, while lower than the EU average, has already increased between 2008 and 2010, going from 1.6 percent to 1.8 percent.

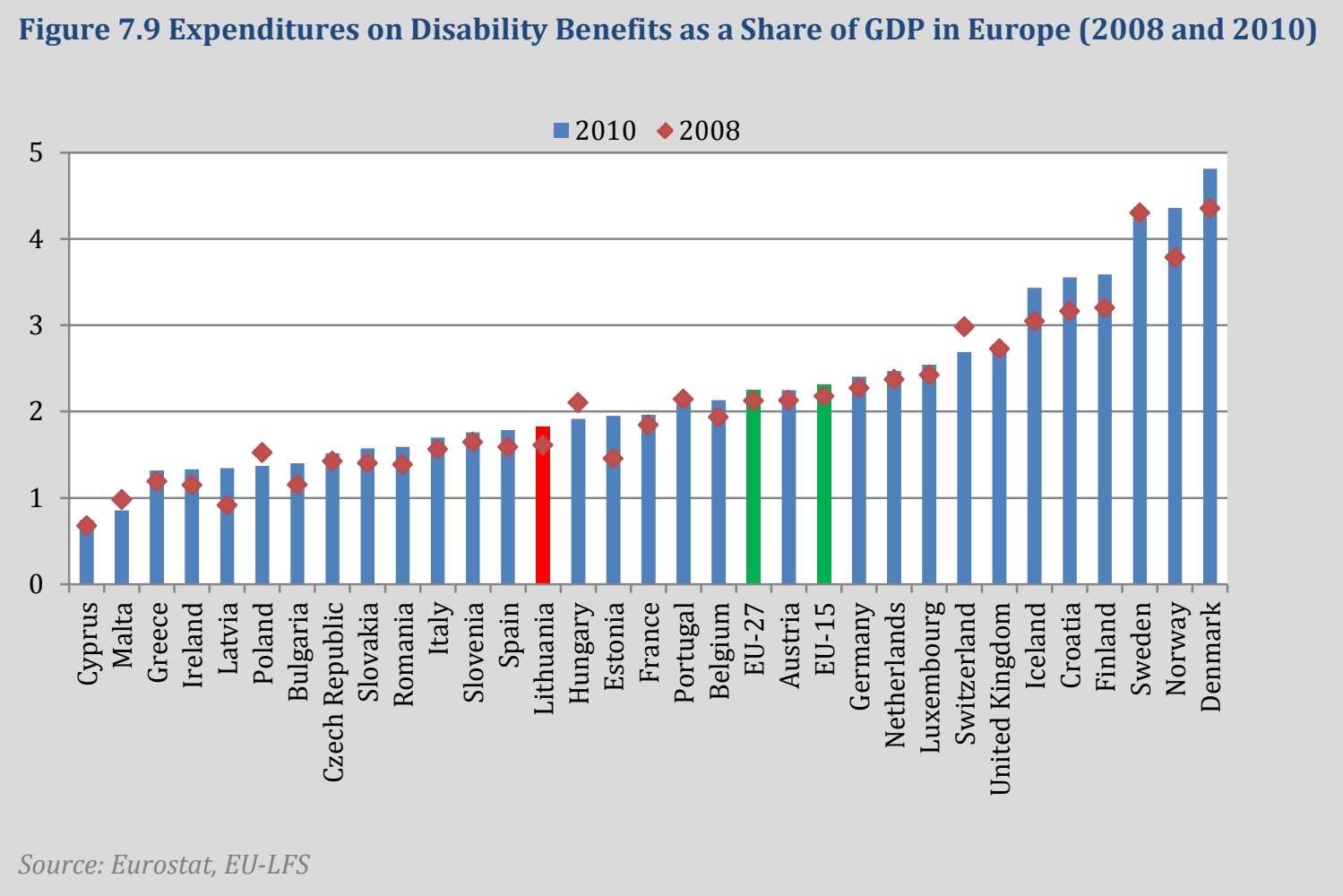

Third, a number of negative developments can be observed within the unemployed category, all of which pose significant and urgent challenges for policymakers. In particular:

$\checkmark \quad$ As already noted above, one of the most striking developments between 2007 and 2011 is the dramatic increase in the size of the middle-age poor rural long-term unemployed group, the size of which more than tripled in absolute numbers over the period. And while part of this increase can almost certainly be ascribed to the global downturn, the data confirms that the existence of a (depending on the business cycle) more or less sizable pool of low-income unemployed adults is a structural feature of the Lithuanian labor market, and one that needs to be dealt with urgently as these individuals and their families are probably at high risk of poverty.

$\checkmark$ A further concerning development is the significant increase in the size of the middleaged educated unemployed family men group; with about 94 percent of the individuals in this cluster having a secondary education or higher, this group of people probably has a relatively high skills endowment and should therefore be another priority when it comes to activation policies.

$\checkmark \quad$ The global downturn is likely at least partly responsible for the rise of a group of young educated rural unemployed, a cluster that did not exist in previous years but absorbed about 11 percent of the out-of-work population in 2011. With about one-third of them having no prior work experience and with 90 percent having secondary education, facilitating the transition of this group into the labor market is key to the long-term wellbeing of these individuals. 
$\checkmark \quad$ The downturn is also probably responsible for at least part of the large increase in the share and number of long-term unemployed in Lithuania. Across all clusters of unemployed individuals, an extremely worrying phenomenon was the growing share of individuals in long-term unemployment over the 2007-2011 period. As shown in the first section, the absolute numbers of those that have been looking for a job for over 12 months has also more than doubled. Long-term unemployment not only imposes a significant financial burden on households, but affects the long-term health status of job-seekers, negatively affects Government finances, and results in a lower overall long-term level of skills among a country's workforce, with permanent negative effects on productivity (Katz, 2012). Once more, addressing the plight of the long-term unemployed should be among the policy priorities for Lithuanian policymakers. 
Finally, by looking at longitudinal EU-SILC data for the period 2008-2010, one can better understand the in-cluster dynamics and notice other movements in the labor market. EU-SILC allows the tracking of a certain number of out-of-work individuals between 2008 and 2010. Of course, because of the difficulties in tracking people across time, the sample size of the panel dataset is considerably smaller than the cross-section surveys; the 2008-2010 longitudinal dataset includes, in fact, 705 observations, as opposed to the 2,300 observations for 2011 . However, the panel data confirms the existence of some latent classes that emerged in the crosssectional analysis. And even though the smaller sample size forces us to reduce the number of clusters identified, some clear patterns emerge. Through longitudinal data five classes can be defined, all of which can also be found in the cross-section datasets:

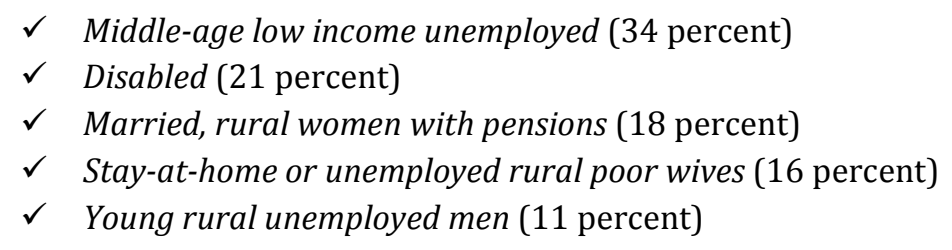

Annex 3 gives the full statistical description of the latent classes, while Table 7.5 below summarizes the key features of each group.

Table 7.5 Longitudinal Analysis: Summary Characteristics of Latent Classes of Out-of-Work Population in Lithuania (2010)

\section{1: Middle-age low income unemployed (34\%)}

- Almost 90\% are unemployed

- Over $90 \%$ is between the age of 25 and 59 , and $70 \%$ is 35 to 59

- $50 \%$ are in the first income quintile, and another $20 \%$ in the second

3: Married rural women with pensions $(18 \%)$

- Almost $90 \%$ are retired

- All are between 60 and 64

- Three out of four are women

- Two out of three live in rural areas

- Almost 95\% receive some benefit, and more than $80 \%$ receive old age benefits or pensions

\section{2: Disabled (21\%)}

- Over 95\% are disabled

- Half have severe disabilities, while the other have suffer from limited disabilities

- Almost $80 \%$ are between 35 and 59 and another $10 \%$ is between 25 and 34

\section{4: Stay-at-home or unemployed rural poor} wives $(16 \%)$

- $71 \%$ are domestic workers and another $15 \%$ unemployed

- Three out of four live in a household with at least one working adult

- Almost $85 \%$ are women

- Over $85 \%$ reside in rural areas

- One third is between the age of 25 and 34, and 90\% are between 25 and 59

- Over $60 \%$ is married

- Almost $60 \%$ belong to the poorest two income quintiles

\section{5: Young rural unemployed men (11\%)}

- Almost $90 \%$ are unemployed

- $93 \%$ are men 
- Almost $95 \%$ live in a household with at least one working adult

- Almost $50 \%$ are between the age of 16 and 24 , and another $15 \%$ is between 25 and 34

- Three out of four live in rural areas

- Almost $60 \%$ is single

- Over $70 \%$ belong to the top 3 income quintiles

Source: World Bank staff analysis based on EU-SILC

Note: "Years of work experience" refers only to those individuals who have worked before. "Dependent children" includes children under 18 and household members aged 18 to 24 who are economically inactive and living with at least one parent. "Working adult" refers to adults aged 24 and over.

A further advantage of the panel analysis is to provide information on the movement of individuals in and out of certain clusters and in and out of jobs between 2008 and 2010. Table 7.6 below presents the flow of individuals into the different clusters as of 2010 according to their labor market status in 2008. The most interesting column is the one for those employed in 2008 because it generally points to a lot of movement out of employment and into one of the out-ofwork statuses. According to the panel data, among those categorized as middle-age unemployed in 2010, 53 percent were employed in 2008; similarly, 45 percent of those falling into the young rural unemployed men category were gainfully employed in 2008, and 39 percent of stay-at-home or unemployed low income middle-aged mothers and wives in 2010 were working in 2008. On the other hand, only 4 percent of those employed in 2010 were unemployed in 2008. Table 7.7 also shows a considerable amount of movement from being out-of-work to employment; 46 percent of those unemployed in 2008 were employed by 2010, while 53 percent of those engaged in domestic activities in 2008 had transitioned to work by 2010. Puzzlingly, this data also shows that 63 percent of those retired in 2008 had moved back into employment by 2010 .

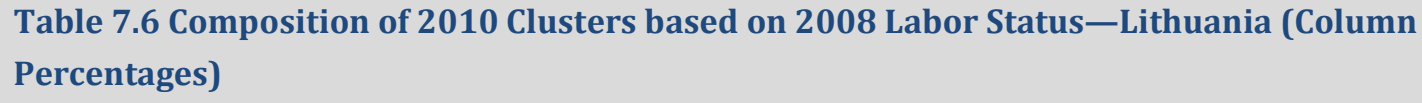

\begin{tabular}{|c|c|c|c|c|c|c|c|}
\hline \multirow[b]{2}{*}{$\begin{array}{l}\text { Clu } \\
\text { ster }\end{array}$} & \multirow[b]{2}{*}{$\begin{array}{l}\text { Working-age population } \\
\text { in } 2010\end{array}$} & \multicolumn{6}{|c|}{ Out-of-Work Status 2008} \\
\hline & & $\begin{array}{c}\text { Un- } \\
\text { employed }\end{array}$ & Retired & Disabled & $\begin{array}{c}\text { Other } \\
\text { Inactive }\end{array}$ & Employed & Total \\
\hline 1 & $\begin{array}{l}\text { Middle-age low income } \\
\text { unemployed }\end{array}$ & 21 & 9 & 3 & 14 & 53 & 100 \\
\hline 2 & Disabled & 10 & 12 & 43 & 6 & 29 & 100 \\
\hline 3 & $\begin{array}{l}\text { Married rural women with } \\
\text { pensions }\end{array}$ & 5 & 35 & 17 & 11 & 32 & 100 \\
\hline 4 & $\begin{array}{l}\text { Stay-at-home or } \\
\text { unemployed rural poor } \\
\text { wives }\end{array}$ & 8 & 9 & 3 & 41 & 39 & 100 \\
\hline 5 & $\begin{array}{l}\text { Young rural unemployed } \\
\text { men }\end{array}$ & 4 & 9 & 9 & 33 & 45 & 100 \\
\hline 6 & Employed & 4 & 9 & 2 & 8 & 78 & 100 \\
\hline \multicolumn{2}{|r|}{ Total } & 6 & 11 & 6 & 10 & 67 & 100 \\
\hline \multicolumn{8}{|c|}{$\begin{array}{l}\text { Source: World Bank staff analysis based on EU-SILC } \\
\text { Note: Students aged } 16 \text { to } 24 \text { who were inactive or unemployed are excluded from the sample. Numbers referred } \\
\text { to in the text appear shaded in blue. }\end{array}$} \\
\hline
\end{tabular}




\begin{tabular}{|c|c|c|c|c|c|c|c|}
\hline \multirow[b]{2}{*}{$\begin{array}{l}\text { Clu } \\
\text { ster }\end{array}$} & \multirow[b]{2}{*}{$\begin{array}{l}\text { Working-age population } \\
\text { in } 2010\end{array}$} & \multicolumn{6}{|c|}{ Out-of-Work Status 2008} \\
\hline & & $\begin{array}{c}\text { Un- } \\
\text { employed }\end{array}$ & Retired & $\begin{array}{l}\text { Dis- } \\
\text { abled }\end{array}$ & $\begin{array}{c}\text { Other } \\
\text { Inactive }\end{array}$ & Employed & Total \\
\hline 1 & $\begin{array}{l}\text { Middle-age low income } \\
\text { unemployed }\end{array}$ & 30 & 7 & 4 & 11 & 7 & 8 \\
\hline 2 & Disabled & 13 & 9 & 56 & 5 & 3 & 8 \\
\hline 3 & $\begin{array}{l}\text { Married rural women with } \\
\text { pensions }\end{array}$ & 4 & 15 & 13 & 5 & 2 & 5 \\
\hline 4 & $\begin{array}{l}\text { Stay-at-home or } \\
\text { unemployed rural poor } \\
\text { wives }\end{array}$ & 5 & 3 & 2 & 16 & 2 & 4 \\
\hline 5 & $\begin{array}{l}\text { Young rural unemployed } \\
\text { men }\end{array}$ & 2 & 3 & 5 & 10 & 2 & 3 \\
\hline 6 & Employed & 46 & 63 & 20 & 53 & 83 & 72 \\
\hline \multicolumn{2}{|c|}{ Total } & 100 & 100 & 100 & 100 & 100 & 100 \\
\hline
\end{tabular}




\section{From Profiling to Activation}

\section{Activation and Inclusion Policies in Lithuania}

Active labor market policies (ALMPs) are implemented by a variety of actors in Lithuania, but the main institution in charge of ALMPs and public employment services (PES) is the Labor Exchange (LLE). Established in 1991, the LLE operates under the Ministry of Social Welfare and labor and was restructured in 2010 in response to the economic downturn. The LLE currently comprises one central office and 10 territorial labor exchange offices (TLEs) - down from 46 previouslythat serve between three and seven municipalities each (and for a total of 60 municipalities). The LLE maintains the overall responsibility for ALMPs and supervises the activities of the 10 territorial labor exchange offices, which in turn provide employment services and implement labor policies for residents and employers at the district, municipality, and sub-district level (EC, 2013).

The range of active labor market policies and employment services is wide. The LLE, in collaboration with local partners and other Ministries implements several ALMPs (Eurostat, 2010, and ILO, 2011). In particular:

$\checkmark \quad$ Supported Employment Programs/Measures. These include subsidized employment programs, support for the acquisition of professional skills, public works programs for the unemployed or employees of firms in financial difficulties, job-rotation or job-sharing schemes, and client services (such as group counseling, vocational counseling, and so forth).

$\checkmark$ Vocational Training Schemes in the form of benefits for both employers and employees, workplace trainings, institutional trainings, support for apprenticeships, and so on.

$\checkmark \quad$ Support Schemes for Job Creation, such as subsidies for job creation, support schemes for selfemployment, start-up incentives, and local initiatives for employment (such as business development plans for firms and job-placement subsidies)

$\checkmark$ Local Mobility and Commuting Support Schemes such as reimbursement of work-related relocation, accommodation, or transportation expenses.

$\checkmark \quad$ New Measures which have also been implemented in the recent past include employability barometers, employment programs for the unemployed aged 55 and over, first employment programs for youth, and skills upgrade programs for the long-term unemployed.

At the same time, several passive measures, such as unemployment or early retirement benefits, are also available. These include full and partial unemployment benefits, redundancy compensation, bankruptcy compensation, and conditional and unconditional early retirement benefits. Importantly, in 2012, an innovative measure to prevent poverty traps and to give the long-term unemployed an extra incentive to take up employment was introduced in the form of an extra benefit payment for long-term unemployed individuals returning to work. This measure extends six months of benefits to individuals that transition from long-term unemployment to employment and do not earn more than double the monthly minimum wage (Eurostat, 2010, and ILO, 2011).

Lithuania spends little on labor market policies (LMPs) relative to other OECD countries, although the crisis resulted in a notable increase in such expenditures, mostly due to the spike in unemployment and early retirement benefits. As Figure 7.10 below shows, in 2011 Lithuania 
spent little more than half a percentage point of GDP on LMPs, almost half of which was devoted to unemployment benefits and early retirement; the average OECD country, on the other hand, spent over 1.4 percent of GDP on LMPs, almost three times the Lithuanian figure. Looking at the evolution of such expenditure items between 2003 and 2011, it is immediately clear that the downturn was associated with a massive increase in unemployment and early retirement benefits. In the pre-crisis period, total LMP expenditure ranged between 0.3 and 0.4 percent of national GDP, while unemployment and early retirement benefits absorbed about 0.1-0.12 percent of GDP; by 2009, at the peak of the crisis, the share of such spending had doubled and then tripled, reaching 0.9 and 0.6 percent of GDP, respectively. In 2012, unemployment and early retirement benefits as a share of GDP were still twice the pre-crisis level (Eurostat and OECD data). It should be noted as positive that Lithuania did not respond to the crisis with a decrease in relative activation spending, the share of ALMPs in GDP remained almost constant at about 0.2 percent GDP.

The large increase in the share of total LMP costs that went toward unemployment benefits was matched by a dramatic rise in the number of beneficiaries. As Figure 7.11 shows, while the 20062011 period did not witness an increase in the number of active labor market policies' beneficiaries, the downturn was clearly linked to a spike in the number of those receiving unemployment or early retirement benefits, with almost 50,000 individuals joining the ranks of the beneficiaries between 2008 and 2009 alone.

\section{Figure 7.10 Labor Market Policy (LMP) Spending in Lithuania as a Share of GDP}
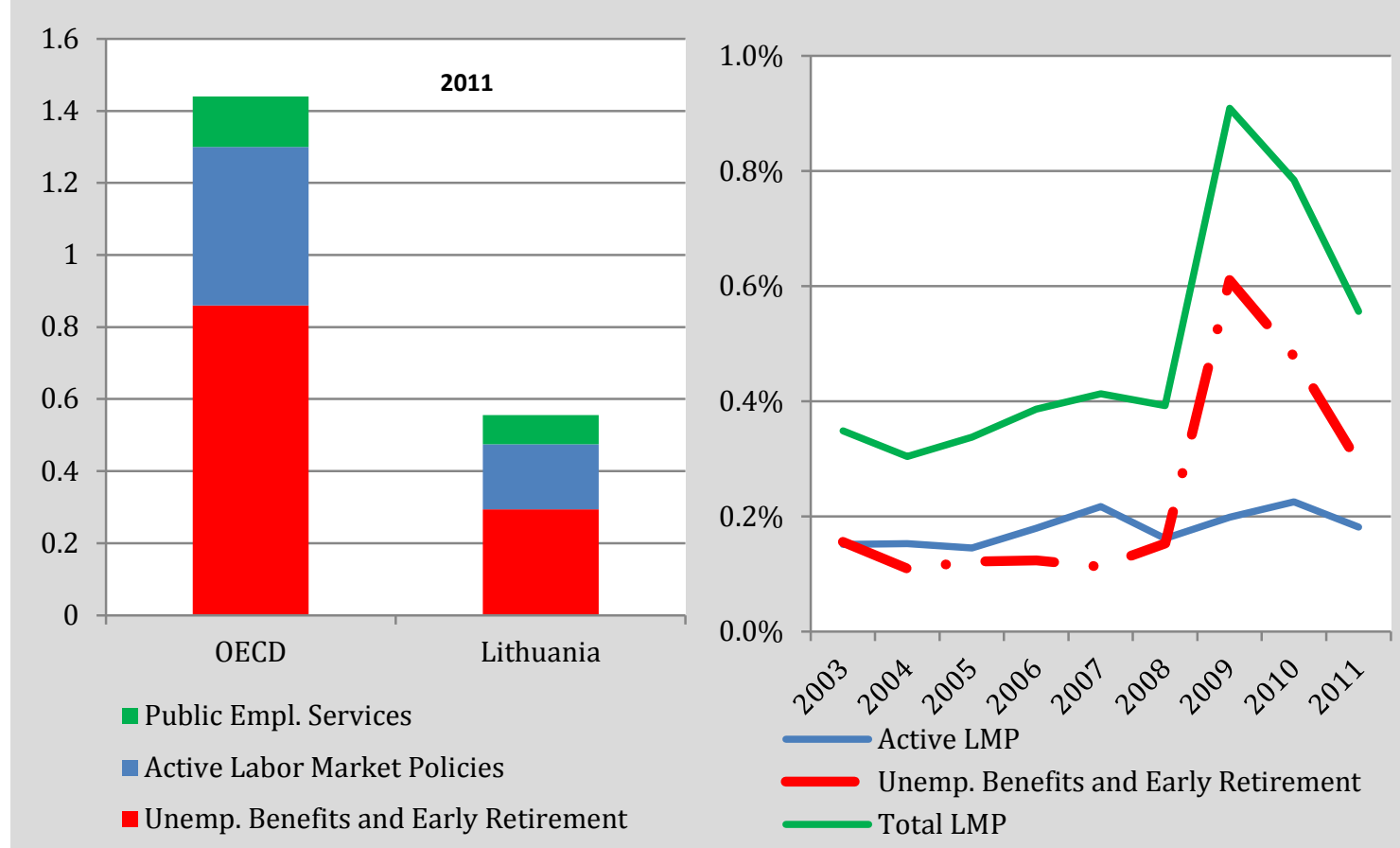

Source: Eurostat, OECD 
Figure 7.11 Labor Market Policy (LMP) Beneficiaries in Lithuania (2006-2010), Number of Individuals

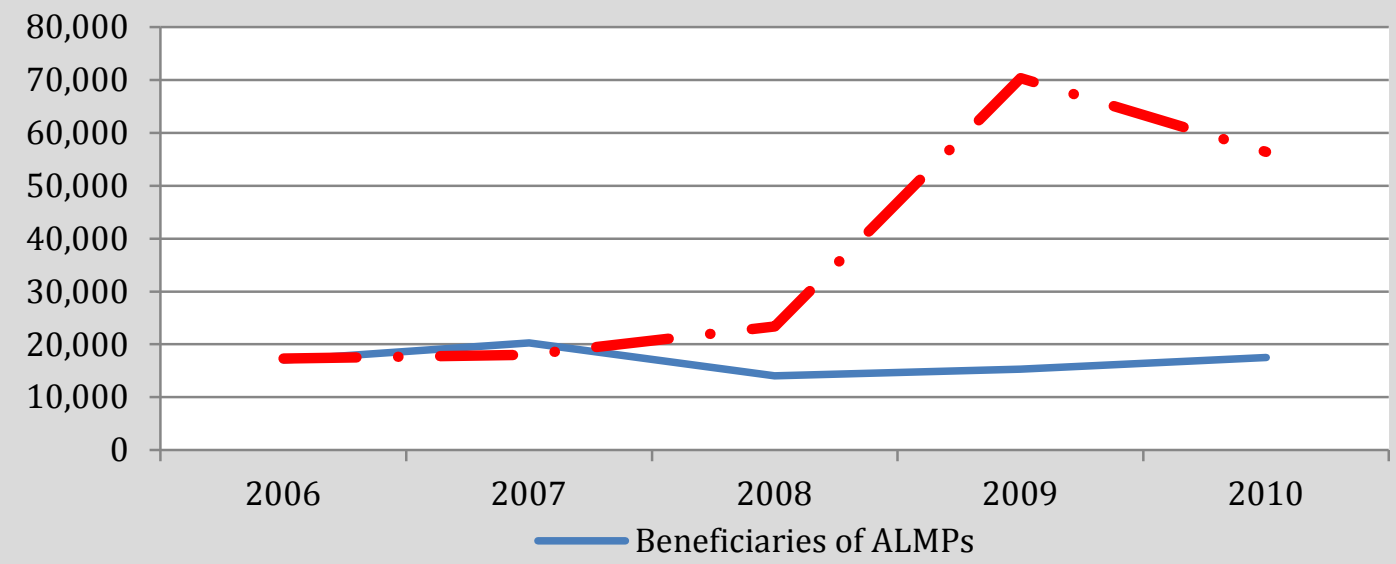

Source: Eurostat, OECD

More particularly, while the level of ALMP spending has remained relatively low and constant with the crisis, the composition and the source of such expenditures have changed. As depicted on Figure 7.12, spending on training fell quite sharply, whereas spending on direct job creation and employment incentives increased (Eurostat, 2010). In addition to the new composition, the crisis also led to a change in the financing source of inclusion measures: after 2009, the main funding source became the EU structural funds, which currently support mainly social enterprises and employment programs for people with disabilities and public works programs, as well as projects that provide vocational training, create subsidized employment, and facilitate job rotation and territorial mobility.

Figure 7.12 Composition of Spending on ALMPs in Lithuania (Euro Millions), 2008 and 2011

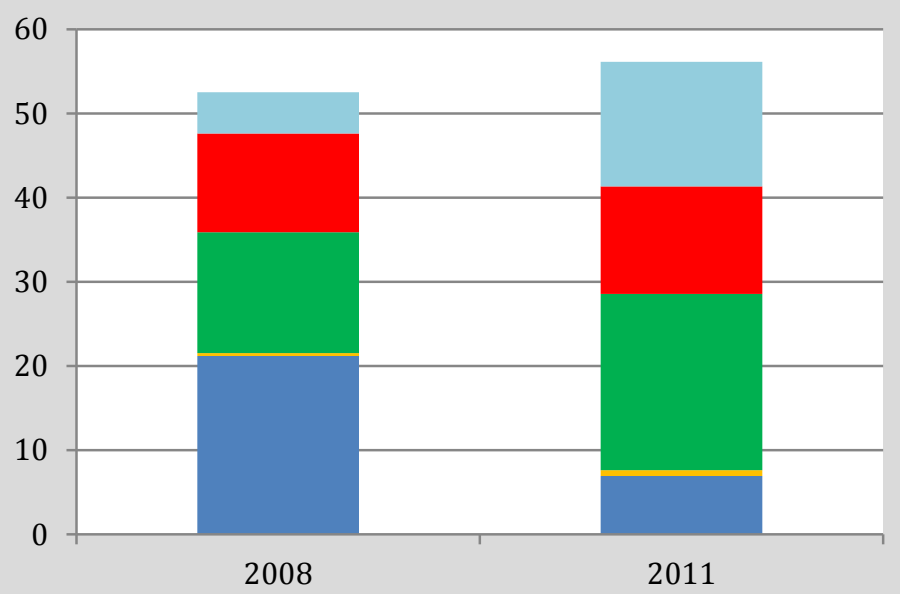

Direct job creation

- Supported employment and rehabilitation

Employment incentives

Job rotation and job sharing

Training

Source: Eurostat, OECD 
In further considering labor market integration, an assessment of the priorities and potentials of the identified groups needs to be undertaken. Given the cautious increase in nominal resources for activation programs, further prioritization of intervention is all the more important. After a first step ("activation priority") of prioritizing the intervention along activation need and activation potential, a second step ("activation type") will attempt to classify the groups according to the kind of activation intervention needed, depending on social or labor market barriers to be overcome. Lastly, as a third step information on household income composition of the different groups will be used to assess potential cross-dependencies of the benefit system with the labor market status and activation approaches.

Activation Priorities. The table below gives an overview of the identified inactive classes and their respective activation need and activation potential. The total number of persons estimated in these clusters was about 610,000 in 2011, representing 32 percent of the working-age (16-64) population of Lithuania in 2011.

In the table, "activation need" refers to a group's level of need for inclusion in the labor market in order to achieve income and reduce or end poverty. "Activation potential" describes that group's ability or motivation to be included in the labor market. High activation need could be driven by high poverty risk (as in the case of the middle-aged poor rural long-term unemployed), whereas high activation potential could be driven by previous work experience or a relatively good educational base (for example, the young educated rural unemployed). Overall priority for action can also be driven by the size of a group.

\begin{tabular}{|c|c|c|c|c|}
\hline \multicolumn{2}{|c|}{ Table 7.8 Activation Need and P } & \multicolumn{3}{|c|}{ otential of Different Clusters in Lithuania } \\
\hline $\begin{array}{l}\text { Share } \\
(2011)\end{array}$ & Cluster & $\begin{array}{l}\text { Activation } \\
\text { need }\end{array}$ & $\begin{array}{l}\text { Activation } \\
\text { potential }\end{array}$ & $\begin{array}{l}\text { Priority for } \\
\text { action }\end{array}$ \\
\hline $27 \%$ & $\begin{array}{l}\text { Middle-aged poor rural long-term } \\
\text { unemployed }\end{array}$ & High & Medium & High \\
\hline $19 \%$ & $\begin{array}{l}\text { Married rural women with old age } \\
\text { pensions }\end{array}$ & Low & Low & Low \\
\hline $18 \%$ & Rural disabled adults with benefits & Low & Low & Low \\
\hline $11 \%$ & Young educated rural unemployed & High & High & High \\
\hline $9 \%$ & $\begin{array}{l}\text { Middle-aged educated unemployed } \\
\text { family men }\end{array}$ & High & High & High \\
\hline $7 \%$ & Single poor rural unemployed women & High & Medium & High \\
\hline $5 \%$ & Stay-at-home poor rural women & High & Medium & Medium \\
\hline $3 \%$ & $\begin{array}{l}\text { Disabled and low-educated urban } \\
\text { young men }\end{array}$ & Low & Low & Low \\
\hline
\end{tabular}


From this overview, an initial set of priorities arises, with the middle-aged poor rural long-term unemployed, young educated rural unemployed, middle-aged educated unemployed family men and single poor rural unemployed women showing the highest priority for activation. Their high priority stems from their relatively large cohort sizes, high or medium activation needs due to high poverty risk, and activation potential due to labor market proximity, given their work history and/or education level. Stay-at-home poor rural women follow close behind, but are classified as slightly lower priority owing to their non-declared unemployment and the significant share that have at least one working adult in the household. Rural disabled adults with benefits, married rural women with old-age pensions, and disabled and low-educated urban young men are not prioritized for activation measures or policies due to lower need and potential (many report strongly limited capacity to work).

In light of the significant portion of disability benefits among the out-of-work population, a potential focus of activation could be the group of rural disabled adults with benefits, of which 26 percent are below the age of 44 but for whom disability benefits make up 49 percent of this group's household income (for year 2011). While it might be difficult to activate some of the members of this group because of their disability despite the fact that they are of prime working age, special attention should be given to not increasing the number of younger disability recipients beyond the minimum necessary, and to tightly controlling the inflow into this group.

Activation Type. As a second step, the relative severity of labor market or social obstacles to be overcome for labor market integration will serve as an orientation for activation approaches.

Figure 7.13 Activation Types of Prioritized Clusters in Lithuania

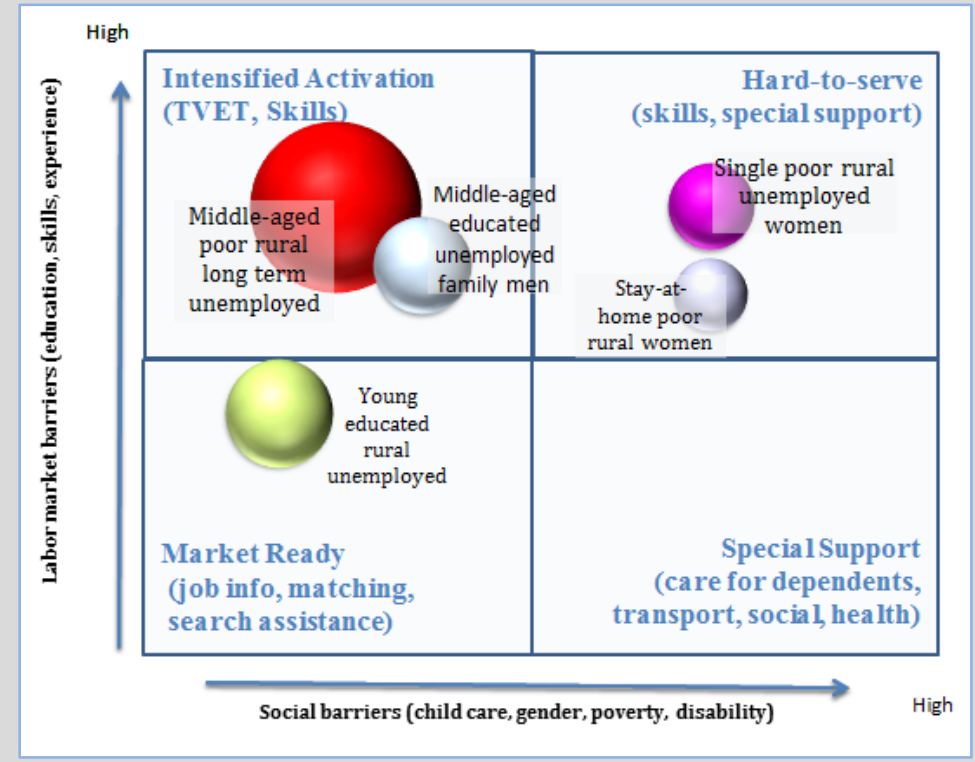

Source: World Bank staff analysis and assessment 2014

When mapping the respective barriers for labor market integration faced by the five prioritized groups, we can see that few of the groups face great social barriers. The two groups of rural women have a different connections to the labor market (work experience, education), but both could probably benefit from greater access to social and public services near their homes (for 
example child care). Groups of middle-aged unemployed could be supported with standard skilland mobility-based measures, while the young educated rural unemployed could probably benefit from mobility support.

Household income composition. When analyzing the 2011 household income of the groups, we can see that three groups have a benefit-share of household income that could be an indication of excessive reliance on benefits: 53 percent of the household income of the middle-aged poor rural long-term unemployed, 72 percent of the household income of the rural disabled adults with benefits and 64 percent of the household income of the single poor rural unemployed women are benefit payments. Other high-benefit share groups (retirees or highly disabled) also have high benefit shares, but this can be seen as a correct function of the social safety net because of legitimate limitations for self-supporting work.

Middle-aged poor rural long-term unemployed adults receive 21 percent of their household income from old-age and disability benefits, although only 1 percent of group members are over the age of 60 . This could be an indication that some members of this group are in early retirement. Single poor rural unemployed women rely on benefits for 64 percent of their household income, most probably social inclusion benefits for their welfare.

For the interesting phenomenon of the young educated rural unemployed, the hypothesis of benefit dependency through intra-family transfers (for example, dependence on old-age pensions or disability pensions of relatives) can most probably be rejected. Only 13 percent of the household income of this group comes from old-age and disability benefits.

Given the overall picture of benefit receipt revealed by EU-SILC data, no actions are needed to counter work disincentive. The pattern of benefits appears to be generally in line with the socioeconomic situation of the specific groups. 
This section sets out a set of potential activation measures for each of the priority groups. Areas for further policy dialogue are also outlined. The suggestions below should be considered as a starting point for further policy dialogue between the EC, the World Bank and Lithuania, bearing in mind that the groups identified still possess heterogeneity that may affect the type of support required. Accordingly, these suggestions are not meant to be an exhaustive set of possible activation measures.

It is important to keep in mind that the groups have been derived from EU-SILC data from the year 2011. Since then, general economic development, policy actions by the government of Lithuania and European Commission country specific recommendations might have reflected some of these policy suggestions or rendered them obsolete.

Middle-aged poor rural long-term unemployed (28 percent, Priority: High). This is the largest group among the out-of-work in Lithuania, with over 170,000 members. All are unemployed, over 70 percent of them for more than one year. This, together with the fact that 98 percent say they do not have any limitation on capacity to work, confirms their high labor availability and activation potential. Sixty percent of them fall in the lowest income quintile. Age wise, 89 percent of the group is between 25 and 59. The distribution between men and women is roughly equal, at 58 to 42 percent. Primary and secondary education levels dominate in 94 percent of the group. Twothirds of its members reside in rural areas. Fifty-two percent of the group are single, but the average household size stands at three, which indicates other relatives (17 percent have a 65plus-aged person) and children (47 percent) in the household. Only 14 percent of households have children under six, indicating reduced caregiving responsibility for children. Potential activation measures for this group include the following:

$\checkmark \quad$ Build activation on previous work experience and skills. Building on the work experience of 93 percent of this group, training and skill-building offerings should be based on previous experience in the labor market. At the same time, the average age and household composition of this cohort makes many of its members eligible for longer-term intervention such as training in foreign languages, or information communication technology (ICT), or "second chance" apprenticeship programs. For some of the more intensified training, the educational basis would probably have to be strengthened. stopped here

$\checkmark$ Self-employment in and around regional cities. With the large share of this group living in a rural environment, potential activation measures can focus on self-employment, cooperatives and services or trades in urban and regional centers. Support for business creation, small loans or micro-credits could help members of this group engage in selfemployed activity.

$\checkmark$ Mobility. Enabling jobseekers and workers to permanently and temporarily move inside the country, could help members of this group. Availability and quality of public transport (not part of specific activation policy, but rather general public infrastructure tasks) and mobility grants for job-search or transition into jobs can be possible measures to support this group.

Young educated rural unemployed (11 percent, Priority: High). This group faces the lowest labor market and social barriers, but is also a potential source for further emigration from the country, a fact that has been getting important attention in the years since the start of the financial and economic crisis. In 2011, the group represented about 67,000 members, of which two thirds 
were declared as unemployed. None reported any work limitations, and all of its members are younger than 34 with an almost equal relations between the sexes. An interesting feature of this group is that 44 percent have a tertiary education or higher (making up the relatively low number of unemployed young Lithuanians with a university degree). The majority of the group lives in rural areas (63 percent), is not married (62 percent) and lives in a household of 4.2 average members, hinting at a residence still at the parent's house. The labor share of income in these households is 62 percent and the benefits received appear plausible for the respective socioeconomic situation. Potential activation measures for this group include the following:

$\checkmark$ "Top-up" courses for practical job skills. Many university graduates lack practical hands-on job skills for a workplace environment. With group intervention training schemes, young jobseekers could be offered supplemental soft and functional skill training on top of their domain knowledge degree.

$\checkmark \quad$ Job fairs. With formal training apparently not the key labor market barrier for this group, job matching and job information must take center stage. For graduates from rural areas and regional centers, accessibility to job fairs ought to be ensured through "job-buses" or other outreach and transportation initiatives.

$\checkmark$ Job placement / internships. ALMP funds could be used to support the temporary placement of graduates with firms for internships or short-term engagements.

$\checkmark$ Job linkage at university / college. To prevent joblessness after graduation and to ensure early attachment to companies and industries, universities and colleges need to link students early on to job skills, job search techniques and work experiences.

$\checkmark$ Mobility support to large cities, near-abroad countries. With most of the unemployed in this group living in non-urban areas, mobility to potential locations of employment becomes all the more critical. At the same instance, temporary access to subsidized housing for young job starters or "foyer" type housing offerings in larger cities could facilitate the mobility of youths within Lithuania. Promoting labor migration to the near-abroad (while helping temporary migrants to retain their ties to home) can be another measure to prevent critical human capital depreciation at an important time of career formation.

Middle-aged educated unemployed family men (9 percent, Priority: High). Two thirds of this group are registered as unemployed and despite a disability-share of 9 percent, only 1 percent declares to have strong limitations to work. Almost all members of this exclusive 35 to 59 year-old group live in a household with a working adult, hinting at a supplementary earner model through the household's wife (87 percent are married). A relatively high household income is achieved through mainly labor income (77 percent). Households have relatively few children but 87 percent have a person over 65 years of age. Education level is medium with only 30 percent holding tertiary education. As with all other groups, previous work experience is very high at 94 percent. Potential activation measures for this group include the following:

$\checkmark \quad$ Linkage to previous occupation / industry. With a working spouse and relatively low risk of poverty (43 percent in bottom two quintiles), this group can be supported in re-linking with the qualifications, occupations and industries that they once gained their work experience in. Re-skilling will probably need to update functional skills (languages, communication, writing, ICT).

$\checkmark \quad$ Job Clubs and group search. Building on the life experience of this group, job search clubs or entrepreneurial start-up groups could be offered to some of these groups' members.

Portraits of Labor Market Exclusion | 237 
$\checkmark$ Self-employment from home. With spouses of these men employed and providing for the family income, opportunities for self-employment from home or local employment ought to be supported. Medium-sized commuting and mobility support could also be provided to allow for job-uptake in nearby regional centers (or with weekly commute) in towns further away in case a good-paying job can be secured to cover travel and extra housing cost.

Single poor rural unemployed women (7 percent, Priority: High). Compared to the previous prioritized groups, only a subset (40 percent) of this group is registered as unemployed but no member appears to report strong limitations to taking up work. With none of the households containing a working adult, this group of mainly rural (86 percent) individuals (62 / 38 percent female / male) has the highest poverty exposure in the sample (81 percent fall in the bottom two quintiles). Owing to the absence or unemployment of spouses, households in this group do not gain income from complementary work uptake. The share of benefit income in total household income is correspondingly very high (64 percent). Members have work experience but 85 only hold primary or secondary education. Potential activation measures for this group include the following:

$\checkmark$ Income support coupled with work and training opportunities. Given the high (and legitimate) benefit share in this group any approach to activation would probably need to be based on the existing income support programs in Lithuania and link them with community work and training offerings. In order to improve the skill and training level of this group, care must be taken to not just operate simple community public works programs.

$\checkmark$ Mobility support and training. When coupled with training and skill-building, the members of this group could also be helped to find employment in regional or larger cities. This would require additional skill training on job search, basic functional skills and (temporary) mobility support for transportation or housing.

$\checkmark$ Community employment and self-organization. Given the recent emphasis on "subsidiarity" and local community decision in social service provision in Lithuania, forms of self-organization for community work and social entrepreneurship could be promoted with members of this group. Guidance on this would probably need to be provided by PES or municipality staff.

Stay-at-home poor rural women (5 percent, Priority: Medium). This small group among the prioritized shows a similar profile to the previous group of women, with the difference, that none of their members is declared as unemployed and all of the households have a working adult in their ranks. The group is 100 percent women and shows a very similar profile to their unemployed "sisters" in terms of rural/urban split, age and education distribution. The vast majority (79 percent) is married, but poverty exposure is much lower (63 percent in bottom two quintiles) with 75 percent of spouses working and gaining a decent income (4300 EUR). Share of labor in household income is correspondingly high (68 percent) and the benefit income can be legitimately attributed to the presence of children ( 53 percent have children below 6 years old) in the household. Potential activation measures for this group include the following:

$\checkmark$ Similar approaches as for the previous group but coupled with child care offerings and community care provision. In light of the significant child caregiving responsibility exercised by these households, any approach to further labor market activation must assist these women to combine (part time) work with child care. 
In general, further policy dialogue with the Lithuanian authorities ought to focus on areas that enable the government and its agencies, municipalities and other labor market actors to better deploy their resources, increase coordination and improve the staffing and resource situation of services. Some of these areas for future dialogue include:

$\checkmark$ Focus on non-urban areas. Labor market exclusion in Lithuania is a predominantly rural phenomenon. Almost all of the groups identified in the Latent Class Analysis show a rural share of well over 65 percent, some of the groups prioritized for activation even shares of over 80 percent. Creation of jobs in secondary cities, transport links and (temporary) mobility support to regional or large centers within Lithuania or toward the neighboring countries must be among the potential answers to this situation

$\checkmark$ Mobility is key. When considering mobilizing more of its citizens for the labor market, Lithuania ought to make mobility within the country (and to near-abroad countries) a key priority. Being able to connect to regional economic centers or to (temporarily) seek employment in a neighboring country can help to reintegrate unemployed but also to prevent skill loss and "scarring" among young jobseekers.

In summary, Lithuania could benefit from maintaining a labor market centric activation approach toward its rural out-of-work population, especially in light of the demographic developments taking place. 


\section{References}

Collins, L. M., and S. T. Lanza, 2010, Latent Class and Latent Transition Analysis: With Applications in the Social, Behavioral, and Health Sciences. Hoboken, NJ: Wiley.

Eurofound, 2012, NEETs-Young people not in employment, education or training: Characteristics, costs and policy responses in Europe, Publications Office of the European Union, Luxembourg.

(EC), European Commission, European Community Programme for Employment and Social Solidarity, 2013, "Assessment of the implementation of the European Commission Recommendation on active inclusion: A study of national policies," January 2013.

(EC) European Commission, 2013a, EU measures to tackle youth unemployment. MEMO, Brussels, 28 May 2013.

Eurostat, 2010, “Labor market policy statistics—Qualitative report: Lithuania 2010."

Eurostat, 2011, ESSPROS Manual: The European System of Integrated Social Protection Statistics. European Union, Luxembourg.

(ILO) International Labor Organization, 2011, “Active Labour Market Programmes implemented by the Lithuanian Labour Exchange."

http://www.ilo.org/public/english/region/afpro/cairo/downloads/almp-lithuania-eng.pdf

Katz, L., 2010, "Long-Term Unemployment in the Great Recession," Testimony for the Joint Economic Committee, U.S. Congress Hearing on "Long-Term Unemployment: Causes, Consequences and Solutions," April 29, 2010

Kaufman, L. and Rousseeuw, P. J., 1990, Finding groups in data. New York, Wiley.

Magidson, Jay and Vermunt, Jeroen, 2002, Latent Class Modeling as a Probabilistic Extension of KMeans Clustering Quirk's Marketing Research Review, March, 20, 77-80. Available at:

http://statisticalinnovations.com/technicalsupport/kmeans2a.htm

Vermunt, J. K. and J. Magidson, 2005, Latent GOLD 4.0 User's Guide. Belmont, Massachusetts: Statistical Innovations Inc. 


\section{Latent Class Analysis of the Out-of- Work Population in Romania 2008-2011}

\section{Background}

After a period of high growth, Romania experienced a severe economic contraction in 2009 and has not yet recovered to its previous level of economic growth. During the period from 2003 to 2008, the Romanian economy grew at very high rates-an average of 6.6 percent per year, compared to 2.2 percent per year among EU-28 countries. However, as in the other countries in the region, in 2009 the crisis hit hard and output contracted by 6.6 percent. Only in 2011 was GDP growth back to a positive level, of 2.3 percent. In 2013 the economy grew 3.5 percent, only surpassed in the region by Latvia (which grew 4.1 percent).

Unemployment rose following the crisis, but the increase was low in comparison to the sharp fall in output. From 2003 to 2008, unemployment was, on average, 7.3 percent; in 2008 it reached its lowest level at 6.1 percent. After the crisis hit the Romanian economy in 2009, unemployment only marginally increased, reaching 7.6 percent in 2013. This pales in comparison to the dramatic rise in unemployment following the crisis that many European countries witnessed. Moreover, labor force participation, albeit low by European standards, remained fairly constant following the crisis, between 63 and 65 percent. ${ }^{96}$

However, youth experienced a sharp rise in unemployment. Figure 8.1 shows that unemployment rates were falling steadily, particularly among youth, prior to the crisis. The percentage of young individuals aged 15 to 24 that were not in employment, education, or training (the NEET rate) reached its lowest level of the decade in 2008-11.6 percent. However, when the crisis hit Romania, youth felt most of the impact. Overall unemployment reached 7.7 percent in 2011, representing a 1.6 percentage point increase from pre-crisis levels. Youth unemployment, on the other hand, peaked at 23.7 percent in 2011, almost 5 percentage points above its pre-crisis level. After a downward trend between 2003 and 2008, the NEET rate also increased, returning in 2012 to the same level it had been in 2005 .

96 Prior to the crisis, the labor force participation rate in 2008 was 62.9 percent. In 2013, it reached 64.6 percent.

Portraits of Labor Market Exclusion | 241 
Figure 8.1 Unemployment and NEET Rates-Romania (2003-2013)

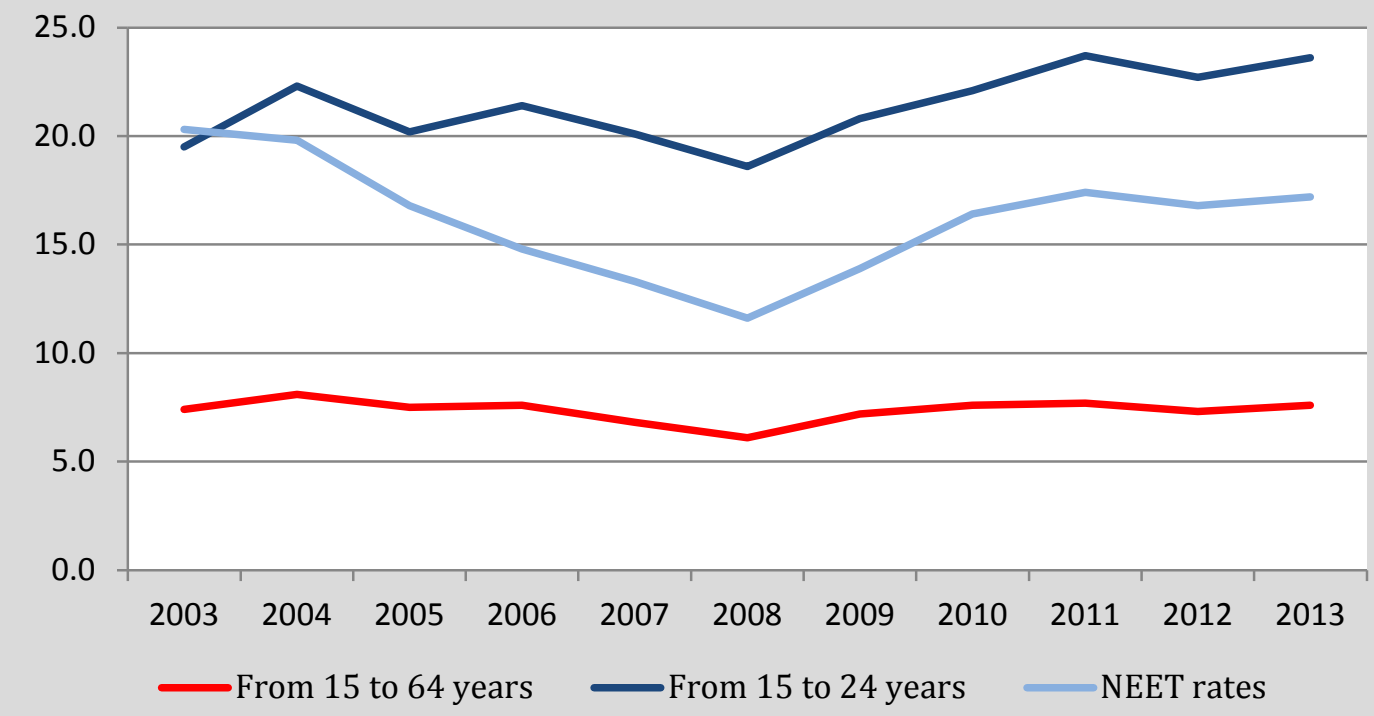

Source: Eurostat, EU-LFS

Note: While the unemployment rate is calculated as a share of the economically active population in the respective age group, the NEET rate is calculated for the percentage of the population aged 15 to 24.

Figure 8.2 Unemployment Rates by Gender and Age-Romania (2007-2013)
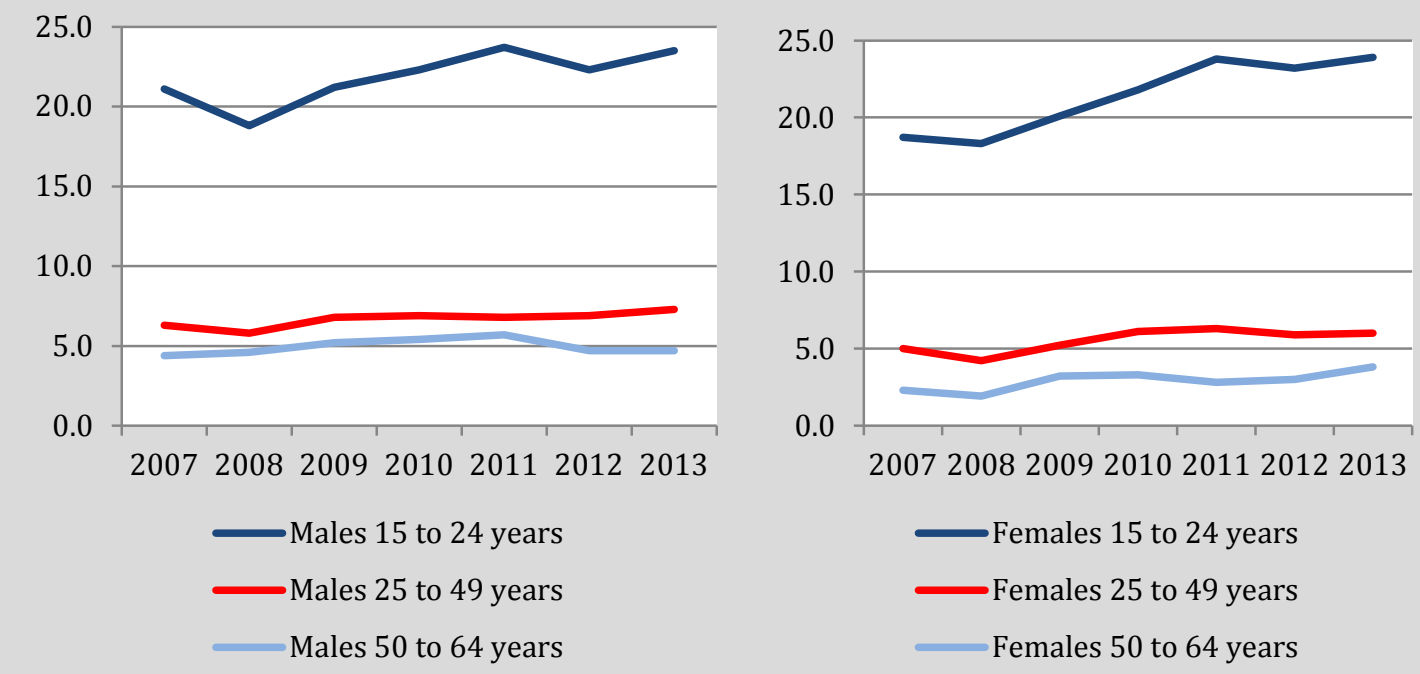

Source: Eurostat, EU-LFS

A look at unemployment rates disaggregated by gender shows that women were generally more affected by the crisis. As shown in Figure 8.2, unemployment rates are usually lower for women. However, the economic downturn affected women most, especially those in the 50- to 64year old group, whose unemployment rate grew from 1.9 to 3.3 percent between 2008 and 2010, representing an increase of over 70 percent. Unemployment rates for men in this age group, in 
contrast, only increased by 18 percent. Women aged 15 to 24 and 25 to 49 also experienced higher proportional increases in unemployment than men in the same age group.

Despite the relatively small change in overall unemployment rates observed during the crisis, one of the most worrisome results was the change in the duration of unemployment, with a significant increase in the share of long-term unemployed. Long-term unemployment as a share of total unemployment hit a low of 31.6 percent in 2009; since then the share has risen to 46.4 percent (as shown in Figure 8.3). The relatively small effect of the crisis on unemployment figures thus appears to be hiding more negative conditions in the labor market.

\section{Figure 8.3 Long-Term Unemployment as a Share of Total Unemployment (2003-2013)}

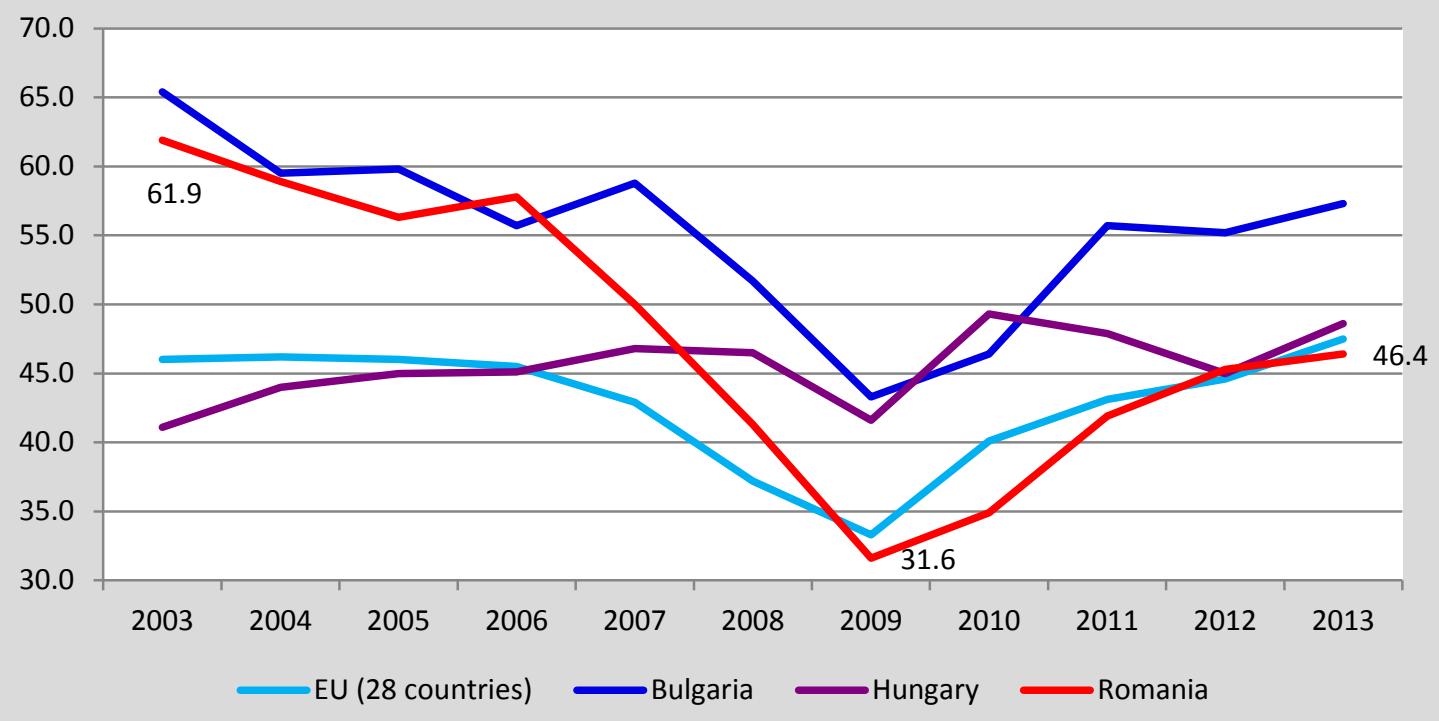

Source: Eurostat, EU-LFS

Although overall employment levels remained relatively stable following the crisis, individuals with tertiary education experienced declining employment rates, while their supply increased. After peaking at 59 percent in 2008, employment rates remained relatively unchanged, with their lowest post-crisis rate being 58.5 percent in 2011. In contrast, the employment rate for individuals with tertiary education reached its lowest point for the 20032013 in 2013, at 81.4 percent, down from 85.7 percent in $2008^{97}$.

What is more, between 2008 and 2013, unemployment rates doubled for individuals with tertiary education. Deteriorating labor market outcomes for the most educated might also reflect lower experience, since youth is usually the more educated group. Nonetheless, although those with less education were less affected during the crisis in terms of relative changes, it is worth noting that, at least in terms of levels, labor market outcomes have generally favored those with higher education. In the meantime, the Romanian labor force has become more educated, reflecting the fact that youth entering the labor force (and replacing the workers who retire) are more educated.

${ }^{97}$ In 2013 this rate was 82.4 percent. 
However, as reported previously, youth have also been the most affected by the crisis, and their higher levels of education have not resulted in improved labor market prospects overall.

During the period from 2008 to 2011, the sample of the out-of-work population considered in this note decreased, from 4.2 to 4.1 million individuals. The analysis of the out-of-work population in this note focuses on the working-age population (16-64 years old). Specifically, only individuals aged 25 to 64 years who are not employed, and individuals aged 16 to 24 who were neither employed nor in education nor training were considered. ${ }^{98}$ Only the working-age population (16to 64-year olds) is analyzed, as labor activation options-the main policy focus of this note-are only viable for that segment of the population. As a percentage of the population of working age under analysis, the out-of-work population fell from 32.3 percent to 31.2 percent. The three groups of the out-of-work population that became smaller during this period were the groups of disabled, short-term unemployed and other inactive, which decreased in size by 37, 21 and 8 percent, respectively. On the other hand, the number of long-term unemployed grew by 27 percent (see Table 8.1). Figure 8.4 shows the composition of the out-of-work population in Romania in 2008 and 2011.

Table 8.1 Number and Percentage of Working Age Individuals (16-64) by Labor Market attachment in Romania (2008 and 2011)(in thousands)

\begin{tabular}{|l|c|c|c|}
\hline & $\mathbf{2 0 0 8}$ & $\mathbf{2 0 1 1}$ & $\begin{array}{c}\text { Percent change } \\
\mathbf{2 0 0 8}-\mathbf{2 0 1 1}\end{array}$ \\
\hline At work & 8,812 & 9,023 & $2.4 \%$ \\
\hline Unemployed & $67.7 \%$ & $68.8 \%$ & $-20.8 \%$ \\
\hline & 192 & 152 & $26.9 \%$ \\
\hline Long-term unemployed & $1.5 \%$ & $1.2 \%$ & $3.9 \%$ \\
\hline & 275 & $2.7 \%$ & \\
\hline (Early) retirement & $2.1 \%$ & 2,006 & $-36.9 \%$ \\
\hline & 1,950 & $15.3 \%$ & \\
\hline Disabled & $15.0 \%$ & 101 & $-8.4 \%$ \\
\hline & 160 & $0.8 \%$ & \\
\hline Other inactive & $1.2 \%$ & 1,486 & $0.8 \%$ \\
\hline & 1,623 & $11.3 \%$ & \\
\hline Total & $12.5 \%$ & 13,117 & \\
\hline & 13,012 & $100 \%$ & \\
\hline
\end{tabular}

Source: World Bank staff analysis based on EU-SILC

Note: Individuals aged 16 to 24 who are out of work and enrolled in education (1.5 million individuals) are excluded from the sample.

98 Individuals aged 16 to 24 who are out of work and enrolled in education are considered to be investing in their final stages of human capital formation and therefore not a particular target group for activation policies. In 2011, this population amounted to about 1,517,000 individuals, representing 58.5 percent of the total population aged 16 to 24 and 27 percent of the total out-of-work population of working age. 
Figure 8.4 Distribution of Out-of-Work Population in Romania (2008 and 2011)

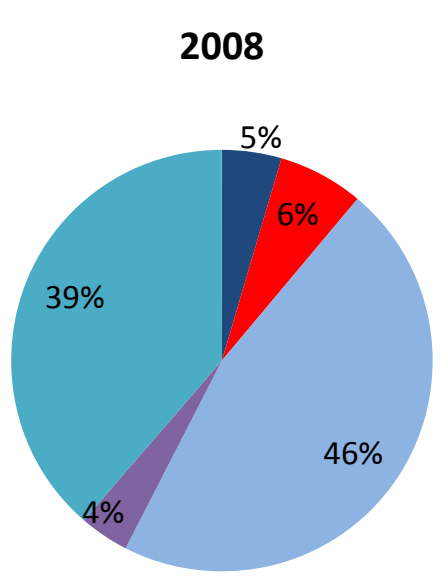

\section{1}

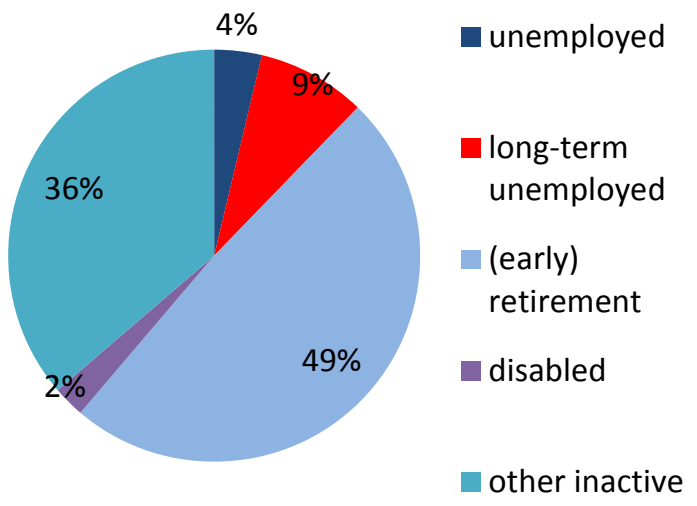

Source: World Bank staff analysis based on EU-SILC 


\section{Methodology: Latent Class Analysis}

In Chapter 1 a general overview of the latent class analysis methodology was presented. This section explains in detail the variables and covariates used to identify classes or groups of out-ofwork individuals that are as homogeneous as possible within each class according to a set of observable characteristics, and as distant as possible between classes. The emerging profiles can then be contrasted with the design and targeting of current activation policies, in order to identify the potential gaps and to enhance their design features. ${ }^{99}$

Variable selection: The definition of latent classes relies on a number of indicator variables to capture different "symptoms" of an overall latent condition (in this case, the typology of joblessness). The challenge in such models is to identify a discrete number of variables that can best explain the heterogeneity of individual outcomes. In this case, two sets of categorical variables were selected: the first set to show the extent of labor market distance and the other to capture some of the main factors that can affect employment on the supply side, such as labor supply conditions (household-level incentives to work and physical ability to work).

$\checkmark$ Distance from labor market: short-term unemployment, long-term unemployment, (early) retirement, disability, and other inactivity (largely unpaid domestic work). ${ }^{100}$

$\checkmark$ Work experience: if individual has worked before and, in this case, whether worked for two or more months in the last year;

$\checkmark$ Labor supply conditions: whether the individual's household has at least one working adult, ${ }^{101}$ and perceived limitations on activities due to health problems. ${ }^{102}$

In addition to indicators, the model includes active covariates, which are used to improve the classification of individuals in each class. In this case the active covariates are the demographic variables that are normally used to disaggregate labor market outcomes:

\section{$\checkmark \quad$ Age-group category (four groups) \\ $\checkmark$ Gender \\ $\checkmark$ Human capital: the highest educational level achieved \\ $\checkmark$ Urban/rural location}

Once the latent classes have been defined, inactive covariates that were not included in the model can be used to characterize the individuals in each class and the households in which they live. The inactive covariates chosen describe those characteristics that may provide valuable information for the design of tailored policies that address barriers to employment, including income level. They include:

\section{$\checkmark$ Household welfare conditions:}

${ }^{99}$ For the latest developments on active inclusion in Romania, see EC (2013b).

100 This variable is constructed using the self-reported current work status in the EU-SILC survey that has four categories: at work, unemployed, retired and inactive. The unemployed are further classified into shortand long-term based on how long they have been actively looking for a job. The inactive is combined with another question to separate this group into students, disabled, military and other inactive.

101 In order to construct this variable, individuals aged 25 or older are considered adults.

102 This is a binary variable that takes the value one if an individual answered "yes, strong limitations" to whether they had been hampered in their usual activities because of health problems for at least the last six months. The value is zero if the answer is "yes, limited" or "no, not limited." 
- Income quintile (defined by equivalized disposable household income ${ }^{103,104}$ )

- Labor, benefit, and other income as share of total gross household income ${ }^{105}$

- Working status of the partner

- Household able to keep dwelling warm

- Partner's labor income

- Quintile of partner's labor income

- Tenure status

- Binary variables denoting whether individuals or their households are beneficiaries of any of eight social protection benefits ${ }^{106}$

- Share of benefits in household gross income

\section{$\checkmark$ Household demographics:}

- Household size

- Household composition

- Binary variable showing whether there are children under 6 in the household

- Binary variable denoting whether there are three or more under-16 children in the household

- Children under 13 receiving child care in the household: all, some or no children under 13 present

- Older person (65 and over) in the household

- Presence of individual's parents in the household

$\checkmark$ Other individual-level demographics:

- More refined age groups (eight groups)

- Marital status

\section{$\checkmark$ Individual human capital:}

- More refined highest educational level achieved (six groups)

- Work experience in years

\section{$\checkmark$ Household location:}

- Degree of urbanization: ${ }^{107}$ densely populated, intermediate area, sparsely populated

- Regional breakdown

103 The equivalized household income takes into account an equivalence factor to weight the number of household members used in the denominator when calculating household income per capita. The first adult aged 18 or over has a weight of 1.0 , children under 14 have a weight of 0.3 , and other individuals 14 and older have a weight of 0.5 . The sum of the weights of all household members is equal to the equivalent household size.

104 Note that income reported in EU-SILC surveys is for the year preceding the survey year.

105 Total household gross income is defined as the sum of: (at the individual level) gross employee cash or near-cash income; company car, gross cash benefits or losses from self-employment (including royalties); unemployment benefits; old-age benefits; survivor benefits; sickness benefits; disability benefits; education allowances; and (at the household level) income from rental of property or land; family/children related allowances; social exclusion not elsewhere classified; housing allowances; regular inter-household cash transfers received; interests, dividends, profit from capital investments in unincorporated business; pensions from individual private plans; and income received by people under 16 . Total household net income, in turn, was calculated by subtracting from total household gross income regular taxes on wealth, taxes on income and social insurance contributions, and regular inter-household case transfers paid.

106 Social benefits are aggregated in eight branches using the European System of integrated Social PROtection Statistics (ESSPROS) definitions. For more information, see Eurostat (2011).

107 According to EU-SILC guidelines, dense areas have more than 500 inhabitants per square kilometer, where the total population for the set is at least 50,000 inhabitants. Intermediate areas have more than 100 inhabitants per square kilometer, and either a total population for the set of at least 50,000 inhabitants or a location adjacent to a dense area. The remaining areas are categorized as sparsely populated. 
Group labeling. The resulting groups are then labeled according to the greatest proportional characteristics within groups that also aid in distinguishing among groups. Granted, a large number of characteristics describe these groups, and only a few are taken into account for the purpose of labeling. In part, some of these characteristics may exhibit a large degree of heterogeneity and may thus not be relevant for defining a group. Additionally, some characteristics may be more relevant for the purposes of policy design than others. In short, though the labeling of groups can be considered more an art than a science, when taken together with detailed descriptions of a group's most prominent characteristics, labeling can serve as an important starting point in the design and prioritization of activation policies.

The analysis relies on cross-sectional as well as panel data from the European Union Statistics of Income and Living Conditions (EU-SILC) surveys for 2008-2011, which combine individual-level information with household characteristics. The first part of the note presents a cross-sectional analysis for the years 2008, 2009, 2010 and 2011. In particular, the latent class analysis on 2008 data shows the main characteristics of the out-of-work before the global economic crisis hit Romania, and thus highlight what could be considered more structural issues of the country's labor market. The 2011 latent class analysis will contrast this initial assessment with more recent developments. The second part of the note exploits longitudinal data between 2008 and $2010^{108}$ to trace the prior labor market status of individuals observed last in 2010 in various classes, and will shed light on the relative persistence in the out-of-work status among different classes of individuals. The set of variables chosen for the cross-section and the longitudinal analysis are slightly different, due to minor differences in the set of variables recorded in each of the two types of datasets.

108 The EU-SILC longitudinal survey consists of a four-year rotating panel. In each year, approximately threequarters of individuals present in the previous year are retained. The samples used in the latent class analysis include about 3,000 observations for each year in the cross-sectional analysis and 500 observations in the longitudinal analysis. The population is weighted with individual weights. 


\section{Main Findings}

\section{Out-of-Work Population: Group Profiles from Cross-Sectional Analysis}

The latent class analysis supports the classification of the out-of-work into eight major groups, some of which have remained stable over time. The groups were named according to their most salient characteristics. Figure 8.5 shows the share of each of the eight classes identified for the year 2011 while Table 8.2 presents their most salient characteristics.

\section{Figure 8.5 Classes of Out-of-Work Individuals in Romania (2011)}

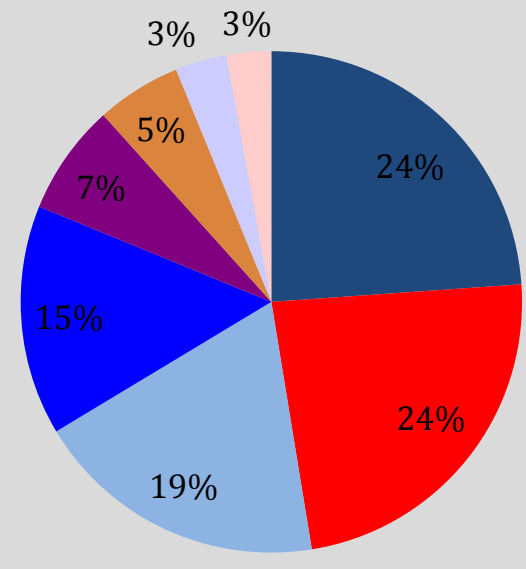

घ1. Retirees

- 2. Early retirees

3. Low-educated rural mothers without work experience

4. Inactive middle-aged wives

- 5. Long-term unemployed educated single youth

6. Working-age long-term unemployed

7.Working-age newly unemployed

8. Low-educated and rural disabled

Source: World Bank staff analysis based on EU-SILC

Table 8.2 Summary Characteristics of Latent Classes of Out-of-Work Population in Romania (2011)

\section{1: Retirees (24\%)}

- $98 \%$ are retired

- $58 \%$ are women

- $94 \%$ are 60-64 years old

- $68 \%$ are married; $23 \%$ are widowed

- $58 \%$ have a partner who is not working; $62 \%$ have no working adults in household

- Low-to-mid-skilled: 38\% have not completed upper secondary; 49\% have complete upper or post-secondary

- $95 \%$ worked before, but less than 2 months in the last year; 33 years of experience on average

- $79 \%$ live in households without dependent children

- Very low poverty risk: $8 \%$ are in poorest quintile

- $87 \%$ receive old-age benefits

\section{2: Early retirees (24\%)}

- $96 \%$ are retired

- $59 \%$ are women

- $91 \%$ are 45-59 years old

- $77 \%$ are married; $11 \%$ are widowed

- $28 \%$ report strongly limited capacity to work

- $50 \%$ have a partner who is not working; $57 \%$ have at least one working adult in household

- Mid-skilled: $73 \%$ have complete upper or post-secondary

- $95 \%$ worked before, but less than 2 months in the last year; 27 years of experience on average

- $64 \%$ live in households without dependent children

- Low poverty risk: $12 \%$ are in poorest quintile

- $49 \%$ receive disability; $42 \%$ receive old-age benefits 
- $97 \%$ are inactive

- $99 \%$ are women

- $84 \%$ are $20-44$ years old

- $73 \%$ are married

- $67 \%$ have a working partner; $91 \%$ have at least one working adult in household

- Low-to-mid-skilled: $46 \%$ have not completed upper secondary; $40 \%$ have complete upper or post-secondary

- Only $22 \%$ have worked before; 9 years of experience on average

- $83 \%$ live in households with dependent children; $46 \%$ in households with children under 6

- $77 \%$ live in rural areas

- High poverty risk: $43 \%$ in poorest quintile

- $76 \%$ receive family/child benefits
- $91 \%$ are inactive

- $100 \%$ are women

- $77 \%$ are $35-54$ years old

- $85 \%$ are married

- $61 \%$ have a working partner; $78 \%$ have at least one working adult in household

- Low-to-mid-skilled: $37 \%$ have not completed upper secondary; $54 \%$ have complete upper or post-secondary

- Only $40 \%$ have worked before; 16 years of experience on average

- $64 \%$ live in households with dependent children; $20 \%$ in households with children under 6

- $69 \%$ live in rural areas

- High poverty risk: $39 \%$ in poorest quintile

- $56 \%$ receive family/child benefits
5: Long-term unemployed educated single youth (7\%)
6: Working-age long-term unemployed (5\%)
- $55 \%$ are long-term unemployed; $33 \%$ are inactive

- $67 \%$ are men

- $76 \%$ are $20-29$ years old

- $80 \%$ are single

- $77 \%$ have at least one working adult in household; $81 \%$ are living with parents

- Mid-to-high-skilled: $47 \%$ with complete upper or post-secondary; 25\% with complete tertiary

- Only $11 \%$ have worked before; 4 years of experience on average

- Very high poverty risk: $48 \%$ in poorest quintile

- $51 \%$ receive family/child benefits; $32 \%$ social exclusion; only $8 \%$ receive unemployment benefits
- $74 \%$ are long-term unemployed

- $72 \%$ are men

- $93 \%$ are $25-54$ years old

- $52 \%$ have at least one working adult in household

- $66 \%$ are married

- Mid-skilled: $66 \%$ have complete upper or post-secondary

- $92 \%$ worked before, but $<2$ mos. in last year; 15 years of experience on average

- $56 \%$ live in households with dependent children

- Very high poverty risk: $46 \%$ in poorest quintile

- $50 \%$ receive family/child benefits; $30 \%$ social exclusion; $21 \%$ receive unemployment benefits 
- $75 \%$ are unemployed

- $68 \%$ are men

- $72 \%$ are $25-54$ years old

- $62 \%$ have at least one working adult in household

- $57 \%$ are married

- Mid-skilled: $66 \%$ have complete upper or postsecondary

- $\quad 99 \%$ have worked 2 or more mos. in last year; 15 years of experience on average

- $66 \%$ live in households with dependent children; $33 \%$ in households with children under 6

- $62 \%$ live in rural areas

- Low poverty risk: $18 \%$ in poorest quintile

- $56 \%$ receive family/child benefits; $16 \%$ receive unemployment benefits
- $71 \%$ are disabled; $18 \%$ are retired

- $61 \%$ are men

- $70 \%$ are $20-44$ years old

- $76 \%$ are without a partner

- $69 \%$ report strongly limited capacity to work

- $76 \%$ have at least one working adult in household

- Low-skilled: $45 \%$ have not completed upper secondary; 33\% have never studied before or are illiterate

- $100 \%$ have never worked before

- $57 \%$ live in households with dependent children

- $87 \%$ live in rural areas

- High poverty risk: $39 \%$ in poorest quintile

- $67 \%$ receive disability benefits; $53 \%$ receive family/child benefits; $46 \%$ receive social exclusion benefits

Source: World Bank analysis based on EU-SILC

Note: Percentages in parentheses following the group names refer to the share of the total out-of-work population." Years of work experience" refer only to those individuals who have worked before. "Dependent children" include children under 18 and household members aged 18 to 24 who are economically inactive and living with at least one parent. "Working adult" refers to adults aged 25 and over. For this report's purposes, we define the at-risk-of-poverty rate as the relative risk of being in the first quintile of the income distribution. The reference period for income reported in EU-SILC surveys is the year preceding the survey year.

The eight main clusters emerging from the LCA analysis in 2011 can be characterized as follows (see Annex 2 for more detail, including the full list of inactive covariates):

$\checkmark \quad$ Cluster 1: Retirees. This group of retired individuals has represented between 21 and 27 percent of the out-of-work throughout the years analyzed. It is largely made up of females (58 percent), and as of 2009, it generally includes individuals who have hit retirement age (60-64). ${ }^{109}$ They can be considered low- to mid-skilled, with 38 percent having less than an upper secondary education and half having upper or post-secondary education. On average, they have 33 years of work experience. Even though 62 percent do not have at least one working adult in their household they are at very low risk of poverty, ${ }^{110}$ with only 8 percent living in the bottom income quintile. In part, this can be explained by the fact that they live in households without dependent children (17 percent also live alone) and almost all receive old-age benefits. On average, benefits make up 77 percent of their total gross household income.

109 The retirement age in Romania is 59 for women and 64 for men.

110 Risk of poverty is here understood as the relative probability of living in the poorest income quintile. By definition, 20 percent of the population lives in this quintile; risk is thus gauged relative to a benchmark of 20 percent. 
$\checkmark$ Cluster 2: Early retirees. This class represents 24 percent of the out-of-work population in 2011, and its relative size has remained fairly stable over time. ${ }^{111}$ Its members are almost exclusively early retirees between the ages of 45 and 59 . Although less than one-third report strong limitations on capacity to work, one-half receive disability benefits; forty-two percent also report receiving old-age benefits. Like their retired counterparts, they are mostly female (59 percent) and, on average, have a similar number of years of work experience (27 years). However, they are somewhat more educated than the retirees, with 73 percent having completed upper or post-secondary school. Although more than half (57 percent) have at least one working adult in the household, benefits still represent most of total household gross income (61 percent). Their relatively small households also explain why only 12 percent live in the bottom income quintile, putting them at a very low risk of poverty.

$\checkmark \quad$ Cluster 3: Low-educated rural mothers without work experience. Representing 19 percent of the out-of-work in 2011, this group makes up the larger of two groups of inactive women, the other being inactive middle-aged wives. What mainly sets this group's members apart from those of the smaller group is their relative youth (84 percent are between 20 and 44 years of age) and the fact that a great majority ( 83 percent) have children, with a large percentage (43 percent) having children under 6 years of age. They are largely concentrated in rural areas (77 percent), most have a working partner, and almost all (91 percent) have at least one working adult in their households. They are also more likely to have never worked before (78 percent), and a significant proportion of them (46 percent) have not completed upper secondary school. Finally, this group is characterized by very high benefit receipt: seventy-six percent receive family/child benefits. Nonetheless, on average benefits represent 28 percent of their total household income, the lowest percentage among all identified groups. Low benefit generosity, as well as their large families (4.7 members on average) in part explain why 43 percent are in the poorest income quintile.

$\checkmark \quad$ Cluster 4: Inactive middle-aged wives. This smaller group of inactive women made up 15 percent of the out-of-work in 2011, and represented as little as 8 percent of our sample in 2010. They are middle-aged (77 percent are between 35 and 54) married women who for the most part have children (64 percent), although only 20 percent have children under 6 . Most (60 percent) have not worked before, but they have more years of work experience than their younger counterparts and are also better educated, with over half having completed upper or post-secondary education. They are more likely to be married than their younger counterparts but also less likely to have a working adult within the household. They, too, are concentrated in rural areas, though less so than their younger counterparts. In terms of welfare, although they live in smaller households (4.0 members on average) than the loweducated rural mothers without work experience, they have slightly lower labor incomes on average, and a lower percentage (56 percent) receives family/child benefits. Overall, they have a similar income profile as the younger inactive women, with as many as 39 percent in the bottom income quintile.

111 With the exception of 2009, when the early retirees were grouped together with a number of "other inactive" individuals and grew to represent 32 percent of the out of work. This group is thus labeled as early retirees and inactive in 2009. 
$\checkmark \quad$ Cluster 5: Long-term unemployed educated single youth. Representing 7 percent of the out-of-work in 2010 and 2011, this group consists of mostly men (67 percent in 2011) between the ages of 20 and 29 and resembles the unemployed youth who have been particularly hit by the economic crisis across the EU. About 55 percent of them are long-term unemployed, and another third are out of the labor market. Some of them could be discouraged workers. In 2011, this group stood out as having the highest percentage of members with a tertiary education (24 percent). Their lack of work experience may thus explain their long-term unemployment status: almost 90 percent have never worked before. Aside from being young, the members of this group are for the most part single and still living at home with their parents. Even though they live in households where there is at least one working adult and just over half receive family/child benefits and one-third receive social exclusion benefits at the household level, a very high percentage of this group is still at a risk for poverty: Forty-eight percent are in the poorest quintile. In part, this is explained by the fact that they live in large households with 4.8 members on average.

$\checkmark \quad$ Cluster 6: Working-age long-term unemployed. This group only emerged in 2010 and represents 5 percent of the out-of-work. Its members are primarily men (72 percent) in their prime age (25 to 54) who have largely been unemployed for over 12 months (74 percent). The majority are married (66 percent) and a smaller majority (56 percent) live in households with dependent children. They are mid-skilled individuals (66 percent have completed upper secondary) and have previous work experience. Another characteristic of this group is its high dependence on benefits. Although just over half have a least one working adult in the household, benefits represent over half of their total household income (one-half of these receive family/child benefits, about a third receive social exclusion benefits, and one-fifth receive unemployment benefits). Despite high benefit receipt, a large percentage (46 percent) are in the bottom income quintile. Finally, it is notable that this group is relatively more urban, with 50 percent living in urban areas.

$\checkmark \quad$ Cluster 7: Working-age newly unemployed. This group, representing 3 percent of the out-of-work in 2011, closely mirrors the group of working-age long-term unemployed. What primarily sets them apart is the fact that they worked for at least two months during the last year, meaning that they have just recently lost their jobs. They have a similar education profile to their long-term unemployed counterparts and are primarily in their prime age, although they are somewhat younger (72 percent are in their prime age and 19 percent are under 25). Although they are somewhat less likely to be married, two-thirds live in households with dependent children. However, due to high labor income within their households, unlike their long-term unemployed counterparts they are at a relatively low risk for poverty, with only 18 percent in the bottom quintile. A majority receive family/child benefits (56 percent) and one-fifth receive social exclusion benefits. Despite the fact that they are newly unemployed, only one-sixth receive unemployment benefits, in contrast to one-fifth of the long-term unemployed. Before 2010, the members of this group belonged to the working-age newly unemployed or inactive.

$\checkmark \quad$ Cluster 8: Low-educated and rural disabled. This group, representing from 3 to 5 percent of the out-of-work population, reports its labor market status as disabled (71 percent) or retired (18 percent), and has very low education levels. A majority (67

Portraits of Labor Market Exclusion | 253 
percent) also report strong limitations on work due to a health condition. In terms of benefit receipt, the most commonly received by this group are disability benefits ( 67 percent) and family/child benefits (46 percent). Benefit dependency is high, with benefits representing 54 percent of total household income. The members of this group are also characterized by the absence of a partner and live in households without a working adult. They are at high risk of falling in poverty, with 39 percent belonging to the poorest income quintile. The great majority live in rural areas. 
The following two tables present the main characteristics of each group in 2011. For the complete table, including inactive covariates, see Annex 2.

Table 8.3 Latent Classes of Out-of-Work Population in Romania-Indicators (2011)

\begin{tabular}{|c|c|c|c|c|c|c|c|c|c|}
\hline & $\begin{array}{l}\text { All Out-of- } \\
\text { Work }\end{array}$ & 1. Retirees & $\begin{array}{l}\text { 2. Early } \\
\text { retirees }\end{array}$ & $\begin{array}{l}\text { 3. Low- } \\
\text { educated } \\
\text { rural } \\
\text { mothers } \\
\text { without work } \\
\text { experience }\end{array}$ & $\begin{array}{l}\text { 4. Inactive } \\
\text { middle- } \\
\text { aged wives }\end{array}$ & $\begin{array}{l}\text { 5. Long-term } \\
\text { unemployed } \\
\text { educated single } \\
\text { youth }\end{array}$ & $\begin{array}{l}\text { 6. Working-age } \\
\text { long-term } \\
\text { unemployed }\end{array}$ & $\begin{array}{l}\text { 7. Working-age } \\
\text { newly } \\
\text { unemployed }\end{array}$ & $\begin{array}{l}\text { 8. Low- } \\
\text { educated } \\
\text { and rural } \\
\text { disabled }\end{array}$ \\
\hline Cluster size & $100 \%$ & $24 \%$ & $24 \%$ & $19 \%$ & $15 \%$ & $7 \%$ & $5 \%$ & $3 \%$ & $3 \%$ \\
\hline Population & $4,093,906$ & 978,034 & 962,887 & 776,614 & 606,307 & 292,714 & 223,937 & 136,327 & 117,086 \\
\hline \multicolumn{10}{|c|}{ INDICATORS } \\
\hline \multicolumn{10}{|l|}{ Labor market attachment } \\
\hline Unemployed & $4 \%$ & $0 \%$ & $0 \%$ & $0 \%$ & $0 \%$ & $8 \%$ & $9 \%$ & $75 \%$ & $0 \%$ \\
\hline Long-term unemployed & $9 \%$ & $0 \%$ & $2 \%$ & $0 \%$ & $0 \%$ & $55 \%$ & $74 \%$ & $0 \%$ & $0 \%$ \\
\hline Retired & $49 \%$ & $98 \%$ & $96 \%$ & $3 \%$ & $8 \%$ & $4 \%$ & $0 \%$ & $9 \%$ & $18 \%$ \\
\hline Disabled & $2 \%$ & $0 \%$ & $1 \%$ & $0 \%$ & $1 \%$ & $0 \%$ & $0 \%$ & $0 \%$ & $71 \%$ \\
\hline Other inactive & $36 \%$ & $1 \%$ & $0 \%$ & $97 \%$ & $91 \%$ & $33 \%$ & $17 \%$ & $16 \%$ & $12 \%$ \\
\hline \multicolumn{10}{|c|}{ At least one working adult in household } \\
\hline No & $37 \%$ & $62 \%$ & $43 \%$ & $9 \%$ & $23 \%$ & $23 \%$ & $48 \%$ & $38 \%$ & $31 \%$ \\
\hline Yes & $63 \%$ & $38 \%$ & $57 \%$ & $91 \%$ & $78 \%$ & $77 \%$ & $52 \%$ & $62 \%$ & $69 \%$ \\
\hline \multicolumn{10}{|l|}{ Work experience } \\
\hline Never worked & $34 \%$ & $2 \%$ & $0 \%$ & $78 \%$ & $60 \%$ & $89 \%$ & $8 \%$ & $0 \%$ & $100 \%$ \\
\hline $\begin{array}{l}\text { Less than } 2 \text { months in } \\
\text { last year }\end{array}$ & $58 \%$ & $95 \%$ & $95 \%$ & $8 \%$ & $39 \%$ & $11 \%$ & $92 \%$ & $1 \%$ & $0 \%$ \\
\hline $\begin{array}{l}2 \text { or more months in last } \\
\text { year }\end{array}$ & $8 \%$ & $3 \%$ & $4 \%$ & $14 \%$ & $0 \%$ & $0 \%$ & $0 \%$ & $99 \%$ & $0 \%$ \\
\hline \multicolumn{10}{|c|}{ Self-assessed physical incapacity } \\
\hline Strongly limited & $13 \%$ & $12 \%$ & $28 \%$ & $1 \%$ & $7 \%$ & $0 \%$ & $2 \%$ & $1 \%$ & $67 \%$ \\
\hline None/limited & $87 \%$ & $88 \%$ & $72 \%$ & $99 \%$ & $93 \%$ & $100 \%$ & $98 \%$ & $99 \%$ & $33 \%$ \\
\hline
\end{tabular}


Table 8.4 Latent Classes of Out-of-Work Population in Romania-Active Covariates (2011)

\begin{tabular}{|c|c|c|c|c|c|c|c|c|c|}
\hline & $\begin{array}{l}\text { All Out-of- } \\
\text { Work }\end{array}$ & $\begin{array}{c}1 . \\
\text { Retirees }\end{array}$ & $\begin{array}{l}\text { 2. Early } \\
\text { retirees }\end{array}$ & $\begin{array}{l}\text { 3. Low- } \\
\text { educated } \\
\text { rural } \\
\text { mothers } \\
\text { without } \\
\text { work } \\
\text { experience }\end{array}$ & $\begin{array}{c}4 . \\
\text { Inactive } \\
\text { middle- } \\
\text { aged } \\
\text { wives }\end{array}$ & $\begin{array}{l}\text { 5. Long-term } \\
\text { unemployed } \\
\text { educated } \\
\text { single youth }\end{array}$ & $\begin{array}{l}\text { 6. Working- } \\
\text { age long-term } \\
\text { unemployed }\end{array}$ & $\begin{array}{l}\text { 7. Working- } \\
\text { age newly } \\
\text { unemployed }\end{array}$ & $\begin{array}{l}\text { 8. Low- } \\
\text { educated } \\
\text { and rural } \\
\text { disabled }\end{array}$ \\
\hline Cluster size & $100 \%$ & $24 \%$ & $24 \%$ & $19 \%$ & $15 \%$ & $7 \%$ & $5 \%$ & $3 \%$ & $3 \%$ \\
\hline Population & $4,093,906$ & 978,034 & 962,887 & 776,614 & 606,307 & 292,714 & 223,937 & 136,327 & 117,086 \\
\hline \multicolumn{10}{|c|}{ ACTIVE COVARIATES } \\
\hline \multicolumn{10}{|l|}{ Age groups (4) } \\
\hline $16-24$ years & $8 \%$ & $0 \%$ & $0 \%$ & $18 \%$ & $2 \%$ & $49 \%$ & $0 \%$ & $19 \%$ & $23 \%$ \\
\hline $25-34$ years & $18 \%$ & $0 \%$ & $1 \%$ & $57 \%$ & $1 \%$ & $51 \%$ & $32 \%$ & $20 \%$ & $27 \%$ \\
\hline $35-59$ years & $50 \%$ & $6 \%$ & $99 \%$ & $26 \%$ & $91 \%$ & $0 \%$ & $68 \%$ & $61 \%$ & $49 \%$ \\
\hline $60-64$ years & $24 \%$ & $94 \%$ & $0 \%$ & $0 \%$ & $6 \%$ & $0 \%$ & $0 \%$ & $0 \%$ & $2 \%$ \\
\hline \multicolumn{10}{|l|}{ Gender } \\
\hline Male & $33 \%$ & $42 \%$ & $41 \%$ & $1 \%$ & $0 \%$ & $67 \%$ & $72 \%$ & $68 \%$ & $61 \%$ \\
\hline Female & $67 \%$ & $58 \%$ & $59 \%$ & $99 \%$ & $100 \%$ & $33 \%$ & $28 \%$ & $32 \%$ & $39 \%$ \\
\hline \multicolumn{10}{|l|}{ Education (4) } \\
\hline Primary & $34 \%$ & $38 \%$ & $25 \%$ & $46 \%$ & $37 \%$ & $23 \%$ & $17 \%$ & $16 \%$ & $45 \%$ \\
\hline Secondary & $54 \%$ & $49 \%$ & $73 \%$ & $40 \%$ & $54 \%$ & $47 \%$ & $66 \%$ & $66 \%$ & $18 \%$ \\
\hline Tertiary & $7 \%$ & $12 \%$ & $0 \%$ & $8 \%$ & $1 \%$ & $24 \%$ & $11 \%$ & $11 \%$ & $0 \%$ \\
\hline Never studied before/illiterate/NA & $5 \%$ & $2 \%$ & $2 \%$ & $6 \%$ & $9 \%$ & $6 \%$ & $6 \%$ & $6 \%$ & $37 \%$ \\
\hline \multicolumn{10}{|l|}{ Urban or Rural } \\
\hline Urban & $38 \%$ & $44 \%$ & $45 \%$ & $23 \%$ & $31 \%$ & $46 \%$ & $50 \%$ & $38 \%$ & $13 \%$ \\
\hline Rural & $62 \%$ & $56 \%$ & $55 \%$ & $77 \%$ & $69 \%$ & $54 \%$ & $50 \%$ & $62 \%$ & $87 \%$ \\
\hline
\end{tabular}


The composition of the identified classes of out-of-work population has experienced considerable changes over the last few years. In Figure 8.6 and Table 8.5, clusters are compared over time between 2008 and 2011, both as a share of the total out-of-work population and in absolute numbers. From the graph, the first important observation is that the size of the out-of-work population has not increased-it has actually decreased by a bit more than 100,000 individuals, or 2.5 percent. Furthermore, the same clusters are not identified in all years, and some of the clusters identified in 2011 that were present in previous years underwent changes in relative size and also in composition. The fact that the composition of the groups changes over time is particularly important to keep in mind when interpreting changes in group size. For instance, significant increases (decreases) in group size are sometimes due to reassignments of individuals across groups, resulting in changes in group composition. Thus, although some groups may retain similar names across years due to their most salient characteristics, they may nonetheless vary in their composition across years. The evolution in terms of group size and group composition over the 20082011 period can be summarized as follows:

$\checkmark$ One striking change is the increase in unemployment, especially in its nature, from short to long-term unemployment. The cluster of working-age long-term unemployed appears for the first time in $2010 .{ }^{112}$ Its size is comparable to the existing cluster of unemployed men. Thus, when considering the two clusters of prime-aged unemployed (short and long-term) together, the absolute number of unemployed in their prime age more than doubled in size between 2008 and 2010.

$\checkmark$ Another important change during the crisis period was the increase in the size of the youth cluster. In 2009, a new group of out-of-work youth emerged (the group labeled as "educated unemployed or inactive youth") alongside the already existing group of long-term unemployed single youth). The result was a 30 percent increase over 2008 in the absolute size of the out-of-work youth population identified in our analysis. This situation was reversed in the following two years, when once again only one youth cluster was identified; however, by 2011, the total number of out-of-work youth still remained about 4 percent higher than in 2008. Moreover, it is worth noting that the youth cluster identified in both 2010 and 2011 represented relatively educated youth. Specifically, in 2008, 72 percent of the group of long-term unemployed single youth was composed of individuals with upper secondary or post-secondary education, and only 2 percent of them had attained tertiary education. In 2009, this group was split along two lines: a more educated cluster (educated) unemployed or inactive youth (36 percent of which had tertiary level education), and a group of long-term unemployed single youth. In 2010 they appear together in one cluster again, but represent a more educated group: 15 percent have tertiary level education.

$\checkmark$ The cluster of retirees became smaller, probably due to an improvement in its differentiation from the other clusters. Between 2008 and 2011, the group of retirees became 15 percent smaller. However, in 2008, 68 percent of the individuals in this cluster were 60 to 64 years old, while 32 percent of them were between 35 and 59 years of age and had for the most part not reached retirement age. ${ }^{113} \mathrm{In}$

112 Before 2010, the only group identified as long-term unemployed consisted of youth.

113 As previously mentioned, the current retirement age in Romania is 59 for women and 64 for men.

Portraits of Labor Market Exclusion | 257 
2011, this cluster became composed of individuals who were likely to have reached retirement age, with 94 percent aged 60 to 64 .

$\checkmark \quad$ The cluster of early retirees has remained roughly comparable in absolute size to the retirees cluster itself; both represented around one million people. In 2008, 19 percent of the individuals in this cluster declared strong health-related limitations on their capacity to work; in 2011 this share increased to 28 percent. The percentage receiving disability benefits also increased during the period, rising from 41 percent to 49 percent. Another significant change occurred after 2008, when the share of males in this group fell from 60 percent to about 40 percent. Of note also is the fact that in 2009 , the group of retirees incorporated a large number of "other inactive" individuals also aged 45 to 54 , constituting a separate group labeled as retirees and inactive.

$\checkmark \quad$ The size of the combined groups of retired individuals fell between 2008 and 2011. Together, the early retirees and the retirees made up about 2.1 million people in 2008. By 2011, this number had fallen by 7 percent, to 1.9 million individuals. Although the largest fall in numbers appears to be among the retirees, it is important to recall that, in 2008, the group of retirees incorporated a significant share of early retirees.

$\checkmark \quad$ The two groups of retirees (retirees and early retirees) demonstrate the lowest share of household poverty (members of the cluster in the poorest income quintile) with 8 and 12 percent respectively. While the average old-age pension payment in Romania was below EUR 200 in 2013 (Government of Romania, 2013), the relative small household sizes (2.77 and 3.36 respectively (the lowest among all the 8 groups)) and the regularity of the old-age payment contributed to the low poverty exposure experienced by this cluster compared to the other out-ofwork clusters in this analysis. Partner labor income appears to play a minor role in the welfare condition of these households, as 90 percent of retirees and 72 percent of early retirees either have no partner or no working partner. This is reflected in the fact that the benefit share of household income among these two groups is the highest among all the 8 groups.

$\checkmark$ Finally, the group of inactive middle-aged wives increased by 50 percent during the period, from 400,000 to 600,000 individuals in 2011. Not only has its size changed but also its characteristics. In 2008, 85 percent were living in households with at least one working adult, 99 percent had worked before, and benefits represented 23 percent of the total household income. In 2011, 78 percent of them were living in households with a working adult, 60 percent had never worked before and benefits represented one-third of their household income.

$\checkmark$ On the other hand, there was a decrease in the size of the cluster of loweducated rural mothers without work experience, whose absolute number was reduced by 320,000 individuals-around 30 percent of its size in 2008. Some characteristics slightly changed, since 91 percent had a working adult present in the household in 2011 compared to 77 percent in 2008, and the share receiving family/child benefits increased from 67 percent to 76 percent. Moreover, in 2008, 88 percent did not have prior work experienced, compared to 78 percent in 2011. It is apparent that across time, some reassignments took place between this group of stay-at-home women and the previously mentioned group, inactive middle-aged wives. 
Table 8.5 Classes of Out-of-Work Population in Romania (2008- 2011) as Percent of Total Out-of-Work Population

\begin{tabular}{|l|c|c|c|c|}
\hline Name of Cluster & $\mathbf{2 0 0 8}$ & $\mathbf{2 0 0 9}$ & $\mathbf{2 0 1 0}$ & $\mathbf{2 0 1 1}$ \\
\hline Retirees & $27 \%$ & $21 \%$ & $21 \%$ & $24 \%$ \\
\hline Early retirees and inactive (only 2009) & - & $32 \%$ & - & - \\
\hline Early retirees (2008, 2010 and 2011) & $22 \%$ & - & $26 \%$ & $24 \%$ \\
\hline Low-educated rural mothers without work experience & $26 \%$ & $29 \%$ & $26 \%$ & $19 \%$ \\
\hline Inactive middle-aged wives (except 2009) & $10 \%$ & - & $8 \%$ & $15 \%$ \\
\hline Educated unemployed or inactive youth (only 2009) & - & $5 \%$ & - & - \\
\hline Long-term unemployed single youth (2008 and 2009) & $7 \%$ & $4 \%$ & - & - \\
\hline Long-term unemployed educated single youth (2010 and 2011) & - & - & $7 \%$ & $7 \%$ \\
\hline Working-age newly unemployed or inactive (2008 and 2009) & $4 \%$ & $4 \%$ & - & - \\
\hline Working-age long-term unemployed (2010 and 2011) & - & - & $5 \%$ & $5 \%$ \\
\hline Working-age newly unemployed (2010 and 2011) & - & - & $4 \%$ & $3 \%$ \\
\hline Low-educated and rural disabled & $3 \%$ & $5 \%$ & $4 \%$ & $3 \%$ \\
\hline
\end{tabular}

Source: World Bank staff analysis based on EU-SILC 
Figure 8.6 Classes of Out-of-Work Population in Romania (2008- 2011), (in thousands of individuals)

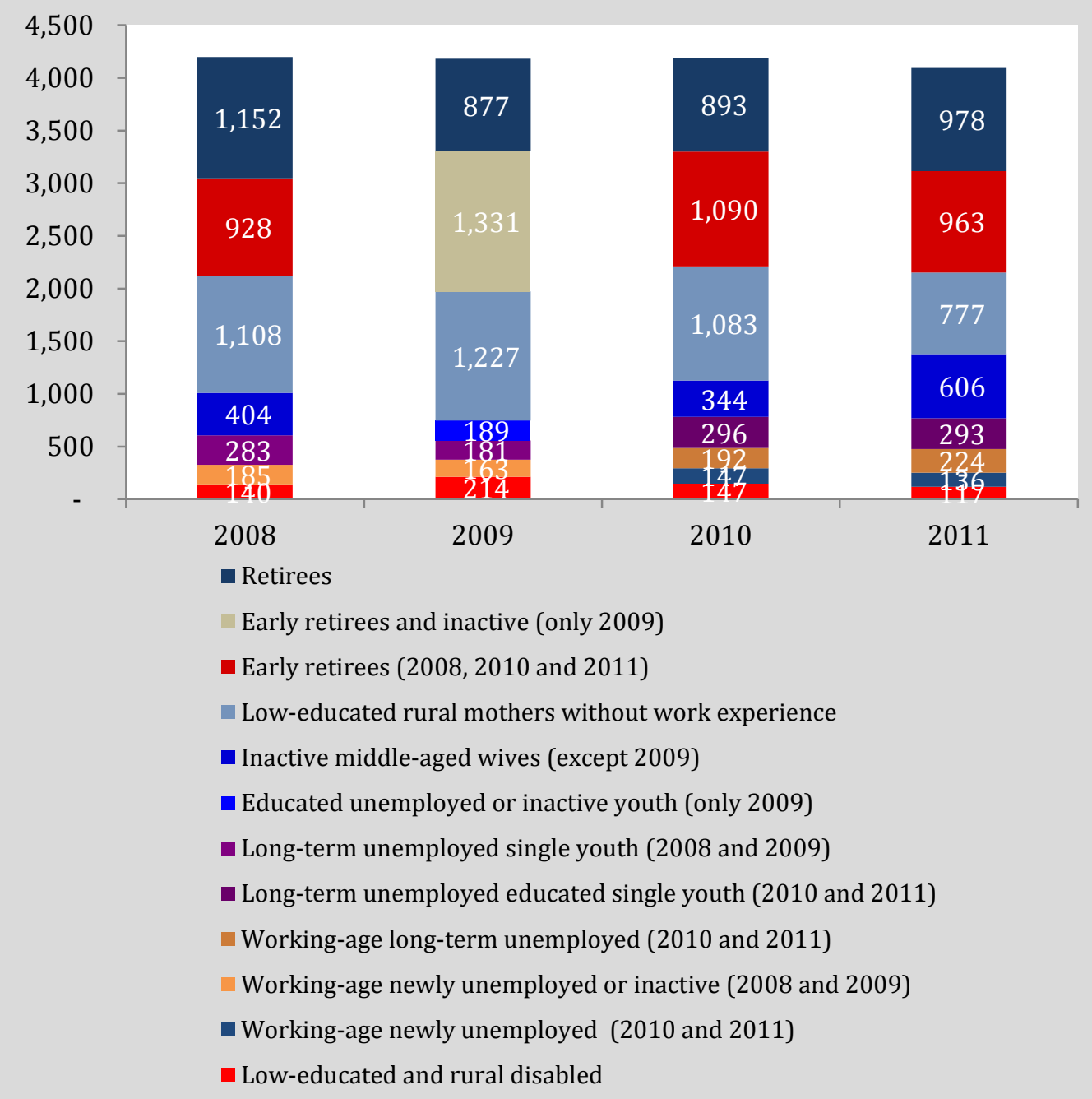

Source: World Bank staff analysis based on EU-SILC 
The clusters identified in the out-of-work population for the period from 2008 to 2011 reflect both structural and cyclical aspects of the labor market. This section identifies some of the key structural aspects of the Romanian labor market and uses cross-sectional and longitudinal analysis of clusters of the out-of-work population to further examine the effects of the crisis.

Among youth, not only is unemployment high and employment low, youth labor force participation rates in Romania are among the lowest in the EU. Since 2008, Romania's NEET rate has increased by 5.6 percentage points, reaching 17.2 percent in 2013. Youth labor force participation rates, at only 30.8 percent in 2013, are well below the EU average of 42.2 percent (Figure 8.7). In part, low labor force participation and employment rates among youth reflect a full-time work tradition in Romania. In many EU countries, youth have higher labor force participation rates because they are able combine their studies with part-time work. For example, as many as 75 and 40 percent of youth in the Netherlands and Slovenia, respectively, report working part time (Dimitrov and Duell, 2013). In Romania, in 2013, only about 18 percent of youth (15 to 24 years old) reported working part-time (Eurostat).

Figure 8.7 Labor Force Participation Among Youth aged 15 to 24, European Countries (2013)

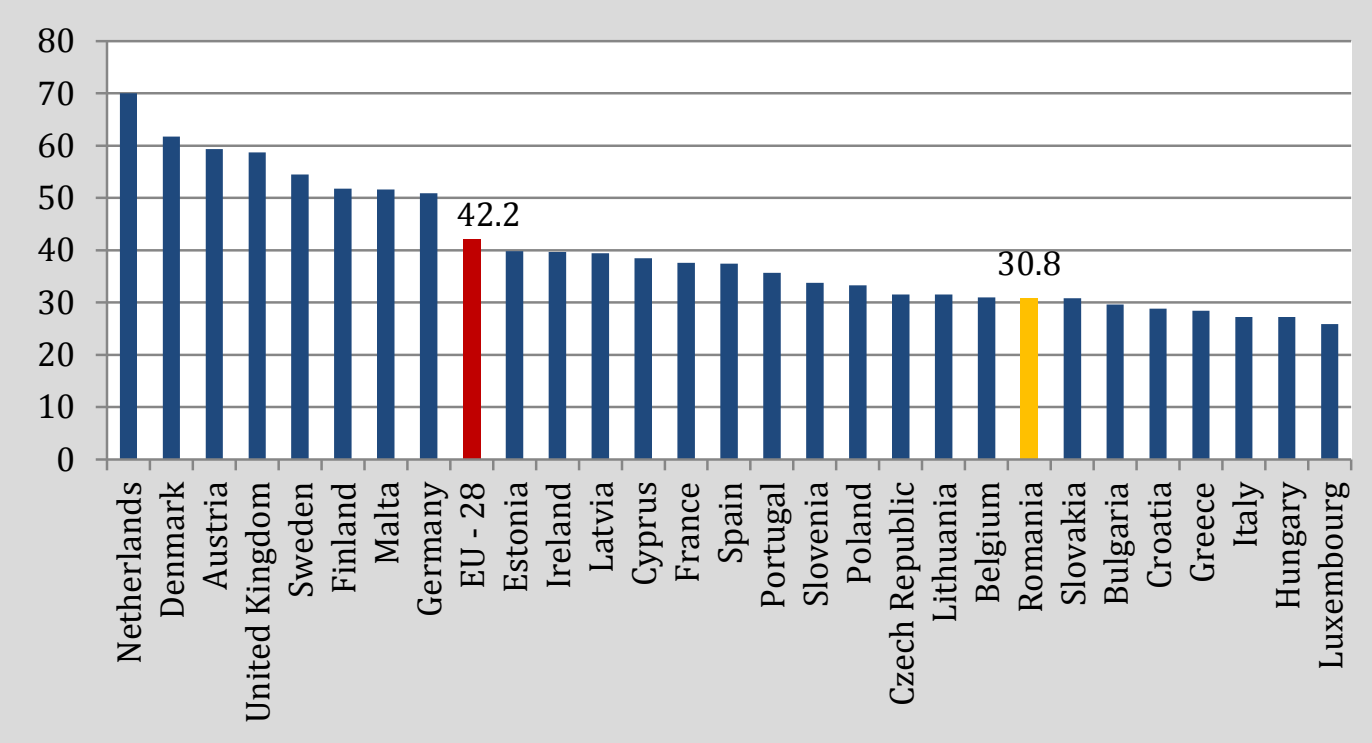

Source: Eurostat, EU-LFS

Retired individuals make up almost half of the out-of-work population analyzed in this note, but about half of retirees have not reached retirement age. In the working-age sample used in this analysis, two main clusters of retirees emerge, representing almost half of the out-of-work population. This may in part reflect that a relatively high percentage of population aged 15 to 64 has already reached retirement age. Retirement comes a very young age in Romania, especially for women, who become eligible at 59 (the male retirement 
age is 64). However, about half of those retired people are considered early retirees: among this group of early retirees, 35 percent are 45 to 54 years old and 57 percent are 55 to 59 years old. In fact, labor force participation for people aged 55 to 59 are among the lowest in the EU (see Figure 8.8). In the case of individuals 55 and 64 years old, rates are 10 percentage points lower than the EU-27 average of 54.5 percent. Such low labor force participation rates are having an effect on old-age benefits. As shown in Figure 8.9, between 2008 and 2010, expenditures on old age benefits as a share of GDP increased by 1.5 percentage points (reaching 7.5 percent), which represents twice the growth for the EU-27 average in the same period. As the working-age population shrinks and life expectancy rises, raising the retirement age and increasing labor force participation among older individuals may prove vital to counteract a shrinking workforce and rising old-age benefit outlays.

Figure 8.8 Labor Force Participation, ages 55 to 59, European Countries (2013)

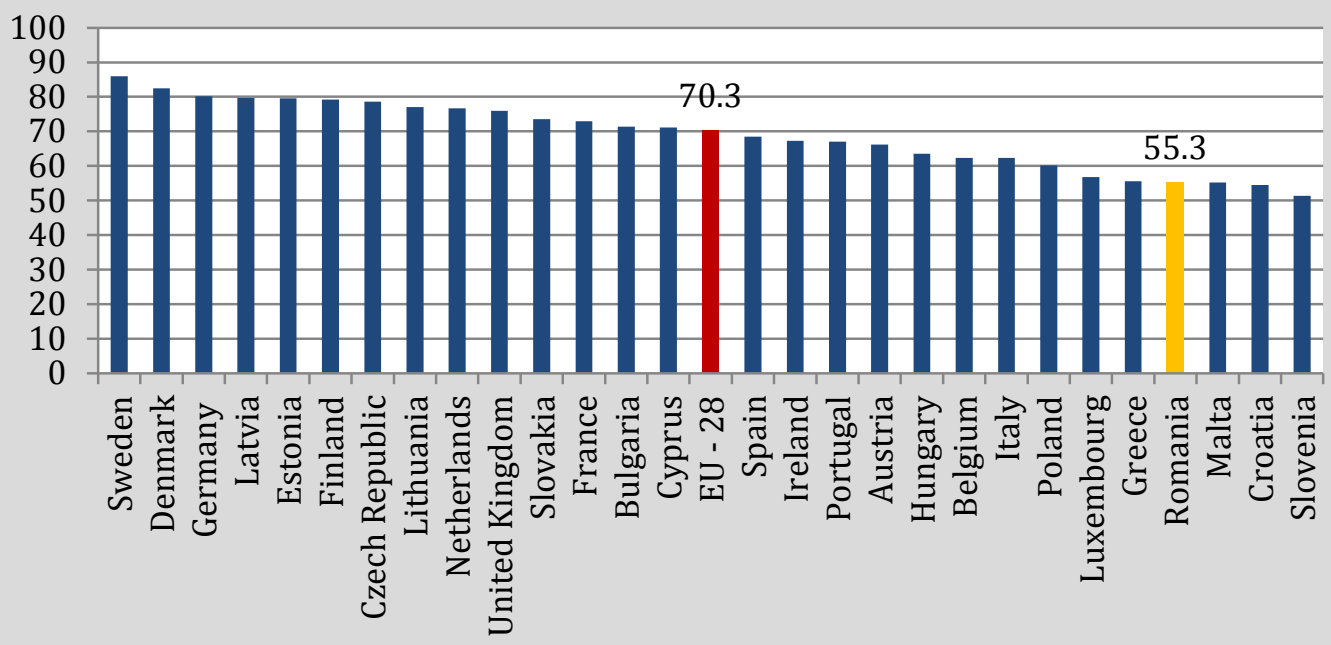


Figure 8.9 Expenditures on Old-age Benefits as a Share of GDP in Europe (2008 and 2010)

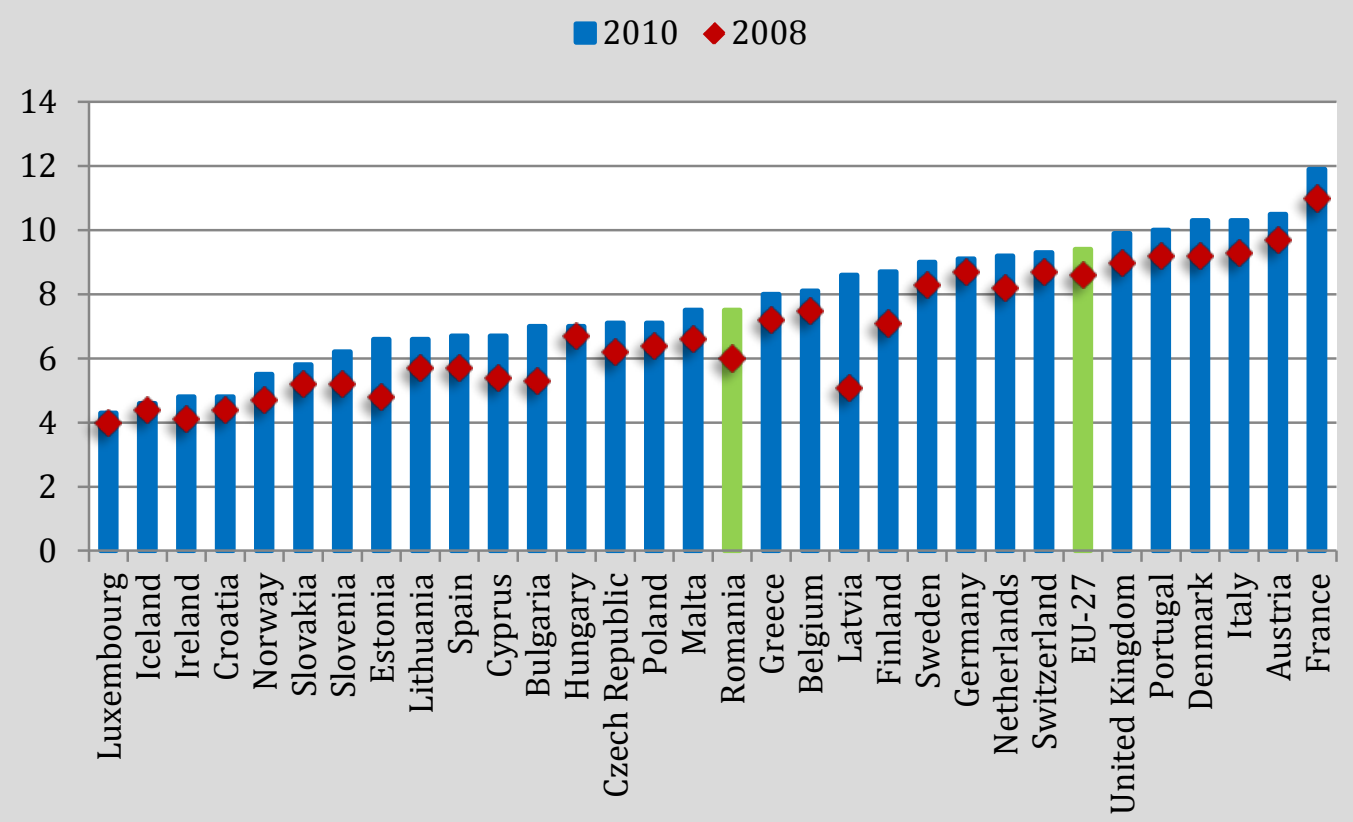

Source: Eurostat, EU-LFS

Figure 8.10 Labor Force Participation among Women Aged 25 to 54, European Countries, (2013)

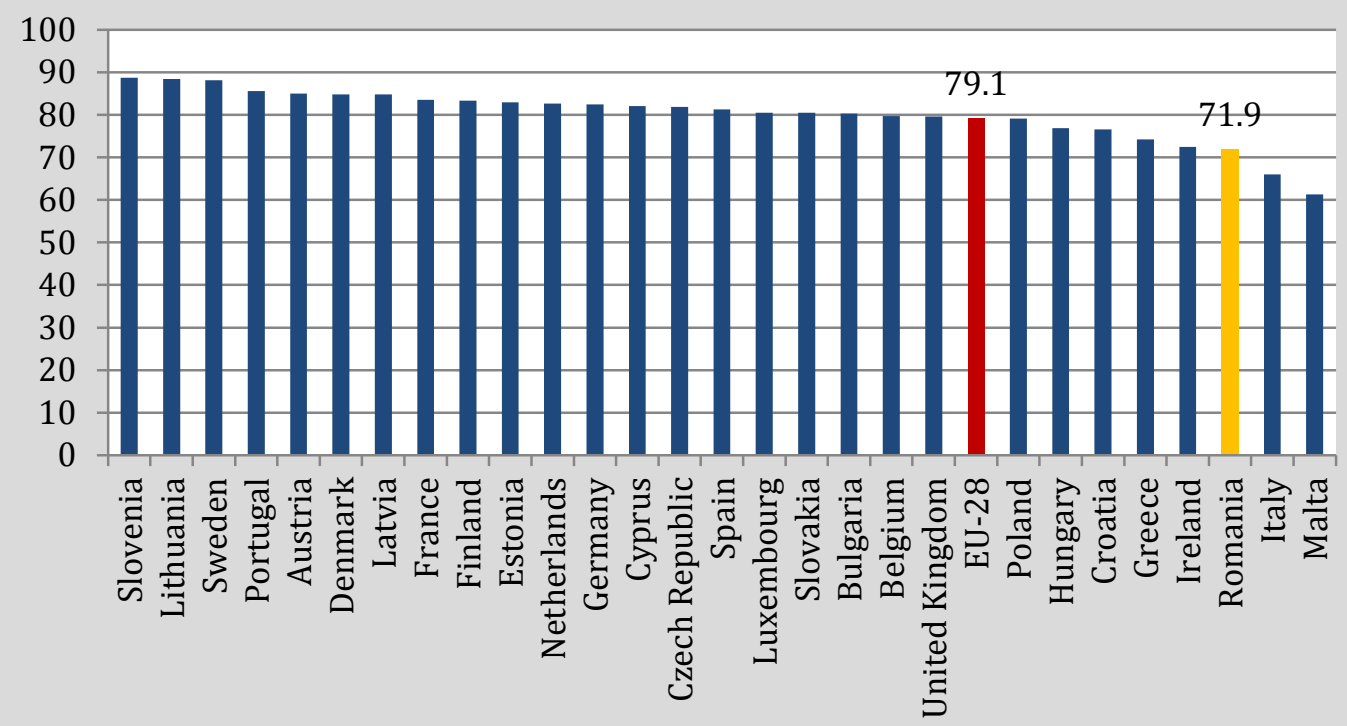

Source: Eurostat, EU-LFS

Inactive women, many of whom are in their prime age, represent one-third of the outof-work. Inactivity among women is a structural issue in Romania, as labor force 
participation rates for women of working age were around 55 percent even before the crisis. In comparison to other European women, Romanian women of prime age (25 to 54) are 7 percentage points less likely to participate in the labor market; only in Italy and Malta are labor force participation rates among women of prime age lower (Figure 8.10). Data from Eurostat also show that among European countries, children in Romania are the least likely to be enrolled in formal child care. However, factors other than lack of available child care seem to be at play in the low labor force participation of Romanian women, as the percentage of women who report being active due to personal and family responsibilities is under 10 percent, compared to an average of over 15 percent within the European Union (Eurostat, LFS 2012). Women have important potential for increasing the labor force, especially as Romania, like other European countries, faces a shrinking population of working-age individuals.

Finally, with respect to the unemployed two main patterns emerged: an absolute increase in the number of individuals in unemployed groups, and the appearance of a cluster of long-term unemployed. One of the most concerning developments between 2008 and 2011 is the increase in the number of unemployed individuals in the out-of-work population. Consider that in 2008 only 57 percent of the 185,000 people in the working-age newly unemployed or inactive group were unemployed (that is, around 100,000 people in their prime age were unemployed). By 2011 this number had increased by almost three times. Long-term unemployment not only imposes a significant financial burden on households, but affects the long-term health status of job-seekers, negatively impacts Government finances, and results in a lower overall long-term level of skills among a country's workforce, with permanent negative effects on productivity (Katz, 2010). Equally worrisome, many individuals who have been unemployed for extended periods become discouraged and drop out of the labor market altogether. In fact, a significant proportion of the groups labeled as unemployed are inactive: around one-sixth of the groups in their prime age and around one-third of the group of young men. It is possible that many of these individuals are discouraged workers. Addressing the plight of the long-term unemployed should be among the policy priorities for Romanian policymakers.

Another topic of immediate concern to policy makers in the Government of Romania is the situation of the working poor. While this group is by design not the focus of this report on the unemployed and out-of-work, some salient facts about them (working households that are in the bottom 20 percent of income distribution, regardless of their inclusion in one of the clusters of this report) can help to illustrate their labor market and social situation. From the EU-SILC data, a picture emerges that shows a mainly middle-aged (83 percent between 25 and 59), majority male (64 percent), very low-educated (over 50 percent with only primary or lower secondary education) and almost fully rural (92 percent) population. Their household income is mainly derived from labor income (72 percent). 
In order to better understand the dynamics within clusters and other labor market movements, LCA analysis was also applied to longitudinal EU-SILC data for the period 20082010. The EU-SILC survey allows the tracking of individuals in both 2008 and 2010, albeit with a smaller sample size than that available in the cross-section surveys. The latent class analysis of the out-of-work population in 2010 yielded similar results in terms of clusters, although due to the reduced sample size, the number of clusters was also smaller. For a sample of around 900 observations, six classes were defined:

- Low-educated rural inactive women without work experience (34 percent)

- Retirees (24 percent)

- Early retirees and inactive with previous work experience (23 percent)

- Low-educated and rural disabled or inactive (8 percent)

- Unemployed rural single youth (7 percent)

- Middle-aged low-educated unemployed (5 percent)

Annex 3 shows the full statistical description of the latent classes, while Table 8.6 below summarizes the key features of each cluster.

A further advantage of the panel analysis is to provide information on the flow of individuals among clusters and in and out of employment. Table 8.7 shows the flow of individuals into each cluster of out-of-work population or into employment in 2010 according to their labor market status in 2008. Between 2008 and 2010, 94 percent of the employed remained at work. Indeed, there is also an interesting flow into employment among those who were unemployed or inactive. In 2010, 42 percent of those who were classified as unemployed and 32 percent who were classified as inactive in 2008 were found to be employed.

Table 8.6 Longitudinal Analysis: Summary Characteristics of Latent Classes of Out-ofWork Individuals in Romania (2010)

\section{1: Low-educated rural inactive women without} work experience (34\%)

- $97 \%$ are inactive

- $95 \%$ are women

- 85\% are 25-54 years old

- $69 \%$ are married; $25 \%$ are single

- $86 \%$ have at least one working adult in household

- Only 15\% have worked before

- Mid to low-skilled: $48 \%$ have not completed upper secondary; 46\% have upper secondary

- $63 \%$ live in households with dependent children

- $78 \%$ live in rural areas

- High poverty risk: 38\% in the poorest income quintiles

- $64 \%$ receive family/child benefits

\section{2: Retirees (24\%)}

- $91 \%$ are retired

- $58 \%$ are women

- 94\% are 60-64 years old

- $11 \%$ report strongly limited capacity to work

- $73 \%$ are married; $20 \%$ are widowed

- $52 \%$ have at least one working adult in household

- $99 \%$ have worked before

- $53 \%$ live in urban areas

- Low poverty risk: $8 \%$ in poorest income quintile

- $82 \%$ receive old-age benefits 


\begin{tabular}{|c|c|}
\hline $\begin{array}{c}\text { 3: Early retirees and inactive with previous } \\
\text { work experience }(23 \%)\end{array}$ & $\begin{array}{l}\text { 4: Low-educated and rural disabled or } \\
\text { inactive (8\%) }\end{array}$ \\
\hline $\begin{array}{l}\text { - } 55 \% \text { are inactive and another } 45 \% \text { retired } \\
\text { - } 66 \% \text { are women } \\
\text { - } 89 \% \text { are } 45-59 \text { years old } \\
\text { - } 22 \% \text { report strongly limited capacity to work } \\
\text { - } 77 \% \text { are married; } 12 \% \text { are widowed } \\
\text { - } 60 \% \text { have at least one working adult in } \\
\text { household } \\
\text { - } 97 \% \text { worked before, but less than } 2 \text { months in } \\
\text { last year } \\
\text { - } 65 \% \text { live in rural areas } \\
\text { - Low poverty risk: } 15 \% \text { in poorest income } \\
\text { quintile } \\
\text { - } 38 \% \text { receive disability benefits; } 35 \% \text { receive } \\
\text { old-age benefits }\end{array}$ & $\begin{array}{l}\text { - } 58 \% \text { are inactive and another } 42 \% \text { are } \\
\text { disabled } \\
\text { - } 56 \% \text { are women } \\
\text { - } 83 \% \text { are } 35-64 \text { years old } \\
\text { - } 66 \% \text { report strongly limited capacity to } \\
\text { work } \\
\text { - } 54 \% \text { have at least one working adult in } \\
\text { household } \\
\text { - } 40 \% \text { live with at least one parent } \\
\text { - } 60 \% \text { have never worked } \\
\text { - Low-skilled: } 59 \% \text { have not completed } \\
\text { upper secondary } \\
\text { - } 69 \% \text { live in rural areas } \\
\text { - Moderate poverty risk: } 31 \% \text { in poorest } \\
\text { income quintile } \\
\text { - } 50 \% \text { receive disability benefits }\end{array}$ \\
\hline 5: Unemployed rural single youth (7\%) & $\begin{array}{l}\text { 6: Middle-aged low-educated unemployed } \\
(5 \%)\end{array}$ \\
\hline $\begin{array}{l}\text { - } 88 \% \text { are unemployed ( } 88 \%) \\
\text { - } 74 \% \text { are men } \\
\text { - } 90 \% \text { are } 20-29 \text { years old } \\
\text { - } 87 \% \text { live with their parent(s) } \\
\text { - } 96 \% \text { are without a partner } \\
\text { - } 73 \% \text { have at least one working adult in } \\
\text { household } \\
\text { - } 15 \% \text { have worked before; } 3 \text { years of work } \\
\text { experience on average } \\
\text { - } 82 \% \text { live in rural areas } \\
\text { - Very high poverty risk: } 47 \% \text { in poorest income } \\
\text { - } 56 \% \text { rintile } \\
\text { - } 56 \% \text { receive family/child benefits }\end{array}$ & $\begin{array}{l}\text { - } 81 \% \text { are unemployed } \\
\text { - } 86 \% \text { are men } \\
\text { - } 75 \% \text { are } 35-59 \text { years old } \\
\text { - } 48 \% \text { have a partner who is not working; } \\
25 \% \text { do not have a partner } \\
\text { - Low to mid-skilled: } 47 \% \text { have not } \\
\text { completed upper secondary; } 48 \% \text { have } \\
\text { completed upper secondary } \\
\text { - } 49 \% \text { live in households with dependent } \\
\text { children } \\
\text { - } 66 \% \text { live in rural areas } \\
\text { - High poverty risk: } 41 \% \text { in poorest income } \\
\text { quintile } \\
\text { - } 57 \% \text { receive family/child benefits; } 28 \% \\
\text { receive unemployment benefits }\end{array}$ \\
\hline$L C$ & $\begin{array}{l}\text { endent } \\
\text { lly inactive }\end{array}$ \\
\hline
\end{tabular}

On the other hand, Table 8.8 shows the labor market status in 2008 for each cluster and atwork population in 2010. Two main results emerge. First, for the cluster of unemployed rural single youth, 46 percent were already unemployed in 2008, which might reflect difficulties in entering the labor market for those starting professional careers. Second, the middle-aged low-educated unemployed were the most affected by employment losses, with 34 percent of them employed in 2008. 
Table 8.7 Composition of 2010 Clusters Based on 2008 Labor Status in Romania (Column Percentages)

\begin{tabular}{|c|l|c|c|c|c|c|c|}
\hline \multicolumn{2}{|c|}{} & \multicolumn{6}{c|}{ Labor Market Status in 2008 } \\
\hline $\begin{array}{c}\text { Clust- } \\
\text { er }\end{array}$ & \multicolumn{1}{|c|}{$\begin{array}{c}\text { Working-age } \\
\text { population in 2010 }\end{array}$} & $\begin{array}{c}\text { Un- } \\
\text { employed }\end{array}$ & Retired & $\begin{array}{c}\text { Dis- } \\
\text { abled }\end{array}$ & $\begin{array}{c}\text { Other } \\
\text { inactive }\end{array}$ & $\begin{array}{c}\text { Em- } \\
\text { ployed }\end{array}$ & Total \\
\hline 1 & $\begin{array}{l}\text { Low-educated rural } \\
\text { inactive women without } \\
\text { work experience }\end{array}$ & 6 & 1 & 31 & 45 & 1 & 9 \\
\hline 2 & Retirees & 4 & 52 & 7 & 2 & 2 & 9 \\
\hline 3 & $\begin{array}{l}\text { Early retirees and } \\
\text { inactive with previous } \\
\text { work experience }\end{array}$ & 3 & 43 & 14 & 12 & 2 & 9 \\
\hline 4 & $\begin{array}{l}\text { Low-educated and rural } \\
\text { disabled or inactive }\end{array}$ & 1 & 3 & 41 & 5 & 0 & 2 \\
\hline 5 & $\begin{array}{l}\text { Unemployed rural single } \\
\text { youth }\end{array}$ & 19 & 0 & 0 & 4 & 0 & 1 \\
\hline 6 & $\begin{array}{l}\text { Middle-aged low- } \\
\text { educated unemployed }\end{array}$ & 26 & 0 & 0 & 1 & 1 & 2 \\
\hline NC & Employed & 42 & 2 & 7 & 32 & 94 & 68 \\
\hline & \multicolumn{1}{|l|}{ Total } & 100 & 100 & 100 & 100 & 100 & 100 \\
\hline
\end{tabular}

Source: World Bank staff analysis based on EU-SILC

Notes: Students aged 16 to 24 who were inactive or unemployed are excluded from the sample. Numbers referred to in the text appear shaded in blue.

Table 8.8 Composition of 2010 Clusters Based on 2008 Labor Status in Romania (Row Percentages)

\begin{tabular}{|c|l|c|c|c|c|c|c|}
\hline \multicolumn{2}{|c|}{} & \multicolumn{6}{c|}{ Labor Market Status in 2008 } \\
\hline $\begin{array}{c}\text { Clust- } \\
\text { er }\end{array}$ & $\begin{array}{l}\text { Working-age } \\
\text { population in 2010 }\end{array}$ & $\begin{array}{c}\text { Un- } \\
\text { employed }\end{array}$ & Retired & $\begin{array}{c}\text { Dis- } \\
\text { abled }\end{array}$ & $\begin{array}{c}\text { Other } \\
\text { inactive }\end{array}$ & $\begin{array}{c}\text { Em- } \\
\text { ployed }\end{array}$ & Total \\
\hline 1 & $\begin{array}{l}\text { Low-educated rural } \\
\text { mothers without work } \\
\text { experience }\end{array}$ & 3 & 1 & 4 & 85 & 7 & 100 \\
\hline 2 & Retirees & 2 & 81 & 1 & 3 & 13 & 100 \\
\hline 3 & $\begin{array}{l}\text { Early retirees and } \\
\text { inactive }\end{array}$ & 1 & 63 & 2 & 20 & 14 & 100 \\
\hline 4 & $\begin{array}{l}\text { Low-educated and rural } \\
\text { disabled or inactive }\end{array}$ & 2 & 21 & 26 & 45 & 6 & 100 \\
\hline 5 & $\begin{array}{l}\text { Unemployed rural } \\
\text { single youth }\end{array}$ & 46 & 0 & 0 & 49 & 5 & 100 \\
\hline 6 & $\begin{array}{l}\text { Middle-aged low- } \\
\text { educated unemployed }\end{array}$ & 59 & 0 & 0 & 7 & 34 & 100 \\
\hline NC & Employed & 2 & 0 & 0 & 8 & 90 & 100 \\
\hline & $\quad$ Total & 4 & 14 & 1 & 16 & 65 & 100 \\
\hline
\end{tabular}

Source: World Bank staff analysis based on EU-SILC

Notes: Students aged 16 to 24 who were inactive or unemployed are excluded from the sample. Numbers referred to in the text appear shaded in blue. 
Box 9.1 Roma Population and Labor Market Exclusion in Romania

Labor market exclusion in Romania cannot be discussed without giving special consideration to the situation of the country's Roma population, a population that faces significant structural barriers. Because EU-SILC data does not include a differentiating indicator for Roma and non-Roma, the groups of out-of-work population identified in this latent class analysis exercise cannot directly be linked to a Roma/non-Roma pattern. A World Bank analysis forthcoming in the year 2014 titled Diagnostics and Policy Advice for Supporting Roma Inclusion in Romania will provide a more focused analysis of the current situation of Roma in Romania, including the employment dimension.

According to the most recent (2011) national census information, approximately 612,000 citizens declared themselves to be of Roma origin living in Romania (corresponding to 2.9 percent of the total population). This number reflects the lower bound of estimates, because many Roma choose to not report their ethnicity in surveys. A 2010 estimate from the Council of Europe put the number of Roma in Romania between 1.2 million and 2.5 million, corresponding to 5.7 to 11.9 percent of the population. However, an increasing share of new labor market entrants come from Roma families: depending on the estimates of the Roma population; ${ }^{114}$ between 6 to 20 percent of labor market entrants in Romania today are Roma. As the working-age population in Romania is projected to fall by 30 percent by 2050 , this share is expected to grow.

Members of the Roma minority are poor, vulnerable, and largely excluded from labor market opportunities in Romania. According to the UNDP/European Commission/World Bank regional Roma survey (2011), in 2011, the at-risk-of-poverty rate for Roma was 84 percent, in contrast with 31 percent among non-Roma families living nearby, and with a national atrisk-of-poverty rate of 22 percent. In the same year, the employment rate of the Roma stood at only 42 and 19 percent, against 66 and 53 percent (respectively) for men and women within the general population. Among the employed Roma, jobs are unstable and informality is abundant: the regional Roma survey (2011) shows that only about 36 percent of Roma employment ${ }^{115}$ is formal (based on a written contract or legal business documents) and includes health and pension insurance. The survey also shows that unemployment rates are also disproportionately high among Roma, standing at 28 and 43 percent for Roma men and women respectively. The high rates of joblessness and unstable employment do not reflect preferences: the vast majority of Roma express a desire for stable jobs, similar to the responses by non-Roma neighbors, with 74 percent of Roma men and 76 percent of women reporting a preference for "Secure employment but low paid" instead of "Having a higher income but insecure and irregular."

114 Estimates range from 535,140 (National Census in 2002) to [730,000-970,000], according to a Romanian Government and World Bank 2005 survey called "The Roma Communities Social Map," to $1,850,000$, according to the EU Communication "An EU framework for National Roma Integration Strategies up to 2020," based on the data from of Council of Europe. Source: Strategy of the Government of Romania for the Inclusion of the Romanian Citizens Belonging to Roma Minority; 2012-2020

115 The employed are defined as those who declared that they worked at least one hour last week (only 36 percent of the working-age population). 
Unfavorable labor market outcomes among the Roma population can be in part explained by a significant education and skills gap between Roma and non-Roma, which starts early in life: in 2011, Roma enrollment in preschool education stood at 37 percent, compared to 63 percent for non-Roma children living nearby. Roma children's opportunities for skills development are further hindered by the high level of classroom-level segregation of Roma pupils, with nearly a quarter of Roma children currently attending basic education in classes where most of the children are Roma. Not surprisingly, only 10 percent of Roma adults report having completed secondary education in 2011, compared to 58 percent of the nonRoma living nearby. In addition to the skills gap, discrimination and other barriers also hinder the employment of Roma: according to the Roma regional survey, among Roma who looked for work in the past five years, 30 percent report that they experienced discrimination because of their ethnicity, while only 11 percent of non-Roma living nearby report the same.

The number of identified Roma who participated in Active Labor Market Policies implemented by the Romanian Public Employment Service in 2013 stood at 72,000 (MLFSPE communication to EC DG EMPL, May 7, 2014). About 4,200 persons were placed in employment ( 60 percent in permanent and 40 percent in temporary contracts). Another 600 individuals were referred to training courses, counseling services or wage-subsidy schemes. In 2013, two persons of Roma origin benefited from labor force mobility support, according to MLFSPE.

Roma inclusion is not only a moral imperative, but also smart economics for Romania. With an aging population, pension and health care costs are bound to increase in the near future. Equal labor market opportunities could enable faster productivity growth, and could contribute fiscal benefits through increased revenue from taxes and lower social assistance spending. According to a World Bank estimate on the basis of 2008 data, ${ }^{116}$ assuming an equal number of working-age Roma men and women, and that average wages in the economy remain unchanged, equalizing labor market earnings in Romania for Roma could result in potential economic benefits ranging between EUR 887 million and 2.9 billion annually, and fiscal benefits ranging between EUR 202 million and 675 million annually. Additionally, the social and economic inclusion of Roma is essential for Romania to meet its EU2020 targets, as Roma are significantly poorer and more vulnerable than the non-Roma, including their non-Roma neighbors.

116 Roma Inclusion: An Economic Opportunity for Bulgaria, Czech Republic, Romania and Serbia. (The World Bank, 2010) 


\section{From Profiling to Activation}

\section{Activation and Inclusion Policies in Romania}

Activation and inclusion policies in Romania operate on a very low level of spending and are mainly articulated around European programs. Policies for social inclusion include a whole range of social assistance benefits that are often categorical in nature (EC, 2013) and are not well targeted to the poorest sections of the population (only 17 percent of the social assistance spending reached the poorest quintile of the population in 2009) (ibid). A guaranteed minimum income (GMI) Program is better targeted but has relatively low coverage of the poor (ibid). With the onset of the economic crisis and ensuing austerity measures, benefit levels and budget allocations have been reduced a number of times. Strategies for the coordination of social inclusion between policy areas are often formulated in strategic documents for EU funds but are "not visible in the implementation" (ibid).

Labor market integration is (in theory) supported by activating design features of the GMI. The design of the guaranteed minimum income program in Romania in theory supports formal paid employment by anchoring the benefit well below a market wage rate and offering a simple working benefit component. In reality, this work incentive is probably not large enough to offset potential earnings from parallel informal employment (ibid).

Nominally, the National Employment Agency (NEA) is tasked with delivering public employment services and activation policies. Functioning under the authority of the Ministry of Labor, Family and Social Protection, the agency operates 41 county offices and more than 150 local offices, as well as regional and national training centers. While a number of priorities for training and activation have been articulated, the number of participants in active labor market programs actually decreased after the start of the crisis (in line with falling budget allocations, see Figure 8.11 and Figure 8.12 (ibid). 
Figure 8.11 Labor Market Policy (LMP) Beneficiaries in Romania (Number of Individuals)

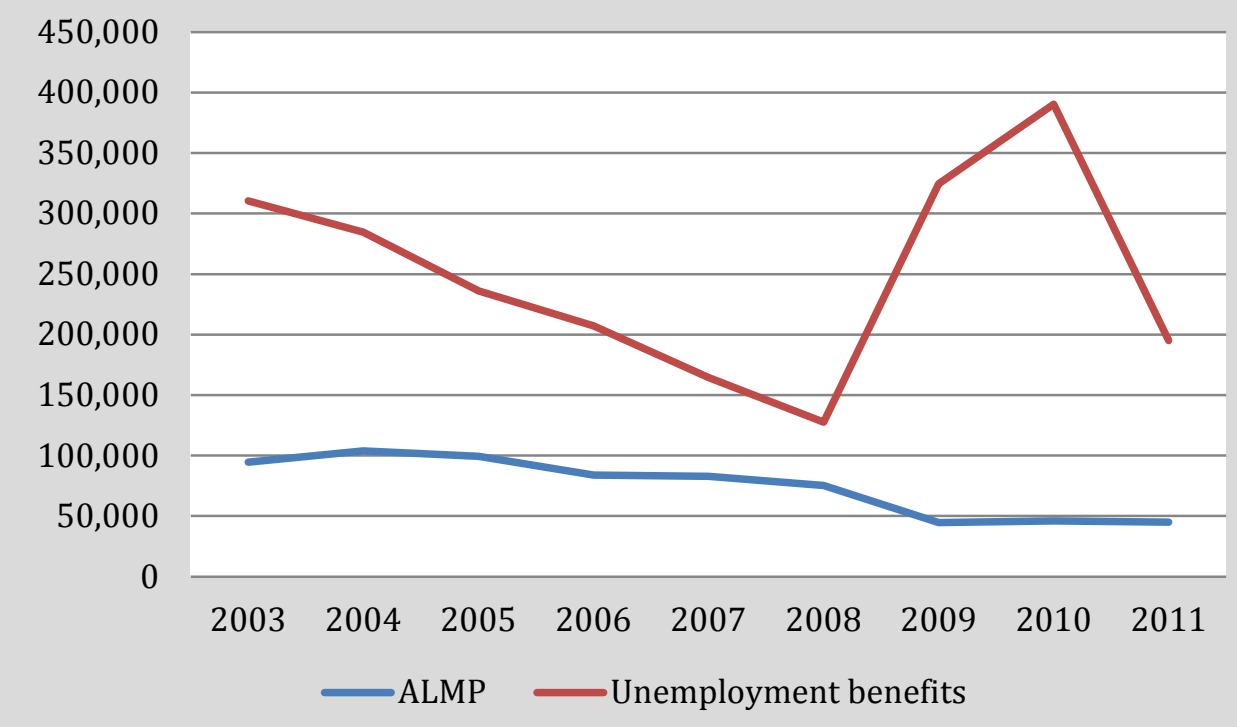

Source: Eurostat, OECD

Figure 8.12 Composition of Spending on ALMPs in Romania (Euro millions), 2008 and 2011

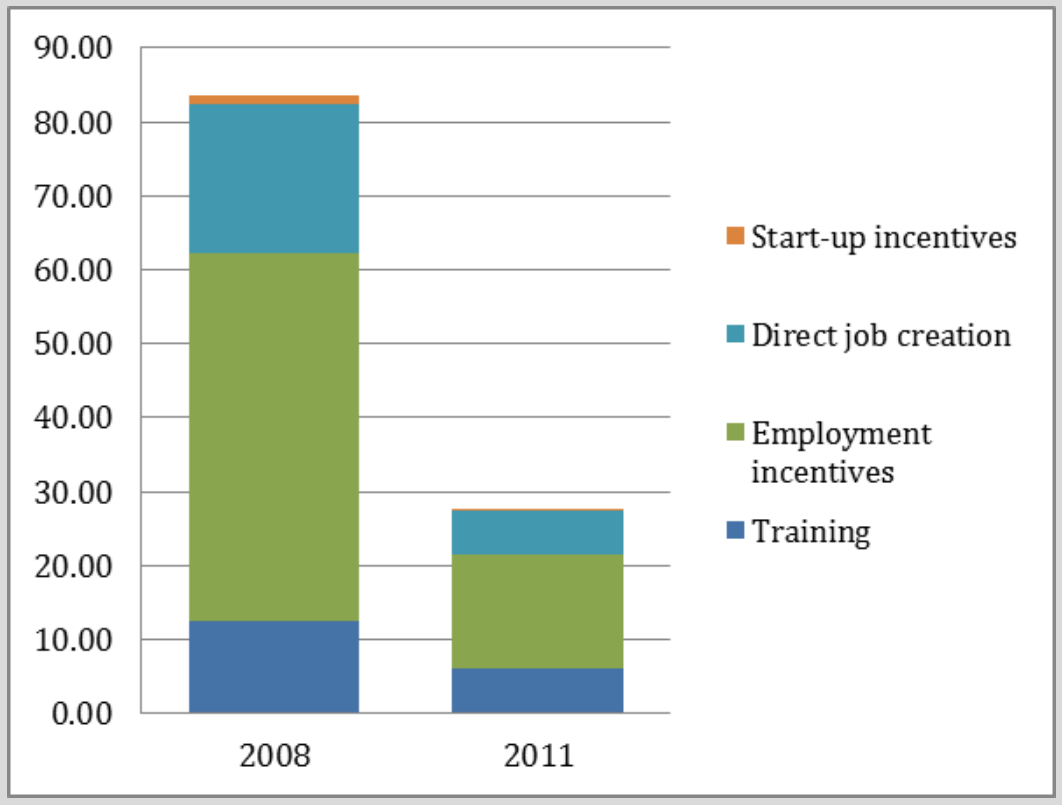

Source: Eurostat, OECD 
From the Annual Employment Action Plan of the NEA, a number of ALMPs can be derived; but measurement of effectiveness appears limited (EC, 2013). With an overall beneficiary base of 1.4 million in 2011, among the measures listed by the NEA are the following (all placement data for 2011):

$\checkmark$ Job fairs. About 360,000 job seekers are reported to have found employment after attending one of the job fairs. Job fairs are organized for specific categories of job seekers: young graduates, single professions, Roma, and so on.

$\checkmark$ General counseling and job orientation. This form of service reportedly helped approximately 65,000 job seekers into employment.

$\checkmark$ Training courses. These were offered for 35,000 participants, of whom 14,000 are reported to have been subsequently placed in employment.

$\checkmark$ Job subsidies. Different job subsidies are reported to have brought 27,000 participants into employment.

$\checkmark$ Various other measures. These include mobility grants, incentives for graduate employment, and business start-up support; all were reported to have led to fewer than 5,000 employment placements.

Since spending on labor market policies is very low in Romania, passive policies make up the bulk of spending. The economic crisis of 2008 precipitated a downward trajectory in spending on ALMPs in Romania, which last stood at 0.029 percent of GDP, one of the lowest figures in the EU. Passive payments for unemployment benefits responded to the uptake in unemployment during the crisis starting in 2008. They have receded since, being subject to cuts in benefit levels and tightening of eligibility requirements (Figure 8.13).

Figure 8.13 Labor Market Policy (LMP) Spending in Romania as a Share of GDP

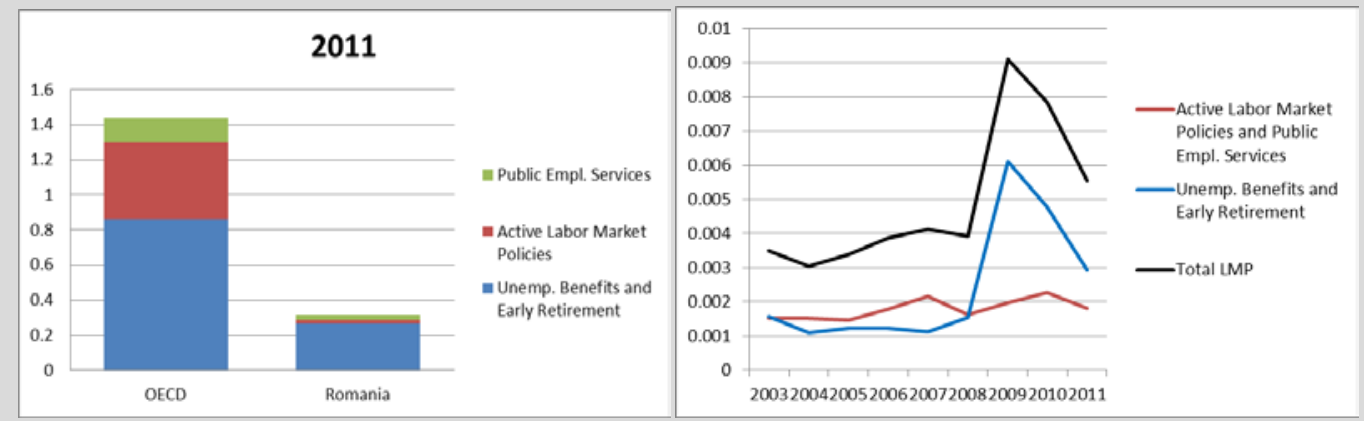

Source: Eurostat, OECD 
When further considering the approach toward labor market integration, an assessment of the priorities and potentials of the identified groups needs to be undertaken. Given the precarious low level of resources for activation programs in Romania, further prioritization of intervention is all the more important. This prioritization does not alleviate any of the pressure to increase funding for a minimum set of intermediation and activation services in the country.

After a first step ("activation priority") of prioritizing the intervention along activation need and activation potential, a second step ("activation type") will attempt to classify the groups according to the kind of activation intervention needed, depending on social or labor market barriers to be overcome. Lastly, as a third step, information on household income composition of the different groups will be used to assess potential cross-dependencies of the benefit system with the labor market status and activation approaches.

Activation priorities. The table below gives an overview of the identified inactive classes and their respective activation need and activation potential. The total number of persons estimated in these clusters was about 4.1 million in 2011, representing 31.2 percent of the working-age (16-64) population of Romania.

In the table, activation need refers to a group's level of need for inclusion in the labor market in order to achieve income and reduce or end poverty. This parameter is mainly driven by the poverty exposure of the household. Activation potential describes that group's ability or motivation to be included in the labor market. A high activation need could be driven by high poverty risk (as in the case of the working-age long-term unemployed) whereas a high activation potential could be driven by previous work experience or a relatively good educational base (for example, the long-term unemployed single youth). Overall priority for action can also be supported by the size of the group. In the end, this matrix is a base for rationalizing a further policy discussion, and not an arithmetic exercise. 
Table 8.9 Activation Need and Potential of Different Clusters-Romania

\begin{tabular}{|c|c|c|c|c|}
\hline $\begin{array}{l}\text { Share } \\
(2011)\end{array}$ & Cluster & $\begin{array}{l}\text { Activation } \\
\text { need }\end{array}$ & $\begin{array}{l}\text { Activation } \\
\text { potential }\end{array}$ & $\begin{array}{l}\text { Priority for } \\
\text { action }\end{array}$ \\
\hline $24 \%$ & Retirees & Low & Low & Low \\
\hline $24 \%$ & Early retirees & Low & Medium & Low \\
\hline $19 \%$ & $\begin{array}{l}\text { Low-educated rural mothers } \\
\text { without work experience }\end{array}$ & High & Low & Medium \\
\hline $15 \%$ & Inactive middle-aged wives & High & Medium & Medium \\
\hline $7 \%$ & $\begin{array}{l}\text { Long-term unemployed } \\
\text { educated single youth }\end{array}$ & High & High & High \\
\hline $5 \%$ & $\begin{array}{l}\text { Working-age long-term } \\
\text { unemployed }\end{array}$ & High & Medium & High \\
\hline $3 \%$ & Working-age newly unemployed & Medium & High & Medium \\
\hline $3 \%$ & Low-educated and rural disabled & Medium & Low & Low \\
\hline
\end{tabular}

Source: World Bank staff analysis and assessment 2014

From this overview, a set of five priority groups arises: low-educated rural mothers without work experience, inactive middle-aged wives, long-term unemployed educated single youth, working-age long-term unemployed and working-age newly unemployed are classified as high or medium priorities for activation. Their high priorities for activation stem mainly from high activation needs, as expressed by strong exposure to poverty. At the same time, they show (potential) labor market proximity by having acquired an education, not having declared and inability to work or a particular disability, and by falling into the prime-age bracket (compared to the large groups of retirees and the small group of disabled). Retirees, early retirees and low-educated and rural disabled are not prioritized for activation measures or policies due to their lower activation need (having reached official retirement age) and potential (many report strong limitations on capacity to work).

When reviewing the receipt of disability benefits among the identified groups, a problematic constellation can be identified for the early retirees. While only 1 percent of the group declares disability as their labor market status and 28 percent of the group report "strong limitations in physical ability," 49 percent of the group's members receive disability benefits. A review of the disability/retirement status of this group could be an additional discussion item when translating the findings from this analysis into possible policy action. While it might be difficult to activate some of the members of this group out of their disabled and prime working-age status ( 92 percent are between 35 and 59 years), special attention should be paid to not increasing the number of younger disability recipients beyond the absolute minimum necessary, and to tightly controlling inflow into this group.

Activation type. As a second step, the relative severity of labor market or social obstacles to be overcome for labor market integration will serve as an orientation for activation approaches. 


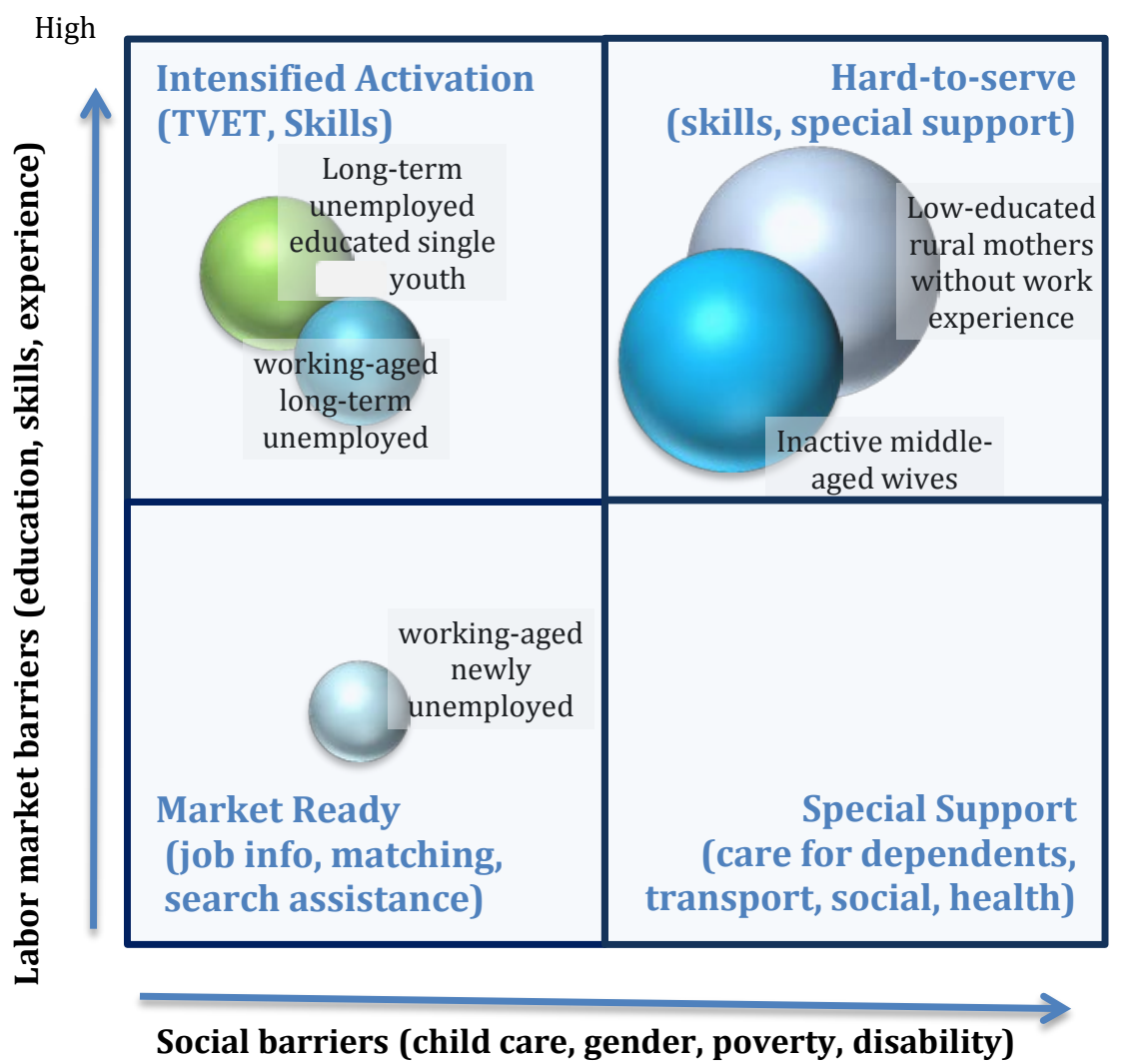

Source: World Bank staff analysis and assessments 2014

When mapping the respective barriers for labor market integration faced by the five prioritized groups, we can see that most of them are quite removed from the labor market by virtue of their long inactivity, generally low qualifications or lack of work experience. The two female groups face higher social barriers as to the availability of child care. Among the other three groups (which are more male-dominated), the working-age newly unemployed can (for now) be regarded as a more "market-ready" group. The two long-term unemployed groups mainly face labor market and mobility barriers.

Household income composition. When analyzing the 2011 household income of the prioritized groups, we can see that only a few groups show a benefit-share of household income that could be an indication of excessive reliance on benefits: As already indicated, 49 percent of early retirees report receiving disability benefits while only 1 percent classify themselves as disabled and only 28 percent report severe physical limitations on work capacity. Other groups (working-age long-term unemployed or low-educated and rural disabled) also have high benefit shares, but this can be seen as a correct function of the social safety net because of legitimate limitations on self-supporting work. However, the fact that the unemployed groups (long-term unemployed educated single youth, working-age long-term unemployed and working-age newly unemployed) only receive an unemployment benefit in 8 , 
21 and 16 percent of cases, respectively, could be interpreted as a sign of a safety net or insurance dysfunction.

Given the overall picture of benefit receipt revealed by EU-SILC data, the greatest need for action emerges around a potential review of disability benefit allocation among early retirees and on the adequacy of the unemployment benefit (especially for the "market ready" newly unemployed groups. 
This section sets out a set of potential activation measures for each of the priority groups. Areas for further policy dialogue are also outlined. The suggestions below should be considered as a starting point for further policy dialogue between EC DG EMPL, the World Bank and the Romanian authorities, bearing in mind that the groups identified still carry some heterogeneity that may affect the level and type of support required. Accordingly, these suggestions are also not meant to be an exhaustive set of possible activation measures.

It is important to keep in mind that the groups have been derived from the 2011 EU-SILC. Since that time, general economic development, policy actions by the government of Romania and European Commission country specific recommendations" might have already reflected some of these policy suggestions or rendered them obsolete.

Low-educated rural mothers without work experience (19 percent, Priority: High). Owing to the relatively young age of this group, it received an A priority. This is the largest among the prioritized groups in Romania (776,000 members). It is almost exclusively female (99 percent) and 77 percent rural. No member of this prime-aged group declared as unemployed. Overall, there is little work experience in this group (78 percent of its members have never worked). Eighty-six percent of the group has a primary or secondary education.

$\checkmark$ Offer short 'second chance' schooling with a focus on professional skills. Given the fact that the secondary schooling of this group's members did not translate into an immediate job start (most probably owing to family formation and child care responsibilities), and 75 percent of the group are between 16 and 34 years old, labor market activation could be based on linkage to simple, short, vocationally oriented school degrees. Ideally, these courses would be offered for about six months in local or regional schools or vocational schools. Child care offerings would need to be provided in parallel to the courses. For older women, potential "second chance" training, schooling or entrepreneurship offerings for this group will need to build on the "life experience" and skills already acquired by them.

$\checkmark$ Improve child care offerings (partly through self-organization). Improved availability of child care and school after-care offerings would enable many of the women in this group to better participate in the labor market and to take part in professional training or entrepreneurship offerings. Some of the child care could be delivered via supported cooperatives from within the same group of women.

$\checkmark$ Provide short-term work placement combined with training offerings. In proximity to urban or regional centers, potential beneficiaries from this group could be linked in short-term work placement programs.

Inactive middle-aged wives (15 percent, Priority: Medium). In terms of its makeup, this group is similar to the previous group, the low-educated rural mothers without work experience. The inactive middle-aged wives are also rural, are a bit older, have slightly more work experience and a slightly higher share of secondary education (54 percent). Their rate of marriage is also higher (85 percent) and they have slightly smaller households (4.0 members instead of 4.7). Households with children represent 64 percent of the cases, but the share of children below six years of age is only half of the previous group ( $20 \mathrm{vs.} 43$ percent). 
Owing to the great distance from the labor market of this group, any activation measure will have to start with very basic professional skills and will need to include self-organization and community approaches toward this group of women.

$\checkmark$ 'Second chance' programs with focus on professional skills. For this group of middle-aged women, potential "second chance" training, schooling or entrepreneurship offerings will need to build on the "life experience" and skills already acquired instead of focusing on remedial school education.

$\checkmark$ Community-based social work and entrepreneurship education. Given the structure of the local economy, self-employment, cooperative structures and entrepreneurship approaches need to be an important part of any labor market integration approach. Potential beneficiaries from this group could be assisted in forming cooperatives for local (social) services with support for professionalization.

$\checkmark$ Social community self-organization and entrepreneurship. Potential employment opportunities for women from this group can also be generated through new and regionally-based forms of community self-organization and entrepreneurship. Groups of women could be assisted to form and operate cooperatives for local services (domestic, child care, elderly care, and so on).

$\checkmark$ Short-term work placement combined with training offerings. In proximity to urban or regional centers, potential beneficiaries from this group could be linked to short-term work placement programs.

Long-term unemployed educated single youth (7 percent, Priority: High). This group is mainly made up of men ( 66 percent) under the age of 35 who have very little work experience (almost 90 percent have never worked). Despite a decent level of education (24 percent of the group has a tertiary degree), this group appears to have never taken root in the labor market in the first place. The rural/urban split is only about 50/50 but at least the urban portion of this group could be helped to better link to available employment in large cities and regional centers. Despite mostly living with their parents, this group represents the highest share of the lowest income quintile (48 percent). Potential activation measures for this group include, but should not be limited to, the following:

$\checkmark$ (Renewed) work placement in the field of study or specialization. Building on any initial experience or exposure to a specific professional (in technical education) or academic field, the members of this group could be linked to the labor market again via subsidized work placement with companies for a limited amount of time.

$\checkmark$ Entrepreneurship support. Given the fact that some of this group's members have relatively good formal and academic skills, the potential for self-employment and small firm creation should be supported.

$\checkmark$ Community activism support for inactive youth. To prevent 'scarring' and further distancing from the labor market or any other form of activity, some members of this group could benefit from community-based and publicly supported volunteering or community types of work.

Working-age long-term unemployed (5 percent, Priority: High). This group is between 25 and 59 years old and 72 percent male. Again, the rural/urban split is exactly 50/50, potentially supporting integration and attachment to employment for those in urban or regional centers. Educational attainment is mainly upper secondary (61 percent), with some 11 percent having tertiary education. The members of this group have an average of 15 
years of work experience prior to their current unemployment. Potential activation measures for this group include, but should not be limited to, the following:

$\checkmark \quad$ Build on work experience for training and work placement. Taking into account the years of work experience and potential industry or trade knowledge of the members of this group, training measures combined with temporary work placement in companies, nonprofits or social enterprises could help to strengthen labor market attachment.

$\checkmark$ Support self-organization, entrepreneurship and cooperatives. As with some of the other groups, self-employment and entrepreneurship support can help some this group's members to attain self-sufficient lives and improve their welfare.

$\checkmark$ Strengthen social and functional skills. Building on any initial experience or exposure to a specific professional (in technical education) or academic field, the members of this group could be linked to the labor market via subsidized work placement with companies for a limited amount of time. In these placements, and the accompanying training, special emphasis should be placed on social and functional skills, foreign language, ICT skills, and so on.

Working-age newly unemployed (3 percent, Priority: Medium). This small group registers the highest proportion of formally unemployed (75 percent), testimony to the recent beginning of their unemployment spell and a potential indicator of immediate interest in work. Men form the majority (68 percent) but women make up a good third of the group. The group is majority rural and has mainly achieved a secondary education. With 15 years of work experience and recent attachment to formal employment, this group will mainly need to be supported with mainstream job-search and self-mobilization assistance. Potential activation measures for this group include, but should not be limited to, the following:

$\checkmark \quad$ Job placement support via PES or private employment agencies. Given the fact that this group of job seekers is still quite close to the labor market because of the recent beginning of unemployment, initial support could be focused on skill certification, application support and job matching intermediation.

In general, further policy dialogue with the Romanian authorities ought to focus on the general level and setup of resources devoted to labor market integration and activation of the inactive and out-of-work. Within this discussion, a deeper conversation could be had around specific measures for specific groups. The following three items appear especially important:

$\checkmark \quad$ Integration with employment demand generation. While active labor market policies, activation and job-matching support can help to smooth friction in the labor market, they will not lead to stable and sustainable employment. Demand for jobs comes from the economic activity of firms and from the social sector. Integration with regional economic development policy is especially important.

$\checkmark$ Bring "active" programs to scale. Reviewing the distribution between active and passive labor market spending as well as the overall spending level on productive inclusion will be a necessary prerequisite for any of the measures described in this note. 
$\checkmark$ Calibrate focus from "unemployment" to "inactivity." While the headline unemployed stood at about 5 to 6 percent in Romania over the last few years, the identified inactive groups in this analysis represented over 30 percent of the working age population.

In summary, Romania could benefit from improving its knowledge of the composition and socio-economic situations of different groups of out-of-work citizens, especially with a unified view across traditional labor market categories (employed/unemployed) and social inclusion dimensions (poverty, living conditions, access to services), because the two are intrinsically linked, especially for the labor market's most marginalized participants. 


\section{References}

Collins, L. M., and S. T. Lanza, 2010, Latent Class and Latent Transition Analysis: With Applications in the Social, Behavioral, and Health Sciences. Hoboken, NJ: Wiley.

Eurofound, 2012, NEETs-Young people not in employment, education or training: Characteristics, costs and policy responses in Europe, Publications Office of the European Union, Luxembourg.

(EC), European Commission, European Community Programme for Employment and Social Solidarity, 2013, "Assessment of the implementation of the European Commission Recommendation on active inclusion: A study of national policies," January 2013.

(EC) European Commission, 2013a, EU measures to tackle youth unemployment. MEMO, Brussels, 28 May 2013.

Eurostat, 2011, ESSPROS Manual: The European System of Integrated Social Protection Statistics. European Union, Luxembourg.

Katz, L., 2010, "Long-Term Unemployment in the Great Recession," Testimony for the Joint Economic Committee, U.S. Congress Hearing on "Long-Term Unemployment: Causes, Consequences and Solutions," April 29, 2010

Kaufman, L. and Rousseeuw, P. J., 1990, Finding groups in data. New York, Wiley.

Magidson, Jay and Vermunt, Jeroen, 2002, Latent Class Modeling as a Probabilistic Extension of K-Means Clustering Quirk's Marketing Research Review, March, 20, 77-80. Available at: http://statisticalinnovations.com/technicalsupport/kmeans2a.htm

UNDP and EU FRA (Fundamental Rights Agency), 2012: The situation of Roma in 11 EU Member States. Survey results of the UNDP, World Bank and EC Regional Roma Survey at a glance. Vienna

Vermunt, J. K. and J. Magidson, 2005, Latent GOLD 4.0 User's Guide. Belmont, Massachusetts: Statistical Innovations Inc.

World Bank, 2010: Roma Inclusion. An Economic Opportunity for Bulgaria, Czech Republic, Romania and Serbia. Policy Note. Europe and Central Asia Region. Human Development Sector Unit. Washington, DC.

World Bank, 2013: Gender at a Glance. Romania. Europe and Central Asia Region. Poverty Reduction and Economic Management Sector Unit. Washington, DC.

World Bank, 2014: Diagnostics and Policy Advice for Supporting Roma Inclusion in Romania. Europe and Central Asia Region, Human Development and Sustainable Development Sector Units. Washington, DC 


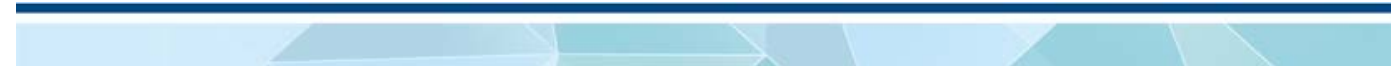

282 | Portraits of Labor Market Exclusion 


\section{Proceedings of Workshop in Brussels}

A results workshop on the Portraits of Labor Market Exclusion (PoLME) study was held in Brussels, Belgium, on May 26, 2014. The workshop's title was "From comprehensive profiles to tailored activation policies" and was jointly organized by the World Bank and the European Commission, in order to present potential themes for discussion derived from the study and receive inputs from national delegations and policy experts.

The list of participants included government counterparts from the participant countries of Bulgaria, Estonia, Greece, Hungary, Lithuania and Romania; policy experts and desk officers from DG Employment, Social Affairs and Inclusion; participants from other EC DG's and experts from the OECD, the Institute for the Study of Labor (IZA), and the Hungarian Academy of Sciences.

In their opening remarks to the Workshop, Dr. Lieve Fransen (Director for Social Policy and Europe 2020 at the European Commission's DG Employment, Social Affairs and Inclusion) and Mamta Murthi (Country Director for Central Europe and the Baltic Countries at the World Bank) provided a setting for the day's discussion. In their remarks, they outlined the cooperative approach between the Member States, the Commission and the World Bank in achieving the results of the "Portraits" analysis. Dr. Fransen highlighted that the workshop, participants would have the dual possibility to understand and challenge the applied methodology but also to exchange insights on approaches in social and labor market policy and national programming of European funds. Ms. Murthi framed the workshop's policy relevance by underlining the demographic challenges for most European countries and the importance of integrated, competiveness, labor demand and labor supply policies.

Following the introduction, the World Bank PoLME Project Team presented two sessions during the workshop. During the morning session, Ramya Sundaram discussed the methodology as well as some of the results and limitations of the study. In the afternoon session, Ulrich Hoerning presented the main findings of the cluster analysis and some policy ideas for activation, based on the clusters' needs, potentials and priorities for activation.

Speakers from the national delegations also contributed presentations. They partly confirmed initial assessments from the joint country missions of the European Commission and World Bank, validating country-specific findings and methodology, while identifying greater needs for dialogue and analysis about potential policy responses and activation approaches for different profiles. The main points from each country presentation and the general plenary discussions are summarized as follows.

\section{Greece}

The Greek representative presented the country's national strategies to tackle youth unemployment. The focus of the presentation was on the group of highly educated youth that is not in employment, education or training (NEETs).

Portraits of Labor Market Exclusion | 283 
As shown in Figure 9.1, there are different programs to support youth employment, lifelong learning and entrepreneurship in Greece. It was shown that the majority of the beneficiaries of the National Action Plan (NAP) receive guidance or job orientation, and another considerable share benefit from support in the transition from education to work and from vocational education to training.

For the period of 2014 to 2020, NAP target groups will include young people not in employment, education or training; unemployed 30- to 64-year olds; long-term unemployed; unemployed individuals with low educational qualifications; jobless households; working mothers facing the risk of unemployment; and other vulnerable groups.

Figure 9.1 Greece: Highly educated youth not in employment, education or training

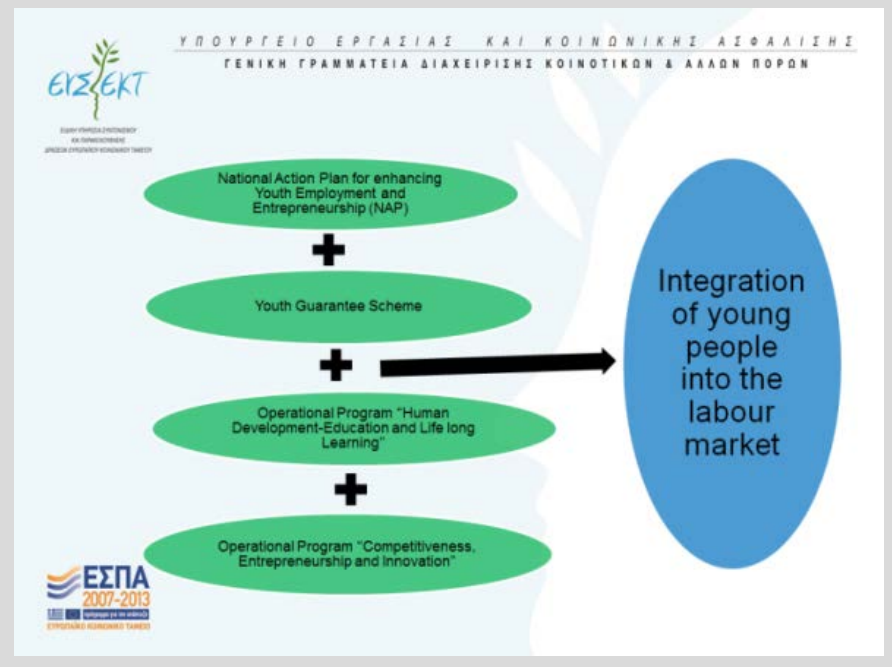

Source: Presentation of Greece at 'Portraits of Labor Market Exclusion' workshop in Brussels, May 26 2014

\section{Lithuania}

Officials from the Government of Lithuania presented the country's experience with measures for reducing youth unemployment. As shown in Figure 9.2, factors related to youth unemployment are lack of work experience, lack of motivation, and displacement, while some factors accounting for its reduction are skills matching, job creation and increase in employability.

In Lithuania, youth unemployment has been decreasing, with youth participation in ALMPs almost doubling in size, from 16.2 percent in 2011 to 31.3 percent in 2013. In 2012, integrated solutions were implemented to reduce youth unemployment, such as vocational guidance (career planning) services, labor market services and labor market monitoring, analysis and evaluation. These initiatives involved different ministries: the Ministry of Education and Science, the Ministry of Social Security and Labor, and the Ministry of 
Economy. The success of these measures is reflected in the decreasing youth unemployment rate, from 35.7 percent in 2010 to 21.9 percent in 2013, according to the country presentation.

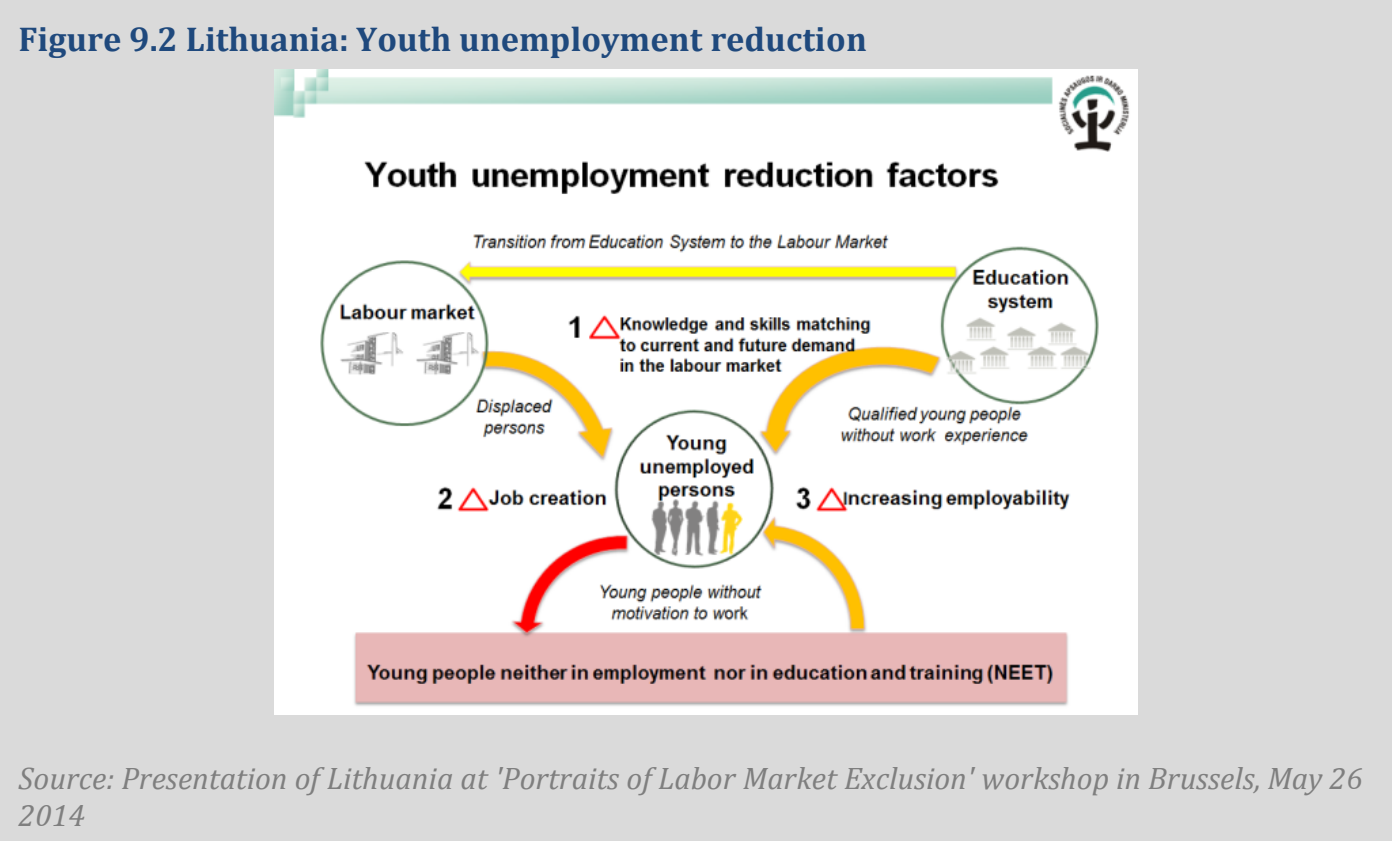

\section{Estonia}

The Estonian representative discussed a reform in Estonia's incapacity for work scheme. Because individuals with some level of incapacity are willing to work and employers are ready to hire them, there was a discussion on how to provide a more individually oriented approach and adapt the work environment for such people. Another change Estonia has made is in the evaluation mechanism for applicants, which now focuses on a person's work ability and not their incapacity for work.

The graph shown in Figure 9.3 depicts the number of persons with permanent incapacity and those in employment, disaggregated by the level of permanent incapacity. It was shown that disabled people will get improved attention, with one managing authority-the Unemployment Insurance Fund-being responsible for the evaluation of work capacity, benefit payments, and the delivery of labor market services, rehabilitation and technical aid. 
Figure 9. 3 Estonia: Reforming incapacity for work scheme

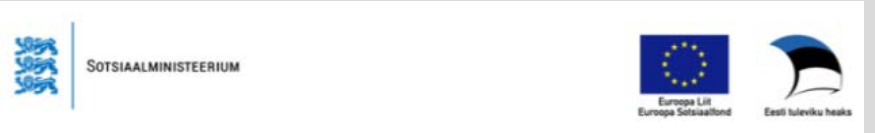

\section{Persons with permanent incapacity for work and their employment (April 2012)}

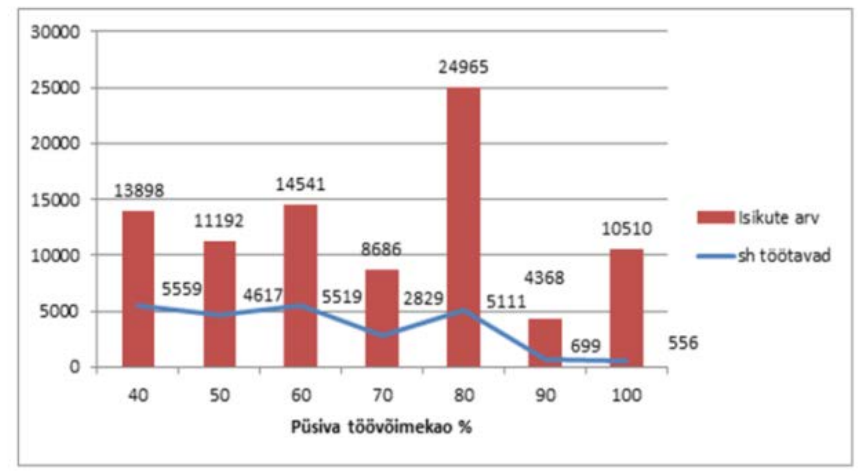

Source: Presentation of Estonia at 'Portraits of Labor Market Exclusion' workshop in Brussels, May 26 2014

\section{Romania}

The Romanian delegation presented some details of the country's social assistance system reform. Two main points are highlighted in Figure 9.4: the Modernization Project and a new benefit called "Minimum Insertion Income."

The idea behind the modernization of the social assistance system is to strengthen performance management, improve equity, improve administrative efficiency, and reduce error and fraud. The new system, which will combine three benefits into only one, is expected to start by January 2016.

Representatives of Romania also highlighted some activation incentives that have been attached to existing benefits: requirements related to school attendance, which is now compulsory for children in households receiving a family allowance (FA); an increase in the guaranteed minimum income (GMI) by 15 percent if one member of the household is in the labor market; and fiscal incentives for employers hiring elderly persons. 
Figure 9.4 Romania: The reform of the Romanian Social Assistance System

\section{Social Assistance System Modernization Project (SASMP)}

Focus on the main governmental programmes for lowincome households, persons with disabilities and families with children;

- Developed through a loan agreement between the Government of Romania and the International Bank for Reconstruction and Development (IBRD or World Bank);

- Implementation timeframe: April 2012 - August 2016;

- $\quad$ Project value: 500 million Euros - equally shared between 20 disbursement linked indicators (DLIs) of 25 million Euro each;

- DLIs: reflect the tangible measures that have to be implemented

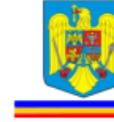

\section{New Benefit}

The minimum insertion income (MII) :

- Three benefits consolidated into one - guaranteed minimum income (GMI), family allowance (FA) and heating benefits (HB);

- Current number of beneficiaries:

- GMI - 225,000 families;

- FA - 260,000 families:

- HB - 1,000,000 families.

- MII aims at targeting the poorest $30 \%$ of population;

- Following the legislative process, the new benefit will come into effect January 2016.

\section{Hungary}

The Hungarian representatives discussed the trends in their labor market indicators and highlighted gaps between their performance and the performance of the EU-28 countries (Figure 9.5).

Despite lagging labor market performance, they pointed out that active labor market programs have been in the forefront since 2007. They presented the Social Renewal Operative Program 1.1.2., whose objective is to improve the employability of a number of disadvantaged groups with personalized, tailor-made, complex labor market programs: the low-skilled, young and career-starters, those over 50 years of age, those returning from child care, and those receiving social benefits. 
Some of the main program elements are: wage subsidies, mobility support, training support, training cost subsidies, child care during training, and services such as counselling, orientation, information provision, mentoring, and entrepreneurship support. County labor offices have developed own local program plans, matching the target groups' needs and reflecting local opportunities. Labor offices have developed individual, tailor-made programme plans together with the participants, reflecting personal potentials and challenges. The program has a decentralised financial allocation mechanism, reflecting local labour markets employment situation.

For the second phase of the program, the expected result is the inclusion of a minimum of 110,000 participants, with a minimum of 16,500 Roma people; 32 percent of the participants will be young people. In 2014 July, already 132,659 participants have been included, from which 19,561 have been Roma.

\section{Figure 9.5 Hungary: Active Labor Market Programs--Good Practices to Prevent Labor Market Exclusion}

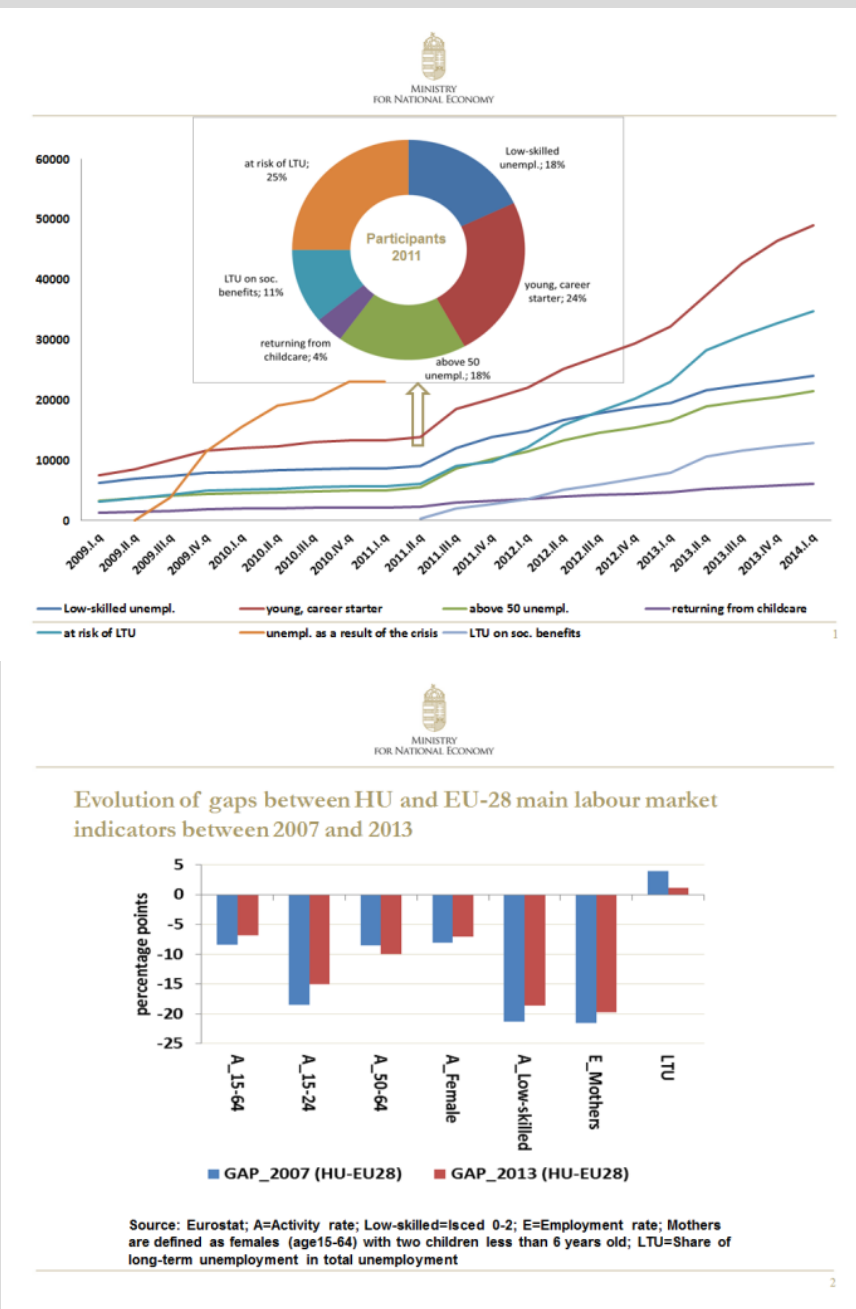

Source: Presentation of Hungary at 'Portraits of Labor Market Exclusion' workshop in Brussels, May 26 2014 


\section{Bulgaria}

The Government of Bulgaria presented some measures that have been taken to increase activity rates. They showed trends in their inactive population, which represented a major challenge in the context of the economic crisis. In Bulgaria, the inactivity level was among the highest in the European Union in 2010.

Policies have focused on training. There are two main programs: the national program "Active Inactive Persons" (some details shown in Figure 9.6) and the grant scheme "Take Your Life in Your Own Hands," which focuses on increasing the activity and integration of vulnerable, inactive and discouraged people into the labor market.

\section{Figure 9. 6 Bulgaria: Measures for Integration of Inactive and Discouraged People}

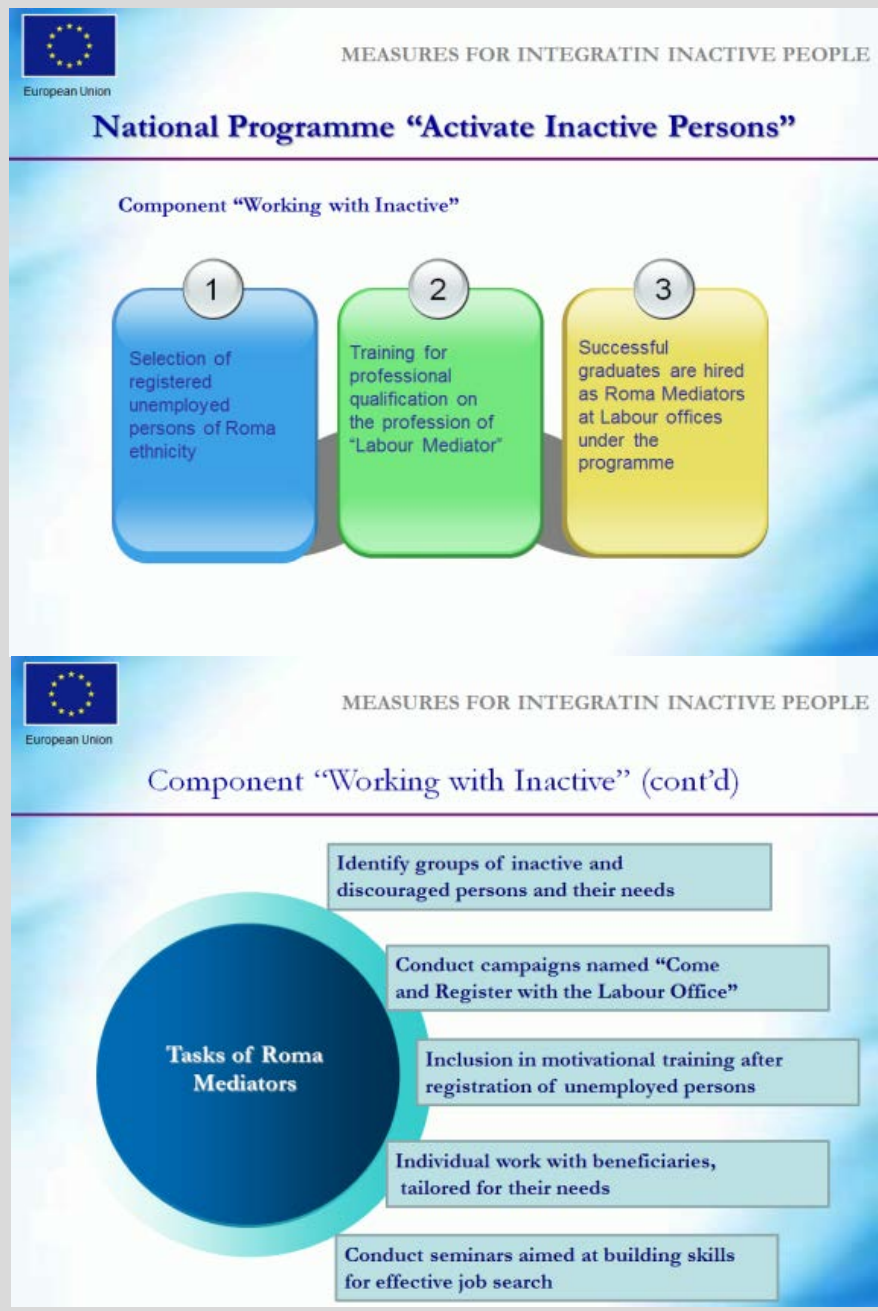

Source: Presentation of Bulgaria at 'Portraits of Labor Market Exclusion' workshop in Brussels, May 26 2014 


\section{Salient points from the plenary discussions:}

Methodological questions focused on the urban/rural divide described in many country reports of the Portraits. Here participants were interested in the EU-SILC base data's ability to adequately measure the welfare of subsistence farming rural households. Other comments focused on the prevalence of "passive" benefits in many countries, benefits that do not carry an incentive for work uptake. Disincentives for (formal) work were further reported to be aggravated in many countries by the wide use of informal work arrangements. Another element of interest raised during the discussion was the phenomenon of the "in-work-poor" (which is a challenge for many Member States but was not captured by the current Portraits analysis because of a focus on the inactive and unemployed). All of the Member States presentations elicited a series of questions and comments from the participants. Discussions arose around the policy approaches to worker incapacity insurance. Strategies of identifying and reclassifying working incapacity benefit recipients were discussed. Also, the role of employers in labor market integration of hard-toplace groups was regular point of interest. On the level of potential interventions, Member State experts underlined the need to link any labor supply side support with general economic development promotion policies and to focus entrepreneurship support to individual recipients who would show a chance to succeed in a competitive market. Also it was underlined the need to enhance the positive interaction between various policies for successful labor market growth.

\section{External Experts' Points of View:}

After the country presentations, academic experts commented on the findings, the methodology, limitations and potential areas for further improvement. The first to speak was Prof. Werner Eichhorst, Director of Labor Policy Europe, IZA, followed by Dr. Zsombor Cseres-Gergely, from the Hungarian Academy of Sciences, Center for Regional and Economic Studies, Institute of Economics. Among the salient points of comment were the following:

$\checkmark \quad$ Recognized the attractiveness of a holistic approach around social protection and labor policies;

$\checkmark$ Underlined that heterogeneity still remains within the clusters, so deriving LCA profiles for policy planning does not substitute for individualized service provision to the citizen (in balance with fiscal affordability and administrative capacity);

$\checkmark$ Stressed the importance of whole-economy/labor-demand side reforms to provide the economic dynamic to absorb the unemployed and inactive;

$\checkmark$ Recommended application of a more extensive analytical approach to deriving policy recommendations from the descriptions of the profiling, underlining the need to address all levels of policy action: (i) whole- economy reforms, (ii) program-level ALMP type interventions, and (iii) benefits and services to individual citizens. 
More specifically, Prof. Eichhorst commented that while the excluded out-of-work population has expected characteristics such as low skills, lack of work experience, health problems, age and gender, rural background and so on, there are some new and interesting findings from the clusters, such as the urban/rural divide, the highly skilled unemployed in Greece, the new population of prime-aged unemployed in Lithuania, the increase in the number disabled and early retirees. Yet, the high heterogeneity within clusters indicates that individual needs within each group may be quite different. Hence, he cautioned that there is a risk of neglecting relevant target groups or subgroups when using LCA-type clustering to identify activation potentials and priorities. In a social investment context, no individual should be left behind, he said. Therefore activation policies should consider all policy action levels, from overall structural policies, to medium-level ALMPs type interventions and tailormade policies derived from individual assessments.

Prof. Eichhorst also emphasized that the analysis is based on data from 2011, and that more recent or ongoing changes may be relevant to setting policy. He concluded that structural issues seem to be more relevant than cyclical ones and that more attention should be paid to these general, structural policies and the policy recommendations derived from them. Many of the policy suggestions derived from the Portraits profiles are focused only on the program level, but structural policies have the potential to affect all the groups. Among the structural policies he mentioned that should receive more emphasis: the importance of stimulating labor demand and its flexibility; removing disincentives to work, particularly for second earners and benefit recipients; and measures that tackle early retirement and urban mobility, among others.

Dr. Zsombor Cseres-Gergely pointed out that LCA is more comprehensive than "ordinary" analysis. Nevertheless, it is a very complex method, intuitive only at a very basic level, and carries with it values and theory implicit in the choices of indicators, active and passive variables and number of groups. Despite its limitations and complexity, Dr. Cseres-Gergely recognized that the analysis is a pragmatic way of looking at individuals through the lenses of both poverty/welfare status and labor market indicators. He concluded that there is an important connection between these fields. He also remarked that the analysis could be repeated locally, and might be initiated by building capacity for regular, high quality, indepth analysis.

In closing remarks, Andrew Mason (Manager for Social Protection in Europe \& Central Asia at the World Bank) and Dr. Lieve Fransen (Director at the European Commission's Directorate General for Employment, Social Affairs and Inclusion) highlighted several points that emerged from the discussion. Speaking on broader terms of the World Bank's analytical and policy dialogue work in countries in and beyond the European Union, Mr. Mason strongly appreciated the feedback received from the Member State delegations and academic experts. Fitting into the Bank's work on efficient and equitable social safety nets across the region, a further development of the Portraits approach would need to reflect an improved analysis of individual life and benefit situations as well as a broader range of possible policy recommendations.

Portraits of Labor Market Exclusion | 291 
In her final remarks, Dr. Fransen mentioned the general quality of the analytical tool and its embedding into the dialogue between the Member States and EC, as well as the quality of the discussion with Member States throughout the project, was appreciated. While there is still the need to derive a more differentiated set of policy responses and not settle for simplistic policy prescriptions for certain demographics, she remarked on the usefulness of the Portraits methodology. Portraits-type analysis is a tool that could be used in the future for "social investment" choices in Member States, and also has the potential to be used in performance monitoring for ESF activities between the European Commission and Member States, she said. 


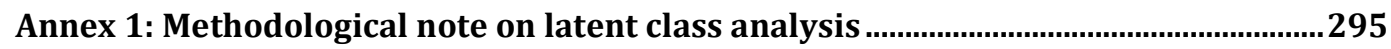

Annex 2: Latent Class Analysis Profiles Cross-Sectional Model .........................................297

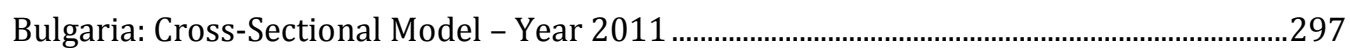

Bulgaria: Cross-Sectional Model - Year 2010 …………………………………………...............303

Bulgaria: Cross-Sectional Model - Year 2009 …………………………………………................308

Bulgaria: Cross-Sectional Model - Year 2008 …………………………………….......................313

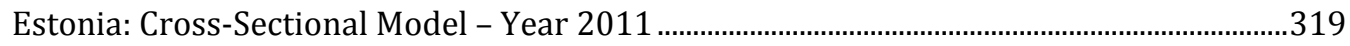

Estonia: Cross-Sectional Model - Year 2009 .................................................................................326

Estonia: Cross-Sectional Model - Year 2007 ………………………………………………….....333

Greece: Cross-Sectional Model - Year 2011 ……………...........................................................341

Greece: Cross-Sectional Model - Year 2009 …………….................................................................347

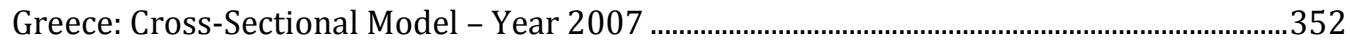

Hungary: Cross-Sectional Model - Year 2011………………………………………………......357

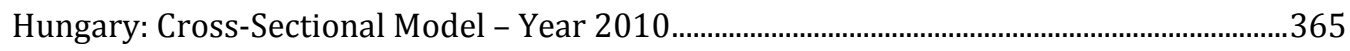

Hungary: Cross-Sectional Model - Year 2009...............................................................................372

Hungary: Cross-Sectional Model - Year 2008………………………………………………......379

Lithuania: Cross-Sectional Model - Year 2011 ………………………………………………....387

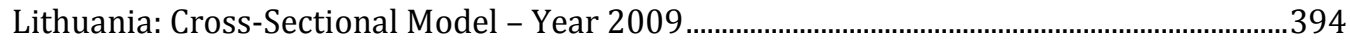

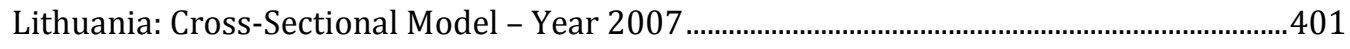

Romania: Cross-Sectional Model - Year 2011 ……………………………………………....409

Romania: Cross-Sectional Model - Year 2010 …………...............................................................416

Romania: Cross-Sectional Model - Year 2009 …………..............................................................423

Romania: Cross-Sectional Model - Year 2008 ………………………………..........................430

Annex 3: Latent Class Analysis Profiles Longitudinal Data ............................................437

Bulgaria: Longitudinal Model - Year 2010 ………………………….......................................437

Estonia: Longitudinal Model - Year 2010...................................................................................443

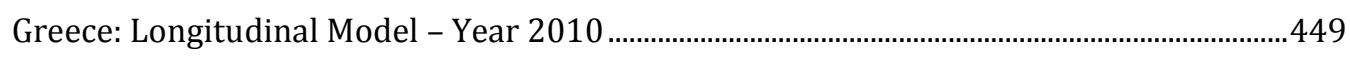

Hungary: Longitudinal Model - Year 2010 ……………...........................................................453

Lithuania: Longitudinal Model - Year 2010 …………….........................................................459

Romania: Longitudinal Model - Year 2010 ……………............................................................463 


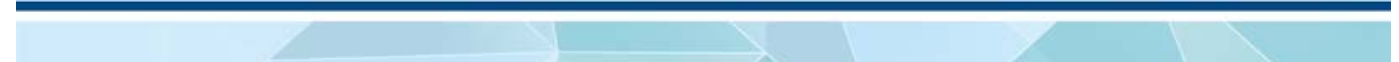

294 | Portraits of Labor Market Exclusion 


\section{Annex 1: Methodological note on latent class analysis}

Latent class analysis (LCA) enables a characterization of categorical latent (unobserved) variables from an analysis of the structure of the relationships among several categorical observed variables. LCA is thus "the classification of similar objects into groups, where the number of groups, as well as their forms is unknown" (Kaufman and Rousseeuw, 1990). The method was originally conceived of as an analytic method for survey data. As an exploratory technique, LCA can be used to reduce a set of categorically scored variables into a single latent variable with a set of underlying types or "classes". As a confirmatory method, the latent class model can be used to test hypotheses regarding the researchers' a priori assertions about the structure of the relationship among the observed variables. In this note, LCA was used as an exploratory technique to create the optimal number of groups of out-ofwork market individuals with the most similar characteristics.

The LCA model can be seen as a probabilistic or model-based variant of traditional nonhierarchical cluster analysis procedures such as the K-means method. Contrary to traditional ad-hoc clustering approaches, the LCA approach to clustering is model-based. The fundamental assumption underlying LCA is that of local independence, which states that observations (out-of-work individuals in our case) in the same latent class share a common joint probability distribution among the observed variables. Since persons in the same latent class (cluster) cannot be distinguished from each other based on their observed responses, they are similar to each other (homogeneous) with respect to these observed variables. Individuals are hence classified into the class for which they have the highest posterior probability of belonging, given their observed characteristics.

LCA is thus most similar to the K-Means approach to cluster analysis in which cases that are "close" to one of K centers are grouped together. In fact, LCA can be viewed as a probabilistic variant of K-Means clustering where probabilities are used to define "closeness" to each center. As such, LCA provides a way not only to formalize the K-Means approach in terms of a statistical model, but also to extend the K-Means approach in several directions: flexible distance to the center of the cluster, determination of the optimal number of clusters, inclusion of categorical and continuous variables, and inclusion of exogenous variables. First, while K-Means uses an ad-hoc distance measure for classification, the LCA approach allows cases to be classified into clusters using model based posterior membership probabilities estimated by maximum likelihood (ML) methods. Second, LCA provides various diagnostics such as the Bayesian Information Criterion (BIC) statistic, which helps determine the optimal number of clusters. Third, while K-Means clustering is limited to interval scale quantitative variables for which Euclidean distance measures can be calculated, LCA can be performed on variables of mixed metrics (continuous, categorical (nominal or ordinal), or counts or any combination of these). Fourth, the LCA model can be easily extended to include exogenous variables (covariates).

Portraits of Labor Market Exclusion | 295 
The LCA model with covariates can be written as:

$$
f\left(y_{i} / z_{i}\right)=\sum_{k} p\left(x=k / z_{i}\right) f\left(y_{i} / x=k\right)
$$

Where $y_{i}$ is a vector of dependent (endogenous) indicators for individual $i, z_{i}$ is a vector of independent (exogenous) covariates for individual $i, x$ is a nominal latent variable (and $k$ denotes a class, $k=1,2, \ldots, K)$, and $f\left(y_{i} / x=k\right)$ denotes the joint distribution specified for $y_{i}$ given latent class $x=k$.

For continuous $\mathrm{y}_{\mathrm{i}}$, the multivariate normal distribution is used with class-specific means. In addition, the within-class covariance matrices can be assumed to be equal or unequal across classes, and the local independence assumption can be relaxed by applying various structures to the within-class covariance matrices. For variables of other/mixed scale types, local independence among the variables imposes restrictions on second-order as well as to higher-order moments.

For this note, out-of-work individuals constitute the population of interest. The population was then restricted to working-age population (individuals aged 16 to 64). As mentioned earlier, age categories, gender, education, economic status, chronic illness and spouse working status represent the observed covariates and were used to predict the inactivity status. In addition to these indicator and active covariates, exogenous variables were included in the model, such as income quintile of household, household composition, urban/rural breakdown, region, economic activity of the spouse, work intensity of households and social protection transfers.

For each year, the LCA model was run with one to ten classes, leading to ten different estimations. To determine the optimal number of clusters into which the population of interest should be divided, we used two criteria that maximize the cohesion within clusters and the distance between clusters: the Akaike and Bayesian Information Criterion (AIC and BIC).

Source: Madigson and Jeroen (2002). 


\section{Annex 2: Latent Class Analysis Profiles Cross-Sectional Model}

Bulgaria: Cross-Sectional Model - Year 2011

\begin{tabular}{|c|c|c|c|c|c|c|c|c|}
\hline & $\begin{array}{l}\text { All Out- } \\
\text { of-Work }\end{array}$ & $\begin{array}{l}\text { 1. Middle- } \\
\text { aged } \\
\text { unemployed }\end{array}$ & $\begin{array}{c}2 . \\
\text { Retired } \\
\text { women }\end{array}$ & $\begin{array}{l}\text { 3. Stay- } \\
\text { at-home } \\
\text { young } \\
\text { mothers }\end{array}$ & $\begin{array}{c}4 . \\
\text { Single } \\
\text { male } \\
\text { NEETs }\end{array}$ & $\begin{array}{c}5 . \\
\text { Retired } \\
\text { and } \\
\text { early- } \\
\text { retired } \\
\text { men }\end{array}$ & $\begin{array}{l}\text { 6. Low- } \\
\text { educated } \\
\text { rural long- } \\
\text { term } \\
\text { unemployed }\end{array}$ & $\begin{array}{l}\text { 7. Low- } \\
\text { educated } \\
\text { early- } \\
\text { retired } \\
\text { and } \\
\text { disabled }\end{array}$ \\
\hline Cluster size & $100 \%$ & $23 \%$ & $20 \%$ & $15 \%$ & $15 \%$ & $13 \%$ & $12 \%$ & $3 \%$ \\
\hline Population & $1,564,723$ & 353,940 & 315,918 & 241,906 & 232,674 & 197,937 & 180,100 & 42,248 \\
\hline \multicolumn{9}{|c|}{ INDICATORS } \\
\hline \multicolumn{9}{|c|}{ Labor market attachment } \\
\hline Unemployed & $19 \%$ & $32 \%$ & $0 \%$ & $23 \%$ & $25 \%$ & $4 \%$ & $31 \%$ & $0 \%$ \\
\hline Long-term unemployed & $28 \%$ & $50 \%$ & $1 \%$ & $10 \%$ & $43 \%$ & $8 \%$ & $61 \%$ & $8 \%$ \\
\hline Retired & $34 \%$ & $11 \%$ & $97 \%$ & $0 \%$ & $1 \%$ & $86 \%$ & $0 \%$ & $50 \%$ \\
\hline Disabled & $2 \%$ & $2 \%$ & $0 \%$ & $0 \%$ & $0 \%$ & $2 \%$ & $0 \%$ & $40 \%$ \\
\hline Other inactive & $17 \%$ & $5 \%$ & $2 \%$ & $67 \%$ & $31 \%$ & $0 \%$ & $8 \%$ & $2 \%$ \\
\hline \multicolumn{9}{|l|}{ Working Partner } \\
\hline Yes & $28 \%$ & $52 \%$ & $8 \%$ & $57 \%$ & $0 \%$ & $44 \%$ & $1 \%$ & $5 \%$ \\
\hline No & $34 \%$ & $17 \%$ & $56 \%$ & $15 \%$ & $5 \%$ & $41 \%$ & $87 \%$ & $14 \%$ \\
\hline NA & $38 \%$ & $32 \%$ & $36 \%$ & $28 \%$ & $95 \%$ & $15 \%$ & $12 \%$ & $81 \%$ \\
\hline \multicolumn{9}{|c|}{ Self-assessed physical incapacity } \\
\hline Strongly limited & $94 \%$ & $1 \%$ & $8 \%$ & $1 \%$ & $1 \%$ & $14 \%$ & $2 \%$ & $77 \%$ \\
\hline None/limited & $6 \%$ & $99 \%$ & $93 \%$ & $99 \%$ & $99 \%$ & $86 \%$ & $98 \%$ & $23 \%$ \\
\hline \multicolumn{9}{|c|}{ ACTIVE COVARIATES } \\
\hline \multicolumn{9}{|l|}{ Age groups (4) } \\
\hline 16-24 years & $15 \%$ & $1 \%$ & $0 \%$ & $25 \%$ & $61 \%$ & $0 \%$ & $10 \%$ & $11 \%$ \\
\hline 25-34 years & $20 \%$ & $13 \%$ & $0 \%$ & $50 \%$ & $35 \%$ & $0 \%$ & $27 \%$ & $31 \%$ \\
\hline $35-59$ years & $41 \%$ & $85 \%$ & $14 \%$ & $24 \%$ & $4 \%$ & $53 \%$ & $56 \%$ & $58 \%$ \\
\hline
\end{tabular}




\begin{tabular}{|c|c|c|c|c|c|c|c|c|}
\hline & $\begin{array}{l}\text { All Out- } \\
\text { of-Work }\end{array}$ & $\begin{array}{l}\text { 1. Middle- } \\
\text { aged } \\
\text { unemployed }\end{array}$ & $\begin{array}{c}2 . \\
\text { Retired } \\
\text { women }\end{array}$ & $\begin{array}{l}\text { 3. Stay- } \\
\text { at-home } \\
\text { young } \\
\text { mothers }\end{array}$ & $\begin{array}{c}4 . \\
\text { Single } \\
\text { male } \\
\text { NEETs }\end{array}$ & $\begin{array}{c}5 . \\
\text { Retired } \\
\text { and } \\
\text { early- } \\
\text { retired } \\
\text { men }\end{array}$ & $\begin{array}{l}\text { 6. Low- } \\
\text { educated } \\
\text { rural long- } \\
\text { term } \\
\text { unemployed }\end{array}$ & $\begin{array}{l}\text { 7. Low- } \\
\text { educated } \\
\text { early- } \\
\text { retired } \\
\text { and } \\
\text { disabled }\end{array}$ \\
\hline 60-64 years & $24 \%$ & $2 \%$ & $86 \%$ & $1 \%$ & $0 \%$ & $47 \%$ & $6 \%$ & $0 \%$ \\
\hline \multicolumn{9}{|l|}{ Gender } \\
\hline Male & $45 \%$ & $51 \%$ & $17 \%$ & $1 \%$ & $73 \%$ & $88 \%$ & $53 \%$ & $60 \%$ \\
\hline Female & $55 \%$ & $49 \%$ & $83 \%$ & $99 \%$ & $27 \%$ & $12 \%$ & $47 \%$ & $40 \%$ \\
\hline \multicolumn{9}{|l|}{ Education } \\
\hline Primary & $39 \%$ & $25 \%$ & $33 \%$ & $48 \%$ & $31 \%$ & $34 \%$ & $82 \%$ & $40 \%$ \\
\hline Secondary & $48 \%$ & $67 \%$ & $54 \%$ & $38 \%$ & $48 \%$ & $49 \%$ & $11 \%$ & $37 \%$ \\
\hline Tertiary & $11 \%$ & $7 \%$ & $12 \%$ & $12 \%$ & $17 \%$ & $16 \%$ & $4 \%$ & $6 \%$ \\
\hline NA & $3 \%$ & $2 \%$ & $1 \%$ & $3 \%$ & $3 \%$ & $2 \%$ & $3 \%$ & $16 \%$ \\
\hline Urban & $44 \%$ & $36 \%$ & $48 \%$ & $53 \%$ & $45 \%$ & $53 \%$ & $30 \%$ & $47 \%$ \\
\hline Rural & $56 \%$ & $64 \%$ & $52 \%$ & $47 \%$ & $55 \%$ & $47 \%$ & $70 \%$ & $53 \%$ \\
\hline \multicolumn{9}{|c|}{ INACTIVE COVARIATES } \\
\hline \multicolumn{9}{|l|}{ Age groups (7) } \\
\hline $16-19$ years & $5 \%$ & $0 \%$ & $0 \%$ & $9 \%$ & $21 \%$ & $0 \%$ & $2 \%$ & $3 \%$ \\
\hline 20-24 years & $10 \%$ & $1 \%$ & $0 \%$ & $16 \%$ & $40 \%$ & $0 \%$ & $8 \%$ & $8 \%$ \\
\hline 25-34 years & $20 \%$ & $13 \%$ & $0 \%$ & $50 \%$ & $35 \%$ & $0 \%$ & $27 \%$ & $31 \%$ \\
\hline $35-44$ years & $13 \%$ & $34 \%$ & $1 \%$ & $11 \%$ & $2 \%$ & $6 \%$ & $19 \%$ & $20 \%$ \\
\hline 45-54 years & $15 \%$ & $32 \%$ & $3 \%$ & $8 \%$ & $1 \%$ & $21 \%$ & $23 \%$ & $16 \%$ \\
\hline 55-59 years & $13 \%$ & $19 \%$ & $9 \%$ & $5 \%$ & $1 \%$ & $26 \%$ & $15 \%$ & $23 \%$ \\
\hline $60-64$ years & $24 \%$ & $2 \%$ & $86 \%$ & $1 \%$ & $0 \%$ & $47 \%$ & $6 \%$ & $0 \%$ \\
\hline \multicolumn{9}{|l|}{ Education } \\
\hline None/less than primary & $3 \%$ & $1 \%$ & $1 \%$ & $7 \%$ & $3 \%$ & $1 \%$ & $5 \%$ & $3 \%$ \\
\hline Primary & $8 \%$ & $4 \%$ & $6 \%$ & $12 \%$ & $10 \%$ & $3 \%$ & $19 \%$ & $8 \%$ \\
\hline Lower secondary & $28 \%$ & $20 \%$ & $27 \%$ & $28 \%$ & $19 \%$ & $30 \%$ & $58 \%$ & $29 \%$ \\
\hline Upper secondary & $47 \%$ & $67 \%$ & $53 \%$ & $37 \%$ & $48 \%$ & $49 \%$ & $11 \%$ & $37 \%$ \\
\hline Post-secondary & $1 \%$ & $0 \%$ & $1 \%$ & $1 \%$ & $0 \%$ & $0 \%$ & $0 \%$ & $1 \%$ \\
\hline Tertiary & $11 \%$ & $7 \%$ & $12 \%$ & $12 \%$ & $17 \%$ & $16 \%$ & $4 \%$ & $6 \%$ \\
\hline
\end{tabular}




\begin{tabular}{|c|c|c|c|c|c|c|c|c|}
\hline & $\begin{array}{l}\text { All Out- } \\
\text { of-Work }\end{array}$ & $\begin{array}{l}\text { 1. Middle- } \\
\text { aged } \\
\text { unemployed }\end{array}$ & $\begin{array}{c}2 . \\
\text { Retired } \\
\text { women }\end{array}$ & $\begin{array}{l}\text { 3. Stay- } \\
\text { at-home } \\
\text { young } \\
\text { mothers }\end{array}$ & $\begin{array}{c}4 . \\
\text { Single } \\
\text { male } \\
\text { NEETs }\end{array}$ & $\begin{array}{c}5 . \\
\text { Retired } \\
\text { and } \\
\text { early- } \\
\text { retired } \\
\text { men }\end{array}$ & $\begin{array}{l}\text { 6. Low- } \\
\text { educated } \\
\text { rural long- } \\
\text { term } \\
\text { unemployed }\end{array}$ & $\begin{array}{l}\text { 7. Low- } \\
\text { educated } \\
\text { early- } \\
\text { retired } \\
\text { and } \\
\text { disabled }\end{array}$ \\
\hline NA & $3 \%$ & $2 \%$ & $1 \%$ & $3 \%$ & $3 \%$ & $2 \%$ & $3 \%$ & $16 \%$ \\
\hline \multicolumn{9}{|c|}{ Enrolled in education ${ }^{a}$} \\
\hline Yes & $2 \%$ & $0 \%$ & $0 \%$ & $6 \%$ & $6 \%$ & $0 \%$ & $0 \%$ & $0 \%$ \\
\hline No & $98 \%$ & $100 \%$ & $100 \%$ & $94 \%$ & $94 \%$ & $100 \%$ & $100 \%$ & $100 \%$ \\
\hline \multicolumn{9}{|l|}{ Marital status } \\
\hline Married & $54 \%$ & $63 \%$ & $64 \%$ & $51 \%$ & $3 \%$ & $83 \%$ & $63 \%$ & $17 \%$ \\
\hline Never married & $32 \%$ & $21 \%$ & $3 \%$ & $43 \%$ & $92 \%$ & $7 \%$ & $30 \%$ & $69 \%$ \\
\hline Divorced/separated & $7 \%$ & $11 \%$ & $9 \%$ & $4 \%$ & $4 \%$ & $6 \%$ & $5 \%$ & $8 \%$ \\
\hline Widowed & $7 \%$ & $5 \%$ & $23 \%$ & $3 \%$ & $1 \%$ & $4 \%$ & $2 \%$ & $6 \%$ \\
\hline \multicolumn{9}{|l|}{ Income quintile ${ }^{b}$} \\
\hline Poorest & $36 \%$ & $37 \%$ & $22 \%$ & $37 \%$ & $38 \%$ & $20 \%$ & $69 \%$ & $33 \%$ \\
\hline Q2 & $22 \%$ & $24 \%$ & $25 \%$ & $21 \%$ & $21 \%$ & $17 \%$ & $15 \%$ & $28 \%$ \\
\hline Q3 & $18 \%$ & $18 \%$ & $24 \%$ & $16 \%$ & $16 \%$ & $21 \%$ & $10 \%$ & $20 \%$ \\
\hline Q4 & $14 \%$ & $12 \%$ & $18 \%$ & $16 \%$ & $15 \%$ & $22 \%$ & $3 \%$ & $12 \%$ \\
\hline Richest & $11 \%$ & $9 \%$ & $12 \%$ & $11 \%$ & $10 \%$ & $19 \%$ & $2 \%$ & $6 \%$ \\
\hline \multicolumn{9}{|c|}{ Household income (mean) } \\
\hline Labor income & 4576 & 4622 & 3643 & 5940 & 5615 & 5273 & 2511 & 3151 \\
\hline Other income & 287 & 325 & 190 & 416 & 296 & 149 & 373 & 189 \\
\hline Benefits & 1792 & 1344 & 2814 & 1300 & 1175 & 2690 & 1231 & 2303 \\
\hline \multicolumn{9}{|c|}{ Household income (mean) } \\
\hline Labor income & $57 \%$ & $64 \%$ & $39 \%$ & $70 \%$ & $68 \%$ & $52 \%$ & $49 \%$ & $42 \%$ \\
\hline Other income & $6 \%$ & $8 \%$ & $3 \%$ & $7 \%$ & $7 \%$ & $2 \%$ & $11 \%$ & $4 \%$ \\
\hline Benefits & $37 \%$ & $29 \%$ & $58 \%$ & $23 \%$ & $24 \%$ & $46 \%$ & $40 \%$ & $53 \%$ \\
\hline \multicolumn{9}{|c|}{ At least one working adult in householdc } \\
\hline No & $40 \%$ & $35 \%$ & $55 \%$ & $21 \%$ & $31 \%$ & $35 \%$ & $67 \%$ & $48 \%$ \\
\hline Yes & $60 \%$ & $65 \%$ & $45 \%$ & $79 \%$ & $69 \%$ & $65 \%$ & $33 \%$ & $52 \%$ \\
\hline \multicolumn{9}{|c|}{ Partner economic status } \\
\hline
\end{tabular}




\begin{tabular}{|c|c|c|c|c|c|c|c|c|}
\hline & $\begin{array}{l}\text { All Out- } \\
\text { of-Work }\end{array}$ & $\begin{array}{l}\text { 1. Middle- } \\
\text { aged } \\
\text { unemployed }\end{array}$ & $\begin{array}{c}2 . \\
\text { Retired } \\
\text { women }\end{array}$ & $\begin{array}{l}\text { 3. Stay- } \\
\text { at-home } \\
\text { young } \\
\text { mothers }\end{array}$ & $\begin{array}{c}4 . \\
\text { Single } \\
\text { male } \\
\text { NEETs }\end{array}$ & $\begin{array}{c}5 . \\
\text { Retired } \\
\text { and } \\
\text { early- } \\
\text { retired } \\
\text { men }\end{array}$ & $\begin{array}{l}\text { 6. Low- } \\
\text { educated } \\
\text { rural long- } \\
\text { term } \\
\text { unemployed }\end{array}$ & $\begin{array}{l}\text { 7. Low- } \\
\text { educated } \\
\text { early- } \\
\text { retired } \\
\text { and } \\
\text { disabled }\end{array}$ \\
\hline Working & $28 \%$ & $52 \%$ & $8 \%$ & $57 \%$ & $0 \%$ & $44 \%$ & $1 \%$ & $5 \%$ \\
\hline Unemployed & $14 \%$ & $11 \%$ & $5 \%$ & $10 \%$ & $3 \%$ & $13 \%$ & $61 \%$ & $6 \%$ \\
\hline Retired & $16 \%$ & $4 \%$ & $50 \%$ & $2 \%$ & $0 \%$ & $25 \%$ & $16 \%$ & $4 \%$ \\
\hline Inactive & $3 \%$ & $1 \%$ & $1 \%$ & $3 \%$ & $2 \%$ & $3 \%$ & $10 \%$ & $3 \%$ \\
\hline Student/military service & $0 \%$ & $0 \%$ & $0 \%$ & $0 \%$ & $0 \%$ & $0 \%$ & $0 \%$ & $0 \%$ \\
\hline No partner & $38 \%$ & $32 \%$ & $36 \%$ & $28 \%$ & $95 \%$ & $15 \%$ & $12 \%$ & $81 \%$ \\
\hline Partner income (mean) & 1715 & $2,397.21$ & 876.29 & $2,954.21$ & 256.87 & $1,836.86$ & 405.95 & 885.53 \\
\hline \multicolumn{9}{|l|}{ Partner income quintile } \\
\hline Poorest & $7 \%$ & $14 \%$ & $2 \%$ & $14 \%$ & $0 \%$ & $12 \%$ & $1 \%$ & $3 \%$ \\
\hline Q2 & $7 \%$ & $11 \%$ & $2 \%$ & $11 \%$ & $0 \%$ & $10 \%$ & $0 \%$ & $1 \%$ \\
\hline Q3 & $5 \%$ & $10 \%$ & $1 \%$ & $10 \%$ & $0 \%$ & $9 \%$ & $0 \%$ & $0 \%$ \\
\hline Q4 & $5 \%$ & $9 \%$ & $1 \%$ & $10 \%$ & $0 \%$ & $9 \%$ & $0 \%$ & $0 \%$ \\
\hline Richest & $4 \%$ & $7 \%$ & $1 \%$ & $13 \%$ & $0 \%$ & $5 \%$ & $0 \%$ & $0 \%$ \\
\hline No partner or partner without income & $72 \%$ & $48 \%$ & $92 \%$ & $43 \%$ & $100 \%$ & $56 \%$ & $99 \%$ & $95 \%$ \\
\hline Household size (mean) & 4.06 & 3.81 & 3.05 & 5.12 & 4.39 & 3.54 & 5.14 & 3.77 \\
\hline \multicolumn{9}{|l|}{ Tenure status } \\
\hline Owner & $89 \%$ & $88 \%$ & $95 \%$ & $81 \%$ & $86 \%$ & $94 \%$ & $84 \%$ & $93 \%$ \\
\hline Tenant & $1 \%$ & $1 \%$ & $0 \%$ & $2 \%$ & $1 \%$ & $0 \%$ & $1 \%$ & $0 \%$ \\
\hline Reduced rate & $3 \%$ & $2 \%$ & $1 \%$ & $5 \%$ & $5 \%$ & $1 \%$ & $4 \%$ & $2 \%$ \\
\hline Free & $8 \%$ & $8 \%$ & $4 \%$ & $12 \%$ & $8 \%$ & $4 \%$ & $12 \%$ & $6 \%$ \\
\hline \multicolumn{9}{|l|}{ Household composition } \\
\hline One-person & $5 \%$ & $5 \%$ & $11 \%$ & $1 \%$ & $2 \%$ & $5 \%$ & $2 \%$ & $10 \%$ \\
\hline Single parent & $2 \%$ & $2 \%$ & $1 \%$ & $3 \%$ & $3 \%$ & $0 \%$ & $0 \%$ & $2 \%$ \\
\hline $2+$ adults without dependent children ${ }^{\mathrm{d}}$ & $42 \%$ & $41 \%$ & $58 \%$ & $17 \%$ & $41 \%$ & $61 \%$ & $28 \%$ & $56 \%$ \\
\hline $2+$ adults with 1 dependent child ${ }^{d}$ & $7 \%$ & $10 \%$ & $3 \%$ & $10 \%$ & $7 \%$ & $5 \%$ & $5 \%$ & $4 \%$ \\
\hline $2+$ adults with $2+$ dependent children ${ }^{d}$ & $45 \%$ & $42 \%$ & $26 \%$ & $70 \%$ & $48 \%$ & $29 \%$ & $65 \%$ & $28 \%$ \\
\hline Children under six & $24 \%$ & $19 \%$ & $11 \%$ & $54 \%$ & $16 \%$ & $15 \%$ & $38 \%$ & $15 \%$ \\
\hline
\end{tabular}




\begin{tabular}{|c|c|c|c|c|c|c|c|c|}
\hline & $\begin{array}{l}\text { All Out- } \\
\text { of-Work }\end{array}$ & $\begin{array}{l}\text { 1. Middle- } \\
\text { aged } \\
\text { unemployed }\end{array}$ & $\begin{array}{c}2 . \\
\text { Retired } \\
\text { women }\end{array}$ & $\begin{array}{l}\text { 3. Stay- } \\
\text { at-home } \\
\text { young } \\
\text { mothers }\end{array}$ & $\begin{array}{c}4 . \\
\text { Single } \\
\text { male } \\
\text { NEETs }\end{array}$ & $\begin{array}{c}5 . \\
\text { Retired } \\
\text { and } \\
\text { early- } \\
\text { retired } \\
\text { men }\end{array}$ & $\begin{array}{l}\text { 6. Low- } \\
\text { educated } \\
\text { rural long- } \\
\text { term } \\
\text { unemployed }\end{array}$ & $\begin{array}{l}\text { 7. Low- } \\
\text { educated } \\
\text { early- } \\
\text { retired } \\
\text { and } \\
\text { disabled }\end{array}$ \\
\hline Three or more children under 16 & $5 \%$ & $3 \%$ & $1 \%$ & $11 \%$ & $3 \%$ & $2 \%$ & $12 \%$ & $6 \%$ \\
\hline Elderly present (over 64) & $23 \%$ & $23 \%$ & $33 \%$ & $19 \%$ & $23 \%$ & $16 \%$ & $16 \%$ & $33 \%$ \\
\hline \multicolumn{9}{|l|}{ Children under 13 in childcare } \\
\hline No children under 13 in household & $58 \%$ & $58 \%$ & $74 \%$ & $24 \%$ & $70 \%$ & $73 \%$ & $37 \%$ & $76 \%$ \\
\hline All of the children & $17 \%$ & $19 \%$ & $13 \%$ & $30 \%$ & $10 \%$ & $11 \%$ & $24 \%$ & $9 \%$ \\
\hline None of the children & $16 \%$ & $15 \%$ & $8 \%$ & $28 \%$ & $15 \%$ & $11 \%$ & $22 \%$ & $11 \%$ \\
\hline Some of the children & $9 \%$ & $8 \%$ & $4 \%$ & $18 \%$ & $5 \%$ & $5 \%$ & $18 \%$ & $4 \%$ \\
\hline Years of work experience ${ }^{e}$ & 21 & 18 & 33 & 9 & 5 & 29 & 15 & 17 \\
\hline \multicolumn{9}{|l|}{ Ever worked } \\
\hline No & $24 \%$ & $9 \%$ & $4 \%$ & $47 \%$ & $61 \%$ & $4 \%$ & $27 \%$ & $49 \%$ \\
\hline Yes & $71 \%$ & $85 \%$ & $94 \%$ & $46 \%$ & $32 \%$ & $93 \%$ & $68 \%$ & $49 \%$ \\
\hline NA & $5 \%$ & $6 \%$ & $2 \%$ & $7 \%$ & $8 \%$ & $3 \%$ & $5 \%$ & $2 \%$ \\
\hline \multicolumn{9}{|l|}{ Able to keep dwelling warm } \\
\hline No & $57 \%$ & $57 \%$ & $55 \%$ & $54 \%$ & $58 \%$ & $51 \%$ & $71 \%$ & $64 \%$ \\
\hline Yes & $43 \%$ & $43 \%$ & $45 \%$ & $46 \%$ & $42 \%$ & $49 \%$ & $29 \%$ & $36 \%$ \\
\hline \multicolumn{9}{|l|}{ Degree of urbanization } \\
\hline Densely populated & $37 \%$ & $31 \%$ & $42 \%$ & $44 \%$ & $37 \%$ & $47 \%$ & $22 \%$ & $42 \%$ \\
\hline Intermediate area & $7 \%$ & $5 \%$ & $7 \%$ & $9 \%$ & $8 \%$ & $6 \%$ & $8 \%$ & $6 \%$ \\
\hline Sparsely populated & $56 \%$ & $64 \%$ & $52 \%$ & $47 \%$ & $55 \%$ & $47 \%$ & $70 \%$ & $53 \%$ \\
\hline \multicolumn{9}{|l|}{ Region } \\
\hline BG3 - Northern \& Eastern & $55 \%$ & $57 \%$ & $53 \%$ & $55 \%$ & $53 \%$ & $49 \%$ & $63 \%$ & $54 \%$ \\
\hline BG4 - South-Western \& South-Central & $45 \%$ & $43 \%$ & $47 \%$ & $45 \%$ & $47 \%$ & $51 \%$ & $37 \%$ & $46 \%$ \\
\hline Receives at least one benefit & $73 \%$ & $65 \%$ & $97 \%$ & $69 \%$ & $41 \%$ & $92 \%$ & $71 \%$ & $93 \%$ \\
\hline \multicolumn{9}{|l|}{ Receives benefits at household level } \\
\hline Family child & $36 \%$ & $39 \%$ & $21 \%$ & $61 \%$ & $28 \%$ & $22 \%$ & $53 \%$ & $21 \%$ \\
\hline Social exclusion & $10 \%$ & $8 \%$ & $5 \%$ & $10 \%$ & $11 \%$ & $8 \%$ & $23 \%$ & $24 \%$ \\
\hline Housing & & . & . & . & . & . & . & . \\
\hline
\end{tabular}




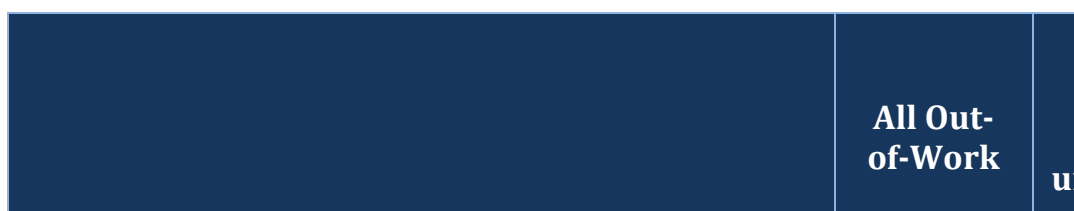

\begin{tabular}{c|c|}
$\begin{array}{c}\text { 1. Middle- } \\
\text { aged } \\
\text { unemployed }\end{array}$ & $\begin{array}{c}2 . \\
\text { Retired } \\
\text { women }\end{array}$ \\
\hline
\end{tabular}

3. Stay-
at-home
young
mothers

5.

\section{6.}

6. Low-

educated

rural long-

term

Single and

early-

retired

unemployed

7. Low-

educated

early-

retired

and

\section{Receives benefits at individual level}

\begin{tabular}{|c|c|c|c|c|c|c|c|c|}
\hline Unemployment & $10 \%$ & $19 \%$ & $4 \%$ & $8 \%$ & $9 \%$ & $7 \%$ & $13 \%$ & $4 \%$ \\
\hline Old age & $27 \%$ & $7 \%$ & $82 \%$ & $1 \%$ & $1 \%$ & $63 \%$ & $2 \%$ & $26 \%$ \\
\hline Survivor & $5 \%$ & $3 \%$ & $15 \%$ & $2 \%$ & $2 \%$ & $3 \%$ & $1 \%$ & $4 \%$ \\
\hline Sickness & $1 \%$ & $1 \%$ & $0 \%$ & $0 \%$ & $0 \%$ & $1 \%$ & $1 \%$ & $5 \%$ \\
\hline Disability & $13 \%$ & $11 \%$ & $17 \%$ & $1 \%$ & $2 \%$ & $31 \%$ & $3 \%$ & $80 \%$ \\
\hline
\end{tabular}

\section{Benefits as share of household income, all households}

\begin{tabular}{|c|c|c|c|c|c|c|c|c|}
\hline Family child & $5 \%$ & $4 \%$ & $1 \%$ & $8 \%$ & $4 \%$ & $2 \%$ & $13 \%$ & $3 \%$ \\
\hline Social exclusion & $1 \%$ & $1 \%$ & $0 \%$ & $1 \%$ & $1 \%$ & $1 \%$ & $3 \%$ & $2 \%$ \\
\hline Housing & $0 \%$ & $0 \%$ & $0 \%$ & $0 \%$ & $0 \%$ & $0 \%$ & $0 \%$ & $0 \%$ \\
\hline Unemployment & $2 \%$ & $3 \%$ & $2 \%$ & $2 \%$ & $2 \%$ & $2 \%$ & $4 \%$ & $1 \%$ \\
\hline Old age & $21 \%$ & $14 \%$ & $46 \%$ & $8 \%$ & $11 \%$ & $29 \%$ & $11 \%$ & $18 \%$ \\
\hline Survivor & $1 \%$ & $2 \%$ & $2 \%$ & $1 \%$ & $1 \%$ & $1 \%$ & $1 \%$ & $2 \%$ \\
\hline Sickness & $0 \%$ & $0 \%$ & $0 \%$ & $0 \%$ & $0 \%$ & $0 \%$ & $1 \%$ & $1 \%$ \\
\hline Disability & $6 \%$ & $4 \%$ & $7 \%$ & $3 \%$ & $4 \%$ & $11 \%$ & $8 \%$ & $26 \%$ \\
\hline Education & $0 \%$ & $0 \%$ & $0 \%$ & $0 \%$ & $0 \%$ & $0 \%$ & $0 \%$ & $0 \%$ \\
\hline
\end{tabular}

a. Applies to individuals aged 25 and over. Students aged 16 to 24 are not included in the sample.

b. Based on total equivalized disposable household income.

c. Refers to individuals aged 25 and over.

d. Dependent children include: 1. household members under 18; 2. household members aged between 18 and 24 who are economically inactive and living with at least one parent.

e. Refers only to individuals who have worked before.

Source: WB staff calculations based on EU-SILC. 


\begin{tabular}{|c|c|c|c|c|c|c|}
\hline & $\begin{array}{l}\text { 1. Middle-aged } \\
\text { unemployed }\end{array}$ & $\begin{array}{l}\text { 2. Retired } \\
\text { women }\end{array}$ & $\begin{array}{l}\text { 3. Single male } \\
\text { NEETs }\end{array}$ & $\begin{array}{l}\text { 4. Stay-at- } \\
\text { home young } \\
\text { mothers }\end{array}$ & $\begin{array}{c}\text { 5. Retired and } \\
\text { early-retired } \\
\text { men }\end{array}$ & $\begin{array}{c}\text { 6. Low- } \\
\text { educated } \\
\text { early-retired } \\
\text { and disabled }\end{array}$ \\
\hline Cluster size & $31 \%$ & $25 \%$ & $17 \%$ & $12 \%$ & $10 \%$ & $4 \%$ \\
\hline Population & 489,241 & 394,128 & 268,399 & 181,212 & 157,744 & 63,253 \\
\hline \multicolumn{7}{|c|}{ INDICATORS } \\
\hline \multicolumn{7}{|c|}{ Labor market attachment } \\
\hline Unemployed & $42 \%$ & $0 \%$ & $32 \%$ & $16 \%$ & $17 \%$ & $10 \%$ \\
\hline Long-term unemployed & $52 \%$ & $1 \%$ & $42 \%$ & $2 \%$ & $4 \%$ & $5 \%$ \\
\hline Retired & $0 \%$ & $96 \%$ & $1 \%$ & $0 \%$ & $79 \%$ & $57 \%$ \\
\hline Disabled & $1 \%$ & $0 \%$ & $0 \%$ & $0 \%$ & $0 \%$ & $22 \%$ \\
\hline Other inactive & $5 \%$ & $3 \%$ & $26 \%$ & $82 \%$ & $0 \%$ & $6 \%$ \\
\hline \multicolumn{7}{|l|}{ Working Partner } \\
\hline Yes & $39 \%$ & $8 \%$ & $2 \%$ & $69 \%$ & $67 \%$ & $5 \%$ \\
\hline No & $42 \%$ & $57 \%$ & $4 \%$ & $7 \%$ & $28 \%$ & $13 \%$ \\
\hline NA & $20 \%$ & $35 \%$ & $95 \%$ & $24 \%$ & $6 \%$ & $82 \%$ \\
\hline \multicolumn{7}{|c|}{ Self-assessed physical incapacity } \\
\hline Strongly limited & $2 \%$ & $8 \%$ & $0 \%$ & $1 \%$ & $5 \%$ & $61 \%$ \\
\hline None/limited & $98 \%$ & $92 \%$ & $100 \%$ & $99 \%$ & $95 \%$ & $39 \%$ \\
\hline \multicolumn{7}{|c|}{ ACTIVE COVARIATES } \\
\hline \multicolumn{7}{|l|}{ Age groups (4) } \\
\hline $16-24$ years & $5 \%$ & $0 \%$ & $59 \%$ & $24 \%$ & $0 \%$ & $6 \%$ \\
\hline $25-34$ years & $22 \%$ & $0 \%$ & $36 \%$ & $51 \%$ & $0 \%$ & $23 \%$ \\
\hline $35-59$ years & $70 \%$ & $20 \%$ & $6 \%$ & $25 \%$ & $70 \%$ & $67 \%$ \\
\hline $60-64$ years & $3 \%$ & $79 \%$ & $0 \%$ & $0 \%$ & $30 \%$ & $4 \%$ \\
\hline \multicolumn{7}{|l|}{ Gender } \\
\hline Male & $42 \%$ & $25 \%$ & $68 \%$ & $0 \%$ & $80 \%$ & $70 \%$ \\
\hline Female & $58 \%$ & $75 \%$ & $32 \%$ & $100 \%$ & $20 \%$ & $30 \%$ \\
\hline Education & & & & & & \\
\hline
\end{tabular}

Education 


\begin{tabular}{|c|c|c|c|c|c|c|}
\hline & $\begin{array}{l}\text { 1. Middle-aged } \\
\text { unemployed }\end{array}$ & $\begin{array}{l}\text { 2. Retired } \\
\text { women }\end{array}$ & $\begin{array}{l}\text { 3. Single male } \\
\text { NEETs }\end{array}$ & $\begin{array}{l}\text { 4. Stay-at- } \\
\text { home young } \\
\text { mothers }\end{array}$ & $\begin{array}{l}\text { 5. Retired and } \\
\text { early-retired } \\
\text { men }\end{array}$ & $\begin{array}{c}\text { 6. Low- } \\
\text { educated } \\
\text { early-retired } \\
\text { and disabled }\end{array}$ \\
\hline Primary & $47 \%$ & $36 \%$ & $29 \%$ & $36 \%$ & $29 \%$ & $35 \%$ \\
\hline Secondary & $45 \%$ & $51 \%$ & $54 \%$ & $46 \%$ & $56 \%$ & $42 \%$ \\
\hline Tertiary & $6 \%$ & $11 \%$ & $13 \%$ & $16 \%$ & $14 \%$ & $8 \%$ \\
\hline NA & $3 \%$ & $2 \%$ & $5 \%$ & $2 \%$ & $1 \%$ & $15 \%$ \\
\hline Urban & $27 \%$ & $45 \%$ & $51 \%$ & $62 \%$ & $53 \%$ & $49 \%$ \\
\hline Rural & $73 \%$ & $55 \%$ & $49 \%$ & $38 \%$ & $47 \%$ & $51 \%$ \\
\hline \multicolumn{7}{|c|}{ INACTIVE COVARIATES } \\
\hline \multicolumn{7}{|l|}{ Age groups (7) } \\
\hline $16-19$ years & $1 \%$ & $0 \%$ & $26 \%$ & $7 \%$ & $0 \%$ & $1 \%$ \\
\hline 20-24 years & $4 \%$ & $0 \%$ & $33 \%$ & $17 \%$ & $0 \%$ & $5 \%$ \\
\hline 25-34 years & $22 \%$ & $0 \%$ & $36 \%$ & $51 \%$ & $0 \%$ & $23 \%$ \\
\hline $35-44$ years & $27 \%$ & $2 \%$ & $2 \%$ & $12 \%$ & $10 \%$ & $22 \%$ \\
\hline 45-54 years & $27 \%$ & $6 \%$ & $3 \%$ & $8 \%$ & $27 \%$ & $20 \%$ \\
\hline $55-59$ years & $15 \%$ & $13 \%$ & $1 \%$ & $5 \%$ & $33 \%$ & $25 \%$ \\
\hline 60-64 years & $3 \%$ & $79 \%$ & $0 \%$ & $0 \%$ & $30 \%$ & $4 \%$ \\
\hline \multicolumn{7}{|l|}{ Education } \\
\hline None/less than primary & $3 \%$ & $1 \%$ & $2 \%$ & $6 \%$ & $1 \%$ & $4 \%$ \\
\hline Primary & $9 \%$ & $5 \%$ & $10 \%$ & $8 \%$ & $3 \%$ & $6 \%$ \\
\hline Lower secondary & $35 \%$ & $30 \%$ & $16 \%$ & $23 \%$ & $26 \%$ & $26 \%$ \\
\hline Upper secondary & $44 \%$ & $50 \%$ & $53 \%$ & $45 \%$ & $56 \%$ & $41 \%$ \\
\hline Post-secondary & $0 \%$ & $1 \%$ & $0 \%$ & $1 \%$ & $0 \%$ & $1 \%$ \\
\hline Tertiary & $6 \%$ & $11 \%$ & $13 \%$ & $16 \%$ & $14 \%$ & $8 \%$ \\
\hline NA & $3 \%$ & $2 \%$ & $5 \%$ & $2 \%$ & $1 \%$ & $15 \%$ \\
\hline \multicolumn{7}{|l|}{ Enrolled in education ${ }^{a}$} \\
\hline Yes & $1 \%$ & $0 \%$ & $7 \%$ & $9 \%$ & $0 \%$ & $0 \%$ \\
\hline No & $99 \%$ & $100 \%$ & $93 \%$ & $91 \%$ & $100 \%$ & $99 \%$ \\
\hline NA & $0 \%$ & $0 \%$ & $0 \%$ & $0 \%$ & $0 \%$ & $1 \%$ \\
\hline Marital status & & & & & & \\
\hline
\end{tabular}




\begin{tabular}{|c|c|c|c|c|c|c|}
\hline & $\begin{array}{l}\text { 1. Middle-aged } \\
\text { unemployed }\end{array}$ & $\begin{array}{l}\text { 2. Retired } \\
\text { women }\end{array}$ & $\begin{array}{c}\text { 3. Single male } \\
\text { NEETs }\end{array}$ & $\begin{array}{l}\text { 4. Stay-at- } \\
\text { home young } \\
\text { mothers }\end{array}$ & $\begin{array}{l}\text { 5. Retired and } \\
\text { early-retired } \\
\text { men }\end{array}$ & $\begin{array}{c}\text { 6. Low- } \\
\text { educated } \\
\text { early-retired } \\
\text { and disabled }\end{array}$ \\
\hline Married & $69 \%$ & $64 \%$ & $4 \%$ & $59 \%$ & $91 \%$ & $18 \%$ \\
\hline Never married & $21 \%$ & $5 \%$ & $90 \%$ & $35 \%$ & $5 \%$ & $55 \%$ \\
\hline Divorced/separated & $7 \%$ & $9 \%$ & $5 \%$ & $4 \%$ & $3 \%$ & $14 \%$ \\
\hline Widowed & $4 \%$ & $22 \%$ & $1 \%$ & $2 \%$ & $2 \%$ & $13 \%$ \\
\hline \multicolumn{7}{|l|}{ Income quintile ${ }^{b}$} \\
\hline Poorest & $48 \%$ & $23 \%$ & $36 \%$ & $27 \%$ & $14 \%$ & $37 \%$ \\
\hline Q2 & $23 \%$ & $25 \%$ & $21 \%$ & $20 \%$ & $20 \%$ & $20 \%$ \\
\hline Q3 & $13 \%$ & $22 \%$ & $17 \%$ & $16 \%$ & $22 \%$ & $18 \%$ \\
\hline Q4 & $9 \%$ & $18 \%$ & $14 \%$ & $18 \%$ & $22 \%$ & $18 \%$ \\
\hline Richest & $7 \%$ & $11 \%$ & $12 \%$ & $19 \%$ & $22 \%$ & $7 \%$ \\
\hline \multicolumn{7}{|l|}{ At least one working adult in householdc } \\
\hline No & $44 \%$ & $57 \%$ & $31 \%$ & $14 \%$ & $21 \%$ & $50 \%$ \\
\hline Yes & $56 \%$ & $43 \%$ & $69 \%$ & $86 \%$ & $79 \%$ & $50 \%$ \\
\hline \multicolumn{7}{|l|}{ Partner economic status } \\
\hline Working & $39 \%$ & $8 \%$ & $2 \%$ & $69 \%$ & $67 \%$ & $5 \%$ \\
\hline Unemployed & $31 \%$ & $5 \%$ & $2 \%$ & $5 \%$ & $10 \%$ & $6 \%$ \\
\hline Retired & $7 \%$ & $50 \%$ & $0 \%$ & $1 \%$ & $16 \%$ & $4 \%$ \\
\hline Inactive & $3 \%$ & $2 \%$ & $1 \%$ & $2 \%$ & $2 \%$ & $4 \%$ \\
\hline Student/military service & . & . & . & . & $\cdot$ & . \\
\hline No partner & $20 \%$ & $35 \%$ & $95 \%$ & $24 \%$ & $6 \%$ & $82 \%$ \\
\hline Partner income (mean) & 1715.62 & 718.29 & 1125.84 & 3962.33 & 2167.30 & 1023.80 \\
\hline \multicolumn{7}{|l|}{ Partner income quintile } \\
\hline Poorest & $11 \%$ & $2 \%$ & $1 \%$ & $13 \%$ & $14 \%$ & $0 \%$ \\
\hline Q2 & $8 \%$ & $2 \%$ & $0 \%$ & $11 \%$ & $16 \%$ & $2 \%$ \\
\hline Q3 & $7 \%$ & $2 \%$ & $0 \%$ & $10 \%$ & $17 \%$ & $1 \%$ \\
\hline Q4 & $7 \%$ & $2 \%$ & $0 \%$ & $14 \%$ & $12 \%$ & $1 \%$ \\
\hline Richest & $6 \%$ & $1 \%$ & $0 \%$ & $20 \%$ & $7 \%$ & $0 \%$ \\
\hline No partner or partner without income & $61 \%$ & $92 \%$ & $98 \%$ & $31 \%$ & $33 \%$ & $95 \%$ \\
\hline
\end{tabular}




\begin{tabular}{|c|c|c|c|c|c|c|}
\hline & $\begin{array}{l}\text { 1. Middle-aged } \\
\text { unemployed }\end{array}$ & $\begin{array}{l}\text { 2. Retired } \\
\text { women }\end{array}$ & $\begin{array}{l}\text { 3. Single male } \\
\text { NEETs }\end{array}$ & $\begin{array}{l}\text { 4. Stay-at- } \\
\text { home young } \\
\text { mothers }\end{array}$ & $\begin{array}{l}\text { 5. Retired and } \\
\text { early-retired } \\
\text { men }\end{array}$ & $\begin{array}{c}\text { 6. Low- } \\
\text { educated } \\
\text { early-retired } \\
\text { and disabled }\end{array}$ \\
\hline Household size (mean) & 4.40 & 3.07 & 4.46 & 5.09 & 3.53 & 3.76 \\
\hline \multicolumn{7}{|l|}{ Tenure status } \\
\hline Owner & $84 \%$ & $94 \%$ & $83 \%$ & $80 \%$ & $93 \%$ & $90 \%$ \\
\hline Tenant & $1 \%$ & $1 \%$ & $2 \%$ & $3 \%$ & $0 \%$ & $0 \%$ \\
\hline Reduced rate & $2 \%$ & $1 \%$ & $4 \%$ & $4 \%$ & $1 \%$ & $3 \%$ \\
\hline Free & $13 \%$ & $4 \%$ & $11 \%$ & $13 \%$ & $6 \%$ & $6 \%$ \\
\hline \multicolumn{7}{|l|}{ Household composition } \\
\hline One-person & $2 \%$ & $12 \%$ & $3 \%$ & $1 \%$ & $2 \%$ & $12 \%$ \\
\hline Single parent & $1 \%$ & $1 \%$ & $2 \%$ & $2 \%$ & $0 \%$ & $2 \%$ \\
\hline $2+$ adults without dependent children ${ }^{d}$ & $34 \%$ & $60 \%$ & $40 \%$ & $17 \%$ & $64 \%$ & $54 \%$ \\
\hline $2+$ adults with 1 dependent child ${ }^{\mathrm{d}}$ & $10 \%$ & $2 \%$ & $9 \%$ & $13 \%$ & $6 \%$ & $3 \%$ \\
\hline $2+$ adults with $2+$ dependent children ${ }^{\mathrm{d}}$ & $53 \%$ & $25 \%$ & $46 \%$ & $67 \%$ & $28 \%$ & $29 \%$ \\
\hline Children under six & $27 \%$ & $12 \%$ & $17 \%$ & $57 \%$ & $12 \%$ & $15 \%$ \\
\hline Three or more children under 16 & $7 \%$ & $2 \%$ & $4 \%$ & $11 \%$ & $1 \%$ & $4 \%$ \\
\hline Elderly present (over 64) & $20 \%$ & $30 \%$ & $21 \%$ & $19 \%$ & $16 \%$ & $30 \%$ \\
\hline \multicolumn{7}{|l|}{ Children under 13 in childcare } \\
\hline No children under 13 in household & $47 \%$ & $75 \%$ & $68 \%$ & $26 \%$ & $75 \%$ & $76 \%$ \\
\hline All of the children & $16 \%$ & $9 \%$ & $6 \%$ & $14 \%$ & $10 \%$ & $5 \%$ \\
\hline None of the children & $27 \%$ & $11 \%$ & $21 \%$ & $42 \%$ & $11 \%$ & $15 \%$ \\
\hline Some of the children & $11 \%$ & $4 \%$ & $5 \%$ & $17 \%$ & $4 \%$ & $5 \%$ \\
\hline Years of work experience ${ }^{e}$ & 16.64 & 31.95 & 5.78 & 8.92 & 28.59 & 20.11 \\
\hline \multicolumn{7}{|l|}{ Ever worked } \\
\hline No & $14 \%$ & $2 \%$ & $55 \%$ & $40 \%$ & $1 \%$ & $35 \%$ \\
\hline Yes & $77 \%$ & $94 \%$ & $38 \%$ & $42 \%$ & $92 \%$ & $60 \%$ \\
\hline NA & $9 \%$ & $3 \%$ & $7 \%$ & $17 \%$ & $6 \%$ & $5 \%$ \\
\hline \multicolumn{7}{|l|}{ Able to keep dwelling warm } \\
\hline No & $80 \%$ & $71 \%$ & $77 \%$ & $64 \%$ & $69 \%$ & $83 \%$ \\
\hline Yes & $20 \%$ & $29 \%$ & $23 \%$ & $36 \%$ & $31 \%$ & $17 \%$ \\
\hline
\end{tabular}




\begin{tabular}{|c|c|c|c|c|c|c|}
\hline & $\begin{array}{l}\text { 1. Middle-aged } \\
\text { unemployed }\end{array}$ & $\begin{array}{l}\text { 2. Retired } \\
\text { women }\end{array}$ & $\begin{array}{l}\text { 3. Single male } \\
\text { NEETs }\end{array}$ & $\begin{array}{l}\text { 4. Stay-at- } \\
\text { home young } \\
\text { mothers }\end{array}$ & $\begin{array}{l}\text { 5. Retired and } \\
\text { early-retired } \\
\text { men }\end{array}$ & $\begin{array}{c}\text { 6. Low- } \\
\text { educated } \\
\text { early-retired } \\
\text { and disabled }\end{array}$ \\
\hline \multicolumn{7}{|l|}{ Degree of urbanization } \\
\hline Densely populated & $22 \%$ & $39 \%$ & $43 \%$ & $54 \%$ & $47 \%$ & $41 \%$ \\
\hline Intermediate area & $5 \%$ & $6 \%$ & $8 \%$ & $8 \%$ & $6 \%$ & $8 \%$ \\
\hline Sparsely populated & $73 \%$ & $55 \%$ & $49 \%$ & $38 \%$ & $47 \%$ & $51 \%$ \\
\hline \multicolumn{7}{|l|}{ Region } \\
\hline BG3 - Northern \& Eastern & $64 \%$ & $54 \%$ & $53 \%$ & $53 \%$ & $50 \%$ & $54 \%$ \\
\hline BG4 - South-Western \& South-Central & $36 \%$ & $46 \%$ & $47 \%$ & $47 \%$ & $50 \%$ & $46 \%$ \\
\hline Receives at least one benefit & $67 \%$ & $96 \%$ & $48 \%$ & $68 \%$ & $91 \%$ & $91 \%$ \\
\hline \multicolumn{7}{|l|}{ Receives benefits at household level } \\
\hline Family child & $46 \%$ & $19 \%$ & $30 \%$ & $58 \%$ & $22 \%$ & $21 \%$ \\
\hline Social exclusion & $16 \%$ & $8 \%$ & $13 \%$ & $10 \%$ & $5 \%$ & $36 \%$ \\
\hline Housing allowance & . & $\cdot$ & . & . & . & . \\
\hline \multicolumn{7}{|l|}{ Receives benefits at individual level } \\
\hline Unemployment & $17 \%$ & $2 \%$ & $7 \%$ & $5 \%$ & $9 \%$ & $3 \%$ \\
\hline Old age & $2 \%$ & $74 \%$ & $0 \%$ & $0 \%$ & $51 \%$ & $10 \%$ \\
\hline Survivor & $0 \%$ & $2 \%$ & $0 \%$ & $1 \%$ & $0 \%$ & $1 \%$ \\
\hline Sickness & $6 \%$ & $5 \%$ & $5 \%$ & $8 \%$ & $11 \%$ & $6 \%$ \\
\hline Disability & $6 \%$ & $30 \%$ & $2 \%$ & $1 \%$ & $31 \%$ & $73 \%$ \\
\hline
\end{tabular}

a. Applies to individuals aged 25 and over. Students aged 16 to 24 are not included in the sample.

b. Based on total equivalized disposable household income.

c. Refers to individuals aged 25 and over.

d. Dependent children include: 1. household members under 18; 2. household members aged between 18 and 24 who are economically inactive and living with at least one parent.

e. Refers only to individuals who have worked before.

Source: WB staff calculations based on EU-SILC. 


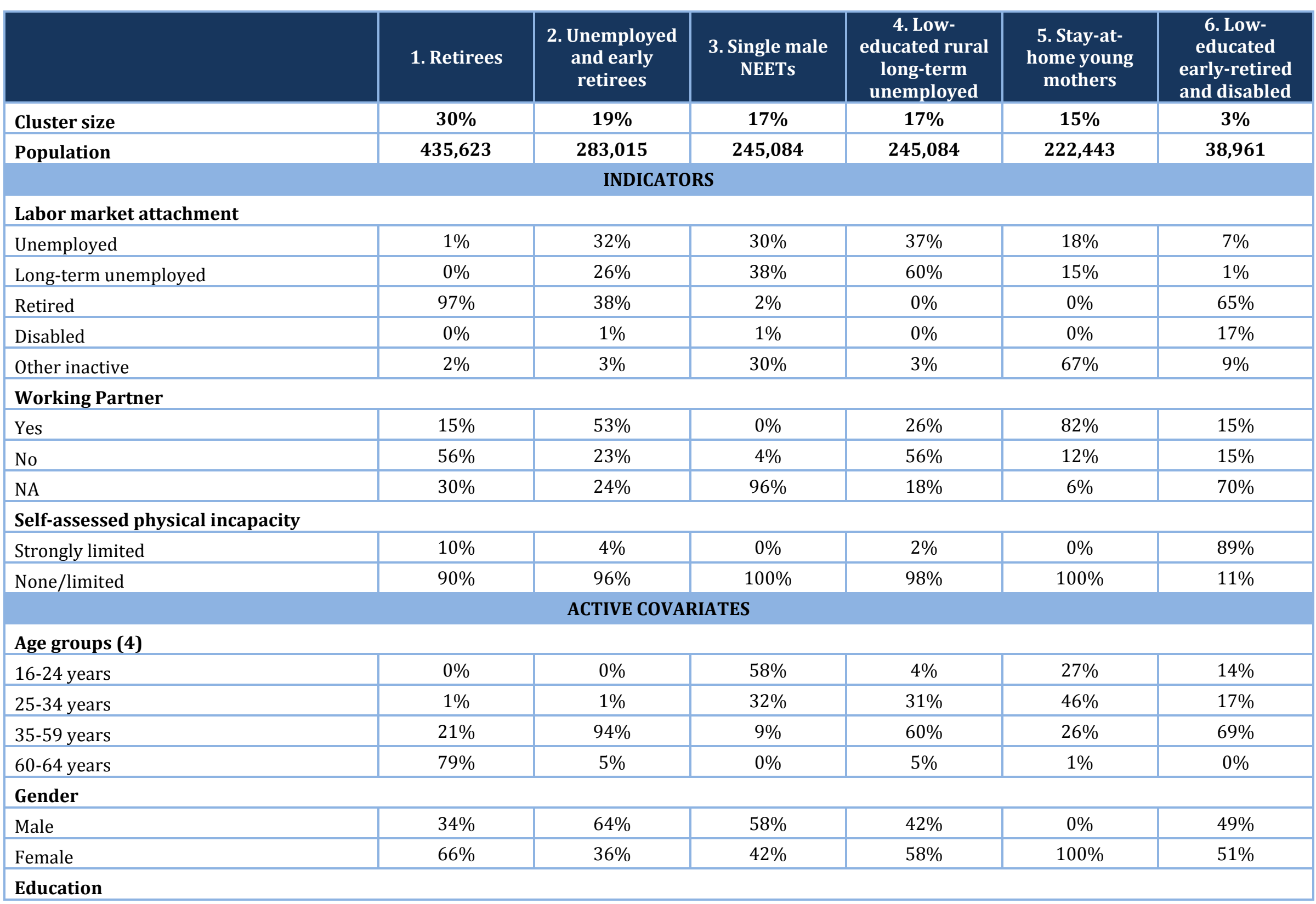




\begin{tabular}{|c|c|c|c|c|c|c|}
\hline & 1. Retirees & $\begin{array}{l}\text { 2. Unemployed } \\
\text { and early } \\
\text { retirees }\end{array}$ & $\begin{array}{l}\text { 3. Single male } \\
\text { NEETs }\end{array}$ & $\begin{array}{c}\text { 4. Low- } \\
\text { educated rural } \\
\text { long-term } \\
\text { unemployed }\end{array}$ & $\begin{array}{l}\text { 5. Stay-at- } \\
\text { home young } \\
\text { mothers }\end{array}$ & $\begin{array}{c}\text { 6. Low- } \\
\text { educated } \\
\text { early-retired } \\
\text { and disabled }\end{array}$ \\
\hline Primary & $42 \%$ & $11 \%$ & $39 \%$ & $80 \%$ & $35 \%$ & $45 \%$ \\
\hline Secondary & $46 \%$ & $74 \%$ & $49 \%$ & $15 \%$ & $51 \%$ & $27 \%$ \\
\hline Tertiary & $10 \%$ & $13 \%$ & $8 \%$ & $2 \%$ & $10 \%$ & $13 \%$ \\
\hline NA & $2 \%$ & $2 \%$ & $4 \%$ & $2 \%$ & $3 \%$ & $15 \%$ \\
\hline Urban & $46 \%$ & $47 \%$ & $55 \%$ & $22 \%$ & $49 \%$ & $49 \%$ \\
\hline Rural & $54 \%$ & $53 \%$ & $45 \%$ & $78 \%$ & $51 \%$ & $51 \%$ \\
\hline \multicolumn{7}{|c|}{ INACTIVE COVARIATES } \\
\hline \multicolumn{7}{|l|}{ Age groups (7) } \\
\hline 16-19 years & $0 \%$ & $0 \%$ & $27 \%$ & $1 \%$ & $6 \%$ & $3 \%$ \\
\hline $20-24$ years & $0 \%$ & $0 \%$ & $31 \%$ & $3 \%$ & $21 \%$ & $11 \%$ \\
\hline $25-34$ years & $1 \%$ & $1 \%$ & $32 \%$ & $31 \%$ & $46 \%$ & $17 \%$ \\
\hline $35-44$ years & $3 \%$ & $27 \%$ & $3 \%$ & $21 \%$ & $14 \%$ & $19 \%$ \\
\hline 45-54 years & $4 \%$ & $37 \%$ & $4 \%$ & $25 \%$ & $8 \%$ & $21 \%$ \\
\hline $55-59$ years & $14 \%$ & $30 \%$ & $2 \%$ & $13 \%$ & $4 \%$ & $28 \%$ \\
\hline 60-64 years & $79 \%$ & $5 \%$ & $0 \%$ & $5 \%$ & $1 \%$ & $0 \%$ \\
\hline \multicolumn{7}{|l|}{ Education } \\
\hline None/less than primary & $1 \%$ & $0 \%$ & $3 \%$ & $4 \%$ & $3 \%$ & $1 \%$ \\
\hline Primary & $6 \%$ & $1 \%$ & $13 \%$ & $17 \%$ & $9 \%$ & $9 \%$ \\
\hline Lower secondary & $35 \%$ & $10 \%$ & $23 \%$ & $60 \%$ & $23 \%$ & $35 \%$ \\
\hline Upper secondary & $45 \%$ & $73 \%$ & $49 \%$ & $15 \%$ & $51 \%$ & $25 \%$ \\
\hline Post-secondary & $1 \%$ & $1 \%$ & $0 \%$ & $0 \%$ & $1 \%$ & $1 \%$ \\
\hline Tertiary & $10 \%$ & $13 \%$ & $8 \%$ & $2 \%$ & $10 \%$ & $13 \%$ \\
\hline NA & $2 \%$ & $2 \%$ & $4 \%$ & $2 \%$ & $3 \%$ & $15 \%$ \\
\hline \multicolumn{7}{|l|}{ Enrolled in education ${ }^{a}$} \\
\hline Yes & $0 \%$ & $0 \%$ & $6 \%$ & $1 \%$ & $3 \%$ & $0 \%$ \\
\hline No & $100 \%$ & $100 \%$ & $94 \%$ & $99 \%$ & $97 \%$ & $100 \%$ \\
\hline \multicolumn{7}{|l|}{ Marital status } \\
\hline Married & $69 \%$ & $72 \%$ & $3 \%$ & $67 \%$ & $71 \%$ & $25 \%$ \\
\hline
\end{tabular}




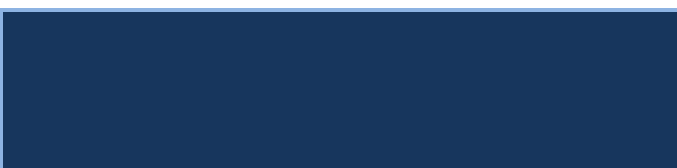

\section{Retirees}

2. Unemployed and early

retirees

3. Single male

4. LowNEETS

educated rural

long-term

unemployed

5. Stay-at-

home young

mothers

6. Low-

educated

Never married

Divorced/separated

$14 \%$

\begin{tabular}{l|l}
$87 \%$ & $24 \%$ \\
\hline
\end{tabular}

\begin{tabular}{l|l}
$87 \%$ & $24 \%$ \\
\hline
\end{tabular}

$27 \%$

early-retired

Widowed

$6 \%$

$10 \%$

and disabled

\section{Income quintile}

Poorest

Q2

Q3

Q4

Richest

\begin{tabular}{l|l}
$20 \%$ & $5 \%$
\end{tabular}

$2 \%$

$5 \%$

$2 \%$

$53 \%$

$26 \%$

$23 \%$

$60 \%$

$11 \%$

\section{At least one working adult in householdc}

\begin{tabular}{|l|l|l|l|l|l|l|}
\hline No & $48 \%$ & $35 \%$ & $30 \%$ & $48 \%$ & $12 \%$ & $44 \%$ \\
\hline Yes & $52 \%$ & $65 \%$ & $70 \%$ & $52 \%$ & $88 \%$ & $56 \%$ \\
\hline
\end{tabular}

\section{Partner economic status}

\begin{tabular}{|c|c|c|c|c|c|c|}
\hline Working & $15 \%$ & $53 \%$ & $0 \%$ & $26 \%$ & $82 \%$ & $15 \%$ \\
\hline Unemployed & $6 \%$ & $13 \%$ & $3 \%$ & $39 \%$ & $8 \%$ & $5 \%$ \\
\hline Retired & $48 \%$ & $8 \%$ & $0 \%$ & $11 \%$ & $2 \%$ & $8 \%$ \\
\hline Inactive & $1 \%$ & $2 \%$ & $1 \%$ & $5 \%$ & $1 \%$ & $2 \%$ \\
\hline Student/military service & $0 \%$ & $0 \%$ & $0 \%$ & $0 \%$ & $0 \%$ & $0 \%$ \\
\hline No partner & $30 \%$ & $24 \%$ & $96 \%$ & $18 \%$ & $6 \%$ & $70 \%$ \\
\hline Partner income (mean) & 809 & 2,283 & 797 & 1,194 & 3,515 & 1,564 \\
\hline \multicolumn{7}{|l|}{ Partner income quintile } \\
\hline Poorest & $4 \%$ & $14 \%$ & $0 \%$ & $10 \%$ & $14 \%$ & $4 \%$ \\
\hline Q2 & $4 \%$ & $10 \%$ & $0 \%$ & $5 \%$ & $11 \%$ & $3 \%$ \\
\hline Q3 & $3 \%$ & $10 \%$ & $0 \%$ & $3 \%$ & $11 \%$ & $5 \%$ \\
\hline Q4 & $1 \%$ & $10 \%$ & $0 \%$ & $4 \%$ & $22 \%$ & $1 \%$ \\
\hline Richest & $2 \%$ & $9 \%$ & $0 \%$ & $4 \%$ & $24 \%$ & $3 \%$ \\
\hline No partner or partner without income & $85 \%$ & $47 \%$ & $100 \%$ & $74 \%$ & $18 \%$ & $85 \%$ \\
\hline Household size (mean) & 3.23 & 3.53 & 4.66 & 4.72 & 5.02 & 3.67 \\
\hline
\end{tabular}




\begin{tabular}{|c|c|c|c|c|c|c|}
\hline & 1. Retirees & $\begin{array}{l}\text { 2. Unemployed } \\
\text { and early } \\
\text { retirees }\end{array}$ & $\begin{array}{l}\text { 3. Single male } \\
\text { NEETs }\end{array}$ & $\begin{array}{c}\text { 4. Low- } \\
\text { educated rural } \\
\text { long-term } \\
\text { unemployed }\end{array}$ & $\begin{array}{l}\text { 5. Stay-at- } \\
\text { home young } \\
\text { mothers }\end{array}$ & $\begin{array}{c}\text { 6. Low- } \\
\text { educated } \\
\text { early-retired } \\
\text { and disabled }\end{array}$ \\
\hline \multicolumn{7}{|l|}{ Tenure status } \\
\hline Owner & $94 \%$ & $91 \%$ & $82 \%$ & $84 \%$ & $78 \%$ & $88 \%$ \\
\hline Tenant & $1 \%$ & $1 \%$ & $2 \%$ & $1 \%$ & $3 \%$ & $1 \%$ \\
\hline Reduced rate & $1 \%$ & $2 \%$ & $6 \%$ & $4 \%$ & $4 \%$ & $5 \%$ \\
\hline Free & $4 \%$ & $6 \%$ & $10 \%$ & $12 \%$ & $15 \%$ & $7 \%$ \\
\hline \multicolumn{7}{|l|}{ Household composition } \\
\hline One-person & $8 \%$ & $6 \%$ & $2 \%$ & $2 \%$ & $0 \%$ & $6 \%$ \\
\hline Single parent & $0 \%$ & $1 \%$ & $3 \%$ & $0 \%$ & $0 \%$ & $4 \%$ \\
\hline $2+$ adults without dependent children ${ }^{\mathrm{d}}$ & $60 \%$ & $51 \%$ & $34 \%$ & $30 \%$ & $14 \%$ & $47 \%$ \\
\hline $2+$ adults with 1 dependent child ${ }^{\mathrm{d}}$ & $4 \%$ & $10 \%$ & $7 \%$ & $7 \%$ & $16 \%$ & $4 \%$ \\
\hline $2+$ adults with $2+$ dependent children ${ }^{\mathrm{d}}$ & $27 \%$ & $32 \%$ & $53 \%$ & $60 \%$ & $70 \%$ & $39 \%$ \\
\hline Children under six & $13 \%$ & $16 \%$ & $21 \%$ & $32 \%$ & $63 \%$ & $17 \%$ \\
\hline Three or more children under 16 & $1 \%$ & $2 \%$ & $8 \%$ & $9 \%$ & $11 \%$ & $5 \%$ \\
\hline Elderly present (over 64) & $29 \%$ & $22 \%$ & $21 \%$ & $17 \%$ & $15 \%$ & $27 \%$ \\
\hline \multicolumn{7}{|l|}{ Children under 13 in childcare } \\
\hline No children under 13 in household & $73 \%$ & $68 \%$ & $61 \%$ & $40 \%$ & $21 \%$ & $71 \%$ \\
\hline All of the children & $15 \%$ & $13 \%$ & $14 \%$ & $24 \%$ & $26 \%$ & $12 \%$ \\
\hline None of the children & $7 \%$ & $14 \%$ & $19 \%$ & $22 \%$ & $34 \%$ & $11 \%$ \\
\hline Some of the children & $5 \%$ & $5 \%$ & $6 \%$ & $14 \%$ & $19 \%$ & $6 \%$ \\
\hline Years of work experience & 32.06 & 22.73 & 6.40 & 14.21 & 8.70 & 19.78 \\
\hline \multicolumn{7}{|l|}{ Ever worked } \\
\hline No & $3 \%$ & $4 \%$ & $58 \%$ & $19 \%$ & $34 \%$ & $36 \%$ \\
\hline Yes & $93 \%$ & $87 \%$ & $36 \%$ & $71 \%$ & $57 \%$ & $61 \%$ \\
\hline NA & $4 \%$ & $9 \%$ & $6 \%$ & $9 \%$ & $10 \%$ & $3 \%$ \\
\hline \multicolumn{7}{|l|}{ Able to keep dwelling warm } \\
\hline No & $69 \%$ & $67 \%$ & $72 \%$ & $80 \%$ & $66 \%$ & $79 \%$ \\
\hline Yes & $31 \%$ & $33 \%$ & $28 \%$ & $20 \%$ & $34 \%$ & $21 \%$ \\
\hline Degree of urbanization & & & & & & \\
\hline
\end{tabular}




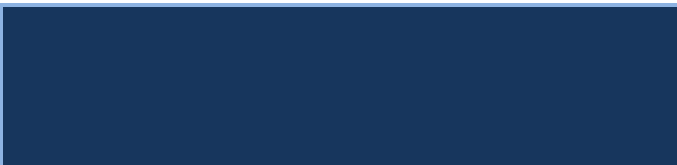

\section{Retirees}

2. Unemployed and early

retirees

\section{Single male NEETS}

4. Low-

Densely populated

Intermediate area

Sparsely populated

\begin{tabular}{|l|l|l}
$40 \%$ & $40 \%$ & $44 \%$
\end{tabular}

Region

BG3 - Northern \& Eastern

BG4 - South-Western \& South-Central

Receives at least one benefit

$44 \%$

$7 \%$
$53 \%$

$11 \%$

$54 \%$

$53 \%$

$45 \%$

4. Low-
educated rural
long-term
unemployed

5. Stay-at-

home young mothers

6. Low-

educated

early-retired and disabled

Receives benefits at household level

\begin{tabular}{|c|c|c|c|c|c|c|}
\hline Family child & $20 \%$ & $27 \%$ & $33 \%$ & $52 \%$ & $66 \%$ & $22 \%$ \\
\hline Social exclusion & $10 \%$ & $9 \%$ & $19 \%$ & $21 \%$ & $7 \%$ & $34 \%$ \\
\hline Housing allowance & . & . & . & . & . & . \\
\hline
\end{tabular}

\section{Receives benefits at individual level}

\begin{tabular}{|c|c|c|c|c|c|c|}
\hline Unemployment & $2 \%$ & $9 \%$ & $3 \%$ & $5 \%$ & $4 \%$ & $0 \%$ \\
\hline Old age & $73 \%$ & $21 \%$ & $0 \%$ & $1 \%$ & $0 \%$ & $7 \%$ \\
\hline Survivor & $3 \%$ & $1 \%$ & $1 \%$ & $2 \%$ & $0 \%$ & $4 \%$ \\
\hline Sickness & $2 \%$ & $6 \%$ & $5 \%$ & $5 \%$ & $8 \%$ & $2 \%$ \\
\hline Disability & $24 \%$ & $19 \%$ & $3 \%$ & $3 \%$ & $1 \%$ & $74 \%$ \\
\hline
\end{tabular}

a. Applies to individuals aged 25 and over. Students aged 16 to 24 are not included in the sample.

b. Based on total equivalized disposable household income.

c. Refers to individuals aged 25 and over.

d. Dependent children include: 1. household members under 18; 2. household members aged between 18 and 24 who are economically inactive and living with at least one parent.

e. Refers only to individuals who have worked before.

Source: WB staff calculations based on EU-SILC. 
Bulgaria: Cross-Sectional Model - Year 2008

\begin{tabular}{|c|c|c|c|c|c|c|}
\hline & $\begin{array}{l}\text { 1. Unemployed } \\
\text { and early } \\
\text { retirees }\end{array}$ & 2. Retirees & $\begin{array}{l}\text { 3. Stay-at- } \\
\text { home young } \\
\text { mothers }\end{array}$ & $\begin{array}{c}\text { 4. Low- } \\
\text { educated rural } \\
\text { long-term } \\
\text { unemployed }\end{array}$ & $\begin{array}{l}\text { 5. Single male } \\
\text { NEETs }\end{array}$ & $\begin{array}{c}\text { 6. Low- } \\
\text { educated } \\
\text { early-retired } \\
\text { and disabled }\end{array}$ \\
\hline Cluster size & $26 \%$ & $25 \%$ & $16 \%$ & $15 \%$ & $13 \%$ & $\mathbf{5 \%}$ \\
\hline Population & 392,066 & 364,741 & 242,962 & 219,201 & 196,924 & 69,206 \\
\hline \multicolumn{7}{|c|}{ INDICATORS } \\
\hline \multicolumn{7}{|c|}{ Labor market attachment } \\
\hline Unemployed & $33 \%$ & $1 \%$ & $20 \%$ & $35 \%$ & $33 \%$ & $0 \%$ \\
\hline Long-term unemployed & $33 \%$ & $0 \%$ & $10 \%$ & $58 \%$ & $38 \%$ & $0 \%$ \\
\hline Retired & $28 \%$ & $98 \%$ & $0 \%$ & $2 \%$ & $0 \%$ & $83 \%$ \\
\hline Disabled & $1 \%$ & $0 \%$ & $0 \%$ & $0 \%$ & $0 \%$ & $15 \%$ \\
\hline Other inactive & $5 \%$ & $0 \%$ & $70 \%$ & $5 \%$ & $28 \%$ & $2 \%$ \\
\hline \multicolumn{7}{|l|}{ Working partner } \\
\hline Yes & $51 \%$ & $12 \%$ & $77 \%$ & $10 \%$ & $0 \%$ & $14 \%$ \\
\hline No & $26 \%$ & $59 \%$ & $8 \%$ & $72 \%$ & $6 \%$ & $10 \%$ \\
\hline NA & $22 \%$ & $29 \%$ & $15 \%$ & $18 \%$ & $94 \%$ & $76 \%$ \\
\hline \multicolumn{7}{|c|}{ Self-assessed physical incapacity } \\
\hline Strongly limited & $2 \%$ & $10 \%$ & $0 \%$ & $2 \%$ & $3 \%$ & $74 \%$ \\
\hline None/limited & $98 \%$ & $90 \%$ & $100 \%$ & $98 \%$ & $97 \%$ & $26 \%$ \\
\hline \multicolumn{7}{|c|}{ ACTIVE COVARIATES } \\
\hline \multicolumn{7}{|l|}{ Age groups (4) } \\
\hline $16-24$ years & $0 \%$ & $0 \%$ & $39 \%$ & $9 \%$ & $76 \%$ & $11 \%$ \\
\hline $25-34$ years & $5 \%$ & $1 \%$ & $43 \%$ & $35 \%$ & $23 \%$ & $18 \%$ \\
\hline 35-59 years & $91 \%$ & $22 \%$ & $17 \%$ & $54 \%$ & $1 \%$ & $71 \%$ \\
\hline 60-64 years & $3 \%$ & $77 \%$ & $1 \%$ & $3 \%$ & $0 \%$ & $0 \%$ \\
\hline \multicolumn{7}{|l|}{ Gender } \\
\hline Male & $45 \%$ & $35 \%$ & $0 \%$ & $51 \%$ & $61 \%$ & $53 \%$ \\
\hline Female & $55 \%$ & $65 \%$ & $100 \%$ & $49 \%$ & $39 \%$ & $47 \%$ \\
\hline
\end{tabular}




\begin{tabular}{|c|c|c|c|c|c|c|}
\hline & $\begin{array}{l}\text { 1. Unemployed } \\
\text { and early } \\
\text { retirees }\end{array}$ & 2. Retirees & $\begin{array}{l}\text { 3. Stay-at- } \\
\text { home young } \\
\text { mothers }\end{array}$ & $\begin{array}{c}\text { 4. Low- } \\
\text { educated rural } \\
\text { long-term } \\
\text { unemployed }\end{array}$ & $\begin{array}{l}\text { 5. Single male } \\
\text { NEETs }\end{array}$ & $\begin{array}{c}\text { 6. Low- } \\
\text { educated } \\
\text { early-retired } \\
\text { and disabled }\end{array}$ \\
\hline Primary & $33 \%$ & $43 \%$ & $41 \%$ & $96 \%$ & $51 \%$ & $50 \%$ \\
\hline Secondary & $59 \%$ & $41 \%$ & $41 \%$ & $3 \%$ & $37 \%$ & $40 \%$ \\
\hline Tertiary & $6 \%$ & $15 \%$ & $14 \%$ & $0 \%$ & $7 \%$ & $3 \%$ \\
\hline NA & $3 \%$ & $1 \%$ & $4 \%$ & $1 \%$ & $5 \%$ & $7 \%$ \\
\hline Urban & $38 \%$ & $45 \%$ & $46 \%$ & $26 \%$ & $36 \%$ & $55 \%$ \\
\hline Rural & $62 \%$ & $55 \%$ & $54 \%$ & $74 \%$ & $64 \%$ & $45 \%$ \\
\hline \multicolumn{7}{|c|}{ INACTIVE COVARIATES } \\
\hline \multicolumn{7}{|l|}{ Age groups (7) } \\
\hline 16-19 years & $0 \%$ & $0 \%$ & $15 \%$ & $3 \%$ & $41 \%$ & $3 \%$ \\
\hline 20-24 years & $0 \%$ & $0 \%$ & $25 \%$ & $6 \%$ & $36 \%$ & $8 \%$ \\
\hline $25-34$ years & $5 \%$ & $1 \%$ & $43 \%$ & $35 \%$ & $23 \%$ & $18 \%$ \\
\hline $35-44$ years & $30 \%$ & $2 \%$ & $8 \%$ & $22 \%$ & $0 \%$ & $19 \%$ \\
\hline $45-54$ years & $34 \%$ & $7 \%$ & $6 \%$ & $19 \%$ & $0 \%$ & $29 \%$ \\
\hline $55-59$ years & $27 \%$ & $13 \%$ & $2 \%$ & $12 \%$ & $0 \%$ & $23 \%$ \\
\hline 60-64 years & $3 \%$ & $77 \%$ & $1 \%$ & $3 \%$ & $0 \%$ & $0 \%$ \\
\hline \multicolumn{7}{|l|}{ Education } \\
\hline None/less than primary & $1 \%$ & $1 \%$ & $5 \%$ & $5 \%$ & $6 \%$ & $0 \%$ \\
\hline Primary & $7 \%$ & $5 \%$ & $12 \%$ & $28 \%$ & $22 \%$ & $12 \%$ \\
\hline Lower secondary & $25 \%$ & $37 \%$ & $24 \%$ & $63 \%$ & $24 \%$ & $37 \%$ \\
\hline Upper secondary & $58 \%$ & $40 \%$ & $41 \%$ & $3 \%$ & $37 \%$ & $40 \%$ \\
\hline Post-secondary & $0 \%$ & $1 \%$ & $1 \%$ & $0 \%$ & $0 \%$ & $0 \%$ \\
\hline Tertiary & $6 \%$ & $15 \%$ & $14 \%$ & $0 \%$ & $7 \%$ & $3 \%$ \\
\hline NA & $3 \%$ & $1 \%$ & $4 \%$ & $1 \%$ & $5 \%$ & $7 \%$ \\
\hline \multicolumn{7}{|l|}{ Enrolled in education ${ }^{a}$} \\
\hline Yes & $0 \%$ & $0 \%$ & $2 \%$ & $0 \%$ & $3 \%$ & $0 \%$ \\
\hline No & $100 \%$ & $100 \%$ & $98 \%$ & $100 \%$ & $97 \%$ & $100 \%$ \\
\hline \multicolumn{7}{|l|}{ Marital status } \\
\hline Married & $74 \%$ & $69 \%$ & $63 \%$ & $63 \%$ & $3 \%$ & $23 \%$ \\
\hline
\end{tabular}




\begin{tabular}{|c|c|c|c|c|c|c|}
\hline & $\begin{array}{l}\text { 1. Unemployed } \\
\text { and early } \\
\text { retirees }\end{array}$ & 2. Retirees & $\begin{array}{l}\text { 3. Stay-at- } \\
\text { home young } \\
\text { mothers }\end{array}$ & $\begin{array}{c}\text { 4. Low- } \\
\text { educated rural } \\
\text { long-term } \\
\text { unemployed }\end{array}$ & $\begin{array}{l}\text { 5. Single male } \\
\text { NEETs }\end{array}$ & $\begin{array}{c}\text { 6. Low- } \\
\text { educated } \\
\text { early-retired } \\
\text { and disabled }\end{array}$ \\
\hline Never married & $12 \%$ & $5 \%$ & $33 \%$ & $30 \%$ & $90 \%$ & $46 \%$ \\
\hline Divorced/separated & $7 \%$ & $7 \%$ & $2 \%$ & $5 \%$ & $6 \%$ & $16 \%$ \\
\hline Widowed & $6 \%$ & $19 \%$ & $2 \%$ & $3 \%$ & $0 \%$ & $15 \%$ \\
\hline \multicolumn{7}{|l|}{ Income quintileb } \\
\hline Poorest & $30 \%$ & $25 \%$ & $27 \%$ & $69 \%$ & $48 \%$ & $31 \%$ \\
\hline Q2 & $23 \%$ & $24 \%$ & $19 \%$ & $18 \%$ & $23 \%$ & $31 \%$ \\
\hline Q3 & $19 \%$ & $26 \%$ & $17 \%$ & $7 \%$ & $10 \%$ & $21 \%$ \\
\hline Q4 & $19 \%$ & $17 \%$ & $20 \%$ & $4 \%$ & $10 \%$ & $12 \%$ \\
\hline Richest & $9 \%$ & $9 \%$ & $16 \%$ & $2 \%$ & $9 \%$ & $5 \%$ \\
\hline \multicolumn{7}{|c|}{ At least one working adult in householdc } \\
\hline No & $33 \%$ & $55 \%$ & $14 \%$ & $64 \%$ & $38 \%$ & $42 \%$ \\
\hline Yes & $67 \%$ & $45 \%$ & $86 \%$ & $36 \%$ & $62 \%$ & $58 \%$ \\
\hline \multicolumn{7}{|l|}{ Partner economic status } \\
\hline Working & $51 \%$ & $12 \%$ & $77 \%$ & $10 \%$ & $0 \%$ & $14 \%$ \\
\hline Unemployed & $16 \%$ & $7 \%$ & $5 \%$ & $54 \%$ & $5 \%$ & $4 \%$ \\
\hline Retired & $10 \%$ & $50 \%$ & $2 \%$ & $11 \%$ & $0 \%$ & $5 \%$ \\
\hline Inactive & $1 \%$ & $2 \%$ & $1 \%$ & $6 \%$ & $2 \%$ & $1 \%$ \\
\hline \multicolumn{7}{|l|}{ Student/military service } \\
\hline No partner & $22 \%$ & $29 \%$ & $15 \%$ & $18 \%$ & $94 \%$ & $76 \%$ \\
\hline Partner income (mean) & 1833 & 795 & 2622 & 587 & 195 & 1129 \\
\hline \multicolumn{7}{|l|}{ Partner income quintile } \\
\hline Poorest & $11 \%$ & $2 \%$ & $14 \%$ & $3 \%$ & $0 \%$ & $4 \%$ \\
\hline Q2 & $11 \%$ & $3 \%$ & $14 \%$ & $3 \%$ & $0 \%$ & $4 \%$ \\
\hline Q3 & $11 \%$ & $3 \%$ & $14 \%$ & $2 \%$ & $0 \%$ & $3 \%$ \\
\hline Q4 & $9 \%$ & $3 \%$ & $16 \%$ & $1 \%$ & $0 \%$ & $2 \%$ \\
\hline Richest & $11 \%$ & $1 \%$ & $20 \%$ & $2 \%$ & $0 \%$ & $1 \%$ \\
\hline No partner or partner without income & $49 \%$ & $88 \%$ & $23 \%$ & $90 \%$ & $100 \%$ & $86 \%$ \\
\hline Household size (mean) & 3.906 & 3.117 & 5.495 & 5.002 & 5.031 & 3.839 \\
\hline
\end{tabular}




\begin{tabular}{|c|c|c|c|c|c|c|}
\hline & $\begin{array}{l}\text { 1. Unemployed } \\
\text { and early } \\
\text { retirees }\end{array}$ & 2. Retirees & $\begin{array}{l}\text { 3. Stay-at- } \\
\text { home young } \\
\text { mothers }\end{array}$ & $\begin{array}{c}\text { 4. Low- } \\
\text { educated rural } \\
\text { long-term } \\
\text { unemployed }\end{array}$ & $\begin{array}{l}\text { 5. Single male } \\
\text { NEETs }\end{array}$ & $\begin{array}{c}\text { 6. Low- } \\
\text { educated } \\
\text { early-retired } \\
\text { and disabled }\end{array}$ \\
\hline \multicolumn{7}{|l|}{ Tenure status } \\
\hline Owner & $88 \%$ & $93 \%$ & $80 \%$ & $74 \%$ & $82 \%$ & $90 \%$ \\
\hline Tenant & $1 \%$ & $0 \%$ & $4 \%$ & $1 \%$ & $1 \%$ & $0 \%$ \\
\hline Reduced rate & $2 \%$ & $1 \%$ & $3 \%$ & $4 \%$ & $5 \%$ & $0 \%$ \\
\hline Free & $9 \%$ & $6 \%$ & $13 \%$ & $20 \%$ & $12 \%$ & $9 \%$ \\
\hline \multicolumn{7}{|l|}{ Household composition } \\
\hline One-person & $3 \%$ & $7 \%$ & $0 \%$ & $2 \%$ & $0 \%$ & $4 \%$ \\
\hline Single parent & $1 \%$ & $1 \%$ & $1 \%$ & $1 \%$ & $3 \%$ & $5 \%$ \\
\hline $2+$ adults without dependent children ${ }^{\mathrm{d}}$ & $47 \%$ & $62 \%$ & $12 \%$ & $27 \%$ & $29 \%$ & $45 \%$ \\
\hline $2+$ adults with 1 dependent child ${ }^{d}$ & $8 \%$ & $5 \%$ & $11 \%$ & $8 \%$ & $9 \%$ & $7 \%$ \\
\hline $2+$ adults with $2+$ dependent children ${ }^{\mathrm{d}}$ & $41 \%$ & $25 \%$ & $76 \%$ & $62 \%$ & $59 \%$ & $39 \%$ \\
\hline Children under six & $17 \%$ & $10 \%$ & $67 \%$ & $38 \%$ & $25 \%$ & $17 \%$ \\
\hline Three or more children under 16 & $4 \%$ & $1 \%$ & $17 \%$ & $14 \%$ & $13 \%$ & $3 \%$ \\
\hline Elderly present (over 64) & $20 \%$ & $34 \%$ & $19 \%$ & $14 \%$ & $24 \%$ & $38 \%$ \\
\hline \multicolumn{7}{|l|}{ Children under 13 in childcare } \\
\hline No children under 13 in household & $64 \%$ & $76 \%$ & $18 \%$ & $38 \%$ & $59 \%$ & $67 \%$ \\
\hline All of the children & $18 \%$ & $14 \%$ & $32 \%$ & $24 \%$ & $14 \%$ & $14 \%$ \\
\hline None of the children & $12 \%$ & $7 \%$ & $29 \%$ & $18 \%$ & $16 \%$ & $12 \%$ \\
\hline Some of the children & $6 \%$ & $4 \%$ & $20 \%$ & $20 \%$ & $10 \%$ & $7 \%$ \\
\hline Years of work experience ${ }^{e}$ & 20.518 & 32.095 & 7.860 & 12.868 & 2.999 & 20.433 \\
\hline Worked more than 2 months in last year & $35 \%$ & $16 \%$ & $26 \%$ & $28 \%$ & $21 \%$ & $8 \%$ \\
\hline \multicolumn{7}{|l|}{ Ever worked } \\
\hline No & $6 \%$ & $2 \%$ & $43 \%$ & $27 \%$ & $72 \%$ & $40 \%$ \\
\hline Yes & $86 \%$ & $94 \%$ & $40 \%$ & $57 \%$ & $21 \%$ & $58 \%$ \\
\hline NA & $8 \%$ & $4 \%$ & $18 \%$ & $15 \%$ & $7 \%$ & $2 \%$ \\
\hline \multicolumn{7}{|l|}{ Able to keep dwelling warm } \\
\hline No & $28 \%$ & $25 \%$ & $39 \%$ & $17 \%$ & $21 \%$ & $24 \%$ \\
\hline Yes & $72 \%$ & $75 \%$ & $60 \%$ & $83 \%$ & $79 \%$ & $76 \%$ \\
\hline
\end{tabular}




\begin{tabular}{|c|c|c|c|c|c|c|}
\hline & $\begin{array}{l}\text { 1. Unemployed } \\
\text { and early } \\
\text { retirees }\end{array}$ & 2. Retirees & $\begin{array}{l}\text { 3. Stay-at- } \\
\text { home young } \\
\text { mothers }\end{array}$ & $\begin{array}{c}\text { 4. Low- } \\
\text { educated rural } \\
\text { long-term } \\
\text { unemployed }\end{array}$ & $\begin{array}{l}\text { 5. Single male } \\
\text { NEETs }\end{array}$ & $\begin{array}{c}\text { 6. Low- } \\
\text { educated } \\
\text { early-retired } \\
\text { and disabled }\end{array}$ \\
\hline NA & $0 \%$ & $0 \%$ & $0 \%$ & $0 \%$ & $0 \%$ & $0 \%$ \\
\hline \multicolumn{7}{|l|}{ Degree of urbanization } \\
\hline Densely populated & $31 \%$ & $39 \%$ & $38 \%$ & $18 \%$ & $29 \%$ & $48 \%$ \\
\hline Intermediate area & $7 \%$ & $6 \%$ & $8 \%$ & $8 \%$ & $7 \%$ & $7 \%$ \\
\hline Sparsely populated & $62 \%$ & $55 \%$ & $54 \%$ & $74 \%$ & $64 \%$ & $45 \%$ \\
\hline \multicolumn{7}{|l|}{ Region } \\
\hline BG3 - Northern \& Eastern & $57 \%$ & $53 \%$ & $61 \%$ & $65 \%$ & $61 \%$ & $54 \%$ \\
\hline BG4 - South-Western \& South-Central & $43 \%$ & $47 \%$ & $39 \%$ & $35 \%$ & $39 \%$ & $47 \%$ \\
\hline Receives at least one benefit & $63 \%$ & $98 \%$ & $73 \%$ & $71 \%$ & $51 \%$ & $93 \%$ \\
\hline \multicolumn{7}{|l|}{ Receives benefits at household level } \\
\hline Family child & $30 \%$ & $19 \%$ & $69 \%$ & $55 \%$ & $39 \%$ & $28 \%$ \\
\hline Social exclusion & $17 \%$ & $11 \%$ & $13 \%$ & $40 \%$ & $30 \%$ & $38 \%$ \\
\hline Housing allowance & $0 \%$ & $0 \%$ & $0 \%$ & $0 \%$ & $0 \%$ & $1 \%$ \\
\hline \multicolumn{7}{|l|}{ Receives benefits at individual level } \\
\hline Unemployment & $6 \%$ & $0 \%$ & $1 \%$ & $3 \%$ & $1 \%$ & $1 \%$ \\
\hline Old age & $15 \%$ & $80 \%$ & $0 \%$ & $1 \%$ & $0 \%$ & $18 \%$ \\
\hline Survivor & $2 \%$ & $14 \%$ & $0 \%$ & $1 \%$ & $0 \%$ & $6 \%$ \\
\hline Sickness & $0 \%$ & $0 \%$ & $1 \%$ & $1 \%$ & $2 \%$ & $2 \%$ \\
\hline Disability & $17 \%$ & $23 \%$ & $3 \%$ & $5 \%$ & $3 \%$ & $74 \%$ \\
\hline
\end{tabular}

a. Applies to individuals aged 25 and over. Students aged 16 to 24 are not included in the sample.

b. Based on total equivalized disposable household income.

c. Refers to individuals aged 25 and over.

d. Dependent children include: 1. household members under 18; 2. household members aged between 18 and 24 who are economically inactive and living with at least one parent.

e. Refers only to individuals who have worked before.

Source: WB staff calculations based on EU-SILC. 


\begin{tabular}{|c|c|c|c|c|c|c|c|c|}
\hline & $\begin{array}{l}\text { All Out- } \\
\text { of-Work }\end{array}$ & $\begin{array}{l}\text { 1. Middle-aged } \\
\text { educated } \\
\text { disabled with } \\
\text { previous work } \\
\text { experience }\end{array}$ & $\begin{array}{l}\text { 2. Prime-age } \\
\text { low income } \\
\text { long-term } \\
\text { unemployed }\end{array}$ & $\begin{array}{c}3 . \\
\text { Educated } \\
\text { retirees }\end{array}$ & $\begin{array}{l}\text { 4. Young } \\
\text { inactive } \\
\text { educated } \\
\text { mothers with } \\
\text { working } \\
\text { partner }\end{array}$ & $\begin{array}{l}\text { 5. Prime- } \\
\text { age } \\
\text { educated } \\
\text { un- } \\
\text { employed }\end{array}$ & $\begin{array}{c}\text { 6. Single } \\
\text { NEETs } \\
\text { without } \\
\text { work } \\
\text { experience }\end{array}$ & $\begin{array}{l}\text { 7. Young } \\
\text { low- } \\
\text { educated } \\
\text { and rural } \\
\text { disabled }\end{array}$ \\
\hline Cluster size & $100 \%$ & $21 \%$ & $19 \%$ & $17 \%$ & $17 \%$ & $13 \%$ & $9 \%$ & $3 \%$ \\
\hline Population & 224,738 & 47,694 & 43,446 & 39,221 & 37,108 & 29,421 & 20,656 & 7,192 \\
\hline \multicolumn{9}{|c|}{ INDICATORS } \\
\hline \multicolumn{9}{|l|}{ Labor market attachment } \\
\hline Unemployed & $18 \%$ & $3 \%$ & $4 \%$ & $0 \%$ & $7 \%$ & $90 \%$ & $35 \%$ & $4 \%$ \\
\hline Long-term unemployed & $19 \%$ & $1 \%$ & $85 \%$ & $0 \%$ & $0 \%$ & $0 \%$ & $25 \%$ & $6 \%$ \\
\hline Retired & $18 \%$ & $3 \%$ & $0 \%$ & $100 \%$ & $0 \%$ & $0 \%$ & $0 \%$ & $0 \%$ \\
\hline Disabled & $22 \%$ & $92 \%$ & $0 \%$ & $0 \%$ & $0 \%$ & $0 \%$ & $1 \%$ & $76 \%$ \\
\hline Other inactive & $23 \%$ & $1 \%$ & $11 \%$ & $0 \%$ & $92 \%$ & $10 \%$ & $39 \%$ & $14 \%$ \\
\hline \multicolumn{9}{|c|}{ At least one working adult in householda } \\
\hline No & $48 \%$ & $65 \%$ & $52 \%$ & $65 \%$ & $15 \%$ & $47 \%$ & $24 \%$ & $68 \%$ \\
\hline Yes & $52 \%$ & $35 \%$ & $48 \%$ & $35 \%$ & $85 \%$ & $53 \%$ & $76 \%$ & $32 \%$ \\
\hline \multicolumn{9}{|l|}{ Work experience } \\
\hline Never worked & $11 \%$ & $0 \%$ & $0 \%$ & $0 \%$ & $3 \%$ & $0 \%$ & $79 \%$ & $96 \%$ \\
\hline Less than 2 months in last year & $68 \%$ & $94 \%$ & $100 \%$ & $87 \%$ & $72 \%$ & $1 \%$ & $20 \%$ & $3 \%$ \\
\hline 2 or more months in last year & $21 \%$ & $6 \%$ & $0 \%$ & $13 \%$ & $26 \%$ & $99 \%$ & $0 \%$ & $1 \%$ \\
\hline \multicolumn{9}{|l|}{ Self-assessed physical incapacity } \\
\hline Strongly limited & $13 \%$ & $43 \%$ & $2 \%$ & $11 \%$ & $0 \%$ & $2 \%$ & $0 \%$ & $51 \%$ \\
\hline None/limited & $85 \%$ & $57 \%$ & $98 \%$ & $89 \%$ & $100 \%$ & $98 \%$ & $100 \%$ & $49 \%$ \\
\hline \multicolumn{9}{|c|}{ ACTIVE COVARIATES } \\
\hline \multicolumn{9}{|l|}{ Age groups (4) } \\
\hline 16-24 years & $11 \%$ & $0 \%$ & $3 \%$ & $0 \%$ & $5 \%$ & $13 \%$ & $82 \%$ & $23 \%$ \\
\hline $25-34$ years & $23 \%$ & $4 \%$ & $25 \%$ & $0 \%$ & $69 \%$ & $22 \%$ & $18 \%$ & $46 \%$ \\
\hline $35-59$ years & $47 \%$ & $86 \%$ & $73 \%$ & $8 \%$ & $26 \%$ & $62 \%$ & $0 \%$ & $31 \%$ \\
\hline
\end{tabular}




\begin{tabular}{|c|c|c|c|c|c|c|c|c|}
\hline & $\begin{array}{l}\text { All Out- } \\
\text { of-Work }\end{array}$ & $\begin{array}{l}\text { 1. Middle-aged } \\
\text { educated } \\
\text { disabled with } \\
\text { previous work } \\
\text { experience }\end{array}$ & $\begin{array}{l}\text { 2. Prime-age } \\
\text { low income } \\
\text { long-term } \\
\text { unemployed }\end{array}$ & $\begin{array}{c}3 . \\
\text { Educated } \\
\text { retirees }\end{array}$ & $\begin{array}{c}\text { 4. Young } \\
\text { inactive } \\
\text { educated } \\
\text { mothers with } \\
\text { working } \\
\text { partner }\end{array}$ & $\begin{array}{l}\text { 5. Prime- } \\
\text { age } \\
\text { educated } \\
\text { un- } \\
\text { employed }\end{array}$ & $\begin{array}{c}\text { 6. Single } \\
\text { NEETs } \\
\text { without } \\
\text { work } \\
\text { experience }\end{array}$ & $\begin{array}{l}\text { 7. Young } \\
\text { low- } \\
\text { educated } \\
\text { and rural } \\
\text { disabled }\end{array}$ \\
\hline 60-64 years & $19 \%$ & $10 \%$ & $0 \%$ & $92 \%$ & $0 \%$ & $3 \%$ & $0 \%$ & $0 \%$ \\
\hline \multicolumn{9}{|l|}{ Gender } \\
\hline Male & $46 \%$ & $58 \%$ & $63 \%$ & $37 \%$ & $6 \%$ & $63 \%$ & $47 \%$ & $54 \%$ \\
\hline Female & $54 \%$ & $42 \%$ & $37 \%$ & $63 \%$ & $94 \%$ & $37 \%$ & $53 \%$ & $46 \%$ \\
\hline \multicolumn{9}{|l|}{ Education (4) } \\
\hline Primary & $20 \%$ & $21 \%$ & $22 \%$ & $16 \%$ & $7 \%$ & $15 \%$ & $36 \%$ & $71 \%$ \\
\hline Secondary & $56 \%$ & $64 \%$ & $68 \%$ & $55 \%$ & $40 \%$ & $56 \%$ & $51 \%$ & $28 \%$ \\
\hline Tertiary & $23 \%$ & $14 \%$ & $10 \%$ & $29 \%$ & $52 \%$ & $27 \%$ & $9 \%$ & $1 \%$ \\
\hline $\begin{array}{l}\text { Never studied } \\
\text { before/illiterate/NA }\end{array}$ & $1 \%$ & $0 \%$ & $0 \%$ & $0 \%$ & $1 \%$ & $2 \%$ & $4 \%$ & $0 \%$ \\
\hline Urban & $47 \%$ & $38 \%$ & $53 \%$ & $44 \%$ & $55 \%$ & $58 \%$ & $37 \%$ & $27 \%$ \\
\hline Rural & $53 \%$ & $62 \%$ & $47 \%$ & $56 \%$ & $45 \%$ & $42 \%$ & $63 \%$ & $73 \%$ \\
\hline \multicolumn{9}{|c|}{ INACTIVE COVARIATES } \\
\hline \multicolumn{9}{|l|}{ Age groups (8) } \\
\hline $16-19$ years & $2 \%$ & $0 \%$ & $0 \%$ & $0 \%$ & $0 \%$ & $2 \%$ & $20 \%$ & $8 \%$ \\
\hline 20-24 years & $9 \%$ & $0 \%$ & $3 \%$ & $0 \%$ & $5 \%$ & $11 \%$ & $61 \%$ & $15 \%$ \\
\hline $25-29$ years & $12 \%$ & $1 \%$ & $14 \%$ & $0 \%$ & $35 \%$ & $12 \%$ & $13 \%$ & $26 \%$ \\
\hline $30-34$ years & $11 \%$ & $3 \%$ & $11 \%$ & $0 \%$ & $34 \%$ & $10 \%$ & $6 \%$ & $20 \%$ \\
\hline $35-44$ years & $15 \%$ & $14 \%$ & $28 \%$ & $0 \%$ & $20 \%$ & $23 \%$ & $0 \%$ & $12 \%$ \\
\hline $45-54$ years & $20 \%$ & $41 \%$ & $31 \%$ & $0 \%$ & $4 \%$ & $30 \%$ & $0 \%$ & $14 \%$ \\
\hline $55-59$ years & $12 \%$ & $31 \%$ & $14 \%$ & $8 \%$ & $2 \%$ & $8 \%$ & $0 \%$ & $4 \%$ \\
\hline $60-64$ years & $19 \%$ & $10 \%$ & $0 \%$ & $92 \%$ & $0 \%$ & $3 \%$ & $0 \%$ & $0 \%$ \\
\hline \multicolumn{9}{|l|}{ Education (6) } \\
\hline None or less than primary & $1 \%$ & $0 \%$ & $0 \%$ & $0 \%$ & $0 \%$ & $0 \%$ & $0 \%$ & $21 \%$ \\
\hline Primary & $2 \%$ & $1 \%$ & $1 \%$ & $1 \%$ & $1 \%$ & $1 \%$ & $5 \%$ & $11 \%$ \\
\hline Lower secondary & $18 \%$ & $20 \%$ & $20 \%$ & $15 \%$ & $6 \%$ & $13 \%$ & $31 \%$ & $40 \%$ \\
\hline Upper secondary & $53 \%$ & $61 \%$ & $65 \%$ & $54 \%$ & $36 \%$ & $52 \%$ & $48 \%$ & $27 \%$ \\
\hline
\end{tabular}




\begin{tabular}{|c|c|c|c|c|c|c|c|c|}
\hline & $\begin{array}{l}\text { All Out- } \\
\text { of-Work }\end{array}$ & $\begin{array}{l}\text { 1. Middle-aged } \\
\text { educated } \\
\text { disabled with } \\
\text { previous work } \\
\text { experience }\end{array}$ & $\begin{array}{l}\text { 2. Prime-age } \\
\text { low income } \\
\text { long-term } \\
\text { unemployed }\end{array}$ & $\begin{array}{c}3 . \\
\text { Educated } \\
\text { retirees }\end{array}$ & $\begin{array}{l}\text { 4. Young } \\
\text { inactive } \\
\text { educated } \\
\text { mothers with } \\
\text { working } \\
\text { partner }\end{array}$ & $\begin{array}{l}\text { 5. Prime- } \\
\text { age } \\
\text { educated } \\
\text { un- } \\
\text { employed }\end{array}$ & $\begin{array}{c}\text { 6. Single } \\
\text { NEETs } \\
\text { without } \\
\text { work } \\
\text { experience }\end{array}$ & $\begin{array}{l}\text { 7. Young } \\
\text { low- } \\
\text { educated } \\
\text { and rural } \\
\text { disabled }\end{array}$ \\
\hline Post-secondary & $3 \%$ & $3 \%$ & $4 \%$ & $1 \%$ & $4 \%$ & $4 \%$ & $2 \%$ & $0 \%$ \\
\hline Tertiary & $23 \%$ & $14 \%$ & $10 \%$ & $29 \%$ & $52 \%$ & $27 \%$ & $9 \%$ & $1 \%$ \\
\hline NA & $1 \%$ & $0 \%$ & $0 \%$ & $0 \%$ & $1 \%$ & $2 \%$ & $4 \%$ & $0 \%$ \\
\hline \multicolumn{9}{|l|}{ Enrolled in education ${ }^{b}$} \\
\hline Yes & $3 \%$ & $0 \%$ & $1 \%$ & $0 \%$ & $12 \%$ & $3 \%$ & $3 \%$ & $1 \%$ \\
\hline No & $96 \%$ & $100 \%$ & $99 \%$ & $100 \%$ & $87 \%$ & $94 \%$ & $93 \%$ & $99 \%$ \\
\hline NA & $1 \%$ & $0 \%$ & $0 \%$ & $0 \%$ & $1 \%$ & $2 \%$ & $4 \%$ & $0 \%$ \\
\hline \multicolumn{9}{|l|}{ Ever worked } \\
\hline No & $11 \%$ & $0 \%$ & $0 \%$ & $0 \%$ & $3 \%$ & $0 \%$ & $76 \%$ & $96 \%$ \\
\hline Yes & $88 \%$ & $100 \%$ & $100 \%$ & $100 \%$ & $96 \%$ & $98 \%$ & $20 \%$ & $4 \%$ \\
\hline NA & $1 \%$ & $0 \%$ & $0 \%$ & $0 \%$ & $1 \%$ & $2 \%$ & $4 \%$ & $0 \%$ \\
\hline Years of work experience & 20 & 22 & 16 & 36 & 8 & 17 & 2 & 10 \\
\hline \multicolumn{9}{|l|}{ Household income (mean) } \\
\hline Labor income & 7129 & 3425 & 5070 & 3759 & 14262 & 10785 & 9538 & 3824 \\
\hline Other income & 120 & 64 & 140 & 52 & 176 & 228 & 106 & 54 \\
\hline Benefits & 3801 & 3876 & 2496 & 5306 & 5391 & 2183 & 2616 & 4785 \\
\hline \multicolumn{9}{|l|}{ Household income shares ${ }^{d}$} \\
\hline Labor income & $48 \%$ & $29 \%$ & $51 \%$ & $26 \%$ & $64 \%$ & $75 \%$ & $68 \%$ & $31 \%$ \\
\hline Other income & $2 \%$ & $1 \%$ & $4 \%$ & $0 \%$ & $2 \%$ & $3 \%$ & $1 \%$ & $0 \%$ \\
\hline Benefits & $50 \%$ & $69 \%$ & $45 \%$ & $74 \%$ & $33 \%$ & $22 \%$ & $30 \%$ & $69 \%$ \\
\hline \multicolumn{9}{|l|}{ Income quintile ${ }^{e}$} \\
\hline Poorest & $41 \%$ & $51 \%$ & $66 \%$ & $26 \%$ & $19 \%$ & $36 \%$ & $43 \%$ & $50 \%$ \\
\hline Q2 & $21 \%$ & $26 \%$ & $15 \%$ & $34 \%$ & $13 \%$ & $15 \%$ & $18 \%$ & $24 \%$ \\
\hline Q3 & $15 \%$ & $13 \%$ & $11 \%$ & $19 \%$ & $17 \%$ & $15 \%$ & $20 \%$ & $17 \%$ \\
\hline Q4 & $12 \%$ & $8 \%$ & $5 \%$ & $13 \%$ & $19 \%$ & $19 \%$ & $13 \%$ & $8 \%$ \\
\hline Richest & $10 \%$ & $2 \%$ & $4 \%$ & $9 \%$ & $31 \%$ & $15 \%$ & $6 \%$ & $1 \%$ \\
\hline
\end{tabular}



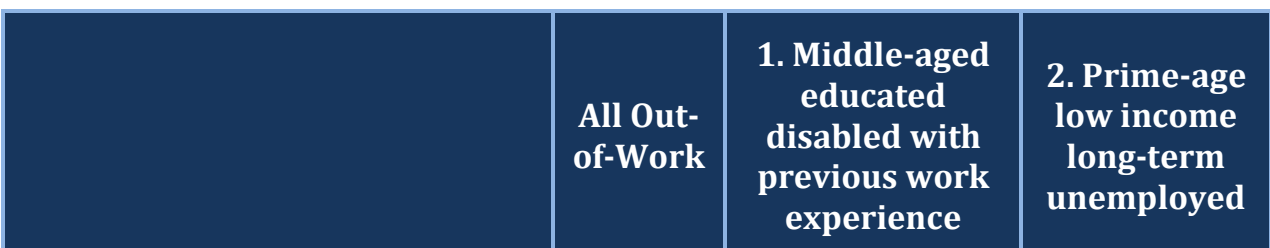

\begin{tabular}{|c|c|}
\hline $\begin{array}{c}3 . \\
\text { Educated } \\
\text { retirees }\end{array}$ & $\begin{array}{l}\text { 4. Young } \\
\text { inactive } \\
\text { educated } \\
\text { mothers with } \\
\text { working } \\
\text { partner }\end{array}$ \\
\hline
\end{tabular}

5. Prime-

age

educated

un-

employed
6. Single

NEETS

without

work

experience
7. Young

low-

educated

and rural

disabled

\section{Poverty Risk}

\begin{tabular}{|c|c|c|c|c|c|c|c|c|}
\hline No & $63 \%$ & $52 \%$ & $39 \%$ & $81 \%$ & $84 \%$ & $67 \%$ & $60 \%$ & $54 \%$ \\
\hline Yes & $37 \%$ & $48 \%$ & $61 \%$ & $19 \%$ & $16 \%$ & $33 \%$ & $40 \%$ & $46 \%$ \\
\hline \multicolumn{9}{|l|}{ Working partner } \\
\hline Yes & $37 \%$ & $28 \%$ & $36 \%$ & $24 \%$ & $77 \%$ & $40 \%$ & $17 \%$ & $9 \%$ \\
\hline No & $22 \%$ & $25 \%$ & $24 \%$ & $44 \%$ & $9 \%$ & $16 \%$ & $11 \%$ & $14 \%$ \\
\hline NA & $40 \%$ & $46 \%$ & $40 \%$ & $32 \%$ & $14 \%$ & $44 \%$ & $72 \%$ & $77 \%$ \\
\hline \multicolumn{9}{|l|}{ Partner economic status } \\
\hline Working & $37 \%$ & $28 \%$ & $36 \%$ & $24 \%$ & $77 \%$ & $40 \%$ & $17 \%$ & $9 \%$ \\
\hline Unemployed & $6 \%$ & $6 \%$ & $10 \%$ & $2 \%$ & $7 \%$ & $6 \%$ & $5 \%$ & $5 \%$ \\
\hline Retired & $8 \%$ & $7 \%$ & $2 \%$ & $35 \%$ & $1 \%$ & $1 \%$ & $0 \%$ & $3 \%$ \\
\hline Inactive & $7 \%$ & $12 \%$ & $11 \%$ & $6 \%$ & $1 \%$ & $7 \%$ & $4 \%$ & $5 \%$ \\
\hline Student/military service & $0 \%$ & $0 \%$ & $0 \%$ & $0 \%$ & $0 \%$ & $1 \%$ & $2 \%$ & $1 \%$ \\
\hline NA & $40 \%$ & $46 \%$ & $40 \%$ & $32 \%$ & $14 \%$ & $44 \%$ & $72 \%$ & $77 \%$ \\
\hline Partner income (mean) & 6302 & 3621 & 4800 & 2741 & 12956 & 5647 & 7148 & 4060 \\
\hline $\begin{array}{l}\text { Working partner income } \\
\text { (mean) }\end{array}$ & 9711 & 6480 & 7404 & 7131 & 14168 & 7439 & 10776 & 9467 \\
\hline \multicolumn{9}{|l|}{ Partner income quintile } \\
\hline Poorest & $8 \%$ & $7 \%$ & $9 \%$ & $6 \%$ & $9 \%$ & $13 \%$ & $3 \%$ & $1 \%$ \\
\hline Q2 & $8 \%$ & $9 \%$ & $10 \%$ & $8 \%$ & $7 \%$ & $7 \%$ & $2 \%$ & $2 \%$ \\
\hline Q3 & $7 \%$ & $7 \%$ & $8 \%$ & $4 \%$ & $11 \%$ & $8 \%$ & $1 \%$ & $2 \%$ \\
\hline Q4 & $6 \%$ & $3 \%$ & $5 \%$ & $4 \%$ & $16 \%$ & $7 \%$ & $4 \%$ & $3 \%$ \\
\hline Richest & $9 \%$ & $2 \%$ & $4 \%$ & $3 \%$ & $35 \%$ & $5 \%$ & $6 \%$ & $2 \%$ \\
\hline $\begin{array}{l}\text { No partner or partner without } \\
\text { income }\end{array}$ & $63 \%$ & $72 \%$ & $64 \%$ & $76 \%$ & $23 \%$ & $60 \%$ & $83 \%$ & $91 \%$ \\
\hline Receives at least one benefit & $84 \%$ & $98 \%$ & $61 \%$ & $100 \%$ & $92 \%$ & $70 \%$ & $74 \%$ & $94 \%$ \\
\hline
\end{tabular}

Receives benefits at household level 


\begin{tabular}{|c|c|c|c|c|c|c|c|c|}
\hline & $\begin{array}{l}\text { All Out- } \\
\text { of-Work }\end{array}$ & $\begin{array}{l}\text { 1. Middle-aged } \\
\text { educated } \\
\text { disabled with } \\
\text { previous work } \\
\text { experience }\end{array}$ & $\begin{array}{l}\text { 2. Prime-age } \\
\text { low income } \\
\text { long-term } \\
\text { unemployed }\end{array}$ & $\begin{array}{c}3 . \\
\text { Educated } \\
\text { retirees }\end{array}$ & $\begin{array}{c}\text { 4. Young } \\
\text { inactive } \\
\text { educated } \\
\text { mothers with } \\
\text { working } \\
\text { partner }\end{array}$ & $\begin{array}{l}\text { 5. Prime- } \\
\text { age } \\
\text { educated } \\
\text { un- } \\
\text { employed }\end{array}$ & $\begin{array}{c}\text { 6. Single } \\
\text { NEETs } \\
\text { without } \\
\text { work } \\
\text { experience }\end{array}$ & $\begin{array}{l}\text { 7. Young } \\
\text { low- } \\
\text { educated } \\
\text { and rural } \\
\text { disabled }\end{array}$ \\
\hline Family child & $40 \%$ & $22 \%$ & $40 \%$ & $10 \%$ & $84 \%$ & $41 \%$ & $63 \%$ & $33 \%$ \\
\hline Social exclusion & $2 \%$ & $2 \%$ & $1 \%$ & $1 \%$ & $2 \%$ & $2 \%$ & $3 \%$ & $6 \%$ \\
\hline Housing & $7 \%$ & $5 \%$ & $16 \%$ & $2 \%$ & $2 \%$ & $8 \%$ & $5 \%$ & $11 \%$ \\
\hline Old age at household level & $33 \%$ & $24 \%$ & $24 \%$ & $98 \%$ & $9 \%$ & $15 \%$ & $17 \%$ & $38 \%$ \\
\hline \multicolumn{9}{|c|}{ Receives benefits at individual level } \\
\hline Unemployment & $13 \%$ & $5 \%$ & $20 \%$ & $4 \%$ & $10 \%$ & $33 \%$ & $14 \%$ & $0 \%$ \\
\hline Old age & $18 \%$ & $4 \%$ & $0 \%$ & $98 \%$ & $0 \%$ & $0 \%$ & $0 \%$ & $0 \%$ \\
\hline Survivor & $1 \%$ & $1 \%$ & $1 \%$ & $0 \%$ & $0 \%$ & $0 \%$ & $3 \%$ & $0 \%$ \\
\hline Sickness & $3 \%$ & $2 \%$ & $0 \%$ & $3 \%$ & $5 \%$ & $11 \%$ & $0 \%$ & $0 \%$ \\
\hline Disability & $27 \%$ & $93 \%$ & $6 \%$ & $11 \%$ & $3 \%$ & $5 \%$ & $2 \%$ & $80 \%$ \\
\hline Education & $2 \%$ & $0 \%$ & $1 \%$ & $0 \%$ & $8 \%$ & $0 \%$ & $8 \%$ & $0 \%$ \\
\hline \multicolumn{9}{|c|}{ Benefits as share of total gross household income, all households } \\
\hline Family child & $8 \%$ & $2 \%$ & $8 \%$ & $1 \%$ & $24 \%$ & $4 \%$ & $11 \%$ & $7 \%$ \\
\hline Social exclusion & $0 \%$ & $0 \%$ & $0 \%$ & $0 \%$ & $0 \%$ & $0 \%$ & $1 \%$ & $0 \%$ \\
\hline Housing & $2 \%$ & $1 \%$ & $7 \%$ & $0 \%$ & $1 \%$ & $2 \%$ & $1 \%$ & $2 \%$ \\
\hline Unemployment & $3 \%$ & $2 \%$ & $6 \%$ & $1 \%$ & $3 \%$ & $5 \%$ & $3 \%$ & $1 \%$ \\
\hline Old age & $19 \%$ & $12 \%$ & $15 \%$ & $65 \%$ & $3 \%$ & $6 \%$ & $6 \%$ & $21 \%$ \\
\hline Survivor & $0 \%$ & $1 \%$ & $0 \%$ & $0 \%$ & $0 \%$ & $0 \%$ & $1 \%$ & $1 \%$ \\
\hline Sickness & $0 \%$ & $0 \%$ & $0 \%$ & $0 \%$ & $0 \%$ & $1 \%$ & $1 \%$ & $0 \%$ \\
\hline Disability & $16 \%$ & $50 \%$ & $7 \%$ & $6 \%$ & $2 \%$ & $4 \%$ & $5 \%$ & $37 \%$ \\
\hline Education & $0 \%$ & $0 \%$ & $0 \%$ & $0 \%$ & $1 \%$ & $0 \%$ & $1 \%$ & $0 \%$ \\
\hline \multicolumn{9}{|c|}{ Benefits as share of total gross household income, only beneficiaries } \\
\hline Family child & $19 \%$ & $11 \%$ & $19 \%$ & $7 \%$ & $29 \%$ & $10 \%$ & $17 \%$ & $21 \%$ \\
\hline Social exclusion & $9 \%$ & $8 \%$ & $9 \%$ & $5 \%$ & $9 \%$ & $2 \%$ & $20 \%$ & $7 \%$ \\
\hline Housing & $32 \%$ & $13 \%$ & $45 \%$ & $21 \%$ & $23 \%$ & $27 \%$ & $23 \%$ & $19 \%$ \\
\hline Unemployment & $17 \%$ & $22 \%$ & $24 \%$ & $15 \%$ & $14 \%$ & $13 \%$ & $15 \%$ & $11 \%$ \\
\hline
\end{tabular}




\begin{tabular}{|c|c|c|c|c|c|c|c|c|}
\hline & $\begin{array}{l}\text { All Out- } \\
\text { of-Work }\end{array}$ & $\begin{array}{l}\text { 1. Middle-aged } \\
\text { educated } \\
\text { disabled with } \\
\text { previous work } \\
\text { experience }\end{array}$ & $\begin{array}{l}\text { 2. Prime-age } \\
\text { low income } \\
\text { long-term } \\
\text { unemployed }\end{array}$ & $\begin{array}{c}3 . \\
\text { Educated } \\
\text { retirees }\end{array}$ & $\begin{array}{l}\text { 4. Young } \\
\text { inactive } \\
\text { educated } \\
\text { mothers with } \\
\text { working } \\
\text { partner }\end{array}$ & $\begin{array}{l}\text { 5. Prime- } \\
\text { age } \\
\text { educated } \\
\text { un- } \\
\text { employed }\end{array}$ & $\begin{array}{l}\text { 6. Single } \\
\text { NEETs } \\
\text { without } \\
\text { work } \\
\text { experience }\end{array}$ & $\begin{array}{l}\text { 7. Young } \\
\text { low- } \\
\text { educated } \\
\text { and rural } \\
\text { disabled }\end{array}$ \\
\hline Old age & $59 \%$ & $52 \%$ & $62 \%$ & $66 \%$ & $33 \%$ & $37 \%$ & $37 \%$ & $55 \%$ \\
\hline Survivor & $22 \%$ & $26 \%$ & $21 \%$ & $22 \%$ & $26 \%$ & $18 \%$ & $21 \%$ & $16 \%$ \\
\hline Sickness & $3 \%$ & $5 \%$ & $3 \%$ & $4 \%$ & $3 \%$ & $2 \%$ & $3 \%$ & $1 \%$ \\
\hline Disability & $43 \%$ & $53 \%$ & $38 \%$ & $26 \%$ & $25 \%$ & $23 \%$ & $22 \%$ & $43 \%$ \\
\hline Education & $6 \%$ & $8 \%$ & $5 \%$ & $5 \%$ & $6 \%$ & $5 \%$ & $7 \%$ & $5 \%$ \\
\hline Household size (mean) & 2.97 & 2.44 & 3.07 & 2.21 & 3.86 & 2.9 & 3.85 & 3.27 \\
\hline \multicolumn{9}{|l|}{ Household composition } \\
\hline One-person & $15 \%$ & $23 \%$ & $14 \%$ & $23 \%$ & $2 \%$ & $16 \%$ & $3 \%$ & $7 \%$ \\
\hline Single parent & $3 \%$ & $3 \%$ & $1 \%$ & $0 \%$ & $3 \%$ & $6 \%$ & $4 \%$ & $7 \%$ \\
\hline $\begin{array}{l}\text { 2+ adults without dependent } \\
\text { children }^{f}\end{array}$ & $42 \%$ & $53 \%$ & $44 \%$ & $64 \%$ & $10 \%$ & $39 \%$ & $31 \%$ & $51 \%$ \\
\hline $2+$ adults with 1 dependent childf & $13 \%$ & $8 \%$ & $13 \%$ & $5 \%$ & $29 \%$ & $15 \%$ & $15 \%$ & $10 \%$ \\
\hline $\begin{array}{l}\text { 2+ adults with } 2+\text { dependent } \\
\text { children }^{f}\end{array}$ & $27 \%$ & $13 \%$ & $28 \%$ & $9 \%$ & $56 \%$ & $22 \%$ & $45 \%$ & $26 \%$ \\
\hline NA & $0 \%$ & $0 \%$ & $0 \%$ & $0 \%$ & $0 \%$ & $1 \%$ & $2 \%$ & $0 \%$ \\
\hline Children under six & $24 \%$ & $5 \%$ & $19 \%$ & $4 \%$ & $78 \%$ & $18 \%$ & $33 \%$ & $15 \%$ \\
\hline $\begin{array}{l}\text { Three or more children under } \\
16\end{array}$ & $4 \%$ & $1 \%$ & $5 \%$ & $0 \%$ & $12 \%$ & $2 \%$ & $6 \%$ & $5 \%$ \\
\hline \multicolumn{9}{|l|}{ Individuals' parents present } \\
\hline One parent & $11 \%$ & $11 \%$ & $14 \%$ & $2 \%$ & $4 \%$ & $9 \%$ & $26 \%$ & $34 \%$ \\
\hline Both parents & $10 \%$ & $2 \%$ & $11 \%$ & $0 \%$ & $7 \%$ & $11 \%$ & $42 \%$ & $32 \%$ \\
\hline None & $80 \%$ & $88 \%$ & $76 \%$ & $98 \%$ & $89 \%$ & $80 \%$ & $33 \%$ & $35 \%$ \\
\hline Elderly present (over 64) & $14 \%$ & $15 \%$ & $16 \%$ & $22 \%$ & $5 \%$ & $11 \%$ & $12 \%$ & $25 \%$ \\
\hline \multicolumn{9}{|l|}{ Children under 13 in childcare } \\
\hline None of the children & $10 \%$ & $5 \%$ & $9 \%$ & $1 \%$ & $26 \%$ & $6 \%$ & $16 \%$ & $4 \%$ \\
\hline Some of the children & $9 \%$ & $3 \%$ & $8 \%$ & $1 \%$ & $28 \%$ & $6 \%$ & $10 \%$ & $6 \%$ \\
\hline $\begin{array}{l}\text { No children under } 13 \text { in } \\
\text { household }\end{array}$ & $65 \%$ & $84 \%$ & $67 \%$ & $92 \%$ & $16 \%$ & $65 \%$ & $55 \%$ & $75 \%$ \\
\hline
\end{tabular}




\begin{tabular}{|c|c|c|c|c|c|c|c|c|}
\hline & $\begin{array}{l}\text { All Out- } \\
\text { of-Work }\end{array}$ & $\begin{array}{l}\text { 1. Middle-aged } \\
\text { educated } \\
\text { disabled with } \\
\text { previous work } \\
\text { experience }\end{array}$ & $\begin{array}{l}\text { 2. Prime-age } \\
\text { low income } \\
\text { long-term } \\
\text { unemployed }\end{array}$ & $\begin{array}{c}3 . \\
\text { Educated } \\
\text { retirees }\end{array}$ & $\begin{array}{l}\text { 4. Young } \\
\text { inactive } \\
\text { educated } \\
\text { mothers with } \\
\text { working } \\
\text { partner }\end{array}$ & $\begin{array}{l}\text { 5. Prime- } \\
\text { age } \\
\text { educated } \\
\text { un- } \\
\text { employed }\end{array}$ & $\begin{array}{c}\text { 6. Single } \\
\text { NEETs } \\
\text { without } \\
\text { work } \\
\text { experience }\end{array}$ & $\begin{array}{l}\text { 7. Young } \\
\text { low- } \\
\text { educated } \\
\text { and rural } \\
\text { disabled }\end{array}$ \\
\hline All of the children & $16 \%$ & $8 \%$ & $17 \%$ & $6 \%$ & $30 \%$ & $23 \%$ & $19 \%$ & $14 \%$ \\
\hline \multicolumn{9}{|l|}{ Marital status } \\
\hline Married & $42 \%$ & $40 \%$ & $43 \%$ & $59 \%$ & $53 \%$ & $39 \%$ & $10 \%$ & $12 \%$ \\
\hline Never married & $38 \%$ & $26 \%$ & $38 \%$ & $10 \%$ & $43 \%$ & $41 \%$ & $87 \%$ & $82 \%$ \\
\hline Divorced/separated & $14 \%$ & $26 \%$ & $17 \%$ & $12 \%$ & $4 \%$ & $17 \%$ & $3 \%$ & $4 \%$ \\
\hline Widowed & $6 \%$ & $8 \%$ & $3 \%$ & $18 \%$ & $0 \%$ & $3 \%$ & $0 \%$ & $1 \%$ \\
\hline NA & $0 \%$ & $0 \%$ & $0 \%$ & $0 \%$ & $0 \%$ & $0 \%$ & $0 \%$ & $0 \%$ \\
\hline \multicolumn{9}{|l|}{ Tenure status } \\
\hline Owner & $82 \%$ & $81 \%$ & $79 \%$ & $89 \%$ & $82 \%$ & $82 \%$ & $78 \%$ & $75 \%$ \\
\hline Tenant & $3 \%$ & $2 \%$ & $3 \%$ & $0 \%$ & $4 \%$ & $2 \%$ & $7 \%$ & $7 \%$ \\
\hline Reduced rate & $2 \%$ & $2 \%$ & $5 \%$ & $1 \%$ & $1 \%$ & $0 \%$ & $4 \%$ & $2 \%$ \\
\hline Free & $13 \%$ & $15 \%$ & $13 \%$ & $9 \%$ & $13 \%$ & $16 \%$ & $12 \%$ & $16 \%$ \\
\hline NA & $0 \%$ & $0 \%$ & $0 \%$ & $0 \%$ & $0 \%$ & $0 \%$ & $0 \%$ & $0 \%$ \\
\hline \multicolumn{9}{|c|}{ Able to keep dwelling warm } \\
\hline No & $6 \%$ & $11 \%$ & $8 \%$ & $3 \%$ & $1 \%$ & $4 \%$ & $6 \%$ & $11 \%$ \\
\hline Yes & $94 \%$ & $89 \%$ & $92 \%$ & $97 \%$ & $99 \%$ & $96 \%$ & $94 \%$ & $89 \%$ \\
\hline NA & $0 \%$ & $0 \%$ & $0 \%$ & $0 \%$ & $0 \%$ & $0 \%$ & $0 \%$ & $0 \%$ \\
\hline \multicolumn{9}{|c|}{ Degree of urbanization } \\
\hline Densely populated & $47 \%$ & $38 \%$ & $53 \%$ & $44 \%$ & $55 \%$ & $58 \%$ & $37 \%$ & $27 \%$ \\
\hline Sparsely populated & $53 \%$ & $62 \%$ & $47 \%$ & $56 \%$ & $45 \%$ & $42 \%$ & $63 \%$ & $73 \%$ \\
\hline
\end{tabular}

a. Refers to individuals aged 25 and over.

b. Applies to individuals aged 25 and over. Students aged 16 to 24 are not included in the sample.

c. Refers only to individuals who have worked before.

d. Based on total gross household income.

e. Based on total equivalized disposable household income.

f. Dependent children include: 1. household members under 18; 2. household members aged between 18 and 24 who are economically inactive and living with at least one parent. 


\begin{tabular}{|c|c|c|c|c|c|c|}
\hline & $\begin{array}{l}\text { 1. Prime-age } \\
\text { educated } \\
\text { unemployed }\end{array}$ & $\begin{array}{l}\text { 2. Middle-aged } \\
\text { educated disabled } \\
\text { with previous } \\
\text { work experience }\end{array}$ & $\begin{array}{l}\text { 3. Young inactive } \\
\text { educated } \\
\text { mothers with } \\
\text { working partner }\end{array}$ & $\begin{array}{l}\text { 4. Educated } \\
\text { retirees }\end{array}$ & $\begin{array}{l}\text { 5. Middle- } \\
\text { aged long- } \\
\text { term } \\
\text { unemployed } \\
\text { men }\end{array}$ & $\begin{array}{l}\text { 6. Single } \\
\text { uneducated and } \\
\text { rural NEETs } \\
\text { without work } \\
\text { experience }\end{array}$ \\
\hline Cluster size & $29 \%$ & $19 \%$ & $18 \%$ & $18 \%$ & $9 \%$ & $\mathbf{7 \%}$ \\
\hline Population & 61,460 & 41,728 & 38,191 & 37,825 & 20,293 & 16,131 \\
\hline \multicolumn{7}{|c|}{ INDICATORS } \\
\hline \multicolumn{7}{|l|}{ Labor market attachment } \\
\hline Unemployed & $85 \%$ & $3 \%$ & $8 \%$ & $0 \%$ & $9 \%$ & $32 \%$ \\
\hline Long-term unemployed & $0 \%$ & $0 \%$ & $0 \%$ & $0 \%$ & $70 \%$ & $9 \%$ \\
\hline Retired & $2 \%$ & $6 \%$ & $0 \%$ & $96 \%$ & $0 \%$ & $0 \%$ \\
\hline Disabled & $0 \%$ & $86 \%$ & $1 \%$ & $0 \%$ & $1 \%$ & $10 \%$ \\
\hline Other inactive & $13 \%$ & $5 \%$ & $92 \%$ & $3 \%$ & $20 \%$ & $49 \%$ \\
\hline \multicolumn{7}{|c|}{ At least one working adult in householda } \\
\hline No & $41 \%$ & $60 \%$ & $14 \%$ & $72 \%$ & $62 \%$ & $29 \%$ \\
\hline Yes & $59 \%$ & $40 \%$ & $86 \%$ & $28 \%$ & $38 \%$ & $71 \%$ \\
\hline \multicolumn{7}{|l|}{ Work experience } \\
\hline Never worked & $0 \%$ & $8 \%$ & $4 \%$ & $0 \%$ & $4 \%$ & $92 \%$ \\
\hline Less than 2 months in last year & $4 \%$ & $82 \%$ & $66 \%$ & $82 \%$ & $96 \%$ & $2 \%$ \\
\hline 2 or more months in last year & $96 \%$ & $11 \%$ & $30 \%$ & $17 \%$ & $0 \%$ & $5 \%$ \\
\hline \multicolumn{7}{|l|}{ Self-assessed physical incapacity } \\
\hline Strongly limited & $2 \%$ & $41 \%$ & $1 \%$ & $8 \%$ & $0 \%$ & $6 \%$ \\
\hline None/limited & $98 \%$ & $59 \%$ & $99 \%$ & $92 \%$ & $100 \%$ & $94 \%$ \\
\hline \multicolumn{7}{|c|}{ ACTIVE COVARIATES } \\
\hline \multicolumn{7}{|l|}{ Age groups (4) } \\
\hline 16-24 years & $20 \%$ & $0 \%$ & $14 \%$ & $0 \%$ & $4 \%$ & $79 \%$ \\
\hline $25-34$ years & $27 \%$ & $5 \%$ & $56 \%$ & $0 \%$ & $16 \%$ & $21 \%$ \\
\hline $35-59$ years & $50 \%$ & $87 \%$ & $30 \%$ & $8 \%$ & $80 \%$ & $0 \%$ \\
\hline
\end{tabular}




\begin{tabular}{|c|c|c|c|c|c|c|}
\hline & $\begin{array}{l}\text { 1. Prime-age } \\
\text { educated } \\
\text { unemployed }\end{array}$ & $\begin{array}{l}\text { 2. Middle-aged } \\
\text { educated disabled } \\
\text { with previous } \\
\text { work experience }\end{array}$ & $\begin{array}{l}\text { 3. Young inactive } \\
\text { educated } \\
\text { mothers with } \\
\text { working partner }\end{array}$ & $\begin{array}{l}\text { 4. Educated } \\
\text { retirees }\end{array}$ & $\begin{array}{l}\text { 5. Middle- } \\
\text { aged long- } \\
\text { term } \\
\text { unemployed } \\
\text { men }\end{array}$ & $\begin{array}{l}\text { 6. Single } \\
\text { uneducated and } \\
\text { rural NEETs } \\
\text { without work } \\
\text { experience }\end{array}$ \\
\hline 60-64 years & $2 \%$ & $7 \%$ & $0 \%$ & $92 \%$ & $0 \%$ & $0 \%$ \\
\hline \multicolumn{7}{|l|}{ Gender } \\
\hline Male & $71 \%$ & $61 \%$ & $1 \%$ & $31 \%$ & $80 \%$ & $47 \%$ \\
\hline Female & $29 \%$ & $39 \%$ & $99 \%$ & $69 \%$ & $20 \%$ & $53 \%$ \\
\hline \multicolumn{7}{|l|}{ Education (4) } \\
\hline Primary & $19 \%$ & $25 \%$ & $10 \%$ & $23 \%$ & $25 \%$ & $52 \%$ \\
\hline Secondary & $64 \%$ & $64 \%$ & $48 \%$ & $58 \%$ & $73 \%$ & $40 \%$ \\
\hline Tertiary & $16 \%$ & $11 \%$ & $41 \%$ & $19 \%$ & $2 \%$ & $5 \%$ \\
\hline NA & $2 \%$ & $1 \%$ & $1 \%$ & $0 \%$ & $0 \%$ & $3 \%$ \\
\hline Urban & $55 \%$ & $34 \%$ & $47 \%$ & $41 \%$ & $39 \%$ & $25 \%$ \\
\hline Rural & $45 \%$ & $66 \%$ & $53 \%$ & $59 \%$ & $61 \%$ & $75 \%$ \\
\hline \multicolumn{7}{|c|}{ INACTIVE COVARIATES } \\
\hline \multicolumn{7}{|l|}{ Age groups (8) } \\
\hline $16-19$ years & $3 \%$ & $0 \%$ & $2 \%$ & $0 \%$ & $1 \%$ & $33 \%$ \\
\hline 20-24 years & $17 \%$ & $0 \%$ & $12 \%$ & $0 \%$ & $3 \%$ & $46 \%$ \\
\hline 25-29 years & $13 \%$ & $1 \%$ & $28 \%$ & $0 \%$ & $7 \%$ & $13 \%$ \\
\hline 30-34 years & $14 \%$ & $4 \%$ & $28 \%$ & $0 \%$ & $8 \%$ & $8 \%$ \\
\hline $35-44$ years & $18 \%$ & $15 \%$ & $19 \%$ & $0 \%$ & $32 \%$ & $0 \%$ \\
\hline $45-54$ years & $23 \%$ & $45 \%$ & $9 \%$ & $1 \%$ & $34 \%$ & $0 \%$ \\
\hline 55-59 years & $9 \%$ & $28 \%$ & $3 \%$ & $7 \%$ & $14 \%$ & $0 \%$ \\
\hline $60-64$ years & $2 \%$ & $7 \%$ & $0 \%$ & $92 \%$ & $0 \%$ & $0 \%$ \\
\hline \multicolumn{7}{|l|}{ Education (6) } \\
\hline None or less than primary & $0 \%$ & $2 \%$ & $0 \%$ & $0 \%$ & $0 \%$ & $1 \%$ \\
\hline Primary & $1 \%$ & $2 \%$ & $1 \%$ & $3 \%$ & $5 \%$ & $12 \%$ \\
\hline Lower secondary & $18 \%$ & $21 \%$ & $9 \%$ & $20 \%$ & $20 \%$ & $39 \%$ \\
\hline Upper secondary & $59 \%$ & $62 \%$ & $42 \%$ & $57 \%$ & $70 \%$ & $38 \%$ \\
\hline
\end{tabular}




\begin{tabular}{|c|c|c|c|c|c|c|}
\hline & $\begin{array}{l}\text { 1. Prime-age } \\
\text { educated } \\
\text { unemployed }\end{array}$ & $\begin{array}{l}\text { 2. Middle-aged } \\
\text { educated disabled } \\
\text { with previous } \\
\text { work experience }\end{array}$ & $\begin{array}{l}\text { 3. Young inactive } \\
\text { educated } \\
\text { mothers with } \\
\text { working partner }\end{array}$ & $\begin{array}{l}\text { 4. Educated } \\
\text { retirees }\end{array}$ & $\begin{array}{l}\text { 5. Middle- } \\
\text { aged long- } \\
\text { term } \\
\text { unemployed } \\
\text { men }\end{array}$ & $\begin{array}{l}\text { 6. Single } \\
\text { uneducated and } \\
\text { rural NEETs } \\
\text { without work } \\
\text { experience }\end{array}$ \\
\hline Post-secondary & $5 \%$ & $2 \%$ & $6 \%$ & $1 \%$ & $4 \%$ & $2 \%$ \\
\hline Tertiary & $16 \%$ & $11 \%$ & $41 \%$ & $19 \%$ & $2 \%$ & $5 \%$ \\
\hline NA & $2 \%$ & $1 \%$ & $1 \%$ & $0 \%$ & $0 \%$ & $3 \%$ \\
\hline \multicolumn{7}{|l|}{ Enrolled in education ${ }^{b}$} \\
\hline Yes & $2 \%$ & $0 \%$ & $9 \%$ & $0 \%$ & $1 \%$ & $2 \%$ \\
\hline No & $96 \%$ & $99 \%$ & $90 \%$ & $99 \%$ & $99 \%$ & $95 \%$ \\
\hline NA & $2 \%$ & $1 \%$ & $1 \%$ & $0 \%$ & $0 \%$ & $3 \%$ \\
\hline \multicolumn{7}{|l|}{ Ever worked } \\
\hline No & $0 \%$ & $8 \%$ & $4 \%$ & $0 \%$ & $3 \%$ & $90 \%$ \\
\hline Yes & $98 \%$ & $92 \%$ & $94 \%$ & $99 \%$ & $96 \%$ & $7 \%$ \\
\hline NA & $2 \%$ & $1 \%$ & $1 \%$ & $0 \%$ & $0 \%$ & $3 \%$ \\
\hline Years of work experience ${ }^{c}$ & 16 & 23 & 8 & 35 & 16 & 3 \\
\hline \multicolumn{7}{|l|}{ Household income (mean) } \\
\hline Labor income & 13790 & 4424 & 15094 & 4236 & 4468 & 11736 \\
\hline Other income & 82 & 60 & 754 & 108 & 110 & 101 \\
\hline Benefits & 1964 & 3797 & 4235 & 4891 & 1980 & 2433 \\
\hline \multicolumn{7}{|l|}{ Household income shares ${ }^{d}$} \\
\hline Labor income & $83 \%$ & $36 \%$ & $73 \%$ & $28 \%$ & $52 \%$ & $75 \%$ \\
\hline Other income & $1 \%$ & $1 \%$ & $3 \%$ & $1 \%$ & $3 \%$ & $1 \%$ \\
\hline Benefits & $16 \%$ & $63 \%$ & $25 \%$ & $71 \%$ & $45 \%$ & $24 \%$ \\
\hline \multicolumn{7}{|l|}{ Income quintile } \\
\hline Poorest & $21 \%$ & $49 \%$ & $18 \%$ & $37 \%$ & $72 \%$ & $32 \%$ \\
\hline Q2 & $22 \%$ & $24 \%$ & $15 \%$ & $24 \%$ & $16 \%$ & $27 \%$ \\
\hline Q3 & $21 \%$ & $17 \%$ & $24 \%$ & $19 \%$ & $8 \%$ & $18 \%$ \\
\hline Q4 & $19 \%$ & $7 \%$ & $18 \%$ & $11 \%$ & $4 \%$ & $18 \%$ \\
\hline Richest & $17 \%$ & $3 \%$ & $24 \%$ & $9 \%$ & $1 \%$ & $5 \%$ \\
\hline
\end{tabular}




\begin{tabular}{|c|c|c|c|c|c|c|}
\hline & $\begin{array}{l}\text { 1. Prime-age } \\
\text { educated } \\
\text { unemployed }\end{array}$ & $\begin{array}{l}\text { 2. Middle-aged } \\
\text { educated disabled } \\
\text { with previous } \\
\text { work experience }\end{array}$ & $\begin{array}{l}\text { 3. Young inactive } \\
\text { educated } \\
\text { mothers with } \\
\text { working partner }\end{array}$ & $\begin{array}{l}\text { 4. Educated } \\
\text { retirees }\end{array}$ & $\begin{array}{l}\text { 5. Middle- } \\
\text { aged long- } \\
\text { term } \\
\text { unemployed } \\
\text { men }\end{array}$ & $\begin{array}{l}\text { 6. Single } \\
\text { uneducated and } \\
\text { rural NEETs } \\
\text { without work } \\
\text { experience }\end{array}$ \\
\hline \multicolumn{7}{|l|}{ Poverty Risk } \\
\hline No & $80 \%$ & $52 \%$ & $82 \%$ & $65 \%$ & $28 \%$ & $68 \%$ \\
\hline Yes & $20 \%$ & $48 \%$ & $18 \%$ & $35 \%$ & $72 \%$ & $32 \%$ \\
\hline \multicolumn{7}{|l|}{ Working partner } \\
\hline Yes & $40 \%$ & $32 \%$ & $78 \%$ & $20 \%$ & $27 \%$ & $20 \%$ \\
\hline No & $16 \%$ & $20 \%$ & $10 \%$ & $38 \%$ & $16 \%$ & $9 \%$ \\
\hline NA & $45 \%$ & $48 \%$ & $13 \%$ & $42 \%$ & $57 \%$ & $71 \%$ \\
\hline \multicolumn{7}{|l|}{ Partner economic status } \\
\hline Working & $40 \%$ & $32 \%$ & $78 \%$ & $20 \%$ & $27 \%$ & $20 \%$ \\
\hline Unemployed & $5 \%$ & $5 \%$ & $6 \%$ & $2 \%$ & $7 \%$ & $5 \%$ \\
\hline Retired & $2 \%$ & $8 \%$ & $1 \%$ & $28 \%$ & $1 \%$ & $0 \%$ \\
\hline Inactive & $8 \%$ & $8 \%$ & $2 \%$ & $7 \%$ & $8 \%$ & $3 \%$ \\
\hline Student/military service & $1 \%$ & $0 \%$ & $0 \%$ & $0 \%$ & $0 \%$ & $0 \%$ \\
\hline NA & $45 \%$ & $48 \%$ & $13 \%$ & $42 \%$ & $57 \%$ & $71 \%$ \\
\hline Partner income (mean) & 6556 & 4722 & 12603 & 3596 & 4541 & 9568 \\
\hline Working partner income (mean) & 8260 & 7004 & 13612 & 7608 & 6196 & 11135 \\
\hline \multicolumn{7}{|l|}{ Partner income quintile } \\
\hline Poorest & $10 \%$ & $9 \%$ & $9 \%$ & $6 \%$ & $11 \%$ & $2 \%$ \\
\hline Q2 & $10 \%$ & $10 \%$ & $6 \%$ & $5 \%$ & $5 \%$ & $3 \%$ \\
\hline Q3 & $7 \%$ & $6 \%$ & $12 \%$ & $4 \%$ & $7 \%$ & $5 \%$ \\
\hline Q4 & $6 \%$ & $5 \%$ & $23 \%$ & $2 \%$ & $3 \%$ & $4 \%$ \\
\hline Richest & $6 \%$ & $2 \%$ & $27 \%$ & $3 \%$ & $1 \%$ & $7 \%$ \\
\hline No partner or partner without income & $60 \%$ & $68 \%$ & $22 \%$ & $80 \%$ & $73 \%$ & $80 \%$ \\
\hline Receives at least one benefit & $70 \%$ & $97 \%$ & $90 \%$ & $98 \%$ & $48 \%$ & $83 \%$ \\
\hline \multicolumn{7}{|l|}{ Receives benefits at household level } \\
\hline Family child & $47 \%$ & $21 \%$ & $85 \%$ & $8 \%$ & $29 \%$ & $69 \%$ \\
\hline
\end{tabular}




\begin{tabular}{|c|c|c|c|c|c|c|}
\hline & $\begin{array}{l}\text { 1. Prime-age } \\
\text { educated } \\
\text { unemployed }\end{array}$ & $\begin{array}{l}\text { 2. Middle-aged } \\
\text { educated disabled } \\
\text { with previous } \\
\text { work experience }\end{array}$ & $\begin{array}{l}\text { 3. Young inactive } \\
\text { educated } \\
\text { mothers with } \\
\text { working partner }\end{array}$ & $\begin{array}{l}\text { 4. Educated } \\
\text { retirees }\end{array}$ & $\begin{array}{l}\text { 5. Middle- } \\
\text { aged long- } \\
\text { term } \\
\text { unemployed } \\
\text { men }\end{array}$ & $\begin{array}{l}\text { 6. Single } \\
\text { uneducated and } \\
\text { rural NEETs } \\
\text { without work } \\
\text { experience }\end{array}$ \\
\hline Social exclusion & $4 \%$ & $1 \%$ & $1 \%$ & $1 \%$ & $1 \%$ & $5 \%$ \\
\hline Housing & $2 \%$ & $8 \%$ & $2 \%$ & $1 \%$ & $11 \%$ & $3 \%$ \\
\hline Old age at household level & $14 \%$ & $33 \%$ & $6 \%$ & $96 \%$ & $24 \%$ & $15 \%$ \\
\hline \multicolumn{7}{|c|}{ Receives benefits at individual level } \\
\hline Unemployment & $16 \%$ & $1 \%$ & $3 \%$ & $2 \%$ & $12 \%$ & $3 \%$ \\
\hline Old age & $2 \%$ & $6 \%$ & $0 \%$ & $93 \%$ & $1 \%$ & $0 \%$ \\
\hline Survivor & $1 \%$ & $1 \%$ & $0 \%$ & $0 \%$ & $0 \%$ & $2 \%$ \\
\hline Sickness & $19 \%$ & $3 \%$ & $5 \%$ & $4 \%$ & $0 \%$ & $3 \%$ \\
\hline Disability & $6 \%$ & $89 \%$ & $4 \%$ & $10 \%$ & $6 \%$ & $16 \%$ \\
\hline Education & $1 \%$ & $0 \%$ & $3 \%$ & $0 \%$ & $1 \%$ & $7 \%$ \\
\hline \multicolumn{7}{|c|}{ Benefits as share of total gross household income, all households } \\
\hline Family child & $4 \%$ & $2 \%$ & $19 \%$ & $1 \%$ & $7 \%$ & $7 \%$ \\
\hline Social exclusion & $0 \%$ & $0 \%$ & $0 \%$ & $0 \%$ & $0 \%$ & $0 \%$ \\
\hline Housing & $0 \%$ & $1 \%$ & $0 \%$ & $0 \%$ & $5 \%$ & $0 \%$ \\
\hline Unemployment & $3 \%$ & $0 \%$ & $0 \%$ & $0 \%$ & $4 \%$ & $0 \%$ \\
\hline Old age & $4 \%$ & $15 \%$ & $2 \%$ & $64 \%$ & $19 \%$ & $6 \%$ \\
\hline Survivor & $0 \%$ & $0 \%$ & $0 \%$ & $0 \%$ & $0 \%$ & $1 \%$ \\
\hline Sickness & $1 \%$ & $0 \%$ & $1 \%$ & $0 \%$ & $0 \%$ & $1 \%$ \\
\hline Disability & $3 \%$ & $43 \%$ & $2 \%$ & $6 \%$ & $9 \%$ & $9 \%$ \\
\hline Education & $0 \%$ & $0 \%$ & $0 \%$ & $0 \%$ & $0 \%$ & $0 \%$ \\
\hline \multicolumn{7}{|c|}{ Benefits as share of total gross household income, only beneficiaries } \\
\hline Family child & $9 \%$ & $10 \%$ & $23 \%$ & $7 \%$ & $21 \%$ & $11 \%$ \\
\hline Social exclusion & $9 \%$ & $4 \%$ & $3 \%$ & $17 \%$ & $3 \%$ & $4 \%$ \\
\hline Housing & $7 \%$ & $11 \%$ & $21 \%$ & $7 \%$ & $38 \%$ & $10 \%$ \\
\hline Unemployment & $13 \%$ & $13 \%$ & $7 \%$ & $12 \%$ & $27 \%$ & $6 \%$ \\
\hline Old age & $32 \%$ & $47 \%$ & $33 \%$ & $67 \%$ & $72 \%$ & $37 \%$ \\
\hline
\end{tabular}




\begin{tabular}{|c|c|c|c|c|c|c|}
\hline & $\begin{array}{l}\text { 1. Prime-age } \\
\text { educated } \\
\text { unemployed }\end{array}$ & $\begin{array}{l}\text { 2. Middle-aged } \\
\text { educated disabled } \\
\text { with previous } \\
\text { work experience }\end{array}$ & $\begin{array}{l}\text { 3. Young inactive } \\
\text { educated } \\
\text { mothers with } \\
\text { working partner }\end{array}$ & $\begin{array}{l}\text { 4. Educated } \\
\text { retirees }\end{array}$ & $\begin{array}{l}\text { 5. Middle- } \\
\text { aged long- } \\
\text { term } \\
\text { unemployed } \\
\text { men }\end{array}$ & $\begin{array}{l}\text { 6. Single } \\
\text { uneducated and } \\
\text { rural NEETs } \\
\text { without work } \\
\text { experience }\end{array}$ \\
\hline Survivor & $7 \%$ & $22 \%$ & $13 \%$ & $13 \%$ & $26 \%$ & $19 \%$ \\
\hline Sickness & $2 \%$ & $3 \%$ & $3 \%$ & $4 \%$ & $3 \%$ & $2 \%$ \\
\hline Disability & $20 \%$ & $48 \%$ & $20 \%$ & $27 \%$ & $42 \%$ & $31 \%$ \\
\hline Education & $2 \%$ & $6 \%$ & $6 \%$ & $5 \%$ & $5 \%$ & $3 \%$ \\
\hline Household size (mean) & 2.96 & 2.44 & 3.90 & 2.00 & 2.72 & 3.83 \\
\hline \multicolumn{7}{|l|}{ Household composition } \\
\hline One-person & $13 \%$ & $22 \%$ & $1 \%$ & $33 \%$ & $23 \%$ & $3 \%$ \\
\hline Single parent & $5 \%$ & $5 \%$ & $3 \%$ & $0 \%$ & $4 \%$ & $12 \%$ \\
\hline $2+$ adults without dependent children ${ }^{f}$ & $39 \%$ & $54 \%$ & $12 \%$ & $59 \%$ & $46 \%$ & $22 \%$ \\
\hline $2+$ adults with 1 dependent child ${ }^{f}$ & $19 \%$ & $7 \%$ & $29 \%$ & $1 \%$ & $6 \%$ & $16 \%$ \\
\hline $2+$ adults with $2+$ dependent children ${ }^{f}$ & $24 \%$ & $13 \%$ & $54 \%$ & $6 \%$ & $21 \%$ & $45 \%$ \\
\hline NA & $1 \%$ & $0 \%$ & $1 \%$ & $0 \%$ & $0 \%$ & $3 \%$ \\
\hline Children under six & $19 \%$ & $6 \%$ & $72 \%$ & $3 \%$ & $15 \%$ & $37 \%$ \\
\hline Three or more children under 16 & $2 \%$ & $1 \%$ & $12 \%$ & $1 \%$ & $4 \%$ & $5 \%$ \\
\hline \multicolumn{7}{|l|}{ Individuals' parents present } \\
\hline One parent & $12 \%$ & $14 \%$ & $6 \%$ & $4 \%$ & $17 \%$ & $27 \%$ \\
\hline Both parents & $13 \%$ & $5 \%$ & $8 \%$ & $0 \%$ & $8 \%$ & $39 \%$ \\
\hline None & $75 \%$ & $82 \%$ & $87 \%$ & $96 \%$ & $74 \%$ & $34 \%$ \\
\hline Elderly present (over 64) & $9 \%$ & $20 \%$ & $4 \%$ & $24 \%$ & $21 \%$ & $11 \%$ \\
\hline \multicolumn{7}{|l|}{ Children under 13 in childcare } \\
\hline None of the children & $8 \%$ & $4 \%$ & $22 \%$ & $1 \%$ & $6 \%$ & $17 \%$ \\
\hline Some of the children & $6 \%$ & $2 \%$ & $25 \%$ & $1 \%$ & $8 \%$ & $7 \%$ \\
\hline No children under 13 in household & $64 \%$ & $85 \%$ & $18 \%$ & $94 \%$ & $74 \%$ & $48 \%$ \\
\hline All of the children & $23 \%$ & $9 \%$ & $35 \%$ & $5 \%$ & $12 \%$ & $28 \%$ \\
\hline \multicolumn{7}{|l|}{ Marital status } \\
\hline Married & $38 \%$ & $38 \%$ & $56 \%$ & $52 \%$ & $29 \%$ & $13 \%$ \\
\hline
\end{tabular}




\begin{tabular}{|c|c|c|c|c|c|c|}
\hline & $\begin{array}{l}\text { 1. Prime-age } \\
\text { educated } \\
\text { unemployed }\end{array}$ & $\begin{array}{l}\text { 2. Middle-aged } \\
\text { educated disabled } \\
\text { with previous } \\
\text { work experience }\end{array}$ & $\begin{array}{l}\text { 3. Young inactive } \\
\text { educated } \\
\text { mothers with } \\
\text { working partner }\end{array}$ & $\begin{array}{l}\text { 4. Educated } \\
\text { retirees }\end{array}$ & $\begin{array}{c}\text { 5. Middle- } \\
\text { aged long- } \\
\text { term } \\
\text { unemployed } \\
\text { men }\end{array}$ & $\begin{array}{l}\text { 6. Single } \\
\text { uneducated and } \\
\text { rural NEETs } \\
\text { without work } \\
\text { experience }\end{array}$ \\
\hline Never married & $45 \%$ & $31 \%$ & $38 \%$ & $11 \%$ & $48 \%$ & $85 \%$ \\
\hline Divorced/separated & $16 \%$ & $25 \%$ & $6 \%$ & $20 \%$ & $23 \%$ & $1 \%$ \\
\hline Widowed & $1 \%$ & $6 \%$ & $1 \%$ & $17 \%$ & $1 \%$ & $0 \%$ \\
\hline \multicolumn{7}{|l|}{ Tenure status } \\
\hline Owner & $85 \%$ & $82 \%$ & $88 \%$ & $89 \%$ & $71 \%$ & $82 \%$ \\
\hline Tenant & $2 \%$ & $4 \%$ & $4 \%$ & $1 \%$ & $4 \%$ & $2 \%$ \\
\hline Reduced rate & $2 \%$ & $2 \%$ & $2 \%$ & $1 \%$ & $5 \%$ & $1 \%$ \\
\hline Free & $10 \%$ & $13 \%$ & $7 \%$ & $9 \%$ & $21 \%$ & $15 \%$ \\
\hline \multicolumn{7}{|c|}{ Able to keep dwelling warm } \\
\hline No & $1 \%$ & $5 \%$ & $1 \%$ & $3 \%$ & $12 \%$ & $5 \%$ \\
\hline Yes & $99 \%$ & $95 \%$ & $99 \%$ & $97 \%$ & $88 \%$ & $95 \%$ \\
\hline \multicolumn{7}{|c|}{ Degree of urbanization } \\
\hline Densely populated & $55 \%$ & $34 \%$ & $47 \%$ & $41 \%$ & $39 \%$ & $25 \%$ \\
\hline Sparsely populated & $45 \%$ & $66 \%$ & $53 \%$ & $59 \%$ & $61 \%$ & $75 \%$ \\
\hline
\end{tabular}

\section{a. Refers to individuals aged 25 and over.}

b. Applies to individuals aged 25 and over. Students aged 16 to 24 are not included in the sample.

c. Refers only to individuals who have worked before.

d. Based on total gross household income.

e. Based on total equivalized disposable household income.

f. Dependent children include: 1. household members under 18; 2. household members aged between 18 and 24 who are economically inactive and living with at least one parent. 


\begin{tabular}{|c|c|c|c|c|c|c|c|}
\hline & $\begin{array}{l}\text { 1. Middle-age } \\
\text { educated } \\
\text { disabled with } \\
\text { previous work } \\
\text { experience }\end{array}$ & $\begin{array}{l}\text { 2. Educated } \\
\text { retired } \\
\text { women }\end{array}$ & $\begin{array}{c}\text { 3. Young } \\
\text { inactive } \\
\text { educated } \\
\text { mothers with } \\
\text { working partner }\end{array}$ & $\begin{array}{l}\text { 4. Prime-age } \\
\text { educated } \\
\text { unemployed }\end{array}$ & $\begin{array}{l}\text { 5. Middle- } \\
\text { age long- } \\
\text { term } \\
\text { unemployed } \\
\text { men }\end{array}$ & $\begin{array}{c}\text { 6. Single } \\
\text { NEETs } \\
\text { without } \\
\text { work } \\
\text { experience }\end{array}$ & $\begin{array}{l}\text { 7. Low- } \\
\text { educated } \\
\text { and rural } \\
\text { disabled } \\
\text { youth }\end{array}$ \\
\hline Cluster size & $23 \%$ & $22 \%$ & $21 \%$ & $13 \%$ & $11 \%$ & $7 \%$ & $3 \%$ \\
\hline Population & 38,545 & 38,021 & 35,871 & 22,210 & 17,893 & 11,647 & 5,095 \\
\hline \multicolumn{8}{|c|}{ INDICATORS } \\
\hline \multicolumn{8}{|l|}{ Labor market attachment } \\
\hline Unemployed & $1 \%$ & $0 \%$ & $0 \%$ & $58 \%$ & $0 \%$ & $21 \%$ & $0 \%$ \\
\hline Long-term unemployed & $1 \%$ & $0 \%$ & $0 \%$ & $0 \%$ & $72 \%$ & $14 \%$ & $5 \%$ \\
\hline Retired & $0 \%$ & $86 \%$ & $0 \%$ & $5 \%$ & $7 \%$ & $0 \%$ & $0 \%$ \\
\hline Disabled & $90 \%$ & $0 \%$ & $0 \%$ & $0 \%$ & $1 \%$ & $1 \%$ & $93 \%$ \\
\hline Other inactive & $8 \%$ & $13 \%$ & $100 \%$ & $36 \%$ & $21 \%$ & $64 \%$ & $2 \%$ \\
\hline \multicolumn{8}{|c|}{ At least one working adult in householda } \\
\hline No & $63 \%$ & $65 \%$ & $11 \%$ & $45 \%$ & $51 \%$ & $19 \%$ & $47 \%$ \\
\hline Yes & $37 \%$ & $35 \%$ & $89 \%$ & $55 \%$ & $49 \%$ & $81 \%$ & $53 \%$ \\
\hline \multicolumn{8}{|l|}{ Work experience } \\
\hline Never worked & $7 \%$ & $1 \%$ & $7 \%$ & $1 \%$ & $0 \%$ & $97 \%$ & $71 \%$ \\
\hline Less than 2 months in last year & $84 \%$ & $88 \%$ & $64 \%$ & $13 \%$ & $100 \%$ & $3 \%$ & $29 \%$ \\
\hline 2 or more months in last year & $9 \%$ & $12 \%$ & $29 \%$ & $86 \%$ & $0 \%$ & $0 \%$ & $0 \%$ \\
\hline \multicolumn{8}{|l|}{ Self-assessed physical incapacity } \\
\hline Strongly limited & $51 \%$ & $17 \%$ & $0 \%$ & $2 \%$ & $1 \%$ & $2 \%$ & $55 \%$ \\
\hline None/limited & $49 \%$ & $83 \%$ & $100 \%$ & $98 \%$ & $99 \%$ & $98 \%$ & $45 \%$ \\
\hline \multicolumn{8}{|c|}{ ACTIVE COVARIATES } \\
\hline \multicolumn{8}{|l|}{ Age groups (4) } \\
\hline $16-24$ years & $0 \%$ & $0 \%$ & $10 \%$ & $19 \%$ & $7 \%$ & $78 \%$ & $24 \%$ \\
\hline 25-34 years & $0 \%$ & $0 \%$ & $56 \%$ & $29 \%$ & $10 \%$ & $19 \%$ & $76 \%$ \\
\hline $35-59$ years & $93 \%$ & $15 \%$ & $34 \%$ & $51 \%$ & $83 \%$ & $4 \%$ & $0 \%$ \\
\hline
\end{tabular}




\begin{tabular}{|c|c|c|c|c|c|c|c|}
\hline & $\begin{array}{l}\text { 1. Middle-age } \\
\text { educated } \\
\text { disabled with } \\
\text { previous work } \\
\text { experience }\end{array}$ & $\begin{array}{l}\text { 2. Educated } \\
\text { retired } \\
\text { women }\end{array}$ & $\begin{array}{c}\text { 3. Young } \\
\text { inactive } \\
\text { educated } \\
\text { mothers with } \\
\text { working partner }\end{array}$ & $\begin{array}{l}\text { 4. Prime-age } \\
\text { educated } \\
\text { unemployed }\end{array}$ & $\begin{array}{l}\text { 5. Middle- } \\
\text { age long- } \\
\text { term } \\
\text { unemployed } \\
\text { men }\end{array}$ & $\begin{array}{l}\text { 6. Single } \\
\text { NEETs } \\
\text { without } \\
\text { work } \\
\text { experience }\end{array}$ & $\begin{array}{l}\text { 7. Low- } \\
\text { educated } \\
\text { and rural } \\
\text { disabled } \\
\text { youth }\end{array}$ \\
\hline 60-64 years & $7 \%$ & $85 \%$ & $0 \%$ & $0 \%$ & $0 \%$ & $0 \%$ & $0 \%$ \\
\hline \multicolumn{8}{|l|}{ Gender } \\
\hline Male & $48 \%$ & $24 \%$ & $0 \%$ & $63 \%$ & $79 \%$ & $44 \%$ & $62 \%$ \\
\hline Female & $52 \%$ & $76 \%$ & $100 \%$ & $37 \%$ & $22 \%$ & $56 \%$ & $38 \%$ \\
\hline \multicolumn{8}{|l|}{ Education (4) } \\
\hline Primary & $27 \%$ & $29 \%$ & $14 \%$ & $22 \%$ & $29 \%$ & $42 \%$ & $61 \%$ \\
\hline Secondary & $58 \%$ & $52 \%$ & $54 \%$ & $66 \%$ & $67 \%$ & $43 \%$ & $33 \%$ \\
\hline Tertiary & $15 \%$ & $19 \%$ & $31 \%$ & $11 \%$ & $4 \%$ & $13 \%$ & $6 \%$ \\
\hline NA & $0 \%$ & $0 \%$ & $1 \%$ & $2 \%$ & $0 \%$ & $2 \%$ & $0 \%$ \\
\hline Urban & $41 \%$ & $41 \%$ & $50 \%$ & $48 \%$ & $51 \%$ & $41 \%$ & $22 \%$ \\
\hline Rural & $59 \%$ & $59 \%$ & $50 \%$ & $52 \%$ & $49 \%$ & $59 \%$ & $78 \%$ \\
\hline \multicolumn{8}{|c|}{ INACTIVE COVARIATES } \\
\hline \multicolumn{8}{|l|}{ Age groups (8) } \\
\hline 16-19 years & $0 \%$ & $0 \%$ & $1 \%$ & $5 \%$ & $0 \%$ & $38 \%$ & $4 \%$ \\
\hline 20-24 years & $0 \%$ & $0 \%$ & $8 \%$ & $15 \%$ & $7 \%$ & $40 \%$ & $20 \%$ \\
\hline 25-29 years & $0 \%$ & $0 \%$ & $30 \%$ & $17 \%$ & $5 \%$ & $14 \%$ & $33 \%$ \\
\hline 30-34 years & $0 \%$ & $0 \%$ & $26 \%$ & $12 \%$ & $6 \%$ & $5 \%$ & $43 \%$ \\
\hline 35-44 years & $21 \%$ & $1 \%$ & $24 \%$ & $23 \%$ & $23 \%$ & $3 \%$ & $0 \%$ \\
\hline 45-54 years & $40 \%$ & $1 \%$ & $7 \%$ & $18 \%$ & $35 \%$ & $0 \%$ & $0 \%$ \\
\hline $55-59$ years & $32 \%$ & $13 \%$ & $3 \%$ & $10 \%$ & $24 \%$ & $0 \%$ & $0 \%$ \\
\hline 60-64 years & $7 \%$ & $85 \%$ & $0 \%$ & $0 \%$ & $0 \%$ & $0 \%$ & $0 \%$ \\
\hline \multicolumn{8}{|l|}{ Education (6) } \\
\hline None or less than primary & $2 \%$ & $0 \%$ & $0 \%$ & $0 \%$ & $0 \%$ & $1 \%$ & $11 \%$ \\
\hline Primary & $2 \%$ & $3 \%$ & $0 \%$ & $2 \%$ & $3 \%$ & $5 \%$ & $19 \%$ \\
\hline Lower secondary & $23 \%$ & $25 \%$ & $13 \%$ & $20 \%$ & $26 \%$ & $36 \%$ & $30 \%$ \\
\hline Upper secondary & $50 \%$ & $45 \%$ & $44 \%$ & $55 \%$ & $61 \%$ & $41 \%$ & $32 \%$ \\
\hline
\end{tabular}




\begin{tabular}{|c|c|c|c|c|c|c|c|}
\hline & $\begin{array}{l}\text { 1. Middle-age } \\
\text { educated } \\
\text { disabled with } \\
\text { previous work } \\
\text { experience }\end{array}$ & $\begin{array}{l}\text { 2. Educated } \\
\text { retired } \\
\text { women }\end{array}$ & $\begin{array}{c}\text { 3. Young } \\
\text { inactive } \\
\text { educated } \\
\text { mothers with } \\
\text { working partner }\end{array}$ & $\begin{array}{l}\text { 4. Prime-age } \\
\text { educated } \\
\text { unemployed }\end{array}$ & $\begin{array}{l}\text { 5. Middle- } \\
\text { age long- } \\
\text { term } \\
\text { unemployed } \\
\text { men }\end{array}$ & $\begin{array}{c}\text { 6. Single } \\
\text { NEETs } \\
\text { without } \\
\text { work } \\
\text { experience }\end{array}$ & $\begin{array}{l}\text { 7. Low- } \\
\text { educated } \\
\text { and rural } \\
\text { disabled } \\
\text { youth }\end{array}$ \\
\hline Post-secondary & $8 \%$ & $7 \%$ & $10 \%$ & $11 \%$ & $6 \%$ & $2 \%$ & $1 \%$ \\
\hline Tertiary & $15 \%$ & $19 \%$ & $31 \%$ & $11 \%$ & $4 \%$ & $13 \%$ & $6 \%$ \\
\hline NA & $0 \%$ & $0 \%$ & $1 \%$ & $2 \%$ & $0 \%$ & $2 \%$ & $0 \%$ \\
\hline \multicolumn{8}{|l|}{ Enrolled in education ${ }^{b}$} \\
\hline Yes & $1 \%$ & $0 \%$ & $8 \%$ & $3 \%$ & $0 \%$ & $4 \%$ & $2 \%$ \\
\hline No & $99 \%$ & $99 \%$ & $91 \%$ & $96 \%$ & $99 \%$ & $94 \%$ & $98 \%$ \\
\hline NA & $0 \%$ & $0 \%$ & $1 \%$ & $2 \%$ & $0 \%$ & $2 \%$ & $0 \%$ \\
\hline \multicolumn{8}{|l|}{ Ever worked } \\
\hline No & $6 \%$ & $1 \%$ & $7 \%$ & $1 \%$ & $0 \%$ & $95 \%$ & $71 \%$ \\
\hline Yes & $93 \%$ & $99 \%$ & $93 \%$ & $97 \%$ & $100 \%$ & $3 \%$ & $29 \%$ \\
\hline NA & $0 \%$ & $0 \%$ & $1 \%$ & $2 \%$ & $0 \%$ & $2 \%$ & $0 \%$ \\
\hline Years of work experiencec & 23 & 35 & 9 & 14 & 19 & 6 & 4 \\
\hline \multicolumn{8}{|l|}{ Household income (mean) } \\
\hline Labor income & 3241 & 3650 & 14201 & 8829 & 3609 & 7709 & 3698 \\
\hline Other income & 76 & 68 & 152 & 110 & 60 & 170 & 18 \\
\hline Benefits & 2476 & 3400 & 2501 & 1536 & 1419 & 1790 & 3236 \\
\hline \multicolumn{8}{|l|}{ Household income shares ${ }^{d}$} \\
\hline Labor income & $34 \%$ & $30 \%$ & $76 \%$ & $76 \%$ & $52 \%$ & $73 \%$ & $37 \%$ \\
\hline Other income & $2 \%$ & $1 \%$ & $2 \%$ & $2 \%$ & $2 \%$ & $3 \%$ & $0 \%$ \\
\hline Benefits & $64 \%$ & $69 \%$ & $22 \%$ & $22 \%$ & $45 \%$ & $24 \%$ & $63 \%$ \\
\hline \multicolumn{8}{|l|}{ Income quintile } \\
\hline Poorest & $54 \%$ & $36 \%$ & $17 \%$ & $30 \%$ & $66 \%$ & $34 \%$ & $52 \%$ \\
\hline Q2 & $25 \%$ & $28 \%$ & $18 \%$ & $23 \%$ & $15 \%$ & $24 \%$ & $28 \%$ \\
\hline Q3 & $9 \%$ & $17 \%$ & $19 \%$ & $16 \%$ & $12 \%$ & $21 \%$ & $8 \%$ \\
\hline Q4 & $8 \%$ & $13 \%$ & $21 \%$ & $17 \%$ & $6 \%$ & $15 \%$ & $11 \%$ \\
\hline Richest & $4 \%$ & $6 \%$ & $25 \%$ & $13 \%$ & $1 \%$ & $5 \%$ & $1 \%$ \\
\hline
\end{tabular}




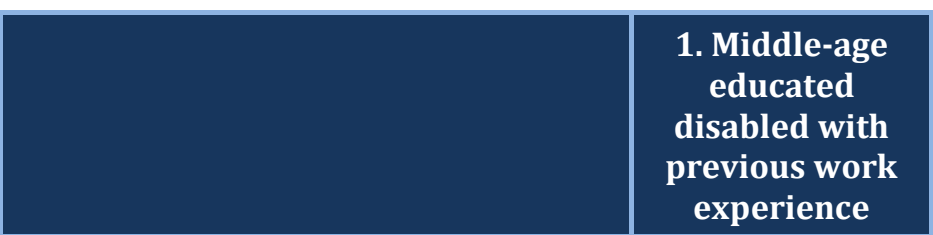

\begin{tabular}{|c|c|}
\hline $\begin{array}{c}\text { 2. Educated } \\
\text { retired } \\
\text { women }\end{array}$ & $\begin{array}{c}\text { 3. Young } \\
\text { inactive } \\
\text { educated } \\
\text { mothers with } \\
\text { working partner }\end{array}$ \\
\hline
\end{tabular}

4. Prime-age
educated
unemployed

5. Middle-
age long-
term
unemployed
men

6. Single NEETs

without

work

experience

7. Low-

educated

and rural

disabled

youth

\section{Poverty Risk}

\begin{tabular}{|c|c|c|c|c|c|c|c|}
\hline No & $46 \%$ & $64 \%$ & $83 \%$ & $71 \%$ & $35 \%$ & $66 \%$ & $48 \%$ \\
\hline Yes & $54 \%$ & $36 \%$ & $17 \%$ & $29 \%$ & $65 \%$ & $34 \%$ & $52 \%$ \\
\hline \multicolumn{8}{|l|}{ Working partner } \\
\hline Yes & $32 \%$ & $21 \%$ & $85 \%$ & $35 \%$ & $37 \%$ & $27 \%$ & $19 \%$ \\
\hline No & $19 \%$ & $35 \%$ & $4 \%$ & $15 \%$ & $16 \%$ & $3 \%$ & $0 \%$ \\
\hline NA & $50 \%$ & $44 \%$ & $11 \%$ & $50 \%$ & $47 \%$ & $71 \%$ & $80 \%$ \\
\hline \multicolumn{8}{|l|}{ Partner economic status } \\
\hline Working & $32 \%$ & $21 \%$ & $85 \%$ & $35 \%$ & $37 \%$ & $27 \%$ & $19 \%$ \\
\hline Unemployed & $2 \%$ & $1 \%$ & $1 \%$ & $5 \%$ & $2 \%$ & $1 \%$ & $0 \%$ \\
\hline Retired & $6 \%$ & $27 \%$ & $1 \%$ & $2 \%$ & $3 \%$ & $0 \%$ & $0 \%$ \\
\hline Inactive & $10 \%$ & $8 \%$ & $2 \%$ & $9 \%$ & $10 \%$ & $2 \%$ & $0 \%$ \\
\hline Student/military service & $0 \%$ & $0 \%$ & $0 \%$ & $0 \%$ & $0 \%$ & $1 \%$ & $0 \%$ \\
\hline NA & $50 \%$ & $44 \%$ & $11 \%$ & $50 \%$ & $47 \%$ & $71 \%$ & $80 \%$ \\
\hline Partner income (mean) & 3832 & 2421 & 12552 & 4445 & 3422 & 7070 & 5127 \\
\hline Working partner income (mean) & 5813 & 5370 & 13036 & 5797 & 4658 & 7680 & 5220 \\
\hline \multicolumn{8}{|l|}{ Partner income quintile } \\
\hline Poorest & $9 \%$ & $4 \%$ & $8 \%$ & $7 \%$ & $10 \%$ & $4 \%$ & $2 \%$ \\
\hline Q2 & $8 \%$ & $8 \%$ & $7 \%$ & $10 \%$ & $14 \%$ & $5 \%$ & $8 \%$ \\
\hline Q3 & $5 \%$ & $4 \%$ & $12 \%$ & $9 \%$ & $7 \%$ & $5 \%$ & $5 \%$ \\
\hline Q4 & $6 \%$ & $3 \%$ & $21 \%$ & $6 \%$ & $6 \%$ & $6 \%$ & $4 \%$ \\
\hline Richest & $4 \%$ & $2 \%$ & $36 \%$ & $4 \%$ & $1 \%$ & $6 \%$ & $0 \%$ \\
\hline No partner or partner without income & $68 \%$ & $79 \%$ & $15 \%$ & $65 \%$ & $63 \%$ & $73 \%$ & $81 \%$ \\
\hline Receives at least one benefit & $97 \%$ & $98 \%$ & $90 \%$ & $67 \%$ & $50 \%$ & $75 \%$ & $98 \%$ \\
\hline \multicolumn{8}{|l|}{ Receives benefits at household level } \\
\hline Family child & $20 \%$ & $12 \%$ & $84 \%$ & $50 \%$ & $30 \%$ & $68 \%$ & $53 \%$ \\
\hline
\end{tabular}




\begin{tabular}{|c|c|c|c|c|c|c|c|}
\hline & $\begin{array}{l}\text { 1. Middle-age } \\
\text { educated } \\
\text { disabled with } \\
\text { previous work } \\
\text { experience }\end{array}$ & $\begin{array}{l}\text { 2. Educated } \\
\text { retired } \\
\text { women }\end{array}$ & $\begin{array}{c}\text { 3. Young } \\
\text { inactive } \\
\text { educated } \\
\text { mothers with } \\
\text { working partner }\end{array}$ & $\begin{array}{l}\text { 4. Prime-age } \\
\text { educated } \\
\text { unemployed }\end{array}$ & $\begin{array}{l}\text { 5. Middle- } \\
\text { age long- } \\
\text { term } \\
\text { unemployed } \\
\text { men }\end{array}$ & $\begin{array}{c}\text { 6. Single } \\
\text { NEETs } \\
\text { without } \\
\text { work } \\
\text { experience }\end{array}$ & $\begin{array}{l}\text { 7. Low- } \\
\text { educated } \\
\text { and rural } \\
\text { disabled } \\
\text { youth }\end{array}$ \\
\hline Social exclusion & $2 \%$ & $0 \%$ & $0 \%$ & $1 \%$ & $0 \%$ & $1 \%$ & $4 \%$ \\
\hline Housing & $6 \%$ & $1 \%$ & $2 \%$ & $6 \%$ & $9 \%$ & $1 \%$ & $8 \%$ \\
\hline Old age at household level & $27 \%$ & $96 \%$ & $11 \%$ & $20 \%$ & $30 \%$ & $20 \%$ & $31 \%$ \\
\hline \multicolumn{8}{|c|}{ Receives benefits at individual level } \\
\hline Unemployment & $1 \%$ & $1 \%$ & $2 \%$ & $10 \%$ & $3 \%$ & $5 \%$ & $2 \%$ \\
\hline Old age & $2 \%$ & $95 \%$ & $1 \%$ & $4 \%$ & $9 \%$ & $0 \%$ & $0 \%$ \\
\hline Survivor & $1 \%$ & $0 \%$ & $0 \%$ & $1 \%$ & $0 \%$ & $2 \%$ & $0 \%$ \\
\hline Sickness & $3 \%$ & $1 \%$ & $8 \%$ & $12 \%$ & $0 \%$ & $0 \%$ & $0 \%$ \\
\hline Disability & $91 \%$ & $6 \%$ & $7 \%$ & $7 \%$ & $8 \%$ & $3 \%$ & $94 \%$ \\
\hline Education & $0 \%$ & $0 \%$ & $3 \%$ & $1 \%$ & $0 \%$ & $5 \%$ & $0 \%$ \\
\hline \multicolumn{8}{|c|}{ Benefits as share of total gross household income, all households } \\
\hline Family child & $2 \%$ & $1 \%$ & $16 \%$ & $6 \%$ & $6 \%$ & $10 \%$ & $7 \%$ \\
\hline Social exclusion & $0 \%$ & $0 \%$ & $0 \%$ & $0 \%$ & $0 \%$ & $0 \%$ & $0 \%$ \\
\hline Housing & $1 \%$ & $0 \%$ & $0 \%$ & $1 \%$ & $6 \%$ & $1 \%$ & $0 \%$ \\
\hline Unemployment & $0 \%$ & $0 \%$ & $0 \%$ & $2 \%$ & $2 \%$ & $0 \%$ & $0 \%$ \\
\hline Old age & $14 \%$ & $64 \%$ & $3 \%$ & $8 \%$ & $21 \%$ & $9 \%$ & $16 \%$ \\
\hline Survivor & $0 \%$ & $0 \%$ & $0 \%$ & $0 \%$ & $0 \%$ & $1 \%$ & $0 \%$ \\
\hline Sickness & $0 \%$ & $0 \%$ & $1 \%$ & $1 \%$ & $0 \%$ & $0 \%$ & $0 \%$ \\
\hline Disability & $45 \%$ & $4 \%$ & $2 \%$ & $3 \%$ & $10 \%$ & $4 \%$ & $39 \%$ \\
\hline Education & $0 \%$ & $0 \%$ & $0 \%$ & $0 \%$ & $0 \%$ & $1 \%$ & $0 \%$ \\
\hline \multicolumn{8}{|c|}{ Benefits as share of total gross household income, only beneficiaries } \\
\hline Family child & $12 \%$ & $9 \%$ & $19 \%$ & $13 \%$ & $18 \%$ & $14 \%$ & $12 \%$ \\
\hline Social exclusion & $9 \%$ & $0 \%$ & $2 \%$ & $6 \%$ & $8 \%$ & $2 \%$ & $4 \%$ \\
\hline Housing & $24 \%$ & $7 \%$ & $15 \%$ & $26 \%$ & $57 \%$ & $41 \%$ & $4 \%$ \\
\hline Unemployment & $18 \%$ & $12 \%$ & $8 \%$ & $14 \%$ & $26 \%$ & $4 \%$ & $19 \%$ \\
\hline Old age & $50 \%$ & $67 \%$ & $28 \%$ & $41 \%$ & $65 \%$ & $43 \%$ & $50 \%$ \\
\hline
\end{tabular}




\begin{tabular}{|c|c|c|c|c|c|c|c|}
\hline & $\begin{array}{l}\text { 1. Middle-age } \\
\text { educated } \\
\text { disabled with } \\
\text { previous work } \\
\text { experience }\end{array}$ & $\begin{array}{l}\text { 2. Educated } \\
\text { retired } \\
\text { women }\end{array}$ & $\begin{array}{c}\text { 3. Young } \\
\text { inactive } \\
\text { educated } \\
\text { mothers with } \\
\text { working partner }\end{array}$ & $\begin{array}{l}\text { 4. Prime-age } \\
\text { educated } \\
\text { unemployed }\end{array}$ & $\begin{array}{l}\text { 5. Middle- } \\
\text { age long- } \\
\text { term } \\
\text { unemployed } \\
\text { men }\end{array}$ & $\begin{array}{l}\text { 6. Single } \\
\text { NEETs } \\
\text { without } \\
\text { work } \\
\text { experience }\end{array}$ & $\begin{array}{l}7 . \text { Low- } \\
\text { educated } \\
\text { and rural } \\
\text { disabled } \\
\text { youth }\end{array}$ \\
\hline Survivor & $33 \%$ & $11 \%$ & $15 \%$ & $20 \%$ & $19 \%$ & $13 \%$ & $12 \%$ \\
\hline Sickness & $4 \%$ & $3 \%$ & $3 \%$ & $3 \%$ & $3 \%$ & $2 \%$ & $3 \%$ \\
\hline Disability & $49 \%$ & $27 \%$ & $16 \%$ & $21 \%$ & $46 \%$ & $23 \%$ & $41 \%$ \\
\hline Education & $7 \%$ & $7 \%$ & $7 \%$ & $5 \%$ & $6 \%$ & $7 \%$ & $4 \%$ \\
\hline Household size (mean) & 2.35 & 2.20 & 4.03 & 3.20 & 2.58 & 3.68 & 3.28 \\
\hline \multicolumn{8}{|l|}{ Household composition } \\
\hline One-person & $24 \%$ & $27 \%$ & $1 \%$ & $12 \%$ & $20 \%$ & $0 \%$ & $8 \%$ \\
\hline Single parent & $4 \%$ & $1 \%$ & $2 \%$ & $6 \%$ & $2 \%$ & $8 \%$ & $17 \%$ \\
\hline $2+$ adults without dependent children ${ }^{f}$ & $53 \%$ & $60 \%$ & $11 \%$ & $35 \%$ & $51 \%$ & $31 \%$ & $30 \%$ \\
\hline $2+$ adults with 1 dependent child ${ }^{f}$ & $7 \%$ & $2 \%$ & $22 \%$ & $14 \%$ & $9 \%$ & $17 \%$ & $14 \%$ \\
\hline $2+$ adults with $2+$ dependent children ${ }^{f}$ & $11 \%$ & $10 \%$ & $65 \%$ & $33 \%$ & $18 \%$ & $43 \%$ & $31 \%$ \\
\hline NA & $0 \%$ & $0 \%$ & $0 \%$ & $0 \%$ & $0 \%$ & $2 \%$ & $0 \%$ \\
\hline Children under six & $4 \%$ & $5 \%$ & $71 \%$ & $23 \%$ & $12 \%$ & $36 \%$ & $27 \%$ \\
\hline Three or more children under 16 & $1 \%$ & $0 \%$ & $13 \%$ & $2 \%$ & $2 \%$ & $4 \%$ & $3 \%$ \\
\hline \multicolumn{8}{|l|}{ Individuals' parents present } \\
\hline One parent & $12 \%$ & $3 \%$ & $4 \%$ & $12 \%$ & $20 \%$ & $29 \%$ & $24 \%$ \\
\hline Both parents & $4 \%$ & $0 \%$ & $6 \%$ & $17 \%$ & $4 \%$ & $39 \%$ & $35 \%$ \\
\hline None & $84 \%$ & $97 \%$ & $89 \%$ & $70 \%$ & $76 \%$ & $32 \%$ & $41 \%$ \\
\hline Elderly present (over 64) & $18 \%$ & $25 \%$ & $7 \%$ & $10 \%$ & $17 \%$ & $17 \%$ & $16 \%$ \\
\hline \multicolumn{8}{|l|}{ Children under 13 in childcare } \\
\hline None of the children & $5 \%$ & $2 \%$ & $23 \%$ & $13 \%$ & $5 \%$ & $16 \%$ & $6 \%$ \\
\hline Some of the children & $3 \%$ & $2 \%$ & $30 \%$ & $10 \%$ & $4 \%$ & $8 \%$ & $6 \%$ \\
\hline No children under 13 in household & $87 \%$ & $91 \%$ & $17 \%$ & $62 \%$ & $78 \%$ & $54 \%$ & $52 \%$ \\
\hline All of the children & $5 \%$ & $5 \%$ & $30 \%$ & $15 \%$ & $13 \%$ & $21 \%$ & $36 \%$ \\
\hline \multicolumn{8}{|l|}{ Marital status } \\
\hline Married & $45 \%$ & $48 \%$ & $56 \%$ & $38 \%$ & $34 \%$ & $13 \%$ & $12 \%$ \\
\hline
\end{tabular}




\begin{tabular}{|c|c|c|c|c|c|c|c|}
\hline & $\begin{array}{l}\text { 1. Middle-age } \\
\text { educated } \\
\text { disabled with } \\
\text { previous work } \\
\text { experience }\end{array}$ & $\begin{array}{l}\text { 2. Educated } \\
\text { retired } \\
\text { women }\end{array}$ & $\begin{array}{c}\text { 3. Young } \\
\text { inactive } \\
\text { educated } \\
\text { mothers with } \\
\text { working partner }\end{array}$ & $\begin{array}{l}\text { 4. Prime-age } \\
\text { educated } \\
\text { unemployed }\end{array}$ & $\begin{array}{l}\text { 5. Middle- } \\
\text { age long- } \\
\text { term } \\
\text { unemployed } \\
\text { men }\end{array}$ & $\begin{array}{c}\text { 6. Single } \\
\text { NEETs } \\
\text { without } \\
\text { work } \\
\text { experience }\end{array}$ & $\begin{array}{l}\text { 7. Low- } \\
\text { educated } \\
\text { and rural } \\
\text { disabled } \\
\text { youth }\end{array}$ \\
\hline Never married & $25 \%$ & $11 \%$ & $35 \%$ & $47 \%$ & $33 \%$ & $87 \%$ & $87 \%$ \\
\hline Divorced/separated & $22 \%$ & $16 \%$ & $7 \%$ & $14 \%$ & $32 \%$ & $0 \%$ & $1 \%$ \\
\hline Widowed & $9 \%$ & $25 \%$ & $2 \%$ & $1 \%$ & $1 \%$ & $0 \%$ & $0 \%$ \\
\hline \multicolumn{8}{|l|}{ Tenure status } \\
\hline Owner & $83 \%$ & $89 \%$ & $85 \%$ & $85 \%$ & $80 \%$ & $83 \%$ & $73 \%$ \\
\hline Tenant & $4 \%$ & $2 \%$ & $5 \%$ & $2 \%$ & $3 \%$ & $6 \%$ & $14 \%$ \\
\hline Reduced rate & $2 \%$ & $1 \%$ & $2 \%$ & $4 \%$ & $1 \%$ & $2 \%$ & $4 \%$ \\
\hline Free & $12 \%$ & $8 \%$ & $8 \%$ & $8 \%$ & $16 \%$ & $9 \%$ & $10 \%$ \\
\hline \multicolumn{8}{|c|}{ Able to keep dwelling warm } \\
\hline No & $10 \%$ & $5 \%$ & $2 \%$ & $5 \%$ & $12 \%$ & $4 \%$ & $6 \%$ \\
\hline Yes & $90 \%$ & $95 \%$ & $98 \%$ & $95 \%$ & $88 \%$ & $96 \%$ & $94 \%$ \\
\hline \multicolumn{8}{|c|}{ Degree of urbanization } \\
\hline Densely populated & $41 \%$ & $41 \%$ & $50 \%$ & $48 \%$ & $51 \%$ & $41 \%$ & $22 \%$ \\
\hline Sparsely populated & $59 \%$ & $59 \%$ & $50 \%$ & $52 \%$ & $49 \%$ & $59 \%$ & $78 \%$ \\
\hline
\end{tabular}

a. Refers to individuals aged 25 and over.

b. Applies to individuals aged 25 and over. Students aged 16 to 24 are not included in the sample.

c. Refers only to individuals who have worked before.

d. Based on total gross household income.

e. Based on total equivalized disposable household income.

f. Dependent children include: 1. household members under 18; 2. household members aged between 18 and 24 who are economically inactive and living with at least one parent.

Source: WB staff calculations based on EU-SILC. 


\begin{tabular}{|c|c|c|c|c|c|c|c|c|}
\hline & $\begin{array}{l}\text { All Out-of- } \\
\text { Work }\end{array}$ & $\begin{array}{l}\text { 1. Stay-at- } \\
\text { home } \\
\text { mothers }\end{array}$ & $\begin{array}{c}\text { 2. Highly } \\
\text { educated } \\
\text { single NEETs }\end{array}$ & $\begin{array}{l}\text { 3. Middle-aged } \\
\text { unemployed } \\
\text { heads of } \\
\text { households }\end{array}$ & $\begin{array}{c}4 . \\
\text { Retirees' } \\
\text { inactive } \\
\text { wives }\end{array}$ & $\begin{array}{l}5 . \text { Low- } \\
\text { educated } \\
\text { retirees }\end{array}$ & $\begin{array}{l}\text { 6. Highly } \\
\text { educated } \\
\text { early } \\
\text { retirees }\end{array}$ & $\begin{array}{l}\text { 7. Low- } \\
\text { educated } \\
\text { mostly } \\
\text { rural } \\
\text { disabled }\end{array}$ \\
\hline Cluster Size & $100 \%$ & $23 \%$ & $18 \%$ & $18 \%$ & $17 \%$ & $13 \%$ & $7 \%$ & $\mathbf{5 \%}$ \\
\hline Population & $2,694,563$ & 608,102 & 496,828 & 476,621 & 464,496 & 345,139 & 179,709 & 123,668 \\
\hline \multicolumn{9}{|c|}{ INDICATORS } \\
\hline \multicolumn{9}{|c|}{ Labor market attachment } \\
\hline Unemployed & $16 \%$ & $11 \%$ & $29 \%$ & $45 \%$ & $0 \%$ & $3 \%$ & $0 \%$ & $2 \%$ \\
\hline Long-term unemployed & $22 \%$ & $13 \%$ & $43 \%$ & $54 \%$ & $0 \%$ & $4 \%$ & $0 \%$ & $21 \%$ \\
\hline Retired & $25 \%$ & $0 \%$ & $2 \%$ & $0 \%$ & $30 \%$ & $90 \%$ & $99 \%$ & $25 \%$ \\
\hline Disabled & $2 \%$ & $0 \%$ & $0 \%$ & $0 \%$ & $0 \%$ & $2 \%$ & $0 \%$ & $44 \%$ \\
\hline Other inactive & $35 \%$ & $76 \%$ & $27 \%$ & $1 \%$ & $69 \%$ & $2 \%$ & $0 \%$ & $8 \%$ \\
\hline \multicolumn{9}{|l|}{ Education } \\
\hline Primary & $36 \%$ & $32 \%$ & $5 \%$ & $37 \%$ & $68 \%$ & $52 \%$ & $1 \%$ & $74 \%$ \\
\hline Secondary & $44 \%$ & $56 \%$ & $54 \%$ & $48 \%$ & $32 \%$ & $37 \%$ & $30 \%$ & $26 \%$ \\
\hline Tertiary & $19 \%$ & $13 \%$ & $41 \%$ & $16 \%$ & $1 \%$ & $11 \%$ & $69 \%$ & $0 \%$ \\
\hline \multicolumn{9}{|l|}{ Working Partner } \\
\hline Yes & $32 \%$ & $86 \%$ & $0 \%$ & $33 \%$ & $5 \%$ & $19 \%$ & $39 \%$ & $15 \%$ \\
\hline No & $34 \%$ & $14 \%$ & $0 \%$ & $35 \%$ & $71 \%$ & $71 \%$ & $46 \%$ & $7 \%$ \\
\hline NA & $34 \%$ & $0 \%$ & $100 \%$ & $32 \%$ & $25 \%$ & $10 \%$ & $15 \%$ & $78 \%$ \\
\hline \multicolumn{9}{|c|}{ Self-assessed physical incapacity } \\
\hline None/limited & $92 \%$ & $99 \%$ & $99 \%$ & $97 \%$ & $90 \%$ & $87 \%$ & $99 \%$ & $33 \%$ \\
\hline Strongly limited & $8 \%$ & $1 \%$ & $1 \%$ & $3 \%$ & $10 \%$ & $13 \%$ & $1 \%$ & $67 \%$ \\
\hline \multicolumn{9}{|c|}{ ACTIVE COVARIATES } \\
\hline \multicolumn{9}{|l|}{ Age groups (4) } \\
\hline $16-24$ years & $7 \%$ & $3 \%$ & $32 \%$ & $4 \%$ & $0 \%$ & $0 \%$ & $0 \%$ & $1 \%$ \\
\hline 25-34 years & $20 \%$ & $25 \%$ & $60 \%$ & $15 \%$ & $0 \%$ & $0 \%$ & $0 \%$ & $19 \%$ \\
\hline $35-59$ years & $55 \%$ & $72 \%$ & $8 \%$ & $81 \%$ & $57 \%$ & $31 \%$ & $86 \%$ & $72 \%$ \\
\hline
\end{tabular}




\begin{tabular}{|c|c|c|c|c|c|c|c|c|}
\hline & $\begin{array}{l}\text { All Out-of- } \\
\text { Work }\end{array}$ & $\begin{array}{l}\text { 1. Stay-at- } \\
\text { home } \\
\text { mothers }\end{array}$ & $\begin{array}{c}\text { 2. Highly } \\
\text { educated } \\
\text { single NEETs }\end{array}$ & $\begin{array}{l}\text { 3. Middle-aged } \\
\text { unemployed } \\
\text { heads of } \\
\text { households }\end{array}$ & $\begin{array}{c}4 . \\
\text { Retirees' } \\
\text { inactive } \\
\text { wives }\end{array}$ & $\begin{array}{l}\text { 5. Low- } \\
\text { educated } \\
\text { retirees }\end{array}$ & $\begin{array}{l}\text { 6. Highly } \\
\text { educated } \\
\text { early } \\
\text { retirees }\end{array}$ & $\begin{array}{l}\text { 7. Low- } \\
\text { educated } \\
\text { mostly } \\
\text { rural } \\
\text { disabled }\end{array}$ \\
\hline 60-64 years & $18 \%$ & $1 \%$ & $0 \%$ & $0 \%$ & $43 \%$ & $69 \%$ & $14 \%$ & $7 \%$ \\
\hline \multicolumn{9}{|l|}{ Gender } \\
\hline Female & $62 \%$ & $100 \%$ & $41 \%$ & $39 \%$ & $100 \%$ & $14 \%$ & $61 \%$ & $37 \%$ \\
\hline Male & $38 \%$ & $0 \%$ & $59 \%$ & $61 \%$ & $0 \%$ & $86 \%$ & $39 \%$ & $63 \%$ \\
\hline \multicolumn{9}{|l|}{ Degree of urbanization } \\
\hline Densely populated & $46 \%$ & $35 \%$ & $49 \%$ & $55 \%$ & $48 \%$ & $51 \%$ & $37 \%$ & $35 \%$ \\
\hline Intermediate area & $15 \%$ & $18 \%$ & $14 \%$ & $16 \%$ & $10 \%$ & $11 \%$ & $34 \%$ & $7 \%$ \\
\hline Sparsely populated & $39 \%$ & $47 \%$ & $37 \%$ & $29 \%$ & $42 \%$ & $38 \%$ & $29 \%$ & $58 \%$ \\
\hline \multicolumn{9}{|c|}{ INACTIVE COVARIATES } \\
\hline \multicolumn{9}{|l|}{ Age groups (7) } \\
\hline 16-19 years & $1 \%$ & $0 \%$ & $7 \%$ & $0 \%$ & $0 \%$ & $0 \%$ & $0 \%$ & $1 \%$ \\
\hline 20-24 years & $6 \%$ & $3 \%$ & $25 \%$ & $3 \%$ & $0 \%$ & $0 \%$ & $0 \%$ & $1 \%$ \\
\hline 25-34 years & $20 \%$ & $25 \%$ & $60 \%$ & $15 \%$ & $0 \%$ & $0 \%$ & $0 \%$ & $19 \%$ \\
\hline $35-44$ years & $19 \%$ & $35 \%$ & $5 \%$ & $42 \%$ & $7 \%$ & $2 \%$ & $3 \%$ & $34 \%$ \\
\hline 45-54 years & $20 \%$ & $28 \%$ & $2 \%$ & $29 \%$ & $23 \%$ & $10 \%$ & $29 \%$ & $17 \%$ \\
\hline $55-59$ years & $16 \%$ & $9 \%$ & $1 \%$ & $11 \%$ & $28 \%$ & $19 \%$ & $53 \%$ & $22 \%$ \\
\hline 60-64 years & $18 \%$ & $1 \%$ & $0 \%$ & $0 \%$ & $43 \%$ & $69 \%$ & $14 \%$ & $7 \%$ \\
\hline \multicolumn{9}{|l|}{ Education } \\
\hline None/less than primary & $2 \%$ & $1 \%$ & $0 \%$ & $1 \%$ & $3 \%$ & $3 \%$ & $0 \%$ & $6 \%$ \\
\hline Primary & $23 \%$ & $17 \%$ & $1 \%$ & $19 \%$ & $52 \%$ & $38 \%$ & $1 \%$ & $35 \%$ \\
\hline Lower secondary & $12 \%$ & $13 \%$ & $4 \%$ & $17 \%$ & $13 \%$ & $11 \%$ & $0 \%$ & $27 \%$ \\
\hline Upper secondary & $36 \%$ & $48 \%$ & $40 \%$ & $38 \%$ & $28 \%$ & $31 \%$ & $23 \%$ & $20 \%$ \\
\hline Post-secondary & $8 \%$ & $8 \%$ & $14 \%$ & $10 \%$ & $3 \%$ & $5 \%$ & $7 \%$ & $4 \%$ \\
\hline Tertiary & $19 \%$ & $13 \%$ & $41 \%$ & $15 \%$ & $1 \%$ & $11 \%$ & $69 \%$ & $0 \%$ \\
\hline NA & $1 \%$ & $0 \%$ & $0 \%$ & $1 \%$ & $1 \%$ & $0 \%$ & $0 \%$ & $9 \%$ \\
\hline \multicolumn{9}{|l|}{ Enrolled in Education $^{a}$} \\
\hline Yes & $3 \%$ & $2 \%$ & $12 \%$ & $1 \%$ & $0 \%$ & $0 \%$ & $0 \%$ & $2 \%$ \\
\hline
\end{tabular}




\begin{tabular}{|c|c|c|c|c|c|c|c|c|}
\hline & $\begin{array}{l}\text { All Out-of- } \\
\text { Work }\end{array}$ & $\begin{array}{l}\text { 1. Stay-at- } \\
\text { home } \\
\text { mothers }\end{array}$ & $\begin{array}{c}\text { 2. Highly } \\
\text { educated } \\
\text { single NEETs }\end{array}$ & $\begin{array}{l}\text { 3. Middle-aged } \\
\text { unemployed } \\
\text { heads of } \\
\text { households }\end{array}$ & $\begin{array}{c}4 . \\
\text { Retirees' } \\
\text { inactive } \\
\text { wives }\end{array}$ & $\begin{array}{l}5 . \text { Low- } \\
\text { educated } \\
\text { retirees }\end{array}$ & $\begin{array}{l}\text { 6. Highly } \\
\text { educated } \\
\text { early } \\
\text { retirees }\end{array}$ & $\begin{array}{l}\text { 7. Low- } \\
\text { educated } \\
\text { mostly } \\
\text { rural } \\
\text { disabled }\end{array}$ \\
\hline No & $97 \%$ & $98 \%$ & $88 \%$ & $99 \%$ & $100 \%$ & $100 \%$ & $100 \%$ & $98 \%$ \\
\hline \multicolumn{9}{|l|}{ Marital status } \\
\hline Never married & $26 \%$ & $0 \%$ & $94 \%$ & $23 \%$ & $5 \%$ & $4 \%$ & $4 \%$ & $61 \%$ \\
\hline Married & $66 \%$ & $99 \%$ & $2 \%$ & $69 \%$ & $76 \%$ & $90 \%$ & $85 \%$ & $22 \%$ \\
\hline Divorced/separated & $4 \%$ & $0 \%$ & $3 \%$ & $7 \%$ & $7 \%$ & $3 \%$ & $6 \%$ & $10 \%$ \\
\hline Widowed & $4 \%$ & $0 \%$ & $0 \%$ & $1 \%$ & $12 \%$ & $3 \%$ & $5 \%$ & $7 \%$ \\
\hline \multicolumn{9}{|c|}{ At least one working adult in household ${ }^{b}$} \\
\hline No & $45 \%$ & $12 \%$ & $40 \%$ & $56 \%$ & $68 \%$ & $58 \%$ & $45 \%$ & $65 \%$ \\
\hline Yes & $55 \%$ & $88 \%$ & $60 \%$ & $44 \%$ & $32 \%$ & $42 \%$ & $55 \%$ & $35 \%$ \\
\hline \multicolumn{9}{|c|}{ Household income (mean) } \\
\hline Labor income & 16,765 & 24576 & 19052 & 14177 & 9430 & 11240 & 25958 & 8740 \\
\hline Other income & 1,497 & 1749 & 1776 & 1067 & 1415 & 1049 & 2351 & 1122 \\
\hline Benefits & 10,319 & 3364 & 9013 & 4986 & 14743 & 18127 & 23677 & 12504 \\
\hline \multicolumn{9}{|c|}{ Household income (share) } \\
\hline Labor income & $53 \%$ & $83 \%$ & $57 \%$ & $64 \%$ & $27 \%$ & $30 \%$ & $40 \%$ & $27 \%$ \\
\hline Other income & $6 \%$ & $5 \%$ & $8 \%$ & $8 \%$ & $6 \%$ & $4 \%$ & $4 \%$ & $5 \%$ \\
\hline Benefits & $41 \%$ & $12 \%$ & $35 \%$ & $29 \%$ & $67 \%$ & $66 \%$ & $56 \%$ & $68 \%$ \\
\hline \multicolumn{9}{|l|}{ Income quintile $^{c}$} \\
\hline Poorest & $28 \%$ & $28 \%$ & $27 \%$ & $44 \%$ & $27 \%$ & $19 \%$ & $4 \%$ & $34 \%$ \\
\hline Q2 & $21 \%$ & $28 \%$ & $20 \%$ & $22 \%$ & $18 \%$ & $16 \%$ & $7 \%$ & $29 \%$ \\
\hline Q3 & $20 \%$ & $18 \%$ & $25 \%$ & $17 \%$ & $22 \%$ & $21 \%$ & $11 \%$ & $18 \%$ \\
\hline Q4 & $15 \%$ & $14 \%$ & $15 \%$ & $11 \%$ & $17 \%$ & $19 \%$ & $23 \%$ & $12 \%$ \\
\hline Richest & $16 \%$ & $12 \%$ & $13 \%$ & $7 \%$ & $15 \%$ & $24 \%$ & $55 \%$ & $7 \%$ \\
\hline \multicolumn{9}{|c|}{ Partner economic status } \\
\hline Working & $32 \%$ & $86 \%$ & $0 \%$ & $33 \%$ & $5 \%$ & $19 \%$ & $39 \%$ & $15 \%$ \\
\hline Unemployed & $8 \%$ & $6 \%$ & $0 \%$ & $21 \%$ & $8 \%$ & $7 \%$ & $2 \%$ & $3 \%$ \\
\hline Retired & $19 \%$ & $7 \%$ & $0 \%$ & $5 \%$ & $62 \%$ & $28 \%$ & $35 \%$ & $2 \%$ \\
\hline
\end{tabular}




\begin{tabular}{|c|c|c|c|c|c|c|c|c|}
\hline & $\begin{array}{l}\text { All Out-of- } \\
\text { Work }\end{array}$ & $\begin{array}{l}\text { 1. Stay-at- } \\
\text { home } \\
\text { mothers }\end{array}$ & $\begin{array}{c}\text { 2. Highly } \\
\text { educated } \\
\text { single NEETs }\end{array}$ & $\begin{array}{l}\text { 3. Middle-aged } \\
\text { unemployed } \\
\text { heads of } \\
\text { households }\end{array}$ & $\begin{array}{c}4 . \\
\text { Retirees' } \\
\text { inactive } \\
\text { wives }\end{array}$ & $\begin{array}{l}\text { 5. Low- } \\
\text { educated } \\
\text { retirees }\end{array}$ & $\begin{array}{c}\text { 6. Highly } \\
\text { educated } \\
\text { early } \\
\text { retirees }\end{array}$ & $\begin{array}{l}\text { 7. Low- } \\
\text { educated } \\
\text { mostly } \\
\text { rural } \\
\text { disabled }\end{array}$ \\
\hline Inactive & $7 \%$ & $0 \%$ & $0 \%$ & $9 \%$ & $1 \%$ & $36 \%$ & $9 \%$ & $2 \%$ \\
\hline Student/military service & . & . & . & . & . & . & . & . \\
\hline No partner & $34 \%$ & $0 \%$ & $100 \%$ & $32 \%$ & $25 \%$ & $10 \%$ & $15 \%$ & $78 \%$ \\
\hline Partner income (mean) & 8,885 & 17,399 & 12,743 & 12,266 & 21,763 & 10,323 & 25,159 & 10,936 \\
\hline \multicolumn{9}{|l|}{ Partner income quintile } \\
\hline Poorest & $5 \%$ & $10 \%$ & $0 \%$ & $6 \%$ & $1 \%$ & $7 \%$ & $5 \%$ & $6 \%$ \\
\hline Q2 & $6 \%$ & $16 \%$ & $0 \%$ & $10 \%$ & $1 \%$ & $5 \%$ & $2 \%$ & $3 \%$ \\
\hline Q3 & $6 \%$ & $16 \%$ & $0 \%$ & $8 \%$ & $1 \%$ & $2 \%$ & $5 \%$ & $2 \%$ \\
\hline Q4 & $7 \%$ & $23 \%$ & $0 \%$ & $6 \%$ & $1 \%$ & $2 \%$ & $6 \%$ & $1 \%$ \\
\hline Richest & $8 \%$ & $23 \%$ & $0 \%$ & $3 \%$ & $1 \%$ & $2 \%$ & $20 \%$ & $2 \%$ \\
\hline No partner or partner without income & $68 \%$ & $14 \%$ & $100 \%$ & $67 \%$ & $95 \%$ & $81 \%$ & $61 \%$ & $85 \%$ \\
\hline Household size (mean) & 3.18 & 3.53 & 3.356 & 3.216 & 2.754 & 2.971 & 2.976 & 3.017 \\
\hline \multicolumn{9}{|l|}{ Tenure status } \\
\hline Free & $6 \%$ & $7 \%$ & $4 \%$ & $8 \%$ & $5 \%$ & $4 \%$ & $3 \%$ & $9 \%$ \\
\hline Owner & $76 \%$ & $71 \%$ & $77 \%$ & $61 \%$ & $84 \%$ & $86 \%$ & $89 \%$ & $76 \%$ \\
\hline Reduced rate & $1 \%$ & $2 \%$ & $0 \%$ & $3 \%$ & $0 \%$ & $1 \%$ & $1 \%$ & $2 \%$ \\
\hline Tenant & $17 \%$ & $20 \%$ & $19 \%$ & $28 \%$ & $10 \%$ & $9 \%$ & $8 \%$ & $13 \%$ \\
\hline \multicolumn{9}{|l|}{ Household composition } \\
\hline One-person & $5 \%$ & $0 \%$ & $9 \%$ & $7 \%$ & $6 \%$ & $3 \%$ & $6 \%$ & $8 \%$ \\
\hline Single parent & $1 \%$ & $0 \%$ & $2 \%$ & $2 \%$ & $1 \%$ & $0 \%$ & $1 \%$ & $1 \%$ \\
\hline $2+$ adults without dependent children ${ }^{\mathrm{d}}$ & $59 \%$ & $33 \%$ & $66 \%$ & $42 \%$ & $81 \%$ & $82 \%$ & $67 \%$ & $77 \%$ \\
\hline $2+$ adults with 1 dependent child ${ }^{d}$ & $9 \%$ & $18 \%$ & $3 \%$ & $15 \%$ & $3 \%$ & $4 \%$ & $7 \%$ & $6 \%$ \\
\hline $2+$ adults with $2+$ dependent children ${ }^{\mathrm{d}}$ & $25 \%$ & $49 \%$ & $20 \%$ & $35 \%$ & $9 \%$ & $11 \%$ & $19 \%$ & $8 \%$ \\
\hline Children under 6 & $11 \%$ & $29 \%$ & $1 \%$ & $22 \%$ & $1 \%$ & $2 \%$ & $1 \%$ & $5 \%$ \\
\hline Three or more children under 16 & $1 \%$ & $2 \%$ & $0 \%$ & $1 \%$ & $0 \%$ & $0 \%$ & $1 \%$ & $0 \%$ \\
\hline \multicolumn{9}{|l|}{ Children under 13 in childcare } \\
\hline No children under 13 in household & $75 \%$ & $45 \%$ & $92 \%$ & $58 \%$ & $93 \%$ & $93 \%$ & $89 \%$ & $89 \%$ \\
\hline
\end{tabular}




\begin{tabular}{|c|c|c|c|c|c|c|c|c|}
\hline & $\begin{array}{l}\text { All Out-of- } \\
\text { Work }\end{array}$ & $\begin{array}{l}\text { 1. Stay-at- } \\
\text { home } \\
\text { mothers }\end{array}$ & $\begin{array}{c}\text { 2. Highly } \\
\text { educated } \\
\text { single NEETs }\end{array}$ & $\begin{array}{l}\text { 3. Middle-aged } \\
\text { unemployed } \\
\text { heads of } \\
\text { households }\end{array}$ & $\begin{array}{c}4 . \\
\text { Retirees' } \\
\text { inactive } \\
\text { wives }\end{array}$ & $\begin{array}{l}5 . \text { Low- } \\
\text { educated } \\
\text { retirees }\end{array}$ & $\begin{array}{l}6 . \text { Highly } \\
\text { educated } \\
\text { early } \\
\text { retirees }\end{array}$ & $\begin{array}{l}\text { 7. Low- } \\
\text { educated } \\
\text { mostly } \\
\text { rural } \\
\text { disabled }\end{array}$ \\
\hline All of the children & $11 \%$ & $25 \%$ & $3 \%$ & $19 \%$ & $3 \%$ & $2 \%$ & $2 \%$ & $5 \%$ \\
\hline None of the children & $10 \%$ & $19 \%$ & $5 \%$ & $14 \%$ & $3 \%$ & $4 \%$ & $8 \%$ & $5 \%$ \\
\hline Some of the children & $5 \%$ & $12 \%$ & $0 \%$ & $8 \%$ & $1 \%$ & $1 \%$ & $1 \%$ & $2 \%$ \\
\hline Elderly present (over 64) & $22 \%$ & $7 \%$ & $20 \%$ & $20 \%$ & $43 \%$ & $18 \%$ & $16 \%$ & $51 \%$ \\
\hline Years of work experience & 19 & 10.78 & 5.36 & 17.31 & 21.11 & 33.64 & 29.47 & 20.17 \\
\hline \multicolumn{9}{|l|}{ Ever worked } \\
\hline No & $29 \%$ & $42 \%$ & $46 \%$ & $6 \%$ & $45 \%$ & $2 \%$ & $2 \%$ & $41 \%$ \\
\hline Yes & $70 \%$ & $56 \%$ & $53 \%$ & $93 \%$ & $55 \%$ & $97 \%$ & $98 \%$ & $59 \%$ \\
\hline NA & $1 \%$ & $2 \%$ & $1 \%$ & $1 \%$ & $1 \%$ & $1 \%$ & $0 \%$ & $0 \%$ \\
\hline \multicolumn{9}{|l|}{ Able to keep dwelling warm } \\
\hline No & $24 \%$ & $24 \%$ & $24 \%$ & $38 \%$ & $18 \%$ & $16 \%$ & $4 \%$ & $34 \%$ \\
\hline Yes & $76 \%$ & $76 \%$ & $76 \%$ & $62 \%$ & $82 \%$ & $84 \%$ & $96 \%$ & $66 \%$ \\
\hline Urban & $39 \%$ & $53 \%$ & $63 \%$ & $71 \%$ & $58 \%$ & $62 \%$ & $71 \%$ & $42 \%$ \\
\hline Rural & $61 \%$ & $47 \%$ & $37 \%$ & $29 \%$ & $42 \%$ & $38 \%$ & $29 \%$ & $58 \%$ \\
\hline \multicolumn{9}{|l|}{ Region } \\
\hline GR1 - Northern Greece & $32 \%$ & $34 \%$ & $33 \%$ & $33 \%$ & $31 \%$ & $30 \%$ & $22 \%$ & $33 \%$ \\
\hline GR2 - Central Greece & $18 \%$ & $21 \%$ & $17 \%$ & $12 \%$ & $18 \%$ & $21 \%$ & $13 \%$ & $29 \%$ \\
\hline GR3 - Athens & $42 \%$ & $34 \%$ & $43 \%$ & $48 \%$ & $41 \%$ & $40 \%$ & $60 \%$ & $33 \%$ \\
\hline GR4 - Aegean Islands, Crete & $8 \%$ & $11 \%$ & $7 \%$ & $6 \%$ & $10 \%$ & $9 \%$ & $5 \%$ & $5 \%$ \\
\hline Receives at least one benefit & $44 \%$ & $21 \%$ & $24 \%$ & $37 \%$ & $44 \%$ & $88 \%$ & $86 \%$ & $78 \%$ \\
\hline \multicolumn{9}{|c|}{ Receives benefits at household level } \\
\hline Family child & $13 \%$ & $14 \%$ & $12 \%$ & $16 \%$ & $12 \%$ & $10 \%$ & $8 \%$ & $26 \%$ \\
\hline Social exclusion & $5 \%$ & $3 \%$ & $6 \%$ & $6 \%$ & $7 \%$ & $6 \%$ & $2 \%$ & $7 \%$ \\
\hline Housing & $1 \%$ & $1 \%$ & $1 \%$ & $1 \%$ & $1 \%$ & $1 \%$ & $1 \%$ & $0 \%$ \\
\hline \multicolumn{9}{|c|}{ Receives benefits at individual level } \\
\hline Unemployment & $6 \%$ & $4 \%$ & $6 \%$ & $19 \%$ & $0 \%$ & $3 \%$ & $0 \%$ & $3 \%$ \\
\hline Old age & $19 \%$ & $1 \%$ & $0 \%$ & $0 \%$ & $21 \%$ & $71 \%$ & $79 \%$ & $10 \%$ \\
\hline
\end{tabular}




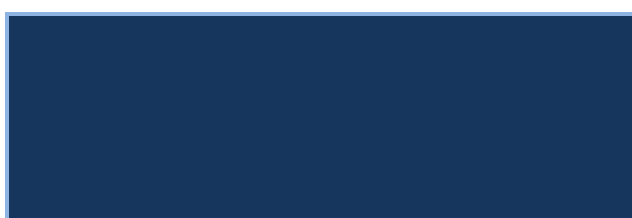

\section{All Out-of- \\ Work}

\begin{tabular}{c|c|}
$\begin{array}{c}\text { 1. Stay-at- } \\
\text { home } \\
\text { mothers }\end{array}$ & $\begin{array}{c}\text { 2. Highly } \\
\text { educated } \\
\text { single NEETs }\end{array}$ \\
\hline
\end{tabular}

3. Middle-aged
unemployed
heads of
households

4.

Retirees'

inactive

5. Low-

educated

households

wives

retirees

6. Highly

educated

early

retirees

7. Low-

educated

mostly

rural

\begin{tabular}{|l|l|}
\hline Survivor & $3 \%$ \\
\hline Sickness & $0 \%$ \\
\hline Disability & $5 \%$ \\
\hline
\end{tabular}

$0 \% \quad 0 \%$

Benefits as share of household income, all households

\begin{tabular}{|c|c|c|c|c|c|c|c|c|}
\hline Family child & $1 \%$ & $1 \%$ & $1 \%$ & $2 \%$ & $1 \%$ & $1 \%$ & $0 \%$ & $2 \%$ \\
\hline Social exclusion & $1 \%$ & $0 \%$ & $1 \%$ & $1 \%$ & $2 \%$ & $1 \%$ & $0 \%$ & $1 \%$ \\
\hline Housing & $0 \%$ & $0 \%$ & $0 \%$ & $0 \%$ & $0 \%$ & $0 \%$ & $0 \%$ & $0 \%$ \\
\hline Unemployment & $3 \%$ & $2 \%$ & $2 \%$ & $9 \%$ & $2 \%$ & $1 \%$ & $1 \%$ & $2 \%$ \\
\hline Old age & $29 \%$ & $7 \%$ & $24 \%$ & $12 \%$ & $51 \%$ & $55 \%$ & $51 \%$ & $29 \%$ \\
\hline Survivor & $3 \%$ & $0 \%$ & $4 \%$ & $3 \%$ & $7 \%$ & $1 \%$ & $1 \%$ & $9 \%$ \\
\hline Sickness & $0 \%$ & $0 \%$ & $0 \%$ & $0 \%$ & $0 \%$ & $0 \%$ & $0 \%$ & $0 \%$ \\
\hline Disability & $4 \%$ & $1 \%$ & $3 \%$ & $2 \%$ & $4 \%$ & $6 \%$ & $2 \%$ & $25 \%$ \\
\hline Education & $0 \%$ & $0 \%$ & $0 \%$ & $0 \%$ & $0 \%$ & $0 \%$ & $0 \%$ & $0 \%$ \\
\hline
\end{tabular}

a. Enrolled in education: Applies to individuals aged 25 and over. Students aged 16 to 24 are not included in the sample.

b. At least one working adult in household: Refers to individuals aged 25 and over

c. Based on total equivalized disposable household income.

d. Dependent children include: 1. household members under 18; 2. household members aged between 18 and 24 who are economically inactive and living with at least one parent.

e. Refers only to individuals who have worked before.

Source: WB staff calculations based on EU-SILC. 


\begin{tabular}{|c|c|c|c|c|c|c|}
\hline & $\begin{array}{l}\text { 1. Stay-at-home } \\
\text { mothers }\end{array}$ & $\begin{array}{c}\text { 2. Retirees' } \\
\text { inactive wives }\end{array}$ & $\begin{array}{c}\text { 3. Highly } \\
\text { educated } \\
\text { single NEETs }\end{array}$ & $\begin{array}{l}\text { 4. Early } \\
\text { retirees/Poor } \\
\text { unemployed }\end{array}$ & $\begin{array}{l}5 . \text { Low- } \\
\text { educated } \\
\text { retirees }\end{array}$ & $\begin{array}{c}\text { 6. Low- } \\
\text { educated } \\
\text { mostly rural } \\
\text { disabled }\end{array}$ \\
\hline Cluster Size & $28.0 \%$ & $22.1 \%$ & $18.8 \%$ & $12.8 \%$ & $11.9 \%$ & $6.4 \%$ \\
\hline Population & 585,214 & 462,242 & 393,344 & 266,196 & 247,615 & 133,202 \\
\hline \multicolumn{7}{|c|}{ INDICATORS } \\
\hline \multicolumn{7}{|c|}{ Labor market attachment } \\
\hline Unemployed & $5 \%$ & $0 \%$ & $37 \%$ & $27 \%$ & $0 \%$ & $0 \%$ \\
\hline Long-term unemployed & $8 \%$ & $2 \%$ & $36 \%$ & $10 \%$ & $1 \%$ & $14 \%$ \\
\hline Retired & $0 \%$ & $20 \%$ & $0 \%$ & $57 \%$ & $96 \%$ & $2 \%$ \\
\hline Disabled & $3 \%$ & $1 \%$ & $3 \%$ & $3 \%$ & $2 \%$ & $78 \%$ \\
\hline Other inactive & $84 \%$ & $77 \%$ & $24 \%$ & $2 \%$ & $1 \%$ & $6 \%$ \\
\hline \multicolumn{7}{|l|}{ Education } \\
\hline Primary & $39 \%$ & $70 \%$ & $17 \%$ & $35 \%$ & $58 \%$ & $73 \%$ \\
\hline Secondary & $47 \%$ & $27 \%$ & $54 \%$ & $41 \%$ & $21 \%$ & $27 \%$ \\
\hline Tertiary & $14 \%$ & $3 \%$ & $29 \%$ & $24 \%$ & $21 \%$ & $0 \%$ \\
\hline \multicolumn{7}{|l|}{ Working Partner } \\
\hline Yes & $95 \%$ & $8 \%$ & $5 \%$ & $49 \%$ & $22 \%$ & $18 \%$ \\
\hline No & $5 \%$ & $67 \%$ & $1 \%$ & $33 \%$ & $72 \%$ & $15 \%$ \\
\hline NA & $0 \%$ & $25 \%$ & $94 \%$ & $18 \%$ & $5 \%$ & $67 \%$ \\
\hline \multicolumn{7}{|c|}{ Self-assessed physical incapacity } \\
\hline None/limited & $99 \%$ & $95 \%$ & $100 \%$ & $97 \%$ & $91 \%$ & $23 \%$ \\
\hline Strongly limited & $1 \%$ & $5 \%$ & $0 \%$ & $3 \%$ & $9 \%$ & $77 \%$ \\
\hline \multicolumn{7}{|c|}{ ACTIVE COVARIATES } \\
\hline \multicolumn{7}{|l|}{ Age groups (4) } \\
\hline 16-24 years & $4 \%$ & $0 \%$ & $29 \%$ & $0 \%$ & $0 \%$ & $1 \%$ \\
\hline 25-34 years & $28 \%$ & $0 \%$ & $58 \%$ & $0 \%$ & $0 \%$ & $20 \%$ \\
\hline 35-59 years & $68 \%$ & $55 \%$ & $13 \%$ & $100 \%$ & $16 \%$ & $62 \%$ \\
\hline $60-64$ years & $0 \%$ & $45 \%$ & $0 \%$ & $0 \%$ & $84 \%$ & $18 \%$ \\
\hline
\end{tabular}




\begin{tabular}{|c|c|c|c|c|c|c|}
\hline & $\begin{array}{l}\text { 1. Stay-at-home } \\
\text { mothers }\end{array}$ & $\begin{array}{c}\text { 2. Retirees' } \\
\text { inactive wives }\end{array}$ & $\begin{array}{l}\text { 3. Highly } \\
\text { educated } \\
\text { single NEETs }\end{array}$ & $\begin{array}{l}\text { 4. Early } \\
\text { retirees/Poor } \\
\text { unemployed }\end{array}$ & $\begin{array}{l}5 . \text { Low- } \\
\text { educated } \\
\text { retirees }\end{array}$ & $\begin{array}{c}\text { 6. Low- } \\
\text { educated } \\
\text { mostly rural } \\
\text { disabled }\end{array}$ \\
\hline \multicolumn{7}{|l|}{ Gender } \\
\hline Female & $100 \%$ & $99 \%$ & $46 \%$ & $40 \%$ & $15 \%$ & $47 \%$ \\
\hline Male & $0 \%$ & $1 \%$ & $54 \%$ & $60 \%$ & $85 \%$ & $53 \%$ \\
\hline \multicolumn{7}{|l|}{ Degree of urbanization } \\
\hline Densely populated & $39 \%$ & $44 \%$ & $48 \%$ & $41 \%$ & $39 \%$ & $32 \%$ \\
\hline Intermediate area & $11 \%$ & $12 \%$ & $11 \%$ & $22 \%$ & $11 \%$ & $2 \%$ \\
\hline Sparsely populated & $50 \%$ & $44 \%$ & $41 \%$ & $37 \%$ & $50 \%$ & $66 \%$ \\
\hline \multicolumn{7}{|c|}{ INACTIVE COVARIATES } \\
\hline \multicolumn{7}{|l|}{ Age groups (7) } \\
\hline 16-19 years & $1 \%$ & $0 \%$ & $8 \%$ & $0 \%$ & $0 \%$ & $0 \%$ \\
\hline 20-24 years & $3 \%$ & $0 \%$ & $22 \%$ & $0 \%$ & $0 \%$ & $1 \%$ \\
\hline 25-34 years & $28 \%$ & $0 \%$ & $58 \%$ & $0 \%$ & $0 \%$ & $20 \%$ \\
\hline $35-44$ years & $36 \%$ & $5 \%$ & $7 \%$ & $24 \%$ & $1 \%$ & $22 \%$ \\
\hline 45-54 years & $25 \%$ & $21 \%$ & $5 \%$ & $34 \%$ & $4 \%$ & $21 \%$ \\
\hline 55-59 years & $7 \%$ & $28 \%$ & $1 \%$ & $42 \%$ & $11 \%$ & $18 \%$ \\
\hline $60-64$ years & $0 \%$ & $45 \%$ & $0 \%$ & $0 \%$ & $84 \%$ & $18 \%$ \\
\hline \multicolumn{7}{|l|}{ Education } \\
\hline None/less than primary & $1 \%$ & $6 \%$ & $0 \%$ & $1 \%$ & $3 \%$ & $6 \%$ \\
\hline Primary & $23 \%$ & $53 \%$ & $9 \%$ & $28 \%$ & $46 \%$ & $37 \%$ \\
\hline Lower secondary & $15 \%$ & $11 \%$ & $8 \%$ & $6 \%$ & $9 \%$ & $25 \%$ \\
\hline Upper secondary & $40 \%$ & $25 \%$ & $43 \%$ & $35 \%$ & $20 \%$ & $23 \%$ \\
\hline Post-secondary & $7 \%$ & $2 \%$ & $10 \%$ & $6 \%$ & $1 \%$ & $2 \%$ \\
\hline Tertiary & $14 \%$ & $3 \%$ & $29 \%$ & $24 \%$ & $21 \%$ & $0 \%$ \\
\hline NA & $0 \%$ & $1 \%$ & $1 \%$ & $0 \%$ & $1 \%$ & $7 \%$ \\
\hline \multicolumn{7}{|l|}{ Enrolled in Education ${ }^{a}$} \\
\hline Yes & $1 \%$ & $0 \%$ & $12 \%$ & $0 \%$ & $0 \%$ & $1 \%$ \\
\hline No & $99 \%$ & $100 \%$ & $88 \%$ & $100 \%$ & $100 \%$ & $99 \%$ \\
\hline
\end{tabular}




\begin{tabular}{|c|c|c|c|c|c|c|}
\hline & $\begin{array}{l}\text { 1. Stay-at-home } \\
\text { mothers }\end{array}$ & $\begin{array}{c}\text { 2. Retirees' } \\
\text { inactive wives }\end{array}$ & $\begin{array}{c}\text { 3. Highly } \\
\text { educated } \\
\text { single NEETs }\end{array}$ & $\begin{array}{l}\text { 4. Early } \\
\text { retirees/Poor } \\
\text { unemployed }\end{array}$ & $\begin{array}{l}5 . \text { Low- } \\
\text { educated } \\
\text { retirees }\end{array}$ & $\begin{array}{c}\text { 6. Low- } \\
\text { educated } \\
\text { mostly rural } \\
\text { disabled }\end{array}$ \\
\hline Never married & $1 \%$ & $3 \%$ & $88 \%$ & $9 \%$ & $1 \%$ & $51 \%$ \\
\hline Married & $99 \%$ & $75 \%$ & $5 \%$ & $81 \%$ & $94 \%$ & $33 \%$ \\
\hline Divorced/separated & $0 \%$ & $5 \%$ & $6 \%$ & $7 \%$ & $1 \%$ & $15 \%$ \\
\hline Widowed & $0 \%$ & $16 \%$ & $1 \%$ & $4 \%$ & $3 \%$ & $2 \%$ \\
\hline \multicolumn{7}{|c|}{ At least one working adult in household ${ }^{b}$} \\
\hline No & $4 \%$ & $57 \%$ & $35 \%$ & $40 \%$ & $50 \%$ & $51 \%$ \\
\hline Yes & $96 \%$ & $44 \%$ & $65 \%$ & $60 \%$ & $50 \%$ & $49 \%$ \\
\hline \multicolumn{7}{|l|}{ Income quintile $^{c}$} \\
\hline Poorest & $35 \%$ & $24 \%$ & $27 \%$ & $19 \%$ & $14 \%$ & $43 \%$ \\
\hline Q2 & $24 \%$ & $22 \%$ & $24 \%$ & $17 \%$ & $19 \%$ & $19 \%$ \\
\hline Q3 & $17 \%$ & $20 \%$ & $19 \%$ & $19 \%$ & $18 \%$ & $20 \%$ \\
\hline Q4 & $13 \%$ & $21 \%$ & $18 \%$ & $23 \%$ & $23 \%$ & $14 \%$ \\
\hline Richest & $11 \%$ & $13 \%$ & $12 \%$ & $22 \%$ & $27 \%$ & $4 \%$ \\
\hline \multicolumn{7}{|l|}{ Partner economic status } \\
\hline Working & $95 \%$ & $8 \%$ & $5 \%$ & $49 \%$ & $22 \%$ & $18 \%$ \\
\hline Unemployed & $1 \%$ & $4 \%$ & $1 \%$ & $6 \%$ & $3 \%$ & $1 \%$ \\
\hline Retired & $3 \%$ & $61 \%$ & $0 \%$ & $11 \%$ & $26 \%$ & $8 \%$ \\
\hline Inactive & $0 \%$ & $2 \%$ & $0 \%$ & $16 \%$ & $43 \%$ & $6 \%$ \\
\hline Student/military service & $0 \%$ & $0 \%$ & $0 \%$ & $0 \%$ & $0 \%$ & $0 \%$ \\
\hline No partner & $0 \%$ & $25 \%$ & $94 \%$ & $18 \%$ & $5 \%$ & $67 \%$ \\
\hline Partner income (mean) & 18311 & 17377 & 12540 & 15705 & 15061 & 8163 \\
\hline \multicolumn{7}{|l|}{ Partner income quintile } \\
\hline Poorest & $7 \%$ & $1 \%$ & $1 \%$ & $10 \%$ & $8 \%$ & $11 \%$ \\
\hline Q2 & $17 \%$ & $2 \%$ & $1 \%$ & $6 \%$ & $3 \%$ & $2 \%$ \\
\hline Q3 & $19 \%$ & $1 \%$ & $2 \%$ & $9 \%$ & $4 \%$ & $1 \%$ \\
\hline Q4 & $24 \%$ & $2 \%$ & $1 \%$ & $10 \%$ & $4 \%$ & $2 \%$ \\
\hline Richest & $28 \%$ & $2 \%$ & $1 \%$ & $13 \%$ & $4 \%$ & $1 \%$ \\
\hline No partner or partner without income & $5 \%$ & $92 \%$ & $95 \%$ & $51 \%$ & $78 \%$ & $82 \%$ \\
\hline
\end{tabular}




\begin{tabular}{|c|c|c|c|c|c|c|}
\hline & $\begin{array}{l}\text { 1. Stay-at-home } \\
\text { mothers }\end{array}$ & $\begin{array}{l}\text { 2. Retirees' } \\
\text { inactive wives }\end{array}$ & $\begin{array}{c}\text { 3. Highly } \\
\text { educated } \\
\text { single NEETs }\end{array}$ & $\begin{array}{c}\text { 4. Early } \\
\text { retirees/Poor } \\
\text { unemployed }\end{array}$ & $\begin{array}{l}5 . \text { Low- } \\
\text { educated } \\
\text { retirees }\end{array}$ & $\begin{array}{c}\text { 6. Low- } \\
\text { educated } \\
\text { mostly rural } \\
\text { disabled }\end{array}$ \\
\hline Household size (mean) & 3.599 & 2.700 & 3.300 & 3.134 & 2.911 & 3.009 \\
\hline \multicolumn{7}{|l|}{ Tenure status } \\
\hline Free & $7 \%$ & $3 \%$ & $4 \%$ & $4 \%$ & $2 \%$ & $3 \%$ \\
\hline Owner & $67 \%$ & $84 \%$ & $80 \%$ & $79 \%$ & $86 \%$ & $83 \%$ \\
\hline Reduced rate & $0 \%$ & $0 \%$ & $1 \%$ & $1 \%$ & $0 \%$ & $0 \%$ \\
\hline Tenant & $26 \%$ & $12 \%$ & $15 \%$ & $16 \%$ & $12 \%$ & $14 \%$ \\
\hline \multicolumn{7}{|l|}{ Household composition } \\
\hline One-person & $0 \%$ & $7 \%$ & $5 \%$ & $5 \%$ & $3 \%$ & $8 \%$ \\
\hline Single parent & $0 \%$ & $1 \%$ & $3 \%$ & $2 \%$ & $0 \%$ & $1 \%$ \\
\hline $2+$ adults without dependent children ${ }^{\mathrm{d}}$ & $30 \%$ & $80 \%$ & $66 \%$ & $57 \%$ & $86 \%$ & $77 \%$ \\
\hline $2+$ adults with 1 dependent child ${ }^{d}$ & $18 \%$ & $3 \%$ & $4 \%$ & $10 \%$ & $4 \%$ & $2 \%$ \\
\hline $2+$ adults with $2+$ dependent children ${ }^{\mathrm{d}}$ & $52 \%$ & $8 \%$ & $22 \%$ & $27 \%$ & $7 \%$ & $12 \%$ \\
\hline Children under 6 & $34 \%$ & $2 \%$ & $5 \%$ & $7 \%$ & $2 \%$ & $3 \%$ \\
\hline Three or more children under 16 & $3 \%$ & $0 \%$ & $0 \%$ & $0 \%$ & $0 \%$ & $0 \%$ \\
\hline \multicolumn{7}{|l|}{ Children under 13 in childcare } \\
\hline No children under 13 in household & $41 \%$ & $92 \%$ & $89 \%$ & $77 \%$ & $94 \%$ & $91 \%$ \\
\hline All of the children & $24 \%$ & $4 \%$ & $5 \%$ & $10 \%$ & $2 \%$ & $3 \%$ \\
\hline None of the children & $21 \%$ & $3 \%$ & $5 \%$ & $7 \%$ & $3 \%$ & $4 \%$ \\
\hline Some of the children & $14 \%$ & $1 \%$ & $1 \%$ & $5 \%$ & $1 \%$ & $2 \%$ \\
\hline Elderly present (over 64) & $6 \%$ & $40 \%$ & $22 \%$ & $13 \%$ & $20 \%$ & $52 \%$ \\
\hline Years of work experience & $\cdot$ & . & . & . & . & . \\
\hline \multicolumn{7}{|l|}{ Ever worked } \\
\hline No & $44 \%$ & $48 \%$ & $46 \%$ & $3 \%$ & $1 \%$ & $43 \%$ \\
\hline Yes & $57 \%$ & $52 \%$ & $54 \%$ & $97 \%$ & $99 \%$ & $57 \%$ \\
\hline \multicolumn{7}{|l|}{ NA } \\
\hline \multicolumn{7}{|l|}{ Able to keep dwelling warm } \\
\hline No & $21 \%$ & $13 \%$ & $21 \%$ & $16 \%$ & $9 \%$ & $36 \%$ \\
\hline Yes & $79 \%$ & $87 \%$ & $79 \%$ & $84 \%$ & $91 \%$ & $64 \%$ \\
\hline
\end{tabular}




\begin{tabular}{|c|c|c|c|c|c|c|}
\hline & $\begin{array}{l}\text { 1. Stay-at-home } \\
\text { mothers }\end{array}$ & $\begin{array}{c}\text { 2. Retirees' } \\
\text { inactive wives }\end{array}$ & $\begin{array}{l}\text { 3. Highly } \\
\text { educated } \\
\text { single NEETs }\end{array}$ & $\begin{array}{l}\text { 4. Early } \\
\text { retirees/Poor } \\
\text { unemployed }\end{array}$ & $\begin{array}{l}\text { 5. Low- } \\
\text { educated } \\
\text { retirees }\end{array}$ & $\begin{array}{l}\text { 6. Low- } \\
\text { educated } \\
\text { mostly rural } \\
\text { disabled }\end{array}$ \\
\hline Urban & $50 \%$ & $56 \%$ & $59 \%$ & $63 \%$ & $50 \%$ & $34 \%$ \\
\hline Rural & $50 \%$ & $44 \%$ & $41 \%$ & $37 \%$ & $50 \%$ & $66 \%$ \\
\hline \multicolumn{7}{|l|}{ Region } \\
\hline GR1 - Northern Greece & $31 \%$ & $30 \%$ & $35 \%$ & $29 \%$ & $34 \%$ & $27 \%$ \\
\hline GR2 - Central Greece & $18 \%$ & $19 \%$ & $21 \%$ & $18 \%$ & $21 \%$ & $39 \%$ \\
\hline GR3 - Athens & $39 \%$ & $42 \%$ & $34 \%$ & $45 \%$ & $35 \%$ & $26 \%$ \\
\hline GR4 - Aegean Islands, Crete & $12 \%$ & $8 \%$ & $10 \%$ & $8 \%$ & $10 \%$ & $8 \%$ \\
\hline Receives at least one benefit & $21 \%$ & $41 \%$ & $27 \%$ & $72 \%$ & $92 \%$ & $74 \%$ \\
\hline \multicolumn{7}{|c|}{ Receives benefits at household level } \\
\hline Family child & $16 \%$ & $9 \%$ & $13 \%$ & $17 \%$ & $8 \%$ & $13 \%$ \\
\hline Social exclusion & $2 \%$ & $8 \%$ & $4 \%$ & $5 \%$ & $8 \%$ & $15 \%$ \\
\hline Housing & $2 \%$ & $1 \%$ & $0 \%$ & $3 \%$ & $1 \%$ & $0 \%$ \\
\hline \multicolumn{7}{|c|}{ Receives benefits at individual level } \\
\hline Unemployment & $2 \%$ & $1 \%$ & $10 \%$ & $11 \%$ & $2 \%$ & $1 \%$ \\
\hline Old age & $0 \%$ & $16 \%$ & $0 \%$ & $44 \%$ & $83 \%$ & $5 \%$ \\
\hline Survivor & $0 \%$ & $13 \%$ & $1 \%$ & $2 \%$ & $1 \%$ & $3 \%$ \\
\hline Sickness & $0 \%$ & $1 \%$ & $0 \%$ & $1 \%$ & $0 \%$ & $2 \%$ \\
\hline Disability & $1 \%$ & $3 \%$ & $2 \%$ & $9 \%$ & $8 \%$ & $54 \%$ \\
\hline
\end{tabular}

a. Enrolled in education: Applies to individuals aged 25 and over. Students aged 16 to 24 are not included in the sample.

b. At least one working adult in household: Refers to individuals aged 25 and over

c. Based on total equivalized disposable household income.

d. Dependent children include: 1. household members under 18; 2. household members aged between 18 and 24 who are economically inactive and living with at least one parent.

e. Refers only to individuals who have worked before. 


\begin{tabular}{|c|c|c|c|c|c|c|}
\hline & $\begin{array}{l}\text { 1. Stay-at-home } \\
\text { mothers }\end{array}$ & $\begin{array}{c}\text { 2. Highly } \\
\text { educated } \\
\text { single NEETs }\end{array}$ & $\begin{array}{l}\text { 3. Retirees' } \\
\text { inactive } \\
\text { wives }\end{array}$ & $\begin{array}{l}\text { 4. Low- } \\
\text { educated } \\
\text { retirees }\end{array}$ & $\begin{array}{l}\text { 5. Early } \\
\text { retirees/Poor } \\
\text { unemployed }\end{array}$ & $\begin{array}{l}\text { 6. Low- } \\
\text { educated } \\
\text { mostly rural } \\
\text { disabled }\end{array}$ \\
\hline Cluster Size & $30.5 \%$ & $18.4 \%$ & $16.9 \%$ & $15.5 \%$ & $12.5 \%$ & $6.2 \%$ \\
\hline Population & 653,187 & 393,965 & 360,600 & 331,940 & 267,135 & 131,963 \\
\hline \multicolumn{7}{|c|}{ INDICATORS } \\
\hline \multicolumn{7}{|c|}{ Labor market attachment } \\
\hline Unemployed & $5 \%$ & $30 \%$ & $0 \%$ & $2 \%$ & $18 \%$ & $0 \%$ \\
\hline Long-term unemployed & $7 \%$ & $41 \%$ & $1 \%$ & $2 \%$ & $18 \%$ & $4 \%$ \\
\hline Retired & $0 \%$ & $0 \%$ & $3 \%$ & $93 \%$ & $55 \%$ & $9 \%$ \\
\hline Disabled & $0 \%$ & $1 \%$ & $0 \%$ & $1 \%$ & $6 \%$ & $85 \%$ \\
\hline Other inactive & $88 \%$ & $27 \%$ & $96 \%$ & $3 \%$ & $4 \%$ & $1 \%$ \\
\hline \multicolumn{7}{|l|}{ Education } \\
\hline Primary & $45 \%$ & $20 \%$ & $77 \%$ & $62 \%$ & $50 \%$ & $75 \%$ \\
\hline Secondary & $44 \%$ & $56 \%$ & $23 \%$ & $23 \%$ & $25 \%$ & $24 \%$ \\
\hline Tertiary & $11 \%$ & $24 \%$ & $0 \%$ & $15 \%$ & $25 \%$ & $1 \%$ \\
\hline \multicolumn{7}{|l|}{ Working Partner } \\
\hline Yes & $94 \%$ & $3 \%$ & $11 \%$ & $18 \%$ & $41 \%$ & $26 \%$ \\
\hline No & $4 \%$ & $1 \%$ & $72 \%$ & $68 \%$ & $36 \%$ & $18 \%$ \\
\hline NA & $2 \%$ & $96 \%$ & $17 \%$ & $14 \%$ & $23 \%$ & $56 \%$ \\
\hline \multicolumn{7}{|c|}{ Self-assessed physical incapacity } \\
\hline None/limited & $97 \%$ & $99 \%$ & $92 \%$ & $89 \%$ & $93 \%$ & $32 \%$ \\
\hline Strongly limited & $3 \%$ & $1 \%$ & $8 \%$ & $11 \%$ & $7 \%$ & $68 \%$ \\
\hline \multicolumn{7}{|c|}{ ACTIVE COVARIATES } \\
\hline \multicolumn{7}{|l|}{ Age groups (4) } \\
\hline 16-24 years & $4 \%$ & $35 \%$ & $0 \%$ & $0 \%$ & $0 \%$ & $3 \%$ \\
\hline 25-34 years & $30 \%$ & $51 \%$ & $0 \%$ & $0 \%$ & $0 \%$ & $20 \%$ \\
\hline $35-59$ years & $65 \%$ & $14 \%$ & $62 \%$ & $26 \%$ & $100 \%$ & $62 \%$ \\
\hline $60-64$ years & $0 \%$ & $0 \%$ & $38 \%$ & $74 \%$ & $0 \%$ & $15 \%$ \\
\hline
\end{tabular}




\begin{tabular}{|c|c|c|c|c|c|c|}
\hline & $\begin{array}{l}\text { 1. Stay-at-home } \\
\text { mothers }\end{array}$ & $\begin{array}{l}\text { 2. Highly } \\
\text { educated } \\
\text { single NEETs }\end{array}$ & $\begin{array}{l}\text { 3. Retirees' } \\
\text { inactive } \\
\text { wives }\end{array}$ & $\begin{array}{l}\text { 4. Low- } \\
\text { educated } \\
\text { retirees }\end{array}$ & $\begin{array}{l}\text { 5. Early } \\
\text { retirees/Poor } \\
\text { unemployed }\end{array}$ & $\begin{array}{c}\text { 6. Low- } \\
\text { educated } \\
\text { mostly rural } \\
\text { disabled }\end{array}$ \\
\hline \multicolumn{7}{|l|}{ Gender } \\
\hline Female & $100 \%$ & $54 \%$ & $100 \%$ & $28 \%$ & $58 \%$ & $45 \%$ \\
\hline Male & $0 \%$ & $46 \%$ & $0 \%$ & $72 \%$ & $42 \%$ & $55 \%$ \\
\hline \multicolumn{7}{|l|}{ Degree of urbanization } \\
\hline Densely populated & $35 \%$ & $46 \%$ & $43 \%$ & $45 \%$ & $47 \%$ & $24 \%$ \\
\hline Intermediate area & $12 \%$ & $12 \%$ & $15 \%$ & $13 \%$ & $19 \%$ & $9 \%$ \\
\hline Sparsely populated & $53 \%$ & $42 \%$ & $43 \%$ & $42 \%$ & $34 \%$ & $66 \%$ \\
\hline \multicolumn{7}{|c|}{ INACTIVE COVARIATES } \\
\hline \multicolumn{7}{|l|}{ Age groups (7) } \\
\hline $16-19$ years & $0 \%$ & $8 \%$ & $0 \%$ & $0 \%$ & $0 \%$ & $1 \%$ \\
\hline 20-24 years & $4 \%$ & $27 \%$ & $0 \%$ & $0 \%$ & $0 \%$ & $2 \%$ \\
\hline 25-34 years & $30 \%$ & $51 \%$ & $0 \%$ & $0 \%$ & $0 \%$ & $20 \%$ \\
\hline $35-44$ years & $34 \%$ & $7 \%$ & $8 \%$ & $1 \%$ & $21 \%$ & $22 \%$ \\
\hline 45-54 years & $24 \%$ & $5 \%$ & $28 \%$ & $8 \%$ & $38 \%$ & $23 \%$ \\
\hline $55-59$ years & $8 \%$ & $1 \%$ & $26 \%$ & $17 \%$ & $41 \%$ & $17 \%$ \\
\hline 60-64 years & $0 \%$ & $0 \%$ & $38 \%$ & $74 \%$ & $0 \%$ & $15 \%$ \\
\hline \multicolumn{7}{|l|}{ Education } \\
\hline None/less than primary & . & . & . & . & . & . \\
\hline Primary & $29 \%$ & $11 \%$ & $65 \%$ & $51 \%$ & $36 \%$ & $48 \%$ \\
\hline Lower secondary & $16 \%$ & $9 \%$ & $11 \%$ & $11 \%$ & $13 \%$ & $20 \%$ \\
\hline Upper secondary & $39 \%$ & $46 \%$ & $21 \%$ & $20 \%$ & $21 \%$ & $20 \%$ \\
\hline Post-secondary & $5 \%$ & $10 \%$ & $2 \%$ & $3 \%$ & $3 \%$ & $1 \%$ \\
\hline Tertiary & $11 \%$ & $24 \%$ & $0 \%$ & $15 \%$ & $25 \%$ & $1 \%$ \\
\hline NA & $1 \%$ & $1 \%$ & $1 \%$ & $0 \%$ & $1 \%$ & $10 \%$ \\
\hline \multicolumn{7}{|l|}{ Enrolled in Education ${ }^{a}$} \\
\hline Yes & $1 \%$ & $12 \%$ & $0 \%$ & $0 \%$ & $0 \%$ & $0 \%$ \\
\hline No & $99 \%$ & $88 \%$ & $100 \%$ & $100 \%$ & $100 \%$ & $100 \%$ \\
\hline
\end{tabular}




\begin{tabular}{|c|c|c|c|c|c|c|}
\hline & $\begin{array}{l}\text { 1. Stay-at-home } \\
\text { mothers }\end{array}$ & $\begin{array}{c}\text { 2. Highly } \\
\text { educated } \\
\text { single NEETs }\end{array}$ & $\begin{array}{l}\text { 3. Retirees' } \\
\text { inactive } \\
\text { wives }\end{array}$ & $\begin{array}{l}\text { 4. Low- } \\
\text { educated } \\
\text { retirees }\end{array}$ & $\begin{array}{l}\text { 5. Early } \\
\text { retirees/Poor } \\
\text { unemployed }\end{array}$ & $\begin{array}{c}\text { 6. Low- } \\
\text { educated } \\
\text { mostly rural } \\
\text { disabled }\end{array}$ \\
\hline Never married & $1 \%$ & $89 \%$ & $3 \%$ & $3 \%$ & $9 \%$ & $44 \%$ \\
\hline Married & $98 \%$ & $4 \%$ & $82 \%$ & $85 \%$ & $76 \%$ & $43 \%$ \\
\hline Divorced/separated & $0 \%$ & $6 \%$ & $3 \%$ & $3 \%$ & $7 \%$ & $8 \%$ \\
\hline Widowed & $1 \%$ & $1 \%$ & $12 \%$ & $10 \%$ & $9 \%$ & $5 \%$ \\
\hline \multicolumn{7}{|c|}{ At least one working adult in the household } \\
\hline No & $4 \%$ & $36 \%$ & $54 \%$ & $51 \%$ & $42 \%$ & $46 \%$ \\
\hline Yes & $96 \%$ & $64 \%$ & $46 \%$ & $50 \%$ & $58 \%$ & $55 \%$ \\
\hline \multicolumn{7}{|l|}{ Income quintilec } \\
\hline Poorest & $29 \%$ & $30 \%$ & $21 \%$ & $13 \%$ & $22 \%$ & $36 \%$ \\
\hline Q2 & $27 \%$ & $25 \%$ & $23 \%$ & $17 \%$ & $19 \%$ & $27 \%$ \\
\hline Q3 & $21 \%$ & $20 \%$ & $21 \%$ & $19 \%$ & $17 \%$ & $22 \%$ \\
\hline Q4 & $13 \%$ & $13 \%$ & $20 \%$ & $25 \%$ & $21 \%$ & $11 \%$ \\
\hline Richest & $11 \%$ & $11 \%$ & $15 \%$ & $26 \%$ & $21 \%$ & $4 \%$ \\
\hline \multicolumn{7}{|l|}{ Partner economic status } \\
\hline Working & $94 \%$ & $3 \%$ & $11 \%$ & $18 \%$ & $41 \%$ & $26 \%$ \\
\hline Unemployed & $1 \%$ & $1 \%$ & $3 \%$ & $3 \%$ & $7 \%$ & $4 \%$ \\
\hline Retired & $3 \%$ & $0 \%$ & $65 \%$ & $28 \%$ & $17 \%$ & $6 \%$ \\
\hline Inactive & $1 \%$ & $0 \%$ & $3 \%$ & $37 \%$ & $13 \%$ & $8 \%$ \\
\hline Student/military service & $0 \%$ & $0 \%$ & $0 \%$ & $0 \%$ & $0 \%$ & $0 \%$ \\
\hline No partner & $2 \%$ & $96 \%$ & $17 \%$ & $14 \%$ & $23 \%$ & $57 \%$ \\
\hline Partner income (mean) & 17289 & 11090 & 15733 & 13348 & 14886 & 8990 \\
\hline \multicolumn{7}{|l|}{ Partner income quintile } \\
\hline Poorest & $7 \%$ & $1 \%$ & $1 \%$ & $5 \%$ & $6 \%$ & $4 \%$ \\
\hline Q2 & $15 \%$ & $1 \%$ & $2 \%$ & $2 \%$ & $7 \%$ & $14 \%$ \\
\hline Q3 & $23 \%$ & $1 \%$ & $2 \%$ & $2 \%$ & $9 \%$ & $5 \%$ \\
\hline Q4 & $21 \%$ & $1 \%$ & $2 \%$ & $4 \%$ & $7 \%$ & $1 \%$ \\
\hline Richest & $29 \%$ & $0 \%$ & $3 \%$ & $5 \%$ & $12 \%$ & $2 \%$ \\
\hline No partner or partner without income & $6 \%$ & $97 \%$ & $89 \%$ & $82 \%$ & $59 \%$ & $74 \%$ \\
\hline
\end{tabular}




\begin{tabular}{|c|c|c|c|c|c|c|}
\hline & $\begin{array}{l}\text { 1. Stay-at-home } \\
\text { mothers }\end{array}$ & $\begin{array}{l}\text { 2. Highly } \\
\text { educated } \\
\text { single NEETs }\end{array}$ & $\begin{array}{l}\text { 3. Retirees' } \\
\text { inactive } \\
\text { wives }\end{array}$ & $\begin{array}{l}\text { 4. Low- } \\
\text { educated } \\
\text { retirees }\end{array}$ & $\begin{array}{l}\text { 5. Early } \\
\text { retirees/Poor } \\
\text { unemployed }\end{array}$ & $\begin{array}{c}\text { 6. Low- } \\
\text { educated } \\
\text { mostly rural } \\
\text { disabled }\end{array}$ \\
\hline Household size (mean) & 3.646 & 3.397 & 2.849 & 2.851 & 3.063 & 3.295 \\
\hline \multicolumn{7}{|l|}{ Tenure status } \\
\hline Free & $7 \%$ & $5 \%$ & $4 \%$ & $3 \%$ & $5 \%$ & $4 \%$ \\
\hline Owner & $69 \%$ & $76 \%$ & $87 \%$ & $85 \%$ & $77 \%$ & $84 \%$ \\
\hline Reduced rate & $1 \%$ & $1 \%$ & $0 \%$ & $0 \%$ & $2 \%$ & $2 \%$ \\
\hline Tenant & $23 \%$ & $19 \%$ & $9 \%$ & $12 \%$ & $16 \%$ & $10 \%$ \\
\hline \multicolumn{7}{|l|}{ Household composition } \\
\hline One-person & $0 \%$ & $7 \%$ & $6 \%$ & $6 \%$ & $7 \%$ & $6 \%$ \\
\hline Single parent & $0 \%$ & $3 \%$ & $1 \%$ & $0 \%$ & $3 \%$ & $1 \%$ \\
\hline $2+$ adults without dependent children ${ }^{\mathrm{d}}$ & $32 \%$ & $60 \%$ & $78 \%$ & $79 \%$ & $54 \%$ & $72 \%$ \\
\hline $2+$ adults with 1 dependent child ${ }^{\mathrm{d}}$ & $17 \%$ & $6 \%$ & $4 \%$ & $3 \%$ & $7 \%$ & $3 \%$ \\
\hline $2+$ adults with $2+$ dependent children ${ }^{d}$ & $51 \%$ & $23 \%$ & $12 \%$ & $12 \%$ & $30 \%$ & $18 \%$ \\
\hline Children under 6 & $33 \%$ & $5 \%$ & $2 \%$ & $1 \%$ & $4 \%$ & $6 \%$ \\
\hline Three or more children under 16 & $4 \%$ & $1 \%$ & $1 \%$ & $0 \%$ & $1 \%$ & $2 \%$ \\
\hline \multicolumn{7}{|l|}{ Children under 13 in childcare } \\
\hline No children under 13 in household & $42 \%$ & $87 \%$ & $91 \%$ & $95 \%$ & $80 \%$ & $86 \%$ \\
\hline All of the children & $27 \%$ & $5 \%$ & $4 \%$ & $2 \%$ & $9 \%$ & $6 \%$ \\
\hline None of the children & $18 \%$ & $7 \%$ & $4 \%$ & $3 \%$ & $8 \%$ & $4 \%$ \\
\hline Some of the children & $13 \%$ & $1 \%$ & $1 \%$ & $0 \%$ & $3 \%$ & $4 \%$ \\
\hline Elderly present (over 64) & $7 \%$ & $25 \%$ & $39 \%$ & $20 \%$ & $14 \%$ & $42 \%$ \\
\hline Years of work experience & $\cdot$ & $\cdot$ & $\cdot$ & $\cdot$ & $\cdot$ & $\cdot$ \\
\hline Worked more than 2 months in last year & $6 \%$ & $21 \%$ & $1 \%$ & $10 \%$ & $21 \%$ & $5 \%$ \\
\hline \multicolumn{7}{|l|}{ Ever worked } \\
\hline No & $49 \%$ & $56 \%$ & $57 \%$ & $1 \%$ & $6 \%$ & $39 \%$ \\
\hline Yes & $51 \%$ & $44 \%$ & $43 \%$ & $99 \%$ & $94 \%$ & $61 \%$ \\
\hline \multicolumn{7}{|l|}{ NA } \\
\hline \multicolumn{7}{|l|}{ Able to keep dwelling warm } \\
\hline No & $14 \%$ & $21 \%$ & $13 \%$ & $13 \%$ & $17 \%$ & $38 \%$ \\
\hline
\end{tabular}




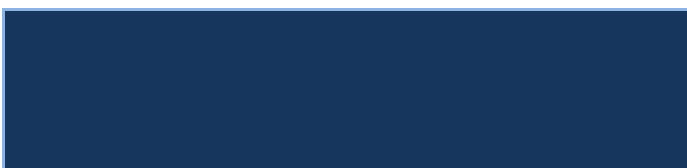

\section{Stay-at-home mothers}

2. Highly educated single NEETs

Yes

Urban

Rural

Region

GR1 - Northern Greece

GR2 - Central Greece

GR3 - Athens

GR4 - Aegean Islands, Crete

Receives at least one benefit

\section{Receives benefits at household level}

\begin{tabular}{|l|c|c|}
\hline Family child & $16 \%$ & $11 \%$ \\
\hline Social exclusion & $2 \%$ & $4 \%$ \\
\hline Housing & $2 \%$ & $1 \%$ \\
\hline
\end{tabular}

\section{Receives benefits at individual level}

\begin{tabular}{|c|c|c|c|c|c|c|}
\hline Unemployment & $3 \%$ & $4 \%$ & $1 \%$ & $1 \%$ & $9 \%$ & $1 \%$ \\
\hline Old age & $0 \%$ & $0 \%$ & $3 \%$ & $80 \%$ & $44 \%$ & $9 \%$ \\
\hline Survivor & $1 \%$ & $2 \%$ & $10 \%$ & $4 \%$ & $5 \%$ & $3 \%$ \\
\hline Sickness & $0 \%$ & $0 \%$ & $1 \%$ & $0 \%$ & $0 \%$ & $12 \%$ \\
\hline Disability & $1 \%$ & $2 \%$ & $3 \%$ & $8 \%$ & $10 \%$ & $58 \%$ \\
\hline
\end{tabular}

a. Enrolled in education: Applies to individuals aged 25 and over. Students aged 16 to 24 are not included in the sample.

b. At least one working adult in household: Refers to individuals aged 25 and over

c. Based on total equivalized disposable household income.

d. Dependent children include: 1. household members under 18; 2. household members aged between 18 and 24 who are economically inactive and living with at least one parent.

e. Refers only to individuals who have worked before.

Source: WB staff calculations based on EU-SILC. 


\begin{tabular}{|c|c|c|c|c|c|c|c|c|c|c|c|}
\hline & $\begin{array}{l}\text { All Out-of- } \\
\text { Work }\end{array}$ & $\begin{array}{c}1 . \\
\text { Disabled } \\
\text { with } \\
\text { previous } \\
\text { work } \\
\text { experien } \\
\text { ce }\end{array}$ & $\begin{array}{l}\text { 2. Mostly } \\
\text { male early } \\
\text { retirees } \\
\text { and } \\
\text { retirees }\end{array}$ & $\begin{array}{c}3 . \\
\text { Urban } \\
\text { retired } \\
\text { women }\end{array}$ & $\begin{array}{c}4 . \\
\text { Prime- } \\
\text { aged } \\
\text { unempl } \\
\text { oyed }\end{array}$ & $\begin{array}{c}5 . \\
\text { Prime- } \\
\text { aged } \\
\text { inactive } \\
\text { mother } \\
\text { s with } \\
\text { work } \\
\text { experie } \\
\text { nce }\end{array}$ & $\begin{array}{c}6 . \\
\text { Prime- } \\
\text { aged } \\
\text { long- } \\
\text { term } \\
\text { unempl } \\
\text { oyed }\end{array}$ & $\begin{array}{c}7 . \\
\text { Unempl } \\
\text { oyed } \\
\text { youth }\end{array}$ & $\begin{array}{c}\text { 8. Low- } \\
\text { educate } \\
\text { d rural } \\
\text { inactive } \\
\text { mothers } \\
\text { without } \\
\text { work } \\
\text { experie } \\
\text { nce }\end{array}$ & $\begin{array}{c}9 . \\
\text { Educat } \\
\text { ed } \\
\text { single } \\
\text { studen } \\
\text { ts }\end{array}$ & $\begin{array}{c}10 . \\
\text { Low- } \\
\text { educate } \\
\text { d } \\
\text { disable } \\
\text { d } \\
\text { without } \\
\text { work } \\
\text { experie } \\
\text { nce }\end{array}$ \\
\hline Cluster size & $100 \%$ & $19 \%$ & $15 \%$ & $15 \%$ & $14 \%$ & $13 \%$ & $12 \%$ & $4 \%$ & $4 \%$ & $2 \%$ & $2 \%$ \\
\hline Population & $2,277,342$ & 432,012 & 351,394 & 346,839 & 318,600 & 301,065 & 265,310 & 95,648 & 91,094 & 39,170 & 36,210 \\
\hline \multicolumn{12}{|c|}{ INDICATORS } \\
\hline \multicolumn{12}{|c|}{ Labor market attachment } \\
\hline Unemployed & $16 \%$ & $1 \%$ & $0 \%$ & $0 \%$ & $97 \%$ & $3 \%$ & $0 \%$ & $43 \%$ & $0 \%$ & $6 \%$ & $1 \%$ \\
\hline Long-term unemployed & $13 \%$ & $3 \%$ & $0 \%$ & $0 \%$ & $0 \%$ & $3 \%$ & $86 \%$ & $47 \%$ & $12 \%$ & $3 \%$ & $6 \%$ \\
\hline Retired & $30 \%$ & $0 \%$ & $100 \%$ & $95 \%$ & $0 \%$ & $0 \%$ & $0 \%$ & $0 \%$ & $0 \%$ & $0 \%$ & $2 \%$ \\
\hline Disabled & $20 \%$ & $94 \%$ & $0 \%$ & $5 \%$ & $0 \%$ & $0 \%$ & $0 \%$ & $0 \%$ & $0 \%$ & $1 \%$ & $85 \%$ \\
\hline Other inactive & $21 \%$ & $2 \%$ & $0 \%$ & $0 \%$ & $3 \%$ & $94 \%$ & $14 \%$ & $11 \%$ & $88 \%$ & $90 \%$ & $6 \%$ \\
\hline \multicolumn{12}{|c|}{ At least one working adult in householda } \\
\hline No & $51 \%$ & $55 \%$ & $52 \%$ & $79 \%$ & $55 \%$ & $18 \%$ & $59 \%$ & $22 \%$ & $47 \%$ & $21 \%$ & $58 \%$ \\
\hline Yes & $49 \%$ & $45 \%$ & $48 \%$ & $21 \%$ & $45 \%$ & $82 \%$ & $41 \%$ & $78 \%$ & $53 \%$ & $79 \%$ & $42 \%$ \\
\hline \multicolumn{12}{|l|}{ Work experience } \\
\hline Never worked & $10 \%$ & $0 \%$ & $0 \%$ & $1 \%$ & $0 \%$ & $0 \%$ & $1 \%$ & $82 \%$ & $78 \%$ & $99 \%$ & $100 \%$ \\
\hline $\begin{array}{l}\text { Less than } 2 \text { months in } \\
\text { last year }\end{array}$ & $73 \%$ & $98 \%$ & $90 \%$ & $98 \%$ & $7 \%$ & $89 \%$ & $99 \%$ & $18 \%$ & $21 \%$ & $1 \%$ & $0 \%$ \\
\hline $\begin{array}{l}2 \text { or more months in last } \\
\text { year }\end{array}$ & $16 \%$ & $2 \%$ & $9 \%$ & $1 \%$ & $93 \%$ & $11 \%$ & $0 \%$ & $0 \%$ & $2 \%$ & $0 \%$ & $0 \%$ \\
\hline \multicolumn{12}{|c|}{ Self-assessed physical incapacity } \\
\hline Strongly limited & $12 \%$ & $35 \%$ & $12 \%$ & $8 \%$ & $3 \%$ & $2 \%$ & $3 \%$ & $0 \%$ & $0 \%$ & $0 \%$ & $67 \%$ \\
\hline None/limited & $88 \%$ & $65 \%$ & $88 \%$ & $92 \%$ & $97 \%$ & $98 \%$ & $97 \%$ & $100 \%$ & $100 \%$ & $100 \%$ & $33 \%$ \\
\hline
\end{tabular}



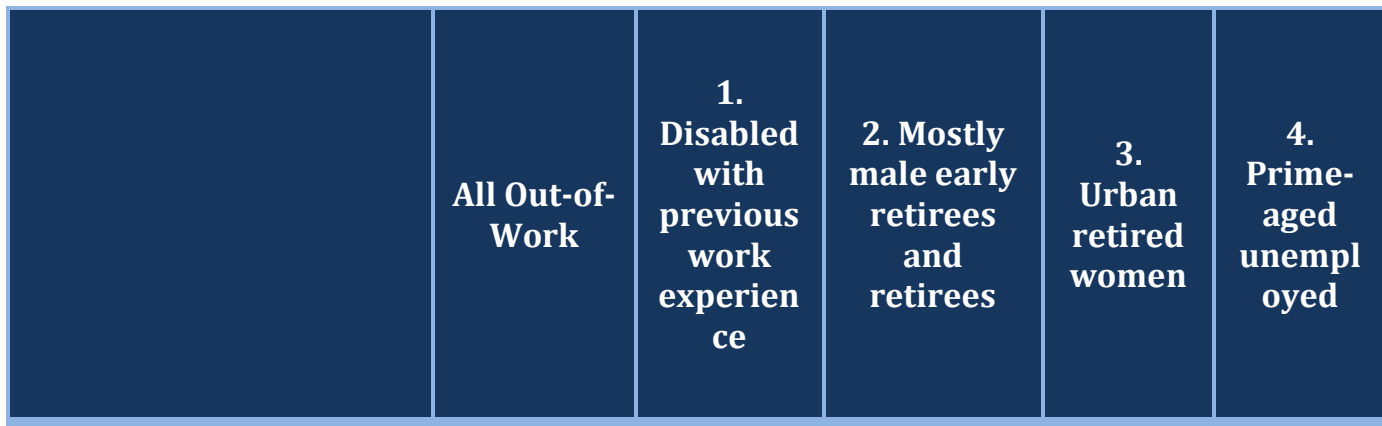

5.
Prime-
aged
inactive
mother
s with
work
experie
nce

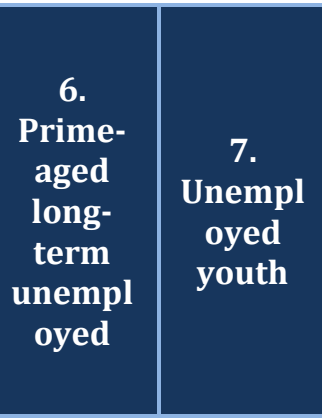

8. Low-

educate

d rural

inactive

mothers

without

work

experie

nce

ACTIVE COVARIATES

\section{Age groups (4)}

\begin{tabular}{|c|c|c|c|c|c|c|c|c|c|c|c|}
\hline $16-24$ years & $9 \%$ & $0 \%$ & $0 \%$ & $0 \%$ & $14 \%$ & $3 \%$ & $5 \%$ & $91 \%$ & $52 \%$ & $0 \%$ & $31 \%$ \\
\hline $25-34$ years & $17 \%$ & $2 \%$ & $0 \%$ & $0 \%$ & $25 \%$ & $50 \%$ & $20 \%$ & $9 \%$ & $32 \%$ & $100 \%$ & $33 \%$ \\
\hline $35-59$ years & $48 \%$ & $88 \%$ & $43 \%$ & $4 \%$ & $60 \%$ & $45 \%$ & $73 \%$ & $0 \%$ & $15 \%$ & $0 \%$ & $34 \%$ \\
\hline 60-64 years & $26 \%$ & $10 \%$ & $57 \%$ & $96 \%$ & $1 \%$ & $1 \%$ & $2 \%$ & $0 \%$ & $1 \%$ & $0 \%$ & $2 \%$ \\
\hline
\end{tabular}

Gender

\begin{tabular}{|c|c|c|c|c|c|c|c|c|c|c|c|}
\hline Male & $42 \%$ & $50 \%$ & $62 \%$ & $20 \%$ & $60 \%$ & $0 \%$ & $57 \%$ & $56 \%$ & $10 \%$ & $63 \%$ & $48 \%$ \\
\hline Female & $58 \%$ & $50 \%$ & $38 \%$ & $80 \%$ & $40 \%$ & $100 \%$ & $43 \%$ & $44 \%$ & $90 \%$ & $37 \%$ & $52 \%$ \\
\hline
\end{tabular}

\section{Education (4)}

\begin{tabular}{|c|c|c|c|c|c|c|c|c|c|c|c|}
\hline Primary & $32 \%$ & $37 \%$ & $29 \%$ & $21 \%$ & $36 \%$ & $19 \%$ & $38 \%$ & $20 \%$ & $78 \%$ & $0 \%$ & $60 \%$ \\
\hline Secondary & $57 \%$ & $58 \%$ & $59 \%$ & $62 \%$ & $59 \%$ & $57 \%$ & $56 \%$ & $60 \%$ & $21 \%$ & $68 \%$ & $23 \%$ \\
\hline Tertiary & $11 \%$ & $5 \%$ & $12 \%$ & $17 \%$ & $5 \%$ & $24 \%$ & $6 \%$ & $20 \%$ & $2 \%$ & $32 \%$ & $1 \%$ \\
\hline $\begin{array}{l}\text { Never studied } \\
\text { before/illiterate/NA }\end{array}$ & $0 \%$ & $0 \%$ & $0 \%$ & $1 \%$ & $0 \%$ & $0 \%$ & $0 \%$ & $0 \%$ & $0 \%$ & $0 \%$ & $15 \%$ \\
\hline Urban & $48 \%$ & $37 \%$ & $46 \%$ & $64 \%$ & $41 \%$ & $52 \%$ & $50 \%$ & $45 \%$ & $30 \%$ & $77 \%$ & $47 \%$ \\
\hline Rural & $52 \%$ & $63 \%$ & $54 \%$ & $36 \%$ & $59 \%$ & $48 \%$ & $50 \%$ & $55 \%$ & $70 \%$ & $23 \%$ & $53 \%$ \\
\hline \multicolumn{12}{|c|}{ INACTIVE COVARIATES } \\
\hline \multicolumn{12}{|l|}{ Age groups (8) } \\
\hline $16-19$ years & $2 \%$ & $0 \%$ & $0 \%$ & $0 \%$ & $1 \%$ & $0 \%$ & $1 \%$ & $23 \%$ & $12 \%$ & $0 \%$ & $6 \%$ \\
\hline 20-24 years & $8 \%$ & $0 \%$ & $0 \%$ & $0 \%$ & $13 \%$ & $3 \%$ & $4 \%$ & $68 \%$ & $40 \%$ & $0 \%$ & $25 \%$ \\
\hline $25-29$ years & $8 \%$ & $1 \%$ & $0 \%$ & $0 \%$ & $14 \%$ & $19 \%$ & $9 \%$ & $7 \%$ & $18 \%$ & $91 \%$ & $15 \%$ \\
\hline 30-34 years & $8 \%$ & $1 \%$ & $0 \%$ & $0 \%$ & $12 \%$ & $32 \%$ & $11 \%$ & $2 \%$ & $14 \%$ & $9 \%$ & $18 \%$ \\
\hline
\end{tabular}




\begin{tabular}{|c|c|c|c|c|c|c|c|c|c|c|c|}
\hline & $\begin{array}{l}\text { All Out-of- } \\
\text { Work }\end{array}$ & $\begin{array}{c}1 . \\
\text { Disabled } \\
\text { with } \\
\text { previous } \\
\text { work } \\
\text { experien } \\
\text { ce }\end{array}$ & $\begin{array}{l}\text { 2. Mostly } \\
\text { male early } \\
\text { retirees } \\
\text { and } \\
\text { retirees }\end{array}$ & $\begin{array}{c}3 . \\
\text { Urban } \\
\text { retired } \\
\text { women }\end{array}$ & $\begin{array}{c}4 . \\
\text { Prime- } \\
\text { aged } \\
\text { unempl } \\
\text { oyed }\end{array}$ & $\begin{array}{c}5 . \\
\text { Prime- } \\
\text { aged } \\
\text { inactive } \\
\text { mother } \\
\text { s with } \\
\text { work } \\
\text { experie } \\
\text { nce }\end{array}$ & $\begin{array}{c}6 . \\
\text { Prime- } \\
\text { aged } \\
\text { long- } \\
\text { term } \\
\text { unempl } \\
\text { oyed }\end{array}$ & $\begin{array}{c}7 . \\
\text { Unempl } \\
\text { oyed } \\
\text { youth }\end{array}$ & $\begin{array}{c}\text { 8. Low- } \\
\text { educate } \\
\text { d rural } \\
\text { inactive } \\
\text { mothers } \\
\text { without } \\
\text { work } \\
\text { experie } \\
\text { nce }\end{array}$ & $\begin{array}{c}9 . \\
\text { Educat } \\
\text { ed } \\
\text { single } \\
\text { studen } \\
\text { ts }\end{array}$ & $\begin{array}{c}10 . \\
\text { Low- } \\
\text { educate } \\
\text { d } \\
\text { disable } \\
\text { d } \\
\text { without } \\
\text { work } \\
\text { experie } \\
\text { nce }\end{array}$ \\
\hline $35-44$ years & $14 \%$ & $10 \%$ & $4 \%$ & $0 \%$ & $26 \%$ & $33 \%$ & $26 \%$ & $0 \%$ & $11 \%$ & $0 \%$ & $19 \%$ \\
\hline $45-54$ years & $17 \%$ & $41 \%$ & $8 \%$ & $1 \%$ & $25 \%$ & $8 \%$ & $28 \%$ & $0 \%$ & $3 \%$ & $0 \%$ & $11 \%$ \\
\hline 55-59 years & $17 \%$ & $37 \%$ & $31 \%$ & $3 \%$ & $9 \%$ & $5 \%$ & $18 \%$ & $0 \%$ & $1 \%$ & $0 \%$ & $4 \%$ \\
\hline $60-64$ years & $26 \%$ & $10 \%$ & $57 \%$ & $96 \%$ & $1 \%$ & $1 \%$ & $2 \%$ & $0 \%$ & $1 \%$ & $0 \%$ & $2 \%$ \\
\hline \multicolumn{12}{|l|}{ Education (6) } \\
\hline Primary & $4 \%$ & $5 \%$ & $3 \%$ & $2 \%$ & $4 \%$ & $2 \%$ & $6 \%$ & $3 \%$ & $11 \%$ & $0 \%$ & $22 \%$ \\
\hline Lower secondary & $27 \%$ & $32 \%$ & $26 \%$ & $19 \%$ & $33 \%$ & $17 \%$ & $32 \%$ & $17 \%$ & $67 \%$ & $0 \%$ & $38 \%$ \\
\hline Upper secondary & $52 \%$ & $55 \%$ & $54 \%$ & $56 \%$ & $55 \%$ & $52 \%$ & $52 \%$ & $49 \%$ & $19 \%$ & $58 \%$ & $23 \%$ \\
\hline Post-secondary & $5 \%$ & $3 \%$ & $5 \%$ & $6 \%$ & $4 \%$ & $5 \%$ & $4 \%$ & $11 \%$ & $1 \%$ & $10 \%$ & $0 \%$ \\
\hline Tertiary & $11 \%$ & $5 \%$ & $12 \%$ & $17 \%$ & $5 \%$ & $24 \%$ & $6 \%$ & $20 \%$ & $2 \%$ & $32 \%$ & $1 \%$ \\
\hline $\begin{array}{l}\text { Never studied } \\
\text { before/illiterate/NA }\end{array}$ & $0 \%$ & $0 \%$ & $0 \%$ & $1 \%$ & $0 \%$ & $0 \%$ & $0 \%$ & $0 \%$ & $0 \%$ & $0 \%$ & $15 \%$ \\
\hline \multicolumn{12}{|c|}{ Enrolled in education ${ }^{b}$} \\
\hline Yes & $3 \%$ & $0 \%$ & $0 \%$ & $0 \%$ & $1 \%$ & $3 \%$ & $3 \%$ & $1 \%$ & $4 \%$ & $81 \%$ & $2 \%$ \\
\hline No & $97 \%$ & $100 \%$ & $100 \%$ & $100 \%$ & $99 \%$ & $97 \%$ & $97 \%$ & $99 \%$ & $96 \%$ & $19 \%$ & $98 \%$ \\
\hline \multicolumn{12}{|l|}{ Ever worked } \\
\hline No & $10 \%$ & $0 \%$ & $0 \%$ & $1 \%$ & $0 \%$ & $0 \%$ & $1 \%$ & $82 \%$ & $78 \%$ & $99 \%$ & $100 \%$ \\
\hline Yes & $90 \%$ & $100 \%$ & $100 \%$ & $99 \%$ & $100 \%$ & $100 \%$ & $99 \%$ & $18 \%$ & $22 \%$ & $1 \%$ & $0 \%$ \\
\hline $\begin{array}{l}\text { Years of work } \\
\text { experience }\end{array}$ & 24 & 25 & 36 & 36 & 16 & 11 & 18 & 2 & 6 & 7 & 15 \\
\hline \multicolumn{12}{|c|}{ Partner economic status } \\
\hline Working & $29 \%$ & $30 \%$ & $26 \%$ & $8 \%$ & $24 \%$ & $73 \%$ & $26 \%$ & $6 \%$ & $30 \%$ & $7 \%$ & $6 \%$ \\
\hline Unemployed & $7 \%$ & $7 \%$ & $3 \%$ & $2 \%$ & $12 \%$ & $7 \%$ & $13 \%$ & $3 \%$ & $26 \%$ & $4 \%$ & $2 \%$ \\
\hline Retired & $17 \%$ & $12 \%$ & $36 \%$ & $50 \%$ & $3 \%$ & $3 \%$ & $4 \%$ & $0 \%$ & $1 \%$ & $0 \%$ & $1 \%$ \\
\hline
\end{tabular}




\begin{tabular}{|c|c|c|c|c|c|c|c|c|c|c|c|}
\hline & $\begin{array}{l}\text { All Out-of- } \\
\text { Work }\end{array}$ & $\begin{array}{c}1 . \\
\text { Disabled } \\
\text { with } \\
\text { previous } \\
\text { work } \\
\text { experien } \\
\text { ce }\end{array}$ & $\begin{array}{l}\text { 2. Mostly } \\
\text { male early } \\
\text { retirees } \\
\text { and } \\
\text { retirees }\end{array}$ & $\begin{array}{c}3 . \\
\text { Urban } \\
\text { retired } \\
\text { women }\end{array}$ & $\begin{array}{c}4 . \\
\text { Prime- } \\
\text { aged } \\
\text { unempl } \\
\text { oyed }\end{array}$ & $\begin{array}{c}5 . \\
\text { Prime- } \\
\text { aged } \\
\text { inactive } \\
\text { mother } \\
\text { s with } \\
\text { work } \\
\text { experie } \\
\text { nce }\end{array}$ & $\begin{array}{c}6 . \\
\text { Prime- } \\
\text { aged } \\
\text { long- } \\
\text { term } \\
\text { unempl } \\
\text { oyed }\end{array}$ & $\begin{array}{c}7 . \\
\text { Unempl } \\
\text { oyed } \\
\text { youth }\end{array}$ & $\begin{array}{c}\text { 8. Low- } \\
\text { educate } \\
\text { d rural } \\
\text { inactive } \\
\text { mothers } \\
\text { without } \\
\text { work } \\
\text { experie } \\
\text { nce }\end{array}$ & $\begin{array}{c}\text { 9. } \\
\text { Educat } \\
\text { ed } \\
\text { single } \\
\text { studen } \\
\text { ts }\end{array}$ & $\begin{array}{c}10 . \\
\text { Low- } \\
\text { educate } \\
\text { d } \\
\text { disable } \\
\text { d } \\
\text { without } \\
\text { work } \\
\text { experie } \\
\text { nce }\end{array}$ \\
\hline Inactive & $10 \%$ & $19 \%$ & $11 \%$ & $4 \%$ & $14 \%$ & $4 \%$ & $14 \%$ & $2 \%$ & $7 \%$ & $0 \%$ & $4 \%$ \\
\hline Student/military service & $0 \%$ & $0 \%$ & $0 \%$ & $0 \%$ & $0 \%$ & $0 \%$ & $0 \%$ & $1 \%$ & $0 \%$ & $0 \%$ & $0 \%$ \\
\hline No partner & $36 \%$ & $32 \%$ & $24 \%$ & $35 \%$ & $47 \%$ & $13 \%$ & $42 \%$ & $87 \%$ & $37 \%$ & $89 \%$ & $87 \%$ \\
\hline Partner income (mean) & 3486 & 2.788 & 2.632 & 1.44 & 3.008 & 7.685 & 3.042 & 3.594 & 2.539 & 5.653 & 1.117 \\
\hline $\begin{array}{l}\text { Working partner } \\
\text { income (mean) }\end{array}$ & 7024 & 5.741 & 6.817 & 9.242 & 5.654 & 8.795 & 6.039 & 5.591 & 4.127 & 8.386 & 2.047 \\
\hline \multicolumn{12}{|l|}{ Partner income quintile } \\
\hline Poorest & $7 \%$ & $8 \%$ & $6 \%$ & $1 \%$ & $9 \%$ & $10 \%$ & $7 \%$ & $3 \%$ & $15 \%$ & $1 \%$ & $6 \%$ \\
\hline Q2 & $6 \%$ & $8 \%$ & $6 \%$ & $1 \%$ & $5 \%$ & $13 \%$ & $6 \%$ & $1 \%$ & $9 \%$ & $0 \%$ & $0 \%$ \\
\hline Q3 & $5 \%$ & $6 \%$ & $4 \%$ & $2 \%$ & $4 \%$ & $12 \%$ & $5 \%$ & $1 \%$ & $3 \%$ & $1 \%$ & $0 \%$ \\
\hline Q4 & $5 \%$ & $5 \%$ & $5 \%$ & $2 \%$ & $3 \%$ & $16 \%$ & $4 \%$ & $0 \%$ & $1 \%$ & $1 \%$ & $0 \%$ \\
\hline Richest & $6 \%$ & $3 \%$ & $4 \%$ & $2 \%$ & $3 \%$ & $22 \%$ & $4 \%$ & $2 \%$ & $2 \%$ & $3 \%$ & $0 \%$ \\
\hline $\begin{array}{l}\text { No partner or partner } \\
\text { without income }\end{array}$ & $71 \%$ & $70 \%$ & $74 \%$ & $92 \%$ & $76 \%$ & $27 \%$ & $74 \%$ & $94 \%$ & $70 \%$ & $93 \%$ & $94 \%$ \\
\hline \multicolumn{12}{|l|}{ Income quintiled $^{d}$} \\
\hline Poorest & $35 \%$ & $36 \%$ & $13 \%$ & $12 \%$ & $49 \%$ & $32 \%$ & $65 \%$ & $44 \%$ & $77 \%$ & $23 \%$ & $46 \%$ \\
\hline Q2 & $21 \%$ & $25 \%$ & $20 \%$ & $21 \%$ & $22 \%$ & $22 \%$ & $19 \%$ & $20 \%$ & $12 \%$ & $12 \%$ & $17 \%$ \\
\hline Q3 & $17 \%$ & $19 \%$ & $23 \%$ & $23 \%$ & $12 \%$ & $18 \%$ & $8 \%$ & $17 \%$ & $6 \%$ & $14 \%$ & $15 \%$ \\
\hline Q4 & $15 \%$ & $13 \%$ & $24 \%$ & $23 \%$ & $10 \%$ & $15 \%$ & $6 \%$ & $11 \%$ & $3 \%$ & $14 \%$ & $16 \%$ \\
\hline Richest & $12 \%$ & $6 \%$ & $21 \%$ & $22 \%$ & $8 \%$ & $13 \%$ & $2 \%$ & $8 \%$ & $2 \%$ & $37 \%$ & $7 \%$ \\
\hline \multicolumn{12}{|c|}{ Household income shares } \\
\hline Labor income & $41 \%$ & $34 \%$ & $32 \%$ & $15 \%$ & $62 \%$ & $57 \%$ & $39 \%$ & $65 \%$ & $40 \%$ & $72 \%$ & $28 \%$ \\
\hline Other income & $2 \%$ & $2 \%$ & $1 \%$ & $2 \%$ & $2 \%$ & $3 \%$ & $5 \%$ & $3 \%$ & $2 \%$ & $6 \%$ & $1 \%$ \\
\hline Benefits & $57 \%$ & $64 \%$ & $67 \%$ & $83 \%$ & $35 \%$ & $40 \%$ & $56 \%$ & $33 \%$ & $57 \%$ & $22 \%$ & $71 \%$ \\
\hline
\end{tabular}




\begin{tabular}{|c|c|c|c|c|c|c|c|c|c|c|c|}
\hline & $\begin{array}{l}\text { All Out-of- } \\
\text { Work }\end{array}$ & $\begin{array}{c}1 . \\
\text { Disabled } \\
\text { with } \\
\text { previous } \\
\text { work } \\
\text { experien } \\
\text { ce }\end{array}$ & $\begin{array}{l}\text { 2. Mostly } \\
\text { male early } \\
\text { retirees } \\
\text { and } \\
\text { retirees }\end{array}$ & $\begin{array}{c}3 . \\
\text { Urban } \\
\text { retired } \\
\text { women }\end{array}$ & $\begin{array}{c}4 . \\
\text { Prime- } \\
\text { aged } \\
\text { unempl } \\
\text { oyed }\end{array}$ & $\begin{array}{c}5 . \\
\text { Prime- } \\
\text { aged } \\
\text { inactive } \\
\text { mother } \\
\text { s with } \\
\text { work } \\
\text { experie } \\
\text { nce }\end{array}$ & $\begin{array}{c}6 . \\
\text { Prime- } \\
\text { aged } \\
\text { long- } \\
\text { term } \\
\text { unempl } \\
\text { oyed }\end{array}$ & $\begin{array}{c}7 . \\
\text { Unempl } \\
\text { oyed } \\
\text { youth }\end{array}$ & $\begin{array}{c}\text { 8. Low- } \\
\text { educate } \\
\text { d rural } \\
\text { inactive } \\
\text { mothers } \\
\text { without } \\
\text { work } \\
\text { experie } \\
\text { nce }\end{array}$ & $\begin{array}{c}9 . \\
\text { Educat } \\
\text { ed } \\
\text { single } \\
\text { studen } \\
\text { ts }\end{array}$ & $\begin{array}{c}10 . \\
\text { Low- } \\
\text { educate } \\
\text { d } \\
\text { disable } \\
\text { d } \\
\text { without } \\
\text { work } \\
\text { experie } \\
\text { nce }\end{array}$ \\
\hline $\begin{array}{l}\text { Receives at least one } \\
\text { benefit }\end{array}$ & $91 \%$ & $98 \%$ & $98 \%$ & $100 \%$ & $83 \%$ & $95 \%$ & $80 \%$ & $69 \%$ & $91 \%$ & $40 \%$ & $98 \%$ \\
\hline \multicolumn{12}{|c|}{ Receives benefits at household level } \\
\hline Family child & $41 \%$ & $27 \%$ & $18 \%$ & $8 \%$ & $50 \%$ & $92 \%$ & $49 \%$ & $55 \%$ & $86 \%$ & $19 \%$ & $59 \%$ \\
\hline Social exclusion & $12 \%$ & $11 \%$ & $5 \%$ & $4 \%$ & $20 \%$ & $12 \%$ & $17 \%$ & $14 \%$ & $29 \%$ & $5 \%$ & $14 \%$ \\
\hline Housing & $14 \%$ & $15 \%$ & $4 \%$ & $4 \%$ & $24 \%$ & $14 \%$ & $20 \%$ & $19 \%$ & $38 \%$ & $5 \%$ & $20 \%$ \\
\hline Old age at household level & $44 \%$ & $29 \%$ & $94 \%$ & $96 \%$ & $19 \%$ & $14 \%$ & $23 \%$ & $17 \%$ & $12 \%$ & $25 \%$ & $45 \%$ \\
\hline \multicolumn{12}{|c|}{ Receives benefits at individual level } \\
\hline Unemployment & $17 \%$ & $4 \%$ & $1 \%$ & $0 \%$ & $55 \%$ & $8 \%$ & $49 \%$ & $19 \%$ & $8 \%$ & $2 \%$ & $2 \%$ \\
\hline Old age & $29 \%$ & $2 \%$ & $90 \%$ & $94 \%$ & $0 \%$ & $0 \%$ & $0 \%$ & $0 \%$ & $0 \%$ & $0 \%$ & $4 \%$ \\
\hline Survivor & $3 \%$ & $4 \%$ & $5 \%$ & $4 \%$ & $1 \%$ & $1 \%$ & $2 \%$ & $0 \%$ & $1 \%$ & $0 \%$ & $2 \%$ \\
\hline Sickness & $2 \%$ & $1 \%$ & $1 \%$ & $0 \%$ & $8 \%$ & $7 \%$ & $0 \%$ & $0 \%$ & $0 \%$ & $0 \%$ & $0 \%$ \\
\hline Disability & $20 \%$ & $89 \%$ & $6 \%$ & $5 \%$ & $1 \%$ & $1 \%$ & $1 \%$ & $0 \%$ & $1 \%$ & $1 \%$ & $74 \%$ \\
\hline Education & $1 \%$ & $0 \%$ & $0 \%$ & $0 \%$ & $0 \%$ & $0 \%$ & $0 \%$ & $7 \%$ & $2 \%$ & $23 \%$ & $2 \%$ \\
\hline \multicolumn{12}{|c|}{ Benefits as share of total gross household income, all households } \\
\hline Family child & $10 \%$ & $5 \%$ & $2 \%$ & $1 \%$ & $10 \%$ & $27 \%$ & $13 \%$ & $10 \%$ & $33 \%$ & $3 \%$ & $14 \%$ \\
\hline Social exclusion & $1 \%$ & $1 \%$ & $0 \%$ & $0 \%$ & $2 \%$ & $1 \%$ & $3 \%$ & $2 \%$ & $3 \%$ & $0 \%$ & $2 \%$ \\
\hline Housing & $1 \%$ & $1 \%$ & $0 \%$ & $0 \%$ & $1 \%$ & $1 \%$ & $1 \%$ & $1 \%$ & $2 \%$ & $0 \%$ & $1 \%$ \\
\hline Unemployment & $6 \%$ & $4 \%$ & $1 \%$ & $1 \%$ & $9 \%$ & $3 \%$ & $18 \%$ & $7 \%$ & $9 \%$ & $2 \%$ & $4 \%$ \\
\hline Old age & $27 \%$ & $14 \%$ & $57 \%$ & $76 \%$ & $8 \%$ & $5 \%$ & $14 \%$ & $7 \%$ & $5 \%$ & $11 \%$ & $23 \%$ \\
\hline Survivor & $1 \%$ & $1 \%$ & $1 \%$ & $1 \%$ & $1 \%$ & $0 \%$ & $1 \%$ & $1 \%$ & $1 \%$ & $1 \%$ & $3 \%$ \\
\hline Sickness & $0 \%$ & $0 \%$ & $0 \%$ & $0 \%$ & $1 \%$ & $1 \%$ & $0 \%$ & $0 \%$ & $0 \%$ & $0 \%$ & $0 \%$ \\
\hline Disability & $11 \%$ & $38 \%$ & $5 \%$ & $4 \%$ & $4 \%$ & $2 \%$ & $6 \%$ & $4 \%$ & $3 \%$ & $1 \%$ & $24 \%$ \\
\hline
\end{tabular}




\begin{tabular}{|c|c|c|c|c|c|c|c|c|c|c|c|}
\hline & $\begin{array}{l}\text { All Out-of- } \\
\text { Work }\end{array}$ & $\begin{array}{c}1 . \\
\text { Disabled } \\
\text { with } \\
\text { previous } \\
\text { work } \\
\text { experien } \\
\text { ce }\end{array}$ & $\begin{array}{l}\text { 2. Mostly } \\
\text { male early } \\
\text { retirees } \\
\text { and } \\
\text { retirees }\end{array}$ & $\begin{array}{c}3 . \\
\text { Urban } \\
\text { retired } \\
\text { women }\end{array}$ & $\begin{array}{c}4 . \\
\text { Prime- } \\
\text { aged } \\
\text { unempl } \\
\text { oyed }\end{array}$ & $\begin{array}{c}5 . \\
\text { Prime- } \\
\text { aged } \\
\text { inactive } \\
\text { mother } \\
\text { s with } \\
\text { work } \\
\text { experie } \\
\text { nce }\end{array}$ & $\begin{array}{c}6 . \\
\text { Prime- } \\
\text { aged } \\
\text { long- } \\
\text { term } \\
\text { unempl } \\
\text { oyed }\end{array}$ & $\begin{array}{c}7 . \\
\text { Unempl } \\
\text { oyed } \\
\text { youth }\end{array}$ & $\begin{array}{l}\text { 8. Low- } \\
\text { educate } \\
\text { d rural } \\
\text { inactive } \\
\text { mothers } \\
\text { without } \\
\text { work } \\
\text { experie } \\
\text { nce }\end{array}$ & $\begin{array}{c}9 . \\
\text { Educat } \\
\text { ed } \\
\text { single } \\
\text { studen } \\
\text { ts }\end{array}$ & $\begin{array}{c}10 . \\
\text { Low- } \\
\text { educate } \\
\text { d } \\
\text { disable } \\
\text { d } \\
\text { without } \\
\text { work } \\
\text { experie } \\
\text { nce }\end{array}$ \\
\hline Education & $0 \%$ & $0 \%$ & $0 \%$ & $0 \%$ & $0 \%$ & $0 \%$ & $0 \%$ & $1 \%$ & $0 \%$ & $3 \%$ & $0 \%$ \\
\hline \multicolumn{12}{|c|}{ Benefits as share of total gross household income, only beneficiaries } \\
\hline Family child & $24 \%$ & $18 \%$ & $12 \%$ & $12 \%$ & $20 \%$ & $30 \%$ & $27 \%$ & $18 \%$ & $39 \%$ & $17 \%$ & $24 \%$ \\
\hline Social exclusion & $10 \%$ & $10 \%$ & $6 \%$ & $5 \%$ & $9 \%$ & $8 \%$ & $16 \%$ & $11 \%$ & $10 \%$ & $8 \%$ & $12 \%$ \\
\hline Housing & $4 \%$ & $4 \%$ & $4 \%$ & $5 \%$ & $4 \%$ & $4 \%$ & $6 \%$ & $5 \%$ & $5 \%$ & $3 \%$ & $5 \%$ \\
\hline Unemployment & $20 \%$ & $19 \%$ & $13 \%$ & $17 \%$ & $15 \%$ & $16 \%$ & $32 \%$ & $19 \%$ & $20 \%$ & $18 \%$ & $17 \%$ \\
\hline Old age & $62 \%$ & $49 \%$ & $61 \%$ & $79 \%$ & $41 \%$ & $37 \%$ & $61 \%$ & $43 \%$ & $41 \%$ & $44 \%$ & $50 \%$ \\
\hline Survivor & $22 \%$ & $20 \%$ & $22 \%$ & $20 \%$ & $19 \%$ & $21 \%$ & $29 \%$ & $17 \%$ & $21 \%$ & $20 \%$ & $38 \%$ \\
\hline Sickness & $4 \%$ & $5 \%$ & $4 \%$ & $3 \%$ & $3 \%$ & $5 \%$ & $3 \%$ & $2 \%$ & $5 \%$ & $2 \%$ & $6 \%$ \\
\hline Disability & $38 \%$ & $42 \%$ & $31 \%$ & $40 \%$ & $26 \%$ & $26 \%$ & $39 \%$ & $28 \%$ & $23 \%$ & $21 \%$ & $32 \%$ \\
\hline Education & $8 \%$ & $8 \%$ & $6 \%$ & $7 \%$ & $7 \%$ & $6 \%$ & $14 \%$ & $5 \%$ & $11 \%$ & $11 \%$ & $3 \%$ \\
\hline Household size (mean) & 3.24 & 2,9 & 2,7 & 2,2 & 3,5 & 4,2 & 3,4 & 4,2 & 5,2 & 3,4 & 3,9 \\
\hline \multicolumn{12}{|l|}{ Household composition } \\
\hline One-person & $9 \%$ & $11 \%$ & $10 \%$ & $23 \%$ & $8 \%$ & $0 \%$ & $9 \%$ & $0 \%$ & $1 \%$ & $6 \%$ & $3 \%$ \\
\hline Single parent & $2 \%$ & $2 \%$ & $1 \%$ & $1 \%$ & $3 \%$ & $4 \%$ & $3 \%$ & $2 \%$ & $5 \%$ & $0 \%$ & $3 \%$ \\
\hline $\begin{array}{l}2+\text { adults without } \\
\text { dependent children }\end{array}$ & $48 \%$ & $61 \%$ & $69 \%$ & $68 \%$ & $41 \%$ & $9 \%$ & $42 \%$ & $42 \%$ & $11 \%$ & $62 \%$ & $42 \%$ \\
\hline $\begin{array}{l}2+\text { adults with } 1 \\
\text { dependent child }^{\mathrm{f}}\end{array}$ & $9 \%$ & $8 \%$ & $5 \%$ & $1 \%$ & $12 \%$ & $22 \%$ & $11 \%$ & $9 \%$ & $9 \%$ & $5 \%$ & $10 \%$ \\
\hline $\begin{array}{l}2+\text { adults with } 2+ \\
\text { dependent children }\end{array}$ & $31 \%$ & $19 \%$ & $14 \%$ & $7 \%$ & $35 \%$ & $65 \%$ & $36 \%$ & $46 \%$ & $74 \%$ & $27 \%$ & $42 \%$ \\
\hline Children under six & $20 \%$ & $8 \%$ & $4 \%$ & $2 \%$ & $18 \%$ & $72 \%$ & $19 \%$ & $14 \%$ & $62 \%$ & $7 \%$ & $9 \%$ \\
\hline $\begin{array}{l}\text { Three or more children } \\
\text { under } 16\end{array}$ & $7 \%$ & $3 \%$ & $1 \%$ & $1 \%$ & $6 \%$ & $20 \%$ & $8 \%$ & $7 \%$ & $36 \%$ & $4 \%$ & $9 \%$ \\
\hline
\end{tabular}



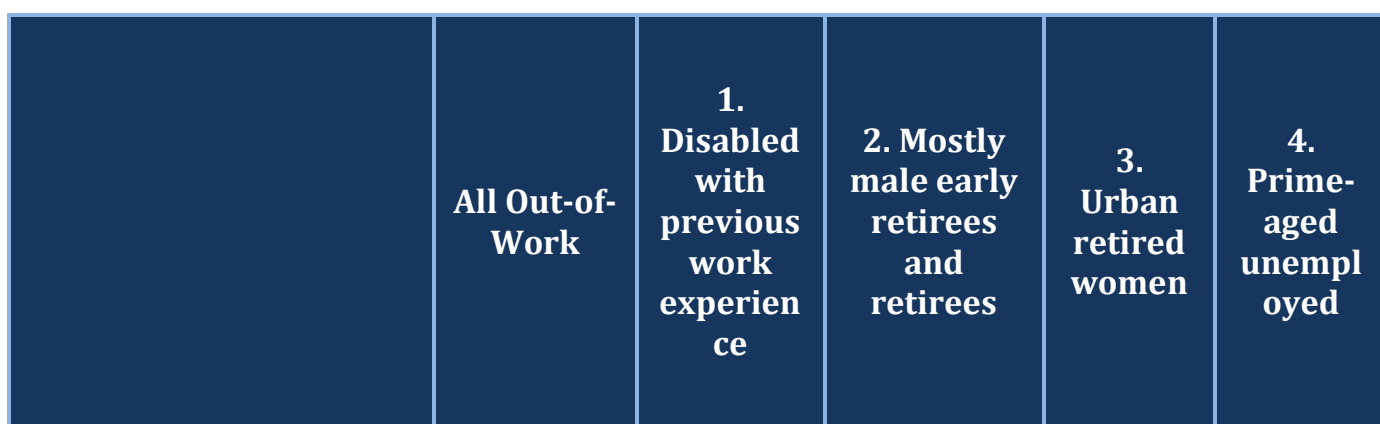

\begin{tabular}{|c|}
5. \\
Prime- \\
aged \\
inactive \\
mother \\
s with \\
work \\
experie \\
nce
\end{tabular}
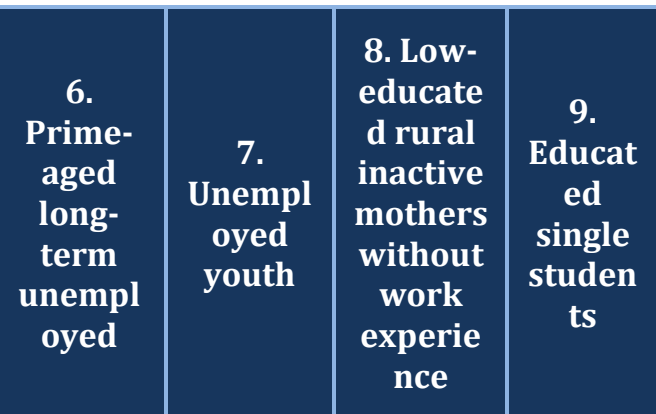

Individual's parents present

\begin{tabular}{|c|c|c|c|c|c|c|c|c|c|c|c|}
\hline One parent & $11 \%$ & $11 \%$ & $4 \%$ & $4 \%$ & $16 \%$ & $7 \%$ & $16 \%$ & $27 \%$ & $16 \%$ & $23 \%$ & $25 \%$ \\
\hline Both parents & $10 \%$ & $3 \%$ & $0 \%$ & $0 \%$ & $16 \%$ & $6 \%$ & $12 \%$ & $62 \%$ & $21 \%$ & $59 \%$ & $52 \%$ \\
\hline None & $79 \%$ & $87 \%$ & $96 \%$ & $96 \%$ & $68 \%$ & $87 \%$ & $72 \%$ & $11 \%$ & $62 \%$ & $18 \%$ & $24 \%$ \\
\hline $\begin{array}{l}\text { Elderly present (over } \\
64 \text { ) }\end{array}$ & $16 \%$ & $18 \%$ & $16 \%$ & $30 \%$ & $12 \%$ & $9 \%$ & $16 \%$ & $7 \%$ & $6 \%$ & $11 \%$ & $27 \%$ \\
\hline
\end{tabular}

\section{Children under 13 in childcare}

\begin{tabular}{|c|c|c|c|c|c|c|c|c|c|c|c|}
\hline None of the children & $12 \%$ & $7 \%$ & $3 \%$ & $2 \%$ & $14 \%$ & $29 \%$ & $16 \%$ & $15 \%$ & $27 \%$ & $3 \%$ & $16 \%$ \\
\hline Some of the children & $10 \%$ & $8 \%$ & $6 \%$ & $3 \%$ & $18 \%$ & $27 \%$ & $14 \%$ & $11 \%$ & $19 \%$ & $3 \%$ & $4 \%$ \\
\hline $\begin{array}{l}\text { No children under } 13 \text { in } \\
\text { household }\end{array}$ & $67 \%$ & $82 \%$ & $88 \%$ & $94 \%$ & $59 \%$ & $14 \%$ & $59 \%$ & $67 \%$ & $21 \%$ & $90 \%$ & $69 \%$ \\
\hline All of the children & $12 \%$ & $3 \%$ & $2 \%$ & $1 \%$ & $9 \%$ & $31 \%$ & $12 \%$ & $8 \%$ & $34 \%$ & $4 \%$ & $11 \%$ \\
\hline
\end{tabular}

\section{Marital status}

\begin{tabular}{|c|c|c|c|c|c|c|c|c|c|c|c|}
\hline Married & $52 \%$ & $60 \%$ & $70 \%$ & $60 \%$ & $38 \%$ & $70 \%$ & $43 \%$ & $3 \%$ & $32 \%$ & $5 \%$ & $11 \%$ \\
\hline Never married & $26 \%$ & $14 \%$ & $4 \%$ & $4 \%$ & $43 \%$ & $19 \%$ & $34 \%$ & $96 \%$ & $62 \%$ & $94 \%$ & $86 \%$ \\
\hline Divorced/separated & $13 \%$ & $17 \%$ & $13 \%$ & $16 \%$ & $15 \%$ & $9 \%$ & $17 \%$ & $0 \%$ & $5 \%$ & $2 \%$ & $2 \%$ \\
\hline Widowed & $9 \%$ & $10 \%$ & $13 \%$ & $21 \%$ & $4 \%$ & $2 \%$ & $5 \%$ & $0 \%$ & $2 \%$ & $0 \%$ & $2 \%$ \\
\hline \multicolumn{12}{|l|}{ Tenure status } \\
\hline Owner & $89 \%$ & $91 \%$ & $95 \%$ & $94 \%$ & $86 \%$ & $86 \%$ & $84 \%$ & $87 \%$ & $79 \%$ & $89 \%$ & $93 \%$ \\
\hline Tenant & $2 \%$ & $2 \%$ & $1 \%$ & $1 \%$ & $3 \%$ & $4 \%$ & $3 \%$ & $3 \%$ & $3 \%$ & $8 \%$ & $1 \%$ \\
\hline Reduced rate & $5 \%$ & $4 \%$ & $2 \%$ & $2 \%$ & $7 \%$ & $4 \%$ & $8 \%$ & $6 \%$ & $9 \%$ & $2 \%$ & $5 \%$ \\
\hline Free & $4 \%$ & $3 \%$ & $2 \%$ & $3 \%$ & $5 \%$ & $7 \%$ & $4 \%$ & $4 \%$ & $8 \%$ & $2 \%$ & $1 \%$ \\
\hline \multicolumn{12}{|c|}{ Able to keep dwelling warm } \\
\hline No & $17 \%$ & $21 \%$ & $10 \%$ & $12 \%$ & $26 \%$ & $9 \%$ & $26 \%$ & $20 \%$ & $25 \%$ & $12 \%$ & $15 \%$ \\
\hline
\end{tabular}




\begin{tabular}{|c|c|c|c|c|c|c|c|c|c|c|c|}
\hline & $\begin{array}{l}\text { All Out-of- } \\
\text { Work }\end{array}$ & $\begin{array}{c}1 . \\
\text { Disabled } \\
\text { with } \\
\text { previous } \\
\text { work } \\
\text { experien } \\
\text { ce }\end{array}$ & $\begin{array}{l}\text { 2. Mostly } \\
\text { male early } \\
\text { retirees } \\
\text { and } \\
\text { retirees }\end{array}$ & $\begin{array}{c}3 . \\
\text { Urban } \\
\text { retired } \\
\text { women }\end{array}$ & $\begin{array}{c}4 . \\
\text { Prime- } \\
\text { aged } \\
\text { unempl } \\
\text { oyed }\end{array}$ & $\begin{array}{c}5 . \\
\text { Prime- } \\
\text { aged } \\
\text { inactive } \\
\text { mother } \\
\text { s with } \\
\text { work } \\
\text { experie } \\
\text { nce }\end{array}$ & $\begin{array}{c}6 . \\
\text { Prime- } \\
\text { aged } \\
\text { long- } \\
\text { term } \\
\text { unempl } \\
\text { oyed }\end{array}$ & $\begin{array}{c}7 . \\
\text { Unempl } \\
\text { oyed } \\
\text { youth }\end{array}$ & $\begin{array}{l}\text { 8. Low- } \\
\text { educate } \\
\text { d rural } \\
\text { inactive } \\
\text { mothers } \\
\text { without } \\
\text { work } \\
\text { experie } \\
\text { nce }\end{array}$ & $\begin{array}{c}9 . \\
\text { Educat } \\
\text { ed } \\
\text { single } \\
\text { studen } \\
\text { ts }\end{array}$ & $\begin{array}{c}10 . \\
\text { Low- } \\
\text { educate } \\
\text { d } \\
\text { disable } \\
\text { d } \\
\text { without } \\
\text { work } \\
\text { experie } \\
\text { nce }\end{array}$ \\
\hline Yes & $83 \%$ & $79 \%$ & $90 \%$ & $88 \%$ & $74 \%$ & $91 \%$ & $74 \%$ & $80 \%$ & $75 \%$ & $88 \%$ & $85 \%$ \\
\hline NA & $0 \%$ & $0 \%$ & $0 \%$ & $0 \%$ & $0 \%$ & $0 \%$ & $0 \%$ & $0 \%$ & $0 \%$ & $0 \%$ & $0 \%$ \\
\hline \multicolumn{12}{|l|}{ Degree of urbanization } \\
\hline Densely populated & $27 \%$ & $20 \%$ & $26 \%$ & $39 \%$ & $22 \%$ & $31 \%$ & $26 \%$ & $21 \%$ & $12 \%$ & $56 \%$ & $22 \%$ \\
\hline Intermediate area & $21 \%$ & $18 \%$ & $20 \%$ & $26 \%$ & $19 \%$ & $21 \%$ & $23 \%$ & $24 \%$ & $18 \%$ & $21 \%$ & $24 \%$ \\
\hline Sparsely populated & $52 \%$ & $63 \%$ & $54 \%$ & $36 \%$ & $59 \%$ & $48 \%$ & $50 \%$ & $55 \%$ & $70 \%$ & $23 \%$ & $53 \%$ \\
\hline \multicolumn{12}{|l|}{ Region } \\
\hline HU1 - Central Hungary & $25 \%$ & $18 \%$ & $24 \%$ & $33 \%$ & $20 \%$ & $31 \%$ & $26 \%$ & $24 \%$ & $19 \%$ & $45 \%$ & $26 \%$ \\
\hline HU2 - Transdanubia & $30 \%$ & $31 \%$ & $40 \%$ & $29 \%$ & $25 \%$ & $27 \%$ & $31 \%$ & $27 \%$ & $26 \%$ & $25 \%$ & $35 \%$ \\
\hline $\begin{array}{l}\text { HU3 - Great Plain and } \\
\text { North }\end{array}$ & $45 \%$ & $51 \%$ & $36 \%$ & $38 \%$ & $55 \%$ & $42 \%$ & $42 \%$ & $49 \%$ & $55 \%$ & $31 \%$ & $40 \%$ \\
\hline
\end{tabular}

a. Refers to individuals aged 25 and over.

b. Applies to individuals aged 25 and over. Students aged 16 to 24 are not included in the sample.

c. Refers only to individuals who have worked before.

d. Based on total equivalized disposable household income.

e. Based on total gross household income.

f. Dependent children include: 1. household members under 18; 2. household members aged between 18 and 24 who are economically inactive and living with at least one parent.

Source: WB staff calculations based on EU-SILC. 


\begin{tabular}{|c|c|c|c|c|c|c|c|c|c|}
\hline & $\begin{array}{c}\text { 1. Early } \\
\text { retirees } \\
\text { and } \\
\text { retirees }\end{array}$ & $\begin{array}{l}\text { 2. Disabled } \\
\text { with } \\
\text { previous } \\
\text { work } \\
\text { experience }\end{array}$ & $\begin{array}{c}3 . \\
\text { Urban } \\
\text { retired } \\
\text { women }\end{array}$ & $\begin{array}{c}\text { 4. Prime- } \\
\text { aged } \\
\text { inactive } \\
\text { mothers } \\
\text { with work } \\
\text { experience }\end{array}$ & $\begin{array}{l}\text { 5. Prime- } \\
\text { aged } \\
\text { unemployed }\end{array}$ & $\begin{array}{l}\text { 6. Prime- } \\
\text { aged long- } \\
\text { term } \\
\text { unemployed }\end{array}$ & $\begin{array}{c}\text { 7. Low- } \\
\text { educated } \\
\text { inactive young } \\
\text { women without } \\
\text { work } \\
\text { experience }\end{array}$ & $\begin{array}{c}8 . \\
\text { Unemployed } \\
\text { youth }\end{array}$ & $\begin{array}{l}\text { 9. Low- } \\
\text { educated } \\
\text { disabled } \\
\text { without } \\
\text { work } \\
\text { experience }\end{array}$ \\
\hline Cluster size & $19 \%$ & $17 \%$ & $15 \%$ & $13 \%$ & $13 \%$ & $11 \%$ & $7 \%$ & $3 \%$ & $2 \%$ \\
\hline Population & 440,485 & 392,859 & 338,624 & 295,100 & 286,896 & 247,018 & 168,628 & 72,920 & 36,460 \\
\hline \multicolumn{10}{|c|}{ INDICATORS } \\
\hline \multicolumn{10}{|c|}{ Labor market attachment } \\
\hline Unemployed & $0 \%$ & $0 \%$ & $0 \%$ & $2 \%$ & $93 \%$ & $11 \%$ & $2 \%$ & $43 \%$ & $1 \%$ \\
\hline $\begin{array}{l}\text { Long-term } \\
\text { unemployed }\end{array}$ & $2 \%$ & $0 \%$ & $1 \%$ & $3 \%$ & $0 \%$ & $76 \%$ & $9 \%$ & $49 \%$ & $6 \%$ \\
\hline Retired & $98 \%$ & $1 \%$ & $94 \%$ & $0 \%$ & $2 \%$ & $1 \%$ & $0 \%$ & $0 \%$ & $8 \%$ \\
\hline Disabled & $0 \%$ & $95 \%$ & $5 \%$ & $1 \%$ & $1 \%$ & $0 \%$ & $1 \%$ & $1 \%$ & $83 \%$ \\
\hline Other inactive & $0 \%$ & $4 \%$ & $0 \%$ & $94 \%$ & $4 \%$ & $13 \%$ & $88 \%$ & $8 \%$ & $2 \%$ \\
\hline \multicolumn{10}{|c|}{ At least one working adult in householda } \\
\hline No & $50 \%$ & $55 \%$ & $82 \%$ & $20 \%$ & $51 \%$ & $57 \%$ & $40 \%$ & $19 \%$ & $68 \%$ \\
\hline Yes & $50 \%$ & $45 \%$ & $18 \%$ & $80 \%$ & $49 \%$ & $43 \%$ & $60 \%$ & $81 \%$ & $32 \%$ \\
\hline \multicolumn{10}{|l|}{ Work experience } \\
\hline Never worked & $0 \%$ & $0 \%$ & $0 \%$ & $0 \%$ & $0 \%$ & $0 \%$ & $79 \%$ & $82 \%$ & $99 \%$ \\
\hline $\begin{array}{l}\text { Less than } 2 \text { months } \\
\text { in last year }\end{array}$ & $94 \%$ & $96 \%$ & $98 \%$ & $88 \%$ & $2 \%$ & $100 \%$ & $20 \%$ & $18 \%$ & $1 \%$ \\
\hline $\begin{array}{l}2 \text { or more months } \\
\text { in last year }\end{array}$ & $6 \%$ & $4 \%$ & $1 \%$ & $12 \%$ & $98 \%$ & $0 \%$ & $2 \%$ & $0 \%$ & $0 \%$ \\
\hline \multicolumn{10}{|c|}{ Self-assessed physical incapacity } \\
\hline Strongly limited & $18 \%$ & $33 \%$ & $7 \%$ & $3 \%$ & $4 \%$ & $5 \%$ & $1 \%$ & $0 \%$ & $56 \%$ \\
\hline None/limited & $82 \%$ & $67 \%$ & $93 \%$ & $97 \%$ & $96 \%$ & $95 \%$ & $99 \%$ & $100 \%$ & $44 \%$ \\
\hline \multicolumn{10}{|c|}{ ACTIVE COVARIATES } \\
\hline \multicolumn{10}{|l|}{ Age groups (4) } \\
\hline 16-24 years & $0 \%$ & $0 \%$ & $0 \%$ & $4 \%$ & $15 \%$ & $4 \%$ & $38 \%$ & $93 \%$ & $20 \%$ \\
\hline $25-34$ years & $0 \%$ & $3 \%$ & $0 \%$ & $58 \%$ & $25 \%$ & $20 \%$ & $50 \%$ & $7 \%$ & $36 \%$ \\
\hline
\end{tabular}




\begin{tabular}{|c|c|c|c|c|c|c|c|c|c|}
\hline & $\begin{array}{l}\text { 1. Early } \\
\text { retirees } \\
\text { and } \\
\text { retirees }\end{array}$ & $\begin{array}{l}\text { 2. Disabled } \\
\text { with } \\
\text { previous } \\
\text { work } \\
\text { experience }\end{array}$ & $\begin{array}{c}3 . \\
\text { Urban } \\
\text { retired } \\
\text { women }\end{array}$ & $\begin{array}{l}\text { 4. Prime- } \\
\text { aged } \\
\text { inactive } \\
\text { mothers } \\
\text { with work } \\
\text { experience }\end{array}$ & $\begin{array}{l}\text { 5. Prime- } \\
\text { aged } \\
\text { unemployed }\end{array}$ & $\begin{array}{l}\text { 6. Prime- } \\
\text { aged long- } \\
\text { term } \\
\text { unemployed }\end{array}$ & $\begin{array}{c}\text { 7. Low- } \\
\text { educated } \\
\text { inactive young } \\
\text { women without } \\
\text { work } \\
\text { experience }\end{array}$ & $\begin{array}{c}8 . \\
\text { Unemployed } \\
\text { youth }\end{array}$ & $\begin{array}{l}\text { 9. Low- } \\
\text { educated } \\
\text { disabled } \\
\text { without } \\
\text { work } \\
\text { experience }\end{array}$ \\
\hline $35-59$ years & $48 \%$ & $83 \%$ & $10 \%$ & $38 \%$ & $59 \%$ & $75 \%$ & $12 \%$ & $0 \%$ & $41 \%$ \\
\hline 60-64 years & $52 \%$ & $14 \%$ & $90 \%$ & $0 \%$ & $0 \%$ & $0 \%$ & $1 \%$ & $0 \%$ & $3 \%$ \\
\hline \multicolumn{10}{|l|}{ Gender } \\
\hline Male & $55 \%$ & $50 \%$ & $25 \%$ & $0 \%$ & $61 \%$ & $57 \%$ & $19 \%$ & $69 \%$ & $60 \%$ \\
\hline Female & $45 \%$ & $50 \%$ & $75 \%$ & $100 \%$ & $40 \%$ & $43 \%$ & $81 \%$ & $31 \%$ & $40 \%$ \\
\hline \multicolumn{10}{|l|}{ Education (4) } \\
\hline Primary & $35 \%$ & $38 \%$ & $11 \%$ & $15 \%$ & $31 \%$ & $37 \%$ & $51 \%$ & $22 \%$ & $60 \%$ \\
\hline Secondary & $55 \%$ & $57 \%$ & $64 \%$ & $60 \%$ & $63 \%$ & $58 \%$ & $39 \%$ & $58 \%$ & $26 \%$ \\
\hline Tertiary & $11 \%$ & $4 \%$ & $24 \%$ & $25 \%$ & $6 \%$ & $5 \%$ & $10 \%$ & $19 \%$ & $5 \%$ \\
\hline $\begin{array}{l}\text { Never studied } \\
\text { before/illiterate/N } \\
\text { A }\end{array}$ & $0 \%$ & $1 \%$ & $0 \%$ & $0 \%$ & $0 \%$ & $0 \%$ & $0 \%$ & $0 \%$ & $10 \%$ \\
\hline Urban & $51 \%$ & $35 \%$ & $66 \%$ & $49 \%$ & $39 \%$ & $40 \%$ & $46 \%$ & $46 \%$ & $39 \%$ \\
\hline Rural & $49 \%$ & $65 \%$ & $34 \%$ & $51 \%$ & $61 \%$ & $60 \%$ & $55 \%$ & $54 \%$ & $61 \%$ \\
\hline
\end{tabular}

\section{Age groups (8)}

16-19 years

20-24 years

25-29 years

30-34 years

35-44 years

45-54 years

55-59 years

60-64 years

$0 \%$

INACTIVE COVARIATES

\section{Education (6)}

\begin{tabular}{|c|c|c|c|c|c|c|c|c|c|}
\hline Primary & $4 \%$ & $4 \%$ & $1 \%$ & $2 \%$ & $2 \%$ & $5 \%$ & $8 \%$ & $2 \%$ & $19 \%$ \\
\hline Lower secondary & $31 \%$ & $34 \%$ & $10 \%$ & $14 \%$ & $28 \%$ & $32 \%$ & $43 \%$ & $20 \%$ & $41 \%$ \\
\hline Upper secondary & $51 \%$ & $55 \%$ & $58 \%$ & $54 \%$ & $59 \%$ & $54 \%$ & $35 \%$ & $44 \%$ & $26 \%$ \\
\hline
\end{tabular}




\begin{tabular}{|c|c|c|c|c|c|c|c|c|c|}
\hline & $\begin{array}{l}\text { 1. Early } \\
\text { retirees } \\
\text { and } \\
\text { retirees }\end{array}$ & $\begin{array}{l}\text { 2. Disabled } \\
\text { with } \\
\text { previous } \\
\text { work } \\
\text { experience }\end{array}$ & $\begin{array}{c}3 . \\
\text { Urban } \\
\text { retired } \\
\text { women }\end{array}$ & $\begin{array}{l}\text { 4. Prime- } \\
\text { aged } \\
\text { inactive } \\
\text { mothers } \\
\text { with work } \\
\text { experience }\end{array}$ & $\begin{array}{l}\text { 5. Prime- } \\
\text { aged } \\
\text { unemployed }\end{array}$ & $\begin{array}{l}\text { 6. Prime- } \\
\text { aged long- } \\
\text { term } \\
\text { unemployed }\end{array}$ & $\begin{array}{c}\text { 7. Low- } \\
\text { educated } \\
\text { inactive young } \\
\text { women without } \\
\text { work } \\
\text { experience }\end{array}$ & $\begin{array}{c}8 . \\
\text { Unemployed } \\
\text { youth }\end{array}$ & $\begin{array}{l}\text { 9. Low- } \\
\text { educated } \\
\text { disabled } \\
\text { without } \\
\text { work } \\
\text { experience }\end{array}$ \\
\hline Post-secondary & $4 \%$ & $2 \%$ & $6 \%$ & $5 \%$ & $5 \%$ & $4 \%$ & $4 \%$ & $15 \%$ & $0 \%$ \\
\hline Tertiary & $11 \%$ & $4 \%$ & $24 \%$ & $25 \%$ & $6 \%$ & $5 \%$ & $10 \%$ & $19 \%$ & $5 \%$ \\
\hline $\begin{array}{l}\text { Never studied } \\
\text { before/illiterate/N } \\
\text { A }\end{array}$ & $0 \%$ & $1 \%$ & $0 \%$ & $0 \%$ & $0 \%$ & $0 \%$ & $0 \%$ & $0 \%$ & $10 \%$ \\
\hline \multicolumn{10}{|c|}{ Enrolled in education ${ }^{b}$} \\
\hline Yes & $0 \%$ & $0 \%$ & $0 \%$ & $4 \%$ & $1 \%$ & $2 \%$ & $21 \%$ & $1 \%$ & $0 \%$ \\
\hline No & $100 \%$ & $100 \%$ & $100 \%$ & $96 \%$ & $99 \%$ & $98 \%$ & $79 \%$ & $99 \%$ & $100 \%$ \\
\hline \multicolumn{10}{|l|}{ Ever worked } \\
\hline No & $0 \%$ & $0 \%$ & $0 \%$ & $0 \%$ & $0 \%$ & $0 \%$ & $79 \%$ & $82 \%$ & $99 \%$ \\
\hline Yes & $100 \%$ & $100 \%$ & $100 \%$ & $100 \%$ & $100 \%$ & $100 \%$ & $21 \%$ & $18 \%$ & $1 \%$ \\
\hline $\begin{array}{l}\text { Years of work } \\
\text { experience }\end{array}$ & 35 & 25 & 36 & 11 & 17 & 17 & 6 & 2 & 16 \\
\hline \multicolumn{10}{|c|}{ Partner economic status } \\
\hline Working & $26 \%$ & $31 \%$ & $7 \%$ & $75 \%$ & $30 \%$ & $29 \%$ & $29 \%$ & $3 \%$ & $4 \%$ \\
\hline Unemployed & $3 \%$ & $5 \%$ & $1 \%$ & $8 \%$ & $10 \%$ & $13 \%$ & $16 \%$ & $1 \%$ & $6 \%$ \\
\hline Retired & $36 \%$ & $12 \%$ & $52 \%$ & $2 \%$ & $4 \%$ & $3 \%$ & $1 \%$ & $0 \%$ & $2 \%$ \\
\hline Inactive & $8 \%$ & $22 \%$ & $5 \%$ & $3 \%$ & $16 \%$ & $14 \%$ & $7 \%$ & $1 \%$ & $2 \%$ \\
\hline $\begin{array}{l}\text { Student/military } \\
\text { service }\end{array}$ & $0 \%$ & $0 \%$ & $0 \%$ & $0 \%$ & $0 \%$ & $0 \%$ & $0 \%$ & $1 \%$ & $0 \%$ \\
\hline No partner & $28 \%$ & $30 \%$ & $35 \%$ & $12 \%$ & $41 \%$ & $40 \%$ & $48 \%$ & $94 \%$ & $85 \%$ \\
\hline $\begin{array}{l}\text { Partner income } \\
\text { (mean) }\end{array}$ & 2416 & 2699 & 1194 & 7301 & 3031 & 2999 & 3195 & 2617 & 1603 \\
\hline $\begin{array}{l}\text { Working partner } \\
\text { income (mean) }\end{array}$ & 5971 & 5587 & 7477 & 8285 & 5122 & 5452 & 4903 & 4635 & 4451 \\
\hline \multicolumn{10}{|c|}{ Partner income quintile } \\
\hline Poorest & $6 \%$ & $8 \%$ & $1 \%$ & $11 \%$ & $8 \%$ & $9 \%$ & $11 \%$ & $1 \%$ & $2 \%$ \\
\hline Q2 & $6 \%$ & $6 \%$ & $1 \%$ & $12 \%$ & $7 \%$ & $7 \%$ & $7 \%$ & $0 \%$ & $1 \%$ \\
\hline Q3 & $5 \%$ & $8 \%$ & $1 \%$ & $14 \%$ & $7 \%$ & $3 \%$ & $5 \%$ & $1 \%$ & $0 \%$ \\
\hline Q4 & $5 \%$ & $5 \%$ & $1 \%$ & $14 \%$ & $4 \%$ & $5 \%$ & $3 \%$ & $0 \%$ & $0 \%$ \\
\hline
\end{tabular}




\begin{tabular}{|c|c|c|c|c|c|c|c|c|c|}
\hline & $\begin{array}{l}\text { 1. Early } \\
\text { retirees } \\
\text { and } \\
\text { retirees }\end{array}$ & $\begin{array}{l}\text { 2. Disabled } \\
\text { with } \\
\text { previous } \\
\text { work } \\
\text { experience }\end{array}$ & $\begin{array}{c}3 . \\
\text { Urban } \\
\text { retired } \\
\text { women }\end{array}$ & $\begin{array}{l}\text { 4. Prime- } \\
\text { aged } \\
\text { inactive } \\
\text { mothers } \\
\text { with work } \\
\text { experience }\end{array}$ & $\begin{array}{l}\text { 5. Prime- } \\
\text { aged } \\
\text { unemployed }\end{array}$ & $\begin{array}{l}\text { 6. Prime- } \\
\text { aged long- } \\
\text { term } \\
\text { unemployed }\end{array}$ & $\begin{array}{c}\text { 7. Low- } \\
\text { educated } \\
\text { inactive young } \\
\text { women without } \\
\text { work } \\
\text { experience }\end{array}$ & $\begin{array}{c}8 . \\
\text { Unemployed } \\
\text { youth }\end{array}$ & $\begin{array}{l}\text { 9. Low- } \\
\text { educated } \\
\text { disabled } \\
\text { without } \\
\text { work } \\
\text { experience }\end{array}$ \\
\hline Richest & $4 \%$ & $4 \%$ & $2 \%$ & $23 \%$ & $4 \%$ & $5 \%$ & $3 \%$ & $0 \%$ & $1 \%$ \\
\hline $\begin{array}{l}\text { No partner or } \\
\text { partner without } \\
\text { income }\end{array}$ & $74 \%$ & $69 \%$ & $93 \%$ & $25 \%$ & $70 \%$ & $71 \%$ & $71 \%$ & $97 \%$ & $96 \%$ \\
\hline \multicolumn{10}{|l|}{ Income quintiled } \\
\hline Poorest & $15 \%$ & $36 \%$ & $11 \%$ & $35 \%$ & $41 \%$ & $66 \%$ & $58 \%$ & $45 \%$ & $41 \%$ \\
\hline Q2 & $21 \%$ & $27 \%$ & $19 \%$ & $22 \%$ & $22 \%$ & $18 \%$ & $15 \%$ & $25 \%$ & $25 \%$ \\
\hline Q3 & $20 \%$ & $18 \%$ & $20 \%$ & $18 \%$ & $17 \%$ & $8 \%$ & $9 \%$ & $14 \%$ & $14 \%$ \\
\hline Q4 & $23 \%$ & $11 \%$ & $24 \%$ & $13 \%$ & $14 \%$ & $5 \%$ & $12 \%$ & $13 \%$ & $17 \%$ \\
\hline Richest & $22 \%$ & $8 \%$ & $26 \%$ & $12 \%$ & $7 \%$ & $3 \%$ & $7 \%$ & $3 \%$ & $3 \%$ \\
\hline \multicolumn{10}{|c|}{ Household income shares } \\
\hline Labor income & $32 \%$ & $34 \%$ & $15 \%$ & $58 \%$ & $64 \%$ & $42 \%$ & $48 \%$ & $66 \%$ & $24 \%$ \\
\hline Other income & $1 \%$ & $1 \%$ & $2 \%$ & $3 \%$ & $2 \%$ & $3 \%$ & $3 \%$ & $3 \%$ & $2 \%$ \\
\hline Benefits & $66 \%$ & $65 \%$ & $84 \%$ & $39 \%$ & $34 \%$ & $55 \%$ & $48 \%$ & $31 \%$ & $74 \%$ \\
\hline $\begin{array}{l}\text { Receives at least } \\
\text { one benefit }\end{array}$ & $98 \%$ & $99 \%$ & $99 \%$ & $96 \%$ & $88 \%$ & $82 \%$ & $82 \%$ & $72 \%$ & $99 \%$ \\
\hline \multicolumn{10}{|c|}{ Receives benefits at household level } \\
\hline Family child & $19 \%$ & $29 \%$ & $7 \%$ & $93 \%$ & $55 \%$ & $56 \%$ & $72 \%$ & $59 \%$ & $48 \%$ \\
\hline Social exclusion & $6 \%$ & $15 \%$ & $4 \%$ & $15 \%$ & $25 \%$ & $18 \%$ & $26 \%$ & $11 \%$ & $21 \%$ \\
\hline Housing & $6 \%$ & $16 \%$ & $6 \%$ & $16 \%$ & $20 \%$ & $22 \%$ & $29 \%$ & $18 \%$ & $22 \%$ \\
\hline $\begin{array}{l}\text { Old age at } \\
\text { household level }\end{array}$ & $90 \%$ & $32 \%$ & $96 \%$ & $14 \%$ & $20 \%$ & $22 \%$ & $18 \%$ & $15 \%$ & $49 \%$ \\
\hline \multicolumn{10}{|c|}{ Receives benefits at individual level } \\
\hline Unemployment & $1 \%$ & $3 \%$ & $0 \%$ & $7 \%$ & $52 \%$ & $48 \%$ & $7 \%$ & $14 \%$ & $4 \%$ \\
\hline Old age & $86 \%$ & $7 \%$ & $92 \%$ & $0 \%$ & $1 \%$ & $0 \%$ & $0 \%$ & $0 \%$ & $5 \%$ \\
\hline Survivor & $5 \%$ & $3 \%$ & $4 \%$ & $1 \%$ & $1 \%$ & $3 \%$ & $0 \%$ & $0 \%$ & $3 \%$ \\
\hline Sickness & $1 \%$ & $3 \%$ & $0 \%$ & $8 \%$ & $13 \%$ & $1 \%$ & $1 \%$ & $0 \%$ & $0 \%$ \\
\hline Disability & $11 \%$ & $87 \%$ & $6 \%$ & $1 \%$ & $3 \%$ & $2 \%$ & $1 \%$ & $1 \%$ & $82 \%$ \\
\hline Education & $0 \%$ & $0 \%$ & $0 \%$ & $0 \%$ & $0 \%$ & $0 \%$ & $7 \%$ & $6 \%$ & $0 \%$ \\
\hline
\end{tabular}




\begin{tabular}{|c|c|c|c|c|c|c|c|c|c|}
\hline & $\begin{array}{l}\text { 1. Early } \\
\text { retirees } \\
\text { and } \\
\text { retirees }\end{array}$ & $\begin{array}{l}\text { 2. Disabled } \\
\text { with } \\
\text { previous } \\
\text { work } \\
\text { experience }\end{array}$ & $\begin{array}{c}3 . \\
\text { Urban } \\
\text { retired } \\
\text { women }\end{array}$ & $\begin{array}{l}\text { 4. Prime- } \\
\text { aged } \\
\text { inactive } \\
\text { mothers } \\
\text { with work } \\
\text { experience }\end{array}$ & $\begin{array}{l}\text { 5. Prime- } \\
\text { aged } \\
\text { unemployed }\end{array}$ & $\begin{array}{l}\text { 6. Prime- } \\
\text { aged long- } \\
\text { term } \\
\text { unemployed }\end{array}$ & $\begin{array}{c}\text { 7. Low- } \\
\text { educated } \\
\text { inactive young } \\
\text { women without } \\
\text { work } \\
\text { experience }\end{array}$ & $\begin{array}{c}8 . \\
\text { Unemployed } \\
\text { youth }\end{array}$ & $\begin{array}{l}\text { 9. Low- } \\
\text { educated } \\
\text { disabled } \\
\text { without } \\
\text { work } \\
\text { experience }\end{array}$ \\
\hline \multicolumn{10}{|c|}{ Benefits as share of total gross household income, all households } \\
\hline Family child & $2 \%$ & $5 \%$ & $1 \%$ & $26 \%$ & $9 \%$ & $14 \%$ & $24 \%$ & $10 \%$ & $11 \%$ \\
\hline Social exclusion & $0 \%$ & $1 \%$ & $0 \%$ & $1 \%$ & $3 \%$ & $2 \%$ & $3 \%$ & $1 \%$ & $3 \%$ \\
\hline Housing & $0 \%$ & $1 \%$ & $0 \%$ & $1 \%$ & $1 \%$ & $1 \%$ & $1 \%$ & $1 \%$ & $1 \%$ \\
\hline Unemployment & $1 \%$ & $2 \%$ & $1 \%$ & $3 \%$ & $8 \%$ & $17 \%$ & $6 \%$ & $6 \%$ & $4 \%$ \\
\hline Old age & $54 \%$ & $16 \%$ & $76 \%$ & $5 \%$ & $7 \%$ & $12 \%$ & $8 \%$ & $7 \%$ & $27 \%$ \\
\hline Survivor & $1 \%$ & $1 \%$ & $1 \%$ & $1 \%$ & $1 \%$ & $1 \%$ & $1 \%$ & $1 \%$ & $3 \%$ \\
\hline Sickness & $0 \%$ & $1 \%$ & $0 \%$ & $1 \%$ & $1 \%$ & $1 \%$ & $0 \%$ & $1 \%$ & $0 \%$ \\
\hline Disability & $7 \%$ & $37 \%$ & $5 \%$ & $2 \%$ & $4 \%$ & $5 \%$ & $4 \%$ & $5 \%$ & $27 \%$ \\
\hline Education & $0 \%$ & $0 \%$ & $0 \%$ & $0 \%$ & $0 \%$ & $0 \%$ & $1 \%$ & $1 \%$ & $0 \%$ \\
\hline \multicolumn{10}{|c|}{ Benefits as share of total gross household income, only beneficiaries } \\
\hline Family child & $11 \%$ & $18 \%$ & $14 \%$ & $28 \%$ & $17 \%$ & $26 \%$ & $33 \%$ & $16 \%$ & $22 \%$ \\
\hline Social exclusion & $4 \%$ & $10 \%$ & $4 \%$ & $6 \%$ & $11 \%$ & $14 \%$ & $13 \%$ & $8 \%$ & $12 \%$ \\
\hline Housing & $4 \%$ & $4 \%$ & $3 \%$ & $4 \%$ & $4 \%$ & $6 \%$ & $4 \%$ & $4 \%$ & $5 \%$ \\
\hline Unemployment & $14 \%$ & $14 \%$ & $15 \%$ & $14 \%$ & $14 \%$ & $31 \%$ & $20 \%$ & $18 \%$ & $21 \%$ \\
\hline Old age & $60 \%$ & $51 \%$ & $79 \%$ & $37 \%$ & $37 \%$ & $55 \%$ & $42 \%$ & $47 \%$ & $55 \%$ \\
\hline Survivor & $24 \%$ & $20 \%$ & $23 \%$ & $25 \%$ & $19 \%$ & $30 \%$ & $22 \%$ & $24 \%$ & $37 \%$ \\
\hline Sickness & $4 \%$ & $7 \%$ & $4 \%$ & $5 \%$ & $4 \%$ & $5 \%$ & $3 \%$ & $4 \%$ & $10 \%$ \\
\hline Disability & $34 \%$ & $42 \%$ & $41 \%$ & $26 \%$ & $24 \%$ & $35 \%$ & $24 \%$ & $27 \%$ & $32 \%$ \\
\hline Education & $6 \%$ & $5 \%$ & $7 \%$ & $5 \%$ & $4 \%$ & $9 \%$ & $9 \%$ & $6 \%$ & $14 \%$ \\
\hline $\begin{array}{l}\text { Household size } \\
\text { (mean) }\end{array}$ & 2.63 & 2.94 & 2.09 & 4.09 & 3.53 & 3.58 & 4.66 & 4.17 & 3.44 \\
\hline \multicolumn{10}{|c|}{ Household composition } \\
\hline One-person & $11 \%$ & $10 \%$ & $23 \%$ & $0 \%$ & $6 \%$ & $7 \%$ & $2 \%$ & $1 \%$ & $5 \%$ \\
\hline Single parent & $1 \%$ & $2 \%$ & $1 \%$ & $4 \%$ & $3 \%$ & $4 \%$ & $5 \%$ & $3 \%$ & $7 \%$ \\
\hline $\begin{array}{l}2+\text { adults without } \\
\text { dependent children }\end{array}$ & $68 \%$ & $59 \%$ & $67 \%$ & $8 \%$ & $36 \%$ & $37 \%$ & $23 \%$ & $40 \%$ & $51 \%$ \\
\hline $\begin{array}{l}2+\text { adults with } 1 \\
\text { dependent childf }\end{array}$ & $7 \%$ & $8 \%$ & $4 \%$ & $27 \%$ & $15 \%$ & $11 \%$ & $8 \%$ & $9 \%$ & $9 \%$ \\
\hline
\end{tabular}




\begin{tabular}{|c|c|c|c|c|c|c|c|c|c|}
\hline & $\begin{array}{l}\text { 1. Early } \\
\text { retirees } \\
\text { and } \\
\text { retirees }\end{array}$ & $\begin{array}{l}\text { 2. Disabled } \\
\text { with } \\
\text { previous } \\
\text { work } \\
\text { experience }\end{array}$ & $\begin{array}{c}3 . \\
\text { Urban } \\
\text { retired } \\
\text { women }\end{array}$ & $\begin{array}{l}\text { 4. Prime- } \\
\text { aged } \\
\text { inactive } \\
\text { mothers } \\
\text { with work } \\
\text { experience }\end{array}$ & $\begin{array}{l}\text { 5. Prime- } \\
\text { aged } \\
\text { unemployed }\end{array}$ & $\begin{array}{l}\text { 6. Prime- } \\
\text { aged long- } \\
\text { term } \\
\text { unemployed }\end{array}$ & $\begin{array}{c}\text { 7. Low- } \\
\text { educated } \\
\text { inactive young } \\
\text { women without } \\
\text { work } \\
\text { experience }\end{array}$ & $\begin{array}{c}8 . \\
\text { Unemployed } \\
\text { youth }\end{array}$ & $\begin{array}{l}\text { 9. Low- } \\
\text { educated } \\
\text { disabled } \\
\text { without } \\
\text { work } \\
\text { experience }\end{array}$ \\
\hline $\begin{array}{l}2+\text { adults with } 2+ \\
\text { dependent children }\end{array}$ & $14 \%$ & $21 \%$ & $5 \%$ & $61 \%$ & $40 \%$ & $41 \%$ & $62 \%$ & $47 \%$ & $29 \%$ \\
\hline Children under six & $6 \%$ & $9 \%$ & $2 \%$ & $72 \%$ & $19 \%$ & $20 \%$ & $48 \%$ & $13 \%$ & $2 \%$ \\
\hline $\begin{array}{l}\text { Three or more } \\
\text { children under } 16\end{array}$ & $0 \%$ & $3 \%$ & $0 \%$ & $17 \%$ & $7 \%$ & $9 \%$ & $23 \%$ & $8 \%$ & $4 \%$ \\
\hline \multicolumn{10}{|c|}{ Individual's parents present } \\
\hline One parent & $4 \%$ & $10 \%$ & $3 \%$ & $7 \%$ & $13 \%$ & $16 \%$ & $16 \%$ & $21 \%$ & $28 \%$ \\
\hline Both parents & $0 \%$ & $2 \%$ & $0 \%$ & $5 \%$ & $17 \%$ & $10 \%$ & $32 \%$ & $71 \%$ & $36 \%$ \\
\hline None & $96 \%$ & $87 \%$ & $97 \%$ & $88 \%$ & $70 \%$ & $74 \%$ & $52 \%$ & $8 \%$ & $36 \%$ \\
\hline $\begin{array}{l}\text { Elderly present } \\
\text { (over 64) }\end{array}$ & $15 \%$ & $17 \%$ & $25 \%$ & $9 \%$ & $11 \%$ & $13 \%$ & $9 \%$ & $6 \%$ & $36 \%$ \\
\hline \multicolumn{10}{|c|}{ Children under 13 in childcare } \\
\hline None of the children & $6 \%$ & $8 \%$ & $2 \%$ & $31 \%$ & $17 \%$ & $15 \%$ & $20 \%$ & $15 \%$ & $14 \%$ \\
\hline $\begin{array}{l}\text { Some of the } \\
\text { children }\end{array}$ & $1 \%$ & $4 \%$ & $0 \%$ & $27 \%$ & $10 \%$ & $12 \%$ & $27 \%$ & $8 \%$ & $5 \%$ \\
\hline $\begin{array}{l}\text { No children under } \\
13 \text { in household }\end{array}$ & $88 \%$ & $80 \%$ & $95 \%$ & $12 \%$ & $56 \%$ & $56 \%$ & $36 \%$ & $70 \%$ & $74 \%$ \\
\hline All of the children & $5 \%$ & $8 \%$ & $2 \%$ & $30 \%$ & $17 \%$ & $17 \%$ & $18 \%$ & $8 \%$ & $7 \%$ \\
\hline \multicolumn{10}{|l|}{ Marital status } \\
\hline Married & $67 \%$ & $62 \%$ & $61 \%$ & $72 \%$ & $42 \%$ & $47 \%$ & $33 \%$ & $1 \%$ & $14 \%$ \\
\hline Never married & $5 \%$ & $14 \%$ & $4 \%$ & $18 \%$ & $39 \%$ & $31 \%$ & $63 \%$ & $98 \%$ & $76 \%$ \\
\hline Divorced/separated & $13 \%$ & $15 \%$ & $15 \%$ & $9 \%$ & $17 \%$ & $17 \%$ & $4 \%$ & $1 \%$ & $6 \%$ \\
\hline Widowed & $15 \%$ & $9 \%$ & $19 \%$ & $2 \%$ & $2 \%$ & $5 \%$ & $1 \%$ & $0 \%$ & $4 \%$ \\
\hline \multicolumn{10}{|l|}{ Tenure status } \\
\hline Owner & $94 \%$ & $92 \%$ & $94 \%$ & $84 \%$ & $85 \%$ & $87 \%$ & $83 \%$ & $91 \%$ & $88 \%$ \\
\hline Tenant & $1 \%$ & $2 \%$ & $1 \%$ & $4 \%$ & $4 \%$ & $3 \%$ & $4 \%$ & $1 \%$ & $5 \%$ \\
\hline Reduced rate & $2 \%$ & $3 \%$ & $2 \%$ & $3 \%$ & $5 \%$ & $5 \%$ & $7 \%$ & $4 \%$ & $5 \%$ \\
\hline Free & $3 \%$ & $3 \%$ & $3 \%$ & $9 \%$ & $7 \%$ & $6 \%$ & $6 \%$ & $3 \%$ & $2 \%$ \\
\hline NA & $0 \%$ & $0 \%$ & $0 \%$ & $0 \%$ & $0 \%$ & $0 \%$ & $0 \%$ & $0 \%$ & $0 \%$ \\
\hline
\end{tabular}




\begin{tabular}{|c|c|c|c|c|c|c|c|c|c|}
\hline & $\begin{array}{l}\text { 1. Early } \\
\text { retirees } \\
\text { and } \\
\text { retirees }\end{array}$ & $\begin{array}{l}\text { 2. Disabled } \\
\text { with } \\
\text { previous } \\
\text { work } \\
\text { experience }\end{array}$ & $\begin{array}{c}3 . \\
\text { Urban } \\
\text { retired } \\
\text { women }\end{array}$ & $\begin{array}{l}\text { 4. Prime- } \\
\text { aged } \\
\text { inactive } \\
\text { mothers } \\
\text { with work } \\
\text { experience }\end{array}$ & $\begin{array}{l}\text { 5. Prime- } \\
\text { aged } \\
\text { unemployed }\end{array}$ & $\begin{array}{l}\text { 6. Prime- } \\
\text { aged long- } \\
\text { term } \\
\text { unemployed }\end{array}$ & $\begin{array}{c}\text { 7. Low- } \\
\text { educated } \\
\text { inactive young } \\
\text { women without } \\
\text { work } \\
\text { experience }\end{array}$ & $\begin{array}{c}8 . \\
\text { Unemployed } \\
\text { youth }\end{array}$ & $\begin{array}{l}\text { 9. Low- } \\
\text { educated } \\
\text { disabled } \\
\text { without } \\
\text { work } \\
\text { experience }\end{array}$ \\
\hline No & $11 \%$ & $18 \%$ & $10 \%$ & $9 \%$ & $19 \%$ & $23 \%$ & $21 \%$ & $16 \%$ & $17 \%$ \\
\hline Yes & $89 \%$ & $82 \%$ & $90 \%$ & $91 \%$ & $81 \%$ & $77 \%$ & $79 \%$ & $84 \%$ & $83 \%$ \\
\hline NA & $0 \%$ & $0 \%$ & $0 \%$ & $0 \%$ & $0 \%$ & $0 \%$ & $0 \%$ & $0 \%$ & $0 \%$ \\
\hline \multicolumn{10}{|c|}{ Degree of urbanization } \\
\hline Densely populated & $29 \%$ & $17 \%$ & $44 \%$ & $30 \%$ & $22 \%$ & $19 \%$ & $27 \%$ & $19 \%$ & $26 \%$ \\
\hline Intermediate area & $22 \%$ & $18 \%$ & $22 \%$ & $18 \%$ & $17 \%$ & $21 \%$ & $19 \%$ & $27 \%$ & $13 \%$ \\
\hline Sparsely populated & $49 \%$ & $65 \%$ & $34 \%$ & $51 \%$ & $61 \%$ & $60 \%$ & $55 \%$ & $54 \%$ & $61 \%$ \\
\hline \multicolumn{10}{|l|}{ Region } \\
\hline $\begin{array}{l}\text { HU1 - Central } \\
\text { Hungary }\end{array}$ & $28 \%$ & $17 \%$ & $36 \%$ & $30 \%$ & $18 \%$ & $21 \%$ & $27 \%$ & $23 \%$ & $24 \%$ \\
\hline HU2 - Transdanubia & $34 \%$ & $29 \%$ & $28 \%$ & $29 \%$ & $31 \%$ & $31 \%$ & $24 \%$ & $32 \%$ & $38 \%$ \\
\hline $\begin{array}{l}\text { HU3 - Great Plain } \\
\text { and North }\end{array}$ & $39 \%$ & $54 \%$ & $36 \%$ & $41 \%$ & $51 \%$ & $48 \%$ & $48 \%$ & $45 \%$ & $37 \%$ \\
\hline
\end{tabular}

a. Refers to individuals aged 25 and over.

b. Applies to individuals aged 25 and over. Students aged 16 to 24 are not included in the sample.

c. Refers only to individuals who have worked before.

d. Based on total equivalized disposable household income.

e. Based on total gross household income.

f. Dependent children include: 1. household members under 18; 2. household members aged between 18 and 24 who are economically inactive and living with at least one parent.

Source: WB staff calculations based on EU-SILC. 


\begin{tabular}{|c|c|c|c|c|c|c|c|c|}
\hline & $\begin{array}{c}\text { 1. Disabled } \\
\text { with previous } \\
\text { work } \\
\text { experience }\end{array}$ & $\begin{array}{l}\text { 2. Urban } \\
\text { retired } \\
\text { women }\end{array}$ & $\begin{array}{l}\text { 3. Prime-aged } \\
\text { inactive } \\
\text { mothers with } \\
\text { work } \\
\text { experience }\end{array}$ & $\begin{array}{l}\text { 4. Early } \\
\text { retirees } \\
\text { and } \\
\text { retirees }\end{array}$ & $\begin{array}{l}\text { 5. Prime- } \\
\text { aged long- } \\
\text { term } \\
\text { unemployed }\end{array}$ & $\begin{array}{l}\text { 6. Prime- } \\
\text { aged } \\
\text { unemployed }\end{array}$ & $\begin{array}{l}\text { 7. Low-educated } \\
\text { inactive young } \\
\text { women without } \\
\text { work experience }\end{array}$ & $\begin{array}{c}\text { 8. Low- } \\
\text { educated } \\
\text { disabled } \\
\text { without work } \\
\text { experience }\end{array}$ \\
\hline Cluster size & $25 \%$ & $18 \%$ & $14 \%$ & $13 \%$ & $10 \%$ & $10 \%$ & $8 \%$ & $2 \%$ \\
\hline Population & 531,882 & 394,051 & 299,643 & 287,977 & 224,894 & 208,043 & 181,039 & 32,622 \\
\hline \multicolumn{9}{|c|}{ INDICATORS } \\
\hline \multicolumn{9}{|c|}{ Labor market attachment } \\
\hline Unemployed & $1 \%$ & $0 \%$ & $2 \%$ & $0 \%$ & $8 \%$ & $68 \%$ & $12 \%$ & $0 \%$ \\
\hline $\begin{array}{l}\text { Long-term } \\
\text { unemployed }\end{array}$ & $3 \%$ & $0 \%$ & $0 \%$ & $0 \%$ & $68 \%$ & $0 \%$ & $13 \%$ & $11 \%$ \\
\hline Retired & $0 \%$ & $85 \%$ & $1 \%$ & $96 \%$ & $0 \%$ & $8 \%$ & $0 \%$ & $0 \%$ \\
\hline Disabled & $94 \%$ & $15 \%$ & $0 \%$ & $0 \%$ & $0 \%$ & $1 \%$ & $0 \%$ & $74 \%$ \\
\hline Other inactive & $2 \%$ & $1 \%$ & $96 \%$ & $4 \%$ & $25 \%$ & $23 \%$ & $75 \%$ & $14 \%$ \\
\hline \multicolumn{9}{|c|}{ At least one working adult in householda } \\
\hline No & $53 \%$ & $97 \%$ & $17 \%$ & $24 \%$ & $57 \%$ & $48 \%$ & $37 \%$ & $64 \%$ \\
\hline Yes & $47 \%$ & $3 \%$ & $83 \%$ & $76 \%$ & $43 \%$ & $52 \%$ & $63 \%$ & $36 \%$ \\
\hline \multicolumn{9}{|l|}{ Work experience } \\
\hline Never worked & $0 \%$ & $0 \%$ & $0 \%$ & $1 \%$ & $0 \%$ & $0 \%$ & $79 \%$ & $99 \%$ \\
\hline $\begin{array}{l}\text { Less than } 2 \text { months in } \\
\text { last year }\end{array}$ & $98 \%$ & $98 \%$ & $87 \%$ & $95 \%$ & $100 \%$ & $1 \%$ & $14 \%$ & $1 \%$ \\
\hline $\begin{array}{l}2 \text { or more months in } \\
\text { last year }\end{array}$ & $2 \%$ & $2 \%$ & $13 \%$ & $5 \%$ & $0 \%$ & $99 \%$ & $7 \%$ & $0 \%$ \\
\hline \multicolumn{9}{|c|}{ Self-assessed physical incapacity } \\
\hline Strongly limited & $31 \%$ & $10 \%$ & $1 \%$ & $8 \%$ & $4 \%$ & $5 \%$ & $3 \%$ & $58 \%$ \\
\hline None/limited & $69 \%$ & $90 \%$ & $99 \%$ & $92 \%$ & $96 \%$ & $95 \%$ & $97 \%$ & $42 \%$ \\
\hline \multicolumn{9}{|c|}{ ACTIVE COVARIATES } \\
\hline \multicolumn{9}{|l|}{ Age groups (4) } \\
\hline 16-24 years & $0 \%$ & $0 \%$ & $5 \%$ & $0 \%$ & $9 \%$ & $16 \%$ & $55 \%$ & $23 \%$ \\
\hline $25-34$ years & $2 \%$ & $0 \%$ & $58 \%$ & $0 \%$ & $26 \%$ & $24 \%$ & $36 \%$ & $41 \%$ \\
\hline
\end{tabular}




\begin{tabular}{|c|c|c|c|c|c|c|c|c|}
\hline & $\begin{array}{c}\text { 1. Disabled } \\
\text { with previous } \\
\text { work } \\
\text { experience }\end{array}$ & $\begin{array}{c}\text { 2. Urban } \\
\text { retired } \\
\text { women }\end{array}$ & $\begin{array}{l}\text { 3. Prime-aged } \\
\text { inactive } \\
\text { mothers with } \\
\text { work } \\
\text { experience }\end{array}$ & $\begin{array}{l}\text { 4. Early } \\
\text { retirees } \\
\text { and } \\
\text { retirees }\end{array}$ & $\begin{array}{l}\text { 5. Prime- } \\
\text { aged long- } \\
\text { term } \\
\text { unemployed }\end{array}$ & $\begin{array}{l}\text { 6. Prime- } \\
\text { aged } \\
\text { unemployed }\end{array}$ & $\begin{array}{l}\text { 7. Low-educated } \\
\text { inactive young } \\
\text { women without } \\
\text { work experience }\end{array}$ & $\begin{array}{c}\text { 8. Low- } \\
\text { educated } \\
\text { disabled } \\
\text { without work } \\
\text { experience }\end{array}$ \\
\hline $35-59$ years & $81 \%$ & $24 \%$ & $36 \%$ & $36 \%$ & $64 \%$ & $58 \%$ & $8 \%$ & $30 \%$ \\
\hline $60-64$ years & $17 \%$ & $76 \%$ & $0 \%$ & $64 \%$ & $0 \%$ & $1 \%$ & $0 \%$ & $5 \%$ \\
\hline \multicolumn{9}{|l|}{ Gender } \\
\hline Male & $49 \%$ & $32 \%$ & $2 \%$ & $45 \%$ & $56 \%$ & $60 \%$ & $33 \%$ & $67 \%$ \\
\hline Female & $51 \%$ & $68 \%$ & $98 \%$ & $55 \%$ & $44 \%$ & $40 \%$ & $67 \%$ & $33 \%$ \\
\hline \multicolumn{9}{|l|}{ Education (4) } \\
\hline Primary & $39 \%$ & $19 \%$ & $16 \%$ & $32 \%$ & $42 \%$ & $28 \%$ & $48 \%$ & $70 \%$ \\
\hline Secondary & $57 \%$ & $63 \%$ & $61 \%$ & $53 \%$ & $55 \%$ & $64 \%$ & $41 \%$ & $26 \%$ \\
\hline Tertiary & $5 \%$ & $18 \%$ & $23 \%$ & $16 \%$ & $3 \%$ & $9 \%$ & $11 \%$ & $4 \%$ \\
\hline Urban & $39 \%$ & $57 \%$ & $45 \%$ & $55 \%$ & $36 \%$ & $44 \%$ & $42 \%$ & $28 \%$ \\
\hline Rural & $61 \%$ & $43 \%$ & $55 \%$ & $45 \%$ & $64 \%$ & $56 \%$ & $58 \%$ & $72 \%$ \\
\hline \multicolumn{9}{|c|}{ INACTIVE COVARIATES } \\
\hline \multicolumn{9}{|l|}{ Age groups (8) } \\
\hline 16-19 years & $0 \%$ & $0 \%$ & $0 \%$ & $0 \%$ & $1 \%$ & $2 \%$ & $17 \%$ & $4 \%$ \\
\hline 20-24 years & $0 \%$ & $0 \%$ & $5 \%$ & $0 \%$ & $8 \%$ & $14 \%$ & $38 \%$ & $19 \%$ \\
\hline 25-29 years & $1 \%$ & $0 \%$ & $25 \%$ & $0 \%$ & $12 \%$ & $14 \%$ & $24 \%$ & $19 \%$ \\
\hline $30-34$ years & $1 \%$ & $0 \%$ & $33 \%$ & $0 \%$ & $14 \%$ & $11 \%$ & $12 \%$ & $23 \%$ \\
\hline 35-44 years & $12 \%$ & $2 \%$ & $25 \%$ & $4 \%$ & $26 \%$ & $26 \%$ & $5 \%$ & $19 \%$ \\
\hline $45-54$ years & $36 \%$ & $4 \%$ & $9 \%$ & $8 \%$ & $30 \%$ & $22 \%$ & $2 \%$ & $7 \%$ \\
\hline 55-59 years & $34 \%$ & $18 \%$ & $3 \%$ & $25 \%$ & $8 \%$ & $10 \%$ & $1 \%$ & $4 \%$ \\
\hline 60-64 years & $17 \%$ & $76 \%$ & $0 \%$ & $64 \%$ & $0 \%$ & $1 \%$ & $0 \%$ & $5 \%$ \\
\hline \multicolumn{9}{|l|}{ Education (6) } \\
\hline Primary & $4 \%$ & $1 \%$ & $1 \%$ & $3 \%$ & $7 \%$ & $3 \%$ & $8 \%$ & $29 \%$ \\
\hline Lower secondary & $34 \%$ & $18 \%$ & $15 \%$ & $28 \%$ & $35 \%$ & $24 \%$ & $40 \%$ & $41 \%$ \\
\hline Upper secondary & $53 \%$ & $57 \%$ & $56 \%$ & $48 \%$ & $52 \%$ & $58 \%$ & $36 \%$ & $26 \%$ \\
\hline Post-secondary & $4 \%$ & $6 \%$ & $6 \%$ & $4 \%$ & $3 \%$ & $5 \%$ & $5 \%$ & $1 \%$ \\
\hline Tertiary & $5 \%$ & $18 \%$ & $23 \%$ & $16 \%$ & $3 \%$ & $9 \%$ & $11 \%$ & $4 \%$ \\
\hline
\end{tabular}




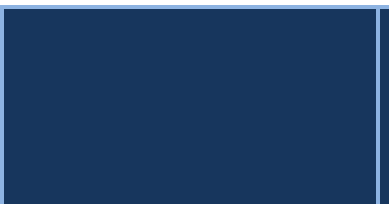

1. Disabled

with previous

work

2. Urban

retired

experience

women

3. Prime-aged

inactive

mothers with

work

4. Early 5. Prime-

retirees

aged long-

term

experience

retirees unemployed

6. Prime-
aged
unemployed

7. Low-educated

inactive young

women without

work experience
8. Low-

educated

disabled

without work

experience

\section{Enrolled in education ${ }^{b}$}

\begin{tabular}{|c|c|c|c|c|c|c|c|c|}
\hline Yes & $0 \%$ & $0 \%$ & $5 \%$ & $0 \%$ & $4 \%$ & $1 \%$ & $13 \%$ & $3 \%$ \\
\hline No & $100 \%$ & $100 \%$ & $95 \%$ & $100 \%$ & $96 \%$ & $99 \%$ & $87 \%$ & $97 \%$ \\
\hline \multicolumn{9}{|l|}{ Ever worked } \\
\hline No & $0 \%$ & $0 \%$ & $0 \%$ & $1 \%$ & $0 \%$ & $0 \%$ & $79 \%$ & $100 \%$ \\
\hline Yes & $100 \%$ & $100 \%$ & $100 \%$ & $99 \%$ & $100 \%$ & $100 \%$ & $21 \%$ & $0 \%$ \\
\hline $\begin{array}{l}\text { Years of work } \\
\text { experience }\end{array}$ & 26 & 36 & 11 & 36 & 15 & 17 & 6 & 15 \\
\hline \multicolumn{9}{|c|}{ Partner economic status } \\
\hline Working & $30 \%$ & $1 \%$ & $73 \%$ & $33 \%$ & $26 \%$ & $28 \%$ & $22 \%$ & $4 \%$ \\
\hline Unemployed & $4 \%$ & $1 \%$ & $3 \%$ & $1 \%$ & $12 \%$ & $9 \%$ & $10 \%$ & $4 \%$ \\
\hline Retired & $13 \%$ & $48 \%$ & $2 \%$ & $28 \%$ & $2 \%$ & $2 \%$ & $1 \%$ & $3 \%$ \\
\hline Inactive & $23 \%$ & $16 \%$ & $6 \%$ & $11 \%$ & $18 \%$ & $14 \%$ & $7 \%$ & $9 \%$ \\
\hline $\begin{array}{l}\text { Student/military } \\
\text { service }\end{array}$ & $0 \%$ & $0 \%$ & $0 \%$ & $0 \%$ & $0 \%$ & $0 \%$ & $1 \%$ & $0 \%$ \\
\hline No partner & $30 \%$ & $34 \%$ & $16 \%$ & $27 \%$ & $42 \%$ & $46 \%$ & $60 \%$ & $79 \%$ \\
\hline $\begin{array}{l}\text { Partner income } \\
\text { (mean) }\end{array}$ & 2817 & 647 & 7672 & 3597 & 3045 & 3526 & 3320 & 840 \\
\hline $\begin{array}{l}\text { Working partner } \\
\text { income (mean) }\end{array}$ & 6213 & 8317 & 8630 & 7469 & 6116 & 5973 & 5121 & 3615 \\
\hline \multicolumn{9}{|c|}{ Partner income quintile } \\
\hline Poorest & $6 \%$ & $0 \%$ & $13 \%$ & $7 \%$ & $7 \%$ & $9 \%$ & $9 \%$ & $4 \%$ \\
\hline Q2 & $8 \%$ & $0 \%$ & $14 \%$ & $6 \%$ & $6 \%$ & $4 \%$ & $6 \%$ & $0 \%$ \\
\hline Q3 & $6 \%$ & $0 \%$ & $12 \%$ & $7 \%$ & $5 \%$ & $5 \%$ & $2 \%$ & $0 \%$ \\
\hline Q4 & $4 \%$ & $0 \%$ & $15 \%$ & $6 \%$ & $3 \%$ & $6 \%$ & $3 \%$ & $0 \%$ \\
\hline Richest & $4 \%$ & $0 \%$ & $19 \%$ & $7 \%$ & $4 \%$ & $3 \%$ & $2 \%$ & $0 \%$ \\
\hline $\begin{array}{l}\text { No partner or partner } \\
\text { without income }\end{array}$ & $70 \%$ & $99 \%$ & $27 \%$ & $67 \%$ & $74 \%$ & $72 \%$ & $78 \%$ & $96 \%$ \\
\hline
\end{tabular}




\begin{tabular}{|c|c|c|c|c|c|c|c|c|}
\hline & $\begin{array}{c}\text { 1. Disabled } \\
\text { with previous } \\
\text { work } \\
\text { experience }\end{array}$ & $\begin{array}{l}\text { 2. Urban } \\
\text { retired } \\
\text { women }\end{array}$ & $\begin{array}{l}\text { 3. Prime-aged } \\
\text { inactive } \\
\text { mothers with } \\
\text { work } \\
\text { experience }\end{array}$ & $\begin{array}{l}\text { 4. Early } \\
\text { retirees } \\
\text { and } \\
\text { retirees }\end{array}$ & $\begin{array}{l}\text { 5. Prime- } \\
\text { aged long- } \\
\text { term } \\
\text { unemployed }\end{array}$ & $\begin{array}{l}\text { 6. Prime- } \\
\text { aged } \\
\text { unemployed }\end{array}$ & $\begin{array}{l}\text { 7. Low-educated } \\
\text { inactive young } \\
\text { women without } \\
\text { work experience }\end{array}$ & $\begin{array}{c}\text { 8. Low- } \\
\text { educated } \\
\text { disabled } \\
\text { without work } \\
\text { experience }\end{array}$ \\
\hline Poorest & $30 \%$ & $14 \%$ & $37 \%$ & $8 \%$ & $66 \%$ & $40 \%$ & $57 \%$ & $54 \%$ \\
\hline Q2 & $26 \%$ & $21 \%$ & $23 \%$ & $17 \%$ & $19 \%$ & $19 \%$ & $18 \%$ & $19 \%$ \\
\hline Q3 & $21 \%$ & $22 \%$ & $16 \%$ & $20 \%$ & $9 \%$ & $18 \%$ & $11 \%$ & $11 \%$ \\
\hline Q4 & $14 \%$ & $22 \%$ & $12 \%$ & $26 \%$ & $6 \%$ & $14 \%$ & $8 \%$ & $10 \%$ \\
\hline Richest & $9 \%$ & $21 \%$ & $11 \%$ & $29 \%$ & $1 \%$ & $10 \%$ & $7 \%$ & $7 \%$ \\
\hline \multicolumn{9}{|c|}{ Household income shares } \\
\hline Labor income & $36 \%$ & $10 \%$ & $59 \%$ & $44 \%$ & $38 \%$ & $64 \%$ & $53 \%$ & $26 \%$ \\
\hline Other income & $1 \%$ & $2 \%$ & $3 \%$ & $1 \%$ & $2 \%$ & $2 \%$ & $3 \%$ & $1 \%$ \\
\hline Benefits & $63 \%$ & $89 \%$ & $39 \%$ & $55 \%$ & $59 \%$ & $34 \%$ & $44 \%$ & $74 \%$ \\
\hline $\begin{array}{l}\text { Receives at least one } \\
\text { benefit }\end{array}$ & $99 \%$ & $99 \%$ & $94 \%$ & $99 \%$ & $87 \%$ & $76 \%$ & $81 \%$ & $93 \%$ \\
\hline \multicolumn{9}{|c|}{ Receives benefits at household level } \\
\hline Family child & $28 \%$ & $6 \%$ & $90 \%$ & $22 \%$ & $57 \%$ & $46 \%$ & $70 \%$ & $53 \%$ \\
\hline Social exclusion & $9 \%$ & $3 \%$ & $11 \%$ & $3 \%$ & $23 \%$ & $16 \%$ & $21 \%$ & $19 \%$ \\
\hline Housing & $13 \%$ & $7 \%$ & $13 \%$ & $6 \%$ & $24 \%$ & $19 \%$ & $24 \%$ & $27 \%$ \\
\hline $\begin{array}{l}\text { Old age at household } \\
\text { level }\end{array}$ & $36 \%$ & $93 \%$ & $13 \%$ & $94 \%$ & $23 \%$ & $23 \%$ & $13 \%$ & $34 \%$ \\
\hline \multicolumn{9}{|c|}{ Receives benefits at individual level } \\
\hline Unemployment & $4 \%$ & $1 \%$ & $8 \%$ & $2 \%$ & $46 \%$ & $38 \%$ & $11 \%$ & $4 \%$ \\
\hline Old age & $11 \%$ & $89 \%$ & $1 \%$ & $91 \%$ & $1 \%$ & $3 \%$ & $0 \%$ & $3 \%$ \\
\hline Survivor & $3 \%$ & $3 \%$ & $1 \%$ & $3 \%$ & $2 \%$ & $1 \%$ & $0 \%$ & $0 \%$ \\
\hline Sickness & $2 \%$ & $1 \%$ & $6 \%$ & $1 \%$ & $0 \%$ & $9 \%$ & $1 \%$ & $2 \%$ \\
\hline Disability & $84 \%$ & $9 \%$ & $1 \%$ & $3 \%$ & $3 \%$ & $2 \%$ & $2 \%$ & $76 \%$ \\
\hline Education & $0 \%$ & $0 \%$ & $0 \%$ & $0 \%$ & $1 \%$ & $0 \%$ & $5 \%$ & $0 \%$ \\
\hline \multicolumn{9}{|c|}{ Benefits as share of total gross household income, all households } \\
\hline Family child & $4 \%$ & $1 \%$ & $25 \%$ & $2 \%$ & $15 \%$ & $9 \%$ & $20 \%$ & $13 \%$ \\
\hline Social exclusion & $1 \%$ & $0 \%$ & $1 \%$ & $0 \%$ & $5 \%$ & $2 \%$ & $3 \%$ & $3 \%$ \\
\hline Housing & $0 \%$ & $0 \%$ & $0 \%$ & $0 \%$ & $1 \%$ & $1 \%$ & $1 \%$ & $1 \%$ \\
\hline
\end{tabular}




\begin{tabular}{|c|c|c|c|c|c|c|c|c|}
\hline & $\begin{array}{c}\text { 1. Disabled } \\
\text { with previous } \\
\text { work } \\
\text { experience }\end{array}$ & $\begin{array}{l}\text { 2. Urban } \\
\text { retired } \\
\text { women }\end{array}$ & $\begin{array}{l}\text { 3. Prime-aged } \\
\text { inactive } \\
\text { mothers with } \\
\text { work } \\
\text { experience }\end{array}$ & $\begin{array}{l}\text { 4. Early } \\
\text { retirees } \\
\text { and } \\
\text { retirees }\end{array}$ & $\begin{array}{l}\text { 5. Prime- } \\
\text { aged long- } \\
\text { term } \\
\text { unemployed }\end{array}$ & $\begin{array}{l}\text { 6. Prime- } \\
\text { aged } \\
\text { unemployed }\end{array}$ & $\begin{array}{l}\text { 7. Low-educated } \\
\text { inactive young } \\
\text { women without } \\
\text { work experience }\end{array}$ & $\begin{array}{c}\text { 8. Low- } \\
\text { educated } \\
\text { disabled } \\
\text { without work } \\
\text { experience }\end{array}$ \\
\hline Unemployment & $2 \%$ & $1 \%$ & $2 \%$ & $1 \%$ & $16 \%$ & $7 \%$ & $7 \%$ & $6 \%$ \\
\hline Old age & $17 \%$ & $77 \%$ & $5 \%$ & $47 \%$ & $13 \%$ & $10 \%$ & $6 \%$ & $18 \%$ \\
\hline Survivor & $1 \%$ & $1 \%$ & $1 \%$ & $1 \%$ & $1 \%$ & $0 \%$ & $1 \%$ & $2 \%$ \\
\hline Sickness & $0 \%$ & $0 \%$ & $1 \%$ & $0 \%$ & $0 \%$ & $1 \%$ & $1 \%$ & $1 \%$ \\
\hline Disability & $36 \%$ & $8 \%$ & $3 \%$ & $3 \%$ & $8 \%$ & $5 \%$ & $6 \%$ & $30 \%$ \\
\hline Education & $0 \%$ & $0 \%$ & $0 \%$ & $0 \%$ & $0 \%$ & $0 \%$ & $1 \%$ & $0 \%$ \\
\hline \multicolumn{9}{|c|}{ Benefits as share of total gross household income, only beneficiaries } \\
\hline Family child & $15 \%$ & $15 \%$ & $28 \%$ & $11 \%$ & $26 \%$ & $19 \%$ & $28 \%$ & $25 \%$ \\
\hline Social exclusion & $9 \%$ & $5 \%$ & $8 \%$ & $5 \%$ & $23 \%$ & $11 \%$ & $13 \%$ & $13 \%$ \\
\hline Housing & $3 \%$ & $3 \%$ & $3 \%$ & $2 \%$ & $5 \%$ & $3 \%$ & $4 \%$ & $4 \%$ \\
\hline Unemployment & $18 \%$ & $16 \%$ & $14 \%$ & $11 \%$ & $30 \%$ & $17 \%$ & $23 \%$ & $23 \%$ \\
\hline Old age & $49 \%$ & $83 \%$ & $39 \%$ & $50 \%$ & $55 \%$ & $44 \%$ & $42 \%$ & $53 \%$ \\
\hline Survivor & $21 \%$ & $28 \%$ & $24 \%$ & $22 \%$ & $30 \%$ & $17 \%$ & $24 \%$ & $15 \%$ \\
\hline Sickness & $4 \%$ & $6 \%$ & $4 \%$ & $4 \%$ & $5 \%$ & $4 \%$ & $5 \%$ & $10 \%$ \\
\hline Disability & $42 \%$ & $43 \%$ & $32 \%$ & $26 \%$ & $38 \%$ & $32 \%$ & $30 \%$ & $37 \%$ \\
\hline Education & $5 \%$ & $8 \%$ & $5 \%$ & $7 \%$ & $7 \%$ & $4 \%$ & $8 \%$ & $6 \%$ \\
\hline $\begin{array}{l}\text { Household size } \\
\text { (mean) }\end{array}$ & 2.87 & 1.98 & 4.10 & 2.92 & 3.67 & 3.47 & 4.40 & 3.84 \\
\hline \multicolumn{9}{|c|}{ Household composition } \\
\hline One-person & $11 \%$ & $25 \%$ & $1 \%$ & $5 \%$ & $5 \%$ & $8 \%$ & $1 \%$ & $1 \%$ \\
\hline Single parent & $1 \%$ & $1 \%$ & $3 \%$ & $0 \%$ & $4 \%$ & $2 \%$ & $4 \%$ & $3 \%$ \\
\hline $\begin{array}{l}2+\text { adults without } \\
\text { dependent children }\end{array}$ & $60 \%$ & $67 \%$ & $11 \%$ & $71 \%$ & $36 \%$ & $43 \%$ & $26 \%$ & $46 \%$ \\
\hline $\begin{array}{l}2+\text { adults with } 1 \\
\text { dependent child }\end{array}$ & $9 \%$ & $3 \%$ & $25 \%$ & $6 \%$ & $10 \%$ & $11 \%$ & $11 \%$ & $8 \%$ \\
\hline $\begin{array}{l}2+\text { adults with } 2+ \\
\text { dependent children }\end{array}$ & $19 \%$ & $3 \%$ & $61 \%$ & $18 \%$ & $44 \%$ & $36 \%$ & $59 \%$ & $42 \%$ \\
\hline Children under six & $6 \%$ & $2 \%$ & $69 \%$ & $7 \%$ & $23 \%$ & $20 \%$ & $38 \%$ & $17 \%$ \\
\hline Three or more & $2 \%$ & $0 \%$ & $19 \%$ & $1 \%$ & $9 \%$ & $7 \%$ & $17 \%$ & $6 \%$ \\
\hline
\end{tabular}




\begin{tabular}{|c|c|c|c|c|c|c|c|c|}
\hline & $\begin{array}{c}\text { 1. Disabled } \\
\text { with previous } \\
\text { work } \\
\text { experience }\end{array}$ & $\begin{array}{l}\text { 2. Urban } \\
\text { retired } \\
\text { women }\end{array}$ & $\begin{array}{l}\text { 3. Prime-aged } \\
\text { inactive } \\
\text { mothers with } \\
\text { work } \\
\text { experience }\end{array}$ & $\begin{array}{l}\text { 4. Early } \\
\text { retirees } \\
\text { and } \\
\text { retirees }\end{array}$ & $\begin{array}{l}\text { 5. Prime- } \\
\text { aged long- } \\
\text { term } \\
\text { unemployed }\end{array}$ & $\begin{array}{l}\text { 6. Prime- } \\
\text { aged } \\
\text { unemployed }\end{array}$ & $\begin{array}{l}\text { 7. Low-educated } \\
\text { inactive young } \\
\text { women without } \\
\text { work experience }\end{array}$ & $\begin{array}{c}\text { 8. Low- } \\
\text { educated } \\
\text { disabled } \\
\text { without work } \\
\text { experience }\end{array}$ \\
\hline \multicolumn{9}{|l|}{ children under 16} \\
\hline \multicolumn{9}{|c|}{ Individuals' parents present } \\
\hline One parent & $9 \%$ & $3 \%$ & $8 \%$ & $3 \%$ & $16 \%$ & $14 \%$ & $21 \%$ & $29 \%$ \\
\hline Both parents & $2 \%$ & $0 \%$ & $7 \%$ & $1 \%$ & $14 \%$ & $19 \%$ & $38 \%$ & $37 \%$ \\
\hline None & $89 \%$ & $97 \%$ & $85 \%$ & $97 \%$ & $70 \%$ & $67 \%$ & $41 \%$ & $34 \%$ \\
\hline $\begin{array}{l}\text { Elderly present } \\
\text { (over 64) }\end{array}$ & $16 \%$ & $25 \%$ & $7 \%$ & $18 \%$ & $16 \%$ & $13 \%$ & $7 \%$ & $21 \%$ \\
\hline \multicolumn{9}{|c|}{ Children under 13 in childcare } \\
\hline None of the children & $8 \%$ & $2 \%$ & $34 \%$ & $8 \%$ & $20 \%$ & $16 \%$ & $20 \%$ & $14 \%$ \\
\hline Some of the children & $4 \%$ & $1 \%$ & $26 \%$ & $2 \%$ & $13 \%$ & $9 \%$ & $18 \%$ & $9 \%$ \\
\hline $\begin{array}{l}\text { No children under } 13 \\
\text { in household }\end{array}$ & $82 \%$ & $97 \%$ & $16 \%$ & $85 \%$ & $53 \%$ & $64 \%$ & $46 \%$ & $68 \%$ \\
\hline All of the children & $6 \%$ & $1 \%$ & $24 \%$ & $5 \%$ & $15 \%$ & $12 \%$ & $16 \%$ & $9 \%$ \\
\hline \multicolumn{9}{|l|}{ Marital status } \\
\hline Married & $62 \%$ & $61 \%$ & $70 \%$ & $68 \%$ & $45 \%$ & $41 \%$ & $25 \%$ & $12 \%$ \\
\hline Never married & $12 \%$ & $5 \%$ & $20 \%$ & $5 \%$ & $37 \%$ & $42 \%$ & $71 \%$ & $85 \%$ \\
\hline Divorced/separated & $16 \%$ & $16 \%$ & $8 \%$ & $9 \%$ & $13 \%$ & $13 \%$ & $4 \%$ & $2 \%$ \\
\hline Widowed & $10 \%$ & $18 \%$ & $2 \%$ & $18 \%$ & $5 \%$ & $3 \%$ & $1 \%$ & $1 \%$ \\
\hline \multicolumn{9}{|l|}{ Tenure status } \\
\hline Owner & $93 \%$ & $92 \%$ & $87 \%$ & $95 \%$ & $87 \%$ & $89 \%$ & $84 \%$ & $85 \%$ \\
\hline Tenant & $2 \%$ & $1 \%$ & $3 \%$ & $0 \%$ & $2 \%$ & $2 \%$ & $3 \%$ & $2 \%$ \\
\hline Reduced rate & $3 \%$ & $3 \%$ & $4 \%$ & $3 \%$ & $5 \%$ & $5 \%$ & $7 \%$ & $7 \%$ \\
\hline Free & $3 \%$ & $5 \%$ & $6 \%$ & $2 \%$ & $6 \%$ & $4 \%$ & $6 \%$ & $6 \%$ \\
\hline \multicolumn{9}{|c|}{ Able to keep dwelling warm } \\
\hline No & $15 \%$ & $10 \%$ & $7 \%$ & $7 \%$ & $17 \%$ & $14 \%$ & $13 \%$ & $10 \%$ \\
\hline Yes & $85 \%$ & $90 \%$ & $93 \%$ & $93 \%$ & $83 \%$ & $86 \%$ & $87 \%$ & $90 \%$ \\
\hline \multicolumn{9}{|c|}{ Degree of urbanization } \\
\hline Densely populated & $19 \%$ & $35 \%$ & $27 \%$ & $36 \%$ & $17 \%$ & $25 \%$ & $22 \%$ & $14 \%$ \\
\hline
\end{tabular}




\begin{tabular}{|c|c|c|c|c|c|c|c|c|}
\hline & $\begin{array}{c}\text { 1. Disabled } \\
\text { with previous } \\
\text { work } \\
\text { experience }\end{array}$ & $\begin{array}{l}\text { 2. Urban } \\
\text { retired } \\
\text { women }\end{array}$ & $\begin{array}{l}\text { 3. Prime-aged } \\
\text { inactive } \\
\text { mothers with } \\
\text { work } \\
\text { experience }\end{array}$ & $\begin{array}{l}\text { 4. Early } \\
\text { retirees } \\
\text { and } \\
\text { retirees }\end{array}$ & $\begin{array}{l}\text { 5. Prime- } \\
\text { aged long- } \\
\text { term } \\
\text { unemployed }\end{array}$ & $\begin{array}{l}\text { 6. Prime- } \\
\text { aged } \\
\text { unemployed }\end{array}$ & $\begin{array}{l}\text { 7. Low-educated } \\
\text { inactive young } \\
\text { women without } \\
\text { work experience }\end{array}$ & $\begin{array}{c}\text { 8. Low- } \\
\text { educated } \\
\text { disabled } \\
\text { without work } \\
\text { experience }\end{array}$ \\
\hline Intermediate area & $20 \%$ & $22 \%$ & $18 \%$ & $18 \%$ & $20 \%$ & $19 \%$ & $20 \%$ & $14 \%$ \\
\hline Sparsely populated & $61 \%$ & $43 \%$ & $55 \%$ & $45 \%$ & $64 \%$ & $56 \%$ & $58 \%$ & $72 \%$ \\
\hline \multicolumn{9}{|l|}{ Region } \\
\hline HU1 - Central Hungary & $19 \%$ & $32 \%$ & $26 \%$ & $32 \%$ & $16 \%$ & $24 \%$ & $21 \%$ & $12 \%$ \\
\hline HU2 - Transdanubia & $30 \%$ & $28 \%$ & $32 \%$ & $33 \%$ & $26 \%$ & $32 \%$ & $25 \%$ & $33 \%$ \\
\hline $\begin{array}{l}\text { HU3 - Great Plain and } \\
\text { North }\end{array}$ & $51 \%$ & $40 \%$ & $43 \%$ & $35 \%$ & $58 \%$ & $44 \%$ & $55 \%$ & $54 \%$ \\
\hline
\end{tabular}

a. Refers to individuals aged 25 and over.

b. Applies to individuals aged 25 and over. Students aged 16 to 24 are not included in the sample.

c. Refers only to individuals who have worked before.

d. Based on total equivalized disposable household income.

e. Based on total gross household income.

f. Dependent children include: 1. household members under 18; 2. household members aged between 18 and 24 who are economically inactive and living with at least one parent.

Source: WB staff calculations based on EU-SILC. 


\begin{tabular}{|c|c|c|c|c|c|c|c|}
\hline & $\begin{array}{c}\text { 1. Disabled } \\
\text { with } \\
\text { previous } \\
\text { work } \\
\text { experience }\end{array}$ & $\begin{array}{l}\text { 2. Early } \\
\text { retirees } \\
\text { and } \\
\text { retirees }\end{array}$ & $\begin{array}{l}\text { 3. Prime-aged } \\
\text { inactive } \\
\text { mothers with } \\
\text { work } \\
\text { experience }\end{array}$ & $\begin{array}{l}\text { 4. Prime- } \\
\text { aged } \\
\text { unemployed }\end{array}$ & $\begin{array}{l}\text { 5. Prime-aged } \\
\text { long-term } \\
\text { unemployed }\end{array}$ & $\begin{array}{l}\text { 6. Low-educated } \\
\text { inactive young } \\
\text { women without } \\
\text { work experience }\end{array}$ & $\begin{array}{c}\text { 7. Low- } \\
\text { educated } \\
\text { disabled } \\
\text { without work } \\
\text { experience }\end{array}$ \\
\hline Cluster size & $29 \%$ & $28 \%$ & $14 \%$ & $10 \%$ & $9 \%$ & $8 \%$ & $2 \%$ \\
\hline Population & 649,133 & 630,670 & 323,779 & 232,139 & 196,789 & 184,856 & 34,224 \\
\hline \multicolumn{8}{|c|}{ INDICATORS } \\
\hline \multicolumn{8}{|l|}{ Labor market attachment } \\
\hline Unemployed & $1 \%$ & $0 \%$ & $2 \%$ & $64 \%$ & $3 \%$ & $7 \%$ & $0 \%$ \\
\hline Long-term unemployed & $2 \%$ & $0 \%$ & $3 \%$ & $0 \%$ & $70 \%$ & $19 \%$ & $2 \%$ \\
\hline Retired & $1 \%$ & $92 \%$ & $0 \%$ & $4 \%$ & $0 \%$ & $0 \%$ & $1 \%$ \\
\hline Disabled & $91 \%$ & $7 \%$ & $0 \%$ & $0 \%$ & $0 \%$ & $0 \%$ & $80 \%$ \\
\hline Other inactive & $5 \%$ & $1 \%$ & $94 \%$ & $31 \%$ & $27 \%$ & $74 \%$ & $17 \%$ \\
\hline \multicolumn{8}{|c|}{ At least one working adult in householda } \\
\hline No & $57 \%$ & $65 \%$ & $8 \%$ & $54 \%$ & $69 \%$ & $49 \%$ & $61 \%$ \\
\hline Yes & $43 \%$ & $35 \%$ & $92 \%$ & $46 \%$ & $31 \%$ & $51 \%$ & $39 \%$ \\
\hline \multicolumn{8}{|l|}{ Work experience } \\
\hline Never worked & $0 \%$ & $0 \%$ & $0 \%$ & $0 \%$ & $0 \%$ & $82 \%$ & $93 \%$ \\
\hline Less than 2 months in last year & $98 \%$ & $94 \%$ & $86 \%$ & $12 \%$ & $100 \%$ & $18 \%$ & $2 \%$ \\
\hline 2 or more months in last year & $2 \%$ & $6 \%$ & $14 \%$ & $89 \%$ & $0 \%$ & $0 \%$ & $5 \%$ \\
\hline \multicolumn{8}{|l|}{ Self-assessed physical incapacity } \\
\hline Strongly limited & $35 \%$ & $10 \%$ & $1 \%$ & $5 \%$ & $7 \%$ & $2 \%$ & $61 \%$ \\
\hline None/limited & $65 \%$ & $90 \%$ & $99 \%$ & $95 \%$ & $93 \%$ & $98 \%$ & $39 \%$ \\
\hline \multicolumn{8}{|c|}{ ACTIVE COVARIATES } \\
\hline \multicolumn{8}{|l|}{ Age groups (4) } \\
\hline $16-24$ years & $0 \%$ & $0 \%$ & $10 \%$ & $21 \%$ & $7 \%$ & $58 \%$ & $18 \%$ \\
\hline $25-34$ years & $2 \%$ & $0 \%$ & $60 \%$ & $30 \%$ & $21 \%$ & $35 \%$ & $43 \%$ \\
\hline $35-59$ years & $85 \%$ & $30 \%$ & $29 \%$ & $49 \%$ & $72 \%$ & $6 \%$ & $35 \%$ \\
\hline
\end{tabular}




\begin{tabular}{|c|c|c|c|c|c|c|c|}
\hline & $\begin{array}{c}\text { 1. Disabled } \\
\text { with } \\
\text { previous } \\
\text { work } \\
\text { experience }\end{array}$ & $\begin{array}{l}\text { 2. Early } \\
\text { retirees } \\
\text { and } \\
\text { retirees }\end{array}$ & $\begin{array}{l}\text { 3. Prime-aged } \\
\text { inactive } \\
\text { mothers with } \\
\text { work } \\
\text { experience }\end{array}$ & $\begin{array}{l}\text { 4. Prime- } \\
\text { aged } \\
\text { unemployed }\end{array}$ & $\begin{array}{l}\text { 5. Prime-aged } \\
\text { long-term } \\
\text { unemployed }\end{array}$ & $\begin{array}{l}\text { 6. Low-educated } \\
\text { inactive young } \\
\text { women without } \\
\text { work experience }\end{array}$ & $\begin{array}{c}\text { 7. Low- } \\
\text { educated } \\
\text { disabled } \\
\text { without work } \\
\text { experience }\end{array}$ \\
\hline $60-64$ years & $12 \%$ & $70 \%$ & $0 \%$ & $0 \%$ & $0 \%$ & $0 \%$ & $4 \%$ \\
\hline \multicolumn{8}{|l|}{ Gender } \\
\hline Male & $50 \%$ & $38 \%$ & $3 \%$ & $62 \%$ & $54 \%$ & $31 \%$ & $59 \%$ \\
\hline Female & $50 \%$ & $62 \%$ & $97 \%$ & $38 \%$ & $46 \%$ & $69 \%$ & $41 \%$ \\
\hline \multicolumn{8}{|l|}{ Education (4) } \\
\hline Primary & $38 \%$ & $25 \%$ & $14 \%$ & $32 \%$ & $43 \%$ & $48 \%$ & $77 \%$ \\
\hline Secondary & $58 \%$ & $59 \%$ & $61 \%$ & $57 \%$ & $55 \%$ & $44 \%$ & $19 \%$ \\
\hline Tertiary & $4 \%$ & $17 \%$ & $26 \%$ & $11 \%$ & $2 \%$ & $8 \%$ & $4 \%$ \\
\hline Urban & $41 \%$ & $59 \%$ & $51 \%$ & $39 \%$ & $38 \%$ & $42 \%$ & $37 \%$ \\
\hline Rural & $59 \%$ & $41 \%$ & $49 \%$ & $61 \%$ & $62 \%$ & $58 \%$ & $63 \%$ \\
\hline \multicolumn{8}{|c|}{ INACTIVE COVARIATES } \\
\hline \multicolumn{8}{|l|}{ Age groups (8) } \\
\hline $16-19$ years & $0 \%$ & $0 \%$ & $1 \%$ & $4 \%$ & $1 \%$ & $19 \%$ & $3 \%$ \\
\hline 20-24 years & $0 \%$ & $0 \%$ & $10 \%$ & $17 \%$ & $7 \%$ & $39 \%$ & $15 \%$ \\
\hline $25-29$ years & $1 \%$ & $0 \%$ & $28 \%$ & $14 \%$ & $10 \%$ & $27 \%$ & $17 \%$ \\
\hline 30-34 years & $1 \%$ & $0 \%$ & $32 \%$ & $15 \%$ & $11 \%$ & $9 \%$ & $25 \%$ \\
\hline $35-44$ years & $12 \%$ & $2 \%$ & $20 \%$ & $22 \%$ & $31 \%$ & $4 \%$ & $18 \%$ \\
\hline $45-54$ years & $38 \%$ & $5 \%$ & $7 \%$ & $19 \%$ & $31 \%$ & $1 \%$ & $12 \%$ \\
\hline $55-59$ years & $36 \%$ & $23 \%$ & $2 \%$ & $7 \%$ & $10 \%$ & $1 \%$ & $5 \%$ \\
\hline $60-64$ years & $12 \%$ & $70 \%$ & $0 \%$ & $0 \%$ & $0 \%$ & $0 \%$ & $4 \%$ \\
\hline \multicolumn{8}{|l|}{ Education (6) } \\
\hline Primary & $5 \%$ & $3 \%$ & $1 \%$ & $6 \%$ & $7 \%$ & $10 \%$ & $33 \%$ \\
\hline Lower secondary & $32 \%$ & $22 \%$ & $12 \%$ & $27 \%$ & $36 \%$ & $37 \%$ & $44 \%$ \\
\hline Upper secondary & $55 \%$ & $54 \%$ & $53 \%$ & $53 \%$ & $51 \%$ & $39 \%$ & $18 \%$ \\
\hline Post-secondary & $3 \%$ & $4 \%$ & $7 \%$ & $4 \%$ & $4 \%$ & $5 \%$ & $2 \%$ \\
\hline Tertiary & $4 \%$ & $17 \%$ & $26 \%$ & $11 \%$ & $2 \%$ & $8 \%$ & $4 \%$ \\
\hline
\end{tabular}




\begin{tabular}{|c|c|c|c|c|c|c|c|}
\hline & $\begin{array}{c}\text { 1. Disabled } \\
\text { with } \\
\text { previous } \\
\text { work } \\
\text { experience }\end{array}$ & $\begin{array}{l}\text { 2. Early } \\
\text { retirees } \\
\text { and } \\
\text { retirees }\end{array}$ & $\begin{array}{l}\text { 3. Prime-aged } \\
\text { inactive } \\
\text { mothers with } \\
\text { work } \\
\text { experience }\end{array}$ & $\begin{array}{l}\text { 4. Prime- } \\
\text { aged } \\
\text { unemployed }\end{array}$ & $\begin{array}{l}\text { 5. Prime-aged } \\
\text { long-term } \\
\text { unemployed }\end{array}$ & $\begin{array}{l}\text { 6. Low-educated } \\
\text { inactive young } \\
\text { women without } \\
\text { work experience }\end{array}$ & $\begin{array}{c}\text { 7. Low- } \\
\text { educated } \\
\text { disabled } \\
\text { without work } \\
\text { experience }\end{array}$ \\
\hline \multicolumn{8}{|l|}{ Enrolled in education ${ }^{b}$} \\
\hline Yes & $1 \%$ & $0 \%$ & $7 \%$ & $3 \%$ & $1 \%$ & $14 \%$ & $6 \%$ \\
\hline No & $99 \%$ & $100 \%$ & $93 \%$ & $97 \%$ & $99 \%$ & $86 \%$ & $94 \%$ \\
\hline \multicolumn{8}{|l|}{ Ever worked } \\
\hline No & $0 \%$ & $0 \%$ & $0 \%$ & $0 \%$ & $0 \%$ & $82 \%$ & $93 \%$ \\
\hline Yes & $100 \%$ & $100 \%$ & $100 \%$ & $100 \%$ & $100 \%$ & $18 \%$ & $7 \%$ \\
\hline Years of work experience ${ }^{c}$ & 25 & 36 & 10 & 15 & 16 & 5 & 15 \\
\hline \multicolumn{8}{|l|}{ Partner economic status } \\
\hline Working & $28 \%$ & $15 \%$ & $79 \%$ & $24 \%$ & $21 \%$ & $22 \%$ & $4 \%$ \\
\hline Unemployed & $4 \%$ & $1 \%$ & $2 \%$ & $9 \%$ & $15 \%$ & $10 \%$ & $1 \%$ \\
\hline Retired & $13 \%$ & $39 \%$ & $1 \%$ & $3 \%$ & $3 \%$ & $0 \%$ & $2 \%$ \\
\hline Inactive & $24 \%$ & $15 \%$ & $3 \%$ & $14 \%$ & $19 \%$ & $8 \%$ & $11 \%$ \\
\hline Student/military service & $0 \%$ & $0 \%$ & $0 \%$ & $0 \%$ & $0 \%$ & $2 \%$ & $0 \%$ \\
\hline No partner & $31 \%$ & $31 \%$ & $15 \%$ & $50 \%$ & $41 \%$ & $59 \%$ & $82 \%$ \\
\hline Partner income (mean) & 2657 & 1695 & 7922 & 2972 & 2224 & 2953 & 960 \\
\hline $\begin{array}{l}\text { Working partner income } \\
\text { (mean) }\end{array}$ & 5994 & 6933 & 8506 & 5573 & 5583 & 4962 & 3864 \\
\hline \multicolumn{8}{|l|}{ Partner income quintile } \\
\hline Poorest & $7 \%$ & $4 \%$ & $12 \%$ & $8 \%$ & $5 \%$ & $9 \%$ & $2 \%$ \\
\hline Q2 & $7 \%$ & $2 \%$ & $13 \%$ & $4 \%$ & $6 \%$ & $5 \%$ & $1 \%$ \\
\hline Q3 & $6 \%$ & $3 \%$ & $14 \%$ & $4 \%$ & $4 \%$ & $3 \%$ & $0 \%$ \\
\hline Q4 & $5 \%$ & $2 \%$ & $16 \%$ & $4 \%$ & $3 \%$ & $4 \%$ & $0 \%$ \\
\hline Richest & $3 \%$ & $3 \%$ & $23 \%$ & $4 \%$ & $3 \%$ & $2 \%$ & $0 \%$ \\
\hline $\begin{array}{l}\text { No partner or partner without } \\
\text { income }\end{array}$ & $72 \%$ & $85 \%$ & $21 \%$ & $76 \%$ & $79 \%$ & $78 \%$ & $96 \%$ \\
\hline \multicolumn{8}{|l|}{ Income quintiled $^{d}$} \\
\hline Poorest & $31 \%$ & $12 \%$ & $30 \%$ & $46 \%$ & $70 \%$ & $67 \%$ & $48 \%$ \\
\hline
\end{tabular}




\begin{tabular}{|c|c|c|c|c|c|c|c|}
\hline & $\begin{array}{l}\text { 1. Disabled } \\
\text { with } \\
\text { previous } \\
\text { work } \\
\text { experience }\end{array}$ & $\begin{array}{l}\text { 2. Early } \\
\text { retirees } \\
\text { and } \\
\text { retirees }\end{array}$ & $\begin{array}{l}\text { 3. Prime-aged } \\
\text { inactive } \\
\text { mothers with } \\
\text { work } \\
\text { experience }\end{array}$ & $\begin{array}{l}\text { 4. Prime- } \\
\text { aged } \\
\text { unemployed }\end{array}$ & $\begin{array}{l}\text { 5. Prime-aged } \\
\text { long-term } \\
\text { unemployed }\end{array}$ & $\begin{array}{l}\text { 6. Low-educated } \\
\text { inactive young } \\
\text { women without } \\
\text { work experience }\end{array}$ & $\begin{array}{c}\text { 7. Low- } \\
\text { educated } \\
\text { disabled } \\
\text { without work } \\
\text { experience }\end{array}$ \\
\hline Q2 & $26 \%$ & $19 \%$ & $24 \%$ & $21 \%$ & $17 \%$ & $13 \%$ & $15 \%$ \\
\hline Q3 & $20 \%$ & $23 \%$ & $19 \%$ & $12 \%$ & $8 \%$ & $10 \%$ & $16 \%$ \\
\hline Q4 & $15 \%$ & $22 \%$ & $14 \%$ & $13 \%$ & $3 \%$ & $6 \%$ & $11 \%$ \\
\hline Richest & $9 \%$ & $25 \%$ & $13 \%$ & $7 \%$ & $1 \%$ & $5 \%$ & $10 \%$ \\
\hline \multicolumn{8}{|l|}{ Household income shares ${ }^{e}$} \\
\hline Labor income & $32 \%$ & $25 \%$ & $65 \%$ & $56 \%$ & $31 \%$ & $44 \%$ & $27 \%$ \\
\hline Other income & $1 \%$ & $1 \%$ & $2 \%$ & $2 \%$ & $2 \%$ & $3 \%$ & $2 \%$ \\
\hline Benefits & $67 \%$ & $74 \%$ & $33 \%$ & $42 \%$ & $67 \%$ & $53 \%$ & $71 \%$ \\
\hline Receives at least one benefit & $99 \%$ & $99 \%$ & $92 \%$ & $83 \%$ & $86 \%$ & $82 \%$ & $95 \%$ \\
\hline \multicolumn{8}{|c|}{ Receives benefits at household level } \\
\hline Family child & $25 \%$ & $14 \%$ & $87 \%$ & $52 \%$ & $52 \%$ & $64 \%$ & $56 \%$ \\
\hline Social exclusion & $10 \%$ & $3 \%$ & $10 \%$ & $18 \%$ & $25 \%$ & $25 \%$ & $22 \%$ \\
\hline Housing & $19 \%$ & $9 \%$ & $15 \%$ & $22 \%$ & $33 \%$ & $31 \%$ & $26 \%$ \\
\hline Old age at household level & $33 \%$ & $94 \%$ & $13 \%$ & $22 \%$ & $21 \%$ & $13 \%$ & $36 \%$ \\
\hline \multicolumn{8}{|c|}{ Receives benefits at individual level } \\
\hline Unemployment & $3 \%$ & $1 \%$ & $7 \%$ & $40 \%$ & $45 \%$ & $13 \%$ & $2 \%$ \\
\hline Old age & $10 \%$ & $91 \%$ & $0 \%$ & $2 \%$ & $1 \%$ & $0 \%$ & $4 \%$ \\
\hline Survivor & $5 \%$ & $4 \%$ & $0 \%$ & $1 \%$ & $2 \%$ & $0 \%$ & $0 \%$ \\
\hline Sickness & $1 \%$ & $1 \%$ & $7 \%$ & $9 \%$ & $1 \%$ & $0 \%$ & $3 \%$ \\
\hline Disability & $84 \%$ & $7 \%$ & $2 \%$ & $4 \%$ & $6 \%$ & $2 \%$ & $82 \%$ \\
\hline Education & $0 \%$ & $0 \%$ & $1 \%$ & $0 \%$ & $0 \%$ & $6 \%$ & $0 \%$ \\
\hline \multicolumn{8}{|c|}{ Benefits as share of total gross household income, all households } \\
\hline Family child & $4 \%$ & $2 \%$ & $23 \%$ & $10 \%$ & $16 \%$ & $21 \%$ & $13 \%$ \\
\hline Social exclusion & $1 \%$ & $0 \%$ & $1 \%$ & $3 \%$ & $5 \%$ & $4 \%$ & $3 \%$ \\
\hline Housing & $1 \%$ & $0 \%$ & $0 \%$ & $1 \%$ & $2 \%$ & $1 \%$ & $1 \%$ \\
\hline Unemployment & $2 \%$ & $1 \%$ & $2 \%$ & $10 \%$ & $20 \%$ & $9 \%$ & $3 \%$ \\
\hline
\end{tabular}




\begin{tabular}{|c|c|c|c|c|c|c|c|}
\hline & $\begin{array}{l}\text { 1. Disabled } \\
\text { with } \\
\text { previous } \\
\text { work } \\
\text { experience }\end{array}$ & $\begin{array}{l}\text { 2. Early } \\
\text { retirees } \\
\text { and } \\
\text { retirees }\end{array}$ & $\begin{array}{l}\text { 3. Prime-aged } \\
\text { inactive } \\
\text { mothers with } \\
\text { work } \\
\text { experience }\end{array}$ & $\begin{array}{l}\text { 4. Prime- } \\
\text { aged } \\
\text { unemployed }\end{array}$ & $\begin{array}{l}\text { 5. Prime-aged } \\
\text { long-term } \\
\text { unemployed }\end{array}$ & $\begin{array}{l}\text { 6. Low-educated } \\
\text { inactive young } \\
\text { women without } \\
\text { work experience }\end{array}$ & $\begin{array}{l}\text { 7. Low- } \\
\text { educated } \\
\text { disabled } \\
\text { without work } \\
\text { experience }\end{array}$ \\
\hline Old age & $17 \%$ & $64 \%$ & $4 \%$ & $10 \%$ & $13 \%$ & $7 \%$ & $18 \%$ \\
\hline Survivor & $1 \%$ & $1 \%$ & $0 \%$ & $1 \%$ & $1 \%$ & $1 \%$ & $2 \%$ \\
\hline Sickness & $0 \%$ & $0 \%$ & $1 \%$ & $1 \%$ & $0 \%$ & $0 \%$ & $0 \%$ \\
\hline Disability & $40 \%$ & $6 \%$ & $2 \%$ & $7 \%$ & $10 \%$ & $8 \%$ & $31 \%$ \\
\hline Education & $0 \%$ & $0 \%$ & $0 \%$ & $0 \%$ & $0 \%$ & $2 \%$ & $0 \%$ \\
\hline \multicolumn{8}{|c|}{ Benefits as share of total gross household income, only beneficiaries } \\
\hline Family child & $17 \%$ & $11 \%$ & $26 \%$ & $20 \%$ & $30 \%$ & $32 \%$ & $24 \%$ \\
\hline Social exclusion & $9 \%$ & $6 \%$ & $6 \%$ & $14 \%$ & $21 \%$ & $15 \%$ & $12 \%$ \\
\hline Housing & $4 \%$ & $3 \%$ & $3 \%$ & $4 \%$ & $6 \%$ & $5 \%$ & $5 \%$ \\
\hline Unemployment & $18 \%$ & $15 \%$ & $13 \%$ & $20 \%$ & $37 \%$ & $28 \%$ & $20 \%$ \\
\hline Old age & $52 \%$ & $68 \%$ & $31 \%$ & $44 \%$ & $61 \%$ & $51 \%$ & $50 \%$ \\
\hline Survivor & $23 \%$ & $19 \%$ & $17 \%$ & $20 \%$ & $36 \%$ & $31 \%$ & $21 \%$ \\
\hline Sickness & $4 \%$ & $4 \%$ & $3 \%$ & $5 \%$ & $6 \%$ & $4 \%$ & $3 \%$ \\
\hline Disability & $46 \%$ & $33 \%$ & $23 \%$ & $32 \%$ & $38 \%$ & $31 \%$ & $35 \%$ \\
\hline Education & $4 \%$ & $5 \%$ & $4 \%$ & $8 \%$ & $7 \%$ & $25 \%$ & $24 \%$ \\
\hline Household size (mean) & 2.79 & 2.45 & 4.12 & 3.48 & 3.49 & 4.37 & 3.54 \\
\hline \multicolumn{8}{|l|}{ Household composition } \\
\hline One-person & $12 \%$ & $17 \%$ & $0 \%$ & $6 \%$ & $5 \%$ & $2 \%$ & $4 \%$ \\
\hline Single parent & $2 \%$ & $1 \%$ & $1 \%$ & $4 \%$ & $6 \%$ & $6 \%$ & $3 \%$ \\
\hline $\begin{array}{l}\text { 2+ adults without dependent } \\
\text { children }^{\mathrm{f}}\end{array}$ & $59 \%$ & $69 \%$ & $11 \%$ & $39 \%$ & $39 \%$ & $28 \%$ & $52 \%$ \\
\hline $2+$ adults with 1 dependent childf & $7 \%$ & $4 \%$ & $24 \%$ & $14 \%$ & $12 \%$ & $10 \%$ & $11 \%$ \\
\hline $\begin{array}{l}\text { 2+ adults with } 2+\text { dependent } \\
\text { children }^{f}\end{array}$ & $19 \%$ & $10 \%$ & $63 \%$ & $37 \%$ & $37 \%$ & $55 \%$ & $31 \%$ \\
\hline Children under six & $8 \%$ & $4 \%$ & $72 \%$ & $26 \%$ & $21 \%$ & $40 \%$ & $14 \%$ \\
\hline $\begin{array}{l}\text { Three or more children under } \\
16\end{array}$ & $2 \%$ & $0 \%$ & $15 \%$ & $7 \%$ & $9 \%$ & $14 \%$ & $4 \%$ \\
\hline
\end{tabular}




\begin{tabular}{|c|c|c|c|c|c|c|c|}
\hline & $\begin{array}{l}\text { 1. Disabled } \\
\text { with } \\
\text { previous } \\
\text { work } \\
\text { experience }\end{array}$ & $\begin{array}{l}\text { 2. Early } \\
\text { retirees } \\
\text { and } \\
\text { retirees }\end{array}$ & $\begin{array}{l}\text { 3. Prime-aged } \\
\text { inactive } \\
\text { mothers with } \\
\text { work } \\
\text { experience }\end{array}$ & $\begin{array}{l}\text { 4. Prime- } \\
\text { aged } \\
\text { unemployed }\end{array}$ & $\begin{array}{l}\text { 5. Prime-aged } \\
\text { long-term } \\
\text { unemployed }\end{array}$ & $\begin{array}{l}\text { 6. Low-educated } \\
\text { inactive young } \\
\text { women without } \\
\text { work experience }\end{array}$ & $\begin{array}{l}\text { 7. Low- } \\
\text { educated } \\
\text { disabled } \\
\text { without work } \\
\text { experience }\end{array}$ \\
\hline \multicolumn{8}{|c|}{ Individuals' parents present } \\
\hline One parent & $8 \%$ & $3 \%$ & $9 \%$ & $21 \%$ & $14 \%$ & $20 \%$ & $32 \%$ \\
\hline Both parents & $2 \%$ & $0 \%$ & $9 \%$ & $18 \%$ & $10 \%$ & $33 \%$ & $35 \%$ \\
\hline None & $90 \%$ & $97 \%$ & $82 \%$ & $61 \%$ & $75 \%$ & $46 \%$ & $33 \%$ \\
\hline Elderly present (over 64) & $15 \%$ & $22 \%$ & $8 \%$ & $12 \%$ & $15 \%$ & $9 \%$ & $19 \%$ \\
\hline \multicolumn{8}{|c|}{ Children under 13 in childcare } \\
\hline None of the children & $7 \%$ & $4 \%$ & $23 \%$ & $10 \%$ & $12 \%$ & $17 \%$ & $8 \%$ \\
\hline Some of the children & $4 \%$ & $2 \%$ & $22 \%$ & $11 \%$ & $11 \%$ & $18 \%$ & $6 \%$ \\
\hline $\begin{array}{l}\text { No children under } 13 \text { in } \\
\text { household }\end{array}$ & $83 \%$ & $90 \%$ & $17 \%$ & $57 \%$ & $57 \%$ & $45 \%$ & $77 \%$ \\
\hline All of the children & $7 \%$ & $4 \%$ & $39 \%$ & $22 \%$ & $20 \%$ & $20 \%$ & $9 \%$ \\
\hline \multicolumn{8}{|l|}{ Marital status } \\
\hline Married & $62 \%$ & $66 \%$ & $70 \%$ & $34 \%$ & $49 \%$ & $25 \%$ & $10 \%$ \\
\hline Never married & $12 \%$ & $4 \%$ & $23 \%$ & $48 \%$ & $29 \%$ & $70 \%$ & $84 \%$ \\
\hline Divorced/separated & $15 \%$ & $13 \%$ & $7 \%$ & $15 \%$ & $17 \%$ & $4 \%$ & $4 \%$ \\
\hline Widowed & $10 \%$ & $17 \%$ & $1 \%$ & $3 \%$ & $5 \%$ & $0 \%$ & $1 \%$ \\
\hline \multicolumn{8}{|l|}{ Tenure status } \\
\hline Owner & $91 \%$ & $93 \%$ & $88 \%$ & $87 \%$ & $87 \%$ & $81 \%$ & $92 \%$ \\
\hline Tenant & $2 \%$ & $1 \%$ & $4 \%$ & $3 \%$ & $2 \%$ & $5 \%$ & $3 \%$ \\
\hline Reduced rate & $3 \%$ & $3 \%$ & $2 \%$ & $6 \%$ & $5 \%$ & $8 \%$ & $2 \%$ \\
\hline Free & $4 \%$ & $3 \%$ & $5 \%$ & $4 \%$ & $6 \%$ & $7 \%$ & $4 \%$ \\
\hline \multicolumn{8}{|l|}{ Able to keep dwelling warm } \\
\hline No & $15 \%$ & $10 \%$ & $7 \%$ & $14 \%$ & $20 \%$ & $20 \%$ & $12 \%$ \\
\hline Yes & $85 \%$ & $90 \%$ & $93 \%$ & $86 \%$ & $80 \%$ & $80 \%$ & $88 \%$ \\
\hline NA & $0 \%$ & $0 \%$ & $0 \%$ & $0 \%$ & $0 \%$ & $0 \%$ & $0 \%$ \\
\hline \multicolumn{8}{|l|}{ Degree of urbanization } \\
\hline
\end{tabular}




\begin{tabular}{|c|c|c|c|c|c|c|c|}
\hline & $\begin{array}{c}\text { 1. Disabled } \\
\text { with } \\
\text { previous } \\
\text { work } \\
\text { experience }\end{array}$ & $\begin{array}{l}\text { 2. Early } \\
\text { retirees } \\
\text { and } \\
\text { retirees }\end{array}$ & $\begin{array}{l}\text { 3. Prime-aged } \\
\text { inactive } \\
\text { mothers with } \\
\text { work } \\
\text { experience }\end{array}$ & $\begin{array}{l}\text { 4. Prime- } \\
\text { aged } \\
\text { unemployed }\end{array}$ & $\begin{array}{l}\text { 5. Prime-aged } \\
\text { long-term } \\
\text { unemployed }\end{array}$ & $\begin{array}{l}\text { 6. Low-educated } \\
\text { inactive young } \\
\text { women without } \\
\text { work experience }\end{array}$ & $\begin{array}{c}\text { 7. Low- } \\
\text { educated } \\
\text { disabled } \\
\text { without work } \\
\text { experience }\end{array}$ \\
\hline Densely populated & $20 \%$ & $36 \%$ & $30 \%$ & $19 \%$ & $15 \%$ & $22 \%$ & $19 \%$ \\
\hline Intermediate area & $21 \%$ & $23 \%$ & $21 \%$ & $20 \%$ & $23 \%$ & $20 \%$ & $18 \%$ \\
\hline Sparsely populated & $59 \%$ & $41 \%$ & $49 \%$ & $61 \%$ & $62 \%$ & $58 \%$ & $63 \%$ \\
\hline \multicolumn{8}{|l|}{ Region } \\
\hline HU1 - Central Hungary & $18 \%$ & $31 \%$ & $30 \%$ & $22 \%$ & $16 \%$ & $20 \%$ & $22 \%$ \\
\hline HU2 - Transdanubia & $29 \%$ & $30 \%$ & $28 \%$ & $23 \%$ & $18 \%$ & $22 \%$ & $24 \%$ \\
\hline HU3 - Great Plain and North & $53 \%$ & $39 \%$ & $42 \%$ & $56 \%$ & $66 \%$ & $58 \%$ & $54 \%$ \\
\hline
\end{tabular}

a. Refers to individuals aged 25 and over.

b. Applies to individuals aged 25 and over. Students aged 16 to 24 are not included in the sample.

c. Refers only to individuals who have worked before.

d. Based on total equivalized disposable household income.

e. Based on total gross household income.

f. Dependent children include: 1. household members under 18; 2. household members aged between 18 and 24 who are economically inactive and living with at least one parent.

Source: WB staff calculations based on EU-SILC. 


\begin{tabular}{|c|c|c|c|c|c|c|c|c|c|}
\hline & $\begin{array}{l}\text { All out of } \\
\text { work }\end{array}$ & $\begin{array}{l}\text { 1. Middle- } \\
\text { aged poor } \\
\text { rural long } \\
\text { term } \\
\text { unemployed }\end{array}$ & $\begin{array}{l}\text { 2. Rural } \\
\text { disabled } \\
\text { adults } \\
\text { with } \\
\text { benefits }\end{array}$ & $\begin{array}{l}\text { 3. Married } \\
\text { rural } \\
\text { women with } \\
\text { old age } \\
\text { pensions }\end{array}$ & $\begin{array}{l}\text { 4. Young } \\
\text { educated } \\
\text { rural } \\
\text { unemployed }\end{array}$ & $\begin{array}{l}\text { 5. Middle- } \\
\text { aged } \\
\text { educated } \\
\text { unemployed } \\
\text { family men }\end{array}$ & $\begin{array}{l}\text { 6. Single } \\
\text { poor rural } \\
\text { unemployed } \\
\text { women }\end{array}$ & $\begin{array}{l}\text { 7. Stay- } \\
\text { at-home } \\
\text { poor } \\
\text { rural } \\
\text { women }\end{array}$ & $\begin{array}{l}\text { 8. Disabled } \\
\text { and low- } \\
\text { educated } \\
\text { urban } \\
\text { young men }\end{array}$ \\
\hline Cluster Size & $100 \%$ & $28 \%$ & $19 \%$ & $18 \%$ & $11 \%$ & $9 \%$ & $7 \%$ & $5 \%$ & $3 \%$ \\
\hline Population & 609,134 & 173,299 & 113,969 & 111,715 & 67,187 & 52,446 & 44,345 & 30,639 & 15,472 \\
\hline \multicolumn{10}{|c|}{ INDICATORS } \\
\hline \multicolumn{10}{|c|}{ Labor market attachment } \\
\hline Unemployed & $20 \%$ & $29 \%$ & $1 \%$ & $0 \%$ & $45 \%$ & $44 \%$ & $39 \%$ & $0 \%$ & $0 \%$ \\
\hline $\begin{array}{l}\text { Long-term } \\
\text { unemployed }\end{array}$ & $26 \%$ & $71 \%$ & $8 \%$ & $0 \%$ & $22 \%$ & $22 \%$ & $1 \%$ & $1 \%$ & $0 \%$ \\
\hline Retired & $19 \%$ & $0 \%$ & $0 \%$ & $99 \%$ & $0 \%$ & $15 \%$ & $0 \%$ & $0 \%$ & $0 \%$ \\
\hline Disabled & $20 \%$ & $0 \%$ & $89 \%$ & $1 \%$ & $2 \%$ & $9 \%$ & $0 \%$ & $0 \%$ & $95 \%$ \\
\hline Other inactive & $14 \%$ & $0 \%$ & $1 \%$ & $0 \%$ & $32 \%$ & $10 \%$ & $60 \%$ & $99 \%$ & $5 \%$ \\
\hline \multicolumn{10}{|c|}{ Self-assessed physical incapacity } \\
\hline Strongly limited & $13 \%$ & $2 \%$ & $42 \%$ & $12 \%$ & $0 \%$ & $1 \%$ & $0 \%$ & $0 \%$ & $94 \%$ \\
\hline None/limited & $87 \%$ & $98 \%$ & $58 \%$ & $88 \%$ & $100 \%$ & $99 \%$ & $100 \%$ & $100 \%$ & $6 \%$ \\
\hline \multicolumn{10}{|c|}{ At least one working adult in householda } \\
\hline No & $52 \%$ & $61 \%$ & $67 \%$ & $68 \%$ & $13 \%$ & $2 \%$ & $100 \%$ & $1 \%$ & $40 \%$ \\
\hline Yes & $48 \%$ & $39 \%$ & $33 \%$ & $32 \%$ & $87 \%$ & $98 \%$ & $0 \%$ & $99 \%$ & $60 \%$ \\
\hline \multicolumn{10}{|c|}{ COVARIATES } \\
\hline \multicolumn{10}{|l|}{ Age groups (4) } \\
\hline 16-24 years & $12 \%$ & $11 \%$ & $1 \%$ & $0 \%$ & $53 \%$ & $0 \%$ & $7 \%$ & $16 \%$ & $52 \%$ \\
\hline 25-34 years & $18 \%$ & $24 \%$ & $3 \%$ & $0 \%$ & $47 \%$ & $0 \%$ & $32 \%$ & $40 \%$ & $46 \%$ \\
\hline $35-59$ years & $51 \%$ & $65 \%$ & $85 \%$ & $9 \%$ & $0 \%$ & $99 \%$ & $58 \%$ & $44 \%$ & $0 \%$ \\
\hline 60-64 years & $19 \%$ & $1 \%$ & $11 \%$ & $91 \%$ & $0 \%$ & $1 \%$ & $3 \%$ & $0 \%$ & $1 \%$ \\
\hline \multicolumn{10}{|l|}{ Gender } \\
\hline Male & $48 \%$ & $58 \%$ & $52 \%$ & $32 \%$ & $48 \%$ & $61 \%$ & $38 \%$ & $0 \%$ & $81 \%$ \\
\hline Female & $52 \%$ & $42 \%$ & $48 \%$ & $68 \%$ & $52 \%$ & $39 \%$ & $62 \%$ & $100 \%$ & $19 \%$ \\
\hline
\end{tabular}



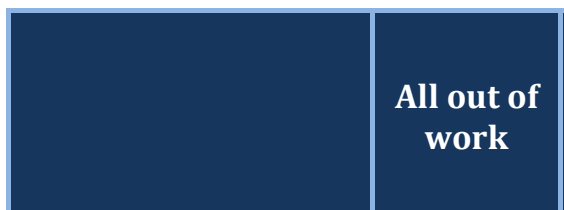

1. Middle-

aged poor

rural long

2. Rural

disabled

adults

term

with

unemployed benefits

\section{Married \\ rural \\ women with \\ old age \\ pensions}

\section{Education}

\begin{tabular}{|l|c|c|c|c|c|c|c|c|c|}
\hline Primary & $23 \%$ & $27 \%$ & $22 \%$ & $29 \%$ & $0 \%$ & $2 \%$ & $35 \%$ & $18 \%$ & $67 \%$ \\
\hline Secondary & $63 \%$ & $67 \%$ & $71 \%$ & $58 \%$ & $44 \%$ & $64 \%$ & $50 \%$ & $78 \%$ & $3 \%$ \\
\hline Tertiary & $14 \%$ & $5 \%$ & $5 \%$ & $13 \%$ & $44 \%$ & $30 \%$ & $11 \%$ & $3 \%$ & $4 \%$ \\
\hline NA & & $1 \%$ & $2 \%$ & $1 \%$ & $12 \%$ & $4 \%$ & $5 \%$ & $1 \%$ & $26 \%$ \\
\hline Urban & $31 \%$ & $34 \%$ & $24 \%$ & $35 \%$ & $37 \%$ & $34 \%$ & $14 \%$ & $17 \%$ & $77 \%$ \\
\hline Rural & $69 \%$ & $66 \%$ & $76 \%$ & $65 \%$ & $63 \%$ & $66 \%$ & $86 \%$ & $83 \%$ & $23 \%$ \\
\end{tabular}

\section{Age groups (8)}

\begin{tabular}{|c|c|c|c|c|c|c|c|c|c|}
\hline $16-19$ years & $2 \%$ & $1 \%$ & $0 \%$ & $0 \%$ & $12 \%$ & $0 \%$ & $1 \%$ & $5 \%$ & $5 \%$ \\
\hline 20-24 years & $10 \%$ & $10 \%$ & $1 \%$ & $0 \%$ & $41 \%$ & $0 \%$ & $6 \%$ & $11 \%$ & $48 \%$ \\
\hline $25-29$ years & $10 \%$ & $12 \%$ & $1 \%$ & $0 \%$ & $29 \%$ & $0 \%$ & $11 \%$ & $31 \%$ & $40 \%$ \\
\hline 30-34 years & $8 \%$ & $12 \%$ & $2 \%$ & $0 \%$ & $18 \%$ & $0 \%$ & $21 \%$ & $9 \%$ & $7 \%$ \\
\hline $35-44$ years & $18 \%$ & $26 \%$ & $22 \%$ & $0 \%$ & $0 \%$ & $38 \%$ & $21 \%$ & $24 \%$ & $0 \%$ \\
\hline $45-54$ years & $20 \%$ & $28 \%$ & $37 \%$ & $0 \%$ & $0 \%$ & $35 \%$ & $25 \%$ & $15 \%$ & $0 \%$ \\
\hline $55-59$ years & $13 \%$ & $11 \%$ & $26 \%$ & $9 \%$ & $0 \%$ & $26 \%$ & $12 \%$ & $5 \%$ & $0 \%$ \\
\hline 60-64 years & $19 \%$ & $1 \%$ & $11 \%$ & $91 \%$ & $0 \%$ & $1 \%$ & $3 \%$ & $0 \%$ & $1 \%$ \\
\hline
\end{tabular}

\section{Education}

\begin{tabular}{|c|c|c|c|c|c|c|c|c|c|}
\hline $\begin{array}{l}\text { None / Less than } \\
\text { primary }\end{array}$ & $1 \%$ & $0 \%$ & $2 \%$ & $0 \%$ & $0 \%$ & $0 \%$ & $0 \%$ & $0 \%$ & $10 \%$ \\
\hline Primary & $3 \%$ & $2 \%$ & $2 \%$ & $2 \%$ & $0 \%$ & $0 \%$ & $5 \%$ & $3 \%$ & $31 \%$ \\
\hline Lower secondary & $19 \%$ & $24 \%$ & $18 \%$ & $26 \%$ & $0 \%$ & $2 \%$ & $30 \%$ & $15 \%$ & $26 \%$ \\
\hline Upper secondary & $39 \%$ & $45 \%$ & $42 \%$ & $28 \%$ & $34 \%$ & $37 \%$ & $32 \%$ & $59 \%$ & $3 \%$ \\
\hline Post-secondary & $24 \%$ & $23 \%$ & $29 \%$ & $30 \%$ & $10 \%$ & $28 \%$ & $18 \%$ & $19 \%$ & $0 \%$ \\
\hline Tertiary & $14 \%$ & $5 \%$ & $5 \%$ & $13 \%$ & $44 \%$ & $30 \%$ & $11 \%$ & $3 \%$ & $4 \%$ \\
\hline NA & & $1 \%$ & $2 \%$ & $1 \%$ & $12 \%$ & $4 \%$ & $5 \%$ & $1 \%$ & $26 \%$ \\
\hline
\end{tabular}




\begin{tabular}{|c|c|c|c|c|c|c|c|c|c|}
\hline & $\begin{array}{l}\text { All out of } \\
\text { work }\end{array}$ & $\begin{array}{l}\text { 1. Middle- } \\
\text { aged poor } \\
\text { rural long } \\
\text { term } \\
\text { unemployed }\end{array}$ & $\begin{array}{l}\text { 2. Rural } \\
\text { disabled } \\
\text { adults } \\
\text { with } \\
\text { benefits }\end{array}$ & $\begin{array}{l}\text { 3. Married } \\
\text { rural } \\
\text { women with } \\
\text { old age } \\
\text { pensions }\end{array}$ & $\begin{array}{l}\text { 4. Young } \\
\text { educated } \\
\text { rural } \\
\text { unemployed }\end{array}$ & $\begin{array}{l}\text { 5. Middle- } \\
\text { aged } \\
\text { educated } \\
\text { unemployed } \\
\text { family men }\end{array}$ & $\begin{array}{l}\text { 6. Single } \\
\text { poor rural } \\
\text { unemployed } \\
\text { women }\end{array}$ & $\begin{array}{l}\text { 7. Stay- } \\
\text { at-home } \\
\text { poor } \\
\text { rural } \\
\text { women }\end{array}$ & $\begin{array}{c}\text { 8. Disabled } \\
\text { and low- } \\
\text { educated } \\
\text { urban } \\
\text { young men }\end{array}$ \\
\hline Yes & $2 \%$ & $1 \%$ & $0 \%$ & $0 \%$ & $9 \%$ & $1 \%$ & $3 \%$ & $8 \%$ & $0 \%$ \\
\hline No & $98 \%$ & $98 \%$ & $100 \%$ & $99 \%$ & $80 \%$ & $95 \%$ & $92 \%$ & $90 \%$ & $97 \%$ \\
\hline NA & & $1 \%$ & $0 \%$ & $1 \%$ & $11 \%$ & $4 \%$ & $5 \%$ & $1 \%$ & $3 \%$ \\
\hline \multicolumn{10}{|l|}{ Marital status } \\
\hline Married & $53 \%$ & $49 \%$ & $50 \%$ & $61 \%$ & $39 \%$ & $87 \%$ & $42 \%$ & $79 \%$ & $4 \%$ \\
\hline Never married & $23 \%$ & $28 \%$ & $21 \%$ & $3 \%$ & $57 \%$ & $3 \%$ & $20 \%$ & $12 \%$ & $96 \%$ \\
\hline Divorced/separated & $15 \%$ & $18 \%$ & $20 \%$ & $15 \%$ & $5 \%$ & $8 \%$ & $31 \%$ & $5 \%$ & $0 \%$ \\
\hline Widowed & $8 \%$ & $6 \%$ & $10 \%$ & $20 \%$ & $0 \%$ & $2 \%$ & $8 \%$ & $3 \%$ & $0 \%$ \\
\hline \multicolumn{10}{|l|}{ Income quintile } \\
\hline Poorest & $38 \%$ & $59 \%$ & $20 \%$ & $32 \%$ & $24 \%$ & $23 \%$ & $68 \%$ & $30 \%$ & $22 \%$ \\
\hline Q2 & $21 \%$ & $21 \%$ & $21 \%$ & $22 \%$ & $19 \%$ & $21 \%$ & $13 \%$ & $33 \%$ & $11 \%$ \\
\hline Q3 & $19 \%$ & $11 \%$ & $24 \%$ & $23 \%$ & $29 \%$ & $18 \%$ & $12 \%$ & $26 \%$ & $8 \%$ \\
\hline Q4 & $14 \%$ & $6 \%$ & $26 \%$ & $14 \%$ & $15 \%$ & $21 \%$ & $5 \%$ & $7 \%$ & $44 \%$ \\
\hline Richest & $8 \%$ & $4 \%$ & $10 \%$ & $10 \%$ & $13 \%$ & $17 \%$ & $2 \%$ & $4 \%$ & $14 \%$ \\
\hline \multicolumn{10}{|c|}{ Partner economic status } \\
\hline Working & $29 \%$ & $27 \%$ & $24 \%$ & $14 \%$ & $34 \%$ & $81 \%$ & $1 \%$ & $75 \%$ & $3 \%$ \\
\hline Unemployed & $8 \%$ & $13 \%$ & $7 \%$ & $3 \%$ & $2 \%$ & $2 \%$ & $25 \%$ & $4 \%$ & $0 \%$ \\
\hline Retired & $10 \%$ & $2 \%$ & $8 \%$ & $39 \%$ & $0 \%$ & $2 \%$ & $1 \%$ & $0 \%$ & $0 \%$ \\
\hline Inactive & $6 \%$ & $6 \%$ & $10 \%$ & $6 \%$ & $0 \%$ & $2 \%$ & $13 \%$ & $1 \%$ & $1 \%$ \\
\hline $\begin{array}{l}\text { Student/military } \\
\text { service }\end{array}$ & $1 \%$ & $1 \%$ & $0 \%$ & $0 \%$ & $2 \%$ & $0 \%$ & $2 \%$ & $0 \%$ & $0 \%$ \\
\hline No partner & $47 \%$ & $52 \%$ & $50 \%$ & $39 \%$ & $62 \%$ & $13 \%$ & $59 \%$ & $21 \%$ & $96 \%$ \\
\hline $\begin{array}{l}\text { Partner income } \\
\text { (mean) }\end{array}$ & 2556 & 3013 & 2610 & 1500 & 4646 & 6035 & 642 & 4378 & 6003 \\
\hline \multicolumn{10}{|c|}{ Partner income quintile } \\
\hline Poorest & $5 \%$ & $5 \%$ & $3 \%$ & $2 \%$ & $9 \%$ & $12 \%$ & $0 \%$ & $19 \%$ & $0 \%$ \\
\hline Q2 & $7 \%$ & $5 \%$ & $8 \%$ & $5 \%$ & $8 \%$ & $16 \%$ & $0 \%$ & $13 \%$ & $0 \%$ \\
\hline
\end{tabular}




\begin{tabular}{|c|c|c|c|c|c|c|c|c|c|}
\hline & $\begin{array}{l}\text { All out of } \\
\text { work }\end{array}$ & $\begin{array}{l}\text { 1. Middle- } \\
\text { aged poor } \\
\text { rural long } \\
\text { term } \\
\text { unemployed }\end{array}$ & $\begin{array}{l}\text { 2. Rural } \\
\text { disabled } \\
\text { adults } \\
\text { with } \\
\text { benefits }\end{array}$ & $\begin{array}{l}\text { 3. Married } \\
\text { rural } \\
\text { women with } \\
\text { old age } \\
\text { pensions }\end{array}$ & $\begin{array}{l}\text { 4. Young } \\
\text { educated } \\
\text { rural } \\
\text { unemployed }\end{array}$ & $\begin{array}{l}\text { 5. Middle- } \\
\text { aged } \\
\text { educated } \\
\text { unemployed } \\
\text { family men }\end{array}$ & $\begin{array}{l}\text { 6. Single } \\
\text { poor rural } \\
\text { unemployed } \\
\text { women }\end{array}$ & $\begin{array}{l}\text { 7. Stay- } \\
\text { at-home } \\
\text { poor } \\
\text { rural } \\
\text { women }\end{array}$ & $\begin{array}{l}\text { 8. Disabled } \\
\text { and low- } \\
\text { educated } \\
\text { urban } \\
\text { young men }\end{array}$ \\
\hline Q3 & $6 \%$ & $7 \%$ & $6 \%$ & $3 \%$ & $2 \%$ & $18 \%$ & $0 \%$ & $18 \%$ & $0 \%$ \\
\hline Q4 & $7 \%$ & $7 \%$ & $6 \%$ & $2 \%$ & $7 \%$ & $20 \%$ & $0 \%$ & $18 \%$ & $2 \%$ \\
\hline Richest & $4 \%$ & $3 \%$ & $2 \%$ & $3 \%$ & $7 \%$ & $16 \%$ & $0 \%$ & $6 \%$ & $1 \%$ \\
\hline $\begin{array}{l}\text { No partner or partner } \\
\text { without income }\end{array}$ & $71 \%$ & $73 \%$ & $76 \%$ & $86 \%$ & $67 \%$ & $19 \%$ & $100 \%$ & $25 \%$ & $97 \%$ \\
\hline $\begin{array}{l}\text { Household size } \\
\text { (mean) }\end{array}$ & 3.10 & 3.07 & 2.51 & 2.39 & 4.20 & 3.73 & 3.03 & 4.47 & 3.35 \\
\hline \multicolumn{10}{|l|}{ Tenure status } \\
\hline Owner & $91 \%$ & $91 \%$ & $92 \%$ & $97 \%$ & $92 \%$ & $93 \%$ & $77 \%$ & $86 \%$ & $62 \%$ \\
\hline Tenant & $1 \%$ & $1 \%$ & $0 \%$ & $0 \%$ & $2 \%$ & $0 \%$ & $2 \%$ & $4 \%$ & $8 \%$ \\
\hline Reduced rate & $2 \%$ & $2 \%$ & $2 \%$ & $2 \%$ & $1 \%$ & $1 \%$ & $2 \%$ & $1 \%$ & $2 \%$ \\
\hline Free & $7 \%$ & $7 \%$ & $6 \%$ & $1 \%$ & $5 \%$ & $5 \%$ & $19 \%$ & $8 \%$ & $29 \%$ \\
\hline \multicolumn{10}{|c|}{ Household composition } \\
\hline One-person & $15 \%$ & $15 \%$ & $22 \%$ & $29 \%$ & $1 \%$ & $0 \%$ & $14 \%$ & $0 \%$ & $22 \%$ \\
\hline Single parent & $4 \%$ & $5 \%$ & $4 \%$ & $0 \%$ & $4 \%$ & $0 \%$ & $18 \%$ & $4 \%$ & $6 \%$ \\
\hline $\begin{array}{l}2+\text { adults without } \\
\text { dependent children }^{\mathrm{d}}\end{array}$ & $41 \%$ & $37 \%$ & $50 \%$ & $54 \%$ & $37 \%$ & $40 \%$ & $31 \%$ & $15 \%$ & $14 \%$ \\
\hline $\begin{array}{l}2+\text { adults with } 1 \\
\text { dependent child }^{\mathrm{d}}\end{array}$ & $11 \%$ & $12 \%$ & $9 \%$ & $2 \%$ & $14 \%$ & $18 \%$ & $13 \%$ & $14 \%$ & $18 \%$ \\
\hline $\begin{array}{l}2+\text { adults with } 2+ \\
\text { dependent children }\end{array}$ & $29 \%$ & $30 \%$ & $15 \%$ & $15 \%$ & $44 \%$ & $41 \%$ & $25 \%$ & $67 \%$ & $41 \%$ \\
\hline \multicolumn{10}{|l|}{ Household income } \\
\hline Labor income & 4189.00 & 3304 & 2662 & 2705 & 7919 & 9211 & 1339 & 7174 & 5117 \\
\hline Other income & 117.00 & 94 & 84 & 98 & 219 & 114 & 220 & 136 & 3 \\
\hline Benefits & 3282.00 & 2250 & 4704 & 3885 & 3224 & 2325 & 2660 & 2583 & 6696 \\
\hline \multicolumn{10}{|c|}{ Household income sharese } \\
\hline Labor income & $41 \%$ & $44 \%$ & $26 \%$ & $23 \%$ & $62 \%$ & $77 \%$ & $27 \%$ & $68 \%$ & $31 \%$ \\
\hline Other income & $3 \%$ & $3 \%$ & $2 \%$ & $2 \%$ & $4 \%$ & $1 \%$ & $9 \%$ & $2 \%$ & $0 \%$ \\
\hline Benefits & $56 \%$ & $53 \%$ & $72 \%$ & $75 \%$ & $33 \%$ & $22 \%$ & $64 \%$ & $30 \%$ & $69 \%$ \\
\hline
\end{tabular}




\begin{tabular}{|c|c|c|c|c|c|c|c|c|c|}
\hline & $\begin{array}{l}\text { All out of } \\
\text { work }\end{array}$ & $\begin{array}{l}\text { 1. Middle- } \\
\text { aged poor } \\
\text { rural long } \\
\text { term } \\
\text { unemployed }\end{array}$ & $\begin{array}{l}\text { 2. Rural } \\
\text { disabled } \\
\text { adults } \\
\text { with } \\
\text { benefits }\end{array}$ & $\begin{array}{l}\text { 3. Married } \\
\text { rural } \\
\text { women with } \\
\text { old age } \\
\text { pensions }\end{array}$ & $\begin{array}{l}\text { 4. Young } \\
\text { educated } \\
\text { rural } \\
\text { unemployed }\end{array}$ & $\begin{array}{l}\text { 5. Middle- } \\
\text { aged } \\
\text { educated } \\
\text { unemployed } \\
\text { family men }\end{array}$ & $\begin{array}{l}\text { 6. Single } \\
\text { poor rural } \\
\text { unemployed } \\
\text { women }\end{array}$ & $\begin{array}{l}\text { 7. Stay- } \\
\text { at-home } \\
\text { poor } \\
\text { rural } \\
\text { women }\end{array}$ & $\begin{array}{c}\text { 8. Disabled } \\
\text { and low- } \\
\text { educated } \\
\text { urban } \\
\text { young men }\end{array}$ \\
\hline Children under six & $18 \%$ & $14 \%$ & $7 \%$ & $11 \%$ & $41 \%$ & $20 \%$ & $23 \%$ & $53 \%$ & $11 \%$ \\
\hline $\begin{array}{l}\text { Three or more } \\
\text { children under } 16\end{array}$ & $5 \%$ & $3 \%$ & $1 \%$ & $1 \%$ & $12 \%$ & $5 \%$ & $10 \%$ & $19 \%$ & $0 \%$ \\
\hline \multicolumn{10}{|c|}{ Children under 13 in childcare } \\
\hline None of the children & $11 \%$ & $9 \%$ & $4 \%$ & $9 \%$ & $19 \%$ & $17 \%$ & $12 \%$ & $27 \%$ & $12 \%$ \\
\hline Some of the children & $7 \%$ & $8 \%$ & $4 \%$ & $1 \%$ & $9 \%$ & $4 \%$ & $18 \%$ & $21 \%$ & $9 \%$ \\
\hline $\begin{array}{l}\text { No children under } 13 \\
\text { in household }\end{array}$ & $69 \%$ & $69 \%$ & $86 \%$ & $86 \%$ & $50 \%$ & $57 \%$ & $53 \%$ & $25 \%$ & $67 \%$ \\
\hline All of the children & $13 \%$ & $14 \%$ & $7 \%$ & $4 \%$ & $23 \%$ & $21 \%$ & $17 \%$ & $27 \%$ & $12 \%$ \\
\hline $\begin{array}{l}\text { Elderly present } \\
\text { (over 64) }\end{array}$ & $18 \%$ & $17 \%$ & $18 \%$ & $21 \%$ & $21 \%$ & $13 \%$ & $18 \%$ & $13 \%$ & $19 \%$ \\
\hline \multicolumn{10}{|l|}{ Ever worked } \\
\hline No & $14 \%$ & $6 \%$ & $12 \%$ & $3 \%$ & $33 \%$ & $2 \%$ & $17 \%$ & $27 \%$ & $93 \%$ \\
\hline Yes & $86 \%$ & $93 \%$ & $88 \%$ & $96 \%$ & $56 \%$ & $94 \%$ & $78 \%$ & $71 \%$ & $4 \%$ \\
\hline NA & & $1 \%$ & $0 \%$ & $0 \%$ & $11 \%$ & $4 \%$ & $5 \%$ & $1 \%$ & $3 \%$ \\
\hline \multicolumn{10}{|c|}{ Able to keep dwelling warm } \\
\hline No & $41 \%$ & $41 \%$ & $40 \%$ & $46 \%$ & $41 \%$ & $37 \%$ & $42 \%$ & $29 \%$ & $48 \%$ \\
\hline Yes & $59 \%$ & $59 \%$ & $60 \%$ & $54 \%$ & $59 \%$ & $63 \%$ & $58 \%$ & $71 \%$ & $52 \%$ \\
\hline \multicolumn{10}{|c|}{ Degree of urbanization } \\
\hline Densely populated & $31 \%$ & $34 \%$ & $24 \%$ & $35 \%$ & $37 \%$ & $34 \%$ & $14 \%$ & $17 \%$ & $77 \%$ \\
\hline Sparsely populated & $69 \%$ & $66 \%$ & $76 \%$ & $65 \%$ & $63 \%$ & $66 \%$ & $86 \%$ & $83 \%$ & $23 \%$ \\
\hline $\begin{array}{l}\text { Receives at least } \\
\text { one benefit }\end{array}$ & $79 \%$ & $69 \%$ & $96 \%$ & $91 \%$ & $67 \%$ & $70 \%$ & $72 \%$ & $81 \%$ & $98 \%$ \\
\hline \multicolumn{10}{|c|}{ Receives benefits at household level } \\
\hline Family child & $32 \%$ & $37 \%$ & $19 \%$ & $9 \%$ & $44 \%$ & $45 \%$ & $48 \%$ & $69 \%$ & $24 \%$ \\
\hline Social exclusion & $31 \%$ & $45 \%$ & $24 \%$ & $10 \%$ & $31 \%$ & $24 \%$ & $53 \%$ & $38 \%$ & $13 \%$ \\
\hline Housing & $4 \%$ & $5 \%$ & $3 \%$ & $2 \%$ & $2 \%$ & $3 \%$ & $7 \%$ & $15 \%$ & $2 \%$ \\
\hline
\end{tabular}




\begin{tabular}{|c|c|c|c|c|c|c|c|c|c|}
\hline & $\begin{array}{l}\text { All out of } \\
\text { work }\end{array}$ & $\begin{array}{l}\text { 1. Middle- } \\
\text { aged poor } \\
\text { rural long } \\
\text { term } \\
\text { unemployed }\end{array}$ & $\begin{array}{l}\text { 2. Rural } \\
\text { disabled } \\
\text { adults } \\
\text { with } \\
\text { benefits }\end{array}$ & $\begin{array}{l}\text { 3. Married } \\
\text { rural } \\
\text { women with } \\
\text { old age } \\
\text { pensions }\end{array}$ & $\begin{array}{l}\text { 4. Young } \\
\text { educated } \\
\text { rural } \\
\text { unemployed }\end{array}$ & $\begin{array}{l}\text { 5. Middle- } \\
\text { aged } \\
\text { educated } \\
\text { unemployed } \\
\text { family men }\end{array}$ & $\begin{array}{l}\text { 6. Single } \\
\text { poor rural } \\
\text { unemployed } \\
\text { women }\end{array}$ & $\begin{array}{l}\text { 7. Stay- } \\
\text { at-home } \\
\text { poor } \\
\text { rural } \\
\text { women }\end{array}$ & $\begin{array}{l}\text { 8. Disabled } \\
\text { and low- } \\
\text { educated } \\
\text { urban } \\
\text { young men }\end{array}$ \\
\hline Unemployment & $10 \%$ & $16 \%$ & $3 \%$ & $8 \%$ & $9 \%$ & $14 \%$ & $14 \%$ & $4 \%$ & $10 \%$ \\
\hline Old age & $16 \%$ & $1 \%$ & $6 \%$ & $77 \%$ & $0 \%$ & $7 \%$ & $1 \%$ & $0 \%$ & $0 \%$ \\
\hline Survivor & $8 \%$ & $5 \%$ & $14 \%$ & $13 \%$ & $3 \%$ & $2 \%$ & $4 \%$ & $5 \%$ & $10 \%$ \\
\hline Sickness & $6 \%$ & $6 \%$ & $5 \%$ & $5 \%$ & $6 \%$ & $9 \%$ & $7 \%$ & $3 \%$ & $0 \%$ \\
\hline Disability & $24 \%$ & $5 \%$ & $84 \%$ & $8 \%$ & $7 \%$ & $17 \%$ & $10 \%$ & $13 \%$ & $81 \%$ \\
\hline Education & $1 \%$ & $0 \%$ & $0 \%$ & $0 \%$ & $9 \%$ & $0 \%$ & $0 \%$ & $0 \%$ & $0 \%$ \\
\hline \multicolumn{10}{|c|}{ Benefits as share of total gross household income, all households } \\
\hline Family child & $4 \%$ & $6 \%$ & $1 \%$ & $1 \%$ & $9 \%$ & $4 \%$ & $7 \%$ & $10 \%$ & $2 \%$ \\
\hline Social exclusion & $8 \%$ & $16 \%$ & $5 \%$ & $1 \%$ & $4 \%$ & $2 \%$ & $25 \%$ & $8 \%$ & $1 \%$ \\
\hline Housing & $0 \%$ & $0 \%$ & $0 \%$ & $0 \%$ & $0 \%$ & $0 \%$ & $0 \%$ & $0 \%$ & $0 \%$ \\
\hline Unemployment & $3 \%$ & $4 \%$ & $1 \%$ & $6 \%$ & $2 \%$ & $2 \%$ & $4 \%$ & $1 \%$ & $1 \%$ \\
\hline Old age & $19 \%$ & $13 \%$ & $11 \%$ & $55 \%$ & $8 \%$ & $6 \%$ & $12 \%$ & $4 \%$ & $7 \%$ \\
\hline Survivor & $2 \%$ & $4 \%$ & $3 \%$ & $1 \%$ & $1 \%$ & $0 \%$ & $4 \%$ & $1 \%$ & $1 \%$ \\
\hline Sickness & $1 \%$ & $1 \%$ & $1 \%$ & $1 \%$ & $1 \%$ & $1 \%$ & $1 \%$ & $1 \%$ & $1 \%$ \\
\hline Disability & $16 \%$ & $8 \%$ & $49 \%$ & $6 \%$ & $5 \%$ & $5 \%$ & $11 \%$ & $5 \%$ & $56 \%$ \\
\hline Education & $1 \%$ & $0 \%$ & $0 \%$ & $3 \%$ & $4 \%$ & $0 \%$ & $0 \%$ & $0 \%$ & $0 \%$ \\
\hline \multicolumn{10}{|c|}{ Benefits as share of total gross household income, only beneficiaries } \\
\hline Family child & $13 \%$ & $14 \%$ & $6 \%$ & $10 \%$ & $21 \%$ & $8 \%$ & $14 \%$ & $14 \%$ & $7 \%$ \\
\hline Social exclusion & $27 \%$ & $34 \%$ & $20 \%$ & $14 \%$ & $12 \%$ & $10 \%$ & $46 \%$ & $22 \%$ & $8 \%$ \\
\hline Housing & $4 \%$ & $5 \%$ & $3 \%$ & $5 \%$ & $3 \%$ & $2 \%$ & $4 \%$ & $1 \%$ & $2 \%$ \\
\hline Unemployment & $22 \%$ & $21 \%$ & $16 \%$ & $44 \%$ & $14 \%$ & $14 \%$ & $26 \%$ & $10 \%$ & $5 \%$ \\
\hline Old age & $52 \%$ & $57 \%$ & $38 \%$ & $64 \%$ & $30 \%$ & $26 \%$ & $59 \%$ & $23 \%$ & $33 \%$ \\
\hline Survivor & $13 \%$ & $19 \%$ & $13 \%$ & $7 \%$ & $5 \%$ & $4 \%$ & $18 \%$ & $6 \%$ & $6 \%$ \\
\hline Sickness & $5 \%$ & $5 \%$ & $5 \%$ & $9 \%$ & $3 \%$ & $4 \%$ & $8 \%$ & $5 \%$ & $2 \%$ \\
\hline Disability & $43 \%$ & $39 \%$ & $55 \%$ & $32 \%$ & $17 \%$ & $19 \%$ & $45 \%$ & $15 \%$ & $68 \%$ \\
\hline Education & $24 \%$ & $8 \%$ & $12 \%$ & $60 \%$ & $34 \%$ & $9 \%$ & $6 \%$ & $2 \%$ & $0 \%$ \\
\hline
\end{tabular}


a. Refers to individuals aged 25 and over.

b. Applies to individuals aged 25 and over. Students aged 16 to 24 are not included in the sample.

c. Based on total equivalized disposable household income.

d. Dependent children include: 1. household members under 18; 2. household members aged between 18 and 24 who are economically inactive and living with at least one parent. e. Based on total gross household income.

Source: WB staff calculations based on EU-SILC. 


\begin{tabular}{|c|c|c|c|c|c|c|c|c|}
\hline & $\begin{array}{l}\text { 1. Middle- } \\
\text { aged } \\
\text { educated } \\
\text { unemployed } \\
\text { family men }\end{array}$ & $\begin{array}{c}\text { 2. Rural } \\
\text { disabled } \\
\text { adults } \\
\text { with } \\
\text { benefits }\end{array}$ & $\begin{array}{c}\text { 3. Married } \\
\text { rural women } \\
\text { with old age } \\
\text { pensions }\end{array}$ & $\begin{array}{l}\text { 4. Single } \\
\text { poor rural } \\
\text { unemployed } \\
\text { women }\end{array}$ & $\begin{array}{c}5 . \\
\text { Unemployed } \\
\text { urban young } \\
\text { women }\end{array}$ & $\begin{array}{l}\text { 6. Stay-at-home } \\
\text { (or } \\
\text { unemployed) } \\
\text { rural married- } \\
\text { with-kids young } \\
\text { women } \\
\end{array}$ & $\begin{array}{c}\text { 7. Middle-aged } \\
\text { poor rural long } \\
\text { term } \\
\text { unemployed }\end{array}$ & $\begin{array}{c}\text { 8. Stay-at- } \\
\text { home low } \\
\text { income } \\
\text { young } \\
\text { women with } \\
\text { children }\end{array}$ \\
\hline Cluster Size & $28 \%$ & $17 \%$ & $17 \%$ & $14 \%$ & $8 \%$ & $6 \%$ & $5 \%$ & $4 \%$ \\
\hline Population & 159,938 & 98,261 & 95,075 & 81,989 & 48,306 & 34,081 & 30,781 & 20,654 \\
\hline \multicolumn{9}{|c|}{ INDICATORS } \\
\hline \multicolumn{9}{|c|}{ Labor market attachment } \\
\hline Unemployed & $70 \%$ & $2 \%$ & $0 \%$ & $12 \%$ & $80 \%$ & $0 \%$ & $39 \%$ & $0 \%$ \\
\hline $\begin{array}{l}\text { Long-term } \\
\text { unemployed }\end{array}$ & $24 \%$ & $2 \%$ & $0 \%$ & $6 \%$ & $9 \%$ & $0 \%$ & $60 \%$ & $1 \%$ \\
\hline Retired & $0 \%$ & $0 \%$ & $98 \%$ & $8 \%$ & $2 \%$ & $0 \%$ & $0 \%$ & $0 \%$ \\
\hline Disabled & $4 \%$ & $96 \%$ & $2 \%$ & $27 \%$ & $0 \%$ & $1 \%$ & $1 \%$ & $0 \%$ \\
\hline Other inactive & $2 \%$ & $0 \%$ & $0 \%$ & $48 \%$ & $9 \%$ & $99 \%$ & $0 \%$ & $98 \%$ \\
\hline \multicolumn{9}{|c|}{ Self-assessed physical incapacity } \\
\hline Strongly limited & $1 \%$ & $57 \%$ & $17 \%$ & $3 \%$ & $0 \%$ & $0 \%$ & $0 \%$ & $0 \%$ \\
\hline None/limited & $99 \%$ & $43 \%$ & $83 \%$ & $97 \%$ & $100 \%$ & $100 \%$ & $100 \%$ & $100 \%$ \\
\hline \multicolumn{9}{|c|}{ At least one working adult in household ${ }^{a}$} \\
\hline No & $39 \%$ & $60 \%$ & $74 \%$ & $61 \%$ & $35 \%$ & $12 \%$ & $67 \%$ & $26 \%$ \\
\hline Yes & $61 \%$ & $40 \%$ & $26 \%$ & $39 \%$ & $65 \%$ & $88 \%$ & $33 \%$ & $74 \%$ \\
\hline \multicolumn{9}{|c|}{ COVARIATES } \\
\hline \multicolumn{9}{|l|}{ Age groups (4) } \\
\hline 16-24 years & $24 \%$ & $4 \%$ & $0 \%$ & $2 \%$ & $25 \%$ & $3 \%$ & $0 \%$ & $98 \%$ \\
\hline $25-34$ years & $23 \%$ & $7 \%$ & $0 \%$ & $13 \%$ & $34 \%$ & $64 \%$ & $46 \%$ & $1 \%$ \\
\hline $35-59$ years & $52 \%$ & $80 \%$ & $3 \%$ & $85 \%$ & $40 \%$ & $31 \%$ & $51 \%$ & $1 \%$ \\
\hline 60-64 years & $1 \%$ & $9 \%$ & $97 \%$ & $1 \%$ & $1 \%$ & $2 \%$ & $3 \%$ & $0 \%$ \\
\hline \multicolumn{9}{|l|}{ Gender } \\
\hline Male & $65 \%$ & $61 \%$ & $30 \%$ & $26 \%$ & $36 \%$ & $14 \%$ & $86 \%$ & $27 \%$ \\
\hline
\end{tabular}




\begin{tabular}{|c|c|c|c|c|c|c|c|c|}
\hline & $\begin{array}{l}\text { 1. Middle- } \\
\text { aged } \\
\text { educated } \\
\text { unemployed } \\
\text { family men }\end{array}$ & $\begin{array}{l}\text { 2. Rural } \\
\text { disabled } \\
\text { adults } \\
\text { with } \\
\text { benefits }\end{array}$ & $\begin{array}{l}\text { 3. Married } \\
\text { rural women } \\
\text { with old age } \\
\text { pensions }\end{array}$ & $\begin{array}{l}\text { 4. Single } \\
\text { poor rural } \\
\text { unemployed } \\
\text { women }\end{array}$ & $\begin{array}{c}5 . \\
\text { Unemployed } \\
\text { urban young } \\
\text { women }\end{array}$ & $\begin{array}{l}\text { 6. Stay-at-home } \\
\text { (or } \\
\text { unemployed) } \\
\text { rural married- } \\
\text { with-kids young } \\
\text { women }\end{array}$ & $\begin{array}{l}\text { 7. Middle-aged } \\
\text { poor rural long } \\
\text { term } \\
\text { unemployed }\end{array}$ & $\begin{array}{l}\text { 8. Stay-at- } \\
\text { home low } \\
\text { income } \\
\text { young } \\
\text { women with } \\
\text { children }\end{array}$ \\
\hline Female & $35 \%$ & $39 \%$ & $70 \%$ & $74 \%$ & $64 \%$ & $86 \%$ & $14 \%$ & $73 \%$ \\
\hline \multicolumn{9}{|l|}{ Education } \\
\hline Primary & $9 \%$ & $27 \%$ & $38 \%$ & $39 \%$ & $0 \%$ & $13 \%$ & $91 \%$ & $42 \%$ \\
\hline Secondary & $91 \%$ & $59 \%$ & $48 \%$ & $61 \%$ & $0 \%$ & $58 \%$ & $0 \%$ & $58 \%$ \\
\hline Tertiary & $0 \%$ & $6 \%$ & $14 \%$ & $0 \%$ & $100 \%$ & $26 \%$ & $9 \%$ & $0 \%$ \\
\hline NA & $0 \%$ & $7 \%$ & $1 \%$ & $0 \%$ & $0 \%$ & $2 \%$ & $0 \%$ & $0 \%$ \\
\hline Urban & $42 \%$ & $38 \%$ & $40 \%$ & $6 \%$ & $64 \%$ & $35 \%$ & $34 \%$ & $54 \%$ \\
\hline Rural & $58 \%$ & $62 \%$ & $60 \%$ & $94 \%$ & $36 \%$ & $65 \%$ & $66 \%$ & $46 \%$ \\
\hline \multicolumn{9}{|c|}{ INACTIVE COVARIATES } \\
\hline \multicolumn{9}{|l|}{ Age groups (8) } \\
\hline 16-19 years & $5 \%$ & $0 \%$ & $0 \%$ & $0 \%$ & $0 \%$ & $0 \%$ & $0 \%$ & $20 \%$ \\
\hline 20-24 years & $18 \%$ & $4 \%$ & $0 \%$ & $1 \%$ & $25 \%$ & $3 \%$ & $0 \%$ & $77 \%$ \\
\hline 25-29 years & $10 \%$ & $3 \%$ & $0 \%$ & $3 \%$ & $22 \%$ & $36 \%$ & $15 \%$ & $1 \%$ \\
\hline 30-34 years & $14 \%$ & $4 \%$ & $0 \%$ & $9 \%$ & $12 \%$ & $28 \%$ & $32 \%$ & $0 \%$ \\
\hline $35-44$ years & $23 \%$ & $22 \%$ & $0 \%$ & $27 \%$ & $23 \%$ & $18 \%$ & $20 \%$ & $0 \%$ \\
\hline 45-54 years & $21 \%$ & $32 \%$ & $0 \%$ & $32 \%$ & $9 \%$ & $8 \%$ & $15 \%$ & $0 \%$ \\
\hline 55-59 years & $9 \%$ & $26 \%$ & $2 \%$ & $26 \%$ & $8 \%$ & $5 \%$ & $15 \%$ & $0 \%$ \\
\hline 60-64 years & $1 \%$ & $9 \%$ & $97 \%$ & $1 \%$ & $1 \%$ & $2 \%$ & $3 \%$ & $0 \%$ \\
\hline \multicolumn{9}{|l|}{ Education } \\
\hline $\begin{array}{l}\text { None / Less than } \\
\text { primary }\end{array}$ & $0 \%$ & $2 \%$ & $1 \%$ & $1 \%$ & $0 \%$ & $0 \%$ & $0 \%$ & $0 \%$ \\
\hline Primary & $1 \%$ & $3 \%$ & $8 \%$ & $2 \%$ & $0 \%$ & $0 \%$ & $8 \%$ & $1 \%$ \\
\hline Lower secondary & $9 \%$ & $22 \%$ & $29 \%$ & $36 \%$ & $0 \%$ & $13 \%$ & $83 \%$ & $42 \%$ \\
\hline Upper secondary & $58 \%$ & $35 \%$ & $26 \%$ & $33 \%$ & $0 \%$ & $40 \%$ & $0 \%$ & $54 \%$ \\
\hline Post-secondary & $33 \%$ & $24 \%$ & $21 \%$ & $28 \%$ & $0 \%$ & $18 \%$ & $0 \%$ & $4 \%$ \\
\hline Tertiary & $0 \%$ & $6 \%$ & $14 \%$ & $0 \%$ & $100 \%$ & $26 \%$ & $9 \%$ & $0 \%$ \\
\hline
\end{tabular}




\begin{tabular}{|c|c|c|c|c|c|c|c|c|}
\hline & $\begin{array}{l}\text { 1. Middle- } \\
\text { aged } \\
\text { educated } \\
\text { unemployed } \\
\text { family men }\end{array}$ & $\begin{array}{l}\text { 2. Rural } \\
\text { disabled } \\
\text { adults } \\
\text { with } \\
\text { benefits }\end{array}$ & $\begin{array}{l}\text { 3. Married } \\
\text { rural women } \\
\text { with old age } \\
\text { pensions }\end{array}$ & $\begin{array}{l}\text { 4. Single } \\
\text { poor rural } \\
\text { unemployed } \\
\text { women }\end{array}$ & $\begin{array}{c}5 . \\
\text { Unemployed } \\
\text { urban young } \\
\text { women }\end{array}$ & $\begin{array}{l}\text { 6. Stay-at-home } \\
\text { (or } \\
\text { unemployed) } \\
\text { rural married- } \\
\text { with-kids young } \\
\text { women }\end{array}$ & $\begin{array}{l}\text { 7. Middle-aged } \\
\text { poor rural long } \\
\text { term } \\
\text { unemployed }\end{array}$ & $\begin{array}{l}\text { 8. Stay-at- } \\
\text { home low } \\
\text { income } \\
\text { young } \\
\text { women with } \\
\text { children }\end{array}$ \\
\hline NA & $0 \%$ & $7 \%$ & $1 \%$ & $0 \%$ & $0 \%$ & $2 \%$ & $0 \%$ & $0 \%$ \\
\hline \multicolumn{9}{|c|}{ Enrolled in education $b$} \\
\hline Yes & $0 \%$ & $0 \%$ & $0 \%$ & $0 \%$ & $4 \%$ & $15 \%$ & $0 \%$ & $0 \%$ \\
\hline No & $100 \%$ & $100 \%$ & $100 \%$ & $100 \%$ & $96 \%$ & $83 \%$ & $99 \%$ & $100 \%$ \\
\hline NA & $0 \%$ & $0 \%$ & $0 \%$ & $0 \%$ & $0 \%$ & $2 \%$ & $0 \%$ & $0 \%$ \\
\hline \multicolumn{9}{|l|}{ Marital status } \\
\hline Married & $59 \%$ & $51 \%$ & $56 \%$ & $60 \%$ & $54 \%$ & $69 \%$ & $41 \%$ & $44 \%$ \\
\hline Never married & $29 \%$ & $24 \%$ & $4 \%$ & $16 \%$ & $34 \%$ & $21 \%$ & $39 \%$ & $49 \%$ \\
\hline Divorced/separated & $10 \%$ & $17 \%$ & $15 \%$ & $15 \%$ & $8 \%$ & $9 \%$ & $12 \%$ & $7 \%$ \\
\hline Widowed & $2 \%$ & $7 \%$ & $25 \%$ & $8 \%$ & $4 \%$ & $0 \%$ & $7 \%$ & $0 \%$ \\
\hline \multicolumn{9}{|l|}{ Income quintilec } \\
\hline Poorest & $32 \%$ & $39 \%$ & $34 \%$ & $54 \%$ & $19 \%$ & $30 \%$ & $62 \%$ & $37 \%$ \\
\hline Q2 & $21 \%$ & $28 \%$ & $27 \%$ & $23 \%$ & $9 \%$ & $26 \%$ & $17 \%$ & $27 \%$ \\
\hline Q3 & $18 \%$ & $19 \%$ & $19 \%$ & $12 \%$ & $19 \%$ & $19 \%$ & $13 \%$ & $16 \%$ \\
\hline Q4 & $17 \%$ & $11 \%$ & $11 \%$ & $9 \%$ & $32 \%$ & $10 \%$ & $7 \%$ & $19 \%$ \\
\hline Richest & $11 \%$ & $3 \%$ & $9 \%$ & $2 \%$ & $21 \%$ & $15 \%$ & $2 \%$ & $1 \%$ \\
\hline \multicolumn{9}{|c|}{ Partner economic status } \\
\hline Working & $39 \%$ & $29 \%$ & $13 \%$ & $30 \%$ & $35 \%$ & $58 \%$ & $16 \%$ & $35 \%$ \\
\hline Unemployed & $10 \%$ & $7 \%$ & $3 \%$ & $11 \%$ & $17 \%$ & $9 \%$ & $9 \%$ & $9 \%$ \\
\hline Retired & $2 \%$ & $6 \%$ & $34 \%$ & $6 \%$ & $1 \%$ & $1 \%$ & $4 \%$ & $0 \%$ \\
\hline Inactive & $8 \%$ & $10 \%$ & $5 \%$ & $13 \%$ & $0 \%$ & $1 \%$ & $12 \%$ & $0 \%$ \\
\hline $\begin{array}{l}\text { Student/military } \\
\text { service }\end{array}$ & $1 \%$ & $0 \%$ & $0 \%$ & $0 \%$ & $0 \%$ & $0 \%$ & $0 \%$ & $0 \%$ \\
\hline No partner & $41 \%$ & $49 \%$ & $44 \%$ & $40 \%$ & $46 \%$ & $31 \%$ & $59 \%$ & $56 \%$ \\
\hline $\begin{array}{l}\text { Partner income } \\
\text { (mean) }\end{array}$ & 4606 & 3471 & 2774 & 3953 & 7572 & 9809 & 2968 & 8566 \\
\hline
\end{tabular}




\begin{tabular}{|c|c|c|c|c|c|c|c|c|}
\hline & $\begin{array}{l}\text { 1. Middle- } \\
\text { aged } \\
\text { educated } \\
\text { unemployed } \\
\text { family men }\end{array}$ & $\begin{array}{l}\text { 2. Rural } \\
\text { disabled } \\
\text { adults } \\
\text { with } \\
\text { benefits }\end{array}$ & $\begin{array}{l}\text { 3. Married } \\
\text { rural women } \\
\text { with old age } \\
\text { pensions }\end{array}$ & $\begin{array}{l}\text { 4. Single } \\
\text { poor rural } \\
\text { unemployed } \\
\text { women }\end{array}$ & $\begin{array}{c}5 . \\
\text { Unemployed } \\
\text { urban young } \\
\text { women }\end{array}$ & $\begin{array}{l}\text { 6. Stay-at-home } \\
\text { (or } \\
\text { unemployed) } \\
\text { rural married- } \\
\text { with-kids young } \\
\text { women }\end{array}$ & $\begin{array}{l}\text { 7. Middle-aged } \\
\text { poor rural long } \\
\text { term } \\
\text { unemployed }\end{array}$ & $\begin{array}{l}\text { 8. Stay-at- } \\
\text { home low } \\
\text { income } \\
\text { young } \\
\text { women with } \\
\text { children }\end{array}$ \\
\hline \multicolumn{9}{|c|}{ Partner income quintile } \\
\hline Poorest & $6 \%$ & $8 \%$ & $2 \%$ & $6 \%$ & $3 \%$ & $14 \%$ & $4 \%$ & $0 \%$ \\
\hline Q2 & $9 \%$ & $9 \%$ & $3 \%$ & $8 \%$ & $2 \%$ & $4 \%$ & $5 \%$ & $7 \%$ \\
\hline Q3 & $11 \%$ & $5 \%$ & $3 \%$ & $5 \%$ & $7 \%$ & $15 \%$ & $5 \%$ & $14 \%$ \\
\hline Q4 & $7 \%$ & $4 \%$ & $2 \%$ & $6 \%$ & $16 \%$ & $8 \%$ & $1 \%$ & $0 \%$ \\
\hline Richest & $5 \%$ & $3 \%$ & $3 \%$ & $6 \%$ & $8 \%$ & $16 \%$ & $1 \%$ & $13 \%$ \\
\hline $\begin{array}{l}\text { No partner or } \\
\text { partner without } \\
\text { income }\end{array}$ & $61 \%$ & $71 \%$ & $87 \%$ & $70 \%$ & $65 \%$ & $42 \%$ & $84 \%$ & $65 \%$ \\
\hline $\begin{array}{l}\text { Household size } \\
\text { (mean) }\end{array}$ & 3.47 & 2.75 & 2.32 & 3.21 & 3.23 & 3.93 & 2.90 & 4.08 \\
\hline \multicolumn{9}{|l|}{ Tenure status } \\
\hline Owner & $87 \%$ & $87 \%$ & $93 \%$ & $89 \%$ & $88 \%$ & $88 \%$ & $88 \%$ & $81 \%$ \\
\hline Tenant & $1 \%$ & $1 \%$ & $3 \%$ & $1 \%$ & $5 \%$ & $3 \%$ & $0 \%$ & $19 \%$ \\
\hline Reduced rate & $3 \%$ & $6 \%$ & $0 \%$ & $2 \%$ & $1 \%$ & $3 \%$ & $0 \%$ & $0 \%$ \\
\hline Free & $9 \%$ & $6 \%$ & $4 \%$ & $9 \%$ & $7 \%$ & $6 \%$ & $12 \%$ & $0 \%$ \\
\hline \multicolumn{9}{|c|}{ Household composition } \\
\hline One-person & $7 \%$ & $17 \%$ & $26 \%$ & $14 \%$ & $9 \%$ & $0 \%$ & $27 \%$ & $0 \%$ \\
\hline Single parent & $3 \%$ & $3 \%$ & $4 \%$ & $5 \%$ & $4 \%$ & $2 \%$ & $1 \%$ & $3 \%$ \\
\hline $\begin{array}{l}2+\text { adults without } \\
\text { dependent children }\end{array}$ & $40 \%$ & $49 \%$ & $57 \%$ & $36 \%$ & $41 \%$ & $26 \%$ & $36 \%$ & $22 \%$ \\
\hline $\begin{array}{l}\text { 2+ adults with } 1 \\
\text { dependent childd }^{\text {d }}\end{array}$ & $15 \%$ & $11 \%$ & $3 \%$ & $14 \%$ & $19 \%$ & $23 \%$ & $9 \%$ & $16 \%$ \\
\hline $\begin{array}{l}2+\text { adults with } 2+ \\
\text { dependent children }^{\text {d }}\end{array}$ & $35 \%$ & $20 \%$ & $10 \%$ & $30 \%$ & $27 \%$ & $49 \%$ & $27 \%$ & $59 \%$ \\
\hline \multicolumn{9}{|l|}{ Household income } \\
\hline Labor income & 9224 & 3991 & 3868 & 4500 & 13930 & 11000 & 4161 & 8829 \\
\hline Other income & 129 & 215 & 436 & 96 & 145 & 172 & 72 & 76 \\
\hline
\end{tabular}




\begin{tabular}{|c|c|c|c|c|c|c|c|c|}
\hline & $\begin{array}{l}\text { 1. Middle- } \\
\text { aged } \\
\text { educated } \\
\text { unemployed } \\
\text { family men }\end{array}$ & $\begin{array}{l}\text { 2. Rural } \\
\text { disabled } \\
\text { adults } \\
\text { with } \\
\text { benefits }\end{array}$ & $\begin{array}{l}\text { 3. Married } \\
\text { rural women } \\
\text { with old age } \\
\text { pensions }\end{array}$ & $\begin{array}{l}\text { 4. Single } \\
\text { poor rural } \\
\text { unemployed } \\
\text { women }\end{array}$ & $\begin{array}{c}5 . \\
\text { Unemployed } \\
\text { urban young } \\
\text { women }\end{array}$ & $\begin{array}{l}\text { 6. Stay-at-home } \\
\text { (or } \\
\text { unemployed) } \\
\text { rural married- } \\
\text { with-kids young } \\
\text { women }\end{array}$ & $\begin{array}{l}\text { 7. Middle-aged } \\
\text { poor rural long } \\
\text { term } \\
\text { unemployed }\end{array}$ & $\begin{array}{l}\text { 8. Stay-at- } \\
\text { home low } \\
\text { income } \\
\text { young } \\
\text { women with } \\
\text { children } \\
\end{array}$ \\
\hline Benefits & 2054 & 3809 & 4364 & 2459 & 2270 & 2845 & 1891 & 2174 \\
\hline \multicolumn{9}{|c|}{ Household income sharese } \\
\hline Labor income & $75 \%$ & $36 \%$ & $26 \%$ & $52 \%$ & $77 \%$ & $71 \%$ & $55 \%$ & $74 \%$ \\
\hline Other income & $1 \%$ & $2 \%$ & $1 \%$ & $2 \%$ & $5 \%$ & $3 \%$ & $5 \%$ & $1 \%$ \\
\hline Benefits & $24 \%$ & $62 \%$ & $73 \%$ & $46 \%$ & $18 \%$ & $26 \%$ & $39 \%$ & $24 \%$ \\
\hline Children under six & $20 \%$ & $8 \%$ & $5 \%$ & $15 \%$ & $28 \%$ & $46 \%$ & $18 \%$ & $56 \%$ \\
\hline $\begin{array}{l}\text { Three or more } \\
\text { children under } 16\end{array}$ & $5 \%$ & $1 \%$ & $2 \%$ & $7 \%$ & $1 \%$ & $13 \%$ & $6 \%$ & $17 \%$ \\
\hline \multicolumn{9}{|c|}{ Children under 13 in childcare } \\
\hline None of the children & $16 \%$ & $9 \%$ & $4 \%$ & $17 \%$ & $18 \%$ & $24 \%$ & $13 \%$ & $59 \%$ \\
\hline Some of the children & $6 \%$ & $4 \%$ & $3 \%$ & $9 \%$ & $4 \%$ & $27 \%$ & $7 \%$ & $0 \%$ \\
\hline $\begin{array}{l}\text { No children under } \\
13 \text { in household }\end{array}$ & $61 \%$ & $80 \%$ & $87 \%$ & $63 \%$ & $60 \%$ & $38 \%$ & $70 \%$ & $37 \%$ \\
\hline All of the children & $17 \%$ & $8 \%$ & $6 \%$ & $11 \%$ & $18 \%$ & $12 \%$ & $10 \%$ & $4 \%$ \\
\hline $\begin{array}{l}\text { Elderly present } \\
\text { (over 64) }\end{array}$ & $10 \%$ & $17 \%$ & $24 \%$ & $14 \%$ & $16 \%$ & $15 \%$ & $16 \%$ & $5 \%$ \\
\hline \multicolumn{9}{|l|}{ Ever worked } \\
\hline No & $12 \%$ & $20 \%$ & $6 \%$ & $12 \%$ & $19 \%$ & $21 \%$ & $6 \%$ & $57 \%$ \\
\hline Yes & $88 \%$ & $80 \%$ & $94 \%$ & $88 \%$ & $81 \%$ & $77 \%$ & $94 \%$ & $43 \%$ \\
\hline NA & $0 \%$ & $0 \%$ & $0 \%$ & $0 \%$ & $0 \%$ & $2 \%$ & $0 \%$ & $0 \%$ \\
\hline \multicolumn{9}{|c|}{ Able to keep dwelling warm } \\
\hline No & $32 \%$ & $33 \%$ & $27 \%$ & $30 \%$ & $32 \%$ & $23 \%$ & $40 \%$ & $37 \%$ \\
\hline Yes & $68 \%$ & $67 \%$ & $73 \%$ & $70 \%$ & $68 \%$ & $77 \%$ & $60 \%$ & $63 \%$ \\
\hline \multicolumn{9}{|c|}{ Degree of urbanization } \\
\hline Densely populated & $42 \%$ & $38 \%$ & $40 \%$ & $6 \%$ & $64 \%$ & $35 \%$ & $34 \%$ & $54 \%$ \\
\hline Sparsely populated & $58 \%$ & $62 \%$ & $60 \%$ & $94 \%$ & $36 \%$ & $65 \%$ & $66 \%$ & $46 \%$ \\
\hline Receives at least & $66 \%$ & $96 \%$ & $98 \%$ & $72 \%$ & $66 \%$ & $73 \%$ & $49 \%$ & $70 \%$ \\
\hline
\end{tabular}




\begin{tabular}{|c|c|c|c|c|c|c|c|c|}
\hline & $\begin{array}{l}\text { 1. Middle- } \\
\text { aged } \\
\text { educated } \\
\text { unemployed } \\
\text { family men }\end{array}$ & $\begin{array}{l}\text { 2. Rural } \\
\text { disabled } \\
\text { adults } \\
\text { with } \\
\text { benefits }\end{array}$ & $\begin{array}{l}\text { 3. Married } \\
\text { rural women } \\
\text { with old age } \\
\text { pensions }\end{array}$ & $\begin{array}{l}\text { 4. Single } \\
\text { poor rural } \\
\text { unemployed } \\
\text { women }\end{array}$ & $\begin{array}{c}5 . \\
\text { Unemployed } \\
\text { urban young } \\
\text { women }\end{array}$ & $\begin{array}{l}\text { 6. Stay-at-home } \\
\text { (or } \\
\text { unemployed) } \\
\text { rural married- } \\
\text { with-kids young } \\
\text { women }\end{array}$ & $\begin{array}{l}\text { 7. Middle-aged } \\
\text { poor rural long } \\
\text { term } \\
\text { unemployed }\end{array}$ & $\begin{array}{l}\text { 8. Stay-at- } \\
\text { home low } \\
\text { income } \\
\text { young } \\
\text { women with } \\
\text { children }\end{array}$ \\
\hline \multicolumn{9}{|l|}{ one benefit } \\
\hline \multicolumn{9}{|c|}{ Receives benefits at household level } \\
\hline Family child & $36 \%$ & $20 \%$ & $12 \%$ & $32 \%$ & $38 \%$ & $58 \%$ & $26 \%$ & $60 \%$ \\
\hline Social exclusion & $12 \%$ & $12 \%$ & $6 \%$ & $17 \%$ & $3 \%$ & $10 \%$ & $11 \%$ & $15 \%$ \\
\hline Housing & $2 \%$ & $6 \%$ & $6 \%$ & $6 \%$ & $1 \%$ & $2 \%$ & $1 \%$ & $2 \%$ \\
\hline \multicolumn{9}{|c|}{ Receives benefits at individual level } \\
\hline Unemployment & $14 \%$ & $1 \%$ & $5 \%$ & $8 \%$ & $13 \%$ & $1 \%$ & $5 \%$ & $4 \%$ \\
\hline Old age & $1 \%$ & $3 \%$ & $91 \%$ & $2 \%$ & $2 \%$ & $0 \%$ & $1 \%$ & $0 \%$ \\
\hline Survivor & $3 \%$ & $10 \%$ & $2 \%$ & $5 \%$ & $1 \%$ & $1 \%$ & $4 \%$ & $4 \%$ \\
\hline Sickness & $25 \%$ & $4 \%$ & $6 \%$ & $6 \%$ & $21 \%$ & $7 \%$ & $12 \%$ & $6 \%$ \\
\hline Disability & $6 \%$ & $89 \%$ & $8 \%$ & $30 \%$ & $1 \%$ & $9 \%$ & $4 \%$ & $0 \%$ \\
\hline Education & $2 \%$ & $0 \%$ & $0 \%$ & $0 \%$ & $3 \%$ & $3 \%$ & $0 \%$ & $2 \%$ \\
\hline \multicolumn{9}{|c|}{ Benefits as share of total gross household income, all households } \\
\hline Family child & $5 \%$ & $1 \%$ & $2 \%$ & $4 \%$ & $5 \%$ & $10 \%$ & $7 \%$ & $12 \%$ \\
\hline Social exclusion & $2 \%$ & $1 \%$ & $1 \%$ & $6 \%$ & $1 \%$ & $3 \%$ & $2 \%$ & $2 \%$ \\
\hline Housing & $0 \%$ & $0 \%$ & $0 \%$ & $0 \%$ & $0 \%$ & $0 \%$ & $0 \%$ & $0 \%$ \\
\hline Unemployment & $2 \%$ & $1 \%$ & $2 \%$ & $4 \%$ & $2 \%$ & $0 \%$ & $2 \%$ & $1 \%$ \\
\hline Old age & $6 \%$ & $12 \%$ & $59 \%$ & $10 \%$ & $6 \%$ & $7 \%$ & $14 \%$ & $3 \%$ \\
\hline Survivor & $1 \%$ & $2 \%$ & $1 \%$ & $1 \%$ & $1 \%$ & $0 \%$ & $1 \%$ & $1 \%$ \\
\hline Sickness & $2 \%$ & $1 \%$ & $1 \%$ & $1 \%$ & $2 \%$ & $1 \%$ & $2 \%$ & $2 \%$ \\
\hline Disability & $6 \%$ & $44 \%$ & $7 \%$ & $19 \%$ & $1 \%$ & $4 \%$ & $12 \%$ & $3 \%$ \\
\hline Education & $0 \%$ & $0 \%$ & $0 \%$ & $0 \%$ & $0 \%$ & $0 \%$ & $0 \%$ & $0 \%$ \\
\hline \multicolumn{9}{|c|}{ Benefits as share of total gross household income, only beneficiaries } \\
\hline Family child & $13 \%$ & $6 \%$ & $14 \%$ & $14 \%$ & $13 \%$ & $16 \%$ & $21 \%$ & $20 \%$ \\
\hline Social exclusion & $13 \%$ & $7 \%$ & $10 \%$ & $34 \%$ & $22 \%$ & $25 \%$ & $17 \%$ & $14 \%$ \\
\hline
\end{tabular}




\begin{tabular}{|c|c|c|c|c|c|c|c|c|}
\hline & $\begin{array}{l}\text { 1. Middle- } \\
\text { aged } \\
\text { educated } \\
\text { unemployed } \\
\text { family men }\end{array}$ & $\begin{array}{l}\text { 2. Rural } \\
\text { disabled } \\
\text { adults } \\
\text { with } \\
\text { benefits }\end{array}$ & $\begin{array}{l}\text { 3. Married } \\
\text { rural women } \\
\text { with old age } \\
\text { pensions }\end{array}$ & $\begin{array}{l}\text { 4. Single } \\
\text { poor rural } \\
\text { unemployed } \\
\text { women }\end{array}$ & $\begin{array}{c}5 . \\
\text { Unemployed } \\
\text { urban young } \\
\text { women }\end{array}$ & $\begin{array}{l}\text { 6. Stay-at-home } \\
\text { (or } \\
\text { unemployed) } \\
\text { rural married- } \\
\text { with-kids young } \\
\text { women }\end{array}$ & $\begin{array}{l}\text { 7. Middle-aged } \\
\text { poor rural long } \\
\text { term } \\
\text { unemployed }\end{array}$ & $\begin{array}{l}\text { 8. Stay-at- } \\
\text { home low } \\
\text { income } \\
\text { young } \\
\text { women with } \\
\text { children }\end{array}$ \\
\hline Housing & $5 \%$ & $4 \%$ & $4 \%$ & $5 \%$ & $4 \%$ & $7 \%$ & $5 \%$ & $4 \%$ \\
\hline Unemployment & $11 \%$ & $13 \%$ & $37 \%$ & $36 \%$ & $8 \%$ & $25 \%$ & $16 \%$ & $13 \%$ \\
\hline Old age & $38 \%$ & $42 \%$ & $63 \%$ & $49 \%$ & $28 \%$ & $37 \%$ & $45 \%$ & $43 \%$ \\
\hline Survivor & $23 \%$ & $17 \%$ & $19 \%$ & $18 \%$ & $16 \%$ & $7 \%$ & $14 \%$ & $12 \%$ \\
\hline Sickness & $4 \%$ & $5 \%$ & $4 \%$ & $4 \%$ & $4 \%$ & $4 \%$ & $5 \%$ & $6 \%$ \\
\hline Disability & $26 \%$ & $48 \%$ & $36 \%$ & $46 \%$ & $17 \%$ & $22 \%$ & $44 \%$ & $26 \%$ \\
\hline Education & $6 \%$ & $7 \%$ & $11 \%$ & $7 \%$ & $7 \%$ & $4 \%$ & $8 \%$ & $4 \%$ \\
\hline
\end{tabular}

a. Refers to individuals aged 25 and over.

b. Applies to individuals aged 25 and over. Students aged 16 to 24 are not included in the sample.

c. Based on total equivalized disposable household income.

d. Dependent children include: 1. household members under 18; 2. household members aged between 18 and 24 who are economically inactive and living with at least one parent.

e. Based on total gross household income.

Source: WB staff calculations based on EU-SILC. 


\begin{tabular}{|c|c|c|c|c|c|c|c|c|}
\hline & $\begin{array}{c}1 . \\
\text { Married } \\
\text { rural } \\
\text { women } \\
\text { with old } \\
\text { age } \\
\text { pensions }\end{array}$ & $\begin{array}{l}\text { 2. Rural } \\
\text { disabled } \\
\text { adults } \\
\text { with } \\
\text { benefits }\end{array}$ & $\begin{array}{l}\text { 3. Stay-at- } \\
\text { home (or } \\
\text { unemployed) } \\
\text { rural married- } \\
\text { with-kids } \\
\text { young women }\end{array}$ & $\begin{array}{l}\text { 4. Middle- } \\
\text { aged poor } \\
\text { rural long } \\
\text { term } \\
\text { unemployed }\end{array}$ & $\begin{array}{l}\text { 5. Single } \\
\text { poor rural } \\
\text { unemployed } \\
\text { women }\end{array}$ & $\begin{array}{l}\text { 6. Stay-at- } \\
\text { home (or } \\
\text { unemployed) } \\
\text { well-educated } \\
\text { rural married- } \\
\text { with-kids } \\
\text { young women }\end{array}$ & $\begin{array}{l}\text { 7. Middle- } \\
\text { aged } \\
\text { educated } \\
\text { unemployed } \\
\text { family men }\end{array}$ & $\begin{array}{c}\text { 8. Middle-aged } \\
\text { mostly urban } \\
\text { low educated } \\
\text { low income } \\
\text { (mostly long } \\
\text { term) } \\
\text { unemployed } \\
\text { men }\end{array}$ \\
\hline Cluster Size & $25 \%$ & $21 \%$ & $13 \%$ & $11 \%$ & $9 \%$ & $9 \%$ & $8 \%$ & $4 \%$ \\
\hline Population & 111,916 & 96,208 & 59,405 & 51,871 & 41,369 & 41,323 & 36,803 & 17,717 \\
\hline \multicolumn{9}{|c|}{ INDICATORS } \\
\hline \multicolumn{9}{|c|}{ Labor market attachment } \\
\hline Unemployed & $0 \%$ & $0 \%$ & $15 \%$ & $18 \%$ & $36 \%$ & $12 \%$ & $58 \%$ & $21 \%$ \\
\hline Long-term unemployed & $0 \%$ & $0 \%$ & $15 \%$ & $49 \%$ & $0 \%$ & $3 \%$ & $10 \%$ & $66 \%$ \\
\hline Retired & $99 \%$ & $1 \%$ & $0 \%$ & $0 \%$ & $0 \%$ & $0 \%$ & $15 \%$ & $0 \%$ \\
\hline Disabled & $1 \%$ & $95 \%$ & $7 \%$ & $26 \%$ & $0 \%$ & $0 \%$ & $18 \%$ & $1 \%$ \\
\hline Other inactive & $0 \%$ & $4 \%$ & $63 \%$ & $7 \%$ & $64 \%$ & $85 \%$ & $0 \%$ & $13 \%$ \\
\hline \multicolumn{9}{|c|}{ Self-assessed physical incapacity } \\
\hline Strongly limited & $59 \%$ & $49 \%$ & $0 \%$ & $88 \%$ & $96 \%$ & $9 \%$ & $19 \%$ & $0 \%$ \\
\hline None/limited & $41 \%$ & $51 \%$ & $100 \%$ & $12 \%$ & $4 \%$ & $91 \%$ & $81 \%$ & $100 \%$ \\
\hline \multicolumn{9}{|c|}{ At least one working adult in household ${ }^{a}$} \\
\hline No & $13 \%$ & $64 \%$ & $3 \%$ & $10 \%$ & $0 \%$ & $1 \%$ & $1 \%$ & $12 \%$ \\
\hline Yes & $87 \%$ & $36 \%$ & $97 \%$ & $90 \%$ & $100 \%$ & $99 \%$ & $99 \%$ & $88 \%$ \\
\hline \multicolumn{9}{|c|}{ COVARIATES } \\
\hline \multicolumn{9}{|l|}{ Age groups (4) } \\
\hline 16-24 years & $0 \%$ & $5 \%$ & $26 \%$ & $0 \%$ & $16 \%$ & $10 \%$ & $10 \%$ & $17 \%$ \\
\hline 25-34 years & $0 \%$ & $12 \%$ & $16 \%$ & $12 \%$ & $30 \%$ & $79 \%$ & $8 \%$ & $41 \%$ \\
\hline 35-59 years & $8 \%$ & $76 \%$ & $58 \%$ & $78 \%$ & $54 \%$ & $11 \%$ & $80 \%$ & $42 \%$ \\
\hline 60-64 years & $92 \%$ & $6 \%$ & $0 \%$ & $10 \%$ & $0 \%$ & $0 \%$ & $2 \%$ & $0 \%$ \\
\hline Gender & & & & & & & & \\
\hline
\end{tabular}




\begin{tabular}{|c|c|c|c|c|c|c|c|c|}
\hline & $\begin{array}{c}1 . \\
\text { Married } \\
\text { rural } \\
\text { women } \\
\text { with old } \\
\text { age } \\
\text { pensions }\end{array}$ & $\begin{array}{l}\text { 2. Rural } \\
\text { disabled } \\
\text { adults } \\
\text { with } \\
\text { benefits }\end{array}$ & $\begin{array}{l}\text { 3. Stay-at- } \\
\text { home (or } \\
\text { unemployed) } \\
\text { rural married- } \\
\text { with-kids } \\
\text { young women }\end{array}$ & $\begin{array}{l}\text { 4. Middle- } \\
\text { aged poor } \\
\text { rural long } \\
\text { term } \\
\text { unemployed }\end{array}$ & $\begin{array}{l}\text { 5. Single } \\
\text { poor rural } \\
\text { unemployed } \\
\text { women }\end{array}$ & $\begin{array}{l}\text { 6. Stay-at- } \\
\text { home (or } \\
\text { unemployed) } \\
\text { well-educated } \\
\text { rural married- } \\
\text { with-kids } \\
\text { young women }\end{array}$ & $\begin{array}{l}\text { 7. Middle- } \\
\text { aged } \\
\text { educated } \\
\text { unemployed } \\
\text { family men }\end{array}$ & $\begin{array}{c}\text { 8. Middle-aged } \\
\text { mostly urban } \\
\text { low educated } \\
\text { low income } \\
\text { (mostly long } \\
\text { term) } \\
\text { unemployed } \\
\text { men }\end{array}$ \\
\hline Male & $29 \%$ & $49 \%$ & $10 \%$ & $62 \%$ & $48 \%$ & $0 \%$ & $77 \%$ & $100 \%$ \\
\hline Female & $71 \%$ & $51 \%$ & $90 \%$ & $38 \%$ & $52 \%$ & $100 \%$ & $23 \%$ & $0 \%$ \\
\hline \multicolumn{9}{|l|}{ Education } \\
\hline Primary & $38 \%$ & $22 \%$ & $14 \%$ & $30 \%$ & $26 \%$ & $17 \%$ & $0 \%$ & $43 \%$ \\
\hline Secondary & $49 \%$ & $64 \%$ & $86 \%$ & $60 \%$ & $74 \%$ & $30 \%$ & $69 \%$ & $57 \%$ \\
\hline Tertiary & $12 \%$ & $7 \%$ & $0 \%$ & $8 \%$ & $0 \%$ & $52 \%$ & $30 \%$ & $0 \%$ \\
\hline NA & $1 \%$ & $7 \%$ & $0 \%$ & $2 \%$ & $0 \%$ & $1 \%$ & $1 \%$ & $0 \%$ \\
\hline Urban & $36 \%$ & $38 \%$ & $31 \%$ & $19 \%$ & $16 \%$ & $38 \%$ & $58 \%$ & $60 \%$ \\
\hline Rural & $64 \%$ & $62 \%$ & $69 \%$ & $81 \%$ & $84 \%$ & $62 \%$ & $42 \%$ & $40 \%$ \\
\hline \multicolumn{9}{|c|}{ INACTIVE COVARIATES } \\
\hline \multicolumn{9}{|l|}{ Age groups (8) } \\
\hline $16-19$ years & $0 \%$ & $1 \%$ & $7 \%$ & $0 \%$ & $4 \%$ & $0 \%$ & $1 \%$ & $6 \%$ \\
\hline 20-24 years & $0 \%$ & $5 \%$ & $19 \%$ & $0 \%$ & $12 \%$ & $10 \%$ & $9 \%$ & $11 \%$ \\
\hline 25-29 years & $0 \%$ & $5 \%$ & $8 \%$ & $5 \%$ & $17 \%$ & $36 \%$ & $4 \%$ & $20 \%$ \\
\hline 30-34 years & $0 \%$ & $7 \%$ & $8 \%$ & $7 \%$ & $13 \%$ & $43 \%$ & $4 \%$ & $21 \%$ \\
\hline 35-44 years & $0 \%$ & $18 \%$ & $24 \%$ & $26 \%$ & $23 \%$ & $6 \%$ & $30 \%$ & $16 \%$ \\
\hline 45-54 years & $0 \%$ & $32 \%$ & $24 \%$ & $33 \%$ & $22 \%$ & $3 \%$ & $31 \%$ & $22 \%$ \\
\hline 55-59 years & $8 \%$ & $26 \%$ & $10 \%$ & $20 \%$ & $9 \%$ & $2 \%$ & $19 \%$ & $3 \%$ \\
\hline 60-64 years & $92 \%$ & $6 \%$ & $0 \%$ & $10 \%$ & $0 \%$ & $0 \%$ & $2 \%$ & $0 \%$ \\
\hline \multicolumn{9}{|l|}{ Education } \\
\hline $\begin{array}{l}\text { None / Less than } \\
\text { primary }\end{array}$ & $12 \%$ & $4 \%$ & $1 \%$ & $1 \%$ & $0 \%$ & $0 \%$ & $0 \%$ & $6 \%$ \\
\hline Primary & $26 \%$ & $18 \%$ & $13 \%$ & $28 \%$ & $26 \%$ & $17 \%$ & $0 \%$ & $37 \%$ \\
\hline Lower secondary & $24 \%$ & $38 \%$ & $49 \%$ & $37 \%$ & $50 \%$ & $23 \%$ & $36 \%$ & $40 \%$ \\
\hline Upper secondary & $25 \%$ & $26 \%$ & $37 \%$ & $23 \%$ & $24 \%$ & $7 \%$ & $33 \%$ & $17 \%$ \\
\hline
\end{tabular}




\begin{tabular}{|c|c|c|c|c|c|c|c|c|}
\hline & $\begin{array}{c}1 . \\
\text { Married } \\
\text { rural } \\
\text { women } \\
\text { with old } \\
\text { age } \\
\text { pensions }\end{array}$ & $\begin{array}{l}\text { 2. Rural } \\
\text { disabled } \\
\text { adults } \\
\text { with } \\
\text { benefits }\end{array}$ & $\begin{array}{l}\text { 3. Stay-at- } \\
\text { home (or } \\
\text { unemployed) } \\
\text { rural married- } \\
\text { with-kids } \\
\text { young women }\end{array}$ & $\begin{array}{l}\text { 4. Middle- } \\
\text { aged poor } \\
\text { rural long } \\
\text { term } \\
\text { unemployed }\end{array}$ & $\begin{array}{l}\text { 5. Single } \\
\text { poor rural } \\
\text { unemployed } \\
\text { women }\end{array}$ & $\begin{array}{c}\text { 6. Stay-at- } \\
\text { home (or } \\
\text { unemployed) } \\
\text { well-educated } \\
\text { rural married- } \\
\text { with-kids } \\
\text { young women }\end{array}$ & $\begin{array}{l}\text { 7. Middle- } \\
\text { aged } \\
\text { educated } \\
\text { unemployed } \\
\text { family men }\end{array}$ & $\begin{array}{c}\text { 8. Middle-aged } \\
\text { mostly urban } \\
\text { low educated } \\
\text { low income } \\
\text { (mostly long } \\
\text { term) } \\
\text { unemployed } \\
\text { men }\end{array}$ \\
\hline Post-secondary & $12 \%$ & $7 \%$ & $0 \%$ & $8 \%$ & $0 \%$ & $52 \%$ & $30 \%$ & $0 \%$ \\
\hline Tertiary & $1 \%$ & $7 \%$ & $0 \%$ & $2 \%$ & $0 \%$ & $1 \%$ & $1 \%$ & $0 \%$ \\
\hline \multicolumn{9}{|l|}{ Enrolled in education ${ }^{b}$} \\
\hline Yes & $0 \%$ & $0 \%$ & $4 \%$ & $1 \%$ & $4 \%$ & $8 \%$ & $0 \%$ & $2 \%$ \\
\hline No & $100 \%$ & $100 \%$ & $96 \%$ & $99 \%$ & $96 \%$ & $92 \%$ & $99 \%$ & $98 \%$ \\
\hline NA & $0 \%$ & $0 \%$ & $0 \%$ & $0 \%$ & $0 \%$ & $0 \%$ & $1 \%$ & $0 \%$ \\
\hline \multicolumn{9}{|l|}{ Marital status } \\
\hline Married & $64 \%$ & $53 \%$ & $72 \%$ & $39 \%$ & $36 \%$ & $74 \%$ & $70 \%$ & $42 \%$ \\
\hline Never married & $2 \%$ & $25 \%$ & $22 \%$ & $29 \%$ & $34 \%$ & $21 \%$ & $22 \%$ & $54 \%$ \\
\hline Divorced/separated & $10 \%$ & $13 \%$ & $4 \%$ & $24 \%$ & $24 \%$ & $5 \%$ & $7 \%$ & $3 \%$ \\
\hline Widowed & $23 \%$ & $10 \%$ & $2 \%$ & $8 \%$ & $6 \%$ & $0 \%$ & $1 \%$ & $1 \%$ \\
\hline \multicolumn{9}{|l|}{ Income quintilec } \\
\hline Poorest & $25 \%$ & $36 \%$ & $30 \%$ & $71 \%$ & $73 \%$ & $27 \%$ & $17 \%$ & $26 \%$ \\
\hline Q2 & $33 \%$ & $25 \%$ & $21 \%$ & $16 \%$ & $17 \%$ & $18 \%$ & $25 \%$ & $36 \%$ \\
\hline Q3 & $21 \%$ & $19 \%$ & $19 \%$ & $6 \%$ & $6 \%$ & $29 \%$ & $25 \%$ & $20 \%$ \\
\hline Q4 & $11 \%$ & $15 \%$ & $17 \%$ & $6 \%$ & $2 \%$ & $14 \%$ & $19 \%$ & $15 \%$ \\
\hline Richest & $10 \%$ & $6 \%$ & $13 \%$ & $2 \%$ & $2 \%$ & $12 \%$ & $14 \%$ & $3 \%$ \\
\hline \multicolumn{9}{|l|}{ Partner economic status } \\
\hline Working & $21 \%$ & $33 \%$ & $71 \%$ & $9 \%$ & $6 \%$ & $71 \%$ & $61 \%$ & $40 \%$ \\
\hline Unemployed & $1 \%$ & $4 \%$ & $0 \%$ & $9 \%$ & $14 \%$ & $2 \%$ & $2 \%$ & $0 \%$ \\
\hline Retired & $38 \%$ & $6 \%$ & $1 \%$ & $6 \%$ & $1 \%$ & $0 \%$ & $3 \%$ & $0 \%$ \\
\hline Inactive & $4 \%$ & $10 \%$ & $0 \%$ & $16 \%$ & $15 \%$ & $0 \%$ & $4 \%$ & $2 \%$ \\
\hline Student/military service & $0 \%$ & $0 \%$ & $0 \%$ & $0 \%$ & $0 \%$ & $0 \%$ & $0 \%$ & $0 \%$ \\
\hline No partner & $36 \%$ & $47 \%$ & $28 \%$ & $61 \%$ & $64 \%$ & $26 \%$ & $30 \%$ & $58 \%$ \\
\hline
\end{tabular}




\begin{tabular}{|c|c|c|c|c|c|c|c|c|}
\hline & $\begin{array}{c}1 . \\
\text { Married } \\
\text { rural } \\
\text { women } \\
\text { with old } \\
\text { age } \\
\text { pensions }\end{array}$ & $\begin{array}{l}\text { 2. Rural } \\
\text { disabled } \\
\text { adults } \\
\text { with } \\
\text { benefits }\end{array}$ & $\begin{array}{l}\text { 3. Stay-at- } \\
\text { home (or } \\
\text { unemployed) } \\
\text { rural married- } \\
\text { with-kids } \\
\text { young women }\end{array}$ & $\begin{array}{l}\text { 4. Middle- } \\
\text { aged poor } \\
\text { rural long } \\
\text { term } \\
\text { unemployed }\end{array}$ & $\begin{array}{l}\text { 5. Single } \\
\text { poor rural } \\
\text { unemployed } \\
\text { women }\end{array}$ & $\begin{array}{l}\text { 6. Stay-at- } \\
\text { home (or } \\
\text { unemployed) } \\
\text { well-educated } \\
\text { rural married- } \\
\text { with-kids } \\
\text { young women }\end{array}$ & $\begin{array}{l}\text { 7. Middle- } \\
\text { aged } \\
\text { educated } \\
\text { unemployed } \\
\text { family men }\end{array}$ & $\begin{array}{l}\text { 8. Middle-aged } \\
\text { mostly urban } \\
\text { low educated } \\
\text { low income } \\
\text { (mostly long } \\
\text { term) } \\
\text { unemployed } \\
\text { men }\end{array}$ \\
\hline $\begin{array}{l}\text { Partner income } \\
\text { (mean) }\end{array}$ & 2029 & 2925 & 5264 & 1474 & 1436 & 6165 & 4619 & 4047 \\
\hline \multicolumn{9}{|l|}{ Partner income quintile } \\
\hline Poorest & $6 \%$ & $9 \%$ & $12 \%$ & $2 \%$ & $2 \%$ & $10 \%$ & $7 \%$ & $6 \%$ \\
\hline Q2 & $5 \%$ & $8 \%$ & $16 \%$ & $2 \%$ & $1 \%$ & $9 \%$ & $20 \%$ & $13 \%$ \\
\hline Q3 & $3 \%$ & $6 \%$ & $15 \%$ & $1 \%$ & $0 \%$ & $11 \%$ & $12 \%$ & $10 \%$ \\
\hline Q4 & $2 \%$ & $6 \%$ & $15 \%$ & $1 \%$ & $2 \%$ & $19 \%$ & $11 \%$ & $6 \%$ \\
\hline Richest & $5 \%$ & $4 \%$ & $12 \%$ & $2 \%$ & $1 \%$ & $21 \%$ & $11 \%$ & $5 \%$ \\
\hline $\begin{array}{l}\text { No partner or partner } \\
\text { without income }\end{array}$ & $79 \%$ & $67 \%$ & $29 \%$ & $91 \%$ & $94 \%$ & $29 \%$ & $39 \%$ & $60 \%$ \\
\hline Household size (mean) & 2.42 & 3.00 & 3.91 & 2.58 & 3.11 & 4.55 & 3.35 & 4.06 \\
\hline \multicolumn{9}{|l|}{ Tenure status } \\
\hline Owner & $97 \%$ & $95 \%$ & $86 \%$ & $83 \%$ & $82 \%$ & $80 \%$ & $94 \%$ & $96 \%$ \\
\hline Tenant & $0 \%$ & $1 \%$ & $1 \%$ & $1 \%$ & $2 \%$ & $1 \%$ & $0 \%$ & $0 \%$ \\
\hline Reduced rate & $1 \%$ & $1 \%$ & $2 \%$ & $1 \%$ & $2 \%$ & $0 \%$ & $0 \%$ & $0 \%$ \\
\hline Free & $2 \%$ & $4 \%$ & $10 \%$ & $15 \%$ & $14 \%$ & $19 \%$ & $6 \%$ & $4 \%$ \\
\hline \multicolumn{9}{|l|}{ Household composition } \\
\hline One-person & $20 \%$ & $12 \%$ & $0 \%$ & $28 \%$ & $13 \%$ & $1 \%$ & $6 \%$ & $0 \%$ \\
\hline Single parent & $2 \%$ & $5 \%$ & $1 \%$ & $3 \%$ & $16 \%$ & $3 \%$ & $1 \%$ & $1 \%$ \\
\hline $\begin{array}{l}\text { 2+ adults without } \\
\text { dependent children }\end{array}$ & $63 \%$ & $48 \%$ & $25 \%$ & $42 \%$ & $29 \%$ & $13 \%$ & $44 \%$ & $42 \%$ \\
\hline $\begin{array}{l}\text { 2+ adults with } 1 \\
\text { dependent childd }\end{array}$ & $3 \%$ & $10 \%$ & $23 \%$ & $8 \%$ & $16 \%$ & $17 \%$ & $12 \%$ & $12 \%$ \\
\hline $\begin{array}{l}\text { 2+ adults with } 2+ \\
\text { dependent children }\end{array}$ & $13 \%$ & $24 \%$ & $51 \%$ & $19 \%$ & $25 \%$ & $66 \%$ & $37 \%$ & $46 \%$ \\
\hline \multicolumn{9}{|l|}{ Household income } \\
\hline Labor income & 3357 & 3573 & 7556 & 1683 & 1885 & 7200 & 7608 & 6800 \\
\hline
\end{tabular}




\begin{tabular}{|c|c|c|c|c|c|c|c|c|}
\hline & $\begin{array}{c}1 . \\
\text { Married } \\
\text { rural } \\
\text { women } \\
\text { with old } \\
\text { age } \\
\text { pensions }\end{array}$ & $\begin{array}{l}\text { 2. Rural } \\
\text { disabled } \\
\text { adults } \\
\text { with } \\
\text { benefits }\end{array}$ & $\begin{array}{l}\text { 3. Stay-at- } \\
\text { home (or } \\
\text { unemployed) } \\
\text { rural married- } \\
\text { with-kids } \\
\text { young women }\end{array}$ & $\begin{array}{l}\text { 4. Middle- } \\
\text { aged poor } \\
\text { rural long } \\
\text { term } \\
\text { unemployed }\end{array}$ & $\begin{array}{l}\text { 5. Single } \\
\text { poor rural } \\
\text { unemployed } \\
\text { women }\end{array}$ & $\begin{array}{l}\text { 6. Stay-at- } \\
\text { home (or } \\
\text { unemployed) } \\
\text { well-educated } \\
\text { rural married- } \\
\text { with-kids } \\
\text { young women }\end{array}$ & $\begin{array}{l}\text { 7. Middle- } \\
\text { aged } \\
\text { educated } \\
\text { unemployed } \\
\text { family men }\end{array}$ & $\begin{array}{c}\text { 8. Middle-aged } \\
\text { mostly urban } \\
\text { low educated } \\
\text { low income } \\
\text { (mostly long } \\
\text { term) } \\
\text { unemployed } \\
\text { men }\end{array}$ \\
\hline Other income & 57 & 99 & 83 & 151 & 246 & 308 & 73 & 77 \\
\hline Benefits & 2985 & 2684 & 1136 & 1541 & 1302 & 1621 & 1572 & 1274 \\
\hline \multicolumn{9}{|c|}{ Household income shares } \\
\hline Labor income & $33 \%$ & $39 \%$ & $84 \%$ & $34 \%$ & $44 \%$ & $73 \%$ & $76 \%$ & $82 \%$ \\
\hline Other income & $1 \%$ & $2 \%$ & $1 \%$ & $11 \%$ & $8 \%$ & $4 \%$ & $1 \%$ & $1 \%$ \\
\hline Benefits & $66 \%$ & $59 \%$ & $15 \%$ & $55 \%$ & $48 \%$ & $23 \%$ & $23 \%$ & $17 \%$ \\
\hline Children under six & $5 \%$ & $10 \%$ & $27 \%$ & $5 \%$ & $23 \%$ & $62 \%$ & $10 \%$ & $27 \%$ \\
\hline $\begin{array}{l}\text { Three or more } \\
\text { children under } 16\end{array}$ & $1 \%$ & $2 \%$ & $7 \%$ & $4 \%$ & $6 \%$ & $21 \%$ & $2 \%$ & $0 \%$ \\
\hline \multicolumn{9}{|c|}{ Children under 13 in childcare } \\
\hline None of the children & $4 \%$ & $7 \%$ & $24 \%$ & $9 \%$ & $16 \%$ & $29 \%$ & $9 \%$ & $8 \%$ \\
\hline Some of the children & $3 \%$ & $5 \%$ & $11 \%$ & $4 \%$ & $8 \%$ & $36 \%$ & $8 \%$ & $9 \%$ \\
\hline $\begin{array}{l}\text { No children under } 13 \text { in } \\
\text { household }\end{array}$ & $87 \%$ & $78 \%$ & $45 \%$ & $79 \%$ & $60 \%$ & $18 \%$ & $72 \%$ & $59 \%$ \\
\hline All of the children & $7 \%$ & $10 \%$ & $20 \%$ & $8 \%$ & $16 \%$ & $17 \%$ & $12 \%$ & $24 \%$ \\
\hline $\begin{array}{l}\text { Elderly present (over } \\
64 \text { ) }\end{array}$ & $28 \%$ & $20 \%$ & $10 \%$ & $24 \%$ & $24 \%$ & $9 \%$ & $11 \%$ & $19 \%$ \\
\hline \multicolumn{9}{|l|}{ Ever worked } \\
\hline No & $1 \%$ & $16 \%$ & $15 \%$ & $4 \%$ & $24 \%$ & $25 \%$ & $5 \%$ & $20 \%$ \\
\hline Yes & $99 \%$ & $84 \%$ & $85 \%$ & $96 \%$ & $75 \%$ & $74 \%$ & $93 \%$ & $80 \%$ \\
\hline NA & $0 \%$ & $0 \%$ & $0 \%$ & $0 \%$ & $0 \%$ & $0 \%$ & $1 \%$ & $0 \%$ \\
\hline \multicolumn{9}{|c|}{ Able to keep dwelling warm } \\
\hline No & $26 \%$ & $35 \%$ & $24 \%$ & $47 \%$ & $37 \%$ & $20 \%$ & $30 \%$ & $41 \%$ \\
\hline Yes & $74 \%$ & $65 \%$ & $76 \%$ & $53 \%$ & $63 \%$ & $80 \%$ & $70 \%$ & $59 \%$ \\
\hline \multicolumn{9}{|l|}{ Degree of urbanization } \\
\hline Densely populated & $36 \%$ & $38 \%$ & $31 \%$ & $19 \%$ & $16 \%$ & $38 \%$ & $58 \%$ & $60 \%$ \\
\hline
\end{tabular}




\begin{tabular}{|c|c|c|c|c|c|c|c|c|}
\hline & $\begin{array}{c}1 . \\
\text { Married } \\
\text { rural } \\
\text { women } \\
\text { with old } \\
\text { age } \\
\text { pensions }\end{array}$ & $\begin{array}{l}\text { 2. Rural } \\
\text { disabled } \\
\text { adults } \\
\text { with } \\
\text { benefits }\end{array}$ & $\begin{array}{l}\text { 3. Stay-at- } \\
\text { home (or } \\
\text { unemployed) } \\
\text { rural married- } \\
\text { with-kids } \\
\text { young women }\end{array}$ & $\begin{array}{l}\text { 4. Middle- } \\
\text { aged poor } \\
\text { rural long } \\
\text { term } \\
\text { unemployed }\end{array}$ & $\begin{array}{l}\text { 5. Single } \\
\text { poor rural } \\
\text { unemployed } \\
\text { women }\end{array}$ & $\begin{array}{l}\text { 6. Stay-at- } \\
\text { home (or } \\
\text { unemployed) } \\
\text { well-educated } \\
\text { rural married- } \\
\text { with-kids } \\
\text { young women }\end{array}$ & $\begin{array}{l}\text { 7. Middle- } \\
\text { aged } \\
\text { educated } \\
\text { unemployed } \\
\text { family men }\end{array}$ & $\begin{array}{c}\text { 8. Middle-aged } \\
\text { mostly urban } \\
\text { low educated } \\
\text { low income } \\
\text { (mostly long } \\
\text { term) } \\
\text { unemployed } \\
\text { men }\end{array}$ \\
\hline Sparsely populated & $64 \%$ & $62 \%$ & $69 \%$ & $81 \%$ & $84 \%$ & $62 \%$ & $42 \%$ & $40 \%$ \\
\hline & $97 \%$ & $96 \%$ & $55 \%$ & $52 \%$ & $48 \%$ & $75 \%$ & $60 \%$ & $40 \%$ \\
\hline \multicolumn{9}{|c|}{ Receives at least one benefit } \\
\hline $\begin{array}{l}\text { Receives benefits at } \\
\text { household level }\end{array}$ & $8 \%$ & $14 \%$ & $37 \%$ & $10 \%$ & $31 \%$ & $69 \%$ & $15 \%$ & $30 \%$ \\
\hline Family child & $3 \%$ & $5 \%$ & $5 \%$ & $11 \%$ & $14 \%$ & $10 \%$ & $2 \%$ & $1 \%$ \\
\hline Social exclusion & $5 \%$ & $7 \%$ & $3 \%$ & $7 \%$ & $5 \%$ & $2 \%$ & $3 \%$ & $1 \%$ \\
\hline \multicolumn{9}{|l|}{ Housing } \\
\hline $\begin{array}{l}\text { Receives benefits at } \\
\text { individual level }\end{array}$ & $10 \%$ & $2 \%$ & $4 \%$ & $3 \%$ & $6 \%$ & $3 \%$ & $7 \%$ & $4 \%$ \\
\hline Unemployment & $85 \%$ & $2 \%$ & $1 \%$ & $1 \%$ & $2 \%$ & $0 \%$ & $9 \%$ & $4 \%$ \\
\hline Old age & $1 \%$ & $8 \%$ & $1 \%$ & $4 \%$ & $2 \%$ & $0 \%$ & $2 \%$ & $0 \%$ \\
\hline Sickness & $2 \%$ & $5 \%$ & $3 \%$ & $3 \%$ & $4 \%$ & $5 \%$ & $10 \%$ & $2 \%$ \\
\hline Disability & $4 \%$ & $91 \%$ & $12 \%$ & $29 \%$ & $3 \%$ & $3 \%$ & $20 \%$ & $2 \%$ \\
\hline Education & $0 \%$ & $0 \%$ & $2 \%$ & $0 \%$ & $0 \%$ & $3 \%$ & $3 \%$ & $2 \%$ \\
\hline \multicolumn{9}{|c|}{ Benefits as share of total gross household income, all households } \\
\hline Family child & $1 \%$ & $1 \%$ & $4 \%$ & $3 \%$ & $9 \%$ & $11 \%$ & $1 \%$ & $1 \%$ \\
\hline Social exclusion & $0 \%$ & $0 \%$ & $0 \%$ & $4 \%$ & $6 \%$ & $3 \%$ & $0 \%$ & $0 \%$ \\
\hline Housing & $0 \%$ & $0 \%$ & $0 \%$ & $0 \%$ & $0 \%$ & $0 \%$ & $0 \%$ & $0 \%$ \\
\hline Unemployment & $5 \%$ & $1 \%$ & $1 \%$ & $1 \%$ & $2 \%$ & $1 \%$ & $2 \%$ & $1 \%$ \\
\hline Old age & $55 \%$ & $13 \%$ & $4 \%$ & $21 \%$ & $20 \%$ & $5 \%$ & $10 \%$ & $8 \%$ \\
\hline Survivor & $1 \%$ & $2 \%$ & $0 \%$ & $1 \%$ & $1 \%$ & $0 \%$ & $0 \%$ & $0 \%$ \\
\hline Sickness & $0 \%$ & $1 \%$ & $1 \%$ & $0 \%$ & $1 \%$ & $1 \%$ & $1 \%$ & $0 \%$ \\
\hline Disability & $4 \%$ & $40 \%$ & $4 \%$ & $23 \%$ & $7 \%$ & $2 \%$ & $7 \%$ & $4 \%$ \\
\hline Education & $0 \%$ & $0 \%$ & $1 \%$ & $1 \%$ & $1 \%$ & $0 \%$ & $0 \%$ & $2 \%$ \\
\hline
\end{tabular}




\begin{tabular}{|c|c|c|c|c|c|c|c|c|}
\hline & $\begin{array}{c}1 . \\
\text { Married } \\
\text { rural } \\
\text { women } \\
\text { with old } \\
\text { age } \\
\text { pensions }\end{array}$ & $\begin{array}{l}\text { 2. Rural } \\
\text { disabled } \\
\text { adults } \\
\text { with } \\
\text { benefits }\end{array}$ & $\begin{array}{l}\text { 3. Stay-at- } \\
\text { home (or } \\
\text { unemployed) } \\
\text { rural married- } \\
\text { with-kids } \\
\text { young women }\end{array}$ & $\begin{array}{l}\text { 4. Middle- } \\
\text { aged poor } \\
\text { rural long } \\
\text { term } \\
\text { unemployed }\end{array}$ & $\begin{array}{l}\text { 5. Single } \\
\text { poor rural } \\
\text { unemployed } \\
\text { women }\end{array}$ & $\begin{array}{l}\text { 6. Stay-at- } \\
\text { home (or } \\
\text { unemployed) } \\
\text { well-educated } \\
\text { rural married- } \\
\text { with-kids } \\
\text { young women }\end{array}$ & $\begin{array}{l}\text { 7. Middle- } \\
\text { aged } \\
\text { educated } \\
\text { unemployed } \\
\text { family men }\end{array}$ & $\begin{array}{c}\text { 8. Middle-aged } \\
\text { mostly urban } \\
\text { low educated } \\
\text { low income } \\
\text { (mostly long } \\
\text { term) } \\
\text { unemployed } \\
\text { men }\end{array}$ \\
\hline \multicolumn{9}{|c|}{ Benefits as share of total gross household income, only beneficiaries } \\
\hline Family child & $8 \%$ & $10 \%$ & $11 \%$ & $28 \%$ & $27 \%$ & $15 \%$ & $7 \%$ & $4 \%$ \\
\hline Social exclusion & $7 \%$ & $7 \%$ & $10 \%$ & $36 \%$ & $40 \%$ & $36 \%$ & $21 \%$ & $6 \%$ \\
\hline Housing & $4 \%$ & $5 \%$ & $3 \%$ & $5 \%$ & $7 \%$ & $4 \%$ & $3 \%$ & $1 \%$ \\
\hline Unemployment & $35 \%$ & $15 \%$ & $13 \%$ & $13 \%$ & $15 \%$ & $11 \%$ & $21 \%$ & $12 \%$ \\
\hline Old age & $61 \%$ & $42 \%$ & $25 \%$ & $65 \%$ & $63 \%$ & $28 \%$ & $38 \%$ & $24 \%$ \\
\hline Survivor & $16 \%$ & $14 \%$ & $7 \%$ & $16 \%$ & $18 \%$ & $10 \%$ & $9 \%$ & $15 \%$ \\
\hline Sickness & $3 \%$ & $6 \%$ & $5 \%$ & $5 \%$ & $6 \%$ & $5 \%$ & $4 \%$ & $3 \%$ \\
\hline Disability & $29 \%$ & $44 \%$ & $19 \%$ & $58 \%$ & $40 \%$ & $22 \%$ & $26 \%$ & $22 \%$ \\
\hline Education & $8 \%$ & $4 \%$ & $7 \%$ & $19 \%$ & $10 \%$ & $5 \%$ & $4 \%$ & $20 \%$ \\
\hline
\end{tabular}

a. Refers to individuals aged 25 and over.

b. Applies to individuals aged 25 and over. Students aged 16 to 24 are not included in the sample.

c. Based on total equivalized disposable household income.

d. Dependent children include: 1. household members under 18; 2. household members aged between 18 and 24 who are economically inactive and living with at least one parent.

e. Based on total gross household income.

Source: WB staff calculations based on EU-SILC. 


\begin{tabular}{|c|c|c|c|c|c|c|c|c|c|}
\hline & $\begin{array}{l}\text { All Out- } \\
\text { of-Work }\end{array}$ & $\begin{array}{c}1 . \\
\text { Retirees }\end{array}$ & $\begin{array}{l}\text { 2. Early } \\
\text { retirees }\end{array}$ & $\begin{array}{l}\text { 3. Low- } \\
\text { educated } \\
\text { rural } \\
\text { mothers } \\
\text { without } \\
\text { work } \\
\text { experience }\end{array}$ & $\begin{array}{c}4 . \\
\text { Inactive } \\
\text { middle- } \\
\text { aged } \\
\text { wives }\end{array}$ & $\begin{array}{l}\text { 5. Long-term } \\
\text { unemployed } \\
\text { educated } \\
\text { single youth }\end{array}$ & $\begin{array}{l}\text { 6. Working- } \\
\text { age long-term } \\
\text { unemployed }\end{array}$ & $\begin{array}{l}\text { 7. Working- } \\
\text { age newly } \\
\text { unemployed }\end{array}$ & $\begin{array}{l}\text { 8. Low- } \\
\text { educated } \\
\text { and rural } \\
\text { disabled }\end{array}$ \\
\hline Cluster size & $100 \%$ & $24 \%$ & $24 \%$ & $19 \%$ & $15 \%$ & $7 \%$ & $5 \%$ & $3 \%$ & $3 \%$ \\
\hline Population & $4,093,906$ & 978,034 & 962,887 & 776,614 & 606,307 & 292,714 & 223,937 & 136,327 & 117,086 \\
\hline \multicolumn{10}{|c|}{ INDICATORS } \\
\hline \multicolumn{10}{|c|}{ Labor market attachment } \\
\hline Unemployed & $4 \%$ & $0 \%$ & $0 \%$ & $0 \%$ & $0 \%$ & $8 \%$ & $9 \%$ & $75 \%$ & $0 \%$ \\
\hline $\begin{array}{l}\text { Long-term } \\
\text { unemployed }\end{array}$ & $9 \%$ & $0 \%$ & $2 \%$ & $0 \%$ & $0 \%$ & $55 \%$ & $74 \%$ & $0 \%$ & $0 \%$ \\
\hline Retired & $49 \%$ & $98 \%$ & $96 \%$ & $3 \%$ & $8 \%$ & $4 \%$ & $0 \%$ & $9 \%$ & $18 \%$ \\
\hline Disabled & $2 \%$ & $0 \%$ & $1 \%$ & $0 \%$ & $1 \%$ & $0 \%$ & $0 \%$ & $0 \%$ & $71 \%$ \\
\hline Other inactive & $36 \%$ & $1 \%$ & $0 \%$ & $97 \%$ & $91 \%$ & $33 \%$ & $17 \%$ & $16 \%$ & $12 \%$ \\
\hline \multicolumn{10}{|c|}{ At least one working adult in householda } \\
\hline No & $37 \%$ & $62 \%$ & $43 \%$ & $9 \%$ & $23 \%$ & $23 \%$ & $48 \%$ & $38 \%$ & $31 \%$ \\
\hline Yes & $63 \%$ & $38 \%$ & $57 \%$ & $91 \%$ & $78 \%$ & $77 \%$ & $52 \%$ & $62 \%$ & $69 \%$ \\
\hline \multicolumn{10}{|l|}{ Work experience } \\
\hline Never worked & $34 \%$ & $2 \%$ & $0 \%$ & $78 \%$ & $60 \%$ & $89 \%$ & $8 \%$ & $0 \%$ & $100 \%$ \\
\hline Less than 2 months & $58 \%$ & $95 \%$ & $95 \%$ & $8 \%$ & $39 \%$ & $11 \%$ & $92 \%$ & $1 \%$ & $0 \%$ \\
\hline 2 or more months & $8 \%$ & $3 \%$ & $4 \%$ & $14 \%$ & $0 \%$ & $0 \%$ & $0 \%$ & $99 \%$ & $0 \%$ \\
\hline \multicolumn{10}{|c|}{ Self-assessed physical incapacity } \\
\hline Strongly limited & $13 \%$ & $12 \%$ & $28 \%$ & $1 \%$ & $7 \%$ & $0 \%$ & $2 \%$ & $1 \%$ & $67 \%$ \\
\hline None/limited & $87 \%$ & $88 \%$ & $72 \%$ & $99 \%$ & $93 \%$ & $100 \%$ & $98 \%$ & $99 \%$ & $33 \%$ \\
\hline \multicolumn{10}{|c|}{ ACTIVE COVARIATES } \\
\hline \multicolumn{10}{|l|}{ Age groups (4) } \\
\hline $16-24$ years & $8 \%$ & $0 \%$ & $0 \%$ & $18 \%$ & $2 \%$ & $49 \%$ & $0 \%$ & $19 \%$ & $23 \%$ \\
\hline
\end{tabular}




\begin{tabular}{|c|c|c|c|c|c|c|c|c|c|}
\hline & $\begin{array}{l}\text { All Out- } \\
\text { of-Work }\end{array}$ & $\begin{array}{c}1 . \\
\text { Retirees }\end{array}$ & $\begin{array}{l}\text { 2. Early } \\
\text { retirees }\end{array}$ & $\begin{array}{l}\text { 3. Low- } \\
\text { educated } \\
\text { rural } \\
\text { mothers } \\
\text { without } \\
\text { work } \\
\text { experience }\end{array}$ & $\begin{array}{c}4 . \\
\text { Inactive } \\
\text { middle- } \\
\text { aged } \\
\text { wives }\end{array}$ & $\begin{array}{l}\text { 5. Long-term } \\
\text { unemployed } \\
\text { educated } \\
\text { single youth }\end{array}$ & $\begin{array}{l}\text { 6. Working- } \\
\text { age long-term } \\
\text { unemployed }\end{array}$ & $\begin{array}{l}\text { 7. Working- } \\
\text { age newly } \\
\text { unemployed }\end{array}$ & $\begin{array}{l}\text { 8. Low- } \\
\text { educated } \\
\text { and rural } \\
\text { disabled }\end{array}$ \\
\hline 25-34 years & $18 \%$ & $0 \%$ & $1 \%$ & $57 \%$ & $1 \%$ & $51 \%$ & $32 \%$ & $20 \%$ & $27 \%$ \\
\hline $35-59$ years & $50 \%$ & $6 \%$ & $99 \%$ & $26 \%$ & $91 \%$ & $0 \%$ & $68 \%$ & $61 \%$ & $49 \%$ \\
\hline 60-64 years & $24 \%$ & $94 \%$ & $0 \%$ & $0 \%$ & $6 \%$ & $0 \%$ & $0 \%$ & $0 \%$ & $2 \%$ \\
\hline \multicolumn{10}{|l|}{ Gender } \\
\hline Male & $33 \%$ & $42 \%$ & $41 \%$ & $1 \%$ & $0 \%$ & $67 \%$ & $72 \%$ & $68 \%$ & $61 \%$ \\
\hline Female & $67 \%$ & $58 \%$ & $59 \%$ & $99 \%$ & $100 \%$ & $33 \%$ & $28 \%$ & $32 \%$ & $39 \%$ \\
\hline \multicolumn{10}{|l|}{ Education } \\
\hline Primary & $34 \%$ & $38 \%$ & $25 \%$ & $46 \%$ & $37 \%$ & $23 \%$ & $17 \%$ & $16 \%$ & $45 \%$ \\
\hline Secondary & $54 \%$ & $49 \%$ & $73 \%$ & $40 \%$ & $54 \%$ & $47 \%$ & $66 \%$ & $66 \%$ & $18 \%$ \\
\hline Tertiary & $7 \%$ & $12 \%$ & $0 \%$ & $8 \%$ & $1 \%$ & $24 \%$ & $11 \%$ & $11 \%$ & $0 \%$ \\
\hline NA & $5 \%$ & $2 \%$ & $2 \%$ & $6 \%$ & $9 \%$ & $6 \%$ & $6 \%$ & $6 \%$ & $37 \%$ \\
\hline Urban & $38 \%$ & $44 \%$ & $45 \%$ & $23 \%$ & $31 \%$ & $46 \%$ & $50 \%$ & $38 \%$ & $13 \%$ \\
\hline Rural & $62 \%$ & $56 \%$ & $55 \%$ & $77 \%$ & $69 \%$ & $54 \%$ & $50 \%$ & $62 \%$ & $87 \%$ \\
\hline \multicolumn{10}{|c|}{ INACTIVE COVARIATES } \\
\hline \multicolumn{10}{|c|}{ Age groups (8) } \\
\hline $16-19$ years & $2 \%$ & $0 \%$ & $0 \%$ & $4 \%$ & $0 \%$ & $11 \%$ & $0 \%$ & $4 \%$ & $8 \%$ \\
\hline 20-24 years & $6 \%$ & $0 \%$ & $0 \%$ & $13 \%$ & $1 \%$ & $38 \%$ & $0 \%$ & $15 \%$ & $15 \%$ \\
\hline $25-29$ years & $10 \%$ & $0 \%$ & $0 \%$ & $27 \%$ & $1 \%$ & $38 \%$ & $17 \%$ & $9 \%$ & $13 \%$ \\
\hline 30-34 years & $8 \%$ & $0 \%$ & $1 \%$ & $30 \%$ & $1 \%$ & $13 \%$ & $16 \%$ & $11 \%$ & $13 \%$ \\
\hline $35-44$ years & $15 \%$ & $0 \%$ & $8 \%$ & $14 \%$ & $46 \%$ & $0 \%$ & $30 \%$ & $28 \%$ & $29 \%$ \\
\hline $45-54$ years & $18 \%$ & $2 \%$ & $35 \%$ & $8 \%$ & $32 \%$ & $0 \%$ & $31 \%$ & $24 \%$ & $13 \%$ \\
\hline $55-59$ years & $18 \%$ & $4 \%$ & $57 \%$ & $3 \%$ & $14 \%$ & $0 \%$ & $7 \%$ & $9 \%$ & $7 \%$ \\
\hline 60-64 years & $24 \%$ & $94 \%$ & $0 \%$ & $0 \%$ & $6 \%$ & $0 \%$ & $0 \%$ & $0 \%$ & $2 \%$ \\
\hline \multicolumn{10}{|l|}{ Education } \\
\hline Primary & $6 \%$ & $8 \%$ & $2 \%$ & $6 \%$ & $8 \%$ & $3 \%$ & $3 \%$ & $0 \%$ & $25 \%$ \\
\hline
\end{tabular}




\begin{tabular}{|c|c|c|c|c|c|c|c|c|c|}
\hline & $\begin{array}{l}\text { All Out- } \\
\text { of-Work }\end{array}$ & $\begin{array}{c}1 . \\
\text { Retirees }\end{array}$ & $\begin{array}{l}\text { 2. Early } \\
\text { retirees }\end{array}$ & $\begin{array}{l}\text { 3. Low- } \\
\text { educated } \\
\text { rural } \\
\text { mothers } \\
\text { without } \\
\text { work } \\
\text { experience }\end{array}$ & $\begin{array}{c}4 . \\
\text { Inactive } \\
\text { middle- } \\
\text { aged } \\
\text { wives }\end{array}$ & $\begin{array}{l}\text { 5. Long-term } \\
\text { unemployed } \\
\text { educated } \\
\text { single youth }\end{array}$ & $\begin{array}{l}\text { 6. Working- } \\
\text { age long-term } \\
\text { unemployed }\end{array}$ & $\begin{array}{l}\text { 7. Working- } \\
\text { age newly } \\
\text { unemployed }\end{array}$ & $\begin{array}{l}\text { 8. Low- } \\
\text { educated } \\
\text { and rural } \\
\text { disabled }\end{array}$ \\
\hline Lower secondary & $28 \%$ & $29 \%$ & $23 \%$ & $41 \%$ & $29 \%$ & $20 \%$ & $14 \%$ & $16 \%$ & $21 \%$ \\
\hline Upper secondary & $49 \%$ & $40 \%$ & $67 \%$ & $38 \%$ & $51 \%$ & $44 \%$ & $61 \%$ & $64 \%$ & $17 \%$ \\
\hline Post-secondary & $5 \%$ & $9 \%$ & $6 \%$ & $2 \%$ & $3 \%$ & $3 \%$ & $5 \%$ & $2 \%$ & $1 \%$ \\
\hline Tertiary & $7 \%$ & $12 \%$ & $0 \%$ & $8 \%$ & $1 \%$ & $24 \%$ & $11 \%$ & $11 \%$ & $0 \%$ \\
\hline $\begin{array}{l}\text { Never studied } \\
\text { before/illiterate/NA }\end{array}$ & $5 \%$ & $2 \%$ & $2 \%$ & $6 \%$ & $9 \%$ & $6 \%$ & $6 \%$ & $6 \%$ & $37 \%$ \\
\hline \multicolumn{10}{|c|}{ Enrolled in education ${ }^{b}$} \\
\hline Yes & $34 \%$ & $1 \%$ & $0 \%$ & $6 \%$ & $0 \%$ & $15 \%$ & $1 \%$ & $2 \%$ & $0 \%$ \\
\hline No & $66 \%$ & $99 \%$ & $100 \%$ & $94 \%$ & $100 \%$ & $85 \%$ & $99 \%$ & $98 \%$ & $100 \%$ \\
\hline \multicolumn{10}{|l|}{ Marital status } \\
\hline Married & $68 \%$ & $68 \%$ & $77 \%$ & $73 \%$ & $85 \%$ & $19 \%$ & $66 \%$ & $57 \%$ & $24 \%$ \\
\hline Never married & $17 \%$ & $2 \%$ & $5 \%$ & $23 \%$ & $4 \%$ & $80 \%$ & $22 \%$ & $34 \%$ & $68 \%$ \\
\hline Divorced/separated & $5 \%$ & $6 \%$ & $8 \%$ & $3 \%$ & $4 \%$ & $1 \%$ & $9 \%$ & $5 \%$ & $3 \%$ \\
\hline Widowed & $10 \%$ & $23 \%$ & $11 \%$ & $2 \%$ & $7 \%$ & $1 \%$ & $3 \%$ & $3 \%$ & $4 \%$ \\
\hline \multicolumn{10}{|c|}{ Household income sharesc } \\
\hline Labor income & $48 \%$ & $23 \%$ & $38 \%$ & $72 \%$ & $66 \%$ & $62 \%$ & $43 \%$ & $70 \%$ & $45 \%$ \\
\hline Other income & $1 \%$ & $1 \%$ & $1 \%$ & $1 \%$ & $1 \%$ & $2 \%$ & $4 \%$ & $1 \%$ & $2 \%$ \\
\hline Benefits & $51 \%$ & $77 \%$ & $61 \%$ & $28 \%$ & $33 \%$ & $36 \%$ & $53 \%$ & $29 \%$ & $54 \%$ \\
\hline \multicolumn{10}{|l|}{ Income quintiled } \\
\hline Poorest & $26 \%$ & $8 \%$ & $12 \%$ & $43 \%$ & $39 \%$ & $48 \%$ & $46 \%$ & $18 \%$ & $39 \%$ \\
\hline Q2 & $22 \%$ & $16 \%$ & $18 \%$ & $26 \%$ & $29 \%$ & $19 \%$ & $22 \%$ & $25 \%$ & $31 \%$ \\
\hline Q3 & $20 \%$ & $25 \%$ & $23 \%$ & $13 \%$ & $17 \%$ & $17 \%$ & $17 \%$ & $21 \%$ & $24 \%$ \\
\hline Q4 & $18 \%$ & $27 \%$ & $27 \%$ & $9 \%$ & $10 \%$ & $12 \%$ & $8 \%$ & $21 \%$ & $6 \%$ \\
\hline Richest & $14 \%$ & $25 \%$ & $20 \%$ & $8 \%$ & $5 \%$ & $4 \%$ & $7 \%$ & $15 \%$ & $1 \%$ \\
\hline NA & $0 \%$ & $0 \%$ & $0 \%$ & $0 \%$ & $0 \%$ & $0 \%$ & $0 \%$ & $0 \%$ & $0 \%$ \\
\hline
\end{tabular}




\begin{tabular}{|c|c|c|c|c|c|c|c|c|c|}
\hline & $\begin{array}{l}\text { All Out- } \\
\text { of-Work }\end{array}$ & $\begin{array}{c}1 . \\
\text { Retirees }\end{array}$ & $\begin{array}{l}\text { 2. Early } \\
\text { retirees }\end{array}$ & $\begin{array}{l}\text { 3. Low- } \\
\text { educated } \\
\text { rural } \\
\text { mothers } \\
\text { without } \\
\text { work } \\
\text { experience }\end{array}$ & $\begin{array}{c}4 . \\
\text { Inactive } \\
\text { middle- } \\
\text { aged } \\
\text { wives }\end{array}$ & $\begin{array}{l}\text { 5. Long-term } \\
\text { unemployed } \\
\text { educated } \\
\text { single youth }\end{array}$ & $\begin{array}{l}\text { 6. Working- } \\
\text { age long-term } \\
\text { unemployed }\end{array}$ & $\begin{array}{l}\text { 7. Working- } \\
\text { age newly } \\
\text { unemployed }\end{array}$ & $\begin{array}{l}\text { 8. Low- } \\
\text { educated } \\
\text { and rural } \\
\text { disabled }\end{array}$ \\
\hline Working & $35 \%$ & $10 \%$ & $28 \%$ & $67 \%$ & $61 \%$ & $15 \%$ & $42 \%$ & $35 \%$ & $13 \%$ \\
\hline Unemployed & $2 \%$ & $0 \%$ & $2 \%$ & $2 \%$ & $3 \%$ & $1 \%$ & $6 \%$ & $1 \%$ & $3 \%$ \\
\hline Retired & $26 \%$ & $53 \%$ & $40 \%$ & $3 \%$ & $20 \%$ & $0 \%$ & $6 \%$ & $7 \%$ & $3 \%$ \\
\hline Inactive & $5 \%$ & $5 \%$ & $8 \%$ & $2 \%$ & $1 \%$ & $3 \%$ & $12 \%$ & $14 \%$ & $5 \%$ \\
\hline NA & $31 \%$ & $32 \%$ & $23 \%$ & $26 \%$ & $15 \%$ & $81 \%$ & $33 \%$ & $43 \%$ & $76 \%$ \\
\hline $\begin{array}{l}\text { Partner income } \\
\text { (mean) }\end{array}$ & 1751 & 559 & 1139 & 2987 & 2497 & 2880 & 2270 & 2258 & 993 \\
\hline $\begin{array}{l}\text { Working partner } \\
\text { income (mean) }\end{array}$ & 3256 & 3187 & 2994 & 3276 & 3429 & 3590 & 3581 & 3011 & 1377 \\
\hline \multicolumn{10}{|c|}{ Working partner income quintile } \\
\hline Poorest & $6 \%$ & $3 \%$ & $5 \%$ & $14 \%$ & $8 \%$ & $2 \%$ & $4 \%$ & $6 \%$ & $8 \%$ \\
\hline Q2 & $8 \%$ & $2 \%$ & $6 \%$ & $15 \%$ & $12 \%$ & $2 \%$ & $11 \%$ & $11 \%$ & $1 \%$ \\
\hline Q3 & $7 \%$ & $1 \%$ & $6 \%$ & $12 \%$ & $15 \%$ & $3 \%$ & $8 \%$ & $7 \%$ & $2 \%$ \\
\hline Q4 & $7 \%$ & $2 \%$ & $5 \%$ & $12 \%$ & $12 \%$ & $6 \%$ & $9 \%$ & $4 \%$ & $0 \%$ \\
\hline Richest & $7 \%$ & $2 \%$ & $5 \%$ & $13 \%$ & $13 \%$ & $2 \%$ & $10 \%$ & $7 \%$ & $1 \%$ \\
\hline $\begin{array}{l}\text { No partner or partner } \\
\text { without income }\end{array}$ & $65 \%$ & $90 \%$ & $72 \%$ & $33 \%$ & $39 \%$ & $85 \%$ & $58 \%$ & $65 \%$ & $87 \%$ \\
\hline $\begin{array}{l}\text { Household size } \\
\text { (mean) }\end{array}$ & 3.75 & 2.77 & 3.36 & 4.71 & 3.99 & 4.82 & 3.83 & 4.06 & 4.22 \\
\hline \multicolumn{10}{|c|}{ Household composition } \\
\hline One-person & $7 \%$ & $17 \%$ & $7 \%$ & $0 \%$ & $2 \%$ & $1 \%$ & $7 \%$ & $3 \%$ & $2 \%$ \\
\hline Single parent & $1 \%$ & $0 \%$ & $1 \%$ & $0 \%$ & $1 \%$ & $1 \%$ & $2 \%$ & $1 \%$ & $1 \%$ \\
\hline $\begin{array}{l}2+\text { adults without } \\
\text { dependent children }\end{array}$ & $43 \%$ & $62 \%$ & $57 \%$ & $17 \%$ & $34 \%$ & $34 \%$ & $38 \%$ & $31 \%$ & $41 \%$ \\
\hline $\begin{array}{l}2+\text { adults with } 1 \\
\text { dependent childe }\end{array}$ & $9 \%$ & $3 \%$ & $7 \%$ & $15 \%$ & $15 \%$ & $5 \%$ & $16 \%$ & $10 \%$ & $8 \%$ \\
\hline $\begin{array}{l}2+\text { adults with } 2+ \\
\text { dependent children }\end{array}$ & $40 \%$ & $18 \%$ & $28 \%$ & $67 \%$ & $49 \%$ & $58 \%$ & $38 \%$ & $55 \%$ & $48 \%$ \\
\hline
\end{tabular}




\begin{tabular}{|c|c|c|c|c|c|c|c|c|c|}
\hline & $\begin{array}{l}\text { All Out- } \\
\text { of-Work }\end{array}$ & $\begin{array}{c}1 . \\
\text { Retirees }\end{array}$ & $\begin{array}{l}\text { 2. Early } \\
\text { retirees }\end{array}$ & $\begin{array}{l}\text { 3. Low- } \\
\text { educated } \\
\text { rural } \\
\text { mothers } \\
\text { without } \\
\text { work } \\
\text { experience }\end{array}$ & $\begin{array}{c}4 . \\
\text { Inactive } \\
\text { middle- } \\
\text { aged } \\
\text { wives }\end{array}$ & $\begin{array}{l}\text { 5. Long-term } \\
\text { unemployed } \\
\text { educated } \\
\text { single youth }\end{array}$ & $\begin{array}{l}\text { 6. Working- } \\
\text { age long-term } \\
\text { unemployed }\end{array}$ & $\begin{array}{l}\text { 7. Working- } \\
\text { age newly } \\
\text { unemployed }\end{array}$ & $\begin{array}{l}\text { 8. Low- } \\
\text { educated } \\
\text { and rural } \\
\text { disabled }\end{array}$ \\
\hline \multicolumn{10}{|c|}{ Individuals' parents present } \\
\hline One parent & $8 \%$ & $2 \%$ & $6 \%$ & $10 \%$ & $5 \%$ & $17 \%$ & $13 \%$ & $17 \%$ & $24 \%$ \\
\hline Both parents & $11 \%$ & $0 \%$ & $2 \%$ & $13 \%$ & $3 \%$ & $63 \%$ & $16 \%$ & $24 \%$ & $40 \%$ \\
\hline None & $81 \%$ & $97 \%$ & $92 \%$ & $77 \%$ & $92 \%$ & $19 \%$ & $71 \%$ & $59 \%$ & $37 \%$ \\
\hline Children under six & $21 \%$ & $8 \%$ & $14 \%$ & $43 \%$ & $20 \%$ & $25 \%$ & $25 \%$ & $33 \%$ & $11 \%$ \\
\hline $\begin{array}{l}\text { Three or more } \\
\text { children under } 16\end{array}$ & $4 \%$ & $1 \%$ & $1 \%$ & $9 \%$ & $4 \%$ & $5 \%$ & $4 \%$ & $3 \%$ & $6 \%$ \\
\hline $\begin{array}{l}\text { Elderly present } \\
\text { (over 64) }\end{array}$ & $17 \%$ & $23 \%$ & $13 \%$ & $15 \%$ & $18 \%$ & $9 \%$ & $19 \%$ & $27 \%$ & $23 \%$ \\
\hline \multicolumn{10}{|c|}{ Children under 13 in childcare } \\
\hline None of the children & $9 \%$ & $3 \%$ & $6 \%$ & $15 \%$ & $16 \%$ & $11 \%$ & $10 \%$ & $9 \%$ & $14 \%$ \\
\hline Some of the children & $6 \%$ & $3 \%$ & $2 \%$ & $12 \%$ & $9 \%$ & $5 \%$ & $5 \%$ & $9 \%$ & $7 \%$ \\
\hline $\begin{array}{l}\text { No children under } 13 \\
\text { in household }\end{array}$ & $60 \%$ & $84 \%$ & $75 \%$ & $26 \%$ & $50 \%$ & $55 \%$ & $54 \%$ & $52 \%$ & $65 \%$ \\
\hline All of the children & $24 \%$ & $10 \%$ & $17 \%$ & $47 \%$ & $25 \%$ & $29 \%$ & $31 \%$ & $30 \%$ & $15 \%$ \\
\hline \multicolumn{10}{|l|}{ Ever worked } \\
\hline No & $34 \%$ & $2 \%$ & $0 \%$ & $78 \%$ & $60 \%$ & $89 \%$ & $8 \%$ & $0 \%$ & $100 \%$ \\
\hline Yes & $66 \%$ & $98 \%$ & $100 \%$ & $22 \%$ & $40 \%$ & $11 \%$ & $92 \%$ & $100 \%$ & $0 \%$ \\
\hline $\begin{array}{l}\text { Years of work } \\
\text { experience }\end{array}$ & 26 & 33 & 27 & 9 & 16 & 4 & 15 & 15 & 18 \\
\hline \multicolumn{10}{|c|}{ Able to keep dwelling warm } \\
\hline No & $20 \%$ & $15 \%$ & $18 \%$ & $24 \%$ & $18 \%$ & $27 \%$ & $31 \%$ & $23 \%$ & $12 \%$ \\
\hline Yes & $80 \%$ & $85 \%$ & $82 \%$ & $76 \%$ & $82 \%$ & $73 \%$ & $69 \%$ & $77 \%$ & $88 \%$ \\
\hline \multicolumn{10}{|c|}{ Degree of urbanization } \\
\hline Densely populated & $36 \%$ & $43 \%$ & $44 \%$ & $22 \%$ & $30 \%$ & $43 \%$ & $45 \%$ & $35 \%$ & $13 \%$ \\
\hline Intermediate area & $1 \%$ & $1 \%$ & $1 \%$ & $1 \%$ & $1 \%$ & $2 \%$ & $5 \%$ & $3 \%$ & $0 \%$ \\
\hline Sparsely populated & $62 \%$ & $56 \%$ & $55 \%$ & $77 \%$ & $69 \%$ & $54 \%$ & $50 \%$ & $62 \%$ & $87 \%$ \\
\hline
\end{tabular}




\begin{tabular}{|c|c|c|c|c|c|c|c|c|c|}
\hline & $\begin{array}{l}\text { All Out- } \\
\text { of-Work }\end{array}$ & $\begin{array}{c}1 . \\
\text { Retirees }\end{array}$ & $\begin{array}{l}\text { 2. Early } \\
\text { retirees }\end{array}$ & $\begin{array}{l}\text { 3. Low- } \\
\text { educated } \\
\text { rural } \\
\text { mothers } \\
\text { without } \\
\text { work } \\
\text { experience }\end{array}$ & $\begin{array}{c}4 . \\
\text { Inactive } \\
\text { middle- } \\
\text { aged } \\
\text { wives }\end{array}$ & $\begin{array}{l}\text { 5. Long-term } \\
\text { unemployed } \\
\text { educated } \\
\text { single youth }\end{array}$ & $\begin{array}{l}\text { 6. Working- } \\
\text { age long-term } \\
\text { unemployed }\end{array}$ & $\begin{array}{l}\text { 7. Working- } \\
\text { age newly } \\
\text { unemployed }\end{array}$ & $\begin{array}{l}\text { 8. Low- } \\
\text { educated } \\
\text { and rural } \\
\text { disabled }\end{array}$ \\
\hline \multicolumn{10}{|l|}{ Region } \\
\hline $\begin{array}{l}\text { R01 - Nord-Vest, } \\
\text { Centru }\end{array}$ & $23 \%$ & $24 \%$ & $25 \%$ & $22 \%$ & $22 \%$ & $25 \%$ & $23 \%$ & $25 \%$ & $20 \%$ \\
\hline $\begin{array}{l}\text { RO2 - Nord-Est, Sud- } \\
\text { Est }\end{array}$ & $29 \%$ & $27 \%$ & $27 \%$ & $29 \%$ & $33 \%$ & $26 \%$ & $29 \%$ & $32 \%$ & $38 \%$ \\
\hline $\begin{array}{l}\text { RO3 - Sud, Bucharest- } \\
\text { Ilfov }\end{array}$ & $28 \%$ & $27 \%$ & $29 \%$ & $32 \%$ & $24 \%$ & $30 \%$ & $26 \%$ & $33 \%$ & $23 \%$ \\
\hline R04 - Sud-Vest, Vest & $19 \%$ & $22 \%$ & $18 \%$ & $17 \%$ & $21 \%$ & $19 \%$ & $23 \%$ & $10 \%$ & $19 \%$ \\
\hline $\begin{array}{l}\text { Receives at least one } \\
\text { benefit }\end{array}$ & $85 \%$ & $99 \%$ & $97 \%$ & $80 \%$ & $68 \%$ & $63 \%$ & $72 \%$ & $72 \%$ & $93 \%$ \\
\hline \multicolumn{10}{|c|}{ Receives benefits at household level } \\
\hline Family child & $44 \%$ & $19 \%$ & $29 \%$ & $76 \%$ & $56 \%$ & $51 \%$ & $50 \%$ & $56 \%$ & $46 \%$ \\
\hline Social exclusion & $23 \%$ & $14 \%$ & $16 \%$ & $33 \%$ & $27 \%$ & $32 \%$ & $33 \%$ & $21 \%$ & $46 \%$ \\
\hline Housing & & & & & & & & & \\
\hline $\begin{array}{l}\text { Old age at household } \\
\text { level }\end{array}$ & $47 \%$ & $91 \%$ & $55 \%$ & $17 \%$ & $25 \%$ & $24 \%$ & $25 \%$ & $30 \%$ & $35 \%$ \\
\hline \multicolumn{10}{|c|}{ Receives benefits at individual level } \\
\hline Unemployment & $3 \%$ & $0 \%$ & $1 \%$ & $0 \%$ & $1 \%$ & $8 \%$ & $21 \%$ & $16 \%$ & $0 \%$ \\
\hline Old age & $31 \%$ & $87 \%$ & $42 \%$ & $0 \%$ & $3 \%$ & $0 \%$ & $1 \%$ & $1 \%$ & $2 \%$ \\
\hline Survivor & $2 \%$ & $3 \%$ & $1 \%$ & $1 \%$ & $2 \%$ & $1 \%$ & $0 \%$ & $0 \%$ & $2 \%$ \\
\hline Sickness & & & & & & & & & \\
\hline Disability & $16 \%$ & $8 \%$ & $49 \%$ & $0 \%$ & $3 \%$ & $2 \%$ & $1 \%$ & $0 \%$ & $67 \%$ \\
\hline Education & & & & & & & & & \\
\hline \multicolumn{10}{|c|}{ Benefits as share of total gross household income, all households } \\
\hline Family child & $5 \%$ & $1 \%$ & $2 \%$ & $11 \%$ & $6 \%$ & $6 \%$ & $8 \%$ & $6 \%$ & $4 \%$ \\
\hline Social exclusion & $2 \%$ & $1 \%$ & $1 \%$ & $5 \%$ & $3 \%$ & $5 \%$ & $5 \%$ & $1 \%$ & $2 \%$ \\
\hline Housing & $0 \%$ & $0 \%$ & $0 \%$ & $0 \%$ & $0 \%$ & $0 \%$ & $0 \%$ & $0 \%$ & $0 \%$ \\
\hline Unemployment & $1 \%$ & $0 \%$ & $1 \%$ & $1 \%$ & $1 \%$ & $4 \%$ & $10 \%$ & $3 \%$ & $2 \%$ \\
\hline
\end{tabular}




\begin{tabular}{|c|c|c|c|c|c|c|c|c|c|}
\hline & $\begin{array}{l}\text { All Out- } \\
\text { of-Work }\end{array}$ & $\begin{array}{c}1 . \\
\text { Retirees }\end{array}$ & $\begin{array}{l}\text { 2. Early } \\
\text { retirees }\end{array}$ & $\begin{array}{l}\text { 3. Low- } \\
\text { educated } \\
\text { rural } \\
\text { mothers } \\
\text { without } \\
\text { work } \\
\text { experience }\end{array}$ & $\begin{array}{c}4 . \\
\text { Inactive } \\
\text { middle- } \\
\text { aged } \\
\text { wives }\end{array}$ & $\begin{array}{l}\text { 5. Long-term } \\
\text { unemployed } \\
\text { educated } \\
\text { single youth }\end{array}$ & $\begin{array}{l}\text { 6. Working- } \\
\text { age long-term } \\
\text { unemployed }\end{array}$ & $\begin{array}{l}\text { 7. Working- } \\
\text { age newly } \\
\text { unemployed }\end{array}$ & $\begin{array}{l}\text { 8. Low- } \\
\text { educated } \\
\text { and rural } \\
\text { disabled }\end{array}$ \\
\hline Old age & $30 \%$ & $67 \%$ & $33 \%$ & $7 \%$ & $15 \%$ & $12 \%$ & $16 \%$ & $13 \%$ & $20 \%$ \\
\hline Survivor & $2 \%$ & $2 \%$ & $2 \%$ & $2 \%$ & $2 \%$ & $1 \%$ & $5 \%$ & $1 \%$ & $2 \%$ \\
\hline Sickness & $0 \%$ & $0 \%$ & $0 \%$ & $0 \%$ & $0 \%$ & $0 \%$ & $0 \%$ & $0 \%$ & $0 \%$ \\
\hline Disability & $10 \%$ & $6 \%$ & $23 \%$ & $3 \%$ & $5 \%$ & $9 \%$ & $8 \%$ & $6 \%$ & $23 \%$ \\
\hline Education & $0 \%$ & $0 \%$ & $0 \%$ & $0 \%$ & $0 \%$ & $0 \%$ & $0 \%$ & $0 \%$ & $0 \%$ \\
\hline \multicolumn{10}{|c|}{ Benefits as share of total gross household income, only beneficiaries } \\
\hline Family child & $11 \%$ & $6 \%$ & $6 \%$ & $15 \%$ & $11 \%$ & $12 \%$ & $16 \%$ & $10 \%$ & $8 \%$ \\
\hline Social exclusion & $10 \%$ & $4 \%$ & $5 \%$ & $14 \%$ & $11 \%$ & $14 \%$ & $14 \%$ & $6 \%$ & $5 \%$ \\
\hline \multicolumn{10}{|l|}{ Housing } \\
\hline Unemployment & $31 \%$ & $18 \%$ & $27 \%$ & $41 \%$ & $34 \%$ & $30 \%$ & $42 \%$ & $13 \%$ & $37 \%$ \\
\hline Old age & $64 \%$ & $73 \%$ & $60 \%$ & $44 \%$ & $61 \%$ & $51 \%$ & $62 \%$ & $42 \%$ & $57 \%$ \\
\hline Survivor & $38 \%$ & $41 \%$ & $40 \%$ & $31 \%$ & $33 \%$ & $31 \%$ & $58 \%$ & $15 \%$ & $31 \%$ \\
\hline Sickness & $27 \%$ & $68 \%$ & $16 \%$ & $12 \%$ & $34 \%$ & $12 \%$ & $13 \%$ & $13 \%$ & $16 \%$ \\
\hline Disability & $41 \%$ & $40 \%$ & $43 \%$ & $30 \%$ & $42 \%$ & $49 \%$ & $45 \%$ & $29 \%$ & $31 \%$ \\
\hline Education & $11 \%$ & $4 \%$ & $9 \%$ & $28 \%$ & $36 \%$ & $32 \%$ & $39 \%$ & $6 \%$ & $5 \%$ \\
\hline
\end{tabular}

a. Refers to individuals aged 25 and over.

b. Applies to individuals aged 25 and over. Students aged 16 to 24 are not included in the sample.

c. Based on total gross household income.

d. Based on total equivalized disposable household income.

e. Dependent children include: 1. household members under 18; 2. household members aged between 18 and 24 who are economically inactive and living with at least one parent. f. Refers only to individuals who have worked before.

Source: WB staff calculations based on EU-SILC. 


\begin{tabular}{|c|c|c|c|c|c|c|c|c|}
\hline & $\begin{array}{l}\text { 1. Early } \\
\text { retirees }\end{array}$ & $\begin{array}{l}\text { 2. Low-educated } \\
\text { rural mothers } \\
\text { without work } \\
\text { experience }\end{array}$ & $\begin{array}{c}3 . \\
\text { Retirees }\end{array}$ & $\begin{array}{l}\text { 4. Inactive } \\
\text { middle- } \\
\text { aged } \\
\text { wives }\end{array}$ & $\begin{array}{l}\text { 5. Long-term } \\
\text { unemployed } \\
\text { educated } \\
\text { single youth }\end{array}$ & $\begin{array}{l}\text { 6. Working- } \\
\text { age long- } \\
\text { term } \\
\text { unemployed }\end{array}$ & $\begin{array}{l}\text { 7. Working- } \\
\text { age newly } \\
\text { unemployed }\end{array}$ & $\begin{array}{l}\text { 8. Low- } \\
\text { educated } \\
\text { and rural } \\
\text { disabled }\end{array}$ \\
\hline Cluster size & $26 \%$ & $26 \%$ & $21 \%$ & $\mathbf{8 \%}$ & $7 \%$ & $\mathbf{5 \%}$ & $4 \%$ & $4 \%$ \\
\hline Population & $1,090,340$ & $1,083,211$ & 893,240 & 344,296 & 296,069 & 192,068 & 147,196 & 147,196 \\
\hline \multicolumn{9}{|c|}{ INDICATORS } \\
\hline \multicolumn{9}{|c|}{ Labor market attachment } \\
\hline Unemployed & $0 \%$ & $0 \%$ & $0 \%$ & $3 \%$ & $17 \%$ & $10 \%$ & $74 \%$ & $0 \%$ \\
\hline Long-term unemployed & $0 \%$ & $0 \%$ & $0 \%$ & $1 \%$ & $62 \%$ & $86 \%$ & $0 \%$ & $0 \%$ \\
\hline Retired & $97 \%$ & $11 \%$ & $99 \%$ & $0 \%$ & $1 \%$ & $0 \%$ & $0 \%$ & $10 \%$ \\
\hline Disabled & $0 \%$ & $0 \%$ & $0 \%$ & $0 \%$ & $1 \%$ & $0 \%$ & $0 \%$ & $64 \%$ \\
\hline Other inactive & $3 \%$ & $88 \%$ & $1 \%$ & $97 \%$ & $19 \%$ & $4 \%$ & $26 \%$ & $26 \%$ \\
\hline \multicolumn{9}{|c|}{ At least one working adult in household ${ }^{a}$} \\
\hline No & $44 \%$ & $17 \%$ & $61 \%$ & $11 \%$ & $25 \%$ & $51 \%$ & $48 \%$ & $45 \%$ \\
\hline Yes & $56 \%$ & $83 \%$ & $39 \%$ & $89 \%$ & $75 \%$ & $49 \%$ & $52 \%$ & $55 \%$ \\
\hline \multicolumn{9}{|l|}{ Work experience } \\
\hline Never worked & $1 \%$ & $93 \%$ & $2 \%$ & $6 \%$ & $86 \%$ & $10 \%$ & $0 \%$ & $83 \%$ \\
\hline Less than 2 months & $94 \%$ & $0 \%$ & $95 \%$ & $94 \%$ & $14 \%$ & $90 \%$ & $0 \%$ & $17 \%$ \\
\hline 2 or more months & $5 \%$ & $7 \%$ & $2 \%$ & $0 \%$ & $0 \%$ & $0 \%$ & $100 \%$ & $0 \%$ \\
\hline \multicolumn{9}{|c|}{ Self-assessed physical incapacity } \\
\hline Strongly limited & $22 \%$ & $1 \%$ & $7 \%$ & $4 \%$ & $0 \%$ & $1 \%$ & $2 \%$ & $76 \%$ \\
\hline None/limited & $78 \%$ & $99 \%$ & $93 \%$ & $96 \%$ & $100 \%$ & $99 \%$ & $98 \%$ & $24 \%$ \\
\hline \multicolumn{9}{|c|}{ ACTIVE COVARIATES } \\
\hline \multicolumn{9}{|l|}{ Age groups (4) } \\
\hline $16-24$ years & $0 \%$ & $16 \%$ & $0 \%$ & $2 \%$ & $72 \%$ & $0 \%$ & $15 \%$ & $15 \%$ \\
\hline 25-34 years & $1 \%$ & $37 \%$ & $0 \%$ & $23 \%$ & $28 \%$ & $25 \%$ & $28 \%$ & $15 \%$ \\
\hline $35-59$ years & $98 \%$ & $45 \%$ & $8 \%$ & $73 \%$ & $0 \%$ & $74 \%$ & $57 \%$ & $63 \%$ \\
\hline 60-64 years & $2 \%$ & $2 \%$ & $91 \%$ & $3 \%$ & $0 \%$ & $1 \%$ & $0 \%$ & $7 \%$ \\
\hline Gender & & & & & & & & \\
\hline
\end{tabular}




\begin{tabular}{|c|c|c|c|c|c|c|c|c|}
\hline & $\begin{array}{l}\text { 1. Early } \\
\text { retirees }\end{array}$ & $\begin{array}{l}\text { 2. Low-educated } \\
\text { rural mothers } \\
\text { without work } \\
\text { experience }\end{array}$ & $\begin{array}{c}3 . \\
\text { Retirees }\end{array}$ & $\begin{array}{l}\text { 4. Inactive } \\
\text { middle- } \\
\text { aged } \\
\text { wives }\end{array}$ & $\begin{array}{l}\text { 5. Long-term } \\
\text { unemployed } \\
\text { educated } \\
\text { single youth }\end{array}$ & $\begin{array}{l}\text { 6. Working- } \\
\text { age long- } \\
\text { term } \\
\text { unemployed }\end{array}$ & $\begin{array}{l}\text { 7. Working- } \\
\text { age newly } \\
\text { unemployed }\end{array}$ & $\begin{array}{l}\text { 8. Low- } \\
\text { educated } \\
\text { and rural } \\
\text { disabled }\end{array}$ \\
\hline Male & $41 \%$ & $4 \%$ & $42 \%$ & $4 \%$ & $67 \%$ & $80 \%$ & $67 \%$ & $55 \%$ \\
\hline Female & $59 \%$ & $96 \%$ & $58 \%$ & $96 \%$ & $34 \%$ & $20 \%$ & $33 \%$ & $45 \%$ \\
\hline \multicolumn{9}{|l|}{ Education } \\
\hline Primary & $30 \%$ & $53 \%$ & $38 \%$ & $31 \%$ & $31 \%$ & $30 \%$ & $20 \%$ & $53 \%$ \\
\hline Secondary & $70 \%$ & $42 \%$ & $48 \%$ & $63 \%$ & $48 \%$ & $63 \%$ & $69 \%$ & $17 \%$ \\
\hline Tertiary & $0 \%$ & $3 \%$ & $12 \%$ & $4 \%$ & $15 \%$ & $6 \%$ & $11 \%$ & $1 \%$ \\
\hline NA & $0 \%$ & $3 \%$ & $1 \%$ & $1 \%$ & $6 \%$ & $1 \%$ & $0 \%$ & $29 \%$ \\
\hline Urban & $45 \%$ & $22 \%$ & $41 \%$ & $43 \%$ & $31 \%$ & $41 \%$ & $30 \%$ & $16 \%$ \\
\hline Rural & $55 \%$ & $78 \%$ & $59 \%$ & $57 \%$ & $69 \%$ & $59 \%$ & $70 \%$ & $84 \%$ \\
\hline \multicolumn{9}{|c|}{ INACTIVE COVARIATES } \\
\hline \multicolumn{9}{|l|}{ Age groups (8) } \\
\hline 16-19 years & $0 \%$ & $4 \%$ & $0 \%$ & $0 \%$ & $20 \%$ & $0 \%$ & $3 \%$ & $7 \%$ \\
\hline 20-24 years & $0 \%$ & $12 \%$ & $0 \%$ & $2 \%$ & $51 \%$ & $0 \%$ & $12 \%$ & $7 \%$ \\
\hline 25-29 years & $0 \%$ & $18 \%$ & $0 \%$ & $7 \%$ & $19 \%$ & $12 \%$ & $12 \%$ & $6 \%$ \\
\hline 30-34 years & $0 \%$ & $20 \%$ & $0 \%$ & $16 \%$ & $9 \%$ & $14 \%$ & $16 \%$ & $9 \%$ \\
\hline $35-44$ years & $6 \%$ & $25 \%$ & $0 \%$ & $28 \%$ & $0 \%$ & $34 \%$ & $27 \%$ & $31 \%$ \\
\hline 45-54 years & $38 \%$ & $14 \%$ & $3 \%$ & $34 \%$ & $0 \%$ & $34 \%$ & $25 \%$ & $21 \%$ \\
\hline $55-59$ years & $54 \%$ & $6 \%$ & $5 \%$ & $10 \%$ & $0 \%$ & $6 \%$ & $5 \%$ & $11 \%$ \\
\hline $60-64$ years & $2 \%$ & $2 \%$ & $91 \%$ & $3 \%$ & $0 \%$ & $1 \%$ & $0 \%$ & $7 \%$ \\
\hline \multicolumn{9}{|l|}{ Education } \\
\hline Primary & $3 \%$ & $9 \%$ & $10 \%$ & $5 \%$ & $4 \%$ & $4 \%$ & $3 \%$ & $20 \%$ \\
\hline Lower secondary & $27 \%$ & $44 \%$ & $29 \%$ & $27 \%$ & $27 \%$ & $27 \%$ & $17 \%$ & $33 \%$ \\
\hline Upper secondary & $63 \%$ & $40 \%$ & $39 \%$ & $58 \%$ & $47 \%$ & $62 \%$ & $63 \%$ & $15 \%$ \\
\hline Post-secondary & $7 \%$ & $2 \%$ & $9 \%$ & $5 \%$ & $1 \%$ & $2 \%$ & $6 \%$ & $2 \%$ \\
\hline Tertiary & $0 \%$ & $3 \%$ & $12 \%$ & $4 \%$ & $15 \%$ & $6 \%$ & $11 \%$ & $1 \%$ \\
\hline NA & $0 \%$ & $3 \%$ & $1 \%$ & $1 \%$ & $6 \%$ & $1 \%$ & $0 \%$ & $29 \%$ \\
\hline \multicolumn{9}{|c|}{ Have never studied before/illiterate } \\
\hline No & $100 \%$ & $97 \%$ & $99 \%$ & $99 \%$ & $94 \%$ & $99 \%$ & $100 \%$ & $71 \%$ \\
\hline
\end{tabular}




\begin{tabular}{|c|c|c|c|c|c|c|c|c|}
\hline & $\begin{array}{l}\text { 1. Early } \\
\text { retirees }\end{array}$ & $\begin{array}{l}\text { 2. Low-educated } \\
\text { rural mothers } \\
\text { without work } \\
\text { experience }\end{array}$ & $\begin{array}{c}3 . \\
\text { Retirees }\end{array}$ & $\begin{array}{l}\text { 4. Inactive } \\
\text { middle- } \\
\text { aged } \\
\text { wives }\end{array}$ & $\begin{array}{l}\text { 5. Long-term } \\
\text { unemployed } \\
\text { educated } \\
\text { single youth }\end{array}$ & $\begin{array}{l}\text { 6. Working- } \\
\text { age long- } \\
\text { term } \\
\text { unemployed }\end{array}$ & $\begin{array}{l}\text { 7. Working- } \\
\text { age newly } \\
\text { unemployed }\end{array}$ & $\begin{array}{l}\text { 8. Low- } \\
\text { educated } \\
\text { and rural } \\
\text { disabled }\end{array}$ \\
\hline Yes & $0 \%$ & $3 \%$ & $1 \%$ & $1 \%$ & $6 \%$ & $1 \%$ & $0 \%$ & $29 \%$ \\
\hline \multicolumn{9}{|c|}{ Enrolled in education ${ }^{b}$} \\
\hline Yes & $0 \%$ & $5 \%$ & $0 \%$ & $1 \%$ & $5 \%$ & $0 \%$ & $1 \%$ & $0 \%$ \\
\hline No & $100 \%$ & $95 \%$ & $100 \%$ & $99 \%$ & $95 \%$ & $100 \%$ & $99 \%$ & $100 \%$ \\
\hline \multicolumn{9}{|l|}{ Marital status } \\
\hline Married & $78 \%$ & $74 \%$ & $68 \%$ & $84 \%$ & $13 \%$ & $70 \%$ & $55 \%$ & $34 \%$ \\
\hline Never married & $4 \%$ & $20 \%$ & $2 \%$ & $6 \%$ & $87 \%$ & $17 \%$ & $38 \%$ & $56 \%$ \\
\hline Divorced/separated & $6 \%$ & $4 \%$ & $5 \%$ & $4 \%$ & $0 \%$ & $12 \%$ & $7 \%$ & $7 \%$ \\
\hline Widowed & $12 \%$ & $3 \%$ & $25 \%$ & $6 \%$ & $0 \%$ & $2 \%$ & $1 \%$ & $3 \%$ \\
\hline \multicolumn{9}{|l|}{ Household income } \\
\hline Labor income & 3460 & 3636 & 2225 & 4260 & 3558 & 2492 & 4605 & 2346 \\
\hline Other income & 110 & 43 & 41 & 77 & 73 & 146 & 91 & 98 \\
\hline Benefits & 2815 & 978 & 3567 & 1068 & 1265 & 1437 & 1086 & 1818 \\
\hline \multicolumn{9}{|c|}{ Household income shares ${ }^{c}$} \\
\hline Labor income & $40 \%$ & $70 \%$ & $25 \%$ & $74 \%$ & $63 \%$ & $44 \%$ & $75 \%$ & $44 \%$ \\
\hline Other income & $1 \%$ & $1 \%$ & $1 \%$ & $2 \%$ & $2 \%$ & $7 \%$ & $2 \%$ & $3 \%$ \\
\hline Benefits & $59 \%$ & $29 \%$ & $75 \%$ & $24 \%$ & $35 \%$ & $49 \%$ & $23 \%$ & $53 \%$ \\
\hline \multicolumn{9}{|l|}{ Income quintiled } \\
\hline Poorest & $11 \%$ & $45 \%$ & $9 \%$ & $30 \%$ & $48 \%$ & $50 \%$ & $24 \%$ & $41 \%$ \\
\hline Q2 & $18 \%$ & $28 \%$ & $16 \%$ & $24 \%$ & $21 \%$ & $24 \%$ & $18 \%$ & $29 \%$ \\
\hline Q3 & $24 \%$ & $14 \%$ & $24 \%$ & $24 \%$ & $16 \%$ & $12 \%$ & $28 \%$ & $16 \%$ \\
\hline Q4 & $26 \%$ & $8 \%$ & $27 \%$ & $14 \%$ & $12 \%$ & $10 \%$ & $23 \%$ & $10 \%$ \\
\hline Richest & $20 \%$ & $5 \%$ & $24 \%$ & $9 \%$ & $4 \%$ & $4 \%$ & $7 \%$ & $5 \%$ \\
\hline \multicolumn{9}{|l|}{ Working partner } \\
\hline Yes & $28 \%$ & $61 \%$ & $12 \%$ & $69 \%$ & $10 \%$ & $35 \%$ & $31 \%$ & $10 \%$ \\
\hline No & $50 \%$ & $15 \%$ & $56 \%$ & $15 \%$ & $2 \%$ & $36 \%$ & $25 \%$ & $24 \%$ \\
\hline NA & $22 \%$ & $24 \%$ & $32 \%$ & $16 \%$ & $87 \%$ & $29 \%$ & $44 \%$ & $66 \%$ \\
\hline
\end{tabular}




\begin{tabular}{|c|c|c|c|c|c|c|c|c|}
\hline & $\begin{array}{l}\text { 1. Early } \\
\text { retirees }\end{array}$ & $\begin{array}{l}\text { 2. Low-educated } \\
\text { rural mothers } \\
\text { without work } \\
\text { experience }\end{array}$ & $\begin{array}{c}3 . \\
\text { Retirees }\end{array}$ & $\begin{array}{l}\text { 4. Inactive } \\
\text { middle- } \\
\text { aged } \\
\text { wives }\end{array}$ & $\begin{array}{l}\text { 5. Long-term } \\
\text { unemployed } \\
\text { educated } \\
\text { single youth }\end{array}$ & $\begin{array}{l}\text { 6. Working- } \\
\text { age long- } \\
\text { term } \\
\text { unemployed }\end{array}$ & $\begin{array}{l}\text { 7. Working- } \\
\text { age newly } \\
\text { unemployed }\end{array}$ & $\begin{array}{l}\text { 8. Low- } \\
\text { educated } \\
\text { and rural } \\
\text { disabled }\end{array}$ \\
\hline Working & $28 \%$ & $61 \%$ & $12 \%$ & $69 \%$ & $10 \%$ & $35 \%$ & $31 \%$ & $10 \%$ \\
\hline Unemployed & $2 \%$ & $5 \%$ & $1 \%$ & $1 \%$ & $0 \%$ & $3 \%$ & $3 \%$ & $5 \%$ \\
\hline Retired & $41 \%$ & $8 \%$ & $50 \%$ & $13 \%$ & $0 \%$ & $11 \%$ & $7 \%$ & $13 \%$ \\
\hline Inactive & $7 \%$ & $2 \%$ & $5 \%$ & $1 \%$ & $2 \%$ & $22 \%$ & $15 \%$ & $6 \%$ \\
\hline NA & $22 \%$ & $24 \%$ & $32 \%$ & $16 \%$ & $87 \%$ & $29 \%$ & $44 \%$ & $66 \%$ \\
\hline Partner income (mean) & 1247 & 2542 & 627 & 3055 & 2920 & 1556 & 1985 & 926 \\
\hline $\begin{array}{l}\text { Working partner income } \\
\text { (mean) }\end{array}$ & 3288 & 3116 & 3359 & 3665 & 3539 & 3097 & 2938 & 2325 \\
\hline \multicolumn{9}{|l|}{ Partner income quintile } \\
\hline Poorest & $4 \%$ & $11 \%$ & $3 \%$ & $6 \%$ & $1 \%$ & $2 \%$ & $8 \%$ & $3 \%$ \\
\hline Q2 & $7 \%$ & $12 \%$ & $2 \%$ & $17 \%$ & $2 \%$ & $15 \%$ & $6 \%$ & $2 \%$ \\
\hline Q3 & $6 \%$ & $14 \%$ & $3 \%$ & $16 \%$ & $2 \%$ & $7 \%$ & $8 \%$ & $4 \%$ \\
\hline Q4 & $4 \%$ & $14 \%$ & $1 \%$ & $13 \%$ & $4 \%$ & $6 \%$ & $4 \%$ & $1 \%$ \\
\hline Richest & $6 \%$ & $10 \%$ & $3 \%$ & $18 \%$ & $2 \%$ & $5 \%$ & $5 \%$ & $1 \%$ \\
\hline $\begin{array}{l}\text { No partner or partner without } \\
\text { income }\end{array}$ & $72 \%$ & $39 \%$ & $88 \%$ & $31 \%$ & $90 \%$ & $65 \%$ & $69 \%$ & $90 \%$ \\
\hline Household size (mean) & 3.35 & 4.57 & 2.82 & 4.08 & 4.96 & 4.07 & 4.15 & 3.90 \\
\hline \multicolumn{9}{|l|}{ Tenure status } \\
\hline Owner & $99 \%$ & $96 \%$ & $100 \%$ & $95 \%$ & $96 \%$ & $97 \%$ & $97 \%$ & $96 \%$ \\
\hline Tenant & $0 \%$ & $2 \%$ & $0 \%$ & $2 \%$ & $1 \%$ & $0 \%$ & $1 \%$ & $0 \%$ \\
\hline Reduced rate & $0 \%$ & $1 \%$ & $0 \%$ & $0 \%$ & $2 \%$ & $1 \%$ & $1 \%$ & $2 \%$ \\
\hline Free & $0 \%$ & $2 \%$ & $0 \%$ & $3 \%$ & $1 \%$ & $1 \%$ & $1 \%$ & $2 \%$ \\
\hline \multicolumn{9}{|l|}{ Household composition } \\
\hline One-person & $8 \%$ & $1 \%$ & $16 \%$ & $1 \%$ & $1 \%$ & $7 \%$ & $3 \%$ & $5 \%$ \\
\hline Single parent & $1 \%$ & $0 \%$ & $1 \%$ & $1 \%$ & $1 \%$ & $1 \%$ & $4 \%$ & $0 \%$ \\
\hline $\begin{array}{l}2+\text { adults without dependent } \\
\text { children }\end{array}$ & $55 \%$ & $21 \%$ & $59 \%$ & $28 \%$ & $26 \%$ & $30 \%$ & $25 \%$ & $50 \%$ \\
\hline $\begin{array}{l}\text { 2+ adults with } 1 \text { dependent } \\
\text { child }^{\text {e }}\end{array}$ & $6 \%$ & $15 \%$ & $4 \%$ & $14 \%$ & $5 \%$ & $14 \%$ & $12 \%$ & $9 \%$ \\
\hline $\begin{array}{l}2+\text { adults with } 2+\text { dependent } \\
\text { children }\end{array}$ & $29 \%$ & $62 \%$ & $20 \%$ & $56 \%$ & $66 \%$ & $49 \%$ & $56 \%$ & $37 \%$ \\
\hline
\end{tabular}




\begin{tabular}{|c|c|c|c|c|c|c|c|c|}
\hline & $\begin{array}{l}\text { 1. Early } \\
\text { retirees }\end{array}$ & $\begin{array}{l}\text { 2. Low-educated } \\
\text { rural mothers } \\
\text { without work } \\
\text { experience }\end{array}$ & $\begin{array}{c}3 . \\
\text { Retirees }\end{array}$ & $\begin{array}{l}\text { 4. Inactive } \\
\text { middle- } \\
\text { aged } \\
\text { wives }\end{array}$ & $\begin{array}{l}\text { 5. Long-term } \\
\text { unemployed } \\
\text { educated } \\
\text { single youth }\end{array}$ & $\begin{array}{l}\text { 6. Working- } \\
\text { age long- } \\
\text { term } \\
\text { unemployed }\end{array}$ & $\begin{array}{l}\text { 7. Working- } \\
\text { age newly } \\
\text { unemployed }\end{array}$ & $\begin{array}{l}\text { 8. Low- } \\
\text { educated } \\
\text { and rural } \\
\text { disabled }\end{array}$ \\
\hline \multicolumn{9}{|c|}{ Individuals' parents in household } \\
\hline One parent & $5 \%$ & $7 \%$ & $3 \%$ & $7 \%$ & $19 \%$ & $13 \%$ & $12 \%$ & $25 \%$ \\
\hline Both parents & $1 \%$ & $11 \%$ & $0 \%$ & $3 \%$ & $66 \%$ & $14 \%$ & $21 \%$ & $28 \%$ \\
\hline None & $94 \%$ & $82 \%$ & $97 \%$ & $90 \%$ & $15 \%$ & $73 \%$ & $67 \%$ & $47 \%$ \\
\hline Children under six & $13 \%$ & $37 \%$ & $6 \%$ & $30 \%$ & $25 \%$ & $23 \%$ & $31 \%$ & $8 \%$ \\
\hline $\begin{array}{l}\text { Three or more children } \\
\text { under } 16\end{array}$ & $1 \%$ & $9 \%$ & $1 \%$ & $4 \%$ & $5 \%$ & $4 \%$ & $7 \%$ & $3 \%$ \\
\hline Elderly present (over 64) & $12 \%$ & $15 \%$ & $24 \%$ & $18 \%$ & $15 \%$ & $18 \%$ & $8 \%$ & $30 \%$ \\
\hline \multicolumn{9}{|c|}{ Children under 13 in childcare } \\
\hline None of the children & $4 \%$ & $15 \%$ & $3 \%$ & $15 \%$ & $12 \%$ & $17 \%$ & $9 \%$ & $12 \%$ \\
\hline Some of the children & $3 \%$ & $13 \%$ & $3 \%$ & $8 \%$ & $6 \%$ & $7 \%$ & $12 \%$ & $5 \%$ \\
\hline $\begin{array}{l}\text { No children under } 13 \text { in } \\
\text { household }\end{array}$ & $76 \%$ & $32 \%$ & $82 \%$ & $42 \%$ & $56 \%$ & $47 \%$ & $46 \%$ & $67 \%$ \\
\hline All of the children & $16 \%$ & $40 \%$ & $11 \%$ & $36 \%$ & $26 \%$ & $29 \%$ & $33 \%$ & $15 \%$ \\
\hline \multicolumn{9}{|l|}{ Ever worked } \\
\hline No & $1 \%$ & $93 \%$ & $2 \%$ & $6 \%$ & $86 \%$ & $10 \%$ & $0 \%$ & $83 \%$ \\
\hline Yes & $99 \%$ & $7 \%$ & $98 \%$ & $94 \%$ & $14 \%$ & $90 \%$ & $100 \%$ & $17 \%$ \\
\hline Years of work experiencef & 27 & 13 & 33 & 14 & 3 & 17 & 15 & 18 \\
\hline \multicolumn{9}{|l|}{ Worked in last year } \\
\hline 2 or more months & $5 \%$ & $7 \%$ & $2 \%$ & $0 \%$ & $4 \%$ & $0 \%$ & $100 \%$ & $1 \%$ \\
\hline Less than 2 months & $95 \%$ & $93 \%$ & $98 \%$ & $100 \%$ & $96 \%$ & $100 \%$ & $0 \%$ & $99 \%$ \\
\hline \multicolumn{9}{|l|}{ Able to keep dwelling warm } \\
\hline No & $21 \%$ & $27 \%$ & $20 \%$ & $28 \%$ & $34 \%$ & $39 \%$ & $31 \%$ & $32 \%$ \\
\hline Yes & $79 \%$ & $73 \%$ & $80 \%$ & $72 \%$ & $66 \%$ & $61 \%$ & $69 \%$ & $68 \%$ \\
\hline \multicolumn{9}{|l|}{ Degree of urbanization } \\
\hline Densely populated & $44 \%$ & $21 \%$ & $40 \%$ & $42 \%$ & $30 \%$ & $38 \%$ & $29 \%$ & $16 \%$ \\
\hline Intermediate area & $1 \%$ & $1 \%$ & $1 \%$ & $0 \%$ & $1 \%$ & $3 \%$ & $0 \%$ & $0 \%$ \\
\hline Sparsely populated & $55 \%$ & $78 \%$ & $59 \%$ & $57 \%$ & $69 \%$ & $59 \%$ & $70 \%$ & $84 \%$ \\
\hline
\end{tabular}




\begin{tabular}{|c|c|c|c|c|c|c|c|c|}
\hline & $\begin{array}{l}\text { 1. Early } \\
\text { retirees }\end{array}$ & $\begin{array}{l}\text { 2. Low-educated } \\
\text { rural mothers } \\
\text { without work } \\
\text { experience }\end{array}$ & $\begin{array}{c}3 . \\
\text { Retirees }\end{array}$ & $\begin{array}{l}\text { 4. Inactive } \\
\text { middle- } \\
\text { aged } \\
\text { wives }\end{array}$ & $\begin{array}{l}\text { 5. Long-term } \\
\text { unemployed } \\
\text { educated } \\
\text { single youth }\end{array}$ & $\begin{array}{l}\text { 6. Working- } \\
\text { age long- } \\
\text { term } \\
\text { unemployed }\end{array}$ & $\begin{array}{l}\text { 7. Working- } \\
\text { age newly } \\
\text { unemployed }\end{array}$ & $\begin{array}{l}\text { 8. Low- } \\
\text { educated } \\
\text { and rural } \\
\text { disabled }\end{array}$ \\
\hline R01 - Nord-Vest, Centru & $23 \%$ & $20 \%$ & $25 \%$ & $23 \%$ & $25 \%$ & $18 \%$ & $30 \%$ & $19 \%$ \\
\hline R02 - Nord-Est, Sud-Est & $28 \%$ & $28 \%$ & $26 \%$ & $34 \%$ & $28 \%$ & $31 \%$ & $33 \%$ & $40 \%$ \\
\hline R03 - Sud, Bucharest-Ilfov & $30 \%$ & $31 \%$ & $28 \%$ & $28 \%$ & $30 \%$ & $30 \%$ & $23 \%$ & $27 \%$ \\
\hline R04 - Sud-Vest, Vest & $18 \%$ & $21 \%$ & $21 \%$ & $15 \%$ & $16 \%$ & $20 \%$ & $14 \%$ & $14 \%$ \\
\hline Receives at least one benefit & $96 \%$ & $77 \%$ & $98 \%$ & $73 \%$ & $70 \%$ & $75 \%$ & $79 \%$ & $87 \%$ \\
\hline \multicolumn{9}{|c|}{ Receives benefits at household level } \\
\hline Family child & $27 \%$ & $71 \%$ & $20 \%$ & $62 \%$ & $53 \%$ & $53 \%$ & $62 \%$ & $41 \%$ \\
\hline Social exclusion & $21 \%$ & $36 \%$ & $17 \%$ & $30 \%$ & $34 \%$ & $43 \%$ & $33 \%$ & $40 \%$ \\
\hline \multicolumn{9}{|l|}{ Housing } \\
\hline Old age at household level & $54 \%$ & $19 \%$ & $90 \%$ & $23 \%$ & $23 \%$ & $22 \%$ & $16 \%$ & $39 \%$ \\
\hline \multicolumn{9}{|c|}{ Receives benefits at individual level } \\
\hline Unemployment & $0 \%$ & $0 \%$ & $0 \%$ & $1 \%$ & $12 \%$ & $21 \%$ & $20 \%$ & $1 \%$ \\
\hline Old age & $42 \%$ & $0 \%$ & $88 \%$ & $3 \%$ & $0 \%$ & $0 \%$ & $0 \%$ & $5 \%$ \\
\hline Survivor & $2 \%$ & $1 \%$ & $3 \%$ & $0 \%$ & $1 \%$ & $0 \%$ & $0 \%$ & $4 \%$ \\
\hline Sickness & $0 \%$ & $0 \%$ & $0 \%$ & $0 \%$ & $0 \%$ & $0 \%$ & $0 \%$ & $0 \%$ \\
\hline Disability & $48 \%$ & $1 \%$ & $7 \%$ & $1 \%$ & $1 \%$ & $1 \%$ & $0 \%$ & $57 \%$ \\
\hline Education & $0 \%$ & $0 \%$ & $0 \%$ & $0 \%$ & $0 \%$ & $0 \%$ & $0 \%$ & $0 \%$ \\
\hline \multicolumn{9}{|c|}{ Benefits as share of total gross household income, all households } \\
\hline Family child & $2 \%$ & $9 \%$ & $1 \%$ & $6 \%$ & $6 \%$ & $8 \%$ & $9 \%$ & $4 \%$ \\
\hline Social exclusion & $1 \%$ & $4 \%$ & $1 \%$ & $1 \%$ & $4 \%$ & $9 \%$ & $2 \%$ & $4 \%$ \\
\hline Housing & $0 \%$ & $0 \%$ & $0 \%$ & $0 \%$ & $0 \%$ & $0 \%$ & $0 \%$ & $0 \%$ \\
\hline Unemployment & $1 \%$ & $1 \%$ & $0 \%$ & $0 \%$ & $3 \%$ & $8 \%$ & $3 \%$ & $1 \%$ \\
\hline Old age & $33 \%$ & $10 \%$ & $65 \%$ & $11 \%$ & $12 \%$ & $12 \%$ & $6 \%$ & $22 \%$ \\
\hline Survivor & $1 \%$ & $2 \%$ & $3 \%$ & $1 \%$ & $2 \%$ & $4 \%$ & $0 \%$ & $3 \%$ \\
\hline Sickness & $0 \%$ & $0 \%$ & $0 \%$ & $0 \%$ & $0 \%$ & $0 \%$ & $0 \%$ & $0 \%$ \\
\hline Disability & $22 \%$ & $3 \%$ & $5 \%$ & $4 \%$ & $7 \%$ & $9 \%$ & $3 \%$ & $19 \%$ \\
\hline Education & $0 \%$ & $0 \%$ & $0 \%$ & $0 \%$ & $0 \%$ & $0 \%$ & $0 \%$ & $0 \%$ \\
\hline
\end{tabular}




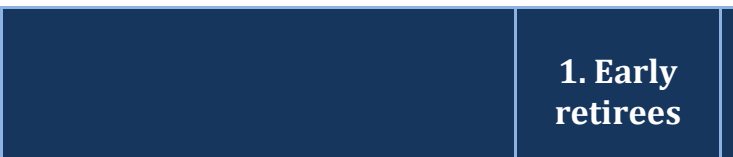

2. Low-educated rural mothers

without work experience

Family child

Social exclusion

Housing

Unemployment

Old age

Survivor

Sickness

Disability

Education

$6 \%$

$4 \% \quad 12 \%$

\begin{tabular}{|c|c|}
\hline $2 \%$ & $4 \%$ \\
\hline & $4 \%$ \\
\hline
\end{tabular}

Inactive

5. Long-term
unemployed

educated

age long-

7. Working-

8. Low-

aged

term

age newly

unemployed

educated

and rural disabled

a. Refers to individuals aged 25 and over.

b. Applies to individuals aged 25 and over. Students aged 16 to 24 are not included in the sample.

c. Based on total gross household income.

d. Based on total equivalized disposable household income.

e. Dependent children include: 1. household members under 18; 2. household members aged between 18 and 24 who are economically inactive and living with at least one parent.

$f$. Refers only to individuals who have worked before.

Source: WB staff calculations based on EU-SILC. 


\begin{tabular}{|c|c|c|c|c|c|c|c|}
\hline & $\begin{array}{l}\text { 1. Early } \\
\text { retirees } \\
\text { and } \\
\text { inactive }\end{array}$ & $\begin{array}{l}\text { 2. Low-educated } \\
\text { rural mothers } \\
\text { without work } \\
\text { experience }\end{array}$ & $\begin{array}{c}3 . \\
\text { Retirees }\end{array}$ & $\begin{array}{l}\text { 4. Low- } \\
\text { educated } \\
\text { and rural } \\
\text { disabled }\end{array}$ & $\begin{array}{l}\text { 5. Educated } \\
\text { unemployed } \\
\text { or inactive } \\
\text { youth }\end{array}$ & $\begin{array}{l}\text { 6. Long-term } \\
\text { unemployed } \\
\text { single youth }\end{array}$ & $\begin{array}{l}\text { 7. Working- } \\
\text { age newly- } \\
\text { unemployed } \\
\text { or inactive }\end{array}$ \\
\hline Cluster size & $32 \%$ & $29 \%$ & $21 \%$ & $\mathbf{5 \%}$ & $\mathbf{5 \%}$ & $4 \%$ & $4 \%$ \\
\hline Population & $1,331,315$ & $1,226,783$ & 877,230 & 213,663 & 188,575 & 181,049 & 162,651 \\
\hline \multicolumn{8}{|c|}{ INDICATORS } \\
\hline \multicolumn{8}{|c|}{ Labor market attachment } \\
\hline Unemployed & $1 \%$ & $1 \%$ & $0 \%$ & $2 \%$ & $42 \%$ & $4 \%$ & $57 \%$ \\
\hline Long-term unemployed & $7 \%$ & $0 \%$ & $1 \%$ & $0 \%$ & $0 \%$ & $96 \%$ & $0 \%$ \\
\hline Retired & $46 \%$ & $0 \%$ & $95 \%$ & $1 \%$ & $0 \%$ & $0 \%$ & $5 \%$ \\
\hline Disabled & $0 \%$ & $0 \%$ & $0 \%$ & $62 \%$ & $2 \%$ & $0 \%$ & $0 \%$ \\
\hline Other inactive & $46 \%$ & $99 \%$ & $5 \%$ & $35 \%$ & $56 \%$ & $0 \%$ & $39 \%$ \\
\hline \multicolumn{8}{|c|}{ At least one working adult in householda } \\
\hline No & $45 \%$ & $20 \%$ & $61 \%$ & $36 \%$ & $13 \%$ & $27 \%$ & $58 \%$ \\
\hline Yes & $55 \%$ & $80 \%$ & $39 \%$ & $64 \%$ & $87 \%$ & $73 \%$ & $42 \%$ \\
\hline \multicolumn{8}{|l|}{ Work experience } \\
\hline Never worked & $1 \%$ & $79 \%$ & $2 \%$ & $69 \%$ & $36 \%$ & $78 \%$ & $8 \%$ \\
\hline Less than 2 months & $96 \%$ & $14 \%$ & $96 \%$ & $17 \%$ & $7 \%$ & $22 \%$ & $0 \%$ \\
\hline 2 or more months & $3 \%$ & $8 \%$ & $2 \%$ & $14 \%$ & $56 \%$ & $0 \%$ & $92 \%$ \\
\hline \multicolumn{8}{|c|}{ Self-assessed physical incapacity } \\
\hline Strongly limited & $16 \%$ & $0 \%$ & $8 \%$ & $79 \%$ & $0 \%$ & $0 \%$ & $4 \%$ \\
\hline None/limited & $84 \%$ & $100 \%$ & $92 \%$ & $21 \%$ & $100 \%$ & $100 \%$ & $96 \%$ \\
\hline \multicolumn{8}{|c|}{ ACTIVE COVARIATES } \\
\hline \multicolumn{8}{|l|}{ Age groups (4) } \\
\hline $16-24$ years & $0 \%$ & $13 \%$ & $0 \%$ & $9 \%$ & $44 \%$ & $60 \%$ & $8 \%$ \\
\hline $25-34$ years & $0 \%$ & $37 \%$ & $0 \%$ & $23 \%$ & $44 \%$ & $33 \%$ & $28 \%$ \\
\hline $35-59$ years & $100 \%$ & $46 \%$ & $4 \%$ & $62 \%$ & $12 \%$ & $6 \%$ & $62 \%$ \\
\hline 60-64 years & $0 \%$ & $3 \%$ & $96 \%$ & $6 \%$ & $0 \%$ & $0 \%$ & $1 \%$ \\
\hline Gender & & & & & & & \\
\hline
\end{tabular}




\begin{tabular}{|c|c|c|c|c|c|c|c|}
\hline & $\begin{array}{l}\text { 1. Early } \\
\text { retirees } \\
\text { and } \\
\text { inactive }\end{array}$ & $\begin{array}{l}\text { 2. Low-educated } \\
\text { rural mothers } \\
\text { without work } \\
\text { experience }\end{array}$ & $\begin{array}{c}3 . \\
\text { Retirees }\end{array}$ & $\begin{array}{l}\text { 4. Low- } \\
\text { educated } \\
\text { and rural } \\
\text { disabled }\end{array}$ & $\begin{array}{l}\text { 5. Educated } \\
\text { unemployed } \\
\text { or inactive } \\
\text { youth }\end{array}$ & $\begin{array}{l}\text { 6. Long-term } \\
\text { unemployed } \\
\text { single youth }\end{array}$ & $\begin{array}{l}\text { 7. Working- } \\
\text { age newly- } \\
\text { unemployed } \\
\text { or inactive }\end{array}$ \\
\hline Male & $39 \%$ & $3 \%$ & $46 \%$ & $51 \%$ & $37 \%$ & $73 \%$ & $95 \%$ \\
\hline Female & $61 \%$ & $97 \%$ & $54 \%$ & $49 \%$ & $63 \%$ & $27 \%$ & $5 \%$ \\
\hline \multicolumn{8}{|l|}{ Education } \\
\hline Primary & $33 \%$ & $56 \%$ & $40 \%$ & $45 \%$ & $0 \%$ & $27 \%$ & $51 \%$ \\
\hline Secondary & $67 \%$ & $42 \%$ & $47 \%$ & $25 \%$ & $64 \%$ & $66 \%$ & $46 \%$ \\
\hline Tertiary & $0 \%$ & $0 \%$ & $12 \%$ & $3 \%$ & $36 \%$ & $5 \%$ & $0 \%$ \\
\hline NA & $0 \%$ & $2 \%$ & $1 \%$ & $26 \%$ & $0 \%$ & $2 \%$ & $2 \%$ \\
\hline Urban & $44 \%$ & $22 \%$ & $40 \%$ & $23 \%$ & $56 \%$ & $28 \%$ & $23 \%$ \\
\hline Rural & $56 \%$ & $78 \%$ & $60 \%$ & $77 \%$ & $44 \%$ & $72 \%$ & $77 \%$ \\
\hline \multicolumn{8}{|c|}{ INACTIVE COVARIATES } \\
\hline \multicolumn{8}{|l|}{ Age groups (8) } \\
\hline 16-19 years & $0 \%$ & $2 \%$ & $0 \%$ & $4 \%$ & $11 \%$ & $13 \%$ & $2 \%$ \\
\hline 20-24 years & $0 \%$ & $11 \%$ & $0 \%$ & $5 \%$ & $33 \%$ & $47 \%$ & $6 \%$ \\
\hline 25-29 years & $0 \%$ & $15 \%$ & $0 \%$ & $11 \%$ & $19 \%$ & $21 \%$ & $10 \%$ \\
\hline 30-34 years & $0 \%$ & $22 \%$ & $0 \%$ & $12 \%$ & $25 \%$ & $12 \%$ & $19 \%$ \\
\hline $35-44$ years & $10 \%$ & $21 \%$ & $0 \%$ & $25 \%$ & $5 \%$ & $5 \%$ & $33 \%$ \\
\hline $45-54$ years & $39 \%$ & $19 \%$ & $1 \%$ & $26 \%$ & $6 \%$ & $1 \%$ & $20 \%$ \\
\hline 55-59 years & $50 \%$ & $7 \%$ & $3 \%$ & $11 \%$ & $1 \%$ & $0 \%$ & $9 \%$ \\
\hline $60-64$ years & $0 \%$ & $3 \%$ & $96 \%$ & $6 \%$ & $0 \%$ & $0 \%$ & $1 \%$ \\
\hline \multicolumn{8}{|l|}{ Education } \\
\hline Primary & $4 \%$ & $8 \%$ & $12 \%$ & $13 \%$ & $0 \%$ & $3 \%$ & $7 \%$ \\
\hline Lower secondary & $28 \%$ & $48 \%$ & $29 \%$ & $32 \%$ & $0 \%$ & $24 \%$ & $45 \%$ \\
\hline Upper secondary & $59 \%$ & $41 \%$ & $40 \%$ & $25 \%$ & $63 \%$ & $65 \%$ & $45 \%$ \\
\hline Post-secondary & $7 \%$ & $1 \%$ & $7 \%$ & $1 \%$ & $1 \%$ & $1 \%$ & $2 \%$ \\
\hline Tertiary & $0 \%$ & $0 \%$ & $12 \%$ & $3 \%$ & $36 \%$ & $5 \%$ & $0 \%$ \\
\hline NA & $0 \%$ & $2 \%$ & $1 \%$ & $26 \%$ & $0 \%$ & $2 \%$ & $2 \%$ \\
\hline \multicolumn{8}{|c|}{ Have never studied before/illiterate } \\
\hline No & $100 \%$ & $98 \%$ & $99 \%$ & $74 \%$ & $100 \%$ & $98 \%$ & $98 \%$ \\
\hline
\end{tabular}




\begin{tabular}{|c|c|c|c|c|c|c|c|}
\hline & $\begin{array}{l}\text { 1. Early } \\
\text { retirees } \\
\text { and } \\
\text { inactive }\end{array}$ & $\begin{array}{l}\text { 2. Low-educated } \\
\text { rural mothers } \\
\text { without work } \\
\text { experience }\end{array}$ & $\begin{array}{c}3 . \\
\text { Retirees }\end{array}$ & $\begin{array}{l}\text { 4. Low- } \\
\text { educated } \\
\text { and rural } \\
\text { disabled }\end{array}$ & $\begin{array}{l}\text { 5. Educated } \\
\text { unemployed } \\
\text { or inactive } \\
\text { youth }\end{array}$ & $\begin{array}{l}\text { 6. Long-term } \\
\text { unemployed } \\
\text { single youth }\end{array}$ & $\begin{array}{l}\text { 7. Working- } \\
\text { age newly- } \\
\text { unemployed } \\
\text { or inactive }\end{array}$ \\
\hline Yes & $0 \%$ & $2 \%$ & $1 \%$ & $26 \%$ & $0 \%$ & $2 \%$ & $2 \%$ \\
\hline \multicolumn{8}{|c|}{ Enrolled in education ${ }^{b}$} \\
\hline Yes & $0 \%$ & $3 \%$ & $0 \%$ & $1 \%$ & $5 \%$ & $0 \%$ & $1 \%$ \\
\hline No & $100 \%$ & $97 \%$ & $100 \%$ & $99 \%$ & $95 \%$ & $100 \%$ & $99 \%$ \\
\hline \multicolumn{8}{|l|}{ Marital status } \\
\hline Married & $79 \%$ & $76 \%$ & $69 \%$ & $33 \%$ & $46 \%$ & $19 \%$ & $57 \%$ \\
\hline Never married & $3 \%$ & $18 \%$ & $2 \%$ & $51 \%$ & $52 \%$ & $79 \%$ & $33 \%$ \\
\hline Divorced/separated & $6 \%$ & $3 \%$ & $4 \%$ & $9 \%$ & $2 \%$ & $1 \%$ & $7 \%$ \\
\hline Widowed & $11 \%$ & $3 \%$ & $24 \%$ & $8 \%$ & $1 \%$ & $0 \%$ & $3 \%$ \\
\hline \multicolumn{8}{|l|}{ Household income } \\
\hline Labor income & 3463 & 3943 & 2415 & 2695 & 6577 & 3452 & 3090 \\
\hline Other income & 71 & 24 & 43 & 40 & 92 & 106 & 38 \\
\hline Benefits & 2544 & 1084 & 3661 & 2015 & 1433 & 1389 & 1185 \\
\hline \multicolumn{8}{|c|}{ Household income sharesc } \\
\hline Labor income & $42 \%$ & $69 \%$ & $25 \%$ & $47 \%$ & $76 \%$ & $61 \%$ & $65 \%$ \\
\hline Other income & $1 \%$ & $1 \%$ & $1 \%$ & $1 \%$ & $3 \%$ & $2 \%$ & $1 \%$ \\
\hline Benefits & $57 \%$ & $31 \%$ & $75 \%$ & $52 \%$ & $21 \%$ & $37 \%$ & $34 \%$ \\
\hline \multicolumn{8}{|l|}{ Income quintiled } \\
\hline Poorest & $17 \%$ & $41 \%$ & $9 \%$ & $35 \%$ & $15 \%$ & $48 \%$ & $49 \%$ \\
\hline Q2 & $21 \%$ & $28 \%$ & $18 \%$ & $28 \%$ & $18 \%$ & $29 \%$ & $19 \%$ \\
\hline Q3 & $24 \%$ & $17 \%$ & $24 \%$ & $20 \%$ & $21 \%$ & $14 \%$ & $16 \%$ \\
\hline Q4 & $22 \%$ & $10 \%$ & $27 \%$ & $9 \%$ & $24 \%$ & $5 \%$ & $13 \%$ \\
\hline Richest & $16 \%$ & $4 \%$ & $22 \%$ & $8 \%$ & $22 \%$ & $5 \%$ & $2 \%$ \\
\hline \multicolumn{8}{|l|}{ NA } \\
\hline \multicolumn{8}{|l|}{ Working partner } \\
\hline Yes & $31 \%$ & $56 \%$ & $9 \%$ & $16 \%$ & $41 \%$ & $8 \%$ & $22 \%$ \\
\hline No & $47 \%$ & $19 \%$ & $59 \%$ & $16 \%$ & $3 \%$ & $11 \%$ & $33 \%$ \\
\hline NA & $22 \%$ & $25 \%$ & $32 \%$ & $68 \%$ & $56 \%$ & $81 \%$ & $45 \%$ \\
\hline
\end{tabular}




\begin{tabular}{|c|c|c|c|}
\hline & $\begin{array}{l}\text { 1. Early } \\
\text { retirees } \\
\text { and } \\
\text { inactive }\end{array}$ & $\begin{array}{l}\text { 2. Low-educated } \\
\text { rural mothers } \\
\text { without work } \\
\text { experience }\end{array}$ & $\begin{array}{c}3 . \\
\text { Retirees }\end{array}$ \\
\hline
\end{tabular}

4. Loweducated and rural disabled

5. Educated

unemployed

or inactive youth

6. Long-term unemployed single youth

7. Workingage newlyunemployed or inactive

\section{Partner economic status}

\begin{tabular}{|c|c|c|c|c|c|c|c|}
\hline Working & $31 \%$ & $56 \%$ & $9 \%$ & $16 \%$ & $41 \%$ & $8 \%$ & $22 \%$ \\
\hline Unemployed & $2 \%$ & $4 \%$ & $0 \%$ & $1 \%$ & $0 \%$ & $4 \%$ & $1 \%$ \\
\hline Retired & $24 \%$ & $9 \%$ & $51 \%$ & $5 \%$ & $0 \%$ & $0 \%$ & $1 \%$ \\
\hline Inactive & $21 \%$ & $6 \%$ & $9 \%$ & $10 \%$ & $2 \%$ & $6 \%$ & $29 \%$ \\
\hline Student/military service & $0 \%$ & $0 \%$ & $0 \%$ & $0 \%$ & $0 \%$ & $0 \%$ & $1 \%$ \\
\hline NA & $22 \%$ & $25 \%$ & $32 \%$ & $68 \%$ & $56 \%$ & $81 \%$ & $45 \%$ \\
\hline Partner income (mean) & 1457 & 2632 & 587 & 1816 & 4896 & 1597 & 982 \\
\hline Working partner income (mean) & 3559 & 3450 & 4226 & 3517 & 5210 & 3738 & 2196 \\
\hline \multicolumn{8}{|l|}{ Working partner income quintile } \\
\hline Poorest & $4 \%$ & $9 \%$ & $2 \%$ & $3 \%$ & $2 \%$ & $0 \%$ & $5 \%$ \\
\hline Q2 & $8 \%$ & $13 \%$ & $1 \%$ & $2 \%$ & $4 \%$ & $3 \%$ & $11 \%$ \\
\hline Q3 & $8 \%$ & $12 \%$ & $2 \%$ & $6 \%$ & $7 \%$ & $2 \%$ & $4 \%$ \\
\hline Q4 & $5 \%$ & $11 \%$ & $2 \%$ & $2 \%$ & $11 \%$ & $2 \%$ & $1 \%$ \\
\hline Richest & $5 \%$ & $11 \%$ & $2 \%$ & $3 \%$ & $17 \%$ & $1 \%$ & $0 \%$ \\
\hline No partner or partner without income & $69 \%$ & $44 \%$ & $91 \%$ & $84 \%$ & $59 \%$ & $92 \%$ & $78 \%$ \\
\hline Household size (mean) & 3.30 & 4.60 & 2.79 & 3.86 & 4.17 & 4.91 & 4.21 \\
\hline \multicolumn{8}{|l|}{ Tenure status } \\
\hline Owner & $99 \%$ & $94 \%$ & $100 \%$ & $98 \%$ & $95 \%$ & $95 \%$ & $92 \%$ \\
\hline Tenant & $0 \%$ & $1 \%$ & $0 \%$ & $1 \%$ & $2 \%$ & $0 \%$ & $0 \%$ \\
\hline Reduced rate & $1 \%$ & $2 \%$ & $0 \%$ & $0 \%$ & $1 \%$ & $3 \%$ & $1 \%$ \\
\hline Free & $0 \%$ & $3 \%$ & $0 \%$ & $1 \%$ & $1 \%$ & $2 \%$ & $7 \%$ \\
\hline \multicolumn{8}{|l|}{ Household composition } \\
\hline One-person & $9 \%$ & $2 \%$ & $16 \%$ & $4 \%$ & $2 \%$ & $2 \%$ & $6 \%$ \\
\hline Single parent & $1 \%$ & $1 \%$ & $0 \%$ & $1 \%$ & $1 \%$ & $1 \%$ & $2 \%$ \\
\hline $2+$ adults without dependent children ${ }^{\mathrm{e}}$ & $55 \%$ & $23 \%$ & $60 \%$ & $56 \%$ & $31 \%$ & $29 \%$ & $32 \%$ \\
\hline $2+$ adults with 1 dependent childe & $8 \%$ & $15 \%$ & $3 \%$ & $7 \%$ & $19 \%$ & $5 \%$ & $10 \%$ \\
\hline $2+$ adults with $2+$ dependent children ${ }^{\mathrm{e}}$ & $27 \%$ & $60 \%$ & $20 \%$ & $34 \%$ & $47 \%$ & $63 \%$ & $49 \%$ \\
\hline
\end{tabular}




\begin{tabular}{|c|c|c|c|c|c|c|c|}
\hline & $\begin{array}{l}\text { 1. Early } \\
\text { retirees } \\
\text { and } \\
\text { inactive }\end{array}$ & $\begin{array}{l}\text { 2. Low-educated } \\
\text { rural mothers } \\
\text { without work } \\
\text { experience }\end{array}$ & $\begin{array}{c}3 . \\
\text { Retirees }\end{array}$ & $\begin{array}{l}\text { 4. Low- } \\
\text { educated } \\
\text { and rural } \\
\text { disabled }\end{array}$ & $\begin{array}{l}\text { 5. Educated } \\
\text { unemployed } \\
\text { or inactive } \\
\text { youth }\end{array}$ & $\begin{array}{l}\text { 6. Long-term } \\
\text { unemployed } \\
\text { single youth }\end{array}$ & $\begin{array}{l}\text { 7. Working- } \\
\text { age newly- } \\
\text { unemployed } \\
\text { or inactive }\end{array}$ \\
\hline \multicolumn{8}{|l|}{ Individuals' parents present } \\
\hline One parent & $6 \%$ & $5 \%$ & $3 \%$ & $23 \%$ & $10 \%$ & $23 \%$ & $14 \%$ \\
\hline Both parents & $1 \%$ & $9 \%$ & $0 \%$ & $29 \%$ & $40 \%$ & $52 \%$ & $18 \%$ \\
\hline None & $93 \%$ & $86 \%$ & $97 \%$ & $48 \%$ & $50 \%$ & $25 \%$ & $68 \%$ \\
\hline Children under six & $11 \%$ & $36 \%$ & $7 \%$ & $10 \%$ & $33 \%$ & $23 \%$ & $26 \%$ \\
\hline Three or more children under 16 & $2 \%$ & $12 \%$ & $0 \%$ & $4 \%$ & $3 \%$ & $7 \%$ & $11 \%$ \\
\hline Elderly present (over 64) & $13 \%$ & $15 \%$ & $21 \%$ & $26 \%$ & $15 \%$ & $24 \%$ & $16 \%$ \\
\hline \multicolumn{8}{|l|}{ Children under 13 in childcare } \\
\hline None of the children & $5 \%$ & $13 \%$ & $3 \%$ & $8 \%$ & $11 \%$ & $11 \%$ & $11 \%$ \\
\hline Some of the children & $3 \%$ & $16 \%$ & $2 \%$ & $5 \%$ & $6 \%$ & $21 \%$ & $12 \%$ \\
\hline No children under 13 in household & $77 \%$ & $34 \%$ & $82 \%$ & $72 \%$ & $56 \%$ & $49 \%$ & $47 \%$ \\
\hline All of the children & $16 \%$ & $36 \%$ & $13 \%$ & $15 \%$ & $27 \%$ & $19 \%$ & $30 \%$ \\
\hline \multicolumn{8}{|l|}{ Ever worked } \\
\hline No & $1 \%$ & $79 \%$ & $2 \%$ & $69 \%$ & $36 \%$ & $78 \%$ & $8 \%$ \\
\hline Yes & $99 \%$ & $21 \%$ & $98 \%$ & $31 \%$ & $64 \%$ & $22 \%$ & $92 \%$ \\
\hline Years of work experiencef & 26 & 13 & 33 & 17 & 7 & 7 & 15 \\
\hline \multicolumn{8}{|l|}{ Worked in last year } \\
\hline 2 or more months & $3 \%$ & $10 \%$ & $2 \%$ & $62 \%$ & $65 \%$ & $2 \%$ & $98 \%$ \\
\hline Less than 2 months & $97 \%$ & $90 \%$ & $98 \%$ & $38 \%$ & $35 \%$ & $98 \%$ & $2 \%$ \\
\hline \multicolumn{8}{|l|}{ Able to keep dwelling warm } \\
\hline No & $24 \%$ & $28 \%$ & $23 \%$ & $34 \%$ & $25 \%$ & $30 \%$ & $33 \%$ \\
\hline Yes & $76 \%$ & $72 \%$ & $77 \%$ & $66 \%$ & $75 \%$ & $70 \%$ & $67 \%$ \\
\hline \multicolumn{8}{|l|}{ Degree of urbanization } \\
\hline Densely populated & $42 \%$ & $21 \%$ & $39 \%$ & $23 \%$ & $56 \%$ & $25 \%$ & $23 \%$ \\
\hline Intermediate area & $2 \%$ & $1 \%$ & $1 \%$ & $1 \%$ & $1 \%$ & $3 \%$ & $0 \%$ \\
\hline Sparsely populated & $56 \%$ & $78 \%$ & $60 \%$ & $77 \%$ & $44 \%$ & $72 \%$ & $77 \%$ \\
\hline \multicolumn{8}{|l|}{ Region } \\
\hline R01 - Nord-Vest, Centru & $24 \%$ & $22 \%$ & $24 \%$ & $23 \%$ & $28 \%$ & $20 \%$ & $25 \%$ \\
\hline
\end{tabular}




\begin{tabular}{|c|c|c|c|c|c|c|c|}
\hline & $\begin{array}{l}\text { 1. Early } \\
\text { retirees } \\
\text { and } \\
\text { inactive }\end{array}$ & $\begin{array}{l}\text { 2. Low-educated } \\
\text { rural mothers } \\
\text { without work } \\
\text { experience }\end{array}$ & $\begin{array}{c}3 . \\
\text { Retirees }\end{array}$ & $\begin{array}{l}\text { 4. Low- } \\
\text { educated } \\
\text { and rural } \\
\text { disabled }\end{array}$ & $\begin{array}{l}\text { 5. Educated } \\
\text { unemployed } \\
\text { or inactive } \\
\text { youth }\end{array}$ & $\begin{array}{l}\text { 6. Long-term } \\
\text { unemployed } \\
\text { single youth }\end{array}$ & $\begin{array}{l}\text { 7. Working- } \\
\text { age newly- } \\
\text { unemployed } \\
\text { or inactive }\end{array}$ \\
\hline R02 - Nord-Est, Sud-Est & $28 \%$ & $26 \%$ & $25 \%$ & $35 \%$ & $26 \%$ & $29 \%$ & $28 \%$ \\
\hline R03 - Sud, Bucharest-Ilfov & $28 \%$ & $31 \%$ & $29 \%$ & $28 \%$ & $26 \%$ & $31 \%$ & $34 \%$ \\
\hline R04 - Sud-Vest, Vest & $21 \%$ & $20 \%$ & $21 \%$ & $15 \%$ & $20 \%$ & $21 \%$ & $12 \%$ \\
\hline Receives at least one benefit & $93 \%$ & $81 \%$ & $99 \%$ & $84 \%$ & $66 \%$ & $67 \%$ & $79 \%$ \\
\hline \multicolumn{8}{|c|}{ Receives benefits at household level } \\
\hline Family child & $29 \%$ & $69 \%$ & $20 \%$ & $31 \%$ & $54 \%$ & $52 \%$ & $58 \%$ \\
\hline Social exclusion & $26 \%$ & $33 \%$ & $22 \%$ & $41 \%$ & $24 \%$ & $25 \%$ & $42 \%$ \\
\hline \multicolumn{8}{|l|}{ Housing } \\
\hline Old age at household level & $55 \%$ & $23 \%$ & $94 \%$ & $37 \%$ & $24 \%$ & $32 \%$ & $28 \%$ \\
\hline \multicolumn{8}{|c|}{ Receives benefits at individual level } \\
\hline Unemployment & $2 \%$ & $0 \%$ & $0 \%$ & $0 \%$ & $7 \%$ & $8 \%$ & $8 \%$ \\
\hline Old age & $42 \%$ & $1 \%$ & $91 \%$ & $4 \%$ & $0 \%$ & $0 \%$ & $1 \%$ \\
\hline Survivor & $1 \%$ & $2 \%$ & $2 \%$ & $3 \%$ & $0 \%$ & $0 \%$ & $1 \%$ \\
\hline \multicolumn{8}{|l|}{ Sickness } \\
\hline Disability & $33 \%$ & $3 \%$ & $4 \%$ & $55 \%$ & $3 \%$ & $0 \%$ & $7 \%$ \\
\hline Education & $0 \%$ & $0 \%$ & $0 \%$ & $0 \%$ & $0 \%$ & $0 \%$ & $0 \%$ \\
\hline \multicolumn{8}{|c|}{ Benefits as share of total gross household income, all households } \\
\hline Family child & $3 \%$ & $9 \%$ & $1 \%$ & $4 \%$ & $7 \%$ & $9 \%$ & $9 \%$ \\
\hline Social exclusion & $2 \%$ & $4 \%$ & $1 \%$ & $4 \%$ & $1 \%$ & $2 \%$ & $6 \%$ \\
\hline Housing & $0 \%$ & $0 \%$ & $0 \%$ & $0 \%$ & $0 \%$ & $0 \%$ & $0 \%$ \\
\hline Unemployment & $1 \%$ & $0 \%$ & $0 \%$ & $0 \%$ & $1 \%$ & $4 \%$ & $1 \%$ \\
\hline Old age & $32 \%$ & $11 \%$ & $68 \%$ & $21 \%$ & $8 \%$ & $15 \%$ & $12 \%$ \\
\hline Survivor & $1 \%$ & $2 \%$ & $2 \%$ & $3 \%$ & $1 \%$ & $2 \%$ & $2 \%$ \\
\hline \multicolumn{8}{|l|}{ Sickness } \\
\hline Disability & $17 \%$ & $4 \%$ & $3 \%$ & $20 \%$ & $4 \%$ & $6 \%$ & $4 \%$ \\
\hline Education & $0 \%$ & $0 \%$ & $0 \%$ & $0 \%$ & $0 \%$ & $0 \%$ & $0 \%$ \\
\hline \multicolumn{8}{|c|}{ Benefits as share of total gross household income, only beneficiaries } \\
\hline Family child & $9 \%$ & $14 \%$ & $5 \%$ & $12 \%$ & $13 \%$ & $16 \%$ & $15 \%$ \\
\hline
\end{tabular}




\begin{tabular}{|c|c|c|c|c|c|c|c|}
\hline & $\begin{array}{l}\text { 1. Early } \\
\text { retirees } \\
\text { and } \\
\text { inactive }\end{array}$ & $\begin{array}{l}\text { 2. Low-educated } \\
\text { rural mothers } \\
\text { without work } \\
\text { experience }\end{array}$ & $\begin{array}{c}3 . \\
\text { Retirees }\end{array}$ & $\begin{array}{l}\text { 4. Low- } \\
\text { educated } \\
\text { and rural } \\
\text { disabled }\end{array}$ & $\begin{array}{l}\text { 5. Educated } \\
\text { unemployed } \\
\text { or inactive } \\
\text { youth }\end{array}$ & $\begin{array}{l}\text { 6. Long-term } \\
\text { unemployed } \\
\text { single youth }\end{array}$ & $\begin{array}{l}\text { 7. Working- } \\
\text { age newly- } \\
\text { unemployed } \\
\text { or inactive }\end{array}$ \\
\hline Social exclusion & $8 \%$ & $13 \%$ & $3 \%$ & $10 \%$ & $2 \%$ & $9 \%$ & $15 \%$ \\
\hline Housing & $0 \%$ & $0 \%$ & $0 \%$ & $0 \%$ & $0 \%$ & $0 \%$ & $0 \%$ \\
\hline Unemployment & $37 \%$ & $21 \%$ & $14 \%$ & $32 \%$ & $10 \%$ & $40 \%$ & $16 \%$ \\
\hline Old age & $59 \%$ & $47 \%$ & $72 \%$ & $55 \%$ & $33 \%$ & $45 \%$ & $42 \%$ \\
\hline Survivor & $34 \%$ & $34 \%$ & $37 \%$ & $40 \%$ & $22 \%$ & $26 \%$ & $39 \%$ \\
\hline \multicolumn{8}{|l|}{ Sickness } \\
\hline Disability & $44 \%$ & $31 \%$ & $33 \%$ & $30 \%$ & $24 \%$ & $49 \%$ & $32 \%$ \\
\hline Education & $14 \%$ & $13 \%$ & $9 \%$ & $6 \%$ & $15 \%$ & $2 \%$ & $8 \%$ \\
\hline
\end{tabular}

a. Refers to individuals aged 25 and over.

b. Applies to individuals aged 25 and over. Students aged 16 to 24 are not included in the sample.

c. Based on total gross household income.

d. Based on total equivalized disposable household income.

e. Dependent children include: 1. household members under 18; 2. household members aged between 18 and 24 who are economically inactive and living with at least one parent.

f. Refers only to individuals who have worked before.

Source: WB staff calculations based on EU-SILC. 


\begin{tabular}{|c|c|c|c|c|c|c|c|}
\hline & 1. Retirees & $\begin{array}{l}\text { 2. Low-educated } \\
\text { rural mothers } \\
\text { without work } \\
\text { experience }\end{array}$ & $\begin{array}{l}\text { 3. Early } \\
\text { retirees }\end{array}$ & $\begin{array}{l}\text { 4. Inactive } \\
\text { middle- } \\
\text { aged wives }\end{array}$ & $\begin{array}{l}\text { 5. Long-term } \\
\text { unemployed } \\
\text { single youth }\end{array}$ & $\begin{array}{l}\text { 6. Working- } \\
\text { age newly- } \\
\text { unemployed } \\
\text { or inactive }\end{array}$ & $\begin{array}{l}\text { 7. Low- } \\
\text { educated } \\
\text { and rural } \\
\text { disabled }\end{array}$ \\
\hline Cluster size & $27 \%$ & $26 \%$ & $22 \%$ & $10 \%$ & $7 \%$ & $4 \%$ & $3 \%$ \\
\hline Population & $1,152,063$ & $1,108,383$ & 928,203 & 403,621 & 282,661 & 185,221 & 139,860 \\
\hline \multicolumn{8}{|c|}{ INDICATORS } \\
\hline \multicolumn{8}{|c|}{ Labor market attachment } \\
\hline Unemployed & $0 \%$ & $2 \%$ & $1 \%$ & $3 \%$ & $13 \%$ & $57 \%$ & $1 \%$ \\
\hline Long-term unemployed & $0 \%$ & $0 \%$ & $9 \%$ & $1 \%$ & $63 \%$ & $0 \%$ & $0 \%$ \\
\hline Retired & $98 \%$ & $0 \%$ & $87 \%$ & $0 \%$ & $0 \%$ & $2 \%$ & $6 \%$ \\
\hline Disabled & $0 \%$ & $3 \%$ & $0 \%$ & $0 \%$ & $0 \%$ & $0 \%$ & $88 \%$ \\
\hline Other inactive & $1 \%$ & $95 \%$ & $3 \%$ & $95 \%$ & $23 \%$ & $41 \%$ & $5 \%$ \\
\hline \multicolumn{8}{|c|}{ At least one working adult in household ${ }^{a}$} \\
\hline No & $61 \%$ & $23 \%$ & $45 \%$ & $15 \%$ & $31 \%$ & $50 \%$ & $44 \%$ \\
\hline Yes & $39 \%$ & $77 \%$ & $55 \%$ & $85 \%$ & $69 \%$ & $50 \%$ & $56 \%$ \\
\hline \multicolumn{8}{|l|}{ Work experience } \\
\hline Never worked & $3 \%$ & $88 \%$ & $0 \%$ & $1 \%$ & $72 \%$ & $15 \%$ & $86 \%$ \\
\hline Less than 2 months & $95 \%$ & $0 \%$ & $96 \%$ & $99 \%$ & $28 \%$ & $1 \%$ & $10 \%$ \\
\hline 2 or more months & $2 \%$ & $11 \%$ & $3 \%$ & $0 \%$ & $0 \%$ & $83 \%$ & $3 \%$ \\
\hline \multicolumn{8}{|c|}{ Self-assessed physical incapacity } \\
\hline Strongly limited & $10 \%$ & $2 \%$ & $19 \%$ & $6 \%$ & $0 \%$ & $2 \%$ & $82 \%$ \\
\hline None/limited & $90 \%$ & $98 \%$ & $81 \%$ & $94 \%$ & $100 \%$ & $98 \%$ & $18 \%$ \\
\hline \multicolumn{8}{|c|}{ ACTIVE COVARIATES } \\
\hline \multicolumn{8}{|l|}{ Age groups (4) } \\
\hline 16-24 years & $0 \%$ & $17 \%$ & $0 \%$ & $3 \%$ & $49 \%$ & $18 \%$ & $20 \%$ \\
\hline 25-34 years & $0 \%$ & $35 \%$ & $0 \%$ & $24 \%$ & $49 \%$ & $30 \%$ & $29 \%$ \\
\hline $35-59$ years & $32 \%$ & $46 \%$ & $100 \%$ & $73 \%$ & $2 \%$ & $53 \%$ & $46 \%$ \\
\hline 60-64 years & $68 \%$ & $2 \%$ & $0 \%$ & $0 \%$ & $0 \%$ & $0 \%$ & $5 \%$ \\
\hline Gender & & & & & & & \\
\hline
\end{tabular}




\begin{tabular}{|c|c|c|c|c|c|c|c|}
\hline & 1. Retirees & $\begin{array}{l}\text { 2. Low-educated } \\
\text { rural mothers } \\
\text { without work } \\
\text { experience }\end{array}$ & $\begin{array}{l}\text { 3. Early } \\
\text { retirees }\end{array}$ & $\begin{array}{l}\text { 4. Inactive } \\
\text { middle- } \\
\text { aged wives }\end{array}$ & $\begin{array}{l}\text { 5. Long-term } \\
\text { unemployed } \\
\text { single youth }\end{array}$ & $\begin{array}{l}\text { 6. Working- } \\
\text { age newly- } \\
\text { unemployed } \\
\text { or inactive }\end{array}$ & $\begin{array}{l}\text { 7. Low- } \\
\text { educated } \\
\text { and rural } \\
\text { disabled }\end{array}$ \\
\hline Male & $37 \%$ & $0 \%$ & $60 \%$ & $3 \%$ & $80 \%$ & $89 \%$ & $65 \%$ \\
\hline Female & $63 \%$ & $100 \%$ & $40 \%$ & $97 \%$ & $20 \%$ & $11 \%$ & $35 \%$ \\
\hline \multicolumn{8}{|l|}{ Education } \\
\hline Primary & $47 \%$ & $55 \%$ & $24 \%$ & $36 \%$ & $24 \%$ & $33 \%$ & $52 \%$ \\
\hline Secondary & $42 \%$ & $40 \%$ & $76 \%$ & $61 \%$ & $72 \%$ & $59 \%$ & $13 \%$ \\
\hline Tertiary & $10 \%$ & $2 \%$ & $0 \%$ & $2 \%$ & $2 \%$ & $5 \%$ & $1 \%$ \\
\hline NA & $1 \%$ & $3 \%$ & $0 \%$ & $1 \%$ & $2 \%$ & $2 \%$ & $33 \%$ \\
\hline Urban & $43 \%$ & $25 \%$ & $45 \%$ & $36 \%$ & $37 \%$ & $33 \%$ & $15 \%$ \\
\hline Rural & $57 \%$ & $75 \%$ & $55 \%$ & $64 \%$ & $63 \%$ & $67 \%$ & $85 \%$ \\
\hline \multicolumn{8}{|c|}{ INACTIVE COVARIATES } \\
\hline \multicolumn{8}{|l|}{ Age groups (8) } \\
\hline 16-19 years & $0 \%$ & $4 \%$ & $0 \%$ & $0 \%$ & $19 \%$ & $4 \%$ & $10 \%$ \\
\hline 20-24 years & $0 \%$ & $13 \%$ & $0 \%$ & $3 \%$ & $30 \%$ & $13 \%$ & $10 \%$ \\
\hline 25-29 years & $0 \%$ & $17 \%$ & $0 \%$ & $9 \%$ & $23 \%$ & $13 \%$ & $11 \%$ \\
\hline 30-34 years & $0 \%$ & $19 \%$ & $0 \%$ & $15 \%$ & $26 \%$ & $16 \%$ & $17 \%$ \\
\hline $35-44$ years & $1 \%$ & $23 \%$ & $7 \%$ & $28 \%$ & $1 \%$ & $27 \%$ & $20 \%$ \\
\hline $45-54$ years & $10 \%$ & $17 \%$ & $42 \%$ & $37 \%$ & $1 \%$ & $20 \%$ & $17 \%$ \\
\hline $55-59$ years & $21 \%$ & $6 \%$ & $51 \%$ & $8 \%$ & $0 \%$ & $5 \%$ & $9 \%$ \\
\hline $60-64$ years & $68 \%$ & $2 \%$ & $0 \%$ & $0 \%$ & $0 \%$ & $0 \%$ & $5 \%$ \\
\hline \multicolumn{8}{|l|}{ Education } \\
\hline Primary & $10 \%$ & $9 \%$ & $4 \%$ & $2 \%$ & $5 \%$ & $9 \%$ & $13 \%$ \\
\hline Lower secondary & $37 \%$ & $46 \%$ & $20 \%$ & $34 \%$ & $20 \%$ & $24 \%$ & $39 \%$ \\
\hline Upper secondary & $36 \%$ & $39 \%$ & $67 \%$ & $59 \%$ & $69 \%$ & $56 \%$ & $13 \%$ \\
\hline Post-secondary & $6 \%$ & $1 \%$ & $10 \%$ & $3 \%$ & $2 \%$ & $3 \%$ & $0 \%$ \\
\hline Tertiary & $10 \%$ & $2 \%$ & $0 \%$ & $2 \%$ & $2 \%$ & $5 \%$ & $1 \%$ \\
\hline NA & $1 \%$ & $3 \%$ & $0 \%$ & $1 \%$ & $2 \%$ & $2 \%$ & $33 \%$ \\
\hline \multicolumn{8}{|c|}{ Have never studied before/illiterate } \\
\hline No & $99 \%$ & $97 \%$ & $100 \%$ & $99 \%$ & $98 \%$ & $98 \%$ & $67 \%$ \\
\hline
\end{tabular}




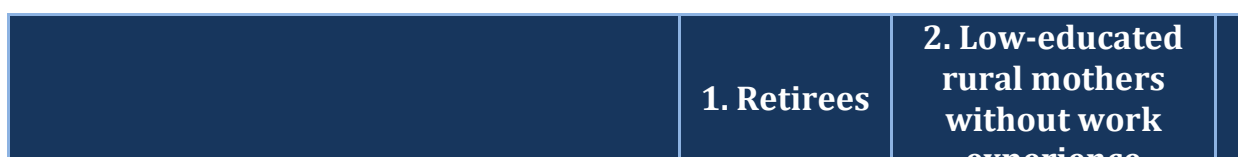

Yes

Enrolled in education

Yes

No

Marital status

Married

Never married

Divorced/separated

Widowed

\section{Household income}

Labor income

Other income

Benefits

Household income sharesc

Labor income

Other income

Benefits

Income quintiled

\begin{tabular}{|l|l}
\hline Poorest & $11 \%$
\end{tabular}

Q2

Q3

Q4

Richest

NA

Working partner

\begin{tabular}{|l|l}
\hline Yes & $10 \%$
\end{tabular}

No

NA

$32 \%$

\begin{tabular}{c|r}
\hline 2256 & 371 \\
\hline 22 & 42 \\
\hline 2970 & 993 \\
\hline
\end{tabular}

\begin{tabular}{|c|c|}
\hline 3714 & \\
\hline 42 & \\
\hline 993 & \\
\hline
\end{tabular}

3. Early retirees

experience

4. Inactive

middle-

aged wives

$0 \%$

$1 \%$

$2 \%$

$98 \%$

$0 \%$

$100 \%$

$2 \%$

$2 \%$
$98 \%$

5. Long-term

unemployed

single youth

6. Working-

age newly

unemployed

or inactive

$2 \%$

$2 \%$

$6 \%$

$9 \%$

$2 \%$

$2 \%$

\begin{tabular}{|c|}
$0 \%$ \\
$100 \%$
\end{tabular}

$75 \%$

$2 \% \quad 20 \%$

$7 \% \quad 4 \%$

2\%

\begin{tabular}{|c|c|}
\hline $80 \%$ & \\
\hline $4 \%$ & \\
\hline $7 \%$ & \\
\hline $9 \%$ & \\
\hline
\end{tabular}

\begin{tabular}{l}
$86 \%$ \\
\hline $7 \%$ \\
\hline $3 \%$ \\
\hline $4 \%$ \\
\hline
\end{tabular}

\begin{tabular}{|c|c|}
\hline $28 \%$ \\
$70 \%$ \\
\hline $2 \%$ \\
\hline
\end{tabular}

\begin{tabular}{|c|}
\hline $28 \%$ \\
\hline $70 \%$ \\
\hline $2 \%$ \\
\hline $0 \%$ \\
\hline
\end{tabular}

\begin{tabular}{|c|c|}
\hline $56 \%$ & $23 \%$ \\
\hline $36 \%$ & $67 \%$ \\
\hline $5 \%$ & $5 \%$ \\
\hline $3 \%$ & $6 \%$ \\
\hline
\end{tabular}

\begin{tabular}{c|r}
\hline 33 & 375 \\
\hline 2437 & 87 \\
\hline
\end{tabular}

\begin{tabular}{|c|r}
\hline 87 & 3148 \\
\hline 859 & 47 \\
\hline
\end{tabular}

\begin{tabular}{|c|c|c|}
\hline 3148 & 3981 & 2322 \\
\hline 47 & 88 & 21 \\
\hline 1268 & 1114 & 1734 \\
\hline
\end{tabular}

\begin{tabular}{l|l} 
& \\
$27 \%$ & $68 \%$
\end{tabular}

$8 \%$

\begin{tabular}{|c|c|c|c|c|c|c|}
\hline & $68 \%$ & $40 \%$ & $74 \%$ & $55 \%$ & $67 \%$ & $44 \%$ \\
\hline $73 \%$ & $1 \%$ & $1 \%$ & $3 \%$ & $3 \%$ & $3 \%$ & $1 \%$ \\
\hline
\end{tabular}

\begin{tabular}{|l|l} 
& \\
$11 \%$ & 39
\end{tabular}

\begin{tabular}{|c|c|c|c|c|c|c|}
\hline $11 \%$ & $39 \%$ & $16 \%$ & $34 \%$ & $43 \%$ & $38 \%$ & $31 \%$ \\
\hline $19 \%$ & $29 \%$ & $19 \%$ & $27 \%$ & $25 \%$ & $17 \%$ & $32 \%$ \\
\hline $30 \%$ & $14 \%$ & $29 \%$ & $18 \%$ & $22 \%$ & $20 \%$ & $19 \%$ \\
\hline $23 \%$ & $12 \%$ & $21 \%$ & $15 \%$ & $9 \%$ & $16 \%$ & $12 \%$ \\
\hline $17 \%$ & $6 \%$ & $14 \%$ & $5 \%$ & $1 \%$ & $9 \%$ & $3 \%$ \\
\hline 0 & $0 \%$ & $0 \%$ & $0 \%$ & $0 \%$ & $0 \%$ & $1 \%$ \\
\hline
\end{tabular}

(




\begin{tabular}{|c|c|c|c|c|c|c|c|}
\hline & 1. Retirees & $\begin{array}{l}\text { 2. Low-educated } \\
\text { rural mothers } \\
\text { without work } \\
\text { experience }\end{array}$ & $\begin{array}{l}\text { 3. Early } \\
\text { retirees }\end{array}$ & $\begin{array}{l}\text { 4. Inactive } \\
\text { middle- } \\
\text { aged wives }\end{array}$ & $\begin{array}{l}\text { 5. Long-term } \\
\text { unemployed } \\
\text { single youth }\end{array}$ & $\begin{array}{l}\text { 6. Working- } \\
\text { age newly- } \\
\text { unemployed } \\
\text { or inactive }\end{array}$ & $\begin{array}{l}\text { 7. Low- } \\
\text { educated } \\
\text { and rural } \\
\text { disabled }\end{array}$ \\
\hline \multicolumn{8}{|l|}{ Partner economic status } \\
\hline Working & $10 \%$ & $54 \%$ & $29 \%$ & $66 \%$ & $13 \%$ & $23 \%$ & $9 \%$ \\
\hline Unemployed & $1 \%$ & $5 \%$ & $3 \%$ & $3 \%$ & $0 \%$ & $2 \%$ & $0 \%$ \\
\hline Retired & $53 \%$ & $12 \%$ & $34 \%$ & $13 \%$ & $0 \%$ & $3 \%$ & $3 \%$ \\
\hline Inactive & $5 \%$ & $3 \%$ & $14 \%$ & $1 \%$ & $11 \%$ & $24 \%$ & $5 \%$ \\
\hline Student/military service & $0 \%$ & $0 \%$ & $0 \%$ & $0 \%$ & $0 \%$ & $2 \%$ & $0 \%$ \\
\hline NA & $32 \%$ & $27 \%$ & $21 \%$ & $17 \%$ & $75 \%$ & $46 \%$ & $82 \%$ \\
\hline Partner income (mean) & 559 & 2591 & 1058 & 2832 & 1783 & 1418 & 916 \\
\hline Working partner income (mean) & 3578 & 3414 & 2876 & 3442 & 3251 & 2613 & 1473 \\
\hline \multicolumn{8}{|l|}{ Working partner income quintile } \\
\hline Poorest & $2 \%$ & $7 \%$ & $5 \%$ & $6 \%$ & $2 \%$ & $4 \%$ & $5 \%$ \\
\hline Q2 & $2 \%$ & $13 \%$ & $8 \%$ & $17 \%$ & $5 \%$ & $5 \%$ & $1 \%$ \\
\hline Q3 & $2 \%$ & $11 \%$ & $7 \%$ & $18 \%$ & $3 \%$ & $7 \%$ & $2 \%$ \\
\hline Q4 & $2 \%$ & $13 \%$ & $6 \%$ & $13 \%$ & $1 \%$ & $4 \%$ & $1 \%$ \\
\hline Richest & $2 \%$ & $10 \%$ & $4 \%$ & $12 \%$ & $2 \%$ & $2 \%$ & $0 \%$ \\
\hline No partner or partner without income & $90 \%$ & $47 \%$ & $71 \%$ & $34 \%$ & $87 \%$ & $77 \%$ & $91 \%$ \\
\hline Household size (mean) & 2.83 & 4.62 & 3.47 & 3.97 & 4.93 & 4.33 & 3.84 \\
\hline \multicolumn{8}{|l|}{ Tenure status } \\
\hline Owner & $99 \%$ & $95 \%$ & $99 \%$ & $95 \%$ & $94 \%$ & $97 \%$ & $100 \%$ \\
\hline Tenant & $0 \%$ & $1 \%$ & $0 \%$ & $1 \%$ & $1 \%$ & $1 \%$ & $0 \%$ \\
\hline Reduced rate & $0 \%$ & $1 \%$ & $1 \%$ & $3 \%$ & $3 \%$ & $2 \%$ & $0 \%$ \\
\hline Free & $0 \%$ & $3 \%$ & $0 \%$ & $2 \%$ & $3 \%$ & $0 \%$ & $0 \%$ \\
\hline \multicolumn{8}{|l|}{ Household composition } \\
\hline One-person & $15 \%$ & $1 \%$ & $8 \%$ & $2 \%$ & $1 \%$ & $4 \%$ & $6 \%$ \\
\hline Single parent & $1 \%$ & $1 \%$ & $1 \%$ & $1 \%$ & $2 \%$ & $2 \%$ & $1 \%$ \\
\hline $2+$ adults without dependent children ${ }^{\mathrm{e}}$ & $59 \%$ & $23 \%$ & $53 \%$ & $28 \%$ & $22 \%$ & $32 \%$ & $44 \%$ \\
\hline $2+$ adults with 1 dependent childe & $4 \%$ & $15 \%$ & $7 \%$ & $14 \%$ & $7 \%$ & $11 \%$ & $4 \%$ \\
\hline $2+$ adults with $2+$ dependent children ${ }^{\mathrm{e}}$ & $20 \%$ & $60 \%$ & $31 \%$ & $55 \%$ & $68 \%$ & $51 \%$ & $45 \%$ \\
\hline
\end{tabular}




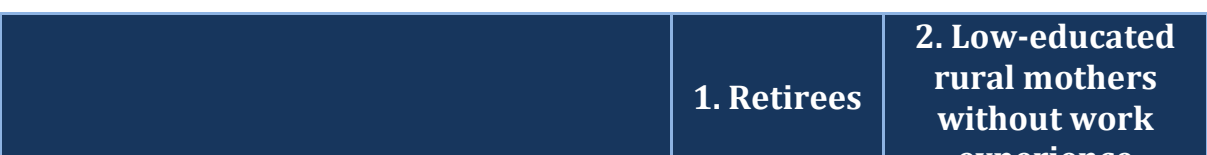

without work

experience
3. Early retirees
4. Inactive middleaged wives
5. Long-term unemployed single youth
6. Workingage newly-

unemployed or inactive

7. Loweducated and rural disabled

\section{Individuals' parents present}

One parent

Both parents

None

Children under six

Three or more children under 16

Elderly present (over 64)

Children under 13 in childcare

\begin{tabular}{|c|c|c|c|c|c|c|c|}
\hline None of the children & $4 \%$ & $16 \%$ & $5 \%$ & $16 \%$ & $10 \%$ & $11 \%$ & $7 \%$ \\
\hline Some of the children & $1 \%$ & $12 \%$ & $3 \%$ & $7 \%$ & $11 \%$ & $6 \%$ & $5 \%$ \\
\hline No children under 13 in household & $82 \%$ & $36 \%$ & $76 \%$ & $48 \%$ & $51 \%$ & $51 \%$ & $72 \%$ \\
\hline All of the children & $12 \%$ & $37 \%$ & $15 \%$ & $30 \%$ & $28 \%$ & $32 \%$ & $16 \%$ \\
\hline
\end{tabular}

\section{Ever worked}

$$
\text { No }
$$

Yes

Years of work experience $f$

\begin{tabular}{|c|r|}
\hline $3 \%$ & $88 \%$ \\
\hline $97 \%$ & $12 \%$ \\
\hline
\end{tabular}

\begin{tabular}{|c|c|r}
\hline $0 \%$ & $1 \%$ & $72 \%$ \\
\hline $100 \%$ & $99 \%$ & $28 \%$ \\
\hline 27 & 14 & 6 \\
\hline
\end{tabular}

6

\begin{tabular}{|c|c|}
\hline $15 \%$ & $86 \%$ \\
\hline $85 \%$ & $14 \%$ \\
\hline 12 & 21 \\
\hline
\end{tabular}

\section{Worked in last year}

2 or more months

Less than 2 months

\begin{tabular}{l|l}
$2 \%$ & $11 \%$
\end{tabular}

$11 \%$

$98 \% \quad 89 \%$

\begin{tabular}{|c|c|c|c}
\hline & $3 \%$ & $0 \%$ & $2 \%$ \\
\hline $89 \%$ & $97 \%$ & $100 \%$ & $98 \%$ \\
\hline
\end{tabular}

\section{Able to keep dwelling warm}

\begin{tabular}{|c|c|c|c|c|c|c|c|}
\hline No & $27 \%$ & $33 \%$ & $23 \%$ & $28 \%$ & $37 \%$ & $37 \%$ & $32 \%$ \\
\hline Yes & $73 \%$ & $67 \%$ & $77 \%$ & $72 \%$ & $63 \%$ & $63 \%$ & $68 \%$ \\
\hline \multicolumn{8}{|c|}{ Degree of urbanization } \\
\hline Densely populated & $42 \%$ & $24 \%$ & $43 \%$ & $35 \%$ & $35 \%$ & $32 \%$ & $15 \%$ \\
\hline Intermediate area & $1 \%$ & $1 \%$ & $2 \%$ & $2 \%$ & $2 \%$ & $1 \%$ & $0 \%$ \\
\hline Sparsely populated & $57 \%$ & $75 \%$ & $55 \%$ & $64 \%$ & $63 \%$ & $67 \%$ & $85 \%$ \\
\hline \multicolumn{8}{|l|}{ Region } \\
\hline R001 - Nord-Est & $11 \%$ & $13 \%$ & $10 \%$ & $12 \%$ & $15 \%$ & $18 \%$ & $25 \%$ \\
\hline
\end{tabular}




\begin{tabular}{|c|c|c|c|c|c|c|c|}
\hline & 1. Retirees & $\begin{array}{l}\text { 2. Low-educated } \\
\text { rural mothers } \\
\text { without work } \\
\text { experience }\end{array}$ & $\begin{array}{l}\text { 3. Early } \\
\text { retirees }\end{array}$ & $\begin{array}{l}\text { 4. Inactive } \\
\text { middle- } \\
\text { aged wives }\end{array}$ & $\begin{array}{l}\text { 5. Long-term } \\
\text { unemployed } \\
\text { single youth }\end{array}$ & $\begin{array}{l}\text { 6. Working- } \\
\text { age newly- } \\
\text { unemployed } \\
\text { or inactive }\end{array}$ & $\begin{array}{l}\text { 7. Low- } \\
\text { educated } \\
\text { and rural } \\
\text { disabled }\end{array}$ \\
\hline R002 - Sud-Est & $12 \%$ & $16 \%$ & $14 \%$ & $22 \%$ & $14 \%$ & $18 \%$ & $13 \%$ \\
\hline R003 - Sud Muntenia & $17 \%$ & $19 \%$ & $19 \%$ & $18 \%$ & $23 \%$ & $17 \%$ & $19 \%$ \\
\hline R004 - Sud-Vest Oltenia & $11 \%$ & $12 \%$ & $12 \%$ & $10 \%$ & $13 \%$ & $10 \%$ & $8 \%$ \\
\hline RO05 - Vest & $11 \%$ & $7 \%$ & $9 \%$ & $10 \%$ & $9 \%$ & $5 \%$ & $4 \%$ \\
\hline R006 - Nord-Vest & $14 \%$ & $11 \%$ & $13 \%$ & $6 \%$ & $14 \%$ & $11 \%$ & $15 \%$ \\
\hline R007 - Centru & $12 \%$ & $9 \%$ & $11 \%$ & $14 \%$ & $9 \%$ & $13 \%$ & $10 \%$ \\
\hline R008 - Bucharest - Ilfov & $12 \%$ & $13 \%$ & $10 \%$ & $9 \%$ & $4 \%$ & $9 \%$ & $7 \%$ \\
\hline Receives at least one benefit & $99 \%$ & $75 \%$ & $97 \%$ & $76 \%$ & $73 \%$ & $66 \%$ & $84 \%$ \\
\hline \multicolumn{8}{|c|}{ Receives benefits at household level } \\
\hline Family child & $20 \%$ & $67 \%$ & $30 \%$ & $60 \%$ & $57 \%$ & $52 \%$ & $30 \%$ \\
\hline Social exclusion & $24 \%$ & $27 \%$ & $28 \%$ & $30 \%$ & $30 \%$ & $33 \%$ & $38 \%$ \\
\hline \multicolumn{8}{|l|}{ Housing } \\
\hline Old age at household level & $88 \%$ & $25 \%$ & $58 \%$ & $20 \%$ & $37 \%$ & $24 \%$ & $37 \%$ \\
\hline \multicolumn{8}{|c|}{ Receives benefits at individual level } \\
\hline Unemployment & $0 \%$ & $0 \%$ & $3 \%$ & $2 \%$ & $6 \%$ & $6 \%$ & $0 \%$ \\
\hline Old age & $82 \%$ & $0 \%$ & $46 \%$ & $1 \%$ & $1 \%$ & $2 \%$ & $6 \%$ \\
\hline Survivor & $4 \%$ & $1 \%$ & $1 \%$ & $0 \%$ & $0 \%$ & $0 \%$ & $2 \%$ \\
\hline \multicolumn{8}{|l|}{ Sickness } \\
\hline Disability & $13 \%$ & $1 \%$ & $41 \%$ & $3 \%$ & $0 \%$ & $0 \%$ & $60 \%$ \\
\hline Education & $0 \%$ & $0 \%$ & $0 \%$ & $0 \%$ & $0 \%$ & $0 \%$ & $0 \%$ \\
\hline \multicolumn{8}{|c|}{ Benefits as share of total gross household income, all households } \\
\hline Family child & $1 \%$ & $8 \%$ & $3 \%$ & $7 \%$ & $8 \%$ & $7 \%$ & $3 \%$ \\
\hline Social exclusion & $1 \%$ & $4 \%$ & $2 \%$ & $2 \%$ & $5 \%$ & $6 \%$ & $6 \%$ \\
\hline Housing & $0 \%$ & $0 \%$ & $0 \%$ & $0 \%$ & $0 \%$ & $0 \%$ & $0 \%$ \\
\hline Unemployment & $0 \%$ & $1 \%$ & $2 \%$ & $1 \%$ & $3 \%$ & $2 \%$ & $0 \%$ \\
\hline Old age & $61 \%$ & $13 \%$ & $33 \%$ & $9 \%$ & $19 \%$ & $9 \%$ & $20 \%$ \\
\hline Survivor & $2 \%$ & $1 \%$ & $1 \%$ & $0 \%$ & $2 \%$ & $2 \%$ & $3 \%$ \\
\hline Sickness & $0 \%$ & $0 \%$ & $0 \%$ & $0 \%$ & $0 \%$ & $0 \%$ & $0 \%$ \\
\hline
\end{tabular}




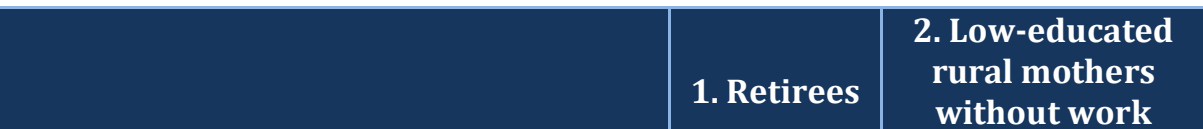

3. Early
retirees

4. Inactive

5. Long-term

6. Working-

age newly-

7. Low-

without work

middle-

unemployed

unemployed

educated

experience

Disability

$3 \%$

Education

$7 \%$

$0 \%$

aged wives

single youth

or inactive

and rural

$0 \%$

$19 \% \quad 3 \%$

$5 \%$

$22 \%$

Benefits as share of total gross household income, only beneficiaries

Family child

Social exclusion

Housing

Unemployment

Old age

Survivor

Sickness

Disability

Education

$6 \%$

$0 \%$

$4 \%$

$22 \%$

$0 \%$

a. Refers to individuals aged 25 and over.

b. Applies to individuals aged 25 and over. Students aged 16 to 24 are not included in the sample.

c. Based on total gross household income.

d. Based on total equivalized disposable household income.

e. Dependent children include: 1. household members under 18; 2. household members aged between 18 and 24 who are economically inactive and living with at least one parent.

f. Refers only to individuals who have worked before.

Source: WB staff calculations based on EU-SILC. 


\section{Annex 3: Latent Class Analysis Profiles \\ Longitudinal Data}

Bulgaria: Longitudinal Model - Year 2010

\begin{tabular}{|c|c|c|c|c|}
\hline & $\begin{array}{l}\text { 1. Married or widowed } \\
\text { retirees }\end{array}$ & $\begin{array}{l}\text { 2. Low-educated rural } \\
\text { unemployed }\end{array}$ & 3. Single NEETs & $\begin{array}{l}\text { 4. Stay-at-home } \\
\text { mothers }\end{array}$ \\
\hline Cluster size & $30 \%$ & $30 \%$ & $26 \%$ & $14 \%$ \\
\hline \multicolumn{5}{|c|}{ INDICATORS } \\
\hline \multicolumn{5}{|c|}{ Labor market attachment } \\
\hline Unemployed & $2 \%$ & $98 \%$ & $67 \%$ & $39 \%$ \\
\hline Retired & $96 \%$ & $0 \%$ & $1 \%$ & $0 \%$ \\
\hline Disabled & $0 \%$ & $1 \%$ & $0 \%$ & $1 \%$ \\
\hline Other inactive & $2 \%$ & $0 \%$ & $32 \%$ & $59 \%$ \\
\hline \multicolumn{5}{|l|}{ Working Partner } \\
\hline Yes & $20 \%$ & $25 \%$ & $0 \%$ & $96 \%$ \\
\hline No & $43 \%$ & $49 \%$ & $7 \%$ & $4 \%$ \\
\hline NA & $38 \%$ & $26 \%$ & $93 \%$ & $0 \%$ \\
\hline \multicolumn{5}{|c|}{ Self-assessed physical incapacity } \\
\hline Strongly limited & $12 \%$ & $3 \%$ & $1 \%$ & $0 \%$ \\
\hline None/limited & $88 \%$ & $97 \%$ & $99 \%$ & $100 \%$ \\
\hline \multicolumn{5}{|c|}{ ACTIVE COVARIATES } \\
\hline \multicolumn{5}{|l|}{ Age groups (4) } \\
\hline $16-24$ years & $0 \%$ & $2 \%$ & $55 \%$ & $10 \%$ \\
\hline 25-34 years & $0 \%$ & $14 \%$ & $44 \%$ & $30 \%$ \\
\hline 35-59 years & $41 \%$ & $78 \%$ & $0 \%$ & $60 \%$ \\
\hline 60-64 years & $59 \%$ & $7 \%$ & $0 \%$ & $0 \%$ \\
\hline \multicolumn{5}{|l|}{ Gender } \\
\hline Male & $32 \%$ & $47 \%$ & $55 \%$ & $0 \%$ \\
\hline
\end{tabular}




\begin{tabular}{|c|c|c|c|c|}
\hline & $\begin{array}{l}\text { 1. Married or widowed } \\
\text { retirees }\end{array}$ & $\begin{array}{l}\text { 2. Low-educated rural } \\
\text { unemployed }\end{array}$ & 3. Single NEETs & $\begin{array}{l}\text { 4. Stay-at-home } \\
\text { mothers }\end{array}$ \\
\hline Female & $68 \%$ & $53 \%$ & $45 \%$ & $100 \%$ \\
\hline \multicolumn{5}{|l|}{ Education } \\
\hline Primary & $38 \%$ & $60 \%$ & $37 \%$ & $39 \%$ \\
\hline Secondary & $48 \%$ & $31 \%$ & $38 \%$ & $50 \%$ \\
\hline Tertiary & $12 \%$ & $1 \%$ & $14 \%$ & $9 \%$ \\
\hline NA & $2 \%$ & $8 \%$ & $12 \%$ & $2 \%$ \\
\hline Urban & $43 \%$ & $30 \%$ & $37 \%$ & $53 \%$ \\
\hline Rural & $57 \%$ & $70 \%$ & $63 \%$ & $47 \%$ \\
\hline \multicolumn{5}{|c|}{ INACTIVE COVARIATES } \\
\hline \multicolumn{5}{|l|}{ Age groups (7) } \\
\hline $16-19$ years & $0 \%$ & $0 \%$ & $17 \%$ & $0 \%$ \\
\hline $20-24$ years & $0 \%$ & $2 \%$ & $38 \%$ & $10 \%$ \\
\hline 25-34 years & $0 \%$ & $14 \%$ & $44 \%$ & $30 \%$ \\
\hline 35-44 years & $11 \%$ & $33 \%$ & $0 \%$ & $30 \%$ \\
\hline $45-54$ years & $10 \%$ & $30 \%$ & $0 \%$ & $21 \%$ \\
\hline $55-59$ years & $20 \%$ & $15 \%$ & $0 \%$ & $9 \%$ \\
\hline 60-64 years & $59 \%$ & $7 \%$ & $0 \%$ & $0 \%$ \\
\hline \multicolumn{5}{|l|}{ Education } \\
\hline None/less than primary & $1 \%$ & $1 \%$ & $4 \%$ & $5 \%$ \\
\hline Primary & $7 \%$ & $13 \%$ & $12 \%$ & $13 \%$ \\
\hline Lower secondary & $30 \%$ & $46 \%$ & $20 \%$ & $22 \%$ \\
\hline Upper secondary & $48 \%$ & $31 \%$ & $38 \%$ & $50 \%$ \\
\hline Post-secondary & $0 \%$ & $0 \%$ & $0 \%$ & $0 \%$ \\
\hline Tertiary & $12 \%$ & $1 \%$ & $14 \%$ & $9 \%$ \\
\hline NA & $2 \%$ & $8 \%$ & $12 \%$ & $2 \%$ \\
\hline \multicolumn{5}{|l|}{ Marital status } \\
\hline Married & $60 \%$ & $59 \%$ & $2 \%$ & $77 \%$ \\
\hline Never married & $11 \%$ & $29 \%$ & $93 \%$ & $17 \%$ \\
\hline
\end{tabular}




\begin{tabular}{|c|c|c|c|c|}
\hline & $\begin{array}{l}\text { 1. Married or widowed } \\
\text { retirees }\end{array}$ & $\begin{array}{c}\text { 2. Low-educated rural } \\
\text { unemployed }\end{array}$ & 3. Single NEETs & $\begin{array}{l}\text { 4. Stay-at-home } \\
\text { mothers }\end{array}$ \\
\hline Divorced/separated & $9 \%$ & $9 \%$ & $4 \%$ & $5 \%$ \\
\hline Widowed & $19 \%$ & $4 \%$ & $0 \%$ & $0 \%$ \\
\hline \multicolumn{5}{|l|}{ Income quintile ${ }^{a}$} \\
\hline Poorest & $21 \%$ & $54 \%$ & $43 \%$ & $26 \%$ \\
\hline Q2 & $30 \%$ & $19 \%$ & $19 \%$ & $26 \%$ \\
\hline Q3 & $22 \%$ & $17 \%$ & $16 \%$ & $24 \%$ \\
\hline Q4 & $22 \%$ & $5 \%$ & $9 \%$ & $11 \%$ \\
\hline Richest & $6 \%$ & $5 \%$ & $13 \%$ & $13 \%$ \\
\hline \multicolumn{5}{|c|}{ At least one working adult in householdb } \\
\hline No & $46 \%$ & $61 \%$ & $31 \%$ & $3 \%$ \\
\hline Yes & $54 \%$ & $39 \%$ & $69 \%$ & $97 \%$ \\
\hline \multicolumn{5}{|l|}{ Partner economic status } \\
\hline Working & $20 \%$ & $25 \%$ & $0 \%$ & $96 \%$ \\
\hline Unemployed & $5 \%$ & $41 \%$ & $5 \%$ & $3 \%$ \\
\hline Retired & $35 \%$ & $6 \%$ & $0 \%$ & $1 \%$ \\
\hline Inactive & $2 \%$ & $2 \%$ & $2 \%$ & $0 \%$ \\
\hline Student/military service & . & . & . & . \\
\hline No partner & $38 \%$ & $26 \%$ & $93 \%$ & $0 \%$ \\
\hline Partner income (mean) & 1016 & 1247 & 609 & 3223 \\
\hline \multicolumn{5}{|l|}{ Partner income quintile } \\
\hline Poorest & $5 \%$ & $10 \%$ & $0 \%$ & $18 \%$ \\
\hline Q2 & $4 \%$ & $5 \%$ & $0 \%$ & $18 \%$ \\
\hline Q3 & $5 \%$ & $6 \%$ & $0 \%$ & $14 \%$ \\
\hline Q4 & $5 \%$ & $2 \%$ & $0 \%$ & $18 \%$ \\
\hline Richest & $1 \%$ & $2 \%$ & $0 \%$ & $24 \%$ \\
\hline No partner or partner without income & $80 \%$ & $76 \%$ & $100 \%$ & $7 \%$ \\
\hline Household size (mean) & 3.458 & 5.283 & 6.022 & 5.343 \\
\hline
\end{tabular}




\begin{tabular}{|c|c|c|c|c|}
\hline & $\begin{array}{l}\text { 1. Married or widowed } \\
\text { retirees }\end{array}$ & $\begin{array}{l}\text { 2. Low-educated rural } \\
\text { unemployed }\end{array}$ & 3. Single NEETs & $\begin{array}{l}\text { 4. Stay-at-home } \\
\text { mothers }\end{array}$ \\
\hline Owner & $94 \%$ & $86 \%$ & $80 \%$ & $76 \%$ \\
\hline Tenant & $0 \%$ & $0 \%$ & $0 \%$ & $0 \%$ \\
\hline Reduced rate & $1 \%$ & $4 \%$ & $2 \%$ & $2 \%$ \\
\hline Free & $5 \%$ & $10 \%$ & $18 \%$ & $21 \%$ \\
\hline \multicolumn{5}{|l|}{ Household composition } \\
\hline One-person & $9 \%$ & $1 \%$ & $0 \%$ & $0 \%$ \\
\hline Single parent & $1 \%$ & $1 \%$ & $0 \%$ & $0 \%$ \\
\hline $2+$ adults without dependent children ${ }^{c}$ & $61 \%$ & $38 \%$ & $49 \%$ & $27 \%$ \\
\hline $2+$ adults with 1 dependent childc & $15 \%$ & $24 \%$ & $21 \%$ & $31 \%$ \\
\hline $2+$ adults with $2+$ dependent children ${ }^{c}$ & $14 \%$ & $36 \%$ & $30 \%$ & $42 \%$ \\
\hline Children under six & $16 \%$ & $26 \%$ & $29 \%$ & $49 \%$ \\
\hline Three or more children under 16 & $3 \%$ & $19 \%$ & $20 \%$ & $17 \%$ \\
\hline Elderly present (over 64) & $35 \%$ & $29 \%$ & $28 \%$ & $18 \%$ \\
\hline Years of work experience ${ }^{d}$ & 28.641 & 16.997 & 3.482 & 12.287 \\
\hline \multicolumn{5}{|l|}{ Able to keep dwelling warm } \\
\hline No & $76 \%$ & $81 \%$ & $69 \%$ & $53 \%$ \\
\hline Yes & $24 \%$ & $19 \%$ & $31 \%$ & $47 \%$ \\
\hline \multicolumn{5}{|l|}{ Degree of urbanization } \\
\hline Densely populated & $35 \%$ & $21 \%$ & $30 \%$ & $46 \%$ \\
\hline Intermediate area & $8 \%$ & $9 \%$ & $7 \%$ & $7 \%$ \\
\hline Sparsely populated & $57 \%$ & $70 \%$ & $63 \%$ & $47 \%$ \\
\hline \multicolumn{5}{|l|}{ Region } \\
\hline BG31 - Northwest & $18 \%$ & $20 \%$ & $18 \%$ & $9 \%$ \\
\hline BG32 - North Central & $18 \%$ & $10 \%$ & $12 \%$ & $11 \%$ \\
\hline BG33 - Northeast & $8 \%$ & $20 \%$ & $17 \%$ & $29 \%$ \\
\hline BG34 - Southeast & $11 \%$ & $14 \%$ & $13 \%$ & $22 \%$ \\
\hline BG41 - Southwestern & $25 \%$ & $13 \%$ & $18 \%$ & $10 \%$ \\
\hline BG42 - South Central & $22 \%$ & $23 \%$ & $23 \%$ & $18 \%$ \\
\hline
\end{tabular}




\begin{tabular}{|c|c|c|c|c|}
\hline & $\begin{array}{l}\text { 1. Married or widowed } \\
\text { retirees }\end{array}$ & $\begin{array}{c}\text { 2. Low-educated rural } \\
\text { unemployed }\end{array}$ & 3. Single NEETs & $\begin{array}{l}\text { 4. Stay-at-home } \\
\text { mothers }\end{array}$ \\
\hline Receives at least one benefit & $99 \%$ & $73 \%$ & $66 \%$ & $77 \%$ \\
\hline \multicolumn{5}{|c|}{ Receives benefits at household level } \\
\hline Family child & $29 \%$ & $56 \%$ & $50 \%$ & $57 \%$ \\
\hline Social exclusion & $18 \%$ & $19 \%$ & $22 \%$ & $6 \%$ \\
\hline Housing & $0 \%$ & $0 \%$ & $0 \%$ & $1 \%$ \\
\hline \multicolumn{5}{|c|}{ Receives benefits at individual level } \\
\hline Unemployment & $5 \%$ & $14 \%$ & $4 \%$ & $12 \%$ \\
\hline Old age & $55 \%$ & $0 \%$ & $1 \%$ & $2 \%$ \\
\hline Survivor & $1 \%$ & $0 \%$ & $2 \%$ & $0 \%$ \\
\hline Sickness & $5 \%$ & $4 \%$ & $3 \%$ & $18 \%$ \\
\hline Disability & $46 \%$ & $5 \%$ & $2 \%$ & $2 \%$ \\
\hline
\end{tabular}

a. Based on total equivalized disposable household income.

b. Refers to individuals aged 25 and over.

c. Dependent children include: 1. household members under 18; 2. household members aged between 18 and 24 who are economically inactive and living with at least one parent.

d. Refers only to individuals who have worked before.

Source: WB staff calculations based on EU-SILC. 


\begin{tabular}{|c|c|c|c|c|c|}
\hline & $\begin{array}{l}\text { 1. Prime-aged } \\
\text { educated } \\
\text { unemployed }\end{array}$ & $\begin{array}{l}\text { 2. Educated } \\
\text { retirees }\end{array}$ & $\begin{array}{l}\text { 3. Young inactive } \\
\text { educated mothers } \\
\text { with working } \\
\text { partner }\end{array}$ & $\begin{array}{l}\text { 4. Middle-aged } \\
\text { low educated } \\
\text { and rural } \\
\text { disabled }\end{array}$ & $\begin{array}{l}\text { 5. Single NEETs } \\
\text { without work } \\
\text { experience }\end{array}$ \\
\hline Cluster size & $38 \%$ & $21 \%$ & $17 \%$ & $15 \%$ & $9 \%$ \\
\hline \multicolumn{6}{|c|}{ INDICATORS } \\
\hline \multicolumn{6}{|l|}{ Labor market attachment } \\
\hline Unemployed & $90 \%$ & $0 \%$ & $19 \%$ & $23 \%$ & $85 \%$ \\
\hline Retired & $4 \%$ & $85 \%$ & $0 \%$ & $0 \%$ & $0 \%$ \\
\hline Disabled & $2 \%$ & $15 \%$ & $5 \%$ & $61 \%$ & $1 \%$ \\
\hline Other inactive & $4 \%$ & $0 \%$ & $76 \%$ & $16 \%$ & $14 \%$ \\
\hline \multicolumn{6}{|c|}{ At least one working adult in householda } \\
\hline No & $39 \%$ & $66 \%$ & $19 \%$ & $77 \%$ & $39 \%$ \\
\hline Yes & $61 \%$ & $34 \%$ & $81 \%$ & $23 \%$ & $61 \%$ \\
\hline \multicolumn{6}{|l|}{ Work experience } \\
\hline Never worked & $0 \%$ & $0 \%$ & $20 \%$ & $10 \%$ & $53 \%$ \\
\hline Less than 2 months in last year & $28 \%$ & $90 \%$ & $65 \%$ & $81 \%$ & $3 \%$ \\
\hline 2 or more months in last year & $72 \%$ & $10 \%$ & $15 \%$ & $10 \%$ & $43 \%$ \\
\hline \multicolumn{6}{|l|}{ Self-assessed physical incapacity } \\
\hline Strongly limited & $2 \%$ & $17 \%$ & $1 \%$ & $34 \%$ & $0 \%$ \\
\hline None/limited & $98 \%$ & $83 \%$ & $99 \%$ & $66 \%$ & $100 \%$ \\
\hline \multicolumn{6}{|c|}{ ACTIVE COVARIATES } \\
\hline \multicolumn{6}{|l|}{ Age groups (4) } \\
\hline $16-24$ years & $2 \%$ & $0 \%$ & $20 \%$ & $0 \%$ & $80 \%$ \\
\hline $25-34$ years & $29 \%$ & $0 \%$ & $58 \%$ & $8 \%$ & $20 \%$ \\
\hline $35-59$ years & $63 \%$ & $4 \%$ & $22 \%$ & $92 \%$ & $0 \%$ \\
\hline $60-64$ years & $5 \%$ & $96 \%$ & $0 \%$ & $0 \%$ & $0 \%$ \\
\hline \multicolumn{6}{|l|}{ Gender } \\
\hline Male & $69 \%$ & $42 \%$ & $3 \%$ & $56 \%$ & $79 \%$ \\
\hline
\end{tabular}




\begin{tabular}{|c|c|c|c|c|c|}
\hline & $\begin{array}{l}\text { 1. Prime-aged } \\
\text { educated } \\
\text { unemployed }\end{array}$ & $\begin{array}{l}\text { 2. Educated } \\
\text { retirees }\end{array}$ & $\begin{array}{l}\text { 3. Young inactive } \\
\text { educated mothers } \\
\text { with working } \\
\text { partner }\end{array}$ & $\begin{array}{l}\text { 4. Middle-aged } \\
\text { low educated } \\
\text { and rural } \\
\text { disabled }\end{array}$ & $\begin{array}{l}\text { 5. Single NEETs } \\
\text { without work } \\
\text { experience }\end{array}$ \\
\hline Female & $31 \%$ & $58 \%$ & $97 \%$ & $44 \%$ & $21 \%$ \\
\hline \multicolumn{6}{|l|}{ Education (4) } \\
\hline Primary & $10 \%$ & $14 \%$ & $20 \%$ & $50 \%$ & $33 \%$ \\
\hline Secondary & $58 \%$ & $69 \%$ & $36 \%$ & $49 \%$ & $59 \%$ \\
\hline Tertiary & $31 \%$ & $17 \%$ & $38 \%$ & $0 \%$ & $8 \%$ \\
\hline NA & $1 \%$ & $0 \%$ & $7 \%$ & $0 \%$ & $0 \%$ \\
\hline Urban & $59 \%$ & $51 \%$ & $50 \%$ & $13 \%$ & $36 \%$ \\
\hline Rural & $41 \%$ & $49 \%$ & $50 \%$ & $87 \%$ & $65 \%$ \\
\hline \multicolumn{6}{|c|}{ INACTIVE COVARIATES } \\
\hline \multicolumn{6}{|l|}{ Age groups (8) } \\
\hline $16-19$ years & $0 \%$ & $0 \%$ & $4 \%$ & $0 \%$ & $10 \%$ \\
\hline 20-24 years & $2 \%$ & $0 \%$ & $16 \%$ & $0 \%$ & $71 \%$ \\
\hline 25-29 years & $12 \%$ & $0 \%$ & $34 \%$ & $5 \%$ & $11 \%$ \\
\hline 30-34 years & $17 \%$ & $0 \%$ & $24 \%$ & $3 \%$ & $8 \%$ \\
\hline $35-44$ years & $18 \%$ & $0 \%$ & $14 \%$ & $26 \%$ & $0 \%$ \\
\hline 45-54 years & $23 \%$ & $1 \%$ & $6 \%$ & $33 \%$ & $0 \%$ \\
\hline $55-59$ years & $22 \%$ & $3 \%$ & $2 \%$ & $33 \%$ & $0 \%$ \\
\hline 60-64 years & $5 \%$ & $96 \%$ & $0 \%$ & $0 \%$ & $0 \%$ \\
\hline \multicolumn{6}{|l|}{ Education (6) } \\
\hline None or less than primary & $0 \%$ & $0 \%$ & $0 \%$ & $0 \%$ & $0 \%$ \\
\hline Primary & $1 \%$ & $0 \%$ & $2 \%$ & $5 \%$ & $5 \%$ \\
\hline Lower secondary & $9 \%$ & $14 \%$ & $17 \%$ & $45 \%$ & $28 \%$ \\
\hline Upper secondary & $56 \%$ & $66 \%$ & $28 \%$ & $46 \%$ & $52 \%$ \\
\hline Post-secondary & $2 \%$ & $2 \%$ & $8 \%$ & $3 \%$ & $6 \%$ \\
\hline Tertiary & $31 \%$ & $17 \%$ & $38 \%$ & $0 \%$ & $8 \%$ \\
\hline NA & $1 \%$ & $0 \%$ & $7 \%$ & $0 \%$ & $0 \%$ \\
\hline Ever worked & & & & & \\
\hline
\end{tabular}




\begin{tabular}{|c|c|c|c|c|c|}
\hline & $\begin{array}{l}\text { 1. Prime-aged } \\
\text { educated } \\
\text { unemployed }\end{array}$ & $\begin{array}{l}\text { 2. Educated } \\
\text { retirees }\end{array}$ & $\begin{array}{l}\text { 3. Young inactive } \\
\text { educated mothers } \\
\text { with working } \\
\text { partner }\end{array}$ & $\begin{array}{l}\text { 4. Middle-aged } \\
\text { low educated } \\
\text { and rural } \\
\text { disabled }\end{array}$ & $\begin{array}{l}\text { 5. Single NEETs } \\
\text { without work } \\
\text { experience }\end{array}$ \\
\hline No & $0 \%$ & $0 \%$ & $20 \%$ & $10 \%$ & $54 \%$ \\
\hline Yes & $98 \%$ & $100 \%$ & $73 \%$ & $90 \%$ & $46 \%$ \\
\hline NA & $2 \%$ & $0 \%$ & $7 \%$ & $1 \%$ & $0 \%$ \\
\hline Years of work experience ${ }^{b}$ & 18 & 34 & 7 & 18 & 3 \\
\hline \multicolumn{6}{|l|}{ Household income (mean) } \\
\hline Labor income & 12091 & 4592 & 19030 & 2855 & 15966 \\
\hline Other income & 249 & 40 & 1546 & 32 & 278 \\
\hline Benefits & 3040 & 5321 & 4312 & 4284 & 2628 \\
\hline \multicolumn{6}{|l|}{ Household income shares } \\
\hline Labor income & $69 \%$ & $28 \%$ & $67 \%$ & $26 \%$ & $72 \%$ \\
\hline Other income & $2 \%$ & $0 \%$ & $3 \%$ & $0 \%$ & $5 \%$ \\
\hline Benefits & $30 \%$ & $71 \%$ & $30 \%$ & $74 \%$ & $23 \%$ \\
\hline \multicolumn{6}{|l|}{ Income quintiled } \\
\hline Poorest & $27 \%$ & $30 \%$ & $15 \%$ & $60 \%$ & $26 \%$ \\
\hline Q2 & $22 \%$ & $31 \%$ & $24 \%$ & $19 \%$ & $26 \%$ \\
\hline Q3 & $15 \%$ & $16 \%$ & $26 \%$ & $16 \%$ & $16 \%$ \\
\hline Q4 & $25 \%$ & $12 \%$ & $16 \%$ & $3 \%$ & $12 \%$ \\
\hline Richest & $10 \%$ & $11 \%$ & $18 \%$ & $1 \%$ & $20 \%$ \\
\hline \multicolumn{6}{|l|}{ Poverty Risk } \\
\hline No & $79 \%$ & $75 \%$ & $87 \%$ & $45 \%$ & $77 \%$ \\
\hline Yes & $21 \%$ & $25 \%$ & $13 \%$ & $55 \%$ & $23 \%$ \\
\hline \multicolumn{6}{|l|}{ Working partner } \\
\hline Yes & $46 \%$ & $27 \%$ & $56 \%$ & $18 \%$ & $8 \%$ \\
\hline No & $9 \%$ & $34 \%$ & $12 \%$ & $26 \%$ & $4 \%$ \\
\hline NA & $45 \%$ & $39 \%$ & $32 \%$ & $57 \%$ & $88 \%$ \\
\hline \multicolumn{6}{|l|}{ Partner economic status } \\
\hline Working & $46 \%$ & $27 \%$ & $56 \%$ & $18 \%$ & $8 \%$ \\
\hline
\end{tabular}




\begin{tabular}{|c|c|c|c|c|c|}
\hline & $\begin{array}{l}\text { 1. Prime-aged } \\
\text { educated } \\
\text { unemployed }\end{array}$ & $\begin{array}{l}\text { 2. Educated } \\
\text { retirees }\end{array}$ & $\begin{array}{l}\text { 3. Young inactive } \\
\text { educated mothers } \\
\text { with working } \\
\text { partner }\end{array}$ & $\begin{array}{l}\text { 4. Middle-aged } \\
\text { low educated } \\
\text { and rural } \\
\text { disabled }\end{array}$ & $\begin{array}{l}\text { 5. Single NEETs } \\
\text { without work } \\
\text { experience }\end{array}$ \\
\hline Unemployed & $4 \%$ & $2 \%$ & $10 \%$ & $6 \%$ & $3 \%$ \\
\hline Retired & $0 \%$ & $26 \%$ & $0 \%$ & $7 \%$ & $0 \%$ \\
\hline Inactive & $5 \%$ & $6 \%$ & $1 \%$ & $12 \%$ & $1 \%$ \\
\hline Student/military service & $0 \%$ & $0 \%$ & $0 \%$ & $1 \%$ & $0 \%$ \\
\hline NA & $45 \%$ & $39 \%$ & $32 \%$ & $57 \%$ & $88 \%$ \\
\hline Partner income (mean) & 9111 & 3508 & 15697 & 3412 & 8724 \\
\hline Working partner income (mean) & 10599 & 7237 & 18379 & 7238 & 12992 \\
\hline \multicolumn{6}{|l|}{ Partner income quintile } \\
\hline Poorest & $12 \%$ & $7 \%$ & $13 \%$ & $7 \%$ & $1 \%$ \\
\hline Q2 & $10 \%$ & $7 \%$ & $3 \%$ & $4 \%$ & $1 \%$ \\
\hline Q3 & $10 \%$ & $5 \%$ & $11 \%$ & $4 \%$ & $1 \%$ \\
\hline Q4 & $7 \%$ & $5 \%$ & $10 \%$ & $2 \%$ & $0 \%$ \\
\hline Richest & $8 \%$ & $2 \%$ & $19 \%$ & $1 \%$ & $4 \%$ \\
\hline NA & $54 \%$ & $73 \%$ & $44 \%$ & $82 \%$ & $92 \%$ \\
\hline Receives at least one benefit & $74 \%$ & $97 \%$ & $93 \%$ & $85 \%$ & $66 \%$ \\
\hline \multicolumn{6}{|l|}{ Receives benefits at household level } \\
\hline Family child & $43 \%$ & $5 \%$ & $84 \%$ & $28 \%$ & $43 \%$ \\
\hline Social exclusion & $1 \%$ & $0 \%$ & $3 \%$ & $1 \%$ & $3 \%$ \\
\hline Housing & $6 \%$ & $0 \%$ & $1 \%$ & $9 \%$ & $6 \%$ \\
\hline Old age at household level & $53 \%$ & $89 \%$ & $83 \%$ & $54 \%$ & $47 \%$ \\
\hline \multicolumn{6}{|l|}{ Receives benefits at individual level } \\
\hline Unemployment & $42 \%$ & $8 \%$ & $12 \%$ & $10 \%$ & $14 \%$ \\
\hline Old age & $4 \%$ & $81 \%$ & $0 \%$ & $0 \%$ & $0 \%$ \\
\hline Survivor & $1 \%$ & $0 \%$ & $0 \%$ & $2 \%$ & $10 \%$ \\
\hline Sickness & $14 \%$ & $1 \%$ & $2 \%$ & $5 \%$ & $8 \%$ \\
\hline Disability & $8 \%$ & $22 \%$ & $13 \%$ & $67 \%$ & $2 \%$ \\
\hline Education & $1 \%$ & $0 \%$ & $10 \%$ & $0 \%$ & $8 \%$ \\
\hline
\end{tabular}




\begin{tabular}{|c|c|c|c|c|c|}
\hline & $\begin{array}{l}\text { 1. Prime-aged } \\
\text { educated } \\
\text { unemployed }\end{array}$ & $\begin{array}{l}\text { 2. Educated } \\
\text { retirees }\end{array}$ & $\begin{array}{l}\text { 3. Young inactive } \\
\text { educated mothers } \\
\text { with working } \\
\text { partner }\end{array}$ & $\begin{array}{l}\text { 4. Middle-aged } \\
\text { low educated } \\
\text { and rural } \\
\text { disabled }\end{array}$ & $\begin{array}{l}\text { 5. Single NEETs } \\
\text { without work } \\
\text { experience }\end{array}$ \\
\hline \multicolumn{6}{|c|}{ Benefits as share of total gross household income, all households } \\
\hline Family child & $5 \%$ & $0 \%$ & $17 \%$ & $6 \%$ & $4 \%$ \\
\hline Social exclusion & $0 \%$ & $0 \%$ & $0 \%$ & $0 \%$ & $0 \%$ \\
\hline Housing & $1 \%$ & $0 \%$ & $0 \%$ & $2 \%$ & $1 \%$ \\
\hline Unemployment & $9 \%$ & $5 \%$ & $4 \%$ & $4 \%$ & $2 \%$ \\
\hline Old age & $10 \%$ & $54 \%$ & $3 \%$ & $23 \%$ & $10 \%$ \\
\hline Survivor & $0 \%$ & $0 \%$ & $0 \%$ & $1 \%$ & $1 \%$ \\
\hline Sickness & $1 \%$ & $0 \%$ & $0 \%$ & $1 \%$ & $0 \%$ \\
\hline Disability & $3 \%$ & $11 \%$ & $3 \%$ & $37 \%$ & $5 \%$ \\
\hline Education & $0 \%$ & $0 \%$ & $1 \%$ & $0 \%$ & $0 \%$ \\
\hline \multicolumn{6}{|c|}{ Benefits as share of total gross household income, only beneficiaries } \\
\hline Family child & $11 \%$ & $9 \%$ & $21 \%$ & $20 \%$ & $10 \%$ \\
\hline Social exclusion & $6 \%$ & $17 \%$ & $5 \%$ & $8 \%$ & $7 \%$ \\
\hline Housing & $19 \%$ & $3 \%$ & $18 \%$ & $25 \%$ & $9 \%$ \\
\hline Unemployment & $18 \%$ & $43 \%$ & $12 \%$ & $26 \%$ & $8 \%$ \\
\hline Old age & $44 \%$ & $61 \%$ & $36 \%$ & $65 \%$ & $50 \%$ \\
\hline Survivor & $14 \%$ & $24 \%$ & $6 \%$ & $18 \%$ & $6 \%$ \\
\hline Sickness & $7 \%$ & $5 \%$ & $1 \%$ & $7 \%$ & $2 \%$ \\
\hline Disability & $16 \%$ & $36 \%$ & $18 \%$ & $49 \%$ & $33 \%$ \\
\hline Education & $5 \%$ & $11 \%$ & $7 \%$ & $12 \%$ & $3 \%$ \\
\hline Household size (mean) & 3.08 & 2.00 & 4.14 & 2.65 & 3.32 \\
\hline \multicolumn{6}{|l|}{ Household composition } \\
\hline One-person & $13 \%$ & $27 \%$ & $1 \%$ & $17 \%$ & $13 \%$ \\
\hline Single parent & $2 \%$ & $0 \%$ & $0 \%$ & $1 \%$ & $0 \%$ \\
\hline $2+$ adults without dependent childrene & $53 \%$ & $70 \%$ & $20 \%$ & $59 \%$ & $60 \%$ \\
\hline $2+$ adults with 1 dependent childe & $17 \%$ & $1 \%$ & $39 \%$ & $11 \%$ & $18 \%$ \\
\hline $2+$ adults with $2+$ dependent children ${ }^{\mathrm{e}}$ & $15 \%$ & $2 \%$ & $40 \%$ & $12 \%$ & $9 \%$ \\
\hline
\end{tabular}




\begin{tabular}{|c|c|c|c|c|c|}
\hline & $\begin{array}{l}\text { 1. Prime-aged } \\
\text { educated } \\
\text { unemployed }\end{array}$ & $\begin{array}{l}\text { 2. Educated } \\
\text { retirees }\end{array}$ & $\begin{array}{l}\text { 3. Young inactive } \\
\text { educated mothers } \\
\text { with working } \\
\text { partner }\end{array}$ & $\begin{array}{l}\text { 4. Middle-aged } \\
\text { low educated } \\
\text { and rural } \\
\text { disabled }\end{array}$ & $\begin{array}{l}\text { 5. Single NEETs } \\
\text { without work } \\
\text { experience }\end{array}$ \\
\hline Children under six & $20 \%$ & $2 \%$ & $63 \%$ & $12 \%$ & $14 \%$ \\
\hline Three or more children under 16 & $5 \%$ & $1 \%$ & $10 \%$ & $2 \%$ & $0 \%$ \\
\hline \multicolumn{6}{|l|}{ Individuals' parents present } \\
\hline One parent & $19 \%$ & $2 \%$ & $18 \%$ & $17 \%$ & $40 \%$ \\
\hline Both parents & $8 \%$ & $0 \%$ & $21 \%$ & $10 \%$ & $33 \%$ \\
\hline None & $73 \%$ & $98 \%$ & $61 \%$ & $73 \%$ & $27 \%$ \\
\hline Elderly present (over 64) & $10 \%$ & $20 \%$ & $3 \%$ & $29 \%$ & $14 \%$ \\
\hline \multicolumn{6}{|l|}{ Marital status } \\
\hline Married & $40 \%$ & $54 \%$ & $45 \%$ & $28 \%$ & $2 \%$ \\
\hline Never married & $42 \%$ & $8 \%$ & $50 \%$ & $41 \%$ & $97 \%$ \\
\hline Divorced/separated & $16 \%$ & $24 \%$ & $4 \%$ & $28 \%$ & $0 \%$ \\
\hline Widowed & $2 \%$ & $15 \%$ & $1 \%$ & $3 \%$ & $0 \%$ \\
\hline \multicolumn{6}{|l|}{ Able to keep dwelling warm } \\
\hline No & $6 \%$ & $4 \%$ & $4 \%$ & $9 \%$ & $14 \%$ \\
\hline Yes & $94 \%$ & $96 \%$ & $96 \%$ & $91 \%$ & $86 \%$ \\
\hline \multicolumn{6}{|l|}{ Degree of urbanization } \\
\hline Densely populated & $59 \%$ & $51 \%$ & $50 \%$ & $13 \%$ & $36 \%$ \\
\hline Sparsely populated & $41 \%$ & $49 \%$ & $50 \%$ & $87 \%$ & $65 \%$ \\
\hline
\end{tabular}

a. Refers to individuals aged 25 and over.

b. Refers only to individuals who have worked before.

c. Based on total gross household income.

d. Based on total equivalized disposable household income.

e. Dependent children include: 1. household members under 18; 2. household members aged between 18 and 24 who are economically inactive and living with at least one parent.

Source: WB staff calculations based on EU-SILC. 


\begin{tabular}{|c|c|c|c|c|c|}
\hline & $\begin{array}{l}\text { 1. Stay-at-home } \\
\text { mothers }\end{array}$ & $\begin{array}{l}\text { 2. Highly educated } \\
\text { single NEETs }\end{array}$ & $\begin{array}{l}\text { 3. Retired and } \\
\text { early retired men }\end{array}$ & $\begin{array}{l}\text { 4. Retirees' } \\
\text { inactive wives }\end{array}$ & $\begin{array}{c}\text { 5. Low-educated } \\
\text { unemployed or } \\
\text { disabled }\end{array}$ \\
\hline Cluster Size & $28 \%$ & $24 \%$ & $18 \%$ & $17 \%$ & $13 \%$ \\
\hline \multicolumn{6}{|c|}{ INDICATORS } \\
\hline \multicolumn{6}{|c|}{ Labor market attachment } \\
\hline Unemployed & $11 \%$ & $64 \%$ & $20 \%$ & $0 \%$ & $57 \%$ \\
\hline Retired & $0 \%$ & $0 \%$ & $76 \%$ & $15 \%$ & $3 \%$ \\
\hline Disabled & $3 \%$ & $0 \%$ & $4 \%$ & $3 \%$ & $35 \%$ \\
\hline Other inactive & $85 \%$ & $36 \%$ & $0 \%$ & $82 \%$ & $5 \%$ \\
\hline \multicolumn{6}{|l|}{ Education } \\
\hline Primary & $43 \%$ & $8 \%$ & $52 \%$ & $78 \%$ & $59 \%$ \\
\hline Secondary & $44 \%$ & $67 \%$ & $25 \%$ & $21 \%$ & $41 \%$ \\
\hline Tertiary & $12 \%$ & $25 \%$ & $23 \%$ & $0 \%$ & $0 \%$ \\
\hline \multicolumn{6}{|l|}{ Working Partner } \\
\hline Yes & $94 \%$ & $1 \%$ & $37 \%$ & $3 \%$ & $26 \%$ \\
\hline No & $6 \%$ & $0 \%$ & $54 \%$ & $70 \%$ & $0 \%$ \\
\hline NA & $0 \%$ & $99 \%$ & $9 \%$ & $27 \%$ & $73 \%$ \\
\hline \multicolumn{6}{|c|}{ Self-assessed physical incapacity } \\
\hline Strongly limited & $2 \%$ & $0 \%$ & $16 \%$ & $8 \%$ & $29 \%$ \\
\hline None/limited & $98 \%$ & $100 \%$ & $84 \%$ & $92 \%$ & $71 \%$ \\
\hline \multicolumn{6}{|c|}{ ACTIVE COVARIATES } \\
\hline \multicolumn{6}{|l|}{ Age groups (4) } \\
\hline 16-24 years & $0 \%$ & $31 \%$ & $0 \%$ & $0 \%$ & $7 \%$ \\
\hline 25-34 years & $23 \%$ & $63 \%$ & $0 \%$ & $0 \%$ & $9 \%$ \\
\hline $35-59$ years & $77 \%$ & $6 \%$ & $53 \%$ & $44 \%$ & $85 \%$ \\
\hline 60-64 years & $0 \%$ & $0 \%$ & $47 \%$ & $56 \%$ & $0 \%$ \\
\hline \multicolumn{6}{|l|}{ Gender } \\
\hline Male & $0 \%$ & $44 \%$ & $73 \%$ & $0 \%$ & $72 \%$ \\
\hline Female & $100 \%$ & $56 \%$ & $27 \%$ & $100 \%$ & $28 \%$ \\
\hline
\end{tabular}

\section{Stay-at-home}




\begin{tabular}{|c|c|c|c|c|c|}
\hline & $\begin{array}{l}\text { 1. Stay-at-home } \\
\text { mothers }\end{array}$ & $\begin{array}{l}\text { 2. Highly educated } \\
\text { single NEETs }\end{array}$ & $\begin{array}{l}\text { 3. Retired and } \\
\text { early retired men }\end{array}$ & $\begin{array}{l}\text { 4. Retirees' } \\
\text { inactive wives }\end{array}$ & $\begin{array}{c}\text { 5. Low-educated } \\
\text { unemployed or } \\
\text { disabled }\end{array}$ \\
\hline \multicolumn{6}{|l|}{ Degree of urbanization } \\
\hline Densely populated & $25 \%$ & $46 \%$ & $38 \%$ & $28 \%$ & $36 \%$ \\
\hline Intermediate area & $11 \%$ & $9 \%$ & $14 \%$ & $13 \%$ & $4 \%$ \\
\hline Sparsely populated & $64 \%$ & $45 \%$ & $47 \%$ & $59 \%$ & $61 \%$ \\
\hline \multicolumn{6}{|c|}{ INACTIVE COVARIATES } \\
\hline \multicolumn{6}{|l|}{ Age groups (7) } \\
\hline $16-19$ years & $0 \%$ & $5 \%$ & $0 \%$ & $0 \%$ & $4 \%$ \\
\hline 20-24 years & $0 \%$ & $26 \%$ & $0 \%$ & $0 \%$ & $3 \%$ \\
\hline 25-34 years & $23 \%$ & $63 \%$ & $0 \%$ & $0 \%$ & $9 \%$ \\
\hline 35-44 years & $38 \%$ & $4 \%$ & $6 \%$ & $7 \%$ & $34 \%$ \\
\hline 45-54 years & $27 \%$ & $1 \%$ & $24 \%$ & $18 \%$ & $41 \%$ \\
\hline $55-59$ years & $12 \%$ & $1 \%$ & $22 \%$ & $19 \%$ & $10 \%$ \\
\hline 60-64 years & $0 \%$ & $0 \%$ & $47 \%$ & $56 \%$ & $0 \%$ \\
\hline \multicolumn{6}{|l|}{ Education } \\
\hline None/less than primary & $1 \%$ & $0 \%$ & $2 \%$ & $6 \%$ & $5 \%$ \\
\hline Primary & $25 \%$ & $1 \%$ & $41 \%$ & $56 \%$ & $34 \%$ \\
\hline Lower secondary & $18 \%$ & $6 \%$ & $8 \%$ & $15 \%$ & $17 \%$ \\
\hline Upper secondary & $36 \%$ & $58 \%$ & $21 \%$ & $20 \%$ & $36 \%$ \\
\hline Post-secondary & $9 \%$ & $10 \%$ & $3 \%$ & $1 \%$ & $4 \%$ \\
\hline Tertiary & $12 \%$ & $25 \%$ & $22 \%$ & $0 \%$ & $0 \%$ \\
\hline NA & $0 \%$ & $0 \%$ & $2 \%$ & $1 \%$ & $4 \%$ \\
\hline \multicolumn{6}{|l|}{ Marital status } \\
\hline Married & $100 \%$ & $2 \%$ & $90 \%$ & $76 \%$ & $27 \%$ \\
\hline Never married & $0 \%$ & $93 \%$ & $3 \%$ & $3 \%$ & $57 \%$ \\
\hline Divorced/separated & $0 \%$ & $3 \%$ & $4 \%$ & $5 \%$ & $15 \%$ \\
\hline Widowed & $0 \%$ & $2 \%$ & $3 \%$ & $17 \%$ & $1 \%$ \\
\hline \multicolumn{6}{|l|}{ Income quintile ${ }^{a}$} \\
\hline Poorest & $36 \%$ & $24 \%$ & $22 \%$ & $28 \%$ & $40 \%$ \\
\hline Q2 & $23 \%$ & $33 \%$ & $17 \%$ & $17 \%$ & $20 \%$ \\
\hline
\end{tabular}




\begin{tabular}{|c|c|c|c|c|c|}
\hline & $\begin{array}{l}\text { 1. Stay-at-home } \\
\text { mothers }\end{array}$ & $\begin{array}{l}\text { 2. Highly educated } \\
\text { single NEETs }\end{array}$ & $\begin{array}{l}\text { 3. Retired and } \\
\text { early retired men }\end{array}$ & $\begin{array}{c}\text { 4. Retirees' } \\
\text { inactive wives }\end{array}$ & $\begin{array}{l}\text { 5. Low-educated } \\
\text { unemployed or } \\
\text { disabled }\end{array}$ \\
\hline Q3 & $18 \%$ & $19 \%$ & $15 \%$ & $16 \%$ & $17 \%$ \\
\hline Q4 & $16 \%$ & $17 \%$ & $24 \%$ & $30 \%$ & $18 \%$ \\
\hline Richest & $7 \%$ & $7 \%$ & $22 \%$ & $9 \%$ & $5 \%$ \\
\hline \multicolumn{6}{|l|}{ Partner economic status } \\
\hline Working & $94 \%$ & $1 \%$ & $37 \%$ & $3 \%$ & $26 \%$ \\
\hline Unemployed & $1 \%$ & $0 \%$ & $5 \%$ & $5 \%$ & $0 \%$ \\
\hline Retired & $5 \%$ & $0 \%$ & $15 \%$ & $63 \%$ & $0 \%$ \\
\hline Inactive & $0 \%$ & $0 \%$ & $34 \%$ & $3 \%$ & $0 \%$ \\
\hline \multicolumn{6}{|l|}{ Student/military service } \\
\hline No partner & $0 \%$ & $99 \%$ & $9 \%$ & $27 \%$ & $73 \%$ \\
\hline Partner income (mean) & 15408 & 10699 & 6639 & 1182 & 9743 \\
\hline \multicolumn{6}{|l|}{ Partner income quintile } \\
\hline Poorest & $9 \%$ & $0 \%$ & $8 \%$ & $0 \%$ & $7 \%$ \\
\hline Q2 & $14 \%$ & $0 \%$ & $4 \%$ & $1 \%$ & $10 \%$ \\
\hline Q3 & $21 \%$ & $0 \%$ & $9 \%$ & $1 \%$ & $5 \%$ \\
\hline Q4 & $24 \%$ & $0 \%$ & $6 \%$ & $0 \%$ & $2 \%$ \\
\hline Richest & $24 \%$ & $0 \%$ & $9 \%$ & $1 \%$ & $3 \%$ \\
\hline No partner or partner without income & $7 \%$ & $99 \%$ & $63 \%$ & $97 \%$ & $74 \%$ \\
\hline Household size (mean) & 3.804 & 3.372 & 3.080 & 2.724 & 3.339 \\
\hline \multicolumn{6}{|l|}{ Tenure status } \\
\hline Owner & $73 \%$ & $73 \%$ & $88 \%$ & $89 \%$ & $87 \%$ \\
\hline Tenant & $24 \%$ & $19 \%$ & $9 \%$ & $7 \%$ & $10 \%$ \\
\hline Reduced rate & $0 \%$ & $2 \%$ & $2 \%$ & $2 \%$ & $0 \%$ \\
\hline Free & $3 \%$ & $6 \%$ & $2 \%$ & $2 \%$ & $2 \%$ \\
\hline \multicolumn{6}{|l|}{ Household composition } \\
\hline One-person & $0 \%$ & $9 \%$ & $4 \%$ & $6 \%$ & $4 \%$ \\
\hline Single parent & $0 \%$ & $2 \%$ & $0 \%$ & $0 \%$ & $0 \%$ \\
\hline $2+$ adults without dependent children ${ }^{b}$ & $38 \%$ & $76 \%$ & $79 \%$ & $80 \%$ & $74 \%$ \\
\hline $2+$ adults with 1 dependent child ${ }^{\mathrm{b}}$ & $25 \%$ & $10 \%$ & $11 \%$ & $10 \%$ & $7 \%$ \\
\hline
\end{tabular}




\begin{tabular}{|c|c|c|c|c|c|}
\hline & $\begin{array}{l}\text { 1. Stay-at-home } \\
\text { mothers }\end{array}$ & $\begin{array}{l}\text { 2. Highly educated } \\
\text { single NEETs }\end{array}$ & $\begin{array}{l}\text { 3. Retired and } \\
\text { early retired men }\end{array}$ & $\begin{array}{c}\text { 4. Retirees' } \\
\text { inactive wives }\end{array}$ & $\begin{array}{c}\text { 5. Low-educated } \\
\text { unemployed or } \\
\text { disabled }\end{array}$ \\
\hline $2+$ adults with $2+$ dependent children ${ }^{b}$ & $37 \%$ & $3 \%$ & $6 \%$ & $4 \%$ & $15 \%$ \\
\hline Children under 6 & $29 \%$ & $5 \%$ & $4 \%$ & $5 \%$ & $6 \%$ \\
\hline Three or more children under 16 & $9 \%$ & $0 \%$ & $1 \%$ & $1 \%$ & $0 \%$ \\
\hline Elderly present (over 64) & $10 \%$ & $24 \%$ & $22 \%$ & $43 \%$ & $50 \%$ \\
\hline Years of work experience & 9.889 & 4.255 & 28.946 & 17.868 & 18.027 \\
\hline \multicolumn{6}{|l|}{ Able to keep dwelling warm } \\
\hline No & $24 \%$ & $19 \%$ & $19 \%$ & $15 \%$ & $37 \%$ \\
\hline Yes & $76 \%$ & $81 \%$ & $81 \%$ & $85 \%$ & $63 \%$ \\
\hline Urban & $36 \%$ & $55 \%$ & $53 \%$ & $41 \%$ & $39 \%$ \\
\hline Rural & $64 \%$ & $45 \%$ & $47 \%$ & $59 \%$ & $61 \%$ \\
\hline \multicolumn{6}{|l|}{ Region } \\
\hline GR1 - Northern Greece & $39 \%$ & $49 \%$ & $39 \%$ & $36 \%$ & $30 \%$ \\
\hline GR2 - Central Greece & $23 \%$ & $20 \%$ & $23 \%$ & $29 \%$ & $32 \%$ \\
\hline GR3 - Athens & $23 \%$ & $23 \%$ & $30 \%$ & $24 \%$ & $26 \%$ \\
\hline GR4 - Aegean Islands, Crete & $15 \%$ & $9 \%$ & $8 \%$ & $11 \%$ & $12 \%$ \\
\hline Receives at least one benefit & $28 \%$ & $39 \%$ & $91 \%$ & $42 \%$ & $66 \%$ \\
\hline \multicolumn{6}{|l|}{ Receives benefits at household level } \\
\hline Social Assistance & $24 \%$ & $33 \%$ & $42 \%$ & $23 \%$ & $49 \%$ \\
\hline \multicolumn{6}{|l|}{ Receives benefits at individual level } \\
\hline Unemployment & $6 \%$ & $5 \%$ & $10 \%$ & $0 \%$ & $11 \%$ \\
\hline Old age & $1 \%$ & $3 \%$ & $59 \%$ & $24 \%$ & $5 \%$ \\
\hline Illness & $1 \%$ & $1 \%$ & $14 \%$ & $3 \%$ & $26 \%$ \\
\hline
\end{tabular}

a. Based on total equivalized disposable household income.

b. Dependent children include: 1. household members under 18; 2. household members aged between 18 and 24 who are economically inactive and living with at least one parent.

c. Refers only to individuals who have worked before. 


\begin{tabular}{|c|c|c|c|c|c|c|}
\hline & $\begin{array}{l}\text { 1. Mostly rural } \\
\text { retired and } \\
\text { disabled with } \\
\text { previous work } \\
\text { experience }\end{array}$ & $\begin{array}{c}2 . \\
\text { Retirees }\end{array}$ & $\begin{array}{l}\text { 3. Middle- } \\
\text { aged } \\
\text { unemployed }\end{array}$ & $\begin{array}{l}\text { 4. Prime-aged } \\
\text { inactive mothers } \\
\text { with work } \\
\text { experience }\end{array}$ & $\begin{array}{c}\text { 5. Inactive } \\
\text { young single } \\
\text { women without } \\
\text { work } \\
\text { experience }\end{array}$ & $\begin{array}{c}6 . \\
\text { Unemployed } \\
\text { rural single } \\
\text { young men }\end{array}$ \\
\hline Cluster size & $28 \%$ & $25 \%$ & $17 \%$ & $16 \%$ & $\mathbf{8 \%}$ & $6 \%$ \\
\hline \multicolumn{7}{|c|}{ INDICATORS } \\
\hline \multicolumn{7}{|l|}{ Labor market attachment } \\
\hline Unemployed & $0 \%$ & $1 \%$ & $84 \%$ & $12 \%$ & $8 \%$ & $100 \%$ \\
\hline Retired & $27 \%$ & $98 \%$ & $5 \%$ & $0 \%$ & $0 \%$ & $0 \%$ \\
\hline Disabled & $70 \%$ & $1 \%$ & $0 \%$ & $0 \%$ & $11 \%$ & $0 \%$ \\
\hline Other inactive & $2 \%$ & $1 \%$ & $11 \%$ & $88 \%$ & $81 \%$ & $0 \%$ \\
\hline \multicolumn{7}{|c|}{ At least one working adult in householda } \\
\hline No & $54 \%$ & $68 \%$ & $59 \%$ & $18 \%$ & $46 \%$ & $24 \%$ \\
\hline Yes & $46 \%$ & $32 \%$ & $41 \%$ & $82 \%$ & $54 \%$ & $76 \%$ \\
\hline \multicolumn{7}{|l|}{ Work experience } \\
\hline Never worked & $1 \%$ & $0 \%$ & $0 \%$ & $0 \%$ & $91 \%$ & $51 \%$ \\
\hline Less than 2 months in last year & $91 \%$ & $97 \%$ & $37 \%$ & $83 \%$ & $9 \%$ & $5 \%$ \\
\hline 2 or more months in last year & $8 \%$ & $3 \%$ & $63 \%$ & $17 \%$ & $0 \%$ & $45 \%$ \\
\hline \multicolumn{7}{|l|}{ Self-assessed physical incapacity } \\
\hline Strongly limited & $33 \%$ & $11 \%$ & $5 \%$ & $3 \%$ & $6 \%$ & $0 \%$ \\
\hline None/limited & $67 \%$ & $89 \%$ & $95 \%$ & $97 \%$ & $94 \%$ & $100 \%$ \\
\hline \multicolumn{7}{|c|}{ ACTIVE COVARIATES } \\
\hline \multicolumn{7}{|l|}{ Age groups (4) } \\
\hline $16-24$ years & $0 \%$ & $0 \%$ & $0 \%$ & $2 \%$ & $32 \%$ & $99 \%$ \\
\hline 25-34 years & $1 \%$ & $0 \%$ & $19 \%$ & $52 \%$ & $58 \%$ & $1 \%$ \\
\hline $35-59$ years & $75 \%$ & $12 \%$ & $76 \%$ & $46 \%$ & $10 \%$ & $0 \%$ \\
\hline 60-64 years & $24 \%$ & $88 \%$ & $4 \%$ & $0 \%$ & $0 \%$ & $0 \%$ \\
\hline \multicolumn{7}{|l|}{ Gender } \\
\hline Male & $45 \%$ & $37 \%$ & $60 \%$ & $1 \%$ & $24 \%$ & $77 \%$ \\
\hline
\end{tabular}




\begin{tabular}{|c|c|c|c|c|c|c|}
\hline & $\begin{array}{l}\text { 1. Mostly rural } \\
\text { retired and } \\
\text { disabled with } \\
\text { previous work } \\
\text { experience }\end{array}$ & $\begin{array}{c}2 . \\
\text { Retirees }\end{array}$ & $\begin{array}{l}\text { 3. Middle- } \\
\text { aged } \\
\text { unemployed }\end{array}$ & $\begin{array}{l}\text { 4. Prime-aged } \\
\text { inactive mothers } \\
\text { with work } \\
\text { experience }\end{array}$ & $\begin{array}{c}\text { 5. Inactive } \\
\text { young single } \\
\text { women without } \\
\text { work } \\
\text { experience }\end{array}$ & $\begin{array}{c}6 . \\
\text { Unemployed } \\
\text { rural single } \\
\text { young men }\end{array}$ \\
\hline \multicolumn{7}{|l|}{ Education (4) } \\
\hline Primary & $35 \%$ & $22 \%$ & $32 \%$ & $13 \%$ & $42 \%$ & $24 \%$ \\
\hline Never studied before/illiterate/NA & $0 \%$ & $0 \%$ & $1 \%$ & $1 \%$ & $3 \%$ & $0 \%$ \\
\hline Urban & $34 \%$ & $62 \%$ & $34 \%$ & $43 \%$ & $34 \%$ & $27 \%$ \\
\hline Rural & $66 \%$ & $38 \%$ & $66 \%$ & $57 \%$ & $66 \%$ & $73 \%$ \\
\hline \multicolumn{7}{|c|}{ INACTIVE COVARIATES } \\
\hline \multicolumn{7}{|l|}{ Age groups (8) } \\
\hline 30-34 years & $0 \%$ & $0 \%$ & $11 \%$ & $37 \%$ & $11 \%$ & $0 \%$ \\
\hline $35-44$ years & $14 \%$ & $1 \%$ & $31 \%$ & $31 \%$ & $8 \%$ & $0 \%$ \\
\hline $45-54$ years & $27 \%$ & $4 \%$ & $32 \%$ & $13 \%$ & $1 \%$ & $0 \%$ \\
\hline $55-59$ years & $34 \%$ & $8 \%$ & $13 \%$ & $2 \%$ & $1 \%$ & $0 \%$ \\
\hline 60-64 years & $24 \%$ & $88 \%$ & $4 \%$ & $0 \%$ & $0 \%$ & $0 \%$ \\
\hline \multicolumn{7}{|l|}{ Education (6) } \\
\hline Primary & $5 \%$ & $2 \%$ & $4 \%$ & $1 \%$ & $8 \%$ & $0 \%$ \\
\hline Lower secondary & $30 \%$ & $21 \%$ & $28 \%$ & $12 \%$ & $34 \%$ & $24 \%$ \\
\hline Upper secondary & $57 \%$ & $57 \%$ & $59 \%$ & $54 \%$ & $39 \%$ & $49 \%$ \\
\hline Post-secondary & $2 \%$ & $4 \%$ & $4 \%$ & $5 \%$ & $7 \%$ & $22 \%$ \\
\hline
\end{tabular}




\begin{tabular}{|c|c|c|c|c|c|c|}
\hline & $\begin{array}{l}\text { 1. Mostly rural } \\
\text { retired and } \\
\text { disabled with } \\
\text { previous work } \\
\text { experience }\end{array}$ & $\begin{array}{c}2 . \\
\text { Retirees }\end{array}$ & $\begin{array}{l}\text { 3. Middle- } \\
\text { aged } \\
\text { unemployed }\end{array}$ & $\begin{array}{l}\text { 4. Prime-aged } \\
\text { inactive mothers } \\
\text { with work } \\
\text { experience }\end{array}$ & $\begin{array}{c}\text { 5. Inactive } \\
\text { young single } \\
\text { women without } \\
\text { work } \\
\text { experience }\end{array}$ & $\begin{array}{l}6 . \\
\text { Unemployed } \\
\text { rural single } \\
\text { young men }\end{array}$ \\
\hline Yes & $99 \%$ & $100 \%$ & $100 \%$ & $100 \%$ & $9 \%$ & $49 \%$ \\
\hline Years of work experience ${ }^{b}$ & 26 & 36 & 20 & 11 & 6 & 2 \\
\hline \multicolumn{7}{|l|}{ Partner economic status } \\
\hline Working & $26 \%$ & $15 \%$ & $28 \%$ & $75 \%$ & $14 \%$ & $0 \%$ \\
\hline Unemployed & $3 \%$ & $3 \%$ & $15 \%$ & $5 \%$ & $21 \%$ & $1 \%$ \\
\hline Retired & $16 \%$ & $47 \%$ & $6 \%$ & $2 \%$ & $1 \%$ & $0 \%$ \\
\hline Inactive & $22 \%$ & $5 \%$ & $14 \%$ & $5 \%$ & $5 \%$ & $3 \%$ \\
\hline No partner & $34 \%$ & $31 \%$ & $38 \%$ & $14 \%$ & $60 \%$ & $95 \%$ \\
\hline Partner income (mean) & 2,541 & 1,757 & 2,986 & 18,447 & 3,311 & 178 \\
\hline Working partner income (mean) & 5,937 & 6,918 & 5,615 & 21,180 & 6,132 & 8,807 \\
\hline \multicolumn{7}{|l|}{ Partner income quintile } \\
\hline Poorest & $8 \%$ & $3 \%$ & $7 \%$ & $5 \%$ & $1 \%$ & $0 \%$ \\
\hline Q2 & $4 \%$ & $2 \%$ & $8 \%$ & $14 \%$ & $10 \%$ & $0 \%$ \\
\hline Q3 & $6 \%$ & $4 \%$ & $5 \%$ & $11 \%$ & $2 \%$ & $0 \%$ \\
\hline Q4 & $4 \%$ & $3 \%$ & $5 \%$ & $17 \%$ & $0 \%$ & $0 \%$ \\
\hline Richest & $3 \%$ & $3 \%$ & $3 \%$ & $28 \%$ & $0 \%$ & $0 \%$ \\
\hline No partner or partner without income & $74 \%$ & $85 \%$ & $73 \%$ & $25 \%$ & $86 \%$ & $100 \%$ \\
\hline \multicolumn{7}{|l|}{ Income quintilec } \\
\hline Poorest & $28 \%$ & $12 \%$ & $50 \%$ & $31 \%$ & $43 \%$ & $49 \%$ \\
\hline Q2 & $26 \%$ & $19 \%$ & $23 \%$ & $22 \%$ & $21 \%$ & $27 \%$ \\
\hline Q3 & $19 \%$ & $21 \%$ & $13 \%$ & $18 \%$ & $16 \%$ & $13 \%$ \\
\hline Q4 & $15 \%$ & $23 \%$ & $8 \%$ & $16 \%$ & $10 \%$ & $4 \%$ \\
\hline Richest & $12 \%$ & $26 \%$ & $6 \%$ & $13 \%$ & $9 \%$ & $6 \%$ \\
\hline \multicolumn{7}{|l|}{ Household income shares ${ }^{d}$} \\
\hline Labor income & $32 \%$ & $22 \%$ & $53 \%$ & $62 \%$ & $46 \%$ & $64 \%$ \\
\hline Other income & $2 \%$ & $1 \%$ & $2 \%$ & $2 \%$ & $3 \%$ & $1 \%$ \\
\hline Benefits & $67 \%$ & $77 \%$ & $45 \%$ & $36 \%$ & $51 \%$ & $35 \%$ \\
\hline
\end{tabular}




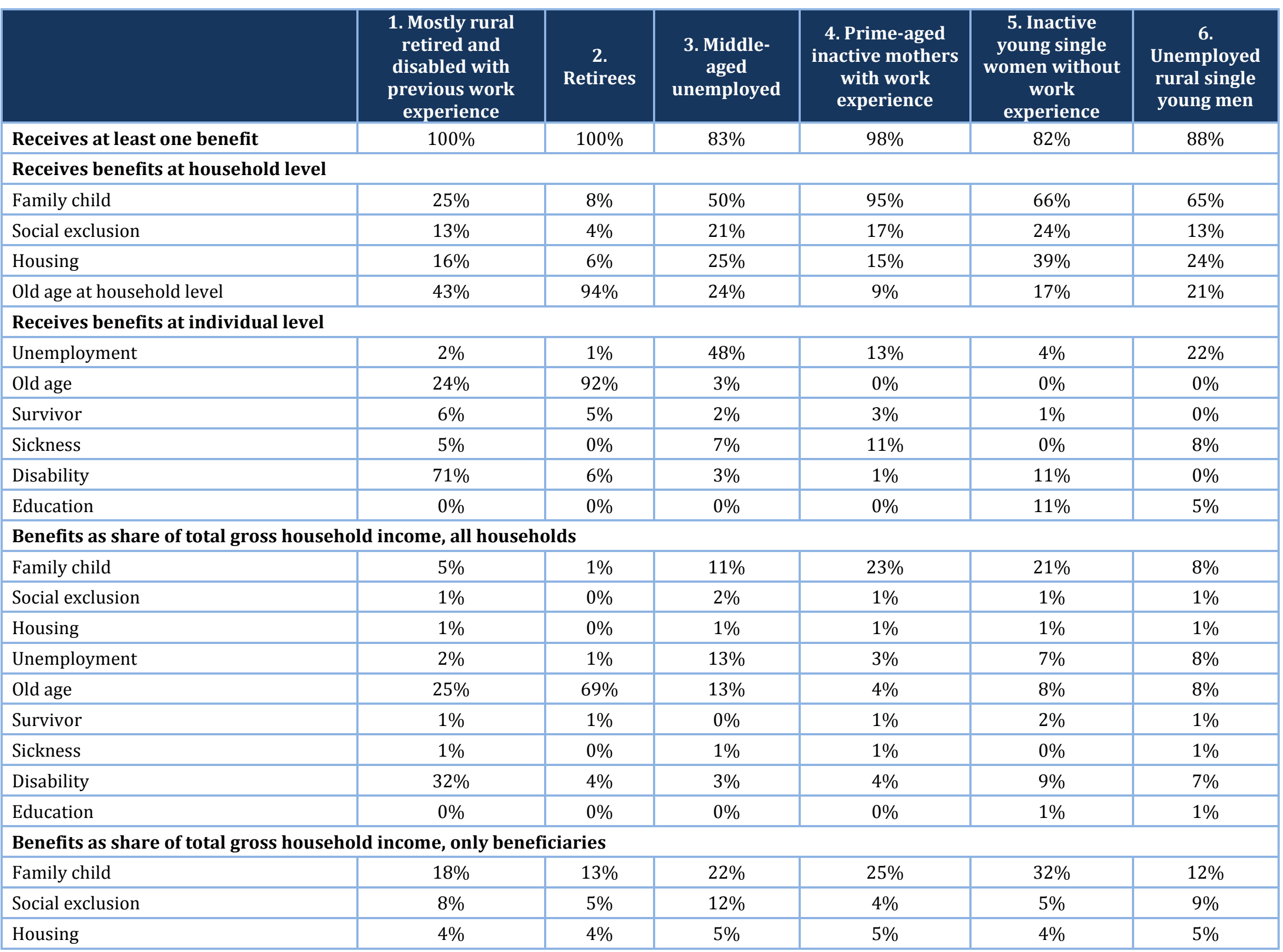




\begin{tabular}{|c|c|c|c|c|c|c|}
\hline & $\begin{array}{l}\text { 1. Mostly rural } \\
\text { retired and } \\
\text { disabled with } \\
\text { previous work } \\
\text { experience }\end{array}$ & $\begin{array}{c}2 . \\
\text { Retirees }\end{array}$ & $\begin{array}{l}\text { 3. Middle- } \\
\text { aged } \\
\text { unemployed }\end{array}$ & $\begin{array}{l}\text { 4. Prime-aged } \\
\text { inactive mothers } \\
\text { with work } \\
\text { experience }\end{array}$ & $\begin{array}{c}\text { 5. Inactive } \\
\text { young single } \\
\text { women without } \\
\text { work } \\
\text { experience }\end{array}$ & $\begin{array}{c}6 . \\
\text { Unemployed } \\
\text { rural single } \\
\text { young men }\end{array}$ \\
\hline Unemployment & $13 \%$ & $13 \%$ & $22 \%$ & $12 \%$ & $20 \%$ & $17 \%$ \\
\hline Old age & $57 \%$ & $73 \%$ & $53 \%$ & $41 \%$ & $49 \%$ & $37 \%$ \\
\hline Survivor & $18 \%$ & $26 \%$ & $17 \%$ & $27 \%$ & $17 \%$ & $29 \%$ \\
\hline Sickness & $8 \%$ & $3 \%$ & $4 \%$ & $4 \%$ & $3 \%$ & $3 \%$ \\
\hline Disability & $43 \%$ & $40 \%$ & $27 \%$ & $39 \%$ & $36 \%$ & $37 \%$ \\
\hline Education & $7 \%$ & $9 \%$ & $7 \%$ & $5 \%$ & $6 \%$ & $5 \%$ \\
\hline Household size (mean) & 2.76 & 2.17 & 3.47 & 4.23 & 4.37 & 4.30 \\
\hline \multicolumn{7}{|l|}{ Household composition } \\
\hline One-person & $11 \%$ & $18 \%$ & $7 \%$ & $0 \%$ & $1 \%$ & $0 \%$ \\
\hline Single parent & $1 \%$ & $0 \%$ & $2 \%$ & $1 \%$ & $1 \%$ & $0 \%$ \\
\hline $2+$ adults without dependent childrene & $71 \%$ & $78 \%$ & $50 \%$ & $13 \%$ & $46 \%$ & $71 \%$ \\
\hline $2+$ adults with 1 dependent childe & $10 \%$ & $3 \%$ & $20 \%$ & $29 \%$ & $16 \%$ & $24 \%$ \\
\hline $2+$ adults with $2+$ dependent children ${ }^{\mathrm{e}}$ & $7 \%$ & $1 \%$ & $21 \%$ & $57 \%$ & $35 \%$ & $6 \%$ \\
\hline Children under six & $6 \%$ & $2 \%$ & $14 \%$ & $60 \%$ & $43 \%$ & $11 \%$ \\
\hline Three or more children under 16 & $2 \%$ & $0 \%$ & $7 \%$ & $17 \%$ & $21 \%$ & $3 \%$ \\
\hline \multicolumn{7}{|l|}{ Individuals' parents present } \\
\hline One parent & $8 \%$ & $1 \%$ & $13 \%$ & $7 \%$ & $28 \%$ & $24 \%$ \\
\hline Both parents & $2 \%$ & $0 \%$ & $8 \%$ & $8 \%$ & $32 \%$ & $74 \%$ \\
\hline None & $90 \%$ & $99 \%$ & $79 \%$ & $85 \%$ & $40 \%$ & $2 \%$ \\
\hline Elderly present (over 64) & $18 \%$ & $18 \%$ & $12 \%$ & $7 \%$ & $9 \%$ & $10 \%$ \\
\hline \multicolumn{7}{|l|}{ Marital status } \\
\hline Married & $64 \%$ & $67 \%$ & $53 \%$ & $76 \%$ & $21 \%$ & $2 \%$ \\
\hline Never married & $14 \%$ & $4 \%$ & $27 \%$ & $15 \%$ & $73 \%$ & $98 \%$ \\
\hline Divorced/separated & $11 \%$ & $12 \%$ & $16 \%$ & $7 \%$ & $6 \%$ & $0 \%$ \\
\hline Widowed & $10 \%$ & $18 \%$ & $5 \%$ & $3 \%$ & $1 \%$ & $0 \%$ \\
\hline \multicolumn{7}{|l|}{ Able to keep dwelling warm } \\
\hline No & $15 \%$ & $10 \%$ & $24 \%$ & $10 \%$ & $30 \%$ & $15 \%$ \\
\hline
\end{tabular}




\begin{tabular}{|c|c|c|c|c|c|c|}
\hline & $\begin{array}{l}\text { 1. Mostly rural } \\
\text { retired and } \\
\text { disabled with } \\
\text { previous work } \\
\text { experience }\end{array}$ & $\begin{array}{c}2 . \\
\text { Retirees }\end{array}$ & $\begin{array}{l}\text { 3. Middle- } \\
\text { aged } \\
\text { unemployed }\end{array}$ & $\begin{array}{l}\text { 4. Prime-aged } \\
\text { inactive mothers } \\
\text { with work } \\
\text { experience }\end{array}$ & $\begin{array}{c}\text { 5. Inactive } \\
\text { young single } \\
\text { women without } \\
\text { work } \\
\text { experience }\end{array}$ & $\begin{array}{l}6 . \\
\text { Unemployed } \\
\text { rural single } \\
\text { young men }\end{array}$ \\
\hline Yes & $85 \%$ & $90 \%$ & $76 \%$ & $90 \%$ & $70 \%$ & $85 \%$ \\
\hline \multicolumn{7}{|l|}{ Degree of urbanization } \\
\hline Densely populated & $18 \%$ & $39 \%$ & $16 \%$ & $27 \%$ & $24 \%$ & $11 \%$ \\
\hline Intermediate area & $16 \%$ & $23 \%$ & $17 \%$ & $16 \%$ & $11 \%$ & $16 \%$ \\
\hline Sparsely populated & $66 \%$ & $38 \%$ & $66 \%$ & $57 \%$ & $66 \%$ & $73 \%$ \\
\hline \multicolumn{7}{|l|}{ Region } \\
\hline HU1 - Central Hungary & $18 \%$ & $32 \%$ & $15 \%$ & $23 \%$ & $24 \%$ & $28 \%$ \\
\hline HU2 - Transdanubia & $28 \%$ & $28 \%$ & $27 \%$ & $38 \%$ & $16 \%$ & $27 \%$ \\
\hline HU3 - Great Plain and North & $55 \%$ & $40 \%$ & $58 \%$ & $39 \%$ & $61 \%$ & $45 \%$ \\
\hline
\end{tabular}

a. Refers to individuals aged 25 and over.

$b$. Refers only to individuals who have worked before.

c. Based on total equivalized disposable household income.

d. Based on total gross household income.

e. Dependent children include: 1. household members under 18; 2. household members aged between 18 and 24 who are economically inactive and living with at least one parent. 


\begin{tabular}{|c|c|c|c|c|c|}
\hline & $\begin{array}{l}\text { 1. Middle-age low } \\
\text { income } \\
\text { unemployed }\end{array}$ & 2. Disabled & $\begin{array}{l}\text { 3. Married rural women } \\
\text { with pensions }\end{array}$ & $\begin{array}{l}\text { 4. Stay-at-home or } \\
\text { unemployed rural } \\
\text { poor wives }\end{array}$ & $\begin{array}{c}\text { 5. Young rural } \\
\text { unemployed } \\
\text { men }\end{array}$ \\
\hline Cluster Size & $34 \%$ & $21 \%$ & $18 \%$ & $16 \%$ & $11 \%$ \\
\hline \multicolumn{6}{|c|}{ INDICATORS } \\
\hline \multicolumn{6}{|c|}{ Labor market attachment } \\
\hline Unemployed & $87 \%$ & $3 \%$ & $3 \%$ & $15 \%$ & $88 \%$ \\
\hline Retired & $1 \%$ & $0 \%$ & $88 \%$ & $1 \%$ & $6 \%$ \\
\hline Disabled & $0 \%$ & $96 \%$ & $7 \%$ & $13 \%$ & $0 \%$ \\
\hline Other inactive & $13 \%$ & $0 \%$ & $2 \%$ & $71 \%$ & $5 \%$ \\
\hline \multicolumn{6}{|c|}{ Self-assessed physical incapacity } \\
\hline Strongly limited & $0 \%$ & $49 \%$ & $13 \%$ & $1 \%$ & $0 \%$ \\
\hline None/limited & $100 \%$ & $51 \%$ & $87 \%$ & $99 \%$ & $100 \%$ \\
\hline \multicolumn{6}{|c|}{ At least one working adult in household ${ }^{a}$} \\
\hline No & $61 \%$ & $61 \%$ & $71 \%$ & $24 \%$ & $6 \%$ \\
\hline Yes & $39 \%$ & $39 \%$ & $29 \%$ & $76 \%$ & $94 \%$ \\
\hline \multicolumn{6}{|c|}{ ACTIVE COVARIATES } \\
\hline \multicolumn{6}{|l|}{ Age groups (4) } \\
\hline $16-24$ years & $2 \%$ & $0 \%$ & $0 \%$ & $10 \%$ & $48 \%$ \\
\hline 25-34 years & $20 \%$ & $9 \%$ & $0 \%$ & $31 \%$ & $15 \%$ \\
\hline $35-59$ years & $72 \%$ & $79 \%$ & $0 \%$ & $59 \%$ & $30 \%$ \\
\hline 60-64 years & $5 \%$ & $12 \%$ & $100 \%$ & $0 \%$ & $7 \%$ \\
\hline \multicolumn{6}{|l|}{ Education (4) } \\
\hline Primary & $24 \%$ & $20 \%$ & $26 \%$ & $22 \%$ & $6 \%$ \\
\hline Secondary & $68 \%$ & $72 \%$ & $61 \%$ & $55 \%$ & $60 \%$ \\
\hline Tertiary & $8 \%$ & $4 \%$ & $12 \%$ & $20 \%$ & $31 \%$ \\
\hline NA & $0 \%$ & $4 \%$ & $1 \%$ & $3 \%$ & $3 \%$ \\
\hline \multicolumn{6}{|l|}{ Gender } \\
\hline Male & $55 \%$ & $53 \%$ & $24 \%$ & $16 \%$ & $93 \%$ \\
\hline Female & $45 \%$ & $47 \%$ & $76 \%$ & $84 \%$ & $7 \%$ \\
\hline
\end{tabular}




\begin{tabular}{|c|c|c|c|c|c|}
\hline & $\begin{array}{l}\text { 1. Middle-age low } \\
\text { income } \\
\text { unemployed }\end{array}$ & 2. Disabled & $\begin{array}{l}\text { 3. Married rural women } \\
\text { with pensions }\end{array}$ & $\begin{array}{l}\text { 4. Stay-at-home or } \\
\text { unemployed rural } \\
\text { poor wives }\end{array}$ & $\begin{array}{c}\text { 5. Young rural } \\
\text { unemployed } \\
\text { men }\end{array}$ \\
\hline Urban & $43 \%$ & $48 \%$ & $36 \%$ & $14 \%$ & $23 \%$ \\
\hline Rural & $57 \%$ & $52 \%$ & $64 \%$ & $86 \%$ & $77 \%$ \\
\hline \multicolumn{6}{|c|}{ INACTIVE COVARIATES } \\
\hline \multicolumn{6}{|l|}{ Age groups (7) } \\
\hline 16-19 years & $0 \%$ & $0 \%$ & $0 \%$ & $2 \%$ & $1 \%$ \\
\hline 20-24 years & $2 \%$ & $0 \%$ & $0 \%$ & $8 \%$ & $47 \%$ \\
\hline 25-34 years & $20 \%$ & $9 \%$ & $0 \%$ & $31 \%$ & $15 \%$ \\
\hline $35-44$ years & $28 \%$ & $21 \%$ & $0 \%$ & $21 \%$ & $6 \%$ \\
\hline 45-54 years & $32 \%$ & $36 \%$ & $0 \%$ & $28 \%$ & $14 \%$ \\
\hline $55-59$ years & $12 \%$ & $23 \%$ & $0 \%$ & $10 \%$ & $10 \%$ \\
\hline 60-64 years & $5 \%$ & $12 \%$ & $100 \%$ & $0 \%$ & $7 \%$ \\
\hline \multicolumn{6}{|l|}{ Education (6) } \\
\hline None or less than primary & $0 \%$ & $2 \%$ & $0 \%$ & $0 \%$ & $0 \%$ \\
\hline Primary & $1 \%$ & $2 \%$ & $6 \%$ & $2 \%$ & $0 \%$ \\
\hline Lower secondary & $23 \%$ & $16 \%$ & $20 \%$ & $20 \%$ & $6 \%$ \\
\hline Upper secondary & $41 \%$ & $51 \%$ & $34 \%$ & $31 \%$ & $40 \%$ \\
\hline Post-secondary & $27 \%$ & $22 \%$ & $26 \%$ & $24 \%$ & $19 \%$ \\
\hline Tertiary & $8 \%$ & $4 \%$ & $12 \%$ & $20 \%$ & $31 \%$ \\
\hline NA & $0 \%$ & $4 \%$ & $1 \%$ & $3 \%$ & $3 \%$ \\
\hline \multicolumn{6}{|l|}{ Marital status } \\
\hline Married & $59 \%$ & $49 \%$ & $59 \%$ & $61 \%$ & $42 \%$ \\
\hline Never married & $24 \%$ & $24 \%$ & $4 \%$ & $28 \%$ & $57 \%$ \\
\hline Divorced/separated & $13 \%$ & $17 \%$ & $17 \%$ & $7 \%$ & $0 \%$ \\
\hline Widowed & $4 \%$ & $10 \%$ & $20 \%$ & $5 \%$ & $0 \%$ \\
\hline \multicolumn{6}{|l|}{ Income quintileb } \\
\hline Poorest & $49 \%$ & $36 \%$ & $31 \%$ & $39 \%$ & $19 \%$ \\
\hline Q2 & $19 \%$ & $27 \%$ & $22 \%$ & $20 \%$ & $10 \%$ \\
\hline Q3 & $14 \%$ & $21 \%$ & $10 \%$ & $15 \%$ & $27 \%$ \\
\hline Q4 & $12 \%$ & $12 \%$ & $22 \%$ & $13 \%$ & $18 \%$ \\
\hline
\end{tabular}




\begin{tabular}{|c|c|c|c|c|c|}
\hline & $\begin{array}{l}\text { 1. Middle-age low } \\
\text { income } \\
\text { unemployed }\end{array}$ & 2. Disabled & $\begin{array}{l}\text { 3. Married rural women } \\
\text { with pensions }\end{array}$ & $\begin{array}{l}\text { 4. Stay-at-home or } \\
\text { unemployed rural } \\
\text { poor wives }\end{array}$ & $\begin{array}{c}\text { 5. Young rural } \\
\text { unemployed } \\
\text { men }\end{array}$ \\
\hline Richest & $6 \%$ & $4 \%$ & $16 \%$ & $14 \%$ & $25 \%$ \\
\hline \multicolumn{6}{|l|}{ Partner economic status } \\
\hline Working & $31 \%$ & $28 \%$ & $13 \%$ & $49 \%$ & $35 \%$ \\
\hline Unemployed & $19 \%$ & $4 \%$ & $4 \%$ & $5 \%$ & $3 \%$ \\
\hline Retired & $2 \%$ & $7 \%$ & $35 \%$ & $1 \%$ & $0 \%$ \\
\hline Inactive & $6 \%$ & $10 \%$ & $7 \%$ & $5 \%$ & $4 \%$ \\
\hline NA & $42 \%$ & $51 \%$ & $41 \%$ & $40 \%$ & $58 \%$ \\
\hline Partner income (mean) & 2592.75 & 2555.09 & 1723.13 & 3611.59 & 2954.08 \\
\hline \multicolumn{6}{|l|}{ Partner income quintile } \\
\hline Poorest & $5 \%$ & $7 \%$ & $2 \%$ & $14 \%$ & $9 \%$ \\
\hline Q2 & $8 \%$ & $7 \%$ & $2 \%$ & $12 \%$ & $11 \%$ \\
\hline Q3 & $10 \%$ & $2 \%$ & $2 \%$ & $6 \%$ & $7 \%$ \\
\hline Q4 & $5 \%$ & $8 \%$ & $4 \%$ & $7 \%$ & $4 \%$ \\
\hline Richest & $3 \%$ & $3 \%$ & $2 \%$ & $10 \%$ & $4 \%$ \\
\hline NA & $69 \%$ & $73 \%$ & $87 \%$ & $51 \%$ & $65 \%$ \\
\hline Household size (mean) & 3.03 & 2.69 & 2.30 & 3.50 & 3.81 \\
\hline \multicolumn{6}{|l|}{ Tenure status } \\
\hline Owner & $91 \%$ & $97 \%$ & $96 \%$ & $91 \%$ & $92 \%$ \\
\hline Tenant & $0 \%$ & $0 \%$ & $0 \%$ & $0 \%$ & $2 \%$ \\
\hline Reduced rate & $2 \%$ & $0 \%$ & $2 \%$ & $3 \%$ & $0 \%$ \\
\hline Free & $7 \%$ & $3 \%$ & $1 \%$ & $7 \%$ & $6 \%$ \\
\hline \multicolumn{6}{|l|}{ Household composition } \\
\hline One-person & $13 \%$ & $16 \%$ & $23 \%$ & $3 \%$ & $0 \%$ \\
\hline Single parent & $1 \%$ & $8 \%$ & $0 \%$ & $2 \%$ & $0 \%$ \\
\hline $2+$ adults without dependent children ${ }^{c}$ & $54 \%$ & $61 \%$ & $65 \%$ & $44 \%$ & $67 \%$ \\
\hline $2+$ adults with 1 dependent childc & $15 \%$ & $7 \%$ & $8 \%$ & $28 \%$ & $21 \%$ \\
\hline $2+$ adults with $2+$ dependent children ${ }^{c}$ & $16 \%$ & $8 \%$ & $3 \%$ & $22 \%$ & $12 \%$ \\
\hline Children under six & $11 \%$ & $6 \%$ & $4 \%$ & $19 \%$ & $14 \%$ \\
\hline Three or more children under 16 & $6 \%$ & $3 \%$ & $1 \%$ & $8 \%$ & $5 \%$ \\
\hline
\end{tabular}




\begin{tabular}{|c|c|c|c|c|c|}
\hline & $\begin{array}{l}\text { 1. Middle-age low } \\
\text { income } \\
\text { unemployed }\end{array}$ & 2. Disabled & $\begin{array}{l}\text { 3. Married rural women } \\
\text { with pensions }\end{array}$ & $\begin{array}{l}\text { 4. Stay-at-home or } \\
\text { unemployed rural } \\
\text { poor wives }\end{array}$ & $\begin{array}{l}\text { 5. Young rural } \\
\text { unemployed } \\
\text { men }\end{array}$ \\
\hline Elderly present (over 64) & $16 \%$ & $17 \%$ & $30 \%$ & $11 \%$ & $12 \%$ \\
\hline Years of work experience ${ }^{d}$ & 17.72 & 20.69 & 33.63 & 13.49 & 15.95 \\
\hline \multicolumn{6}{|l|}{ Able to keep dwelling warm } \\
\hline No & $39 \%$ & $30 \%$ & $29 \%$ & $32 \%$ & $22 \%$ \\
\hline Yes & $61 \%$ & $70 \%$ & $71 \%$ & $68 \%$ & $78 \%$ \\
\hline \multicolumn{6}{|l|}{ Degree of urbanization } \\
\hline Densely populated & $43 \%$ & $48 \%$ & $36 \%$ & $14 \%$ & $23 \%$ \\
\hline Sparsely populated & $57 \%$ & $52 \%$ & $64 \%$ & $86 \%$ & $77 \%$ \\
\hline Receives at least one benefit & $64 \%$ & $87 \%$ & $93 \%$ & $72 \%$ & $69 \%$ \\
\hline \multicolumn{6}{|c|}{ Receives benefits at household level } \\
\hline Family child & $40 \%$ & $27 \%$ & $11 \%$ & $57 \%$ & $55 \%$ \\
\hline Social exclusion & $20 \%$ & $14 \%$ & $4 \%$ & $15 \%$ & $8 \%$ \\
\hline Housing & $11 \%$ & $9 \%$ & $5 \%$ & $8 \%$ & $2 \%$ \\
\hline \multicolumn{6}{|c|}{ Receives benefits at individual level } \\
\hline Unemployment & $16 \%$ & $2 \%$ & $4 \%$ & $3 \%$ & $12 \%$ \\
\hline Old age & $1 \%$ & $3 \%$ & $85 \%$ & $0 \%$ & $1 \%$ \\
\hline Survivor & $2 \%$ & $11 \%$ & $1 \%$ & $1 \%$ & $2 \%$ \\
\hline Sickness & $11 \%$ & $3 \%$ & $8 \%$ & $3 \%$ & $7 \%$ \\
\hline Disability & $1 \%$ & $72 \%$ & $3 \%$ & $11 \%$ & $7 \%$ \\
\hline
\end{tabular}

a. Refers to individuals aged 25 and over.

b. Based on total equivalized disposable household income.

c. Dependent children include: 1. household members under 18; 2. household members aged between 18 and 24 who are economically inactive and living with at least one parent. d. Refers only to individuals who have worked before.

Source: WB staff calculations based on EU-SILC. 


\begin{tabular}{|c|c|c|c|c|c|c|}
\hline & $\begin{array}{l}\text { 1. Low-educated } \\
\text { rural inactive } \\
\text { women without } \\
\text { work experience }\end{array}$ & 2. Retirees & $\begin{array}{l}\text { 3. Early retirees } \\
\text { and inactive with } \\
\text { previous work } \\
\text { experience }\end{array}$ & $\begin{array}{l}\text { 4. Low- } \\
\text { educated and } \\
\text { rural disabled } \\
\text { or inactive }\end{array}$ & $\begin{array}{l}\text { 5. Unemployed } \\
\text { rural single } \\
\text { youth }\end{array}$ & $\begin{array}{l}\text { 6. Middle-aged } \\
\text { low-educated } \\
\text { unemployed }\end{array}$ \\
\hline Cluster size & $34 \%$ & $24 \%$ & $23 \%$ & $8 \%$ & $7 \%$ & $5 \%$ \\
\hline \multicolumn{7}{|c|}{ INDICATORS } \\
\hline \multicolumn{7}{|c|}{ Labor market attachment } \\
\hline Unemployed & $3 \%$ & $0 \%$ & $0 \%$ & $0 \%$ & $88 \%$ & $81 \%$ \\
\hline Retired & $0 \%$ & $91 \%$ & $45 \%$ & $0 \%$ & $0 \%$ & $0 \%$ \\
\hline Disabled & $0 \%$ & $0 \%$ & $0 \%$ & $42 \%$ & $1 \%$ & $0 \%$ \\
\hline Other inactive & $97 \%$ & $9 \%$ & $55 \%$ & $58 \%$ & $11 \%$ & $19 \%$ \\
\hline \multicolumn{7}{|c|}{ At least one working adult in householda } \\
\hline No & $14 \%$ & $48 \%$ & $40 \%$ & $46 \%$ & $27 \%$ & $48 \%$ \\
\hline Yes & $86 \%$ & $52 \%$ & $60 \%$ & $54 \%$ & $73 \%$ & $52 \%$ \\
\hline \multicolumn{7}{|l|}{ Work experience } \\
\hline Never worked & $85 \%$ & $1 \%$ & $1 \%$ & $60 \%$ & $85 \%$ & $0 \%$ \\
\hline Less than 2 months & $12 \%$ & $96 \%$ & $97 \%$ & $40 \%$ & $0 \%$ & $63 \%$ \\
\hline 2 or more months & $4 \%$ & $4 \%$ & $2 \%$ & $0 \%$ & $14 \%$ & $37 \%$ \\
\hline \multicolumn{7}{|c|}{ Self-assessed physical incapacity } \\
\hline Strongly limited & $0 \%$ & $11 \%$ & $22 \%$ & $66 \%$ & $0 \%$ & $2 \%$ \\
\hline None/limited & $100 \%$ & $89 \%$ & $78 \%$ & $34 \%$ & $100 \%$ & $98 \%$ \\
\hline \multicolumn{7}{|c|}{ ACTIVE COVARIATES } \\
\hline \multicolumn{7}{|l|}{ Age groups (4) } \\
\hline $16-24$ years & $8 \%$ & $0 \%$ & $0 \%$ & $6 \%$ & $76 \%$ & $0 \%$ \\
\hline 25-34 years & $44 \%$ & $0 \%$ & $0 \%$ & $10 \%$ & $24 \%$ & $25 \%$ \\
\hline $35-59$ years & $46 \%$ & $6 \%$ & $97 \%$ & $68 \%$ & $0 \%$ & $75 \%$ \\
\hline $60-64$ years & $1 \%$ & $94 \%$ & $3 \%$ & $16 \%$ & $0 \%$ & $0 \%$ \\
\hline \multicolumn{7}{|l|}{ Gender } \\
\hline Male & $5 \%$ & $42 \%$ & $34 \%$ & $44 \%$ & $74 \%$ & $86 \%$ \\
\hline Female & $95 \%$ & $58 \%$ & $66 \%$ & $56 \%$ & $26 \%$ & $14 \%$ \\
\hline
\end{tabular}




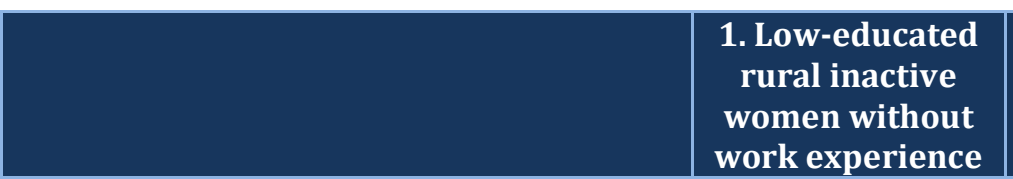

\section{Retirees}

3. Early retirees

and inactive with

previous work

4. Low-

work experience experience

educated and

rural disabled or inactive

\section{Education}

Primary

Secondary

Tertiary

NA

Urban

Rural

\begin{tabular}{|c|c|c|}
\hline $48 \%$ & $35 \%$ & $33 \%$ \\
\hline $49 \%$ & $51 \%$ & $66 \%$ \\
\hline $2 \%$ & $13 \%$ & $0 \%$ \\
\hline $2 \%$ & $1 \%$ & $1 \%$ \\
\hline $78 \%$ & $53 \%$ & $35 \%$ \\
\hline
\end{tabular}

\begin{tabular}{|c|}
\hline $33 \%$ \\
\hline $66 \%$ \\
\hline $0 \%$ \\
\hline $1 \%$ \\
\hline $35 \%$ \\
\hline $65 \%$ \\
\hline
\end{tabular}

\begin{tabular}{|l|l}
\hline \\
\hline \\
\hline
\end{tabular}

\begin{tabular}{|c|c|}
\hline $59 \%$ & \\
\hline $18 \%$ & \\
\hline $7 \%$ & \\
\hline $17 \%$ & \\
\hline $31 \%$ & \\
\hline $69 \%$ & \\
\hline
\end{tabular}

5. Unemployed rural single youth

6. Middle-aged low-educated unemployed

\section{Age groups (8)}

\begin{tabular}{|c|c|c|c|c|c|c|}
\hline $16-19$ years & $2 \%$ & $0 \%$ & $0 \%$ & $5 \%$ & $7 \%$ & $0 \%$ \\
\hline 20-24 years & $6 \%$ & $0 \%$ & $0 \%$ & $1 \%$ & $70 \%$ & $0 \%$ \\
\hline $25-29$ years & $25 \%$ & $0 \%$ & $0 \%$ & $5 \%$ & $20 \%$ & $17 \%$ \\
\hline $30-34$ years & $19 \%$ & $0 \%$ & $0 \%$ & $5 \%$ & $4 \%$ & $8 \%$ \\
\hline $35-44$ years & $24 \%$ & $0 \%$ & $8 \%$ & $28 \%$ & $0 \%$ & $26 \%$ \\
\hline $45-54$ years & $17 \%$ & $1 \%$ & $33 \%$ & $28 \%$ & $0 \%$ & $32 \%$ \\
\hline 55-59 years & $6 \%$ & $5 \%$ & $56 \%$ & $11 \%$ & $0 \%$ & $17 \%$ \\
\hline 60-64 years & $1 \%$ & $94 \%$ & $3 \%$ & $16 \%$ & $0 \%$ & $0 \%$ \\
\hline
\end{tabular}

\section{Education}

Primary

Lower secondary

Upper secondary

Post-secondary

Tertiary

NA

\begin{tabular}{|c|r|}
\hline $7 \%$ & $7 \%$ \\
\hline $41 \%$ & $29 \%$ \\
\hline $46 \%$ & $41 \%$ \\
\hline $3 \%$ & $10 \%$ \\
\hline $2 \%$ & $13 \%$ \\
\hline $2 \%$ & $1 \%$ \\
\hline
\end{tabular}

\begin{tabular}{|c|c|}
\hline $7 \%$ & $5 \%$ \\
\hline $29 \%$ & $28 \%$ \\
\hline $41 \%$ & $60 \%$ \\
\hline $10 \%$ & $6 \%$ \\
\hline $13 \%$ & $0 \%$ \\
\hline $1 \%$ & $1 \%$ \\
\hline
\end{tabular}

\begin{tabular}{|c|c|}
\hline $5 \%$ & $10 \%$ \\
\hline $28 \%$ & $49 \%$ \\
\hline $60 \%$ & $17 \%$ \\
\hline $6 \%$ & $0 \%$ \\
\hline $0 \%$ & $7 \%$ \\
\hline $1 \%$ & $17 \%$ \\
\hline
\end{tabular}

\begin{tabular}{|c|c|}
\hline $28 \%$ & $47 \%$ \\
\hline $59 \%$ & $53 \%$ \\
\hline $11 \%$ & $0 \%$ \\
\hline $2 \%$ & $0 \%$ \\
\hline $18 \%$ & $34 \%$ \\
\hline $82 \%$ & $66 \%$ \\
\hline
\end{tabular}

INACTIVE COVARIATES

Have never studied before/illiterate

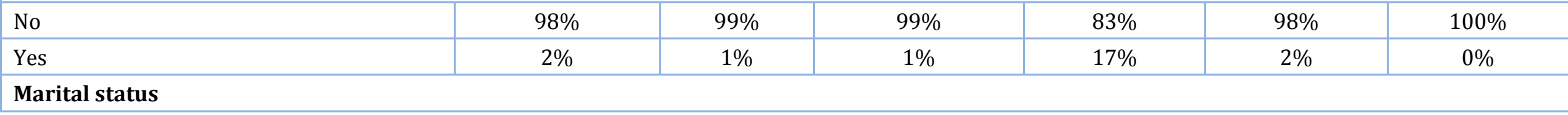




\begin{tabular}{|c|c|c|c|c|c|c|}
\hline & $\begin{array}{l}\text { 1. Low-educated } \\
\text { rural inactive } \\
\text { women without } \\
\text { work experience }\end{array}$ & 2. Retirees & $\begin{array}{l}\text { 3. Early retirees } \\
\text { and inactive with } \\
\text { previous work } \\
\text { experience }\end{array}$ & $\begin{array}{l}\text { 4. Low- } \\
\text { educated and } \\
\text { rural disabled } \\
\text { or inactive }\end{array}$ & $\begin{array}{l}\text { 5. Unemployed } \\
\text { rural single } \\
\text { youth }\end{array}$ & $\begin{array}{l}\text { 6. Middle-aged } \\
\text { low-educated } \\
\text { unemployed }\end{array}$ \\
\hline Married & $69 \%$ & $73 \%$ & $77 \%$ & $45 \%$ & $3 \%$ & $75 \%$ \\
\hline Never married & $25 \%$ & $3 \%$ & $5 \%$ & $40 \%$ & $96 \%$ & $22 \%$ \\
\hline Divorced/separated & $3 \%$ & $5 \%$ & $7 \%$ & $9 \%$ & $1 \%$ & $1 \%$ \\
\hline Widowed & $2 \%$ & $20 \%$ & $12 \%$ & $6 \%$ & $0 \%$ & $2 \%$ \\
\hline \multicolumn{7}{|c|}{ Household income (mean) } \\
\hline Labor income & 4335 & 3110 & 3480 & 2055 & 4228 & 2852 \\
\hline Other income & 138 & 21 & 86 & 79 & 31 & 112 \\
\hline Benefits & 935 & 3330 & 2215 & 1899 & 770 & 1019 \\
\hline \multicolumn{7}{|c|}{ Household income shares ${ }^{b}$} \\
\hline Labor income & $72 \%$ & $32 \%$ & $43 \%$ & $37 \%$ & $74 \%$ & $52 \%$ \\
\hline Other income & $2 \%$ & $1 \%$ & $2 \%$ & $4 \%$ & $1 \%$ & $5 \%$ \\
\hline Benefits & $25 \%$ & $67 \%$ & $55 \%$ & $59 \%$ & $25 \%$ & $43 \%$ \\
\hline \multicolumn{7}{|l|}{ Income quintile ${ }^{c}$} \\
\hline Poorest & $38 \%$ & $8 \%$ & $15 \%$ & $31 \%$ & $47 \%$ & $41 \%$ \\
\hline Q2 & $30 \%$ & $15 \%$ & $25 \%$ & $41 \%$ & $17 \%$ & $35 \%$ \\
\hline Q3 & $15 \%$ & $25 \%$ & $23 \%$ & $11 \%$ & $25 \%$ & $10 \%$ \\
\hline Q4 & $11 \%$ & $24 \%$ & $19 \%$ & $8 \%$ & $9 \%$ & $10 \%$ \\
\hline Richest & $6 \%$ & $28 \%$ & $18 \%$ & $10 \%$ & $2 \%$ & $4 \%$ \\
\hline \multicolumn{7}{|l|}{ Working partner } \\
\hline Yes & $60 \%$ & $16 \%$ & $31 \%$ & $22 \%$ & $2 \%$ & $27 \%$ \\
\hline No & $11 \%$ & $57 \%$ & $46 \%$ & $24 \%$ & $2 \%$ & $48 \%$ \\
\hline NA & $29 \%$ & $27 \%$ & $23 \%$ & $55 \%$ & $96 \%$ & $25 \%$ \\
\hline \multicolumn{7}{|c|}{ Partner economic status } \\
\hline Working & $60 \%$ & $16 \%$ & $31 \%$ & $22 \%$ & $2 \%$ & $27 \%$ \\
\hline Unemployed & $4 \%$ & $0 \%$ & $1 \%$ & $4 \%$ & $0 \%$ & $2 \%$ \\
\hline Retired & $4 \%$ & $49 \%$ & $25 \%$ & $8 \%$ & $0 \%$ & $3 \%$ \\
\hline Inactive & $3 \%$ & $8 \%$ & $20 \%$ & $11 \%$ & $2 \%$ & $42 \%$ \\
\hline NA & $29 \%$ & $27 \%$ & $23 \%$ & $55 \%$ & $96 \%$ & $25 \%$ \\
\hline
\end{tabular}




\begin{tabular}{|c|c|c|c|c|c|c|}
\hline & $\begin{array}{l}\text { 1. Low-educated } \\
\text { rural inactive } \\
\text { women without } \\
\text { work experience }\end{array}$ & 2. Retirees & $\begin{array}{l}\text { 3. Early retirees } \\
\text { and inactive with } \\
\text { previous work } \\
\text { experience }\end{array}$ & $\begin{array}{l}\text { 4. Low- } \\
\text { educated and } \\
\text { rural disabled } \\
\text { or inactive }\end{array}$ & $\begin{array}{l}\text { 5. Unemployed } \\
\text { rural single } \\
\text { youth }\end{array}$ & $\begin{array}{l}\text { 6. Middle-aged } \\
\text { low-educated } \\
\text { unemployed }\end{array}$ \\
\hline Partner income (mean) & 2727 & 1104 & 1422 & 1581 & 1138 & 1173 \\
\hline Working partner income (mean) & 3204 & 4973 & 3459 & 3016 & 2241 & 2944 \\
\hline \multicolumn{7}{|l|}{ Working partner income quintile } \\
\hline Poorest & $10 \%$ & $3 \%$ & $5 \%$ & $5 \%$ & $0 \%$ & $0 \%$ \\
\hline Q2 & $14 \%$ & $3 \%$ & $9 \%$ & $6 \%$ & $1 \%$ & $5 \%$ \\
\hline Q3 & $12 \%$ & $3 \%$ & $6 \%$ & $2 \%$ & $0 \%$ & $13 \%$ \\
\hline Q4 & $16 \%$ & $1 \%$ & $5 \%$ & $1 \%$ & $0 \%$ & $8 \%$ \\
\hline Richest & $8 \%$ & $6 \%$ & $6 \%$ & $7 \%$ & $0 \%$ & $1 \%$ \\
\hline NA & $40 \%$ & $84 \%$ & $69 \%$ & $78 \%$ & $98 \%$ & $73 \%$ \\
\hline Household size (mean) & 4.81 & 3.02 & 3.23 & 3.14 & 5.02 & 4.04 \\
\hline \multicolumn{7}{|l|}{ Tenure status } \\
\hline Owner & $98 \%$ & $100 \%$ & $99 \%$ & $99 \%$ & $98 \%$ & $100 \%$ \\
\hline Tenant & $1 \%$ & $0 \%$ & $0 \%$ & $0 \%$ & $0 \%$ & $0 \%$ \\
\hline Reduced rate & $0 \%$ & $0 \%$ & $0 \%$ & $0 \%$ & $0 \%$ & $0 \%$ \\
\hline Free & $1 \%$ & $0 \%$ & $0 \%$ & $0 \%$ & $2 \%$ & $0 \%$ \\
\hline \multicolumn{7}{|l|}{ Household composition } \\
\hline One-person & $1 \%$ & $15 \%$ & $8 \%$ & $5 \%$ & $2 \%$ & $4 \%$ \\
\hline Single parent & $0 \%$ & $0 \%$ & $0 \%$ & $0 \%$ & $0 \%$ & $0 \%$ \\
\hline $2+$ adults without dependent children ${ }^{\mathrm{d}}$ & $36 \%$ & $65 \%$ & $70 \%$ & $73 \%$ & $58 \%$ & $47 \%$ \\
\hline $2+$ adults with 1 dependent child ${ }^{d}$ & $28 \%$ & $14 \%$ & $15 \%$ & $17 \%$ & $13 \%$ & $33 \%$ \\
\hline $2+$ adults with $2+$ dependent children ${ }^{\mathrm{d}}$ & $35 \%$ & $6 \%$ & $6 \%$ & $5 \%$ & $27 \%$ & $16 \%$ \\
\hline \multicolumn{7}{|l|}{ Individuals' parents present } \\
\hline One parent & $6 \%$ & $3 \%$ & $6 \%$ & $28 \%$ & $18 \%$ & $14 \%$ \\
\hline Both parents & $19 \%$ & $1 \%$ & $1 \%$ & $12 \%$ & $69 \%$ & $12 \%$ \\
\hline None & $75 \%$ & $96 \%$ & $93 \%$ & $61 \%$ & $12 \%$ & $73 \%$ \\
\hline Children under six & $17 \%$ & $5 \%$ & $7 \%$ & $2 \%$ & $8 \%$ & $16 \%$ \\
\hline Three or more children under 16 & $10 \%$ & $1 \%$ & $1 \%$ & $2 \%$ & $1 \%$ & $2 \%$ \\
\hline Elderly present (over 64) & $21 \%$ & $31 \%$ & $18 \%$ & $48 \%$ & $17 \%$ & $11 \%$ \\
\hline
\end{tabular}




\begin{tabular}{|c|c|c|c|c|c|c|}
\hline & $\begin{array}{l}\text { 1. Low-educated } \\
\text { rural inactive } \\
\text { women without } \\
\text { work experience }\end{array}$ & 2. Retirees & $\begin{array}{l}\text { 3. Early retirees } \\
\text { and inactive with } \\
\text { previous work } \\
\text { experience }\end{array}$ & $\begin{array}{l}\text { 4. Low- } \\
\text { educated and } \\
\text { rural disabled } \\
\text { or inactive }\end{array}$ & $\begin{array}{l}\text { 5. Unemployed } \\
\text { rural single } \\
\text { youth }\end{array}$ & $\begin{array}{l}\text { 6. Middle-aged } \\
\text { low-educated } \\
\text { unemployed }\end{array}$ \\
\hline \multicolumn{7}{|l|}{ Ever worked } \\
\hline No & $85 \%$ & $1 \%$ & $1 \%$ & $60 \%$ & $86 \%$ & $0 \%$ \\
\hline Yes & $15 \%$ & $99 \%$ & $99 \%$ & $40 \%$ & $14 \%$ & $100 \%$ \\
\hline Years of work experience & 11 & 30 & 24 & 19 & 3 & 18 \\
\hline \multicolumn{7}{|l|}{ Worked in last year } \\
\hline 2 or more months & $4 \%$ & $4 \%$ & $2 \%$ & $0 \%$ & $14 \%$ & $37 \%$ \\
\hline Less than 2 months & $96 \%$ & $96 \%$ & $98 \%$ & $100 \%$ & $86 \%$ & $63 \%$ \\
\hline \multicolumn{7}{|l|}{ Able to keep dwelling warm } \\
\hline No & $23 \%$ & $22 \%$ & $22 \%$ & $36 \%$ & $27 \%$ & $34 \%$ \\
\hline Yes & $78 \%$ & $78 \%$ & $78 \%$ & $64 \%$ & $73 \%$ & $66 \%$ \\
\hline \multicolumn{7}{|l|}{ Degree of urbanization } \\
\hline Densely populated & $22 \%$ & $51 \%$ & $34 \%$ & $30 \%$ & $15 \%$ & $33 \%$ \\
\hline Intermediate area & $1 \%$ & $1 \%$ & $1 \%$ & $1 \%$ & $3 \%$ & $1 \%$ \\
\hline Sparsely populated & $78 \%$ & $47 \%$ & $65 \%$ & $69 \%$ & $82 \%$ & $66 \%$ \\
\hline \multicolumn{7}{|l|}{ Region } \\
\hline R011 - Nord-Vest & $13 \%$ & $12 \%$ & $11 \%$ & $12 \%$ & $13 \%$ & $14 \%$ \\
\hline R012 - Centru & $11 \%$ & $11 \%$ & $12 \%$ & $5 \%$ & $15 \%$ & $19 \%$ \\
\hline R021 - Nord-Est & $12 \%$ & $10 \%$ & $13 \%$ & $24 \%$ & $15 \%$ & $12 \%$ \\
\hline RO22 - Sud-Est & $10 \%$ & $18 \%$ & $12 \%$ & $17 \%$ & $4 \%$ & $15 \%$ \\
\hline R031 - Sud Muntenia & $20 \%$ & $14 \%$ & $22 \%$ & $19 \%$ & $19 \%$ & $22 \%$ \\
\hline R032 - Bucharest - Ilfov & $12 \%$ & $14 \%$ & $7 \%$ & $12 \%$ & $6 \%$ & $7 \%$ \\
\hline R041 - Sud-Vest Oltenia & $14 \%$ & $10 \%$ & $15 \%$ & $5 \%$ & $12 \%$ & $7 \%$ \\
\hline R042 - Vest & $9 \%$ & $10 \%$ & $8 \%$ & $7 \%$ & $15 \%$ & $5 \%$ \\
\hline Receives at least one benefit & $75 \%$ & $99 \%$ & $89 \%$ & $89 \%$ & $71 \%$ & $78 \%$ \\
\hline \multicolumn{7}{|c|}{ Receives benefits at household level } \\
\hline Family child & $64 \%$ & $22 \%$ & $25 \%$ & $20 \%$ & $56 \%$ & $48 \%$ \\
\hline Social exclusion & $31 \%$ & $19 \%$ & $26 \%$ & $37 \%$ & $32 \%$ & $32 \%$ \\
\hline Housing & & & & & & \\
\hline
\end{tabular}




\begin{tabular}{|c|c|c|c|c|c|c|}
\hline & $\begin{array}{l}\text { 1. Low-educated } \\
\text { rural inactive } \\
\text { women without } \\
\text { work experience }\end{array}$ & 2. Retirees & $\begin{array}{l}\text { 3. Early retirees } \\
\text { and inactive with } \\
\text { previous work } \\
\text { experience }\end{array}$ & $\begin{array}{l}\text { 4. Low- } \\
\text { educated and } \\
\text { rural disabled } \\
\text { or inactive }\end{array}$ & $\begin{array}{l}\text { 5. Unemployed } \\
\text { rural single } \\
\text { youth }\end{array}$ & $\begin{array}{l}\text { 6. Middle-aged } \\
\text { low-educated } \\
\text { unemployed }\end{array}$ \\
\hline Old age at household level & $69 \%$ & $90 \%$ & $65 \%$ & $64 \%$ & $51 \%$ & $57 \%$ \\
\hline \multicolumn{7}{|c|}{ Receives benefits at individual level } \\
\hline Unemployment & $1 \%$ & $0 \%$ & $0 \%$ & $0 \%$ & $7 \%$ & $28 \%$ \\
\hline Old age & $0 \%$ & $82 \%$ & $35 \%$ & $9 \%$ & $0 \%$ & $1 \%$ \\
\hline Survivor & $1 \%$ & $2 \%$ & $4 \%$ & $9 \%$ & $0 \%$ & $0 \%$ \\
\hline \multicolumn{7}{|l|}{ Sickness } \\
\hline Disability & $3 \%$ & $13 \%$ & $38 \%$ & $50 \%$ & $0 \%$ & $8 \%$ \\
\hline Education & $1 \%$ & $0 \%$ & $0 \%$ & $0 \%$ & $0 \%$ & $0 \%$ \\
\hline \multicolumn{7}{|c|}{ Benefits as share of total gross household income, all households } \\
\hline Family child & $6 \%$ & $1 \%$ & $2 \%$ & $3 \%$ & $7 \%$ & $6 \%$ \\
\hline Social exclusion & $2 \%$ & $0 \%$ & $1 \%$ & $3 \%$ & $4 \%$ & $6 \%$ \\
\hline Housing & $0 \%$ & $0 \%$ & $0 \%$ & $0 \%$ & $0 \%$ & $0 \%$ \\
\hline Unemployment & $1 \%$ & $0 \%$ & $0 \%$ & $1 \%$ & $1 \%$ & $15 \%$ \\
\hline Old age & $10 \%$ & $57 \%$ & $30 \%$ & $25 \%$ & $7 \%$ & $8 \%$ \\
\hline Survivor & $1 \%$ & $1 \%$ & $2 \%$ & $6 \%$ & $3 \%$ & $0 \%$ \\
\hline Sickness & $0 \%$ & $0 \%$ & $0 \%$ & $0 \%$ & $0 \%$ & $0 \%$ \\
\hline Disability & $3 \%$ & $7 \%$ & $19 \%$ & $21 \%$ & $3 \%$ & $7 \%$ \\
\hline Education & $0 \%$ & $0 \%$ & $0 \%$ & $0 \%$ & $0 \%$ & $0 \%$ \\
\hline \multicolumn{7}{|c|}{ Benefits as share of total gross household income, only beneficiaries } \\
\hline Family child & $10 \%$ & $5 \%$ & $8 \%$ & $16 \%$ & $12 \%$ & $13 \%$ \\
\hline Social exclusion & $8 \%$ & $2 \%$ & $4 \%$ & $9 \%$ & $13 \%$ & $19 \%$ \\
\hline \multicolumn{7}{|l|}{ Housing } \\
\hline Unemployment & $41 \%$ & $40 \%$ & $83 \%$ & $81 \%$ & $10 \%$ & $55 \%$ \\
\hline Old age & $50 \%$ & $65 \%$ & $62 \%$ & $56 \%$ & $51 \%$ & $50 \%$ \\
\hline Survivor & $25 \%$ & $29 \%$ & $30 \%$ & $26 \%$ & $31 \%$ & $33 \%$ \\
\hline \multicolumn{7}{|l|}{ Sickness } \\
\hline Disability & $28 \%$ & $36 \%$ & $45 \%$ & $34 \%$ & $36 \%$ & $44 \%$ \\
\hline Education & $20 \%$ & $2 \%$ & $25 \%$ & $14 \%$ & $13 \%$ & $28 \%$ \\
\hline
\end{tabular}


a. Refers to individuals aged 25 and over.

b. Based on total gross household income.

c. Based on total equivalized disposable household income.

d. Dependent children include: 1. household members under 18; 2. household members aged between 18 and 24 who are economically inactive and living with at least one parent. e. Refers only to individuals who have worked before.

Source: WB staff calculations based on EU-SILC. 


Portraits of Labor Market Exclusion sheds new light on the life situations and labor market experiences of individuals and households during the financial, economic and employment crisis between 2008 and 2011. Identifying those individuals with limited or no labor market attachment is fundamental for a holistic approach to inclusive policymaking for the inactive and unemployed.

In this joint project of the European Commission and the World Bank, profiles of the unemployed and inactive populations in six EU Member States-Bulgaria, Estonia, Greece, Hungary, Lithuania, and Romania-were developed through cluster analysis and interpretation of data from the European Income and Living Conditions Survey. The profiles that emerge move beyond simple demographics (male/female, young/old, rural/urban) and start to identify life situations and potential barriers to employment (lack of experience, lack of education, caregiving responsibilities, distance from services and jobs, income from transfers, and so on).

Portraits of Labor Market Exclusion provides a basis for national and EU policy design and priority-setting for interventions that are suited to particular life situations among the inactive and unemployed. By shedding light on the social and economic risks faced by this population, as well as on the potential barriers they may encounter, this crosscutting analysis moves the dialogue on labor-market integration from a labor-only view to a broader approach that encompasses social policy and public services. In this way, the book contributes important insights for the employment-oriented design of social policy.
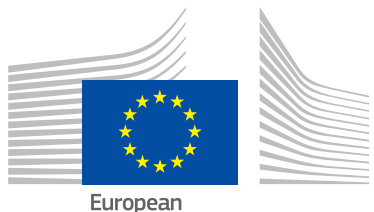